\title{
Next Generation Nuclear Plant Reactor Pressure Vessel Materials Research and Development Plan
}

\author{
R. N. Wright \\ J. K. Wright \\ T. L. Sham \\ R. Nanstad \\ W. Ren
}

April 2008
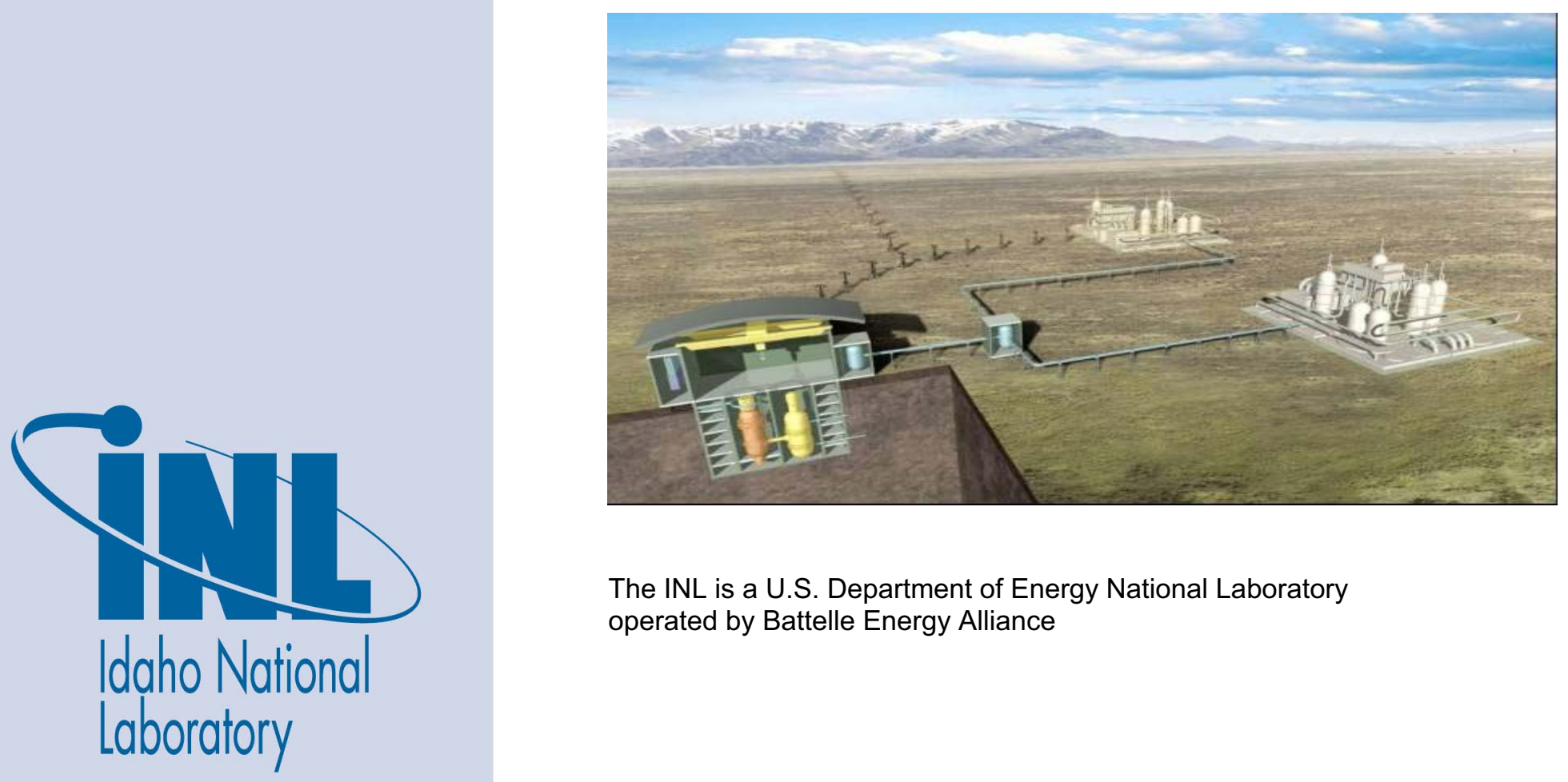

The INL is a U.S. Department of Energy National Laboratory operated by Battelle Energy Alliance 
INL/EXT-08-14108

PLN-2803

\title{
Next Generation Nuclear Plant Reactor Pressure Vessel Materials Research and Development Plan
}

\author{
R. N. Wright \\ J. K. Wright \\ T. L. Sham ${ }^{1}$ \\ R. Nanstad ${ }^{1}$ \\ W. $\operatorname{Ren}^{1}$
}

${ }^{1}$ ORNL

April 2008

Idaho National Laboratory

Idaho Falls, Idaho 83415

http://www.inl.gov

Prepared for the

U.S. Department of Energy

Office of Nuclear Energy

Under DOE Idaho Operations Office

Contract DE-AC07-05ID14517 


\section{DISCLAIMER}

This information was prepared as an account of work sponsored by an agency of the U.S. Government. Neither the U.S. Government nor any agency thereof, nor any of their employees, makes any warranty, expressed or implied, or assumes any legal liability or responsibility for the accuracy, completeness, or usefulness, of any information, apparatus, product, or process disclosed, or represents that its use would not infringe privately owned rights. References herein to any specific commercial product, process, or service by trade name, trade mark, manufacturer, or otherwise, does not necessarily constitute or imply its endorsement, recommendation, or favoring by the U.S. Government or any agency thereof. The views and opinions of authors expressed herein do not necessarily state or reflect those of the U.S. Government or any agency thereof. 


NEXT GENERATION NUCLEAR PLANT
REACTOR PRESSURE VESSEL MATERIALS RESEARCH AND DEVELOPMENT PLAN
Identifier: $\quad$ PLN-2803

Revision: $\quad 0$

Effective Date: $04 / 30 / 08$

Page: ii of xiii

\begin{tabular}{|l|l|l|l|}
\hline $\begin{array}{l}\text { Materials Properties and } \\
\text { Engineering }\end{array}$ & Plan & eCR Number: 560587 \\
\hline
\end{tabular}

REVISION LOG

\begin{tabular}{|l|l|l|l|}
\hline Rev. & Date & Affected Pages & \multicolumn{1}{c|}{ Revision Description } \\
\hline 0 & $4 / 30 / 08$ & All & New document \\
\hline & & & \\
\hline & & & \\
\hline & & & \\
\hline & & & \\
\hline & & & \\
\hline & & & \\
\hline & & & \\
\hline & & & \\
\hline & & & \\
\hline & & & \\
\hline
\end{tabular}


NEXT GENERATION NUCLEAR PLANT REACTOR PRESSURE VESSEL MATERIALS RESEARCH AND DEVELOPMENT PLAN
Identifier:

Revision:

Effective Date: 04/30/08 


\begin{tabular}{|c|lll|}
\hline NEXT GENERATION NUCLEAR PLANT & Identifier: & PLN-2803 & \\
REACTOR PRESSURE VESSEL MATERIALS & Revision: & 0 & \\
RESEARCH AND DEVELOPMENT PLAN & Effective Date: & $04 / 30 / 08$ & Page: iv of xiii \\
\hline
\end{tabular}

\section{SUMMARY}

The U.S. Department of Energy has selected the High Temperature Gascooled Reactor design for the Next Generation Nuclear Plant (NGNP) Project. The NGNP will demonstrate the use of nuclear power for electricity and hydrogen production. It will have an outlet gas temperature in the range of $900^{\circ} \mathrm{C}$ and a plant design service life of 60 years. The reactor design will be a graphite moderated, helium-cooled, prismatic, or pebble-bed reactor and use low-enriched uranium, Tri-Isotopic-coated fuel. The plant size, reactor thermal power, and core configuration will ensure passive decay heat removal without fuel damage or radioactive material releases during accidents.

Selection of the technology and design configuration for the NGNP must consider both the cost and risk profiles to ensure that the demonstration plant establishes a sound foundation for future commercial deployments. The NGNP challenge is to achieve a significant advancement in nuclear technology while setting the stage for an economically viable deployment of the new technology in the commercial sector soon after 2020.

Studies of potential Reactor Pressure Vessel (RPV) steels have been carried out as part of the pre-conceptual design studies. These design studies generally focus on American Society of Mechanical Engineers (ASME) Code status of the steels, temperature limits, and allowable stresses. Three realistic candidate materials have been identified by this process: conventional light water reactor RPV steels A 508/533, 21/4Cr-1Mo in the annealed condition, and Grade 91 steel. Based on superior strength and higher temperature limits, the Grade 91 steel has been identified by the majority of design engineers as the preferred choice for the RPV. All of the vendors have concluded, however, that with adequate engineered cooling of the vessel, the A 508/533 steels are also acceptable. The low strength of $2 \frac{1}{4} \mathrm{Cr}-1 \mathrm{Mo}$ at elevated temperature has eliminated this steel from serious consideration as an NGNP RPV candidate material.

Discussions with the very few vendors that have the potential to produce large forgings for nuclear pressure vessels indicate a strong preference for conventional A 508 steel. This preference is based in part on long experience with forging these steels for nuclear components. It is also based on the inability to cast large ingots of the higher alloy steel due to segregation during ingot solidification. Smaller ingots restrict the possible mass of forging components; Grade 91 is restricted to 120 ton ingots compared to 480 tons for A 508. Smaller forgings increase the amount of welding required for completion of the RPV. The Grade 91 steel is also prone to weld cracking and must be post-weld heat treated to ensure adequate high temperature strength. There are also questions about the ability to produce, and very importantly, verify the through thickness properties of thick sections of the Grade 91 material.

The availability of large components, ease of fabrication, and nuclear service experience with the A 508/533 steels strongly favor their use in the RPV for the NGNP. This material selection reduces the need for further research and development and the associated technical risk to the project. Availability of vendors with experience fabricating nuclear components with these steels minimizes the schedule risk to the project as well. 


\begin{tabular}{c|lll|}
\hline NEXT GENERATION NUCLEAR PLANT & Identifier: & PLN-2803 & \\
REACTOR PRESSURE VESSEL MATERIALS & Revision: & 0 & \\
RESEARCH AND DEVELOPMENT PLAN & Effective Date: & $04 / 30 / 08$ & Page: v of xiii \\
\hline
\end{tabular}

This technology development plan presents in detail the additional research and development required for design and licensing of the NGNP RPV, assuming that A 508/533 is the material of construction. The majority of additional information that is required is related to long term aging behavior at NGNP vessel temperatures, which are somewhat above those commonly encountered in the existing database from Light-Water Reactor (LWR) experience. Additional data are also required for the anticipated NGNP environment.

An assessment of required research and development for a Grade 91 vessel is also presented, in somewhat less detail. Considerably more development is required for this steel compared to A 508/533 including additional irradiation testing for expected NGNP operating temperatures, high temperature mechanical properties, and extensive studies of long-term microstructural stability. 


\begin{tabular}{c|lll|}
\hline NEXT GENERATION NUCLEAR PLANT & Identifier: & PLN-2803 & \\
REACTOR PRESSURE VESSEL MATERIALS & Revision: & 0 & \\
RESEARCH AND DEVELOPMENT PLAN & Effective Date: & $04 / 30 / 08$ & Page: vi of xiii \\
\hline
\end{tabular}

\section{ACKNOWLEDGMENTS}

The authors gratefully acknowledge the assistance of the following: D. Vandel, J. Cox, D. Kunerth, from INL and W.R. Corwin, D. F. Wilson, J.P. Shingledecker, M.A. Sokolov, R.L. Battiste, from ORNL. We would also like to thank R.I. Jetter, Chair, ASME Boiler and Pressure Vessel Code, SC-D, Subgroup Elevated Temperature Design; R.W. Swindeman of Cromtech Inc.; D. Eno of Consulting Statistician; V.K. Vasudevan, Professor, Department of Chemical and Materials Engineering, University of Cincinnati; W. J. O'Donnell of O'Donnell Consulting Engineers, Inc. 
NEXT GENERATION NUCLEAR PLANT REACTOR PRESSURE VESSEL MATERIALS RESEARCH AND DEVELOPMENT PLAN
Identifier:

Revision:

Effective Date: 04/30/08 


\begin{tabular}{|c|lll|}
\hline NEXT GENERATION NUCLEAR PLANT & Identifier: & PLN-2803 \\
REACTOR PRESSURE VESSEL MATERIALS & Revision: & 0 & \\
RESEARCH AND DEVELOPMENT PLAN & Effective Date: & $04 / 30 / 08$ & Page: viii of Xiii \\
\hline
\end{tabular}

\section{CONTENTS}

SUMMARY iv

ACKNOWLEDGMENTS ..... vi

ACRONYMS xii

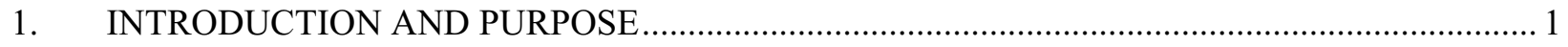

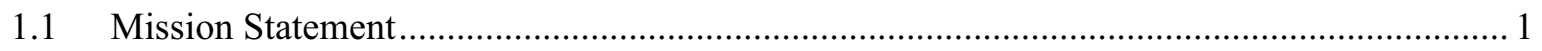

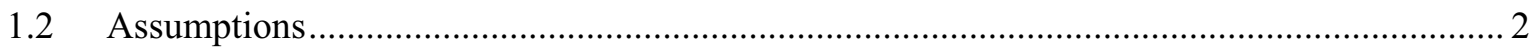

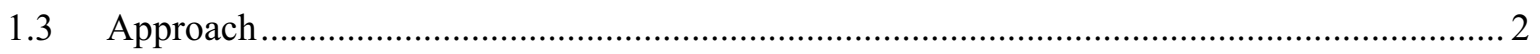

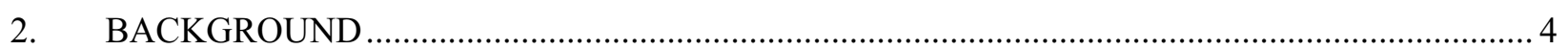

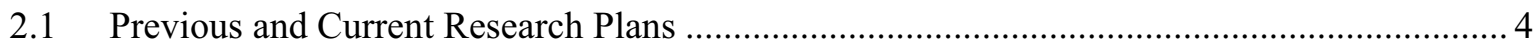

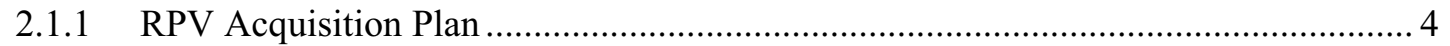

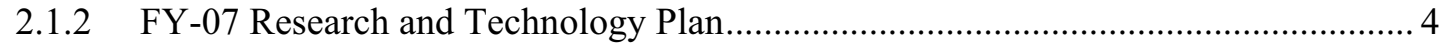

2.2 Reactor Preconceptual Designs and Vendor Recommendations ........................................ 4

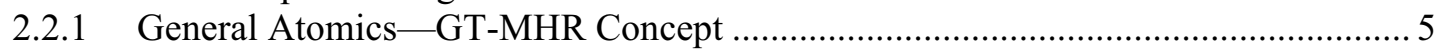

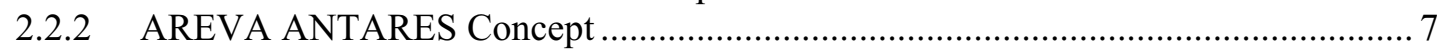

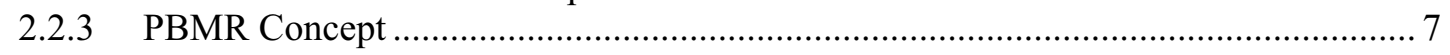

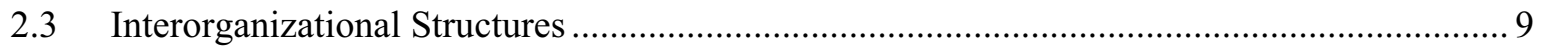

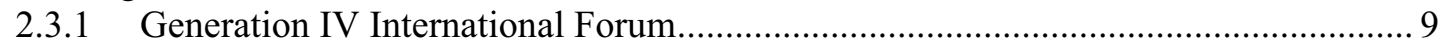

2.3.2 International Nuclear Energy Research Initiative Programs ..................................... 10

2.3.3 University Nuclear Engineering Research Initiative Programs ................................ 10

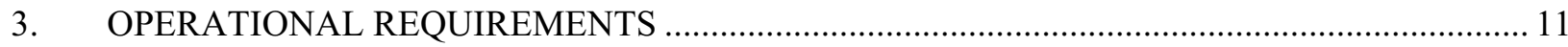

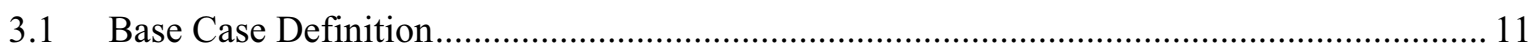

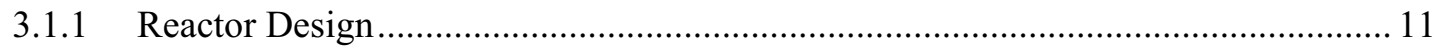

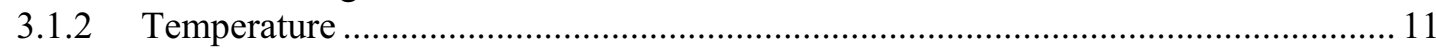

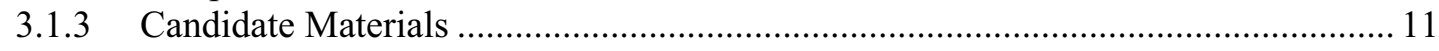

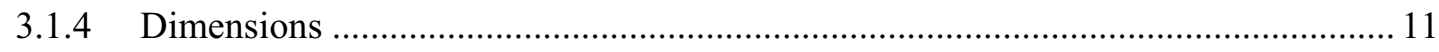

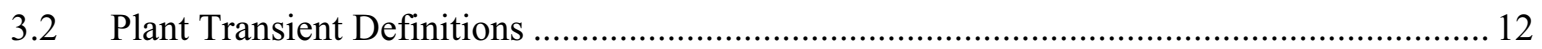

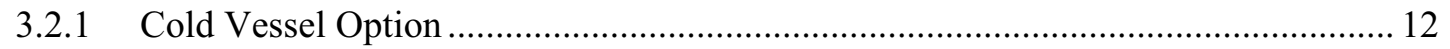

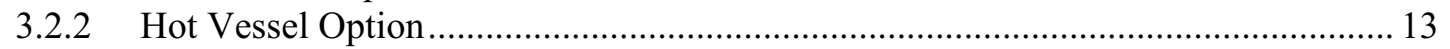

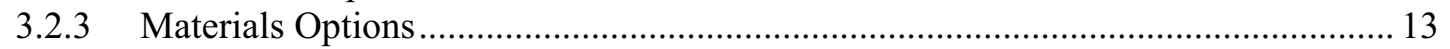

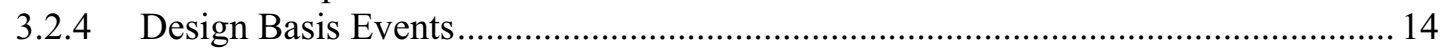

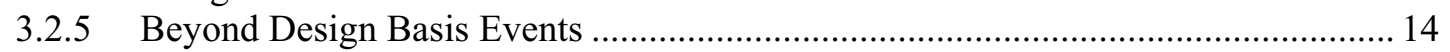

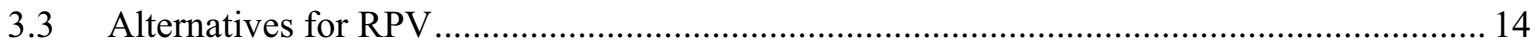

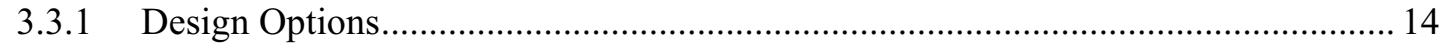

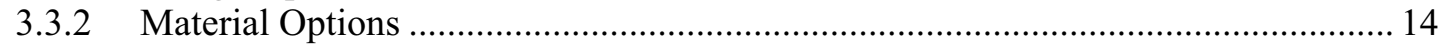

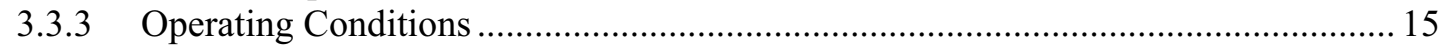

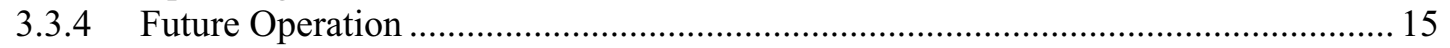




\begin{tabular}{|c|lll|}
\hline NEXT GENERATION NUCLEAR PLANT & Identifier: & PLN-2803 \\
REACTOR PRESSURE VESSEL MATERIALS & Revision: & 0 & \\
RESEARCH AND DEVELOPMENT PLAN & Effective Date: & $04 / 30 / 08$ & Page: ix of xiii \\
\hline
\end{tabular}

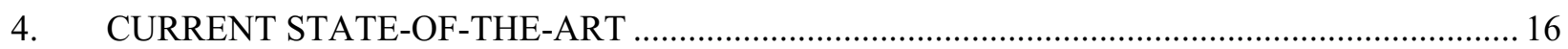

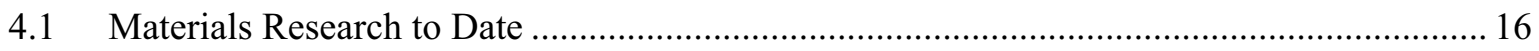

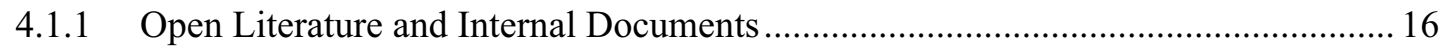

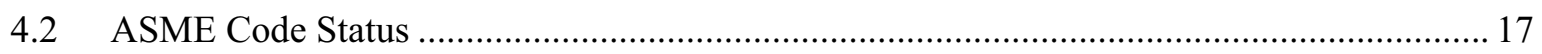

4.3 ASME Boiler and Pressure Vessel Code …................................................................ 18

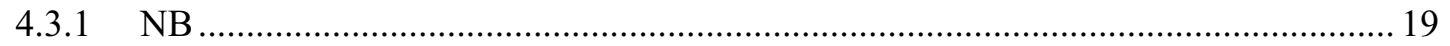

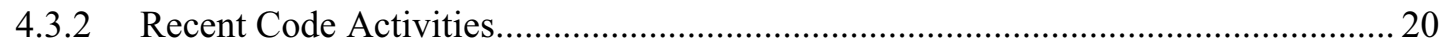

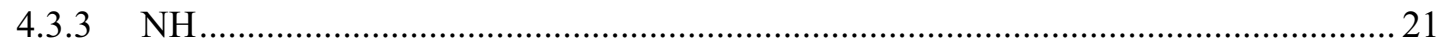

4.3.4 DOE Initiative to Address ASME Code Issues..........................................................2 25

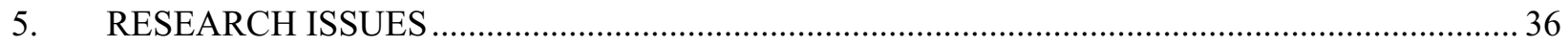

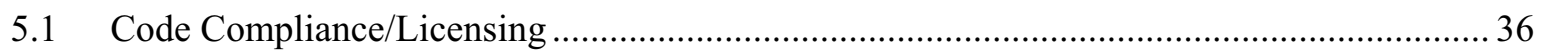

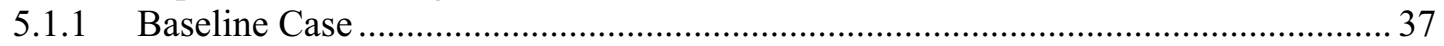

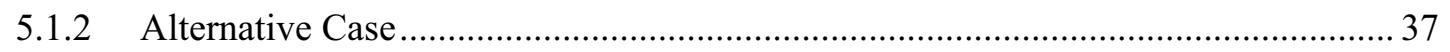

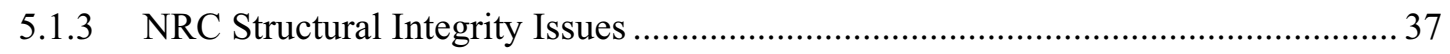

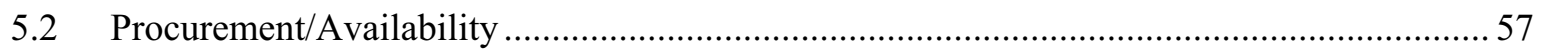

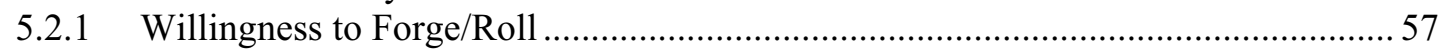

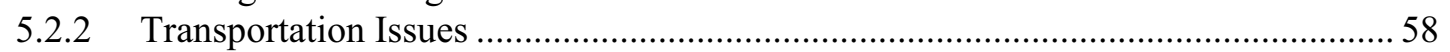

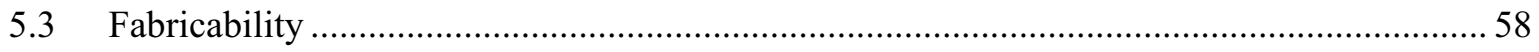

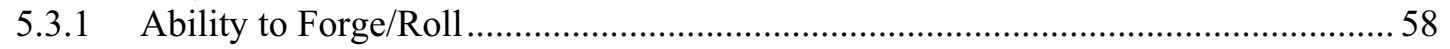

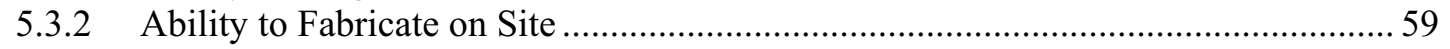

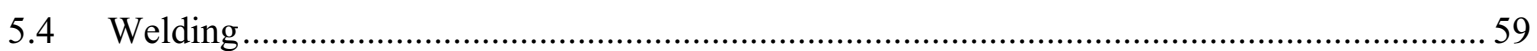

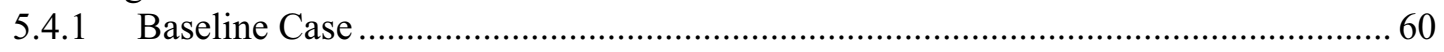

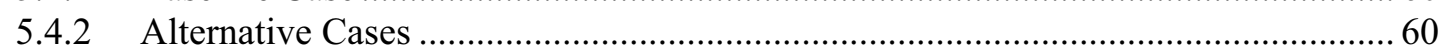

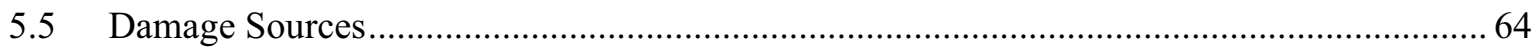

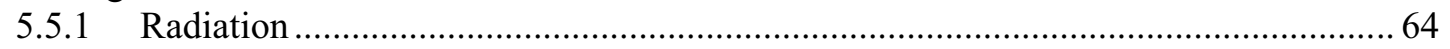

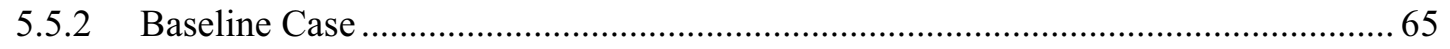

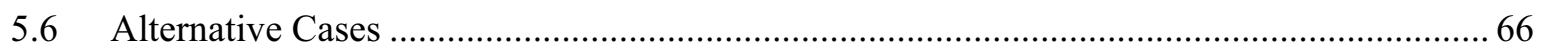

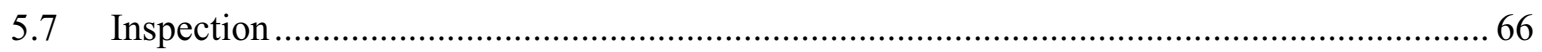

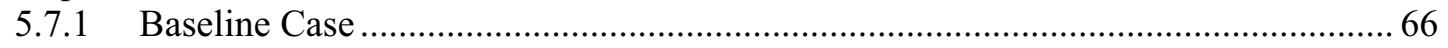

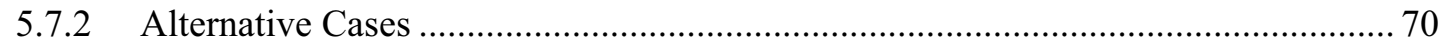

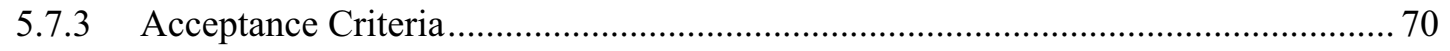

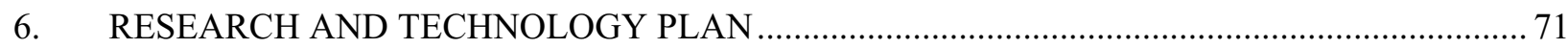

6.1 Required Actions for Code/Licensing Issues ................................................................. 71

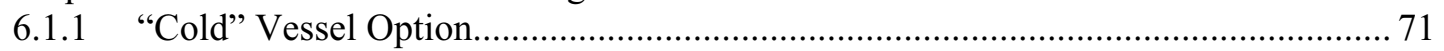

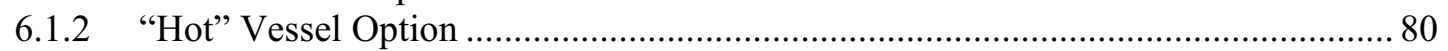

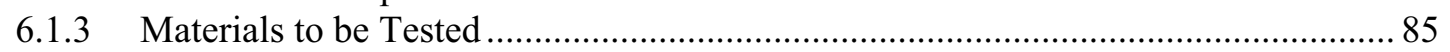

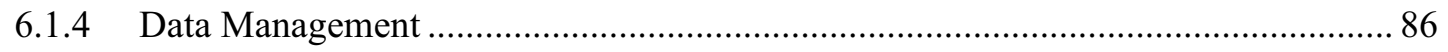

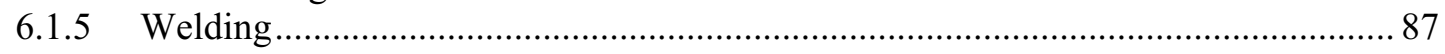

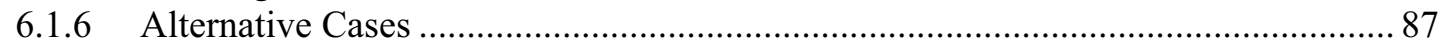

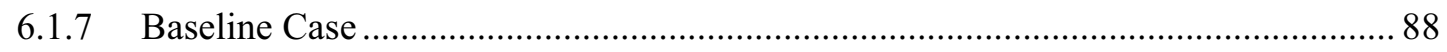

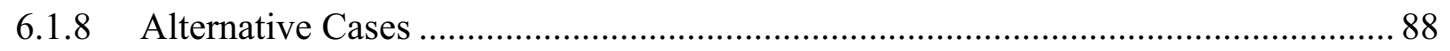

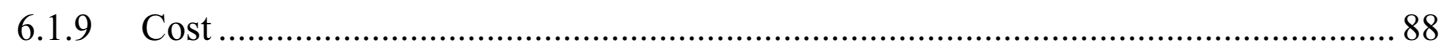

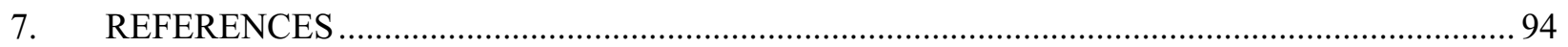




\begin{tabular}{c|lll|} 
NEXT GENERATION NUCLEAR PLANT & Identifier: & \multicolumn{2}{l|}{ PLN-2803 } \\
REACTOR PRESSURE VESSEL MATERIALS & Revision: & 0 & \\
RESEARCH AND DEVELOPMENT PLAN & Effective Date: & $04 / 30 / 08$ & Page: x of xiii \\
\hline
\end{tabular}

\section{FIGURES}

Figure 1. Variation of primary membrane stress intensity and allowable primary membrane stress intensities as functions of temperature and time...... .36

Figure 2. Extrapolated time-dependent primary stress limits for A 533B. 39

Figure 3. Extrapolated time-dependent primary stress limits for A $533 \mathrm{~B}$ at $340^{\circ} \mathrm{C}, 350^{\circ} \mathrm{C}$ and $371^{\circ} \mathrm{C}$.

Figure 4. Extrapolated lower bound creep rupture stress for $\mathrm{A} 533 \mathrm{~B}$ at $340^{\circ} \mathrm{C}, 350^{\circ} \mathrm{C}$ and $371^{\circ} \mathrm{C} \ldots \ldots \ldots . .41$

Figure 5. Effect of environment and temperature on the emissivity of type 304 stainless steel. 65

\section{TABLES}

Table 1. Key operating parameters for the NGNP designs and the Fort St. Vrain HTGR. ....................... 6

Table 2. Applicability of rules in Section III of the ASME Code to component construction................... 18

Table 3. Division 1 Code cases that were developed for elevated temperature service............................. 18

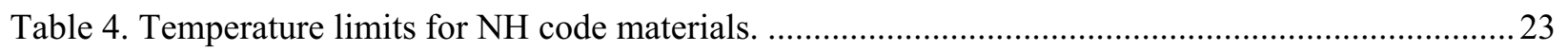

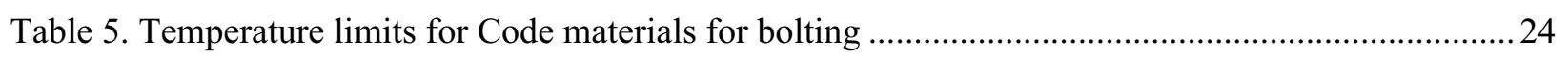

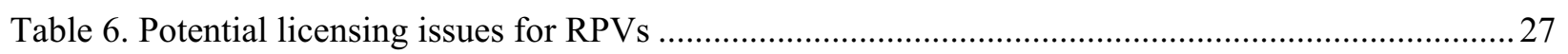

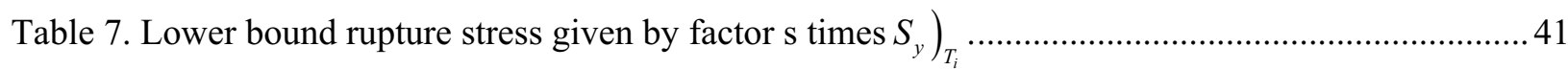

Table 8. Comparison of rupture stress predictions from Code Case N-499-2 and statistical re-

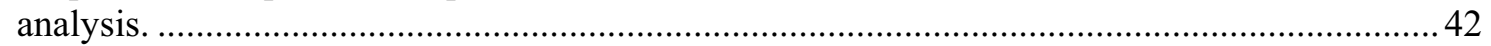

Table 9. Rupture data at $371^{\circ} \mathrm{C}$ from Code Case N-499 database. ....................................................... 42

Table 10. NRC issues list from CRBR Review - Assessment Relative to the "Cold" and "Hot" Vessel Options.

Table 11. Forging capability of Grade 91 for NGNP RPV $(\sim 8 \mathrm{~m}$ dia. $\times 24 \mathrm{~m}$ high with thickness

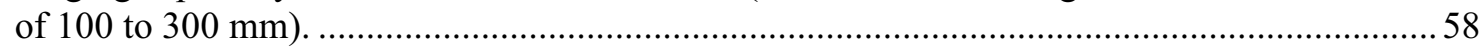

Table 12. Summary of test plan for A 508/A 533B Material - Cold Vessel............................................. 72

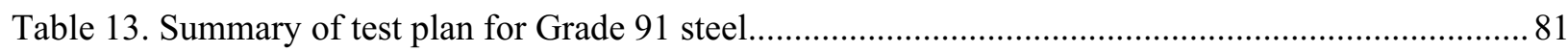

Table 14. Costs associated with sample preparation and testing for A 508/533 .................................... 89

Table 15. Estimated total cost for testing and analysis for A 508/533 ..................................................... 90

Table 16. Estimated costs for specimen fabrication and testing of the $9 \mathrm{Cr}-1 \mathrm{M} 0$ steel........................... 91

Table 17. Estimated cost for testing and analysis of the Grade 91 steel instead of the A 508/533............92 
NEXT GENERATION NUCLEAR PLANT REACTOR PRESSURE VESSEL MATERIALS RESEARCH AND DEVELOPMENT PLAN
Identifier:

Revision:

Effective Date: 04/30/08

0
PLN-2803

Page: xi of xiii 


\begin{tabular}{|c|lll|}
\hline NEXT GENERATION NUCLEAR PLANT & Identifier: & \multicolumn{2}{l|}{ PLN-2803 } \\
REACTOR PRESSURE VESSEL MATERIALS & Revision: & 0 & \\
RESEARCH AND DEVELOPMENT PLAN & Effective Date: & $04 / 30 / 08$ & Page: xii of xiii \\
\hline
\end{tabular}

\section{ACRONYMS}

ACRS Advisory Committee on Reactor Safeguards

AOO Anticipated Operational Occurrence

ASME American Society of Mechanical Engineers

ASTM American Society for Testing and Materials

AVR Albeitsgemeinschaft Versuchsreaktor

BDBE Beyond Design Basis Events

BPVC Boiler and Pressure Vessel Code

CEA Commissariat à l'Énergie Atomique in France

CRBR Clinch River Breeder Reactor

CRIEPI Central Research Institute of Power Industry in Japan

DBE Design Basis Events

DHI Doosan Heavy Industries, South Korea

DOE Department of Energy

EPRI Electric Power Research Institute

FEA Finite Element Analyses

GA General Atomics

GIF Generation IV International Forum

GT-MHR Gas Turbine-Modular Helium Reactor

HAZ Heat Affected Zone

HPCC high pressure conduction cooldown

HTGR High-Temperature Gas Reactor

HTR High-Temperature Reactor

HTTR High-Temperature Engineering Test Reactor

IHX Intermediate/Input Heat Exchanger

INERI International Nuclear Energy Research Initiative

INL Idaho National Laboratory (formerly the Idaho National Engineering and Environmental Laboratory)

JAEA Japan Atomic Energy Agency

JNC Japan Nuclear Cycle Development Institute

KAERI Korean Atomic Energy Research Institute

LPCC low pressure conduction cooldown

LWR Light-Water Reactor

NE DOE Office of Nuclear Energy

NERI Nuclear Energy Research Initiative

NGNP Next Generation Nuclear Plant

NIMS National Institute of Material Science in Japan

NRC Nuclear Regulatory Commission

ORNL Oak Ridge National Laboratory

PA Project Arrangement

PBMR Pebble Bed Modular Helium Reactor 


\begin{tabular}{|c|c|c|c|c|}
\hline \multicolumn{2}{|c|}{$\begin{array}{l}\text { NEXT GENERATION NUCLEAR PLANT } \\
\text { REACTOR PRESSURE VESSEL MATERIALS } \\
\text { RESEARCH AND DEVELOPMENT PLAN }\end{array}$} & $\begin{array}{l}\text { Identifier: } \\
\text { Revision: } \\
\text { Effective Date: }\end{array}$ & $\begin{array}{l}\text { PLN-2803 } \\
0 \\
04 / 30 / 08\end{array}$ & \multirow[t]{2}{*}{ Page: xiii of xiii } \\
\hline PBR & \multirow{2}{*}{\multicolumn{4}{|c|}{$\begin{array}{l}\text { Pebble Bed Reactor } \\
\text { Pebble Bed Modular Reactor }\end{array}$}} \\
\hline PBMR & & & & \\
\hline PCHE & \multicolumn{4}{|l|}{ Printed Circuit Heat Exchangers } \\
\hline PCS & \multicolumn{4}{|l|}{ Primary Cooling System } \\
\hline PCU & \multicolumn{4}{|l|}{ Power Conversion Unit } \\
\hline PMR & \multicolumn{4}{|l|}{ Prismatic Modular Reactor } \\
\hline PRISM & \multicolumn{4}{|l|}{ Power Reactor Innovative Small Module } \\
\hline PWR & \multicolumn{4}{|l|}{ Pressurized Water Reactor } \\
\hline PWHT & \multicolumn{4}{|l|}{ Post Weld Heat Treatment } \\
\hline QA & \multicolumn{4}{|l|}{ Quality Assurance } \\
\hline $\mathrm{R} \& \mathrm{D}$ & \multicolumn{4}{|l|}{ Research and Development } \\
\hline $\mathrm{RCS}$ & \multicolumn{4}{|l|}{ Reactor Control System } \\
\hline RES & \multicolumn{4}{|c|}{ NRC Office of Nuclear Regulatory Research } \\
\hline RPV & \multicolumn{4}{|l|}{ Reactor Pressure Vessel } \\
\hline $\mathrm{SSC}$ & \multicolumn{4}{|l|}{ Safety Significant Components } \\
\hline THTR & \multicolumn{4}{|l|}{ Thorium Hochtemperatur Reaktor } \\
\hline TRISO & \multicolumn{4}{|l|}{ Tri-isotopic (fuel) } \\
\hline VHTR & \multicolumn{4}{|l|}{ Very-High-Temperature Reactor } \\
\hline
\end{tabular}




\begin{tabular}{|c|lll|}
\hline NEXT GENERATION NUCLEAR PLANT & Identifier: & PLN-2803 & \\
REACTOR PRESSURE VESSEL MATERIALS & Revision: & 0 & \\
RESEARCH AND DEVELOPMENT PLAN & Effective Date: & $04 / 30 / 08$ & Page: 1 of 95 \\
\hline
\end{tabular}

\section{INTRODUCTION AND PURPOSE}

The U.S. Department of Energy (DOE) has selected the High Temperature Gas-cooled Reactor (HTGR) design for the Next Generation Nuclear Plant (NGNP) project. The NGNP will demonstrate the use of nuclear power for electricity and hydrogen production. The reactor design will be a graphite moderated, helium-cooled, prismatic or pebble-bed, thermal neutron spectrum reactor. The NGNP will use very high burn-up, low-enriched uranium, Tri-Isotopic (TRISO)-coated fuel, and have a projected plant design service life of 60 years. The HTGR concept is considered to be the nearest-term reactor design that has the capability to efficiently produce hydrogen. The plant size, reactor thermal power, and core configuration will ensure passive decay heat removal without fuel damage or radioactive material releases during accidents.

The basic technology for the NGNP was established in former HTGRs such as DRAGON, Peach Bottom, Albeitsgemeinschaft Versuchsreaktor (AVR), Thorium Hochtemperatur Reaktor (THTR), and Fort St. Vrain. These reactor designs represent two design categories: the Pebble Bed Reactor (PBR) and the Prismatic Modular Reactor (PMR). Commercial examples of potential NGNP candidates are the Gas Turbine-Modular Helium Reactor (GT-MHR) from General Atomics (GA), the high temperature reactor concept (ANTARES) from AREVA, and the Pebble Bed Modular Reactor (PBMR) from the PBMR consortium. The Japanese High-Temperature Engineering Test Reactor (HTTR) and Chinese HighTemperature Reactor (HTR) are currently in operation demonstrating the feasibility of the reactor components and materials needed for NGNP. Therefore, NGNP is focused on building a demonstration plant, rather than simply confirming the basic feasibility of the concept.

The operating conditions for NGNP represent a major departure from existing water-cooled reactor technologies. Few choices exist for metallic alloys for use at NGNP conditions and the design lifetime considerations for the metallic components may restrict the maximum operating temperature. Qualification of materials for successful application at the high-temperature conditions and 60-yeardesign life planned for the NGNP is a large portion of the effort in the NGNP Materials Research and Development (R\&D) Program.

Selection of the technology and design configuration for the NGNP must consider both the cost and risk profiles to ensure that the demonstration plant establishes a sound foundation for future commercial deployments. The NGNP challenge is to achieve a significant advancement in nuclear technology while setting the stage for an economically viable deployment of the new technology in the commercial sector soon after 2020. This document discusses the technical issues that must be resolved for successful design and licensing of the pressure vessel for the NGNP and presents a detailed research and development plan, with associated cost and schedule, to resolve these issues.

\subsection{Mission Statement}

The objective of the NGNP Materials R\&D Program is to provide the essential materials R\&D needed to support the design and licensing of the reactor and balance of plant, excluding the hydrogen plant. The materials $R \& D$ program was initiated prior to the design effort to ensure that materials $R \& D$ activities are initiated early enough to support the design process. The thermal, environmental, and service life conditions of the NGNP will make selection and qualification of the high-temperature materials a significant challenge; thus, new materials and approaches may be required. The mission of the NGNP Materials Program supports the objectives associated with NGNP in the Energy Policy Act of 2005 and provides any materials related support required during the development of the NGNP Project. 


\begin{tabular}{|c|lll|}
\hline NEXT GENERATION NUCLEAR PLANT & Identifier: & PLN-2803 & \\
REACTOR PRESSURE VESSEL MATERIALS & Revision: & 0 & \\
RESEARCH AND DEVELOPMENT PLAN & Effective Date: & $04 / 30 / 08$ & Page: 2 of 95 \\
\hline
\end{tabular}

A number of NGNP materials research objectives are specifically related to materials for high temperature applications such as the intermediate/input heat exchanger (IHX), the core barrel, and core internals such as the control rod sleeves. These activities are described in a separate technology development plan. Although there is currently no active R\&D in the NGNP program relating to pressure vessel materials issues, many of the issues related to ASME Code compliance may apply to the vessel as well as the core internals and heat exchangers. Research is needed to develop improved high-temperature design methodologies for high-temperature metallic alloys for the heat exchanger, and it is possible similar issues will arise for the reactor pressure vessel (RPV). Currently, the data and models for high temperature design are inadequate for some of the alloys and the codes and standards need to be expanded. An improved understanding and new models are needed for the environmental effects and thermal aging of the high temperature alloys and possibly the RPV alloys as well. There are potential issues specific to the pressure vessel such as welding procedures that may need be developed, evaluated, and certified for the very-thick sections. Inspections and the procedures for those inspections must be defined and developed. There are also potential irradiation effects to be considered for both the vessel and some of the core internals. The R\&D Plan also includes activities of selected university materials related $\mathrm{R} \& \mathrm{D}$ activities and international materials related collaboration activities that would be of direct benefit to the NGNP Project.

\subsection{Assumptions}

The following assumptions are incorporated into the mission statements and are fundamental to estimating the scope, cost, and schedule for completing the materials R\&D processes:

- NGNP will be a full-sized reactor plant capable of electricity generation with a hydrogen demonstration unit of appropriate size.

- The reactor design will be helium-cooled, graphite moderated core design fueled with TRISO-design fuel particles in carbon-based compacts or pebbles.

- $\quad$ NGNP must demonstrate the capability to obtain a Nuclear Regulatory Commission (NRC) operating license. The design, materials, and construction will need to meet appropriate Quality Assurance (QA) methods and criteria and other nationally recognized codes and standards.

- The demonstration plant will be designed to operate for a nominal 60 years.

- The NGNP Program, including the materials program, will continue to be directed by Idaho National Laboratory (INL) based on the guidelines given in the Energy Policy Act of 2005. The scope of work will be adjusted to reflect the level of congressional appropriations.

- Application for an NRC operating license and fabrication of the NGNP will occur with direct interaction and involvement of one or more commercial organizations.

\subsection{Approach}

Beyond the general assumptions listed above, this research plan will primarily address a baseline design case for the first NGNP that incorporates the following most likely design features and conditions:

- An outlet gas temperature of $850^{\circ} \mathrm{C}$

- A cooled pressure vessel fabricated from conventional pressure vessel steels A 508 Grade 3 Class 1 for forgings and A 533 Grade B Class 1 for rolled plate. These two steels will be referred to as "A 508 " and "A 533" in this report.

- An indirect cycle 


\begin{tabular}{|c|lll|}
\hline NEXT GENERATION NUCLEAR PLANT & Identifier: & PLN-2803 & \\
REACTOR PRESSURE VESSEL MATERIALS & Revision: & 0 & \\
RESEARCH AND DEVELOPMENT PLAN & Effective Date: & $04 / 30 / 08$ & Page: 3 of 95 \\
\hline
\end{tabular}

- IHX fabricated from nickel based alloy either Alloy 617 or Alloy 230

- A low pressure differential across the heat exchanger from primary to secondary sides

- A gaseous secondary coolant, either $\mathrm{He}$ or a $\mathrm{He} / \mathrm{N}$ mixture.

Although the current understanding of NGNP operating conditions is consistent with the parameters listed above, the design philosophy is to do nothing for the initial plant that would preclude eventual operation at an outlet temperature of $950^{\circ} \mathrm{C}$. Variations of this baseline design to allow higher outlet temperature or incorporation of materials that are not currently of sufficient technical maturity to use in the design of the first plant will be discussed in less detail. These include:

- The $2^{\text {nd }}, 3^{\text {rd }}$, and NGNP reactors built

- Outlet gas temperatures as high as $950^{\circ} \mathrm{C}$

- The pressure vessel uncooled in normal operation

- An RPV fabricated from higher alloy steels rather than A 508/A 533. 


\begin{tabular}{|c|lll|}
\hline NEXT GENERATION NUCLEAR PLANT & Identifier: & PLN-2803 & \\
REACTOR PRESSURE VESSEL MATERIALS & Revision: & 0 & \\
RESEARCH AND DEVELOPMENT PLAN & Effective Date: & $04 / 30 / 08$ & Page: 4 of 95 \\
\hline
\end{tabular}

\section{BACKGROUND}

\subsection{Previous and Current Research Plans}

\subsubsection{RPV Acquisition Plan}

An acquisition plan has been developed for the reactor pressure vessel that considers, in detail, issues that have significant bearing on RPV technology development planning. Principal among these issues are the large size and restricted availability of forgings for NGNP. The very large size of NGNP RPV components dictates that onsite fabrication will likely be necessary. This consideration motivates the discussion below on welding, heat treatment, and inspection methods. It is also clear that the worldwide capability to produce very large forgings is limited. Direct experience with forgings of the size required for NGNP is restricted to conventional pressure vessel steels. Furthermore, limitations on forging capacity, even with these conventional steels, suggest that welded structures from rolled heavy plate must be considered.

\subsubsection{FY-07 Research and Technology Plan}

Work in FY-07 was dramatically reduced from the original FY-07 Research and Technology Plan, which included plans for graphite research, but also for other materials research, including high temperature materials research, only in less detail.

Key material issues outlined in the FY-07 plan were condensed from notes produced at a facilitated meeting of program principal investigators (PIs) and managers, vendor representatives, and additional technical experts held in Salt Lake City, UT in June, 2006. It was suggested that working groups of laboratory and industry/vendor personnel be formed to define the tentative operating parameters and testing needs, and also better define what is critical to demonstrate with the NGNP. The principal concerns pertain to the RPV and IHX and focus on data needed to make decisions about which and how many alloys will be used and kept for development to decrease research requirements.

\subsection{Reactor Preconceptual Designs and Vendor Recommendations}

The HTGR is an inherently safe nuclear reactor concept with an easily understood safety basis that has the potential to substantially reduce emergency planning requirements and improved siting flexibility compared to current and advanced light-water reactors (LWRs). The viability of a graphite core planned for the NGNP has been demonstrated in previous high-temperature gas-cooled reactor plants such as DRAGON, Peach Bottom, AVR, THTR, and Fort St. Vrain). The currently operating Japanese HTTR and Chinese HTR are also demonstrating the feasibility of the reactor components and materials needed for NGNP (the HTTR reached a maximum coolant outlet temperature of $950^{\circ} \mathrm{C}$ in April 2004). These reactor designs represent two categories: the PBR and the PMR, respectively.

This section describes the current HTGR preconceptual designs in summary form which are described in detail in the NGNP Pre-Conceptual Design Report. ${ }^{1}$ Preconceptual design work was initiated in FY-07 by the NGNP Project at INL. This work was completed by three contractor teams with extensive experience in HTGR technology, nuclear power applications, and hydrogen production. Each contractor developed a recommended design for NGNP and a commercial version of the HTGR. R\&D, data needs, and future studies required to achieve operation of the NGNP were identified as part of the work. A number of special studies were also requested from all three or two of the three teams. The special studies include a Reactor Type Trade Study, ${ }^{2}$ Preconceptual Heat Transfer and Transport Studies, ${ }^{3}$ Primary and 


\begin{tabular}{|c|lll|}
\hline NEXT GENERATION NUCLEAR PLANT & Identifier: & PLN-2803 & \\
REACTOR PRESSURE VESSEL MATERIALS & Revision: & 0 & \\
RESEARCH AND DEVELOPMENT PLAN & Effective Date: & $04 / 30 / 08$ & Page: 5 of 95 \\
\hline
\end{tabular}

Secondary Cycle Trade Study. ${ }^{4}$ and Power Conversion System Trade Study. ${ }^{5}$ The three designs developed were:

1. The GT-MHR concept; team led by General Atomics teamed with: Washington Group International; Rolls-Royce (United Kingdom); Toshiba Corporation and Fuji Electric Systems (Japan); Korean Atomic Energy Research Institute and DOOSAN Heavy Industries and Construction (Korea); and OKB Mechanical Design (Russia).

2. The ANTARES concept; team led by AREVA NP, Inc. teamed with: Burns \& Roe; Washington Group International, BWXT, Dominion Engineering, Air Products, Hamilton-SundstrandRocketdyne, Mitsubishi Heavy Industries, Nova Tech, and Entergy.

3. The PBMR concept team led by Westinghouse Electric Company, LLC teamed with: Pebble Bed Modular Reactor (Pty) Ltd. and M-Tech Industrial (Pty) Ltd. (South Africa); The Shaw Group; Technology Insights; Air Products and Chemicals, Inc.; Nuclear Fuel Services; and Kadak Associates.

All three designs use TRISO fuel, graphite moderation and high temperature helium coolant in the primary system in the 800 to $950^{\circ} \mathrm{C}$ temperature range. All of the concepts have various passive neutronic design features that result in a core with relatively low power density and a negative temperature coefficient of neutron reactivity. The shut-down cooling system, the secondary reactivity shut-down system, and the control rod design are similar in all three designs. All of the reactor concepts could be used as a basis for the NGNP HTGR. Although the designs will not be presented in detail here, the features that relate to RPV material selection and challenges will be discussed. The key operating parameters and design features for all three designs are listed in Table 1 along with information for the Fort St. Vrain high-temperature gas reactor, the largest and most recent gas-cooled reactor to operate in the U.S., for comparison.

\subsubsection{General Atomics-GT-MHR Concept}

General Atomics recommended a prismatic reactor design. The core consists of graphite blocks with an annular-fueled region of 1,020 prismatic fuel blocks arranged in three columns. They argue that a prismatic reactor inherently allows higher reactor power density levels, resulting in better plant economics, involves fewer uncertainties (and therefore less risk) and allows more flexibility with respect to the use of alternate fuel cycles, such as those fabricated from surplus weapons grade plutonium or transuranics separated from spent LWR fuel. ${ }^{1,2}$

The temperature rise of the coolant in the various flow paths through the core varies over a wide range. Good mixing of the outlet coolant is needed to avoid excessive thermal stresses in the downstream components resulting from large temperature gradients and fluctuations, and to assure that the gas entering the turbine has a uniform mixed mean temperature.

General Atomics recommends the use of a direct Brayton Cycle vertical primary cooling system (PCS) for electricity generation and an indirect heat transport loop to transport thermal energy to the hydrogen production plant. The primary loop and the hydrogen heat transport loop would both use helium at $7 \mathrm{MPa}$ as a heat transport medium.

\subsubsection{Reactor Pressure Vessel}

The reactor vessel operates at a maximum through-wall average temperature of $440^{\circ} \mathrm{C}$ during normal operation and reaches about $550^{\circ} \mathrm{C}$ during a conduction cool-down event. The core's fuel elements and graphite reflectors, and the shutdown ball channels are all nonmetal, capable of withstanding the prescribed maximum core temperatures $\left(\sim 1,600^{\circ} \mathrm{C}\right)$ or higher in the design-limiting loss-of-coolant accident. 
NEXT GENERATION NUCLEAR PLANT

REACTOR PRESSURE VESSEL MATERIALS

RESEARCH AND DEVELOPMENT PLAN
Identifier: PLN-2803

Revision: $\quad 0$

Effective Date: $04 / 30 / 08$

Page: 6 of 95

Table 1. Key operating parameters for the NGNP designs and the Fort St. Vrain HTGR.

\begin{tabular}{|c|c|c|c|c|}
\hline Condition or Feature & $\begin{array}{c}\text { Fort St. Vrain } \\
\text { HTGR }\end{array}$ & $\begin{array}{c}\text { General Atomics } \\
\text { GT-MHR }\end{array}$ & $\begin{array}{l}\text { AREVA } \\
\text { ANTERES }\end{array}$ & $\begin{array}{l}\text { Westinghouse } \\
\text { PBMR }\end{array}$ \\
\hline Power Output [MW(t)] & 842 & $550-600$ & 565 & 500 \\
\hline $\begin{array}{l}\text { Average power density } \\
\left(\mathrm{w} / \mathrm{cm}^{3}\right)\end{array}$ & 6.3 & 6.5 & & 4.8 \\
\hline Moderator & Graphite & Graphite & Graphite & Graphite \\
\hline Core Geometry & Cylindrical & Annular & Annular & Annular \\
\hline Reactor type & Prismatic & Prismatic & Prismatic & Pebble Bed \\
\hline Safety Design Philosophy & Active & Passive & Passive & Passive \\
\hline Plant Design Life (Years) & 30 & 60 & 60 & 60 \\
\hline Fuel-Coated Particle & $\begin{array}{l}\text { HEU-Th } /{ }^{235} \mathrm{U} \\
\text { (93\% enriched) }\end{array}$ & $\begin{array}{l}\text { TRISO UCO } \\
\left(\text { startup } \mathrm{UO}_{2}\right)\end{array}$ & $\begin{array}{l}\text { TRISO UCO } \\
\text { (backup } \mathrm{UO}_{2} \text { ) }\end{array}$ & TRISO $\mathrm{UO}_{2}$ \\
\hline $\begin{array}{l}\text { Fuel Max Temp-Normal } \\
\text { Operation }\left({ }^{\circ} \mathrm{C}\right)\end{array}$ & 1,260 & 1,250 & 1,300 & 1,057 \\
\hline $\begin{array}{l}\text { Fuel Max Temp-Emergency } \\
\text { Conditions }\left({ }^{\circ} \mathrm{C}\right)\end{array}$ & $\begin{array}{l}\text { NA-Active Safety } \\
\text { System cools fuel }\end{array}$ & 1,600 & 1,600 & 1,600 \\
\hline $\begin{array}{l}\text { Power Conversion } \\
\text { Configuration }\end{array}$ & Direct & Direct & Indirect & Indirect \\
\hline \multirow{3}{*}{$\begin{array}{l}\text { PCS Cycle Type } \\
\text { IHX Design: } \\
\begin{aligned} \text { Power } \\
\text { Process }\end{aligned}\end{array}$} & Reheat Steam & Brayton & Steam Rankine & Rankine \\
\hline & & & Shell and Tube & \\
\hline & NA & PCHE & $\begin{array}{l}\text { PCHE or Fin- } \\
\text { Plate }\end{array}$ & PCHE \\
\hline Core outlet temperature $\left({ }^{\circ} \mathrm{C}\right)$ & 785 & Up to 950 & 900 & 950 \\
\hline Core inlet temperature $\left({ }^{\circ} \mathrm{C}\right)$ & 406 & 590 & 500 & 400 \\
\hline Coolant Pressure (MPa) & 4.8 & 7 & 5 & 9 \\
\hline Coolant Flow Rate $(\mathrm{kg} / \mathrm{s})$ & 428 & 320 & 240 & 193 \\
\hline $\begin{array}{l}\text { Secondary outlet temperature } \\
\left({ }^{\circ} \mathrm{C}\right)\end{array}$ & 538 & 925 & $\begin{array}{l}850 / 875 \\
\mathrm{PCS} / \mathrm{H}_{2}\end{array}$ & 900 \\
\hline $\begin{array}{l}\text { Secondary inlet temperature } \\
\left({ }^{\circ} \mathrm{C}\right)\end{array}$ & NA & 565 & $\begin{array}{l}450 / 475 \\
\mathrm{PCS} / \mathrm{H}_{2}\end{array}$ & NA \\
\hline Secondary Fluid & Steam & $\mathrm{He}$ & $\mathrm{He}$ & $\mathrm{He}-\mathrm{N}$ \\
\hline RPV Material & $\begin{array}{l}\text { Prestressed } \\
\text { concrete }\end{array}$ & 21/4Cr-1Mo steel & Grade 91 & A 508/A 533 \\
\hline RPV Outside Diameter (m) & & 8.2 & 7.5 & 6.8 \\
\hline RPV Height (m) & & 31 & 25 & 30 \\
\hline RPV Thickness (mm) & & 281 & 150 & $>200$ \\
\hline
\end{tabular}




\begin{tabular}{|c|lll|}
\hline NEXT GENERATION NUCLEAR PLANT & Identifier: & PLN-2803 & \\
REACTOR PRESSURE VESSEL MATERIALS & Revision: & 0 & \\
RESEARCH AND DEVELOPMENT PLAN & Effective Date: & $04 / 30 / 08$ & Page: 7 of 95 \\
\hline
\end{tabular}

The RPV of the GT-MHR is approximately $31 \mathrm{~m}$ (meters) high, $8.2 \mathrm{~m}$ in diameter, and $281 \mathrm{~mm}$ thick. The reference RPV material is modified $2^{1 / 4} \mathrm{Cr}-1 \mathrm{Mo}$, but this particular material has low strength at the temperatures of interest, which will require very thick sections. A modified version of this steel, $2 \frac{1 / 4 \mathrm{Cr}-}{}$ $1 \mathrm{Mo}-\mathrm{V}$, has better strength at the temperatures of interest, but is not in Section III (nuclear section) of the ASME code. GA is also considering a design alternative to incorporate cooling of the reactor vessel, which could potentially lower reactor vessel temperatures to a level that would allow use of proven LWR vessel materials such as A 508/A 533 steel.

\subsubsection{AREVA ANTARES Concept}

AREVA recommended that NGNP be a $565 \mathrm{MW}(\mathrm{t})$ prismatic reactor, citing: greater economic potential, higher power level and passive safety, more useable power, greater design flexibility, higher degree of license-ability (concept previously licensed for Fort St. Vrain), perceived higher degree of predictability in core performance, and fewer forced outages and scheduled outages than a pebble-bed reactor design. They suggest a gas outlet temperature of $900^{\circ} \mathrm{C}$ as the best compromise between energy efficiency and the ability to produce hydrogen, and the durability of equipment. AREVA proposes using $\mathrm{He} / \mathrm{N}_{2}$ mixture on a secondary loop in the power conversion unit $(\mathrm{PCU})$, and $900^{\circ} \mathrm{C}$ as the maximum temperature they advise for nitrogen bearing gas because of nitriding concerns. ${ }^{5}$ The use of the high nitrogen gas on the secondary side was specified because it simplifies technology development for the power turbine.

The ANTARES design ${ }^{6,7}$ is also based, in part, on the GT-MHR concept, with 1,020 fuel blocks arranged in three columns to form the annular core between inner and outer graphite reflectors. The primary loop pressure is limited to $5.5 \mathrm{MPa}$, substantially less than the 7 to $9 \mathrm{MPa}$ specified by the other contractors.

AREVA provided two plant configurations: a plant configuration with a Brayton Cycle to generate electrical power, and a plant configuration with steam to generate electricity by using a Rankine Cycle. The Brayton Cycle configuration is based on the original ANTARES design. AREVA has recently concluded that the Rankine Cycle is preferred because it is more mature and may be more adaptable to NGNP requirements.

\subsubsection{Reactor Pressure Vessel}

The RPV is approximately $25 \mathrm{~m}$ high, $7.5 \mathrm{~m}$ in diameter, and $150 \mathrm{~mm}$ thick and made from Grade 91 . This steel is preferred by AREVA because of its superior high-temperature properties compared to A 508/A 533 LWR steel. AREVA has concluded that the properties of this material minimize risk and uncertainty in the design process and maximize operational margins. It would be a developmental material for this application, requiring an ASME code extension. But AREVA believes that qualifying for this application will not be substantially more difficult than qualifying for LWR steel, and the resulting margin during a transient situation would be greater. Issues with availability and fabricability through thickness properties and postweld heat treatment need to be resolved.

\subsubsection{PBMR Concept}

The PBMR Concept reactor is being built in South Africa by PBMR (Pty) Ltd. through a world-wide development effort. ${ }^{8-11}$ The program covers testing of mechanical systems and components, a comprehensive fuel development effort, and a testing and verification program to support the licensing process. A full-sized demonstration PBMR reactor will be built at the Koeberg nuclear reactor site (owned by Eskom, the South African national utility) near Capetown, South Africa. Westinghouse 


\begin{tabular}{|c|lll|}
\hline NEXT GENERATION NUCLEAR PLANT & Identifier: & PLN-2803 & \\
REACTOR PRESSURE VESSEL MATERIALS & Revision: & 0 & \\
RESEARCH AND DEVELOPMENT PLAN & Effective Date: & $04 / 30 / 08$ & Page: 8 of 95 \\
\hline
\end{tabular}

recommended a pebble bed reactor for NGNP over a prismatic reactor design based on: the fuel and fueling system demonstrated in Germany (AVR and THTR), minimal development costs and risks because of progress in South Africa, higher capacity leading to higher performance capability, lower fuel temperatures, and a strong vendor/supplier infrastructure.

The PBMR uses 450,000 graphite-based spherical fuel elements called pebbles, which are approximately $6 \mathrm{~cm}$ in diameter. These pebbles, based on the German HTR, are located in an annular cavity in the reactor vessel. Pebbles proceed vertically downward until they are removed at the bottom. On removal they are checked, and if they are intact and not past the burnup limit, they are circulated to the input queue again. Otherwise, they are replaced with fresh pebbles. This on-line refueling feature makes refueling shutdowns unnecessary and allows the reactor to operate with almost no excess reactivity, which has advantages in safety, economy, and resistance to nuclear weapons proliferation. Limited total core power allows the reactor to be designed for passive heat conduction from the core, thermal radiation and convection from the vessel and conduction to the confinement structure, keeping temperatures low enough to prevent core or fuel damage.

The present PBMR design allows the use of readily available materials that have ASME design allowables. PBMR has concluded that these materials will not need significant development or data base generation for use with NGNP system design conditions. Although discussions in Sections 5 and 6 in this report suggest that testing is required to address ASME Code and NRC licensing issues related to the long design lifetime and normal operating temperatures that are very near, or possibly within, the transition region where long time creep and creep-fatigue effects need to be considered in the design.

Westinghouse recommends the use of an indirect power conversion cycle and an indirect hydrogen heat transport loop arranged in a serial fashion. The intermediate heat exchanger for the hydrogen heat transport loop would first be placed in the series to obtain the highest temperature gas from the nuclear reactor. After the IHX extracts $50 \mathrm{MW}$, the cooled primary loop gas will go to the PCU. The pressure of the primary loop is $9 \mathrm{MPa}$, and the secondary loop between 8.1 and $8.5 \mathrm{MPa}$. The power conversion cycle uses steam generators and a traditional Rankine Cycle to generate electricity and would be designed to receive the full power of the reactor.

\subsubsection{Reactor Pressure Vessel}

The vessel design consists of a welded cylindrical shell welded to the bottom head. The top head, containing numerous penetrations for fuel handling and reactor control systems, will be bolted to the cylindrical section. The dimensions are $6.8 \mathrm{~m}$ in diameter by $30 \mathrm{~m}$ high.

The RPV design configuration is such that its normal operating temperature range is from 300 to $350^{\circ} \mathrm{C}$. The steel specified is A 508 (forgings), A 533 (plates), and A 04 Grade 24B Class 3 (bolts). A separate stream of helium actively cools the RPV; however, calculations during postulated severe accident conditions indicate that the proposed RPV material temperature may be in the creep range. In normal operation, these LWR pressure vessel steels provide the following benefits:

- There is manufacturing experience in forging large-diameter, thick-ring sections, thus ensuring predictability through-thickness material properties.

- There is welding experience with these materials.

- The A 508 Grade 3 and A 533 materials are ASME qualified material for nuclear pressure vessel design. Confirmatory testing is required to address issues with long term creep and creep-fatigue behavior. 


\begin{tabular}{|c|lll|}
\hline NEXT GENERATION NUCLEAR PLANT & Identifier: & PLN-2803 & \\
REACTOR PRESSURE VESSEL MATERIALS & Revision: & 0 & \\
RESEARCH AND DEVELOPMENT PLAN & Effective Date: & $04 / 30 / 08$ & Page: 9 of 95 \\
\hline
\end{tabular}

- ASME design rules in the form of a nuclear code case for limited use of these materials are available in the temperature range of 371 to $538^{\circ} \mathrm{C}$.

- There is an extensive irradiation response database at the normal operating temperatures incorporated in the NRC licensing guidelines (NRC Regulatory Guide 1.99) and other international standards (American Society for Testing and Materials E 900).

- The IHX vessels, made from the same steel as the RPV, connect the primary system to the secondary heat transport loop and contain the heat exchangers.

\subsection{Interorganizational Structures}

\subsubsection{Generation IV International Forum}

The primary mechanism for international collaboration for materials $R \& D$ activities in support of a High-Temperature Gas Reactor (HTGR) is through the Generation IV International Forum (GIF). The GIF is an international effort working to advance nuclear energy to meet future energy needs. It includes eight partners that have now signed the treaty-level GIF International Framework Agreement: Canada, France, Japan, the Republic of Korea, the Republic of South Africa, Switzerland, the United Kingdom, the United States and the European Union. These partners have agreed on a framework for international cooperation in research necessary to build a future generation of nuclear energy systems.

Generation I nuclear reactor systems are early prototype plants such as Magnox. Generation II plants are the current generation of electricity producing commercial nuclear plants. Generation III plants are advanced Light Water Reactors (LWR) including Advanced Boiling Water Reactors. Generation IV plants are envisioned as highly economical, and proliferation resistant and feature enhanced safety and minimal waste; however they have yet to be commercially operated. The objective is to have HTGR systems available for international deployment by about 2030 when many of the worlds currently operating nuclear plants will be at or near the end of their operating lifetimes. Collaboration plans for each materials R\&D area are being developed, and once in place, collaboration will begin immediately.

The specific international vehicle that will govern the exchange of GIF information on structural materials relevant to the NGNP, is the Project Arrangement on Materials for the International Research and Development of the Very-High-Temperature Reactor (VHTR) Nuclear Energy System. This Project Arrangement (PA) is being established by the VHTR Materials Project Management Board and covers both individual and cooperative contributions by the international partners. The initial PA will cover the exchange of materials information generated during the time frame from 2007 to 2012, as well historical information that has heretofore not been publicly available. Information will be generated and exchanged on three major classes of materials: graphite for core components; metals for pressure boundaries, reactor internals, piping, heat exchangers, and balance of plant; and ceramics and ceramic composites for special needs, such as control rods, insulation, reactor internals, etc. All materials data identified within the PA that is produced by any partner shall be shared with all other partners for use in their national programs. Currently, about $\$ 120 \mathrm{M}$ in VHTR materials data has been committed as contributions by the GIF partners, including about $\$ 52 \mathrm{M}$ in generated metals data, plus significant amounts of proprietary historical data. Once the PA is signed and in effect, now anticipated to occur in the fall of 2008, detailed assessments will be made of the portion of the GIF VHTR materials data that will be available to meet the data needs of the NGNP and reduce the resources required by the project. 
NEXT GENERATION NUCLEAR PLANT REACTOR PRESSURE VESSEL MATERIALS RESEARCH AND DEVELOPMENT PLAN
Identifier: Revision: Effective Date: $04 / 30 / 08$

0
PLN-2803

Page: 10 of 95

\subsubsection{International Nuclear Energy Research Initiative Programs}

The International Nuclear Energy Research Initiative (INERI) programs are designed to allow a free exchange of ideas and data between U.S. and international researchers working in similar research areas. This international agreement encourages strong collaboration between research institutions where a benefit to both countries is anticipated. There are currently no active INERI programs addressing RPV materials issues.

\subsubsection{University Nuclear Engineering Research Initiative Programs}

Nuclear Engineering Research Initiative (NERI) programs facilitate technical cooperation between the NGNP Materials Program and universities. There is one NERI project at the University of WisconsinMadison that is addressing emissivity of candidate RPV core internal materials. Emissivity is being determined as a function of the time and temperature of exposure to impure helium and air. These experiments address materials behavior on the interior and exterior surface of the reactor system, respectively. 


\begin{tabular}{|c|lll|}
\hline NEXT GENERATION NUCLEAR PLANT & Identifier: & PLN-2803 & \\
REACTOR PRESSURE VESSEL MATERIALS & Revision: & 0 & \\
RESEARCH AND DEVELOPMENT PLAN & Effective Date: & $04 / 30 / 08$ & Page: 11 of 95 \\
\hline
\end{tabular}

\section{OPERATIONAL REQUIREMENTS}

\subsection{Base Case Definition}

Since the NGNP design has not yet been finalized, the base case discussed in this section has been identified as outlined above. This R\&D plan details the materials issues that result from this base case. A provision has been established to eventually increase the outlet temperature of the reactor or allow the pressure vessel to operate at higher temperature with active cooling reduced or eliminated. Any additional materials R\&D needs that result from this alternative case are specifically identified.

\subsubsection{Reactor Design}

The NGNP program has not yet determined whether the reactor will be of the pebble bed or prismatic type. Modeling and analysis of the two different configurations has indicated that there are small differences in the expected operating conditions of the RPV depending on which type is selected. However, for purposes of this development plan, the base case adequately addresses either configuration.

\subsubsection{Temperature}

The vendor's preconceptual designs all recommended using a phased approach to operate the plant at lower temperature in the startup and early operation of the plant to provide more design margin for the available materials of construction. Base case conditions assume an outlet gas temperature of $850^{\circ} \mathrm{C}$.

The maximum operating temperature of the RPV will depend on the NGNP design (pebble bed or prismatic block), outlet gas temperature, and power level selected. The PBMR design has calculated an RPV nominal operating range of 260 to $300^{\circ} \mathrm{C}$, achieved by using an independent cooling stream. The prismatic GT-MHR design estimated a vessel operating temperature of $495^{\circ} \mathrm{C}$ without active cooling. ${ }^{12}$ using RELAP5 calculated temperatures within these extremes as $360^{\circ} \mathrm{C}$ for the pebble bed design and $427^{\circ} \mathrm{C}$ for the prismatic design. Active cooling for the base case, as specified above, is such that its normal operating temperature range is 300 to $350^{\circ} \mathrm{C}$.

\subsubsection{Candidate Materials}

For these operating conditions the RPV structural material selection is A 508 (forgings) and A 533 (plates). There is extensive use of these materials in light water reactor RPVs for application at about $290^{\circ} \mathrm{C}$ and the alloys are in the nuclear section of the ASME Code for temperatures less than $371^{\circ} \mathrm{C}$.

\subsubsection{Dimensions}

The NGNP RPV will be 8 to $9 \mathrm{~m}$ in diameter and 200 to $300 \mathrm{~mm}$ thick, maximum. Although the reactor's height varies somewhat with the particular design, it is on the order of $20 \mathrm{~m}$ or more in height. Vessels with this diameter present challenges for both fabricability and transportation to the reactor site. These issues are discussed in greater detail in the NGNP Acquisition Strategy ${ }^{13}$ being developed concurrently with this R\&D plan. The likelihood of assembling the pressure vessel on site introduces potential technical difficulties. These issues are discussed in detail below. 


\begin{tabular}{|c|lll|}
\hline NEXT GENERATION NUCLEAR PLANT & Identifier: & PLN-2803 & \\
REACTOR PRESSURE VESSEL MATERIALS & Revision: & 0 & \\
RESEARCH AND DEVELOPMENT PLAN & Effective Date: & $04 / 30 / 08$ & Page: 12 of 95 \\
\hline
\end{tabular}

\subsection{Plant Transient Definitions}

\subsubsection{Cold Vessel Option}

As discussed in Section 1.2, the cold vessel option is the primary reference design case for the current NGNP concept. The Westinghouse design includes this concept and the reference/baseline materials for the cold vessel option (design temperatures $<371{ }^{\circ} \mathrm{C}$ ) are A 508 (forging) and A 533 (plate). These materials are currently the accepted choice for RPVs in U.S. LWRs.

\subsubsection{Normal Operating Temperature}

A separate stream of helium actively cools the RPV during normal operation in the base case. This cooling maintains the RPV below $371^{\circ} \mathrm{C}$.

\subsubsection{Anticipated Operational Occurrences}

An anticipated operational occurrence (AOO) encompasses planned and anticipated events. The doses from AOOs are required to meet normal operation public dose requirements. AOOs are used to set operating limits for normal operation modes and states. AOOs are event sequences with a mean frequency greater than $10^{-2}$ per plant-year. Startup/shutdown is a relatively frequent AOO.

PBMR gives an example as the loss of the power conversion system (PCS) where one of the active core heat removal systems works as specified. Since the heat is successfully removed from the core, this occurrence would have little impact on the RPV.

\subsubsection{Design Basis Events}

Design basis events (DBEs) encompass unplanned, off-normal events not expected in the plant's lifetime, but which might occur in the lifetimes of a fleet of plants. The doses from DBEs are required to meet accident public dose requirements. DBEs are the basis for the design, construction, and operation of the safety significant components (SSCs) during accidents. Separate from the design certification, DBEs are also evaluated in developing emergency planning measures. DBEs have event sequences with mean frequencies less than $10^{-2}$ per plant-year and greater than $10^{-4}$ per plant-year. Any of a number of small break scenarios in the helium pressure boundary are examples of DBEs given by PBMR.

It is likely that a loss of flow leading to a high pressure conduction cooldown (HPCC) and loss of coolant leading to a low pressure conduction cooldown (LPCC) will be defined as DBE's. The HPCC results in decay heat that is more uniformly distributed within the core and vessel than during an LPCC because the system remains at high pressure. The LPCC is typically initiated by a small leak of the primary coolant, resulting in depressurization and initiating a reactor trip. In both events, the shut-down cooling system fails to start and decay heat is removed passively by thermal radiation and natural convection from the reactor vessel. ${ }^{14}$ Peak temperatures for these events have been reported for the fuel, the control rods, and the RPV. The calculated vessel temperature for this case is well above the $371^{\circ} \mathrm{C}$ normal operating condition. Higher vessel temperatures resulting from an LPCC may affect the properties of A 508 and A 533. These possible degradation mechanisms are considered in detail in this report and accounted for in the R\&D plan.

\subsubsection{Beyond Design Basis Events}

Beyond Design Basis Events (BDBEs) are rare, off-normal events of lower frequency than DBEs. BDBEs are evaluated to ensure that they do not pose an unacceptable risk to the public. Separate from the 


\begin{tabular}{|c|lll|}
\hline NEXT GENERATION NUCLEAR PLANT & Identifier: & PLN-2803 & \\
REACTOR PRESSURE VESSEL MATERIALS & Revision: & 0 & \\
RESEARCH AND DEVELOPMENT PLAN & Effective Date: & $04 / 30 / 08$ & Page: 13 of 95 \\
\hline
\end{tabular}

design certification, BDBEs are also evaluated in developing emergency planning measures. Loss of the PCS, where the reactor control system (RCS) does not shut down the reactor is the example given by PBMR. BDBEs are defined as event sequences with mean frequencies less than $10^{-4}$ per plant-year and greater than $5 \times 10^{-7}$ per plant-year. BDBEs will not be considered in this report.

\subsubsection{Hot Vessel Option}

The secondary design case for the NGNP is the hot vessel option. This design option minimizes active cooling of the vessel and requires the RPV to operate at somewhat higher temperature. For this case design temperatures are $>371^{\circ} \mathrm{C}$ and less than the maximum allowable temperature specified in Section III, Subsection NH.

\subsubsection{Materials Options}

The reference/baseline material for this option for the AREVA design, and an alternative for GA, is Grade91 steel (9Cr-1Mo-V), designated as grade 91 in ASME Code specifications. A somewhat lower temperature material, $2 \frac{1}{4} \mathrm{Cr}-1 \mathrm{Mo}$, is the primary choice for the GA design. In the current ASME Code, design temperature limits for the RPV are $<371{ }^{\circ} \mathrm{C}$ for A 508/A 533, and $2 \frac{1}{4} \mathrm{Cr}-1 \mathrm{Mo}$, per Section III, Subsection NB design rules. For the elevated temperature rules in Section III, Subsection NH, the design temperature limits for the RPV (for the maximum design time of $300,000 \mathrm{~h}$ ) are $<575^{\circ} \mathrm{C}$ for $2 \frac{1}{4} \mathrm{Cr}-1 \mathrm{Mo}$ and $<650^{\circ} \mathrm{C}$ for Grade 91 . For these Cr-Mo steels, however, the allowable stress intensity values decrease with increasing temperature, such that the stress intensity values at the maximum temperatures allowed

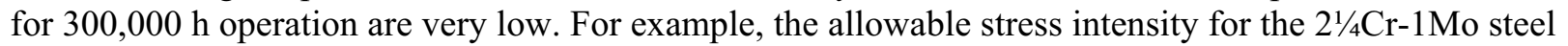
at $575^{\circ} \mathrm{C}$ is only $25 \mathrm{MPa}$, while it is $89 \mathrm{MPa}$ at $450^{\circ} \mathrm{C}$ and $123 \mathrm{MPa}$ at $400^{\circ} \mathrm{C}$. Allowable values for Grade 91 steel are $17 \mathrm{MPa}$ at $650^{\circ} \mathrm{C}, 85 \mathrm{MPa}$ at $550^{\circ} \mathrm{C}$, and $165 \mathrm{MPa}$ at $450^{\circ} \mathrm{C}$. Thus, as the design temperature increases, a thicker RPV will be required to accommodate the lower allowable stress intensity values. The maximum design temperature may be determined by a decision to avoid the thermal creep regime, in which case, the design temperature must be kept below about $425^{\circ} \mathrm{C}$ for the Cr-Mo steels in the hot vessel option.

\subsubsection{Normal Operating Temperature}

The normal operating temperature for the uncooled vessel condition has not been finalized in the preconceptual design. GA suggests a normal operating temperature for the vessel in their prismatic design of $440^{\circ} \mathrm{C}$. AREVA does not specify an operating temperature for their design. It may operate with an RPV temperature higher than $440^{\circ} \mathrm{C}$ since their design calls for the Grade 91 steel that has a higher temperature range compared to the steel that GA prefers. As noted above, if the design is constrained to have negligible creep in the vessel this temperature will be limited to about $425^{\circ} \mathrm{C}$.

\subsubsection{Anticipated Operational Occurrences}

An Anticipated Operational Occurrence (AOO) encompasses planned and anticipated events. The doses from AOOs are required to meet normal operation public dose requirements. AOOs are utilized to set operating limits for normal operation modes and states. AOOs are event sequences with a mean frequency greater than $10^{-2}$ per plant-year. Start-up/shut-down is a relatively frequent AOO that result in some cyclic loading of the vessel.

PBMR gives an example as the loss of the Power Conversion System (PCS) where one of the active core heat removal systems works as specified. Since the heat is successfully removed from the core, this occurrence would have little impact on the RPV. 


\begin{tabular}{|c|lll|}
\hline NEXT GENERATION NUCLEAR PLANT & Identifier: & PLN-2803 & \\
REACTOR PRESSURE VESSEL MATERIALS & Revision: & 0 & \\
RESEARCH AND DEVELOPMENT PLAN & Effective Date: & $04 / 30 / 08$ & Page: 14 of 95 \\
\hline
\end{tabular}

\subsubsection{Design Basis Events}

Design Basis Events (DBEs) encompass unplanned, off-normal events not expected in the plant's lifetime, but which might occur in the lifetimes of a fleet of plants. The doses from DBEs are required to meet accident public dose requirements. DBEs are the basis for the design, construction, and operation of the SSCs during accidents. Separate from the design certification, DBEs are also evaluated in developing emergency planning measures. DBEs have event sequences with mean frequencies less than $10^{-2}$ per plant-year and greater than $10^{-4}$ per plant-year. Any of a number of small break scenarios in the Helium Pressure Boundary are examples of DBEs given by PBMR.

It is likely that a loss of flow leading to a high pressure conduction cooldown (HPCC) and loss of coolant leading to a low pressure conduction cooldown (LPCC) will be defined as DBE's. The HPCC results in decay heat that is more uniformly distributed within the core and vessel than during an LPCC because the system remains at high pressure. The LPCC is typically initiated by a small leak of the primary coolant, resulting in depressurization and initiating a reactor trip. In both events, the shut-down cooling system fails to start and decay heat is removed passively by thermal radiation and natural convection from the reactor vessel. ${ }^{14}$ Peak temperatures for these events have been reported for the fuel, the control rods, and the RPV. The calculated vessel temperature for this case is well above the normal operating condition. It is possible that the temperature excursion resulting from a design basis event will not exceed the capability of the higher alloy vessel materials for a significant period of time. It is possible therefore, that the design basis event is of less concern for the hot vessel option compared to the cooled vessel option.

\subsubsection{Beyond Design Basis Events}

Beyond Design Basis Events (BDBEs) are rare, off-normal events of lower frequency than DBEs. BDBEs are evaluated to ensure that they do not pose an unacceptable risk to the public. Separate from the design certification, BDBEs are also evaluated in developing emergency planning measures. Loss of the PCS where the RCS does not shut down the reactor is the example given by PBMR. BDBEs are defined as event sequences with mean frequencies less than $10^{-4}$ per plant-year and greater than $5 \times 10^{-7}$ per plantyear. BDBEs are not considered in this report.

\subsection{Alternatives for RPV}

\subsubsection{Design Options}

The design options for the RPV are limited. The size of the vessel, as noted above, suggests that onsite fabrication will be necessary. The preferred structure would consist of stacked ring forgings assembled using circumferential welds. The alternative is to weld rolled plates, giving rise to longitudinal welds required to sustain the maximum hoop stresses but are to be avoided to the extent possible.

\subsubsection{Material Options}

There are few reasonable options for the NGNP RPV material beyond the A 508/A 533 and higher alloy steels described above. For consideration of a cold vessel option beyond the NGNP, higher-strength, low-alloy steels such as $3 \mathrm{Cr}-3 \mathrm{WV}$ are attractive alternatives because they offer sufficiently higher design stresses such that the RPV thickness could be reduced by at least $30 \%$. The $3 \mathrm{Cr}-3 \mathrm{WV}$ is not a code qualified material. 


\begin{tabular}{|c|lll|}
\hline NEXT GENERATION NUCLEAR PLANT & Identifier: & \multicolumn{2}{l|}{ PLN-2803 } \\
REACTOR PRESSURE VESSEL MATERIALS & Revision: & 0 & Page: 15 of 95 \\
RESEARCH AND DEVELOPMENT PLAN & Effective Date: & $04 / 30 / 08$ & \\
\hline
\end{tabular}

\subsubsection{Operating Conditions}

For the base case cooled vessel option, the reactor must be operated to maintain the vessel temperature below $371{ }^{\circ} \mathrm{C}$, regardless of changes to other operating conditions such as raising the outlet temperature above $850^{\circ} \mathrm{C}$.

Raising the outlet temperature above $850^{\circ} \mathrm{C}$ may require some active cooling, even for the hot vessel option. Simulations have also suggested that the vessel temperature is increased for a prismatic design compared to a pebble bed design, which may have to be taken into account for the uncooled vessel option.

\subsubsection{Future Operation}

Variants of both Grade 91 and the 2/1/4Cr-1Mo steels offer improved properties for hot vessel options beyond the current NGNP concept that are not presently included in all the necessary sections of the ASME Code. Grades 92 (9Cr-1/2Mo-WV) and 911 (9Cr-1Mo-2-WV), for example, offer increased stress rupture strength compared with Grade 91. Although these grades do not have the same level of maturity of the grade 91, the databases are relatively good and they appear to offer the opportunity for much better high-temperature strength. For the lower chromium steel, a vanadium modified version of the $2 \frac{1}{4} \mathrm{Cr}-1 \mathrm{Mo}$ $\left(2 \frac{1}{4} \mathrm{Cr}-1 \mathrm{Mo}-1 / 4 \mathrm{~V}\right)$ has been used rather extensively in the petrochemical industry. This steel was developed to increase the fabricability in thick sections for pressure vessels. There is a relatively large database available, but limited information on environmental interaction with helium coolant. Although the material is approved for use in Section VIII for non-nuclear service, it is not approved in Section III for nuclear service.

\subsubsection{Increased Outlet Gas Temperature}

As noted in the above sections, increasing the outlet temperature will have minimal impact on the cooled vessel option. There may be issues associated with the nominally uncooled option that will require some active cooling of the vessel for some circumstances with a higher outlet temperature. 


\begin{tabular}{|c|lll|}
\hline NEXT GENERATION NUCLEAR PLANT & Identifier: & PLN-2803 & \\
REACTOR PRESSURE VESSEL MATERIALS & Revision: & 0 & \\
RESEARCH AND DEVELOPMENT PLAN & Effective Date: & $04 / 30 / 08$ & Page: 16 of 95 \\
\hline
\end{tabular}

\section{CURRENT STATE-OF-THE-ART}

\subsection{Materials Research to Date}

\subsubsection{Open Literature and Internal Documents}

Funding priorities have prevented NGNP from supporting extensive RPV materials research to date. The discussion below is based on a review of existing literature.

\subsubsection{Candidate Materials}

Based on the vendor recommendations, three primary candidate alloys were considered for the RPV: low alloy steel A 508 (UNS K12042), Fe-2¹/4Cr-1Mo steel (UNS K21590), and Grade 91 steel (UNS K90901).

A sufficient database is available to validate the mechanical properties of A 508 steel. Data supporting the thermal aging effects on mechanical properties is promising, but additional information on long-term aging effects is needed. At present no data is available on the effects of impure helium on the long-term corrosion and mechanical properties of the material.

Alternative materials for a hot vessel option using materials currently included in the ASME Code include $2 \frac{1}{4} \mathrm{Cr}-1 \mathrm{Mo}$ steel. This alloy is in the nuclear section of the ASME code for steel in the annealed condition. As stated earlier, this was the primary steel of choice for the initial GA preconceptual design. This GA design acknowledged, however, that design alternatives are under review such that a cold vessel option could be considered with the use of the A 508/A 533 steels discussed above. GA favored $2 \frac{1}{4} \mathrm{Cr}-1 \mathrm{Mo}$ steel for the NGNP, primarily because of potential welding difficulties and lack of manufacturing and operating experience with the Grade 91 steel. There is an extensive database for the $2 \frac{1}{4} \mathrm{Cr}-1 \mathrm{Mo}$ alloy, including data in different operating environments such as helium. Another advantage is the extensive industrial experience with this alloy in many different applications around the world. It is commonly used in the petroleum industry for such things as thick and heavy section vessels.

Versions of this steel and modified chemistries exist that have higher strength, but only the annealed version $\left(2 \frac{1}{4} \mathrm{Cr}-1 \mathrm{Mo}\right)$ is incorporated in the nuclear section of the ASME Code because the properties of modified versions of the steel are not stable for extended periods at elevated temperature. Even though a discussion of $2 \frac{1}{4} \mathrm{Cr}-1 \mathrm{Mo}$ steel is retained in this document for completeness, it has become clear that the mechanical properties of the annealed version of the steel are so poor that it cannot be considered for the NGNP pressure vessel. GA will withdraw their recommendation to use this alloy in the April 2008 refinement of their preconceptual design.

In the annealed condition, $2 \frac{1}{4} \mathrm{Cr}-1 \mathrm{Mo}$ steel has relatively low strength and would require a very thick plate or forging to accommodate the NGNP pressure. In the normalized and tempered or quenched and tempered condition, however, $2 \frac{1}{4} \mathrm{Cr}-1 \mathrm{Mo}$ steel has higher strength in the range of LWR steels discussed for the cold vessel option. But, this higher strength version is not included in subsection NH of the ASME Code. This type of steel is currently in use for the RPV of the HTTR in Japan, in which the RPV operates at a nominal temperature of about 400 to $440^{\circ} \mathrm{C}$. There are some data regarding irradiation effects on $2 \frac{1}{4} \mathrm{Cr}-1 \mathrm{Mo}$ steel, but more relevant data would likely be required for this application.

LWRs in Eastern European countries, such as the VVER-440 reactors in Russia, use steels similar to the $2 \frac{1}{4} \mathrm{Cr}-1 \mathrm{Mo}$ steel with about $0.25 \%$ vanadium for which there is a large amount of irradiation effects data available at irradiation temperatures from about 265 to $290^{\circ} \mathrm{C}$. An evaluation of these data must be 


\begin{tabular}{|c|lll|}
\hline NEXT GENERATION NUCLEAR PLANT & Identifier: & PLN-2803 & \\
REACTOR PRESSURE VESSEL MATERIALS & Revision: & 0 & \\
RESEARCH AND DEVELOPMENT PLAN & Effective Date: & $04 / 30 / 08$ & Page: 17 of 95 \\
\hline
\end{tabular}

made in the context that the older steels used in these RPVs have copper and quite high phosphorus levels that contribute to relatively high radiation sensitivity.

It is very likely that a version of the $21 / 4 \mathrm{Cr}$ - 1 Mo steel modified by vanadium additions will be required for the heavy sections required by the NGNP vessel, recognizing that the vanadium modified version of this alloy is not in the nuclear section of the ASME code. There is adequate tensile data on the $\mathrm{Fe}-2 \frac{1}{4} \mathrm{Cr}-1 \mathrm{Mo}-1 / 4 \mathrm{~V}$ in the temperature range of interest in NGNP RPV, but only limited creep data is available for the steel. Additional data are therefore needed, especially at elevated temperatures that encompass depressurized conduction cool down conditions. Substantial data on the creep fatigue properties, performance characteristics in impure helium, and properties of thick section material are also needed prior to selecting $\mathrm{Fe}-2 \frac{1}{4} \mathrm{Cr}-1 \mathrm{Mo}-1 / 4 \mathrm{~V}$ for the NGNP RPV.

A substantial database on the baseline mechanical properties of the Grade 91 steel is currently available. Sufficient data are also available on the long-term thermal aging effects on the mechanical properties for this steel. However, additional data are needed for the mechanical properties of thick sections, where there is the possibility of retained ferrite in this martensitic steel that can lead to embrittlement. As with the other alloys under consideration, properties in impure helium must also be explored. The primary reference material for the hot vessel RPV option is Grade 91, a ferritic-martensitic steel developed for relatively high temperature applications. This is the primary material selected for the AREVA preconceptual design and the alternative material selected for the GA preconceptual design. The Grade 91 is a relatively mature material, as indicated by its inclusion in Section III of the ASME Boiler and Pressure Vessel Code (BPVC), including in subsection NH on high temperature materials. A large database exists on mechanical properties for this material, including the effects of long-term thermal aging, but, additional data on creep-fatigue to evaluate the extremely conservative limits that currently exist for this material and on very thick sections representative of that for the RPV are still needed.

A database also exists on the effects of irradiation on mechanical properties, although there may be data gaps relative to operating conditions for the specific design of the NGNP. Some data exist on behavior of the material in contaminated helium, but the database is insufficient. A substantial amount of data exists relative to irradiation effects at relatively high dose levels, indicating that this ferritic-martensitic steel is quite radiation resistant at temperatures above $400^{\circ} \mathrm{C}$. At lower temperatures, the steel is more sensitive and subject to embrittlement, dependent on the specific temperature and the dose. Assuming the irradiation level is low for the cold-vessel option as discussed above, radiation effects are not expected to present a major issue for this material under the hot-vessel option. For regulatory purposes, however, it is likely that relevant experimental data will be required to demonstrate this.

Other issues to be discussed in more detail include welding, especially in regards to critical observations of Type IV cracking in the heat affected zone, the availability of forging capability for the very large ring forgings, and field fabrication. Subsection NH of the ASME Code applies to all of these issues for operation to $300,000 \mathrm{~h}$, whereas the current design concept of 60 years would require over $420,000 \mathrm{~h}$, if operated at $80 \%$ efficiency.

\subsection{ASME Code Status}

Any new material or engineered material system to be used in the NGNP reactor design will require NRC acceptance prior to implementation in the NGNP. Activities would include development of American Society for Testing and Materials (ASTM) International testing standards, ASME performance specifications, ASME design rules, and ASME inspection requirements. These items would provide NRC with acceptable evidence of the material's suitability for the NGNP application, which may involve years of development activities before a topical report could be submitted to NRC for consideration. 


\begin{tabular}{c|lll|}
\hline NEXT GENERATION NUCLEAR PLANT & Identifier: & PLN-2803 & \\
REACTOR PRESSURE VESSEL MATERIALS & Revision: & 0 & \\
RESEARCH AND DEVELOPMENT PLAN & Effective Date: & $04 / 30 / 08$ & Page: 18 of 95 \\
\hline
\end{tabular}

\subsection{ASME Boiler and Pressure Vessel Code}

The general requirements for Divisions 1 and 2 rules for construction of nuclear facility components are given in Section III, Subsection NCA of the ASME BPVC.

Section III, Division 1 of the BPVC contains specific rules for the construction of different nuclear facility components. The coverage of these construction rules by various subsections in Section III is shown in Table 2.

Table 2. Applicability of rules in Section III of the ASME Code to component construction.

\begin{tabular}{|cl|}
\hline $\begin{array}{c}\text { Subsection of Section III, } \\
\text { Div 1, BPVC }\end{array}$ & Coverage \\
\hline NB & Class 1 Components \\
NC & Class 2 Components \\
ND & Class 3 Components \\
NE & Class MC Components \\
NF & Supports \\
NG & Core Support Structures \\
NH & Class 1 Components in Elevated Temperature Service \\
\hline
\end{tabular}

Table 3.

Section III, Division 1 Code cases that were developed for elevated temperature service are listed in

Table 3. Division 1 Code cases that were developed for elevated temperature service.

\begin{tabular}{|c|c|}
\hline $\begin{array}{l}\text { Code Case, Section III, } \\
\text { Div } 1\end{array}$ & Coverage \\
\hline N-201-5 & $\begin{array}{l}\text { Class CS (Core Support) Components in Elevated } \\
\text { Temperature Service }\end{array}$ \\
\hline N-290-1 & Expansion Joints in Class 1, Liquid Metal Piping \\
\hline $\mathrm{N}-253-14$ & $\begin{array}{l}\text { Construction of Class } 2 \text { or Class } 3 \text { Components for } \\
\text { Elevated Temperature Service }\end{array}$ \\
\hline $\mathrm{N}-254$ & $\begin{array}{l}\text { Fabrication and Installation of Elevated Temperature } \\
\text { Components, Class } 2 \text { and } 3\end{array}$ \\
\hline N-257 & $\begin{array}{l}\text { Protection Against Overpressure of Elevated } \\
\text { Temperature Components, Classes } 2 \text { and } 3\end{array}$ \\
\hline $\mathrm{N}-467$ & $\begin{array}{l}\text { Testing of Elevated Temperature Components, Classes } 2 \\
\text { and } 3\end{array}$ \\
\hline N-499-2 & $\begin{array}{l}\text { Use of A } 533 \text { Plate and A } 508 \text { Forgings and their } \\
\text { Weldments for Limited Elevated Temperature Service }\end{array}$ \\
\hline
\end{tabular}

NGNP RPV is a Class 1 component and the relevant rules of construction are covered under Subsections NB and Code Case N-499 for the cold vessel option and Subsection NH for the hot vessel option. 


\begin{tabular}{|c|lll|}
\hline NEXT GENERATION NUCLEAR PLANT & Identifier: & PLN-2803 & \\
REACTOR PRESSURE VESSEL MATERIALS & Revision: & 0 & \\
RESEARCH AND DEVELOPMENT PLAN & Effective Date: & $04 / 30 / 08$ & Page: 19 of 95 \\
\hline
\end{tabular}

\subsubsection{NB}

\subsubsection{Subsection NB and Relevant Code Case}

The rules of construction in Subsection NB are based on the design-by-analysis approach in which detailed stress analysis is required to demonstrate that stress intensities through sections in the component do not exceed the allowable limits.

The Design-by-Analysis approach requires categorizing stresses into primary (load controlled), secondary (displacement controlled), and peak (local stress elevation) stresses with different stress limits. Different stress limits are used for design conditions; operating conditions grouped into Service Level A (normal), B (upset), C (emergency), and D (faulted) events; and test conditions.

The various stress limits are developed to guard against the structural failure modes of ductile rupture from short-term loading, gross distortion due to incremental collapse and ratcheting, loss of function due to excessive deformation, and buckling due to short-term loadings. Additional considerations in setting the stress limits are the consequence of failure and the probability of occurrence.

The design conditions include design pressure, design temperature, and design mechanical loads. Sizing of component dimensions is established by using the design conditions. Per Subsection NCA, the design temperature is the expected maximum mean metal temperature through the thickness of the part considered for which Level A (normal) service limits are specified.

The maximum temperature limit permitted by Subsection NB for Class 1 components is $371^{\circ} \mathrm{C}$ $\left(700^{\circ} \mathrm{F}\right)$ for ferritic steels and $427^{\circ} \mathrm{C}\left(800^{\circ} \mathrm{F}\right)$ for austenitic steels. The values for the stress limit, $S_{m}$, for Subsection NB code materials are tabulated in Section II, Part D, Tables 2A (ferritic steels) and 2B (austenitic steels). Table 4 of Part D gives the stress limits for bolting materials. The Subsection NB rules shall not be used for materials at metal and design temperatures that exceed the maximum temperature limits listed in the applicability columns of these tables. These maximum temperature limits are adopted to ensure that creep deformation is negligible and does not negatively impact the fatigue performance of a component.

Fracture toughness requirements are specified in Subsection NB for pressure-retaining materials and material welded thereto. A list of materials that are exempted from the fracture toughness requirements is provided. RPV materials are not among the exempted list.

Rules that govern the deterioration of material caused by service are not covered by Subsection NB. The owner is the responsible to account for such effects. For the case of neutron irradiation in light water reactors (LWR), procedures for calculating the effects of neutron irradiation embrittlement of the lowalloy steels are provided in NRC Regulatory Guide 1.99.

The criteria document for Class 1 components covered by Subsection NB is given ${ }^{15}$. A detailed summary of the Subsection NB rules is given in the Companion Guide to the BPVC ${ }^{16}$. A recent overview of the Subsection NB rules is given in an NRC NUREG report. ${ }^{17}$

Significance to NGNP. For the NGNP cold vessel concept, the reactor vendor needs to limit the RPV design temperature, which bounds the maximum through-wall average metal temperature for Service Level A (normal) conditions, to a maximum of $371^{\circ} \mathrm{C}\left(700^{\circ} \mathrm{F}\right)$ in order to apply the Subsection NB rules to the RPV design. 


\begin{tabular}{|c|lll|}
\hline NEXT GENERATION NUCLEAR PLANT & Identifier: & PLN-2803 & \\
REACTOR PRESSURE VESSEL MATERIALS & Revision: & 0 & \\
RESEARCH AND DEVELOPMENT PLAN & Effective Date: & $04 / 30 / 08$ & Page: 20 of 95 \\
\hline
\end{tabular}

\subsubsection{Code Case N-499-2}

Code case N-499-2 was developed to provide rules of construction for two specific low-alloy steels: A 533 (UNS K12539) and A 508 forgings (UNS K12042) and their weldments for short-term temperature excursions above the temperature limit of $371^{\circ} \mathrm{C}\left(700^{\circ} \mathrm{F}\right)$.

Only Level B (upset), C (emergency), and D (faulted) service events are allowed. Metal temperatures are limited to $427^{\circ} \mathrm{C}\left(800^{\circ} \mathrm{F}\right)$ during Level B events, and $538^{\circ} \mathrm{C}\left(1000^{\circ} \mathrm{F}\right)$ during Level $\mathrm{C}$ and $\mathrm{D}$ events. The total duration of such temperature excursions is limited to 3,000 hours in the temperature range of $371^{\circ} \mathrm{C}\left(700^{\circ} \mathrm{F}\right)$ to $427^{\circ} \mathrm{C}\left(800^{\circ} \mathrm{F}\right)$ and 1,000 hours in the range of $427^{\circ} \mathrm{C}\left(800^{\circ} \mathrm{F}\right)$ to $538^{\circ} \mathrm{C}\left(1000^{\circ} \mathrm{F}\right)$. The number of Level $\mathrm{C}$ and $\mathrm{D}$ events above $427^{\circ} \mathrm{C}\left(800^{\circ} \mathrm{F}\right)$ is limited to three. Even for these few cycles, hold time effects reduce design margin. For the events permitted by this code case, Subsection NH rules of construction shall be used with the design data provided in the code case to perform design evaluations.

Significance to NGNP. The use of A 533 plates and/or A 508 forgings and their weldments as the RPV materials in the cold vessel concept permits short term off-normal temperature excursions above $371^{\circ} \mathrm{C}\left(700^{\circ} \mathrm{F}\right)$. This provides design flexibility in the RPV cold vessel concept. However, elevated temperature design rules in Subsection NH have to be used for these permitted temperature excursions.

\subsubsection{Recent Code Activities}

\subsubsection{Section III}

The topic that generated the most controversy in the Section III design and analysis area is the impact of coolant environments (primary water) on fatigue performance of LWR structural materials. It has been demonstrated from laboratory data that LWR environments have a significant adverse impact on the fatigue life of reactor structural materials. Section III fatigue design curves are based on laboratory data tested in air and at ambient temperatures. Due to the inability of the ASME Section III code committees to arrive at a consensus to resolve the matter, NRC has mandated in Regulatory Guide 1.207-the so-called "Fen" approach - to account for LWR environments. This places a severe penalty on fatigue usage, which affects low-alloy steels and stainless steels. ASME code committees are now close to adopting the Fen approach, which is similar to that given in Regulatory Guide 1.207.

Significance to NGNP. This issue has raised significant visibility within NRC, ASME, and the industry on environmental effects. While this is related to LWR coolant environments, it would be prudent for the NGNP project to proactively collect necessary data to demonstrate that this is not an issue for low alloy steels in impure He environments.

\subsubsection{Section VIII}

Significant changes and improvements have been made to code rules in Section VIII Division 2, which are based on design-by-analysis. High level changes are highlighted below:

Design methods:

1. More detailed guidance on elastic-plastic collapse finite element analyses (FEA), limit load FEA, and elastic-plastic fatigue FEA methodology.

2. A new failure mode called local failure has been introduced. This is similar to the "triaxial stress limit" in Subsection NB of Section III. Guidance on elastic method and elastic-plastic method to address this failure mode has been introduced.

3. More detailed guidance on elastic-plastic buckling calculation is provided. 


\begin{tabular}{|c|lll|}
\hline NEXT GENERATION NUCLEAR PLANT & Identifier: & PLN-2803 & \\
REACTOR PRESSURE VESSEL MATERIALS & Revision: & 0 & \\
RESEARCH AND DEVELOPMENT PLAN & Effective Date: & $04 / 30 / 08$ & Page: 21 of 95 \\
\hline
\end{tabular}

4. New fatigue assessment method for welds based on the approach of Dr. Pingsha Dong of Battelle is implemented.

5. New guidance on improved elastic-plastic ratcheting analysis. This is based on applying a limited number of repetitive cycles to demonstrate shakedown. It provides a definite go or no-go assessment on the propensity for ratcheting in a structural component.

Design rules:

1. The design factor is changed from $S_{m}=S_{u} / 3$ to $S_{m}=S_{u} /(2.4)$.

2. The use of Von Mises criterion instead of Tresca criterion is adopted to calculate the stress intensities in structural application.

Significance to NGNP. While these improvements in the design methods and design rules are for non-nuclear applications, many of the advancement made in Section VIII Division 2 will find its way to Subsection NB. It is of interest to the NGNP project to monitor the progress.

\subsubsection{Section $X I$}

Recent laboratory data show that the fatigue crack growth rates for 300 series stainless steels (e.g., 304, 316) in LWR environments are 20 times higher than in air. Again, the ASME fatigue crack growth rate equation is based on air data. The matter has not been resolved within ASME code committees, but it has generated significant interest from all quarters.

Significance to NGNP. Again, this heightens the general awareness of environmental effects within NRC. It is of interest to the NGNP project to monitor this development in order to proactively apply any applicable lessons-learned.

\subsubsection{NH}

The current Subsection NH criteria and material coverage originate largely from the liquid-metal reactor (LMR) program of the late 1960s, 70s, and early 80s. In the late 1960s, the Atomic Energy Commission initiated a Materials and Structures Technology program and simultaneously asked the ASME B\&PV Committee to charge an expanded Subgroup on Elevated Temperature Design with developing the design rules that eventually provided the basis for Subsection NH.

The purpose of the early code cases for elevated temperature service was to provide rules for construction which account for the effects of deformation and damage due to creep with the same rigor that Subsection NB addressed the temperature regime below which creep effects are significant. As in Subsection NB, the rules of construction in Subsection NH are based on the Design-by-Analysis approach. Stresses are still categorized into primary, secondary and peak stresses. However, due to the significant difference in the structural behavior at elevated temperature as compared with that at low temperature, Subsection NH has adopted the approach of placing limits on two basic types of controlled quantities: (i) load-controlled, and (ii) deformation-controlled.

The structural failure modes covered by Subsection NH for elevated temperature service include the following time-independent, structural failure modes of Subsection NB:

1. Ductile rupture from short-term loading.

2. Gross distortion due to incremental collapse and ratcheting.

3. Loss of function due to excessive deformation. 


\begin{tabular}{|c|lll|}
\hline NEXT GENERATION NUCLEAR PLANT & Identifier: & PLN-2803 & \\
REACTOR PRESSURE VESSEL MATERIALS & Revision: & 0 & \\
RESEARCH AND DEVELOPMENT PLAN & Effective Date: & $04 / 30 / 08$ & Page: 22 of 95 \\
\hline
\end{tabular}

4. Buckling due to short-term loading.

5. And new time-dependent structural failure modes.

6. Creep rupture from long-term loading.

7. Creep-fatigue failure.

8. Creep-buckling due to long term loading.

Load-controlled quantities are primary stresses. But at elevated temperatures, some stresses that would have been considered as secondary per the familiar classification of Subsection NB take on the characteristics of primary stresses due to elastic follow-up. To account for differing loads, times and temperatures, the stress allowable $S_{m}$ from Subsection NB is retained for time-independent loads, and a new time-dependent stress allowable $S_{t}$, which is based on the time to $1 \%$ total strain, time to start of tertiary creep, and creep rupture strength, is introduced for time-dependent loads. The stress $S_{m t}$ defined as the lower of $S_{m}$ and $S_{t}$ is also introduced.

These allowable stresses are used to set different primary stress limits for Level A (normal), B (upset), C (emergency), and D (faulted) service events, similarly to Subsection NB. But time-of-loading is an additional variable that needs to be considered due to the time dependency. A different criterion adopted from Sections I and VIII and based on 100,000-hr creep rupture properties and a creep rate of $0.01 \%$ per $1,000 \mathrm{hr}$ is used to set the primary stress limits for design conditions. Only elastic analysis results are required to satisfy the primary stress limits. The primary stress limits cover structural failure modes 1 and 5 listed above.

The deformation-controlled quantities are stresses, strains, and deformations resulting from load, deflection and strain compatibility. Acceptable deformation-controlled limits are given in Appendix T of Subsection NH and they cover strain limits/ratcheting, creep-fatigue damage, and buckling and welds. Strain limits and creep-fatigue damage rules can be satisfied using either elastic or inelastic analysis methods. Elastic analysis rules, sometimes referred to as Simplified Methods, were originally envisioned as simpler, more conservative and less costly screening method. Inelastic rules which required inelastic analyses were envisioned as more costly and time consuming, but adequately conservative "gold standard." Failure modes 2, 3, and 6 listed above are covered by the strain limits and creep-fatigue damage rules of Appendix T.

In addition to deformation-controlled limits Appendix $\mathrm{T}$ also includes rules for general loading conditions evaluated with inelastic analysis, including the time dependent effects of creep. Rules to address structural failure modes 4 and 7 on short-term and long-term buckling are given in Appendix T.

Subsection NH provides analysis requirements for the design and location of all pressure retaining and other primary structural welds under elevated temperature service. Special examination requirements are included for welded joints. Permissible weld materials are limited. Creep stress-rupture reduction factors for weldments are given as a function of temperature and time. Subsection NH further provides special limits on strain accumulations in the weld regions by limiting the weld strains to be one-half of the strain limits permitted for the parent material. The allowable number of design cycles for weldments is restricted to one-half that of the parent metal. The allowable time for creep rupture damage is also reduced by multiplying the stress by the weld strength reduction factor when determining the time-torupture. Subsection $\mathrm{NH}$ also imposes additional examination requirements on category A, B, C, and D vessel weld joints.

Subsection NH also provides component design rules that cover vessels, pumps, valves, and piping. Subsection NH provide numerous restrictions on the use of Subsection NB component rules, charts, and 


\begin{tabular}{|c|lll|}
\hline NEXT GENERATION NUCLEAR PLANT & Identifier: & PLN-2803 & \\
REACTOR PRESSURE VESSEL MATERIALS & Revision: & 0 & \\
RESEARCH AND DEVELOPMENT PLAN & Effective Date: & $04 / 30 / 08$ & Page: 23 of 95 \\
\hline
\end{tabular}

formulas for meeting the design and service limits. These component rules generally require that creep effects are not significant. The exception is piping, where the use of stress indices is specifically permitted for meeting deformation-controlled limits. Guidance on fabrication and installation is provided in Subsection NH as supplement to Subsection NB. It emphasizes cold-work effects such as loss of ductility, particularly for 304 and 316 stainless steels, and loss of creep-rupture strength, particularly at low strain and long times. Guidance on welding and brazing qualifications is provided by reference to Subsection NB, which invokes Section IX.

Guidance on examination is also provided in Subsection NH to supplement Subsection NB. Due to the concern that single radiography of Subsection NB might miss a crack-like defect that is more likely to propagate at elevated temperature, additional volumetric examinations that include radiography plus ultrasonic, radiograph plus eddy current, and radiography from two angles are required. Guidance on testing is provided in Subsection NH to replace that in Subsection NB. Pneumatic testing is made equal to hydrostatic testing. Helium leak testing is required only on certain closure welds. The use of internal pressure testing is permitted as the basis to test components and appurtenances that will be subjected to external pressure loads in service.

Guidance on overpressure protection is provided in Section NH to supplement Subsection NB. Changes are incorporated to reflect the characteristics of sodium systems. Use of rupture disk as a sole means of overpressure protection is permitted.

The number of Subsection NH code materials for elevated temperature service is much smaller than that of Subsection NB. The temperature limits for NH code materials, other than bolting, at 300,000 hr and the maximum temperatures at which fatigue curves are provided are listed in Table 4.

Table 4. Temperature limits for NH code materials.

\begin{tabular}{|c|c|c|}
\hline \multirow[b]{2}{*}{ NH Code Materials, Other Than Bolting } & \multicolumn{2}{|c|}{ Maximum Temperature } \\
\hline & $\begin{array}{l}\text { For Stress Allowables } \\
\qquad S_{o}, S_{m t}, S_{t}, S_{r} \text { up to } \\
\quad 300,000 \mathrm{hrs}^{\mathrm{a}}\end{array}$ & For Fatigue Curves \\
\hline 304 stainless steels (UNS S30400, S30409) & $816^{\circ} \mathrm{C}\left(1,500^{\circ} \mathrm{F}\right)$ & $704^{\circ} \mathrm{C}\left(1,300^{\circ} \mathrm{F}\right)$ \\
\hline 316 stainless steel (UNS S31600, S31609) & $816 \mathrm{C}\left(1,500^{\circ} \mathrm{F}\right)$ & $704^{\circ} \mathrm{C}\left(1,300^{\circ} \mathrm{F}\right)$ \\
\hline Alloy 800H (UNS N08810) & $760^{\circ} \mathrm{C}\left(1,400^{\circ} \mathrm{F}\right)$ & $760^{\circ} \mathrm{C}\left(1,400^{\circ} \mathrm{F}\right)$ \\
\hline 2⿺辶⿳亠丷厂巾 Cr 1Mo steel, annealed condition (UNS K21590) & $593^{\circ} \mathrm{C}\left(1,100^{\circ} \mathrm{F}\right)^{\mathrm{b}}$ & $593^{\circ} \mathrm{C}\left(1,100^{\circ} \mathrm{F}\right)$ \\
\hline Grade 91 steel (UNS K90901) ${ }^{\mathrm{c}}$ & $649^{\circ} \mathrm{C}\left(1,200^{\circ} \mathrm{F}\right)$ & $538^{\circ} \mathrm{C}\left(1,000^{\circ} \mathrm{F}\right)$ \\
\hline \multicolumn{3}{|c|}{$\begin{array}{l}\text { a. The primary stress limits are very low at } 300,000 \mathrm{hr} \text { and the maximum temperature limit } \\
\text { b. Temperatures up to } 649^{\circ} \mathrm{C}\left(1,200^{\circ} \mathrm{F} \text { ) are allowed up to } 1,000 \text { hours }\right. \\
\text { c. The specifications for Grade } 91 \text { steel covered by Subsection NH are A182 (forgings), A213 (small tube), A335 (small pipe), } \\
\text { and A387 (plate). The forging size for A182 is not to exceed } 4540 \mathrm{~kg} \text {. }\end{array}$} \\
\hline
\end{tabular}

The temperature and time limits for $\mathrm{NH}$ code materials for bolting are listed in Table 5.

The delta ferrite limits of 5-FN minimum in Subsection NB is changed to a range of 3-FN to 10-FN in Subsection NH. Ferrite numbers refer to the volume fraction of delta ferrite in the microstructure. Reduction in the yield and tensile strength due to aging is required in Subsection NH. In addition to meeting other materials acceptance requirements specified in Subsection NB, creep-fatigue acceptance test is required for 304 and 316 stainless steels. The creep-fatigue acceptance test requirement was implemented in response to problems encountered in the field where a heat of 304 stainless steel passed 
NEXT GENERATION NUCLEAR PLANT

REACTOR PRESSURE VESSEL MATERIALS

RESEARCH AND DEVELOPMENT PLAN

$\begin{array}{lll}\text { Identifier: } & \text { PLN-2803 } \\ \text { Revision: } & 0 \\ \text { Effective Date: } & 04 / 30 / 08\end{array}$

Page: 24 of 95

the then required acceptance tests but exhibited very low creep ductility, $0.5 \%$ in a $10,000 \mathrm{hr}$ test. The creep-fatigue acceptance test involves fatigue test in air at $595^{\circ} \mathrm{C}\left(1,100^{\circ} \mathrm{F}\right)$ at an axial strain range of $1.0 \%$ with a one-hour hold period at the maximum positive strain point in each cycle. Test should be performed to ASTM Standard E 606. The material lot is acceptable if the test exceeds 200 cycles without fracture or a $20 \%$ drop in the load range.

Table 5. Temperature limits for Code materials for bolting

\begin{tabular}{|c|c|c|}
\hline NH code materials for bolting & $\begin{array}{c}\text { Maximum Temperature for } \\
\text { Stress Allowables } \\
\mathrm{S}_{0}, \mathrm{~S}_{\mathrm{mt}} \\
\end{array}$ & $\begin{array}{c}\text { Maximum Duration for } \\
\text { Stress Allowables } \\
\mathrm{S}_{0}, \mathrm{~S}_{\mathrm{mt}} \\
\end{array}$ \\
\hline $\begin{array}{l}304 \text { stainless steels (B8 Class 1, and B8A, } \\
\text { Class 1A) }\end{array}$ & $704^{\circ} \mathrm{C}\left(1,300^{\circ} \mathrm{F}\right)$ & 200,000 hours \\
\hline $\begin{array}{l}316 \text { stainless steel (B8M Class 1, and B8MA, } \\
\text { Class 1A) }\end{array}$ & $704^{\circ} \mathrm{C}\left(1,300^{\circ} \mathrm{F}\right)$ & 200,000 hours \\
\hline Alloy 718 (UNS N07718) & $566^{\circ} \mathrm{C}\left(1,050^{\circ} \mathrm{F}\right)$ & 300,000 hours \\
\hline
\end{tabular}

Data in support of the development of various stress allowables in Subsection NH are based on tests in air. Similar to Subsection NB, rules that govern the deterioration of material caused by service are not covered by Subsection NH. The owner is responsible to account for such effects. Currently, design correlations to account for the environmental effects due to neutron irradiation or impure helium coolant are unavailable.

The criteria documents for Class 1 components covered by Subsection NH are given in the literature ${ }^{18-21}$ and a detailed summary of the Subsection NH rules is given in the Companion Guide to the BPVC. ${ }^{16}$ A recent overview of the Subsection NH rules is given in a NRC NUREG report ${ }^{17}$.

Significance to NGNP. Per vendor preconceptual design reports, the metal temperatures for the RPV designs from AREVA and GA designs exceed the Subsection NB limit of $371^{\circ} \mathrm{C}\left(700^{\circ} \mathrm{F}\right)$. Thus, the use of the design procedures from Subsection NH is required.

\subsubsection{Recent Code Activities on Subsection NH}

The task activities carried out in the first round of the DOE initiative to address ASME code issues, as summarized in Section 4.1.1, have had the most significant and positive impact on the Subsection NH code rules. Similar impact is expected from the task activities from the second round.

Elevated temperature code rule developments for Section VIII applications are currently being carried out. The tasks include:

- Determine time-dependent allowable stress for Section VIII, Div 1

- Extend time-dependent range for low-chrome alloys

- Extend fatigue rules to $900 \mathrm{~F}$ for low-chrome alloys

- Analyze creep-buckling methods

- Design a bolted flange at elevated temperature

- Insights learned from these projects could be helpful in improving Subsection NH code rules. 


\begin{tabular}{|c|lll|}
\hline NEXT GENERATION NUCLEAR PLANT & Identifier: & PLN-2803 & \\
REACTOR PRESSURE VESSEL MATERIALS & Revision: & 0 & \\
RESEARCH AND DEVELOPMENT PLAN & Effective Date: & $04 / 30 / 08$ & Page: 25 of 95 \\
\hline
\end{tabular}

\subsubsection{DOE Initiative to Address ASME Code Issues}

Nuclear structural component construction in the U.S. complies with Section III of the ASME Boiler and Pressure Vessel Code, although licensing is granted by the NRC. A number of technical topics were identified by DOE, Oak Ridge National Laboratory (ORNL), INL, and ASME to have particular value with respect to the ASME Code. A three-year collaboration between DOE and ASME was established that addresses twelve topics in support of an industrial stakeholder's application for licensing of a Generation IV nuclear reactor.

The majority of these tasks are relevant to action items within ASME Section III Subsection NH, and the nature of the topics inherently include significant overlap, and in some cases parallel activities on the same issue.

\subsubsection{First Round Tasks}

The first five topics had been funded in the first round of this initiative. All of these tasks are now complete and final reports have been submitted by the task investigators to ASME. The results of the investigations are summarized below.

\section{Task 1: Verification of Allowable Stresses-}

The ASME Section III Subsection NH criteria for estimating the time-dependent allowable stress $S_{t}$ include the average strength for $1 \%$ total strain, $80 \%$ of the minimum strength for tertiary creep, and $67 \%$ of the minimum rupture strength values.

- Part I. Alloy $800 H$ base metal

Alloy $800 \mathrm{H}$ is not relevant to components considered in this report and will not be discussed here.

- Part II. Alloy 800H weldment

Alloy $800 \mathrm{H}$ weldment is not relevant to components considered in this report and will not be discussed here.

\section{- Part III. Grade 91 steel}

The objective of Part III of this task was to review the allowable stresses for Grade 91 steel and to perform a data gap analysis for conditions of interest to VHTR.

\section{- Results and Recommendations}

The creep-rupture data for Grade 91 steel were collected and reviewed to determine if it met the needs for recommending time-dependent strength values, $S_{t}$, for coverage in ASME Section III Subsection $\mathrm{NH}$ to $650^{\circ} \mathrm{C}\left(1200^{\circ} \mathrm{F}\right)$ and 600,000 hours.

The accumulated database included over 300 tests for $1 \%$ total strain, nearly 400 tests for tertiary creep, and nearly 1700 tests to rupture. Procedures for analyzing creep and rupture data for Subsection NH were reviewed and compared to the procedures used to develop the current allowable stress values for Grade 91 steel for Section II, Part D.

Time-temperature-stress parametric formulations were selected to correlate the data and make predictions of the long-time strength. It was found that the stress corresponding to $1 \%$ total strain and the initiation of tertiary creep were not the controlling criteria over the temperature-time range of concern. It was found that small adjustments to the current values in Subsection NH could be introduced but that the existing values were conservative and could be retained. The existing database 


\begin{tabular}{|c|lll|}
\hline NEXT GENERATION NUCLEAR PLANT & Identifier: & PLN-2803 & \\
REACTOR PRESSURE VESSEL MATERIALS & Revision: & 0 & \\
RESEARCH AND DEVELOPMENT PLAN & Effective Date: & $04 / 30 / 08$ & Page: 26 of 95 \\
\hline
\end{tabular}

was found to be adequate to extend the coverage to 600,000 hours for temperatures below $650^{\circ} \mathrm{C}$ $\left(1200^{\circ} \mathrm{F}\right)$. A model was developed to extend the allowable stress values to 600,000 hours.

\section{- Significance to NGNP}

The extension in temperature and/or time for the stress allowables established in Task 1 is of significance to the NGNP project. Per the vendor pre-conceptual design reports, Alloy $800 \mathrm{H}$ is used as a control rod cladding material for the Westinghouse and GA designs, as a core barrel material for the AREVA design, and as the material of construction for the lower-temperature IHX. Grade 91 steel is the candidate material for the RPV in the AREVA and GA designs (the hot vessel concept).

\section{Task 2: Regulatory Safety Issues in Structural Design Criteria for ASME Section III Subsection $\mathrm{NH}-$}

The objective of Task 2 was to identify issues relevant to ASME Section III Subsection NH, and related Code Cases that must be resolved for licensing purposes for Very High Temperature Gas Reactor concepts; and to identify the material models, design criteria, and analysis methods that need to be added to the ASME Code to cover the unresolved safety issues.

\section{- Results and Recommendations}

The task report included the description of (1) NRC and Advisory Committee on Reactor Safeguards (ACRS) safety concerns raised during the licensing process of the Clinch River Breeder Reactor (CRBR), and other subsequent high temperature reactor concepts, (2) how some of these issues are addressed by the current Subsection NH of the ASME Code; and (3) the material models, design criteria, and analysis methods that need to be added to the ASME Code and Code Cases to cover unresolved regulatory issues for very high temperature service.

The NRC and ACRS issues which were raised in conjunction with the licensing of CRBR and the Power Reactor Innovative Small Module (PRISM) Liquid-Metal Reactor, and more recent NRC/RES (Office of Nuclear Regulatory Research) efforts on licensing issues for high temperature reactors were summarized.

The CRBR license application for a construction permit was approved by NRC, subject to project R\&D activities to address concerns identified by NRC and ACRS. However, due to the abrupt cancellation of the project that led to the cessation of all activities, NRC had not progressed to a point to either approve or disapprove the ASME Code Case N-47, a precursor to Subsection NH, which was the basis for the design of Class 1 pressure-retaining components for elevated temperature service for CRBR. This remains the status of Subsection NH to date.

Table 6, which is being prepared by the NRC staff in the draft form, summarizes the current understanding of the licensing concerns by the task investigators, based on the elevated temperature structural integrity issues identified by the NRC licensing review of CRBR. The order is not ranked. 
Idaho National Laboratory

\begin{tabular}{c|ll} 
NEXT GENERATION NUCLEAR PLANT & Identifier: & PLN-2803 \\
REACTOR PRESSURE VESSEL MATERIALS & Revision: & 0 \\
RESEARCH AND DEVELOPMENT PLAN & Effective Date: & $04 / 30 / 08$
\end{tabular}

Page: 27 of 95

Table 6. Potential licensing issues for RPVs

\begin{tabular}{|c|c|c|c|c|}
\hline \multirow[b]{2}{*}{$\begin{array}{c}\text { Elevated temperature Structural } \\
\text { Integrity Issues }\end{array}$} & \multicolumn{4}{|c|}{$\begin{array}{l}\text { Priority Level: } \\
\text { (1) issue to be of higher concern or safety significance, } \\
\text { (2) issue addressed by ASME BPV Code or of a lower concern, } \\
\text { (3) issue beyond scope of Subsection NH, } \\
\text { (4) issue considered to be of no concern }\end{array}$} \\
\hline & CRBR & $\begin{array}{l}\text { Pebble-Bed Reactor } \\
\text { ( \& cold vessel } \\
\text { option for VHTR) }\end{array}$ & $\begin{array}{c}\text { VHTR (hot } \\
\text { vessel option) }\end{array}$ & GEN IV \\
\hline \#1 Transition joints & $(1)$ & $(4)$ & $(1)$ & $(1)$ \\
\hline \#2 Weld residual stresses & $(1)$ & $(4)$ & $(1)$ & $(1)$ \\
\hline \#3 Design loading combinations & $(1)$ & (3) & (3) & (3) \\
\hline \#4 Creep-rupture and fatigue damage & (1) & $(2)$ & $(1)$ & $(1)$ \\
\hline $\begin{array}{l}\text { \#5 Simplified bounds for creep } \\
\text { ratcheting }\end{array}$ & (1) & $(2)$ & (1) & (1) \\
\hline \#6 Thermal striping & (1) & (2) & $(2)$ & (1) \\
\hline $\begin{array}{l}\text { \#7 Creep-fatigue analysis of Class } 2 \text { and } \\
3 \text { piping }\end{array}$ & (1) & (2) & (2) & $(2)$ \\
\hline $\begin{array}{l}\# 8 \text { Are limits of Case } \mathrm{N}-253 \text { for Elevated } \\
\text { temperature Class } 2 \text { and } 3 \text { components } \\
\text { met? }\end{array}$ & (1) & (2) & (2) & (2) \\
\hline $\begin{array}{l}\text { \#9 Creep buckling under axial } \\
\text { compression - design margins }\end{array}$ & (1) & (2) & $(2)$ & (2) \\
\hline $\begin{array}{l}\# 10 \text { Identify areas where Appendix } T \\
\text { rules are not met }\end{array}$ & (1) & $(2)$ & (1) & (1) \\
\hline $\begin{array}{l}\text { \#11 Rules for component supports at } \\
\text { elevated temperature }\end{array}$ & (1) & (2) & $(2)$ & (2) \\
\hline $\begin{array}{l}\text { \#12 Strain and deformation limits at } \\
\text { elevated temperature }\end{array}$ & (1) & (2) & (4) & (1) \\
\hline \#13 Evaluation of weldments & (1) & (1) & (1) & (1) \\
\hline $\begin{array}{l}\text { \#14 Material acceptance criteria for } \\
\text { elevated temperature }\end{array}$ & (1) & (2) & (2) & (1) \\
\hline $\begin{array}{l}\# 15 \text { Creep-rupture damage due to } \\
\text { forming and welding }\end{array}$ & (1) & (2) & (1) & (1) \\
\hline \#16 Mass transfer effects & (1) & $(2)$ & $(2)$ & $(2)$ \\
\hline \#17 Environmental effects & (1) & $(1),(3)$ & $(1),(3)$ & $(1),(3)$ \\
\hline \#18 Fracture toughness criteria & $(1)$ & $(2)$ & $(1)$ & $(1)$ \\
\hline \#19 Thermal aging effects & (1) & $(1)$ & $(1)$ & $(1)$ \\
\hline \#20 Irradiation effects & $(1)$ & $(1),(3)$ & $(1),(3)$ & $(1),(3)$ \\
\hline $\begin{array}{l}\text { \#21 Use of simplified bounding rules at } \\
\text { discontinuities }\end{array}$ & (1) & (1) & (1) & (1) \\
\hline \#22 Elastic follow-up & $(1)$ & (4) & (4) & (4) \\
\hline $\begin{array}{l}\# 23 \text { Design criteria for elevated } \\
\text { temperature core support structures and } \\
\text { welds }\end{array}$ & (1) & $(2)$ & (2) & (1) \\
\hline $\begin{array}{l}\# 24 \text { Elevated temperature data base for } \\
\text { mechanical properties }\end{array}$ & (1) & (1) & (1) & (1) \\
\hline $\begin{array}{l}\text { \#25 Basis for leak-before-break at } \\
\text { elevated temperatures }\end{array}$ & (1) & (4) & (1) & (1) \\
\hline
\end{tabular}




\begin{tabular}{|c|lll|}
\hline NEXT GENERATION NUCLEAR PLANT & Identifier: & PLN-2803 & \\
REACTOR PRESSURE VESSEL MATERIALS & Revision: & 0 & \\
RESEARCH AND DEVELOPMENT PLAN & Effective Date: & $04 / 30 / 08$ & Page: 28 of 95 \\
\hline
\end{tabular}

The task investigators provided an account on the manner in which NRC licensing issues for the structural design of VHTR and Gen IV systems are addressed in the current ASME Subsection NH and Code Cases. The creep behavior, creep-fatigue, and environmental effects are addressed in Subsection NH and Code Cases largely in terms of design criteria and allowable stress and strain values. The detailed material properties needed for cyclic finite element creep design analyses are generally not provided in the Code. The minimum strength properties given in the Code are used as anchor values for the more comprehensive material suppliers' average properties. The NRC perspective is that the Code and/or Code Cases currently do not adequately cover the material behavior under cyclic loads in the creep regime, and creep-fatigue and creep-rupture interaction effects.

It is noted that for CRBR, the guidance on inelastic finite element analyses, external to the Code, was provided in NE F9-5T, Nuclear Standard, Guidelines and Procedures for Design of Class 1 Elevated Temperature Nuclear System Components.

Subsection NH has rules for the design of welded joints separated into categories A through $\mathrm{D}$. The permissible types of welded joints and their dimensional requirements are specified. Paragraph 3353 of Subsection NH provides analysis requirements for the design and location of all pressure retaining welds operating at temperatures where creep effects are significant. Reduction factors for creep stress rupture are given as a function of time and temperature. Permissible weld metals are limited and special examination requirements are imposed.

Probably the most restrictive Subsection NH requirements for welds is that the inelastic accumulated strains are limited to one-half the allowable strain limits for the base metal. This has forced designers to keep welds out of high stress areas. The allowable fatigue at weldments is limited to one-half the design cycles allowed for the base metal. The allowable creep rupture damage at weldments is limited in Subsection NH by requiring that the rupture strength be reduced by the weld strength reduction factor when determining the time-to-rupture. The Code also imposes additional examination requirements on Category A through $\mathrm{D}$ welded joints. The adequacy of these and other Code weldment structural design requirements has been questioned by the $\mathrm{NRC}$, even for the temperatures currently covered, which are lower than the VHTR and Gen IV High Temperature Systems.

The task report also provided a discussion on the material models, design criteria, and analysis methods that need to be added to the ASME Code and Code Cases to cover unresolved regulatory issues for very high temperature service. The identified needs are summarized below.

Needs for material creep behavior, creep-fatigue and environmental effects include:

- Extension of temperature and/or time for current code materials to cover VHTR conditions

- New code materials to cover VHTR applications

- Appropriate databases for calculating fatigue, creep, creep-fatigue, and stress corrosion cracking (SCC) lifetimes, including environmental effects of impure helium and crevice concentration

- Aging behavior of alloys

- Degradation by carburization, decarburization, and oxidation

- Sensitization of austenitic alloys and weldments.

Needs for design methods include:

- Treatment of connecting pipe as a vessel for code application

- In-service inspection plans and methods

- Probabilistic risk assessment methodologies for vessels, pipes, and components. 


\begin{tabular}{|c|lll|}
\hline NEXT GENERATION NUCLEAR PLANT & Identifier: & PLN-2803 & \\
REACTOR PRESSURE VESSEL MATERIALS & Revision: & 0 & \\
RESEARCH AND DEVELOPMENT PLAN & Effective Date: & $04 / 30 / 08$ & Page: 29 of 95 \\
\hline
\end{tabular}

\section{- Structural integrity of welds:}

Because of the importance of potential elevated temperature cracking of weldments, NRC wanted the designer to account for potential creep strain concentrations due to metallurgical notch effects. Subsection NH does not include methods for analyzing the effects of varying properties between the base metal, weld metal and Heat Affected Zone (HAZ), or even how to determine these properties after welding and post weld heat treatment. Moreover, NRC expressed concern with potential early crack initiation at the inside wall surface in the HAZ, how crack propagation can be quantified, and the stability of the remaining uncracked wall section.

Methods of evaluating such weldment integrity issues and the corresponding safety margins are needed in the ASME Code to satisfy regulatory concerns. These methods will require:

- materials models

- cyclic creep analysis methods

- crack growth analyses, and

- remaining ligament enhanced creep stability analysis methods.

Such methods essentially parallel Section XI flaw evaluation methods which are only applicable below the creep regime.

The NRC has also requested confirmation of the creep rupture, creep-fatigue, and interaction evaluation procedures at weldments, accounting for load sequence effects.

\section{- Development and verification of simplified design Analysis methods:}

Existing simplified design analysis methods have proven to be very valuable in providing assurance of structural integrity in the moderate creep regime and have been used in France, Germany, Japan, and the U.S. for this purpose. These methods can be further developed to include higher temperatures where creep effects control the design margins, and where structural discontinuity notches and defects need to be evaluated. Cyclic finite element creep analysis results are difficult to trust without having comparative results of simplified design analysis methods.

\section{- Verification testing:}

Verification testing was carried out on representative structural features of CRBR as part of the licensing effort. VHTR temperatures are much higher than the CRBR temperatures; consequently, additional verification testing is desired to validate the elevated temperature designs of VHTRs.

Such tests include validation of the material models needed to perform cyclic creep analyses, and validation of the finite element software capabilities to handle cyclic creep at structural discontinuities, elastic follow-up, creep rupture at notches, weldment behavior, and possibly flaw tolerance evaluation methods.

\section{Task 3: Improvement of ASME Subsection NH Rules for Grade 91 Steel - Negligible Creep and Creep-Fatigue}

- Part I. Negligible creep regime

The objective of Part I of this task was to examine current approaches available to define negligible creep, to check their applicability to Grade 91 steel, and to identify tests required to support the definition of negligible creep for Grade 91 steel. 


\begin{tabular}{|c|lll|}
\hline NEXT GENERATION NUCLEAR PLANT & Identifier: & PLN-2803 & \\
REACTOR PRESSURE VESSEL MATERIALS & Revision: & 0 & \\
RESEARCH AND DEVELOPMENT PLAN & Effective Date: & $04 / 30 / 08$ & Page: 30 of 95 \\
\hline
\end{tabular}

\section{- Results and Recommendations}

Creep data for Grade 91 steel from the Commissariat à l'Énergie Atomique, France $\left(\mathrm{CEA}, 450^{\circ} \mathrm{C}\right.$ to $500^{\circ} \mathrm{C}$ or $842^{\circ} \mathrm{F}$ to $932^{\circ} \mathrm{F}$ ), U.S. (ORNL, $427^{\circ} \mathrm{C}$ to $500^{\circ} \mathrm{C}$ or $800^{\circ} \mathrm{F}$ to $932^{\circ} \mathrm{F}$ ), and Japan (NIMS

[National Institute of Material Science] and JNC [Japan Nuclear Cycle Development Institute], $450^{\circ} \mathrm{C}$ and $500^{\circ} \mathrm{C}$ or $842^{\circ} \mathrm{F}$ and $932^{\circ} \mathrm{F}$ ) were assembled. A review was performed on the creep-stress-torupture data and the different creep strain laws developed by RCC-MR, ORNL and Japanese researchers. Based on the assembled data, a revised creep strain law with a formulation similar to that of the RCC-MR code was developed in order to provide more reliable results in the low temperature range (below $500^{\circ} \mathrm{C}$ or $932^{\circ} \mathrm{F}$ ).

It was concluded that negligible creep criteria developed for austenitic stainless steels used in Subsection NH are not directly applicable to Grade 91 steel and the definition of negligible creep conditions is very dependent on the creep properties that are taken into account (either creep strain laws or creep-stress-to-rupture data).

Creep-stress-to-rupture results were re-analyzed to evaluate if improved design data could be obtained at lower temperatures. The number of available stress-to-rupture data at temperatures lower than $500^{\circ} \mathrm{C}\left(932^{\circ} \mathrm{F}\right)$ is small and the data cover a limited range of stress (for example, 450 to $360 \mathrm{MPa}$ at $450^{\circ} \mathrm{C}$ or $842^{\circ} \mathrm{F}$ ). It was shown that different equations for average values of stress-to-rupture derived from different databases do not describe the time dependence of stress-to-rupture at $450^{\circ} \mathrm{C}$ $\left(842^{\circ} \mathrm{F}\right)$ correctly. However, the Subsection $\mathrm{NH}$ minimum curves seem to provide a conservative estimate of the creep-stress-to-rupture at $450^{\circ} \mathrm{C}\left(842^{\circ} \mathrm{F}\right)$ and below for long-term time durations (beyond 10,000 hours).

The negligible creep criteria from Subsection NH and from RCC-MR were evaluated. It was found that three criteria seem to be applicable to Grade 91 steel:

- Time-fraction criterion with $S_{y}$ as a reference stress

- $\quad$ Strain criterion with $S_{y}$ as reference stress and $0.2 \%$ creep strain

- Relaxation of $1.5 S_{m}$ by $20 \%$.

The first two criteria are those from Subsection NH but are modified to take account of cyclic softening.

The time-fraction and $0.2 \%$ creep-strain criteria would allow up to 535,000 hours and 158,000 hours of operation in the negligible creep regime, respectively, at $400^{\circ} \mathrm{C}\left(752^{\circ} \mathrm{F}\right)$. The criterion based on stress relaxation would provide more favorable negligible creep conditions below $450^{\circ} \mathrm{C}\left(842^{\circ} \mathrm{F}\right)$.

The RCC-MR and Japanese approaches which rely on creep-strain criteria in the order of 0.01 to $0.03 \%$ were shown to be not applicable to Grade 91 steel. Reference stresses would have to be reduced to about the allowable stress $S_{m}$ to achieve negligible creep conditions similar to what were given by the three other criteria listed above.

It was concluded that for further confirmation of the negligible creep limits, more creep strain data at $475^{\circ} \mathrm{C}\left(887^{\circ} \mathrm{F}\right), 450^{\circ} \mathrm{C}\left(842^{\circ} \mathrm{F}\right)$ and, if possible, at $425^{\circ} \mathrm{C}\left(797^{\circ} \mathrm{F}\right)$ will be needed. Further tests should also be performed to improve the creep-stress-to-rupture curves below $500^{\circ} \mathrm{C}\left(932^{\circ} \mathrm{F}\right)$.

Creep tests on Grade 91 steel were proposed to increase the knowledge of creep behavior at moderate temperatures of $425^{\circ} \mathrm{C}$ to $525^{\circ} \mathrm{C}\left(797^{\circ} \mathrm{F}\right.$ to $\left.977^{\circ} \mathrm{F}\right)$ in order to improve the evaluation of negligible creep conditions from different criteria.

Creep-fatigue tests on Grade 91 steel were proposed to evaluate the margin between negligible creep conditions at the moderate temperatures of $450^{\circ} \mathrm{C}$ and $500^{\circ} \mathrm{C}\left(842^{\circ} \mathrm{F}\right.$ and $\left.932^{\circ} \mathrm{F}\right)$ and conditions that produce a significant reduction in fatigue life. 


\begin{tabular}{|c|lll|}
\hline NEXT GENERATION NUCLEAR PLANT & Identifier: & PLN-2803 & \\
REACTOR PRESSURE VESSEL MATERIALS & Revision: & 0 & \\
RESEARCH AND DEVELOPMENT PLAN & Effective Date: & $04 / 30 / 08$ & Page: 31 of 95 \\
\hline
\end{tabular}

- $\quad$ Part II. Creep-fatigue procedure

The objective of Part II of this task was to compare the Subsection NH and RCC-MR creep-fatigue procedures for Grade 91 steel, to explore the extent to which data for Grade 91 steel presently available in Subsection NH and RCC-MR are thought to be validated, to recommend improvements to existing Subsection NH creep-fatigue procedure for Grade 91 steel, and to define a test program to validate the improved creep-fatigue procedure for Grade 91 steel.

\section{- Results and Recommendations}

A total of 103 creep-fatigue test results for Grade 91 steel were assembled from the sources of: the JAPC-USDOE joint Study, the JNC Study, the CEA Studies, the Electric Power Research Institute (EPRI) / Central Research Institute of Power Industry in Japan (CRIEPI) joint studies, the IGCAR studies, and the University of Connecticut. The Subsection NH and RCC-MR creep-fatigue procedures for Grade 91 steel were analyzed using these assembled creep-fatigue data.

It was concluded that the Subsection NH creep-fatigue procedure for Grade 91 steel is very conservative. For the test conditions studied, the Subsection NH design approach was shown to be not executable. With the best-fit approach where the design factor was set to one, the life prediction is very conservative as compared with experimental results when the hold times are non-zero.

It was found that the values of the predicted stresses at the beginning of hold times are far too high. Results could be improved by modifying the procedure for calculating the stress at the beginning of the hold time by taking into account cyclic softening and symmetrization effects for Grade 91 steel. This could be implemented by applying a reduction factor to the stress calculated using the isochronous stress-strain curves.

It was found that the prediction of stress relaxation using the isochronous stress-strain curves is overly conservative (the stress relaxation is under-predicted as compared with the experimental results). Unnecessary conservatism could be reduced in Subsection NH by performing systematic cyclic stress relaxation analyses using a creep-strain law as in the RCC-MR procedure. For that purpose, it was recommended that Subsection NH provides additional creep-strain laws so that such analyses could be performed. It was further recommended that guidance to address elastic follow-up effects be added to Subsection NH for code improvement.

It was concluded that the large safety factor used in the calculation of the creep damage $\left(1 / \mathrm{K}^{\prime}=1 / 0.67\right)$ is too conservative in comparison with data. It was recommended that a $\mathrm{K}^{\prime}$ value of 0.9 instead of 0.67 be adopted for the elastic analysis route in the Subsection NH procedure, as currently employed in RCC-MR. It is noted that a proposal for modifying Subsection NH in this manner for all Subsection NH code materials had been made. The proposal was approved by the Code committees.

It was concluded that the Subsection NH creep-fatigue damage envelope is very conservative for Grade 91 steel (bi-linear damage lines with $(0.1,0.01)$ intersection). On the basis of existing results, this diagram does not seem to be fully justified. It was recommended that for the investigation of true creep-fatigue interaction, tests where environment plays a role (tests with hold time in compression) should not be included. At $593^{\circ} \mathrm{C}\left(1099^{\circ} \mathrm{F}\right)$ or $600^{\circ} \mathrm{C}\left(1112^{\circ} \mathrm{F}\right)$, true creep-fatigue interaction can probably be studied. But at lower temperatures, $550^{\circ} \mathrm{C}\left(1022^{\circ} \mathrm{F}\right)$ or $500^{\circ} \mathrm{C}\left(932^{\circ} \mathrm{F}\right)$, it seems that there is a lack of creep-fatigue data in vacuum from which to select relevant data for the investigation of true creep-fatigue interaction. In the absence of such critical data, it was recommended conservatively that the $(0.3,0.3)$ intersection point in the creep-fatigue damage envelope of RCC-MR be adopted in Subsection NH for Grade 91 steel.

It was concluded that when the environment effects on fatigue life at elevated temperatures must be treated, as it is the case for cycling in air or non-inert gas, the fatigue dependences on frequency, 


\begin{tabular}{|c|lll|}
\hline NEXT GENERATION NUCLEAR PLANT & Identifier: & PLN-2803 & \\
REACTOR PRESSURE VESSEL MATERIALS & Revision: & 0 & \\
RESEARCH AND DEVELOPMENT PLAN & Effective Date: & $04 / 30 / 08$ & Page: 32 of 95 \\
\hline
\end{tabular}

tensile and compressive strain rates instead of creep damage evaluation are probably more appropriate to improve the design rules.

It was pointed out that the RCC-MR creep-fatigue procedure provides results that are consistent with experimental data and could be used to help improving the Subsection NH creep-fatigue procedure. However, when used under combined primary and secondary stresses, the RCC-MR creep-fatigue procedure could be very conservative. The stress calculated at the beginning of the hold time by the RCC-MR procedure is higher than that calculated by using the Subsection NH rules. Improvement of this part of the RCC-MR creep-fatigue procedure, when supported by specific test results, is needed.

An extensive creep-fatigue and fatigue-relaxation test program on Grade 91 steel was proposed. The test program contains the following elements:

- Tests at $500^{\circ} \mathrm{C}\left(932^{\circ} \mathrm{F}\right)$ or $525^{\circ} \mathrm{C}\left(977^{\circ} \mathrm{F}\right)$ for comparison with data at $550^{\circ} \mathrm{C}(1022 \mathrm{~F})$

- Extension of the database at $550^{\circ} \mathrm{C}\left(1022^{\circ} \mathrm{F}\right)$ with tests with longer hold times

- Characterization of cyclically softened material and comparison with thermally aged material

- Effect of reactor environment with priority on testing in impure helium

- Tests after post-weld heat treatment and comparison with data from as-received material

- Screening tests on cross-weld specimens.

\section{- Significance to NGNP}

Per the vendor pre-conceptual design reports, Grade 91 steel is a RPV candidate material for the AREVA and GA designs (the hot vessel concept). Results on negligible creep temperature and creepfatigue procedure for Grade 91 steel from Task 3 directly support the RPV design option from AREVA and GA.

\section{Task 4: Updating of ASME Nuclear Code Case N-201 to Accommodate the Needs of High Temperature Gas Cooled Reactors Currently in Development-}

Code Case N-201 is related to core support structures and thus is not relevant to this report and will not be discussed.

\section{Task 5: Collect Available Creep-Fatigue Data and Study Existing Creep-Fatigue Evaluation Procedures for Grade 91 Steel and Hastelloy XR-}

The object of Task 5 was to collect creep, creep-fatigue and fatigue (when available) data for Grade 91 steel in air, vacuum, and sodium environment and Hastelloy XR in air and helium environment, and to evaluate creep-fatigue procedures from Subsection NH, RCC-MR and the Japanese HTGR Code.

- Part I. Grade 91 steel

Grade 91 steel data were collected from the Japan Atomic Energy Agency (JAEA), EPRI, ORNL, CRIEPI, NIMS. They included 205 creep data, 281 fatigue data, and 78 creep-fatigue data. Product forms included plates, forgings and pipes.

These data were analyzed from the perspective of (i) general trend and sodium environmental effect for the creep properties; (ii) general trend, effect of thermal aging, effect of environment, and stressstrain relationship for the fatigue properties; and (iii) reduction of creep-fatigue life due to strain hold, and effect of strain hold period for creep-fatigue properties.

While there was a fair amount of creep-fatigue data collected, it was pointed out that most of the data were originally obtained for application to fast breeder reactors and the temperature range was limited to $400^{\circ} \mathrm{C}\left(752^{\circ} \mathrm{F}\right)$ to $650^{\circ} \mathrm{C}\left(1202^{\circ} \mathrm{F}\right)$. Within this temperature range, creep-fatigue data had been 


\begin{tabular}{|c|lll|}
\hline NEXT GENERATION NUCLEAR PLANT & Identifier: & PLN-2803 & \\
REACTOR PRESSURE VESSEL MATERIALS & Revision: & 0 & \\
RESEARCH AND DEVELOPMENT PLAN & Effective Date: & $04 / 30 / 08$ & Page: 33 of 95 \\
\hline
\end{tabular}

accumulated to the extent that they served to clarify the mechanisms of creep-fatigue life reduction of Grade 91 steel, even if the data were not sufficient in quantity. Data from tests that included tensile hold time, compressive hold time and both tensile and compressive hold times had been collected. Most of the data were obtained in an air environment but data in sodium and vacuum environments were also available, providing valuable information. For the effect of aging, available data were not necessarily sufficient to clarify the effects on stress-strain response and creep-fatigue life.

Comparison of the creep-fatigue procedures from Subsection NH, RCC-MR and the Japanese HTGR Code was made, with emphasis on the method of determination of strain range, initial stress of stress relaxation, stress relaxation behavior and formulation of creep damage. These creep-fatigue procedures were then applied to the collected data. Specific focus was given to the determination of the initial stress of stress relaxation, the description of stress relaxation behavior during strain hold period, and the creep-fatigue damage diagram. The creep-fatigue evaluations were performed both with and without safety factors employed by each code. It was concluded that the creep-fatigue evaluation procedure of Subsection NH is very conservative.

It was recommended that the use of cyclic stress-strain curve, use of creep-strain law in conjunction with the strain hardening law, or the combination of both be adopted in the creep-fatigue procedure of Subsection NH. It was also recommended that the current intersection point of $(0.1,0.01)$ in the damage envelope of Subsection $\mathrm{NH}$ be changed to $(0.3,0.3)$. Recommendations on (i) long-term material testing, (ii) evaluation method for welded joints, (iii) extrapolation of experimental data to the design regime, and (iv) structural testing for validation were made.

\section{- Hastelloy XR}

Hastelloy XR is not relevant to components considered in this report and will not be discussed here.

\subsubsection{Second Round Tasks}

The original twelve topics developed in the DOE Initiative to address ASME Code issues were drafted almost three years ago. With the completion of the NGNP pre-conceptual design reports from the vendors, a clearer picture of the future NGNP configuration has started to emerge. Thus, the remaining topics from the original list have been re-prioritized, some work scopes have been modified, and new work scopes have been added. Five new tasks in the second round of the DOE Initiative have been agreed upon between DOE and ASME. They are described in the following.

\section{Task 6: Operating Condition Allowable Stress Values}

A spot check of minimum stress to rupture values provided in $\mathrm{NH}$ revealed that there was disagreement between the minimum stress to rupture values, $S_{r}$, at 100,000 hours and the values of Design Condition stress intensity, $S_{o}$. Based on the allowable stress criteria, the values of $S_{o}$ should be no greater than $80 \%$ of $S_{r}$ at 100,000 hours. However, for all the listed NH materials, at higher temperature there were values of $S_{o}$ which exceeded $80 \%$ of $S_{r}$. In most, if not all cases, the values of $S_{o}$ were significantly higher at some temperatures. Since the NH values of $S_{o}$ are in agreement with the allowable stress values listed in Section II, Part D, the expectation is that the values of $S_{r}$ are lower than would be expected if they were derived from the same data as the values for $S_{o}$. Further, the values of $S_{t}$, the allowable stresses for Operating Conditions, appear consistent with the values of $S_{r}$, thus throwing in doubt all the allowable Operating Condition stress values for both load controlled stress limits and displacement controlled limits in NH.

Part I will be a review of current values of $S_{r}$ and $S_{o}$ and identification of discrepancies. The same will be done with $S_{t}$ and $S_{r}$. The database(s) used to establish $S_{r}, S_{t}$ and $S_{o}$ must be reviewed and identified. In 


\begin{tabular}{|c|lll|}
\hline NEXT GENERATION NUCLEAR PLANT & Identifier: & PLN-2803 & \\
REACTOR PRESSURE VESSEL MATERIALS & Revision: & 0 & \\
RESEARCH AND DEVELOPMENT PLAN & Effective Date: & $04 / 30 / 08$ & Page: 34 of 95 \\
\hline
\end{tabular}

part II these assembled databases will be reviewed for completeness and consistency, identifying areas of inconsistency and recommending a course of action to resolve them. This should include additional testing if required. The time and temperature regimes must be identified where the listed values of $S_{t}$ and $S_{r}$ are correct and no further action is required. Finally in part III members will prepare recommended corrections to the currently listed values of $S_{t}$ and $S_{r}$ based on currently available data (where the data is sufficient) for those time/temperature regimes that require corrections. A rough order of magnitude cost estimate for the testing required to complete these corrections will be prepared.

\section{TASK 7: Considerations for the Intermediate Heat EXchanger (IHX)-}

The intent of this task is to recommend how and where within ASME codes and standards, the IHX, safety valve, etc. would be addressed and to provide guidance to equipment suppliers on potential critical code issues to be addressed. Part of this determination is the role of the IHX primary to secondary heat exchanger surface in plant licensing considerations. Although the main focus of this activity is on compact, micro channel heat exchangers due to their unique design features, consideration should also be given to plate-fin and shell-and-tube concepts in considering equivalent reliability and assessing critical "construction" issues at very high temperatures representative of VHTR operation. Note that in this context "construction" refers to the full scope of ASME Code rules, namely: materials, design, fabrication and installation, examination and overpressure protection. In-service examination issues should also be considered.

In part I the objective is to identify, to the extent feasible, the current status of compact/micro channel heat exchanger "construction" (including aging and coolant corrosion effects where available) of representative heat exchanger pressure boundary and internal designs. Heat exchangers with working fluid temperatures at the upper end of the creep regime for their materials of construction will be emphasized. Candidate designs should include shell-and-tube, plate-fin, and compact design. Additional concepts will be identified if possible. This is to be accomplished by soliciting input from component vendors, reactor heat transport system designers and process heat end users. Particular attention will be paid to (a) service experience and problem resolution, (b) design criteria including methods, if any, for evaluation of cyclic life, (c) construction codes of record and designated pressure boundaries, and (d) qualification of materials and fabrication techniques for the intended service.

Once the compact heat exchangers have been assessed, collaborators will recommend key features of a construction code needed to address the unique issues associated with the VHTR IHX and associated equipment. As examples of what might be considered: (a) because the sharp corners associated with many if not all micro channel designs is a key feature, what test(s) should be required to establish cyclic life or to calibrate design methods, and (b) what sort of inspection or process control is required to achieve adequate joint reliability in components with on the order of a million joints and limited accessibility? Candidate Codes to be considered include Subsection NB and NH, Subsection NC and ND and their respective elevated temperature Code Cases and Section VIII, Div 1 and 2. A rough order of magnitude estimate will be prepared for the cost and schedule of implementing the proposed Code approach.

Further, it would be desirable to review the adequacy of existing ASTM specifications for materials, testing, examination, etc. to determine if any new standards will need to be developed to support IHX design, fabrication, operation or inspection. We need to understand in the near term if the ASTM specification infrastructure will also have to be augmented in order to support the new test and inspection requirements for IHX. 


\begin{tabular}{|c|lll|}
\hline NEXT GENERATION NUCLEAR PLANT & Identifier: & PLN-2803 & \\
REACTOR PRESSURE VESSEL MATERIALS & Revision: & 0 & \\
RESEARCH AND DEVELOPMENT PLAN & Effective Date: & $04 / 30 / 08$ & Page: 35 of 95 \\
\hline
\end{tabular}

\section{TASK 8: Creep and Creep-Fatigue Crack Growth at Structural Discontinuities and Welds-}

The lack of a quantitative methodology for evaluating the potential for creep and creep-fatigue crack growth at structural discontinuities and weldments has been identified in NRC reviews as an NH shortcoming. NH does provide a number of design factors and procedures to ensure elevated temperature weldments and stress risers will perform satisfactorily but does not provide for a quantitative assessment of creep crack growth. Although desirable for design, such a methodology is even more needed for evaluation of potential cracks and crack growth detected during in-service inspection. During the early years of the evolution of the current $\mathrm{NH}$, such methodologies for evaluation of creep crack growth were in their infancy. However, there have been numerous advances in the technology in recent years, for both nuclear and non-nuclear applications. A key issue for nuclear applications is whether these methodologies are sufficiently well established. They must give the required assurances without undue conservatism which would preclude designs and/or operating parameters that are actually not susceptible to premature failure.

In part I, investigators will review currently used methods for creep and creep-fatigue crack growth at discontinuities and in weldments to assess their applicability for design and in-service inspection assessment of NH components. Methods used in other nuclear standards such as R5, RCC-MR and KTA shall be considered as well as those employed in assessments of non-nuclear equipment. Currently approved materials for $\mathrm{NH}$ construction shall be considered as well as potential additions such as Alloy 617 and 230, and a low carbon/high nitrogen version of 316 stainless steel. Identify promising technologies and the testing required to implement the specific methodology in NH. In part II collaborators will prepare draft rules based on this assessment for implementation in NH. These rules should be based on existing data where feasible.

\section{TASKS 9 \& 10: Update and Improve Subsection $\mathrm{NH}-$}

Current design analysis rules in Subsection $\mathrm{NH}$ were developed during the decades ending in the late 1980's. Since then there have been notable advances in computing technology that permit evaluation methodologies not previously considered. There have also been advances in the understanding of elevated temperature material behavior and failure mechanisms. Also, as shown by the results from Tasks 3 and 5 of the first round DOE/ASME GEN IV Materials Project, the current methodologies for evaluating creepfatigue interaction have a number of deficiencies.

\section{TASK 9: Simplified Elastic and Inelastic Design Analysis Methods-}

Review and compare current design methods and assessment techniques in ASME NH, RCC-MR, BC5500, DIN, and JNC, R5, API 579 and other relevant sources. Propose a range of design analysis methods consisting of: (i) elastic analysis, (ii) reference stress method, and (iii) limit load, shakedown, and ratcheting analysis. Recommend requisite requirements for codification, including data generation, data extrapolation strategies, round-robin structural analyses, and feature testing to validate methods.

\section{TASK 10: Alternative Simplified Creep-Fatigue Design Methods-}

Review creep-fatigue methodologies, including damage-based, strain-based, and methods not involving separate accounting of creep and fatigue damage in various design codes, assessment procedures and relevant literatures. Assess the potential of deploying these methods in NH either to remove excessive conservatism or to resolve NH issues identified in the final report of Task 2 . Where applicable, provide rationale and propose implementation strategies for these methods. Propose methods to address the effects of aging, surface conditions, and geometric discontinuity. Recommend requisite requirements for codification, including data generation, data extrapolation strategies, and feature testing to validate methods. 


\begin{tabular}{|c|lll|}
\hline NEXT GENERATION NUCLEAR PLANT & Identifier: & PLN-2803 & \\
REACTOR PRESSURE VESSEL MATERIALS & Revision: & 0 & \\
RESEARCH AND DEVELOPMENT PLAN & Effective Date: & $04 / 30 / 08$ & Page: 36 of 95 \\
\hline
\end{tabular}

\section{RESEARCH ISSUES}

This section addresses issues with code qualification of RPV materials. It also addresses application of the ASME code to design of RPV. Detailed test plans to address the code compliance/licensing issues are given in Section 6.

\subsection{Code Compliance/Licensing}

The NGNP RPV needs to be designed using the ASME Section III Code rules. If the RPV wall temperature can be maintained at a sufficiently low temperature $\left(\leq 371^{\circ} \mathrm{C}=700^{\circ} \mathrm{F}\right)$ with only limited excursions as defined under Code Case N 499, Subsection NB of the Code can be used. Otherwise Subsection NH must be applied. Issues associated with using Subsection NB rules of construction near the temperature cut-off of $371^{\circ} \mathrm{C}$ for long periods will be discussed in Section 5.1.2. Figure 7 shows the allowable primary membrane stress intensities vs. temperature for each material and the maximum calculated primary stress intensity/maximum wall temperature data points for the two RPV designs. However, the maximum design lifetime data provided in Subsection NH is $\approx 34 \mathrm{yrs}(300,000 \mathrm{~h})$ for the steel, which is less than the NGNP design lifetime of $60 \mathrm{yrs}$.

A 508 and A 533 steels are ASME Code approved for Class 1 nuclear components and Subsection NB rules apply. A 508 forging can be a potential candidate for the pebble bed RPV design, since the peak temperature as calculated by RELAP5 is $\leq 371{ }^{\circ} \mathrm{C}$; however, temperatures $>371{ }^{\circ} \mathrm{C}$ were calculated when a pebble-bed-specific code was used. Without active cooling A 508 steel is unacceptable for the prismatic core RPV design because the calculated temperatures during normal operation exceed $371^{\circ} \mathrm{C}$. Active cooling will be mandatory, if this steel is selected for the prismatic, and perhaps even for the pebble bed RPV design.

Figure 1 indicates that while $\mathrm{Fe}-2 \frac{1}{4} \mathrm{Cr}-1 \mathrm{Mo}$ (without $\mathrm{V}$ ) does not have adequate strength for either NGNP RPV design, Fe-2 $1 / 4 \mathrm{Cr}-1 \mathrm{Mo}-\mathrm{V}$ has sufficient strength up to $400^{\circ} \mathrm{C}$, and limited creep-rupture data in the literature indicates it may have adequate high temperature strength for either design. However, at

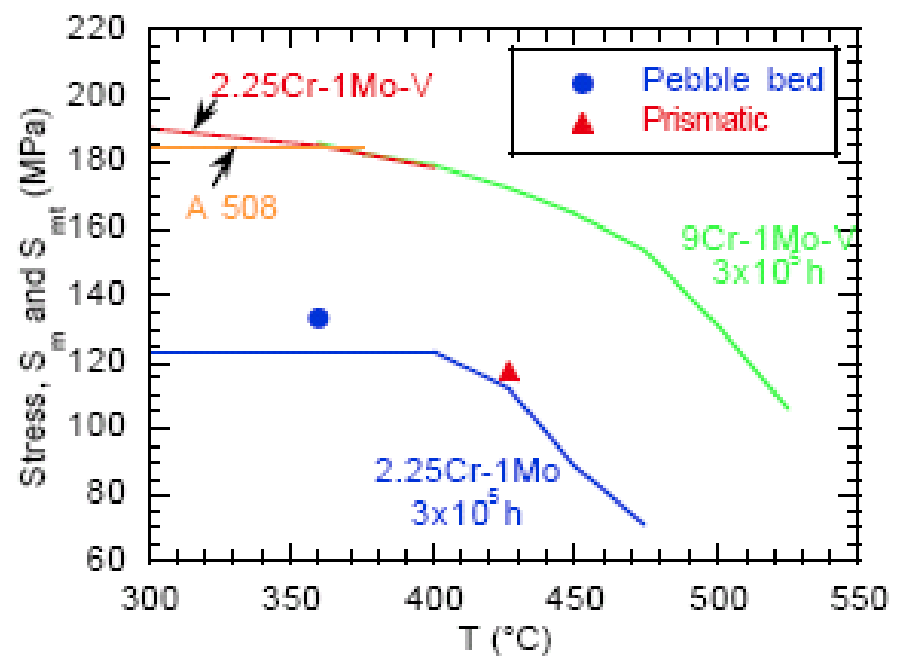

Figure 1. Variation of primary membrane stress intensity and allowable primary membrane stress intensities as functions of temperature and time 


\begin{tabular}{|c|lll|}
\hline NEXT GENERATION NUCLEAR PLANT & Identifier: & PLN-2803 & \\
REACTOR PRESSURE VESSEL MATERIALS & Revision: & 0 & \\
RESEARCH AND DEVELOPMENT PLAN & Effective Date: & $04 / 30 / 08$ & Page: 37 of 95 \\
\hline
\end{tabular}

present, $\mathrm{Fe}-2 \frac{1}{4} \mathrm{Cr}-1 \mathrm{Mo}-\mathrm{V}$ steel is approved under ASME Code Section VIII (non-nuclear applications) but not approved under Section III for nuclear service. The upper temperature limit of $400^{\circ} \mathrm{C}$ is only about $30^{\circ} \mathrm{C}$ above the temperature for which the A 508 and A 533 alloys can be used.

Grade 91 steel is approved in Section III of the ASME Code for nuclear applications; however, the creep-fatigue limits for the steel in the code is highly conservative and it may preclude its selection for the NGNP RPV application. Calculations performed for the Grade 91 steel showed that the peak membrane stress for the pebble bed design RPV is within the ASME Code Subsection NB (elastic) allowable for the steel (see Figure 1). The peak membrane stress for the prismatic design RPV is allowed in ASME Code, Subsection NH (plastic). Stress analysis of the depressurized conduction cooldown condition for both pebble bed and prismatic designs showed the peak temperatures to be within the creep range for the steel, but the stresses are too low to cause any significant creep deformation $\left(<10^{-6}\right)$.

\subsubsection{Baseline Case}

A 508/533B steels are ASME Code approved for Class 1 nuclear components and Subsection NB rules are applicable. A 08 forging can be a potential candidate for the pebble bed RPV design since the peak temperature as calculated by RELAP5 is $\leq 371^{\circ} \mathrm{C}$; however, temperatures $>371^{\circ} \mathrm{C}$ were calculated when a pebble-bed-specific code was used. Without active cooling A 508 steel is unacceptable for the prismatic core RPV design because the calculated temperatures during normal operation exceed $371^{\circ} \mathrm{C}$. Active cooling will be mandatory, if this steel is selected for the prismatic, and perhaps even for the pebble bed RPV design.

For operation below $371^{\circ} \mathrm{C}$ with an actively cooled vessel A 508 forgings and A 533B rolled plate is the material of choice. This material is in the nuclear section of the ASME code, there is extensive experience with these alloys as RPV materials in the US LWR fleet of commercial plants, fabrication and welding are not expected to represent significant technical issues and the irradiation effects are well known. However, confirmatory testing to address long term creep and creep-fatigue effects is needed.

\subsubsection{Alternative Case}

Figure 7 indicates that while Fe-21/4Cr-1Mo (without V) does not have adequate strength for either NGNP RPV design, Fe-2 $1 / 4 \mathrm{Cr}-1 \mathrm{Mo}-\mathrm{V}$ has sufficient strength up to $400^{\circ} \mathrm{C}$ and limited creep-rupture data in the literature indicates it may have adequate high temperature strength for either design. However, at present, Fe-2 $1 / 4 \mathrm{Cr}-1 \mathrm{Mo}-\mathrm{V}$ steel is approved under ASME Code Section VIII (non-nuclear applications) but not approved under Section III for nuclear service. The upper temperature limit of $400^{\circ} \mathrm{C}$ is only about $30^{\circ} \mathrm{C}$ above the temperature for which the A 508/533B alloys can be used.

Grade 91 steel is approved in Section III of the ASME Code for nuclear applications; however, the creep-fatigue limits for the steel in the code is highly conservative and it may preclude its selection for the NGNP RPV application. Calculations performed for the Grade 91 steel showed that the peak membrane stress for the pebble bed design RPV is within the ASME Code Subsection NB (elastic) allowable for the steel (see Figure 1). The peak membrane stress for the prismatic design RPV is within the ASME Code Subsection NH (plastic) allowable. Stress analysis of the depressurized conduction cooldown condition for both pebble bed and prismatic designs showed the peak temperatures to be in the creep range for the steel, but the stresses are too low to cause any significant creep deformation $\left(<10^{-6}\right)$.

\subsubsection{NRC Structural Integrity Issues}

The ASME Boiler and Pressure Vessels Code Section III, Division 1, Subsections NB, NC, ND, $\mathrm{NE}, \mathrm{NF}$, and NG, are incorporated by reference into Section 50.55a of Title 10 of the Code of Federal 


\begin{tabular}{|c|lll|}
\hline NEXT GENERATION NUCLEAR PLANT & Identifier: & PLN-2803 & \\
REACTOR PRESSURE VESSEL MATERIALS & Revision: & 0 & \\
RESEARCH AND DEVELOPMENT PLAN & Effective Date: & $04 / 30 / 08$ & Page: 38 of 95 \\
\hline
\end{tabular}

Regulations (10 CFR 50.55a) as the rules of construction for LWR nuclear power plant components. Section III Code Cases which provide alternatives to the Section III, Division 1 Code requirements under special circumstances are reviewed by the NRC staff and its findings are published in the regulatory guides. The acceptable and conditionally acceptable Section III Code Cases listed in the regulatory guides are then incorporated by reference into 10 CFR 50.55a.

While the rules of construction of the ASME Code and Code Cases cover many aspects related to structural integrity, they do not explicitly address issues such as degradation of properties due to service conditions or environment. However, these structural integrity issues are highlighted in the Code and it is the responsibility of the "Owner" to demonstrate to NRC that these additional issues are adequately addressed.

Section III, Subsection NB and its Code Cases contain rules of construction for the RPV when its design temperature is below $371^{\circ} \mathrm{C}$. Section III, Subsection NH contains rules of construction for the RPV when its design temperature is above $371^{\circ} \mathrm{C}$. For the former, Code Case N-499 provides rules for limited off-normal short term temperature excursions beyond $371^{\circ} \mathrm{C}$ for A 508 and A 533B pressure vessel steels and their associated weldments. The design rules of Code Case N-499 are based on the rules of Subsection NH by reference. Allowable stresses and creep-fatigue data for A 508 and A 533B steels and their weldments are provided in Code Case N-499.

\subsubsection{Issues for "Cold" Vessel Option}

Current consideration of the "cold" vessel option by reactor vendors appears to be based on the logical assumption that if the temperature is within the bounds of Subsection NB $\left(371^{\circ} \mathrm{C}\right.$ for RPV materials) then creep effects do not need to be considered. While this is undoubtedly true for typical LWR operating temperatures, it may not be true for the higher $350^{\circ} \mathrm{C}$ operating temperature and a 60 -year design life, and in particular, with the consideration of localized high stress areas. The reason is that creep deformation depends on stress, time and temperature and does not have a strict temperature cut-off that separates creep from non-creep regimes. This could potentially affect the primary stress limits and impact RPV sizing. The potential impact could also likely show up at structural or metallurgical discontinuities. If there is a real problem in the RPV due to creep effects at $350^{\circ} \mathrm{C}$ it is not likely to show up until the component is well into its operating life.

Such a concern was prompted by a recent statistical re-analysis ${ }^{22}$ of the A $533 \mathrm{~B}$ database reported in the data package $\mathrm{e}^{23}$ that was used to support the development of Code Case N-499. This database consists of 51 creep data from four heats of A 533B plates, with temperatures ranging from $371^{\circ} \mathrm{C}$ to $593^{\circ} \mathrm{C}$ and applied stresses from $7 \mathrm{MPa}$ to $517 \mathrm{MPa}$. Both rupture data and run-out data, where tests were stopped before rupture occurred, are contained in the database. The rupture data were less than 3,500 hours while one run-out datum at $482^{\circ} \mathrm{C}$ and $207 \mathrm{MPa}$ reached $\sim 11,500$ hours and another at $593^{\circ} \mathrm{C}$ and $28 \mathrm{MPa}$ reached $\sim 26,000$ hours. Only the rupture data were used in establishing the rupture stress and timedependent primary stress limits for Code Case N-499 as the objective of the code case was to develop code rules for limited, short term temperature excursions beyond the Subsection NB temperature limit of $371^{\circ} \mathrm{C}$.

The Code Case N-499 database is the only currently available data that could provide limited information in framing the issue of whether or not the consideration of creep is needed for the RPV in the "cold" vessel option. A statistical methodology similar to that employed in analyzing the Alloy 617 and Alloy 230 creep data $^{24}$ was used to re-analyze the Code Case N-499 creep data. This method allows the inclusion of run-out data in the statistical analysis, and hence, making full use of the information from the database. Best estimate and 95/95 lower bounds were developed for stress to one-percent strain, stress to 


\begin{tabular}{|c|lll|}
\hline NEXT GENERATION NUCLEAR PLANT & Identifier: & PLN-2803 \\
REACTOR PRESSURE VESSEL MATERIALS & Revision: & 0 & \\
RESEARCH AND DEVELOPMENT PLAN & Effective Date: & $04 / 30 / 08$ & Page: 39 of 95 \\
\hline
\end{tabular}

onset of tertiary creep, and stress to rupture. Extrapolations to 100,000 hours, 300,000 hours, and 600,000 hours in the temperature range of $340^{\circ} \mathrm{C}$ to $390^{\circ} \mathrm{C}$ were made. The Subsection NH procedure in establishing the time-dependent primary stress limit $S_{t}$ was used and the results are shown in Figures 2 and 3. The Subsection NB time-independent primary stress limit $S_{m}$ is also included in these two figures for reference.

It should be noted that sizing methods in Subsections NB and NH are somewhat different. In Subsection NB, the wall thickness is sized based on the design condition while both design condition (based on 100,000-hour allowables as in Section VIII) and operating conditions are used in Subsection NH. Further, the limit in Subsection NB on $\mathrm{P}_{\mathrm{m}}$ is $S_{m}$ and on $\mathrm{P}_{\mathrm{L}}+\mathrm{P}_{\mathrm{b}}$ is $1.5 S_{m}$, while in Subsection NH the limit on $\mathrm{P}_{\mathrm{m}}$ is $S_{m}$, on $\mathrm{P}_{\mathrm{L}}+\mathrm{P}_{\mathrm{b}}$ is $1.5 S_{m}$, and in addition, the limit on $\mathrm{P}_{\mathrm{L}}+\left(\mathrm{P}_{\mathrm{b}} / 1.25\right)$ is $S_{t}$. Since the Subsection NH limit of $S_{m t}$ is the lesser of $S_{m}$ and $S_{t}$, the limits on the general membrane stress intensity $\mathrm{P}_{\mathrm{m}}$ from Subsections NB and NH can be compared by considering the relative magnitudes of $S_{m}$ and $S_{t}$.

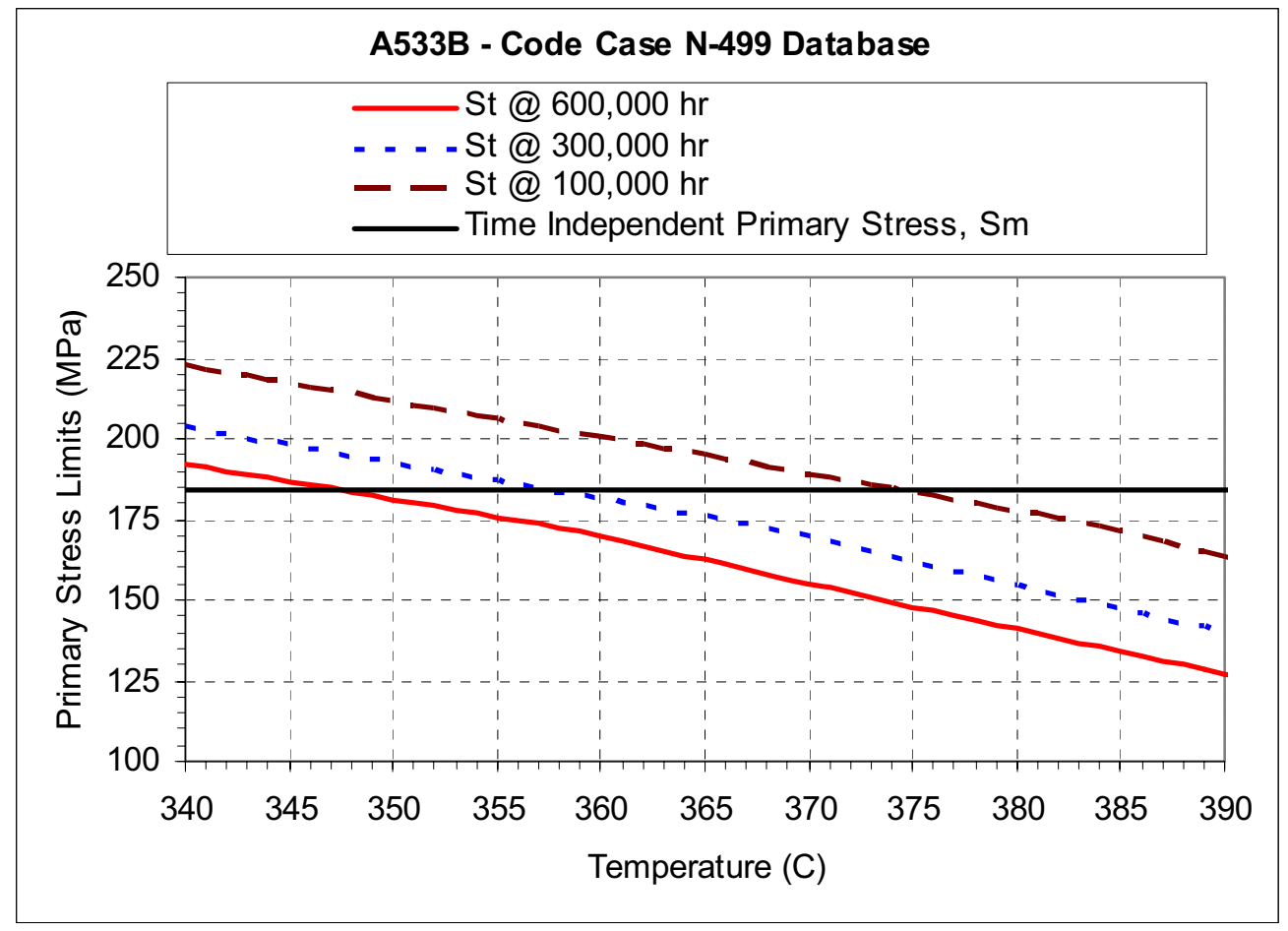

Figure 2. Extrapolated time-dependent primary stress limits for A 533B. 
NEXT GENERATION NUCLEAR PLANT

REACTOR PRESSURE VESSEL MATERIALS

RESEARCH AND DEVELOPMENT PLAN
Identifier: PLN-2803

Revision: $\quad 0$

Effective Date: $04 / 30 / 08$

Page: 40 of 95

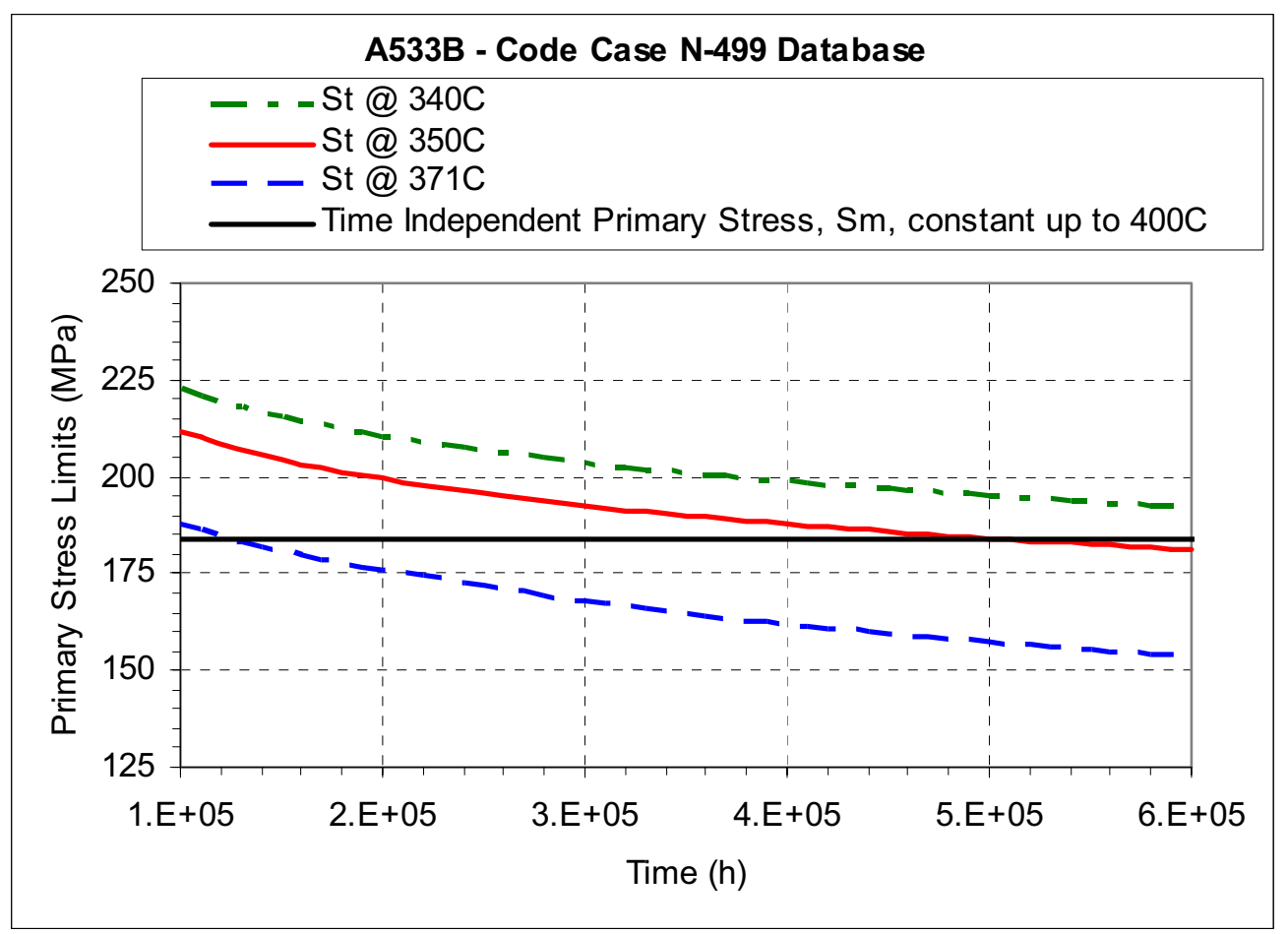

Figure 3. Extrapolated time-dependent primary stress limits for $\mathrm{A} 533 \mathrm{~B}$ at $340^{\circ} \mathrm{C}, 350^{\circ} \mathrm{C}$, and $371^{\circ} \mathrm{C}$.

The extrapolated results in the plots show that the time-independent primary stress limit $S_{m}$ is lower, and hence conservative, than the time-dependent primary stress limit $S_{t}$ for times below 500,000 hours at $350^{\circ} \mathrm{C}$, and slightly non-conservative relative to $S_{t}$ for times between 500,000 and 600,000 hours. For a temperature of $340^{\circ} \mathrm{C}$, the extrapolated values of $S_{t}$ are higher than those for $S_{m}$ in the range of time considered; hence, the use of $S_{m}$ is conservative for at least up to 600,000 hours. At the Subsection NB cut-off temperature of $371^{\circ} \mathrm{C}, S_{m}$ is non-conservative for lifetimes beyond $\sim 125,000$ hours.

Figure 4 shows the extrapolated lower bound creep rupture stress at $340^{\circ} \mathrm{C}, 350^{\circ} \mathrm{C}$, and $371^{\circ} \mathrm{C}$ as a function of time. One of the negligible creep criteria in Subsection NH, article T-1324 is:

$\sum_{i} \frac{t_{i}}{t_{i d}} \leq 0.1$

where $t_{i}$ is total duration of time during the service lifetime that the metal is at temperature $T_{i}$ and $t_{i d}$ is the rupture time given by the lower bound rupture stress that is equal to $\left.S_{y}\right)_{T_{i}}$, the minimum yield strength at temperature $T_{i}$, times a factor $\mathrm{s}$ which is equal to 1.5 . The factor $\mathrm{s}$ is based on a factor of 1.25 to bring the minimum yield strength at temperature to the average value and a factor of 1.2 to account for cyclic hardening of austenitic stainless steel in order to approximate the achievable stress state at geometric discontinuities. 


\begin{tabular}{|c|lll|}
\hline NEXT GENERATION NUCLEAR PLANT & Identifier: & PLN-2803 & \\
REACTOR PRESSURE VESSEL MATERIALS & Revision: & 0 & \\
RESEARCH AND DEVELOPMENT PLAN & Effective Date: & $04 / 30 / 08$ & Page: 41 of 95 \\
\hline
\end{tabular}

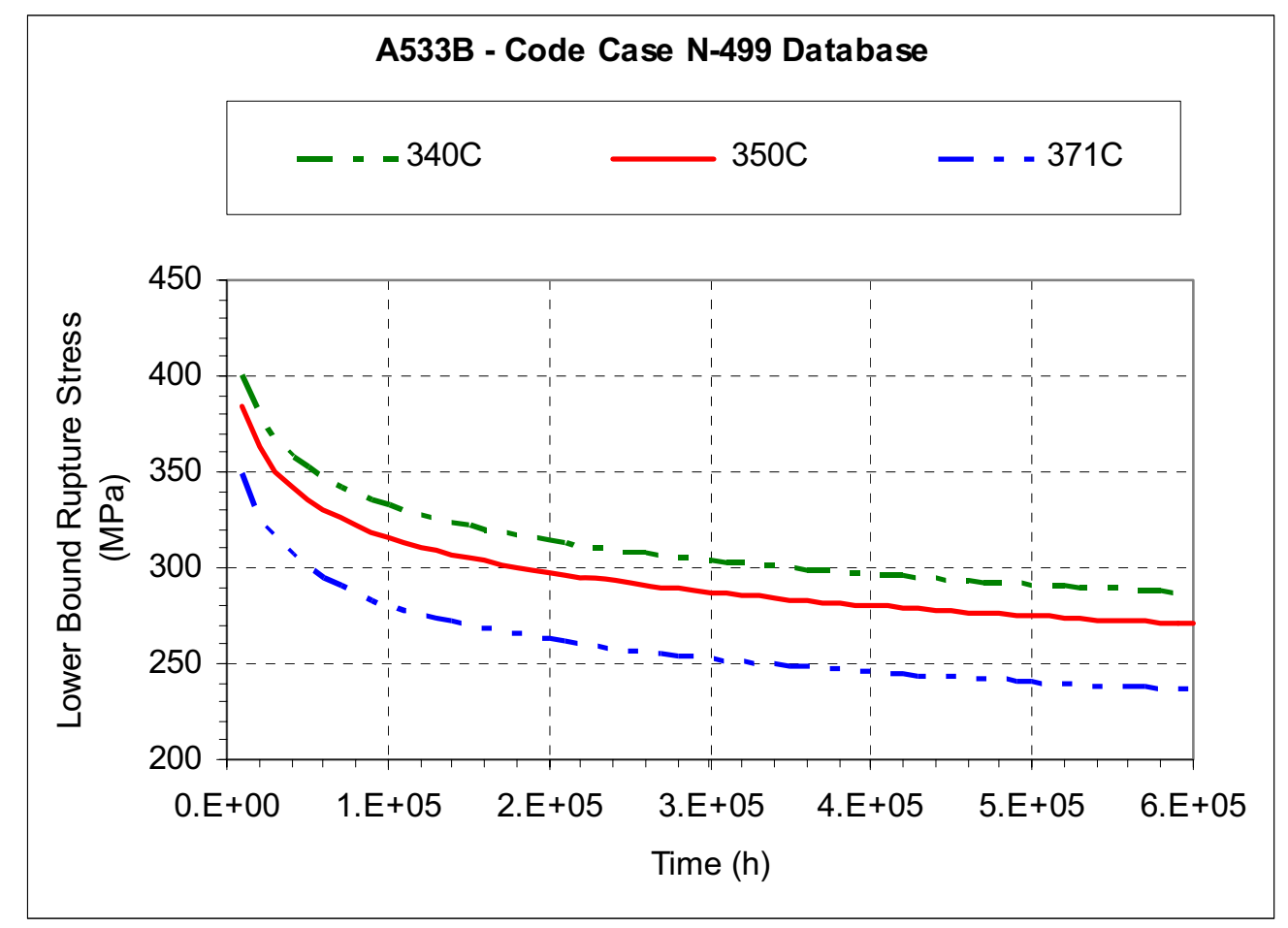

Figure 4. Extrapolated lower bound creep rupture stress for A $533 \mathrm{~B}$ at $340^{\circ} \mathrm{C}, 350^{\circ} \mathrm{C}$, and $371^{\circ} \mathrm{C}$.

The lower bound rupture stress that is required to evaluate the rupture time $t_{i d}$ in the negligible creep criterion as a function of the factor $\mathrm{s}$ is tabulated in Table 7.

Table 7. Lower bound rupture stress given by factor s times $\left.S_{y}\right)_{T_{i}}$.

\begin{tabular}{|c|c|c|c|}
\hline \multirow{2}{*}{ Factor s } & \multicolumn{3}{|c|}{ Lower Bound Rupture Stress to Determine $t_{\text {id }}(\mathrm{MPa})$} \\
\cline { 2 - 4 } & $340^{\circ} \mathrm{C}$ & $350^{\circ} \mathrm{C}$ & $371^{\circ} \mathrm{C}$ \\
\hline 1 & 287 & 285 & 281 \\
\hline 1.25 & 358 & 356 & 351 \\
\hline 1.5 & 430 & 428 & 421 \\
\hline
\end{tabular}

It is seen from Table 7 and the curves in Figure 4 that the rupture time $t_{i d}$ obtained from the rupture stresses given in Table 7 would not satisfy the negligible creep criterion of Subsection NH for $t_{i}$ equal to 60 years.

It is noted that the current re-analysis of the Code Case N-499 database gives values of lower bound creep rupture stress at $371^{\circ} \mathrm{C}$ that are much lower than those given in Table 4 of Code Case N-499-2 for the expected minimum rupture stress. The comparison is shown in Table 8. 


\begin{tabular}{c|lll|} 
NEXT GENERATION NUCLEAR PLANT & Identifier: & \multicolumn{2}{l|}{ PLN-2803 } \\
REACTOR PRESSURE VESSEL MATERIALS & Revision: & 0 & \\
RESEARCH AND DEVELOPMENT PLAN & Effective Date: & $04 / 30 / 08$ & Page: 42 of 95 \\
\hline
\end{tabular}

Table 8. Comparison of rupture stress predictions from Code Case N-499-2 and statistical re-analysis.

\begin{tabular}{|c|c|c|c|c|}
\hline \multirow{2}{*}{$\begin{array}{c}\text { Time to } \\
\text { Rupture }(\mathrm{h})\end{array}$} & \multicolumn{2}{|c|}{ Code Case N-499-2 } & \multicolumn{2}{c|}{ Statistical Re-analysis } \\
\cline { 2 - 5 } & $\begin{array}{c}\text { Rupture Stress at } \\
371^{\circ} \mathrm{C}(\mathrm{ksi})\end{array}$ & $\begin{array}{c}\text { Rupture Stress at } \\
371^{\circ} \mathrm{C}(\mathrm{MPa})\end{array}$ & $\begin{array}{c}\text { Rupture Stress at } \\
371^{\circ} \mathrm{C}(\mathrm{ksi})\end{array}$ & $\begin{array}{c}\text { Rupture Stress at } \\
371^{\circ} \mathrm{C}(\mathrm{MPa})\end{array}$ \\
\hline 1,000 & 77 & 531 & 62 & 425 \\
\hline 10,000 & 70 & 483 & 51 & 349 \\
\hline
\end{tabular}

An inspection of the Code Case N-499 database showed the following two ruptured data in Table 9.

Table 9. Rupture data at $371^{\circ} \mathrm{C}$ from Code Case N-499 database.

\begin{tabular}{|l|c|c|c|}
\hline \multirow{2}{*}{ Heat No. } & \multirow{2}{*}{$\begin{array}{c}\text { Measured Creep Rupture } \\
\text { Time }(\mathrm{h})\end{array}$} & $\mathrm{ksi}$ & $\mathrm{MPa}$ \\
\cline { 3 - 4 } & 956 & 65 & 448 \\
\hline 5795 & 1004 & 75 & 517 \\
\hline
\end{tabular}

It is concluded from the results shown in these two tables that the values of the creep rupture stress given in Code Case N-499-2 are non-conservative relative to the rupture data at $371^{\circ} \mathrm{C}$, and the results from the statistical re-analysis give adequately conservative lower bounds to the rupture data. This provides a level of confidence in the results presented in Figures 2 to 4 from the statistical re-analysis. As the objective of the Code Case N-499 was on creep-fatigue rules at higher temperatures, it could very well be that the discrepancy at the lower temperatures was over looked. As Code Case N-499 is an important code case for the NGNP "cold" vessel option, testing and re-evaluation of the code case are recommended to ascertain the design information is adequately conservative.

To put the results that were presented in Figures 2 to 4 into perspective, it is well to recognize that the extrapolations are based on a small database with relatively short-term creep data as compared with the extrapolated times of 500,000 to 600,000 hours. Thus definitive conclusions could not be drawn based on these results. However, the results shown in these figures do underscore the need to develop longer term confirmatory creep rupture data, and to follow-up on the creep-fatigue issue to ensure that creep effects are properly accounted for in design for very long operating lives.

In light of the above results, the areas that need particular attention for A 508 Class 3 and A 533B steels and their weldments for NGNP RPV application are creep-rupture and fatigue damage, which is closely related to the definition of when creep effects become significant as discussed in more detail in Section 5.1.2 "Issues for the 'Hot' Vessel Option"; and simplified bounds for creep ratcheting, strain and deformation limits, and use of simplified boundary rules at discontinuities which are related issues that also need to be considered. To address these issues, it is important to understand how ratcheting, strain limits and creep fatigue affect the integrity of a structure differently.

Creep-fatigue is a localized issue whereas ratcheting is based, conceptually, on the interaction of the core stress and linearized through-wall stress (in the Bree model). Also, creep-fatigue is a direct failure mode whereas ratcheting is not. Cyclic life can, conceptually, be influenced directly by creep rupture damage at lower temperature whereas ratcheting would most likely be influenced by degraded tensile properties due to aging, or, potentially, cyclic softening, either from long term exposure at normal operation and/or short term, higher temperatures. Within the negligible creep regime, Subsection $\mathrm{NH}$ relies on $3 \bar{S}_{m}$ where the limit is based on $S_{m}$ and the relaxation strength to ensure shakedown. 


\begin{tabular}{|c|lll|}
\hline NEXT GENERATION NUCLEAR PLANT & Identifier: & PLN-2803 & \\
REACTOR PRESSURE VESSEL MATERIALS & Revision: & 0 & \\
RESEARCH AND DEVELOPMENT PLAN & Effective Date: & $04 / 30 / 08$ & Page: 43 of 95 \\
\hline
\end{tabular}

Test programs are proposed in Section 6 to address creep rupture and creep-fatigue, and the issues of whether or not the material properties at normal operating temperatures are compromised by short term, higher temperature off normal conditions. Data on the relaxation strength under these conditions will also be developed.

Due to a lack of operational experience in using A 508 and A 533B pressure vessel steels at $350^{\circ} \mathrm{C}$ for 60 years and under impure helium environment, confirmatory data on thermal aging, environmental effect, and neutron irradiation embrittlement are required to support licensing. Efforts are proposed in Section 6 to address these issues.

A typical new reactor project cycle would generally involve the sequential events of (i) RPV sizing per Subsection NB rules based on time-independent primary stresses, (ii) placement of long-lead forging orders per sizing dimensions, and (iii) detailed design analyses that would include fatigue analysis. However, one of the problems is that developing the creep data at the lower temperatures involves long test times. Thus there is a potential risk that the wall thickness might not be sufficient near the end of RPV design life if long-term test data do show that creep-fatigue is an issue. It is recommended that reactor vendors take this into their design consideration. Subsection NB, article NB 3222.4 (d) provides guidelines on conditions that would exempt components from fatigue analysis for cyclic service. It is also recommended that such avenues be explored and trade-off between a conservative design and this potential risk be considered.

The other code/licensing issue is related to the use of Code Case N-499 to deal with off-normal, limited temperature excursions beyond $371^{\circ} \mathrm{C}$. The creep data that supported Code Case N-499 were mainly based on data from A 533B plates. Confirmatory tests are planned in Section 6 to address the database issue in order to build higher confidence in ensuring the structural integrity of the NGNP RPV. No creep-fatigue data were generated from A 533B plates in support of the Code Case N-499 development. The intersection point of $(0.1,0.1)$ in the creep-fatigue interaction diagram of the code case was taken, presumably, from $2 \frac{1}{4} \mathrm{Cr}-1$ Mo steel. Creep-fatigue tests for the conditions covered by the code case are proposed in Section 6 to confirm the adequacy of the intersection point.

\subsubsection{Issues for "Hot" Vessel Option}

Grade 91 steel is the candidate RPV candidate material for the "hot" vessel option. As discussed in the previous sections, the major concern on Grade 91 steel for NGNP RPV application is the adequacy of thick-section properties of the base metal, as-received and post-weld heat treated, and weldments. The current specification for Grade 91 forgings is A182. Products made to this specification are limited to a maximum weight of $4540 \mathrm{~kg}$ which is too small for NGNP RPV applications. Addition of specification A336 for Grade 91 steel, which permits weight greater than $4540 \mathrm{~kg}$, in Subsections NB and NH is required to support NGNP RPV application.

Current concept on the design of the RPV in the hot vessel option is to restrict the RPV metal temperature to be below the negligible creep temperature for Grade 91 steel. This does not necessarily imply that the Subsection NH rules of construction can be completely exempted. However, it does reduce the design analysis burden as creep-fatigue interaction is no longer a structural integrity issue within the negligible creep regime. The criteria to be satisfied in that case are specified in Subsection $\mathrm{NH}$, article T-1324 which includes (i) NB-3222.2 on primary plus secondary stress intensity, NB-3222.3 on expansion stress intensity, and NB-3222.5 on thermal stress ratchet, by reference; and (ii) restrictions on creep rupture time and accumulated creep strain. For the $3 S_{m}$ limit in NB-3222.2 and NB-3222.3, the lesser of $3 S_{m}$ and $3 \bar{S}_{m}$ is to be used. Whether or not staying within the negligible creep regime will 


\begin{tabular}{|c|lll|}
\hline NEXT GENERATION NUCLEAR PLANT & Identifier: & PLN-2803 \\
REACTOR PRESSURE VESSEL MATERIALS & Revision: & 0 & \\
RESEARCH AND DEVELOPMENT PLAN & Effective Date: & $04 / 30 / 08$ & Page: 44 of 95 \\
\hline
\end{tabular}

lessen any surveillance requirement for monitoring creep and creep-fatigue damage remains to be determined through discussions between the regulators and reactor vendors.

Other code issues related to allowable stresses, negligible creep temperature, and creep-fatigue for Grade 91 steel have been addressed by Tasks 1, 3, and 5 of the DOE/ASME GMP, as summarized in Section 4 . Tests recommended by Task 3 for determining the negligible creep temperature, to extending the Grade 91 database, and to addressing creep-fatigue issues are proposed in Section 6. Thick-section forgings, rolled plates and weldments are selected in the test matrix so that thick-section properties can also be addressed.

There are also new tasks in the DOE/ASME GMP that address some generic design rule issues in Subsection NH that could impact Grade 91 steel. Any recommended testing to support the resolution of these generic design rule issues will be assessed and appropriate testing will be proposed.

\subsubsection{NRC Issues List}

Code Case N-47, a precursor to Subsection NH, had been reviewed by NRC during the application of a construction permit by the Clinch River Breeder Reactor (CRBR) Project in the late 70s and early 80s. The licensing process was stopped due to the abrupt cancellation of the CRBR project. However, a list of safety related issues were identified by NRC. NRC had also performed a pre-application safety evaluation of the Power Reactor Innovative Small Module (PRISM) liquid-metal reactor design in the mid 90s and similar issues were raised. These NRC issues have been documented in Task 2 of the DOE/ASME GMP and the task report was summarized in Section 4.

It is important to note that there are added burdens in licensing NGNP as Subsection NH and Code Case N-499 have not been approved by NRC.

The CRBR safety related issues identified by NRC are discussed with respect to the "cold" and "hot" vessel options separately. The corresponding assessment and recommended actions are given in Table 10 . It is noted that the NRC issues list is not ranked relative to the severity of the concerns. 


Idaho National Laboratory
\begin{tabular}{|c|lll|}
\hline NEXT GENERATION NUCLEAR PLANT & Identifier: & PLN-2803 & \\
REACTOR PRESSURE VESSEL MATERIALS & Revision: & 0 & \\
RESEARCH AND DEVELOPMENT PLAN & Effective Date: & $04 / 30 / 08$ & Page: 45 of 95 \\
\hline
\end{tabular}

Table 10. NRC issues list from CRBR Review - Assessment Relative to the "Cold" and "Hot" Vessel Options.

\begin{tabular}{|c|c|c|c|c|c|}
\hline \multirow{2}{*}{$\begin{array}{c}\text { Issue } \\
\# \\
\end{array}$} & \multirow{2}{*}{$\begin{array}{c}\text { Structural } \\
\text { Integrity Issues } \\
\text { identified by } \\
\text { NRC for CRBR }\end{array}$} & \multicolumn{2}{|c|}{ "Cold" Vessel Option } & \multicolumn{2}{|c|}{ "Hot" Vessel Option } \\
\hline & & Assessment & Required Actions & Assessment & Required Actions \\
\hline 1 & $\begin{array}{l}\text { Transition joints } \\
\text { (i.e., dissimilar } \\
\text { metals) }\end{array}$ & $\begin{array}{l}\text { Effects could be minimized } \\
\text { if materials are a close match } \\
\text { in thermal expansion } \\
\text { coefficient. There is some } \\
\text { experience in LWR to draw } \\
\text { on, e.g., pressurizer nozzles } \\
\text { at a slightly lower } \\
\text { temperature. However, this } \\
\text { could be a possible long term } \\
\text { problem with the long NGNP } \\
\text { design lifetime. }\end{array}$ & $\begin{array}{l}\text { This issue needs to be } \\
\text { addressed if such } \\
\text { transition joints are } \\
\text { present in the down- } \\
\text { selected vendor } \\
\text { design concept. }\end{array}$ & $\begin{array}{l}\text { The Code specified approach is to } \\
\text { model the joint with base metal } \\
\text { properties to the weld centerline } \\
\text { and then include differences in the } \\
\text { connecting base metal properties in } \\
\text { the weldment stress analysis. }\end{array}$ & $\begin{array}{l}\text { This issue needs to be addressed } \\
\text { if such transition joints are } \\
\text { present in the down-selected } \\
\text { vendor design concept. }\end{array}$ \\
\hline 2 & $\begin{array}{l}\text { Weld residual } \\
\text { stresses }\end{array}$ & $\begin{array}{l}\text { Weld residual stress is } \\
\text { considered in Section XI flaw } \\
\text { evaluation procedure in } \\
\text { connection with in-service } \\
\text { inspection. This is a lower } \\
\text { level concern. }\end{array}$ & $\begin{array}{l}\text { Information on } \\
\text { through thickness } \\
\text { weld residual stress } \\
\text { profiles for } \\
\text { A 508/533B steels is } \\
\text { available in } \\
\text { connection with } \\
\text { LWR applications. } \\
\text { Any additional data } \\
\text { required for NGNP } \\
\text { application is judged } \\
\text { to be of confirmatory } \\
\text { in nature and will be } \\
\text { proposed when is } \\
\text { necessary. }\end{array}$ & $\begin{array}{l}\text { Not considered in current } \\
\text { Subsection NH methodology. } \\
\text { Subsection NH approach implies } \\
\text { that the selection of weld wires and } \\
\text { welding process produce ductile } \\
\text { welds and subsequent load cycling } \\
\text { and creep reduce residual stresses, } \\
\text { particular at very high temperatures. } \\
\text { For NGNP RPV applications, } \\
\text { relaxation of weld residual stress } \\
\text { due to creep deformation is not as } \\
\text { effective because of the lower } \\
\text { temperature. Weld residual stresses, } \\
\text { when combined with operation } \\
\text { stresses, could reduce brittle } \\
\text { fracture margin. }\end{array}$ & $\begin{array}{l}\text { Characterization of weld } \\
\text { residual stress through thickness } \\
\text { profiles, by a combination of } \\
\text { measurements and weld } \\
\text { residual stress finite element } \\
\text { simulation, is required. }\end{array}$ \\
\hline 3 & $\begin{array}{l}\text { Design loading } \\
\text { combinations }\end{array}$ & $\begin{array}{l}\text { This is an owner/regulator } \\
\text { issue that is beyond the scope } \\
\text { of Subsection NB. }\end{array}$ & $\begin{array}{l}\text { This is an action for } \\
\text { the reactor vendor. }\end{array}$ & $\begin{array}{l}\text { This is an owner/regulator issue that } \\
\text { is beyond the scope of Subsection } \\
\text { NH. }\end{array}$ & $\begin{array}{l}\text { This is an action for the reactor } \\
\text { vendor. }\end{array}$ \\
\hline
\end{tabular}




Idaho National Laboratory
\begin{tabular}{|c|lll|}
\hline NEXT GENERATION NUCLEAR PLANT & Identifier: & PLN-2803 & \\
REACTOR PRESSURE VESSEL MATERIALS & Revision: & 0 & \\
RESEARCH AND DEVELOPMENT PLAN & Effective Date: & $04 / 30 / 08$ & Page: 46 of 95 \\
\hline
\end{tabular}

Table 10. (continued).

\begin{tabular}{|c|c|c|c|c|c|}
\hline \multirow[b]{2}{*}{$\begin{array}{c}\text { Issue } \\
\#\end{array}$} & \multirow{2}{*}{$\begin{array}{c}\text { Structural } \\
\text { Integrity Issues } \\
\text { identified by } \\
\text { NRC for CRBR }\end{array}$} & \multicolumn{2}{|c|}{ "Cold" Vessel Option } & \multicolumn{2}{|c|}{ "Hot" Vessel Option } \\
\hline & & Assessment & Required Actions & Assessment & Required Actions \\
\hline 4 & $\begin{array}{l}\text { Creep-rupture and } \\
\text { fatigue damage }\end{array}$ & $\begin{array}{l}\text { Creep and creep-fatigue } \\
\text { interaction are not the } \\
\text { applicable failure modes for } \\
\text { Subsection NB. However, } \\
\text { this could be a potential } \\
\text { problem. The combination of } \\
\text { high localized stress levels } \\
\text { and very long term operation } \\
\text { could cause localized cyclic } \\
\text { creep damage below the } \\
\text { Subsection NB to Subsection } \\
\text { NH temperature boundary. } \\
\text { This possibility is not } \\
\text { addressed in the current } \\
\text { Subsection NB rules because } \\
\text { creep is presumed to be } \\
\text { insignificant and Subsection } \\
\text { NH does not apply below } \\
371^{\circ} \mathrm{C} \text {. }\end{array}$ & $\begin{array}{l}\text { Creep rupture tests } \\
\text { are proposed in } \\
\text { Section } 6 \text { to address } \\
\text { this potential } \\
\text { problem. }\end{array}$ & $\begin{array}{l}\text { This is a valid concern. } \\
\text { Extrapolation of creep-fatigue data } \\
\text { is a challenge, particularly at the } \\
\text { extremes of the creep regime. At } \\
\text { the low temperature end the } \\
\text { concern involves the definition of } \\
\text { negligible creep and at the very } \\
\text { high temperature end one of the } \\
\text { issues is whether or not plasticity } \\
\text { and creep can be separated. The } \\
\text { major issues identified for } \\
\text { Subsection NH is that NH is too } \\
\text { conservative for materials such as } \\
\text { Grade } 91 \text { steel, particularly with } \\
\text { respect to other international Codes. } \\
\text { DOE/ASME GMP Tasks } 3 \text { and } 5 \\
\text { have assessed the creep-fatigue } \\
\text { issues for Grade } 91 \text { with respective } \\
\text { to the current Subsection NH time } \\
\text { fraction rules. } \\
\text { There is proposed new work (Task } \\
10 \text { ) in DOE/ASME GMP that will } \\
\text { address this issue by exploring } \\
\text { other creep-fatigue technology. }\end{array}$ & $\begin{array}{l}\text { Creep and creep-fatigue testing } \\
\text { for Grade } 91 \text { was recommended } \\
\text { by Task } 3 \text { of the DOE/ASME } \\
\text { GMP to support the } \\
\text { determination of negligible } \\
\text { creep regime, to improve the } \\
\text { understanding of cyclic } \\
\text { behavior, and to validate the } \\
\text { creep-fatigue procedures. } \\
\text { These test plans are proposed in } \\
\text { Section } 6 \text {. } \\
\text { Recommended testing from } \\
\text { Task } 10 \text { will be assessed and } \\
\text { testing will be proposed when } \\
\text { necessary. }\end{array}$ \\
\hline
\end{tabular}




Idaho National Laboratory
\begin{tabular}{|c|lll|}
\hline NEXT GENERATION NUCLEAR PLANT & Identifier: & PLN-2803 & \\
REACTOR PRESSURE VESSEL MATERIALS & Revision: & 0 & \\
RESEARCH AND DEVELOPMENT PLAN & Effective Date: & $04 / 30 / 08$ & Page: 47 of 95 \\
\hline
\end{tabular}

Table 10. (continued).

\begin{tabular}{|c|c|c|c|c|c|}
\hline \multirow{2}{*}{$\begin{array}{c}\text { Issue } \\
\# \\
\end{array}$} & \multirow{2}{*}{$\begin{array}{c}\text { Structural } \\
\text { Integrity Issues } \\
\text { identified by } \\
\text { NRC for CRBR } \\
\end{array}$} & \multicolumn{2}{|c|}{ "Cold" Vessel Option } & \multicolumn{2}{|c|}{ "Hot" Vessel Option } \\
\hline & & Assessment & Required Actions & Assessment & Required Actions \\
\hline 5 & $\begin{array}{l}\text { Simplified bounds } \\
\text { for creep } \\
\text { ratcheting }\end{array}$ & $\begin{array}{l}\text { Creep ratcheting is not } \\
\text { considered in Subsection NB. } \\
\text { However, ratcheting can } \\
\text { likely be influenced by } \\
\text { degraded tensile properties } \\
\text { due to aging, or, potentially, } \\
\text { cyclic softening, either from } \\
\text { long term exposure at normal } \\
\text { operation and/or short term, } \\
\text { higher temperatures. }\end{array}$ & $\begin{array}{l}\text { Confirmatory testing } \\
\text { to determine tensile } \\
\text { and cyclic properties } \\
\text { of materials aged for } \\
\text { long term at normal } \\
\text { operating and higher } \\
\text { temperatures is } \\
\text { proposed in } \\
\text { Section } 6 \text {. }\end{array}$ & $\begin{array}{l}\text { This is a valid concern. } \\
\text { Proposed new work (Task 9) in } \\
\text { DOE/ASME GMP addresses this } \\
\text { issue. }\end{array}$ & $\begin{array}{l}\text { Recommended testing from } \\
\text { Task } 9 \text { will be assessed and } \\
\text { relevant testing will be } \\
\text { proposed. }\end{array}$ \\
\hline 6 & Thermal striping & $\begin{array}{l}\text { Thermal striping has been a } \\
\text { concern for Pares. Input from } \\
\text { reactor vendors on the } \\
\text { potential threat from thermal } \\
\text { striping due to NGNP } \\
\text { thermal transients is needed. }\end{array}$ & $\begin{array}{l}\text { No action is } \\
\text { recommended at this } \\
\text { point. Future testing } \\
\text { will be proposed if } \\
\text { thermal striping is } \\
\text { judged to be a threat. }\end{array}$ & $\begin{array}{l}\text { Current Subsection NH rules } \\
\text { provide a framework for assessment } \\
\text { of structural response. Generally, } \\
\text { issue is determining thermal } \\
\text { hydraulic response. This is not } \\
\text { considered to be an issue for gas- } \\
\text { cooled reactors. Recent R \& D in } \\
\text { Japan that should be assessed for } \\
\text { relevance and incorporation. }\end{array}$ & No action is recommended. \\
\hline 7 & $\begin{array}{l}\text { Creep-fatigue } \\
\text { analysis of Class } 2 \\
\text { and } 3 \text { piping }\end{array}$ & $\begin{array}{l}\text { Issue is not relevant to } \\
\text { vessels. }\end{array}$ & No action is required. & Issue is not relevant to vessels. & No action is required. \\
\hline 8 & $\begin{array}{l}\text { Are limits of Case } \\
\mathrm{N}-253 \text { for } \\
\text { Elevated } \\
\text { temperature Class } \\
2 \text { and } 3 \\
\text { components met? }\end{array}$ & $\begin{array}{l}\text { Issue is not relevant to "cold } \\
\text { vessel" option. }\end{array}$ & No action is required. & $\begin{array}{l}\text { Issue is not relevant to vessels } \\
\text { which are Class } 1 \text { pressure } \\
\text { boundary components. }\end{array}$ & No action is required. \\
\hline
\end{tabular}




Idaho National Laboratory
\begin{tabular}{|c|lll|}
\hline NEXT GENERATION NUCLEAR PLANT & Identifier: & PLN-2803 & \\
REACTOR PRESSURE VESSEL MATERIALS & Revision: & 0 & \\
RESEARCH AND DEVELOPMENT PLAN & Effective Date: & $04 / 30 / 08$ & Page: 48 of 95 \\
\hline
\end{tabular}

Table 10. (continued).

\begin{tabular}{|c|c|c|c|c|c|}
\hline \multirow{2}{*}{$\begin{array}{c}\text { Issue } \\
\# \\
\end{array}$} & \multirow{2}{*}{$\begin{array}{c}\text { Structural } \\
\text { Integrity Issues } \\
\text { identified by } \\
\text { NRC for CRBR } \\
\end{array}$} & \multicolumn{2}{|c|}{ "Cold" Vessel Option } & \multicolumn{2}{|c|}{ "Hot" Vessel Option } \\
\hline & & Assessment & Required Actions & Assessment & Required Actions \\
\hline 9 & $\begin{array}{l}\text { Creep buckling } \\
\text { under axial } \\
\text { compression } \\
\text { design margins }\end{array}$ & $\begin{array}{l}\text { The buckling design margins } \\
\text { are high and creep is unlikely } \\
\text { to be an issue at low } \\
\text { permitted stress levels. } \\
\text { NGNP has thicker RPV wall } \\
\text { than the thin-walled fast } \\
\text { breeder reactor vessels. }\end{array}$ & No action is required. & $\begin{array}{l}\text { Code committee responsible for } \\
\text { Subsection NH is not aware of any } \\
\text { generic issues or inconsistencies } \\
\text { within the creep-buckling rules - } \\
\text { particularly for thick walled } \\
\text { components. Should consider } \\
\text { French concerns; it may be a local } \\
\text { crimpling issue for very large } \\
\text { diameter, thin-walled vessels. }\end{array}$ & $\begin{array}{l}\text { This is a lower-tier issue. No } \\
\text { immediate action is } \\
\text { recommended. }\end{array}$ \\
\hline 10 & $\begin{array}{l}\text { Identify areas } \\
\text { where Appendix T } \\
\text { rules are not met }\end{array}$ & $\begin{array}{l}\text { Issue is not relevant to "cold } \\
\text { vessel" option. However, } \\
\text { based on the discussion in } \\
\text { Section 5.1.1, further } \\
\text { investigation is needed as the } \\
\text { negligible creep criterion of } \\
\text { Subsection NH might not be } \\
\text { satisfied for the full design } \\
\text { life and temperature. This } \\
\text { will affect failure modes such } \\
\text { as creep and creep-fatigue } \\
\text { which are "local" in nature } \\
\text { (e.g., at stress riser) }\end{array}$ & $\begin{array}{l}\text { Testing is } \\
\text { recommended in } \\
\text { Section } 6 \text { to address } \\
\text { issues related to Code } \\
\text { case N-499. }\end{array}$ & $\begin{array}{l}\text { Appendix T provides procedures to } \\
\text { determine strain range using elastic } \\
\text { analysis. If these rules can not be } \\
\text { satisfied, additional rules are } \\
\text { provided, presumably less } \\
\text { conservative, based on the results of } \\
\text { inelastic analyses. However, } \\
\text { inelastic analysis requires detailed } \\
\text { constitutive models of material } \\
\text { behavior under time varying } \\
\text { loading conditions. For the CRBR } \\
\text { these behavioral models were based } \\
\text { on Nuclear Standard NE F9-5T. } \\
\text { These standards are no longer } \\
\text { maintained and there have been } \\
\text { numerous technical developments } \\
\text { in this area since. Development of } \\
\text { material models for materials not } \\
\text { currently covered or for } \\
\text { temperatures beyond their original } \\
\text { range of verification will be a } \\
\text { considerable effort. }\end{array}$ & $\begin{array}{l}\text { There are a number of } \\
\text { constitutive equations } \\
\text { developed for Grade } 91 \text { in the } \\
\text { literature. Assessment of long } \\
\text { term creep and stress relaxation } \\
\text { predictions of these models is } \\
\text { required. If improvement to the } \\
\text { predictive capability of the } \\
\text { model is needed, testing to } \\
\text { support such effort will be } \\
\text { identified. } \\
\text { Establishment of guidelines } \\
\text { similar to Nuclear Standard NE } \\
\text { F9-5T, developed specifically } \\
\text { for high temperature design of } \\
\text { liquid metal fast breeder reactor } \\
\text { components, is recommended in } \\
\text { Section } 6 \text {. }\end{array}$ \\
\hline
\end{tabular}




Idaho National Laboratory
\begin{tabular}{|c|lll|}
\hline NEXT GENERATION NUCLEAR PLANT & Identifier: & PLN-2803 & \\
REACTOR PRESSURE VESSEL MATERIALS & Revision: & 0 & \\
RESEARCH AND DEVELOPMENT PLAN & Effective Date: & $04 / 30 / 08$ & Page: 49 of 95 \\
\hline
\end{tabular}

Table 10. (continued).

\begin{tabular}{|c|c|c|c|c|c|}
\hline \multirow[b]{2}{*}{$\begin{array}{c}\text { Issue } \\
\#\end{array}$} & \multirow{2}{*}{$\begin{array}{c}\text { Structural } \\
\text { Integrity Issues } \\
\text { identified by } \\
\text { NRC for CRBR }\end{array}$} & \multicolumn{2}{|c|}{ "Cold" Vessel Option } & \multicolumn{2}{|c|}{ "Hot" Vessel Option } \\
\hline & & Assessment & Required Actions & Assessment & Required Actions \\
\hline 11 & $\begin{array}{l}\text { Rules for } \\
\text { component } \\
\text { supports at } \\
\text { elevated } \\
\text { temperature }\end{array}$ & $\begin{array}{l}\text { Issue is not relevant to "cold } \\
\text { vessel" option. }\end{array}$ & No action is required. & Issue is not relevant to vessels. & No action is recommended. \\
\hline 12 & $\begin{array}{l}\text { Strain and } \\
\text { deformation limits } \\
\text { at elevated } \\
\text { temperature }\end{array}$ & $\begin{array}{l}\text { This is not an issue for the } \\
\text { "cold vessel" option for } \\
\text { sustained loading. For } \\
\text { sustained loading this is a } \\
\text { through-thickness issue, thus } \\
\text { the allowable primary stress } \\
\text { limits from Subsection NB } \\
\text { would limit creep, if any, to } \\
\text { insignificant levels. } \\
\text { However, at localized high } \\
\text { stress areas it is a potential } \\
\text { problem as discussed under } \\
\text { issues } \# 5 \text {. }\end{array}$ & $\begin{array}{l}\text { No action is required. } \\
\text { However, see issues } \\
\# 5 \text { for localized, high } \\
\text { stress areas. }\end{array}$ & $\begin{array}{l}\text { This is a valid concern. } \\
\text { Proposed new work (Task 9) in } \\
\text { DOE/ASME GMP addresses this } \\
\text { issue. }\end{array}$ & $\begin{array}{l}\text { Recommended testing from } \\
\text { Task } 9 \text { will be assessed and } \\
\text { relevant testing will be } \\
\text { proposed. }\end{array}$ \\
\hline
\end{tabular}




Idaho National Laboratory
\begin{tabular}{|c|lll|}
\hline NEXT GENERATION NUCLEAR PLANT & Identifier: & PLN-2803 & \\
REACTOR PRESSURE VESSEL MATERIALS & Revision: & 0 & \\
RESEARCH AND DEVELOPMENT PLAN & Effective Date: & $04 / 30 / 08$ & Page: 50 of 95 \\
\hline
\end{tabular}

Table 10. (continued).

\begin{tabular}{|c|c|c|c|c|c|}
\hline \multirow{2}{*}{$\begin{array}{c}\text { Issue } \\
\#\end{array}$} & \multirow{2}{*}{$\begin{array}{c}\text { Structural } \\
\text { Integrity Issues } \\
\text { identified by } \\
\text { NRC for CRBR } \\
\end{array}$} & \multicolumn{2}{|c|}{ "Cold" Vessel Option } & \multicolumn{2}{|c|}{ "Hot" Vessel Option } \\
\hline & & Assessment & Required Actions & Assessment & Required Actions \\
\hline 13 & $\begin{array}{l}\text { Evaluation of } \\
\text { weldments }\end{array}$ & $\begin{array}{l}\text { Weldment evaluation is } \\
\text { considered in the flaw } \\
\text { evaluation procedure of } \\
\text { Section XI in connection } \\
\text { with in-service inspection. } \\
\text { Can draw on LWR practice. }\end{array}$ & $\begin{array}{l}\text { Effort to assess } \\
\text { fatigue crack growth } \\
\text { data for A } 508 / 533 \mathrm{~B} \\
\text { at } 350^{\circ} \mathrm{C} \text { is proposed } \\
\text { in Section } 6 \text {. Test will } \\
\text { be proposed if there } \\
\text { is a data gap. }\end{array}$ & $\begin{array}{l}\text { A number of provisions in } \\
\text { Subsection NH and related } \\
\text { documents assure reliable weld } \\
\text { joints. Subsection NH methods } \\
\text { exceed current requirements for } \\
\text { non-nuclear applications as well as } \\
\text { nuclear applications below the } \\
\text { creep regime. }\end{array}$ & $\begin{array}{l}\text { Type IV cracking of Grade } 91 \\
\text { welds is a concern. The issue of } \\
\text { creep and creep-fatigue crack } \\
\text { growth in geometric (notches) } \\
\text { and material (welds) } \\
\text { discontinuities will be } \\
\text { addressed in the new Task } 8 \text { of } \\
\text { the DOE/ASME GMP. } \\
\text { Recommended testing from this } \\
\text { task will be assessed and } \\
\text { relevant testing will be } \\
\text { proposed. } \\
\text { Task } 3 \text { of the DOE/ASME } \\
\text { GMP has proposed creep- } \\
\text { fatigue tests for Grade } 91 \\
\text { weldments. This test plan is } \\
\text { proposed in Section } 6 \text {. }\end{array}$ \\
\hline 14 & $\begin{array}{l}\text { Material } \\
\text { acceptance criteria } \\
\text { for elevated } \\
\text { temperature }\end{array}$ & $\begin{array}{l}\text { Issue is not relevant to "cold } \\
\text { vessel" option. This probably } \\
\text { is not a concern but long- } \\
\text { term data at } 350^{\circ} \mathrm{C} \text { is needed } \\
\text { to verify and to support } \\
\text { licensing. }\end{array}$ & $\begin{array}{l}\text { Long-term } \\
\text { confirmatory creep } \\
\text { test is proposed in } \\
\text { Section } 6 .\end{array}$ & $\begin{array}{l}\text { Developing data for a } 60 \text {-year } \\
\text { design life at elevated temperatures } \\
\text { is very challenging. } \\
\text { The ability to demonstrate } \\
\text { confidence in using accelerated test } \\
\text { data to predict performance for } \\
\text { NGNP design life time is } \\
\text { paramount for licensing success. }\end{array}$ & $\begin{array}{l}\text { Task } 1 \text { of the DOE/ASME } \\
\text { GMP concluded that the } \\
\text { existing database for Grade } 91 \\
\text { is adequate for extending the } \\
\text { coverage of allowable stresses } \\
\text { to } 600,000 \text { hours for } \\
\text { temperatures below } 650^{\circ} \mathrm{C} \text {. } \\
\text { Effort is required to ensure that } \\
\text { Code action on the Task } 1 \\
\text { recommendation is taken. }\end{array}$ \\
\hline
\end{tabular}




Idaho National Laboratory
\begin{tabular}{|c|lll|}
\hline NEXT GENERATION NUCLEAR PLANT & Identifier: & PLN-2803 & \\
REACTOR PRESSURE VESSEL MATERIALS & Revision: & 0 & \\
RESEARCH AND DEVELOPMENT PLAN & Effective Date: & $04 / 30 / 08$ & Page: 51 of 95 \\
\hline
\end{tabular}

Table 10. (continued).

\begin{tabular}{|c|c|c|c|c|c|}
\hline \multirow{2}{*}{$\begin{array}{c}\text { Issue } \\
\#\end{array}$} & \multirow{2}{*}{$\begin{array}{c}\text { Structural } \\
\text { Integrity Issues } \\
\text { identified by } \\
\text { NRC for CRBR }\end{array}$} & \multicolumn{2}{|c|}{ "Cold" Vessel Option } & \multicolumn{2}{|c|}{ "Hot" Vessel Option } \\
\hline & & Assessment & Required Actions & Assessment & Required Actions \\
\hline 15 & $\begin{array}{l}\text { Creep-rupture } \\
\text { damage due to } \\
\text { forming and } \\
\text { welding }\end{array}$ & $\begin{array}{l}\text { Issue is not relevant to "cold } \\
\text { vessel" option. }\end{array}$ & No action is required. & $\begin{array}{l}\text { This issue is also covered under } \\
\text { issue } \# 2 \text {. }\end{array}$ & $\begin{array}{l}\text { No immediate action is } \\
\text { recommended. }\end{array}$ \\
\hline 16 & $\begin{array}{l}\text { Mass transfer } \\
\text { effects }\end{array}$ & $\begin{array}{l}\text { Issue is not relevant to "cold } \\
\text { vessel" option due to the low } \\
\text { operating temperature. }\end{array}$ & No action is required. & $\begin{array}{l}\text { This is an issue for liquid metal and } \\
\text { molten salt reactors but not for gas- } \\
\text { cooled (helium) reactor. }\end{array}$ & No action is required. \\
\hline 17 & $\begin{array}{l}\text { Environmental } \\
\text { effects }\end{array}$ & $\begin{array}{l}\text { NGNP helium environment } \\
\text { is not covered by specific } \\
\text { code rules in Subsection NB. } \\
\text { This is an Owner/regulator } \\
\text { issue. }\end{array}$ & $\begin{array}{l}\text { Effect of NGNP } \\
\text { helium environment } \\
\text { on allowable stresses } \\
\text { and fatigue } \\
\text { performance needs to } \\
\text { be investigated. Also, } \\
\text { residual damage after } \\
\text { off normal } \\
\text { temperature } \\
\text { excursions needs to } \\
\text { be investigated. }\end{array}$ & $\begin{array}{l}\text { This is an important area which is } \\
\text { not covered by specific code rules } \\
\text { in Subsection NH. This is an } \\
\text { Owner/regulator issue. }\end{array}$ & $\begin{array}{l}\text { Effect of NGNP helium on the } \\
\text { mechanical properties and } \\
\text { allowable stresses of Grade } 91 \\
\text { steel needs to be investigated. } \\
\text { (Irradiation effect is discussed } \\
\text { in Item \#20.) }\end{array}$ \\
\hline
\end{tabular}




Idaho National Laboratory
\begin{tabular}{|c|lll|}
\hline NEXT GENERATION NUCLEAR PLANT & Identifier: & PLN-2803 & \\
REACTOR PRESSURE VESSEL MATERIALS & Revision: & 0 & \\
RESEARCH AND DEVELOPMENT PLAN & Effective Date: & $04 / 30 / 08$ & Page: 52 of 95 \\
\hline
\end{tabular}

Table 10. (continued).

\begin{tabular}{|c|c|c|c|c|c|}
\hline \multirow{2}{*}{$\begin{array}{c}\text { Issue } \\
\#\end{array}$} & \multirow{2}{*}{$\begin{array}{c}\text { Structural } \\
\text { Integrity Issues } \\
\text { identified by } \\
\text { NRC for CRBR }\end{array}$} & \multicolumn{2}{|c|}{ "Cold" Vessel Option } & \multicolumn{2}{|c|}{ "Hot" Vessel Option } \\
\hline & & Assessment & Required Actions & Assessment & Required Actions \\
\hline 18 & $\begin{array}{l}\text { Fracture } \\
\text { toughness criteria }\end{array}$ & $\begin{array}{l}\text { Fracture performance of A } \\
508 / 533 \text { steels and associated } \\
\text { weldments in air is well } \\
\text { characterized. }\end{array}$ & $\begin{array}{l}\text { Confirmatory fracture } \\
\text { toughness data on } \\
\text { materials exposed to } \\
\text { NGNP helium } \\
\text { environment are } \\
\text { needed to support } \\
\text { licensing. Similar } \\
\text { data are needed for } \\
\text { materials that are } \\
\text { thermally aged for } \\
\text { long time as well as } \\
\text { materials that have } \\
\text { received creep- } \\
\text { fatigue damage since } \\
\text { some temperature } \\
\text { excursions beyond } \\
371^{\circ} \mathrm{C} \text {, but within the } \\
\text { limits of Code Case } \\
\mathrm{N}-499 \text { are } \\
\text { anticipated. }\end{array}$ & $\begin{array}{l}\text { Grade } 91 \text { steel exhibits } \\
\text { ductile/brittle transition behavior. } \\
\text { Thus its fracture toughness needs to } \\
\text { be characterized. This should } \\
\text { include the effect of long-term } \\
\text { thermal aging on the fracture } \\
\text { toughness, with emphasis on the } \\
\text { targeted RPV metal temperature. } \\
\text { Since this temperature is lower than } \\
\text { the maximum allowable Code } \\
\text { temperature, there is room to } \\
\text { accelerate the thermal aging process } \\
\text { in testing in order to gain } \\
\text { confidence in extrapolating the } \\
\text { fracture toughness data of aged } \\
\text { materials to end of design life under } \\
\text { service conditions. }\end{array}$ & $\begin{array}{l}\text { ASTM E1921 master curve } \\
\text { testing is proposed in Section } 6 \\
\text { to establish the master curve } \\
\text { transition temperatures for } \\
\text { stress-relieved and stress- } \\
\text { relieved plus thermally aged } \\
\text { Grade } 91 \text { steel. }\end{array}$ \\
\hline
\end{tabular}




Idaho National Laboratory
\begin{tabular}{|c|lll|}
\hline NEXT GENERATION NUCLEAR PLANT & Identifier: & PLN-2803 & \\
REACTOR PRESSURE VESSEL MATERIALS & Revision: & 0 & \\
RESEARCH AND DEVELOPMENT PLAN & Effective Date: & $04 / 30 / 08$ & Page: 53 of 95 \\
\hline
\end{tabular}

Table 10. (continued).

\begin{tabular}{|c|c|c|c|c|c|}
\hline \multirow[b]{2}{*}{$\begin{array}{c}\text { Issue } \\
\#\end{array}$} & \multirow{2}{*}{$\begin{array}{c}\text { Structural } \\
\text { Integrity Issues } \\
\text { identified by } \\
\text { NRC for CRBR }\end{array}$} & \multicolumn{2}{|c|}{ "Cold" Vessel Option } & \multicolumn{2}{|c|}{ "Hot" Vessel Option } \\
\hline & & Assessment & Required Actions & Assessment & Required Actions \\
\hline 19 & $\begin{array}{l}\text { Thermal aging } \\
\text { effects }\end{array}$ & $\begin{array}{l}\text { Data from surveillance } \\
\text { materials consisting of A } 508 \\
\text { Class } 2 \text {, Mn-Mo-Ni Linde } 80 \\
\text { submerged-arc weld, and A } \\
533 \mathrm{~B} \text {, exposed to } \\
\text { temperature of about } 260^{\circ} \mathrm{C} \\
\text { for } 209000 \text { hours show that } \\
\text { there is no statistically } \\
\text { significant degradation on } \\
\text { impact property and upper } \\
\text { shelf and transition region } \\
\text { toughness. However, the } \\
\text { intended NGNP application } \\
\text { is at higher temperature } \\
\left.\text { ( } 350^{\circ} \mathrm{C}\right) \text { and longer time ( } 60 \\
\text { years). Thermal aging is a } \\
\text { time-at-temperature process. } \\
\text { While this is not judged to be } \\
\text { a significant concern, there is } \\
\text { no LWR experience to draw } \\
\text { on under these conditions. A } \\
\text { potential effect would be } \\
\text { degradation of yield and } \\
\text { tensile strength which could } \\
\text { compromise design margins, } \\
\text { particularly for off normal or } \\
\text { faulted conditions near the } \\
\text { end of the design life. It } \\
\text { could also impact facture } \\
\text { toughness, particularly at the } \\
\text { end of design life. }\end{array}$ & $\begin{array}{l}\text { Confirmatory long- } \\
\text { term thermal aging } \\
\text { tests are proposed in } \\
\text { Section } 6 \text { to support } \\
\text { licensing. }\end{array}$ & $\begin{array}{l}\text { Thermal aging effects on allowable } \\
\text { stresses are addressed in Subsection } \\
\mathrm{NH} \text {. Yield and tensile strength } \\
\text { reductions are not required of Grade } \\
91 \text { steel for temperatures below } \\
480^{\circ} \mathrm{C} \text { and service time less than } \\
300,000 \text { hours. Per vendor report, } \\
\text { RPV metal temperature is below } \\
480^{\circ} \mathrm{C} \text {. }\end{array}$ & $\begin{array}{l}\text { Long term thermal aging tests } \\
\text { are proposed in Section } 6 \text { to } \\
\text { qualify the Subsection NH } \\
\text { strength reduction factors of } \\
\text { Grade } 91 \text { steel for the RPV } \\
\text { metal temperature and NGNP } \\
\text { design life. }\end{array}$ \\
\hline
\end{tabular}




Idaho National Laboratory
\begin{tabular}{|c|lll|}
\hline NEXT GENERATION NUCLEAR PLANT & Identifier: & PLN-2803 & \\
REACTOR PRESSURE VESSEL MATERIALS & Revision: & 0 & \\
RESEARCH AND DEVELOPMENT PLAN & Effective Date: & $04 / 30 / 08$ & Page: 54 of 95 \\
\hline
\end{tabular}

Table 10. (continued).

\begin{tabular}{|c|c|c|c|c|c|}
\hline \multirow{2}{*}{$\begin{array}{c}\text { Issue } \\
\#\end{array}$} & \multirow{2}{*}{$\begin{array}{c}\text { Structural } \\
\text { Integrity Issues } \\
\text { identified by } \\
\text { NRC for CRBR }\end{array}$} & \multicolumn{2}{|c|}{ "Cold" Vessel Option } & \multicolumn{2}{|c|}{ "Hot" Vessel Option } \\
\hline & & Assessment & Required Actions & Assessment & Required Actions \\
\hline 20 & Irradiation effects & $\begin{array}{l}\text { There is an extensive } \\
\text { database for LWR } \\
\text { incorporated in the NRC } \\
\text { licensing guidelines (NRC } \\
\text { Regulatory Guide 1.99) and } \\
\text { other international standards } \\
\text { (ASTM E 900). Neutron } \\
\text { irradiation embrittlement is } \\
\text { less severe at the higher } \\
\text { normal operating temperature } \\
\text { of the cold vessel option. }\end{array}$ & $\begin{array}{l}\text { Effort on obtaining } \\
\text { confirmatory } \\
\text { irradiation data is } \\
\text { needed to support } \\
\text { licensing. }\end{array}$ & $\begin{array}{l}\text { This is an important area which is } \\
\text { not covered by specific Code rules } \\
\text { in Subsection NH. This is an } \\
\text { Owner/regulator issue. } \\
\text { Per information provided by reactor } \\
\text { vendors, the dpa for the RPV is low } \\
\text { and hence irradiation embrittlement } \\
\text { is not a significant concern in terms } \\
\text { of fracture performance. But } \\
\text { confirmatory irradiation data are } \\
\text { needed to support licensing. }\end{array}$ & $\begin{array}{l}\text { Irradiation data on tensile } \\
\text { properties and fracture } \\
\text { toughness of Grade } 91 \text { steel } \\
\text { need to be assembled or } \\
\text { developed. }\end{array}$ \\
\hline 21 & $\begin{array}{l}\text { Use of simplified } \\
\text { bounding rules at } \\
\text { discontinuities }\end{array}$ & $\begin{array}{l}\text { Covered by Subsection NB. } \\
\text { Can draw on LWR practice. } \\
\text { However, as for } \# 5 \text {, creep } \\
\text { rate data at yield or near yield } \\
\text { should be obtained to } \\
\text { confirm that this is not a } \\
\text { concern. }\end{array}$ & $\begin{array}{l}\text { Action from } \# 5 \\
\text { applies here. }\end{array}$ & $\begin{array}{l}\text { This is an important issue that is the } \\
\text { subject of ongoing R\&D efforts. }\end{array}$ & $\begin{array}{l}\text { Similar to issue } \# 5 \text {, this will be } \\
\text { addressed by the proposed work } \\
\text { (Task 9) in the DOE/ASME } \\
\text { GMP. } \\
\text { Recommended testing will be } \\
\text { assessed and relevant testing } \\
\text { will be proposed. }\end{array}$ \\
\hline
\end{tabular}




Idaho National Laboratory
\begin{tabular}{|c|lll|}
\hline NEXT GENERATION NUCLEAR PLANT & Identifier: & PLN-2803 & \\
REACTOR PRESSURE VESSEL MATERIALS & Revision: & 0 & \\
RESEARCH AND DEVELOPMENT PLAN & Effective Date: & $04 / 30 / 08$ & Page: 55 of 95 \\
\hline
\end{tabular}

Table 10. (continued).

\begin{tabular}{|c|c|c|c|c|c|}
\hline \multirow{2}{*}{$\begin{array}{c}\text { Issue } \\
\#\end{array}$} & \multirow{2}{*}{$\begin{array}{c}\text { Structural } \\
\text { Integrity Issues } \\
\text { identified by } \\
\text { NRC for CRBR } \\
\end{array}$} & \multicolumn{2}{|c|}{ "Cold" Vessel Option } & \multicolumn{2}{|c|}{ "Hot" Vessel Option } \\
\hline & & Assessment & Required Actions & Assessment & Required Actions \\
\hline 22 & Elastic follow-up & $\begin{array}{l}\text { Not a significant concern at } \\
\text { low temperature for the "cold } \\
\text { vessel" option. Possible long } \\
\text { term problem at local stress } \\
\text { risers. }\end{array}$ & $\begin{array}{l}\text { This is a lower-tier } \\
\text { concern. Effort will } \\
\text { be proposed in the } \\
\text { future. }\end{array}$ & $\begin{array}{l}\text { This is part of issue \# } 21 \text { as } \\
\text { accounting for the effects of elastic } \\
\text { follow-up is a significant part of } \\
\text { simplified bounding rules. }\end{array}$ & $\begin{array}{l}\text { Similar to issues } \# 5 \text { and } \# 21 \text {, } \\
\text { this will be addressed by the } \\
\text { new proposed work (Task 9) in } \\
\text { the DOE/ASME GMP. } \\
\text { Recommended testing from this } \\
\text { task will be assessed and } \\
\text { relevant testing will be } \\
\text { proposed. } \\
\text { A test plan for SMT creep- } \\
\text { fatigue testing of Grade } 91 \text { steel } \\
\text { is proposed in Section } 6 \text {. The } \\
\text { SMT specimen will be designed } \\
\text { to have a significant elastic } \\
\text { follow-up. }\end{array}$ \\
\hline 23 & $\begin{array}{l}\text { Design criteria for } \\
\text { elevated } \\
\text { temperature core } \\
\text { support structures } \\
\text { and welds }\end{array}$ & $\begin{array}{l}\text { Issue is not relevant to } \\
\text { vessels. }\end{array}$ & $\begin{array}{l}\text { No action is } \\
\text { recommended. }\end{array}$ & Issue is not relevant to vessels. & No action is required. \\
\hline 24 & $\begin{array}{l}\text { Elevated } \\
\text { temperature data } \\
\text { base for } \\
\text { mechanical } \\
\text { properties }\end{array}$ & $\begin{array}{l}\text { Code case } \mathrm{N}-499 \text { permits } \\
\text { limited short-term } \\
\text { temperature excursions } \\
\text { beyond } 371^{\circ} \mathrm{C} \text { for Service } \\
\text { Level } \mathrm{B}, \mathrm{C} \text {, and } \mathrm{D} \text {. }\end{array}$ & $\begin{array}{l}\text { Confirmatory creep } \\
\text { rupture test is } \\
\text { proposed in } \\
\text { Section } 6 .\end{array}$ & $\begin{array}{l}\text { This issue is similar to issues } \# 13 \text {, } \\
\# 14, \# 18 \text {, and } \# 19 \text {. } \\
\text { This issue is particularly important } \\
\text { for Grade } 91 \text { thick section forgings } \\
\text { and thick section welds. Forging } \\
\text { thickness currently covered by } \\
\text { Subsection NH does not support } \\
\text { NGNP pressure vessel applications. }\end{array}$ & $\begin{array}{l}\text { This and the related issues need } \\
\text { to be addressed in an integrated } \\
\text { manner. } \\
\text { Testing for thick section base } \\
\text { metal and associated weldments } \\
\text { is required. }\end{array}$ \\
\hline
\end{tabular}




Idaho National Laboratory
\begin{tabular}{|c|lll|}
\hline NEXT GENERATION NUCLEAR PLANT & Identifier: & PLN-2803 & \\
REACTOR PRESSURE VESSEL MATERIALS & Revision: & 0 & \\
RESEARCH AND DEVELOPMENT PLAN & Effective Date: & $04 / 30 / 08$ & Page: 56 of 95 \\
\hline
\end{tabular}

Table 10. (continued).

\begin{tabular}{|c|c|c|c|c|c|}
\hline \multirow{2}{*}{$\begin{array}{c}\text { Issue } \\
\#\end{array}$} & \multirow{2}{*}{$\begin{array}{c}\text { Structural } \\
\text { Integrity Issues } \\
\text { identified by } \\
\text { NRC for CRBR }\end{array}$} & \multicolumn{2}{|c|}{ "Cold" Vessel Option } & \multicolumn{2}{|c|}{ "Hot" Vessel Option } \\
\hline & & Assessment & Required Actions & Assessment & Required Actions \\
\hline 25 & $\begin{array}{l}\text { Basis for leak- } \\
\text { before-break at } \\
\text { elevated } \\
\text { temperatures }\end{array}$ & $\begin{array}{l}\text { This is closely related to } \\
\text { issues \#13 and \#18. Can draw } \\
\text { on LWR practice. }\end{array}$ & $\begin{array}{l}\text { J-R curve testing } \\
\text { covering } \\
\text { temperatures that } \\
\text { include the } \\
\text { temperature limits of } \\
\text { Code Case N-499 is } \\
\text { proposed in } \\
\text { Section } 6 .\end{array}$ & $\begin{array}{l}\text { This is closely related to issues } \# 13 \\
\text { and } \# 18 .\end{array}$ & $\begin{array}{l}\text { This needs to be addressed } \\
\text { together with issues } \# 13 \text { and } \\
\# 18 \text { in an integrated manner. } \\
\text { Creep and creep-fatigue crack } \\
\text { growth rates and J-R curve data } \\
\text { are required to support the } \\
\text { development of leak-before- } \\
\text { break design methodology. }\end{array}$ \\
\hline
\end{tabular}




\begin{tabular}{|c|lll|}
\hline NEXT GENERATION NUCLEAR PLANT & Identifier: & PLN-2803 & \\
REACTOR PRESSURE VESSEL MATERIALS & Revision: & 0 & \\
RESEARCH AND DEVELOPMENT PLAN & Effective Date: & $04 / 30 / 08$ & Page: 57 of 95 \\
\hline
\end{tabular}

\subsubsection{Irradiation Effects}

For the cold vessel option, the design requirements for the NGNP RPV do not require serious consideration of alternative materials as the design parameters have been chosen such that the reference materials are based on about forty years of operating experience in LWRs. The base materials and weld metals have good fracture toughness in the unirradiated condition, and the major factors in irradiation sensitivity for these materials are well known. The Westinghouse preconceptual design provides a maximum end-of-life fast fluence of $2 \times 10^{18} \mathrm{n} / \mathrm{cm}^{2}(>0.1 \mathrm{MeV})$; this estimate is based on Pebble Bed Modular Reactor (PBMR) documents. This is a very low fluence relative to a 40-year life for current LWR RPVs. Assuming that the radiation exposure for the RPV is relatively low for all the NGNP conceptual designs, irradiation embrittlement is not anticipated to be a major issue based on current knowledge accumulated for $250-300^{\circ} \mathrm{C}$ irradiation temperatures for these steels. However given the anticipated irradiation temperature of $\sim 350^{\circ} \mathrm{C}$, there is an obvious gap in knowledge regarding potential synergism between low flux irradiation and long-time aging at temperatures as high as $370^{\circ} \mathrm{C}$. There is a very limited number of studies mostly performed by Russians on VVER-type steels that indicated that irradiation may enhance thermal aging through irradiation-enhanced segregation of impurities (for example phosphorus) on grain boundaries. Unfortunately, short-term irradiation experiments at $\sim 370^{\circ} \mathrm{C}$ will not be able to resolve this concern. There is a need to perform a longer term study (at least two years of irradiation exposure) to address this issue. Required testing effort is proposed in Section 6.

\subsection{Procurement/Availability}

These topics are only addressed briefly in this report to frame the discussion of R\&D needs that arise from issues associated with procurement or availability. Availability of necessary components is considered below, first in terms of the capacity of current facilities to fabricate components of sufficient size for NGNP, and second in the willingness of potential vendors to expand capabilities to support NGNP. Technical issues associated with fabrication of NGNP pressure vessel components is discussed in some detail in a subsequent section.

The current schedule for the NGNP plant requires that the conceptual and preliminary designs and the application for the construction permit from NRC be completed by the middle of calendar year 2010. The selection of material for the NGNP RPV is one of the critical items to meet the schedule.

\subsubsection{Willingness to Forge/Roll}

Japan Steel Works has capability and experience with forging $8 \mathrm{~m}$ diameter rings from A 508 pressure vessel steel. They are willing to forge sections for NGNP, however, the lead time is substantial and an early decision to purchase these forgings will be necessary. An assessment of the potential vendors from all over the world showed that capability and experience to fabricate a Grade 91 vessel of the size required for NGNP are severely lacking (see Table 11). At that time it was apparent that none of the vendors were willing to upgrade their existing capabilities to facilitate forging of this steel unless an incentive is offered in terms of assured market/customers to order RPV of the Grade 91 steel, or in some other form. This procurement limitation may preclude meeting the NGNP schedule and eliminate this material as a candidate for the RPV. 


\begin{tabular}{|c|lll|}
\hline NEXT GENERATION NUCLEAR PLANT & Identifier: & PLN-2803 & \\
REACTOR PRESSURE VESSEL MATERIALS & Revision: & 0 & \\
RESEARCH AND DEVELOPMENT PLAN & Effective Date: & $04 / 30 / 08$ & Page: 58 of 95 \\
\hline
\end{tabular}

Table 11. Forging capability of Grade 91 for NGNP RPV ( 8 $\mathrm{m}$ dia. $\times 24 \mathrm{~m}$ high with thickness of 100 to $300 \mathrm{~mm})$.

\begin{tabular}{|c|c|c|c|}
\hline Manufacturer & $\begin{array}{c}\text { Current Ring } \\
\text { Forging Capability }\end{array}$ & Future/Upgrade Plans & $\begin{array}{c}\text { Viability to forge } \\
\text { Grade } 91\end{array}$ \\
\hline $\begin{array}{l}\text { Japan Steel Works, } \\
\text { Japan }\end{array}$ & $8 \mathrm{~m} \mathrm{OD}$ & $\begin{array}{l}\text { May be inclined to try } 2 \frac{1 / 4}{\mathrm{Cr}}- \\
\text { Mo steel but not Grade } 91 \\
\text { steel }\end{array}$ & $\begin{array}{l}\text { Rings? No } \\
\text { Plates? No }\end{array}$ \\
\hline $\begin{array}{l}\text { Bruck Forgings, } \\
\text { Germany }\end{array}$ & $5.2 \mathrm{~m}$ OD $(\max )$ & $8 \mathrm{~m}$ rings in 2 to 3 years ${ }^{\mathrm{a}}$ & $\begin{array}{l}\text { Rings? No } \\
\text { Plates? No }\end{array}$ \\
\hline $\begin{array}{l}\text { Saarschmeide, } \\
\text { Germany }\end{array}$ & $<5 \mathrm{~m}$ & $\begin{array}{l}\text { Probable investment in large } \\
\text { forging press by } 2009^{\mathrm{a}}\end{array}$ & $\begin{array}{l}\text { Rings? No } \\
\text { Plates? Yes }\end{array}$ \\
\hline Scot Forge, Illinois & $6 \mathrm{~m}$ OD (max) & None & $\begin{array}{l}\text { Rings? No } \\
\text { Plates? No }\end{array}$ \\
\hline $\begin{array}{l}\text { Doosan Heavy } \\
\text { Industries (DHI), } \\
\text { South Korea }\end{array}$ & $\begin{array}{l}\text { Experience with Grade } 91 \\
\text { for non-nuclear } \\
\text { applications. }\end{array}$ & $\begin{array}{l}\text { KAERI in talks with DHI to } \\
\text { fabricate thick section vessel } \\
\text { using Grade } 91 .\end{array}$ & $?$ \\
\hline \multicolumn{4}{|c|}{$\begin{array}{l}\text { a. Not necessarily for Grade } 91 \\
\text { b. } \approx 6 \mathrm{~m} \times 2.5 \mathrm{~m} \text { plates, but no experience in manufacturing Grade } 91 \text { or } 2 \frac{1}{4} 4 \mathrm{Cr}-1 \mathrm{Mo}-\mathrm{V} \text {. } \\
\text { c. Korean Atomic Energy Research Institute (KAERI) is interested in investing/funding DHI for this project. }\end{array}$} \\
\hline
\end{tabular}

\subsubsection{Transportation Issues}

Transportation issues are discussed in detail in the Acquisition Strategy. The maximum diameter of ring that can be delivered to the INL site is considerably less than $8 \mathrm{~m}$. This will drive the need to fabricate the vessel on site from rolled plate, or result in a decision to site the reactor in a location with direct access to a seaport for delivery of large forged components by barge.

\subsection{Fabricability}

In order to fabricate the huge RPV, vendors are needed who can produce seamless rings (forged) or plates (forged or rolled), achieving uniform through-thickness properties with the candidate materials.

\subsubsection{Ability to Forge/Roll}

At present, several vendors around the world have substantial experience in fabrication of RPV's from A 508. Procurement of a vessel of this material may depend primarily on the availability of a vendor to meet the schedule and not on the technical issues with the material.

$\mathrm{Fe}-2 \frac{1}{4} \mathrm{Cr}-1 \mathrm{Mo}-\mathrm{V}$ steel is extensively used in the fossil industries and hydrogenation reactor pressure vessels. There is no available information on existing pressure vessels having dimensions similar to that required in the NGNP RPV; however, because of the large-scale use of this material in fossil, petrochemical industries, etc., it can be concluded that there is some experience in forging/rolling thicksections of this material.

Grade 91 steel has overall superior mechanical properties among the three candidate materials that would enable manufacture of an RPV with thinner walls, thereby reducing thermally induced stresses, 


\begin{tabular}{|c|lll|}
\hline NEXT GENERATION NUCLEAR PLANT & Identifier: & PLN-2803 & \\
REACTOR PRESSURE VESSEL MATERIALS & Revision: & 0 & \\
RESEARCH AND DEVELOPMENT PLAN & Effective Date: & $04 / 30 / 08$ & Page: 59 of 95 \\
\hline
\end{tabular}

minimizing eventual thermal fatigue, and making it a primary candidate for use in the NGNP RPV. However, information is lacking on thick-section properties and fabrication experience of this material.

Ring forging of RPV using Grade 91 steel does not appear to be a feasible option at present; none of the vendors have the capability to forge thick-section large diameter rings of that alloy (refer to Table 2 above). Axial welding of plates/ring segments is the alternate choice; however, none of the vendors has experience in manufacturing thick-section plates, although Saarschmeide of Germany is confident they can (about 55 plates would be required to construct the RPV).

\subsubsection{Ability to Fabricate on Site}

Fabricating a vessel from conventional A 508/A 533 steel would be somewhat complicated compared to a fossil fired plant due to the heavy section thickness. There appears to be few issues that arise from this process that will require $R \& D$.

Fabricating a vessel from $9 \mathrm{Cr}$ steel is considerably more difficult than conventional steels due to the welding and heat treating issues discussed below. It should be noted that in addition to solving technical issues associated with onsite welding and heat treating, post-fabrication heat treatment of $9 \mathrm{Cr}$ structures is likely to require sophisticated inspection methods that are not currently available and may be particularly challenging for field fabrication.

\subsection{Welding}

The RPV will be much larger than the current LWR vessels, requiring field welding of either ring forgings or plates of the selected material. While ring forgings are preferred, since they would result in fewer welds (no longitudinal welds) to assemble the RPV, this may not be possible. Depending on the material selected, welding procedures may include pre- and post-weld heat treatment in the field.

Pressure vessels of low alloy steels have been fabricated and used in U.S. LWRs and there is substantial experience in welding of both plates and rings to form the vessels. Vessels with wall thicknesses varying between 203 to $254 \mathrm{~mm}$ ( 8 to 10 in.) and diameter-to-thickness ratios of $\sim 20$ have been fabricated for the Pressurized Water Reactors (PWR). In contrast, Boiling Water Reactor vessels with much larger diameter and a wall thickness of 152-mm (6-in.) have been fabricated. 21/4Cr-1Mo steels were developed for the petrochemical refinery industry service at high temperatures and high hydrogen pressures. A vanadium-modified version of these steels was developed so that components having wall thickness in excess of $10 \mathrm{in}$., and diameters and lengths on the order of up to 20 and $200 \mathrm{ft}$, respectively, can be fabricated. These steels offer the fabricability and toughness of bainitic microstructures without the difficulties of welding and heat treatment of high chromium martensitic materials like Grade 91 steel. Testing has shown that filler metal, base metal, and HAZ were comparable in strength and within ASME's base metal scatter band. However, for design temperatures in excess of $468^{\circ} \mathrm{C}$, ASME requires performance testing of weldments, so additional long-term test data are needed to qualify the welded components for application in the NGNP RPV. The susceptibility of $\mathrm{Fe}-2^{1 / 4} \mathrm{Cr}-1 \mathrm{Mo}-1 / 4 \mathrm{~V}$ to temper embrittlement is also concern when welding in addition to the aging effects mentioned above. If the grains are insufficiently tempered, the effect is the greatest. Test results for base metal, HAZ, and weld metal exposed for $20,000 \mathrm{~h}$ at $482^{\circ} \mathrm{C}\left(900^{\circ} \mathrm{F}\right)$ have shown that acceptable toughness is retained for the materials, provided impurity levels were maintained within specific limits.

Grade 91 steel is a leading candidate for NGNP RPV; however the superior mechanical properties of the Grade 91 weldment strongly depend on creation of a precise microstructure and maintaining it throughout the service life of the welded component. Welding procedure and post-weld heat treatment 


\begin{tabular}{|c|lll|}
\hline NEXT GENERATION NUCLEAR PLANT & Identifier: & PLN-2803 & \\
REACTOR PRESSURE VESSEL MATERIALS & Revision: & 0 & \\
RESEARCH AND DEVELOPMENT PLAN & Effective Date: & $04 / 30 / 08$ & Page: 60 of 95 \\
\hline
\end{tabular}

play critical roles in creating the desired microstructure and producing a stress-free weld. The most significant problem with welding of Grade 91 steel is its propensity to Type IV cracking in the heat affected zone. Material which has exceeded the minimum transformation temperature during the welding process can partially reaustenitize and coarsen, resulting in substantially reduced creep-rupture strength and leading to cracking at relatively low operating temperatures and early component lifetimes. Boron addition seems to reduce cracking susceptibility but additional data are needed to quantify the effect over the long term. Over-tempering, under-tempering, cold-work, dissimilar metal welds and stress corrosion cracking are also potential problems encountered in Grade 91 weldments. Welding this steel requires more care in fabrication procedure and joint design than lower alloy steels being sensitive to temperature variations both during welding and post-weld heat treatment.

Creep-fatigue interaction could be more severe in Grade 91 weldments compared to $2 \frac{1}{4} \mathrm{Cr}-1 \mathrm{Mo}$ weldments. Creep-fatigue data show that the number of cycles to failure decreases with the introduction of hold time, and the effect is more severe for the weldment than for the base metal. Significant additional data are needed to quantify this effect and establish the maximum reduction in life, if any.

\subsubsection{Baseline Case}

In the cold vessel option, low-alloy steels A 508 and A 533B are considered as candidate materials for the RPV. Both A 508 and A 533B steels were investigated to great extents in U. S. nuclear reactor programs for=light water reactor RPV applications. While improvement to welding procedures could always be made, extensive field data suggest that current welding procedures and vendor welding practice are adequate to support NGNP RPV applications.

\subsubsection{Irradiation Effects}

Due to the large database available from the use of A 508 and A 533 steels in LWRs, the irradiation behavior of weldments in these standard pressure vessel steels is in general adequately understood. It is not anticipated that an extensive irradiation program will be required for welds in these materials.

\subsubsection{Alternative Cases}

Grade 91 steel (9Cr-1Mo-V [UNS K90901]) is considered a candidate material in the hot vessel option. Grade 91 is classified as a martensitic steel. After proper heat treatment that results in the desired tempered matensitic microstructure, Grade 91 offers superior strength at elevated temperatures. With its superior high temperature strength, the thickness of the RPV wall can be significantly reduced in comparison with other candidate hot vessel materials, resulting in lower through-wall thermal stresses during transient events. The reduced mass and weight also allows smaller and less expensive supporting structures for the RPV.

However, experience in welding Grade 91 in heavy section components the size of the NGNP RPV for nuclear application is lacking. Compared to the candidate materials for the cold vessel option, more $R \& D$ efforts are needed to fully explore the advantages of the Grade 91 steel to ensure the success in the intended RPV application.

\subsubsection{Weldability of Vessel Materials}

Some compositions within the standard specifications of Grade 91 have delta ferrite, which is stable at all temperatures. In addition, chemical micro-segregation during welding could produce conditions in weld deposits that effectively stabilize the delta ferrite. The presence of delta ferrite is generally undesirable in $9 \mathrm{Cr}$ steels because it may be detrimental to toughness and creep properties. The influence 


\begin{tabular}{|c|lll|}
\hline NEXT GENERATION NUCLEAR PLANT & Identifier: & PLN-2803 & \\
REACTOR PRESSURE VESSEL MATERIALS & Revision: & 0 & \\
RESEARCH AND DEVELOPMENT PLAN & Effective Date: & $04 / 30 / 08$ & Page: 61 of 95 \\
\hline
\end{tabular}

of delta ferrite on the properties of weld deposits and weldments should be thoroughly characterized, and delta ferrite minimizing measures should be developed for the intended nuclear application.

Because the Grade 91 is classified as martensitic steel, specific microstructure must be obtained to achieve the expected superior strength at elevated temperatures. However, the phase transformations of the steel are very sensitive to the chemical compositions; and the critical points can change significantly as the composition varies. For example, the $\mathrm{M}_{\mathrm{s}}$ can decrease from approximately 400 to $340^{\circ} \mathrm{C}$, and the $\mathrm{M}_{\mathrm{f}}$ from 210 to $150^{\circ} \mathrm{C}$, at the low and high ends of the standard chemistry specification. It is well known that chemical microsegregation inevitably occurs during welding and casting of all alloys other than pure metals. As a result, segregation of-elements such as $\mathrm{C}, \mathrm{Cr}, \mathrm{Mo}, \mathrm{Si}$, and $\mathrm{V}$ etc. in heavy section welding can significantly influence weld deposit microstructures by creating local variations in phase transformation behavior. Unfortunately little systematic study has been done of microsegregation in martensitic steels. These microstructure variations can result in measurable variations in mechanical properties such as creep behavior. More detailed studies of the effects of chemical micro-segregation on microstructures and properties should be conducted. Further, since chemical micro-segregation is unavoidable and it is related to welding parameters, the relationship of chemical micro-segregation in Grade 91 steel to welding parameters should be established.

Grade 91 is a special ferritic/martensitic alloy Cr-Mo steel that requires special consideration and should not be considered just another Cr-Mo material. To obtain the expected superior strength at elevated temperatures for the intended nuclear application, specific microstructures must be obtained and maintained. Gaining the desired microstructure requires rigorous control and great care when processing and heat treating the material. During welding, the solidification of the weld pool is virtually a small casting process and many thermal-mechanical processing measures cannot be used or precisely controlled to obtain the desired microstructure. The heavy section for the intended RPV application further adds difficulties to the control of the thermal-mechanical process during welding. R\&D activities are needed to investigate and address welding issues in a combined manner.

\subsubsection{Maintaining Properties for Thick Section Welds}

Although the high strength of Grade 91 allows relatively thinner wall designs compared to low-alloys candidate materials, the RPV still requires a heavy section wall and large size. Controlling residual stresses could therefore be an important fabrication issue in the thick section weldment. Recent studies indicate that local application during welding of auxiliary heating or cooling can have beneficial effects on residual stresses in weldment. The need for residual stress control should be established for critical components. Strategies for controlling residual stresses should be developed and verified.

Inhomogeneous weld microstructures are often found in complex property gradient in the weld region. The current experimental testing and weld design approach often oversimplify the effect of these complex microstructure and property gradients in the design and assessment of structural performance and integrity of such large welded structural components. Compared to the standard 9Cr-1Mo chemical composition, the Grade 91 steel include additional elements of V, Nb, N, Al, and Ni. Elements such as $\mathrm{Nb}$ are prone to segregation in heavy section product forms. The through-wall macro-segregation can further complicate the property gradient in the welded region. New or improved design approaches that can realistically incorporate the complex microstructure and property gradients of the weld joint should be developed and verified. Advanced computational models to predict the microstructural changes and their impact on the fracture behavior and long-term creep resistance should also be developed.

During fabrication, heavy section weldments may be held at temperatures below those used for post weld heat treatments for extended time periods (possibly days). This may be done to maintain preheating 


\begin{tabular}{|c|lll|}
\hline NEXT GENERATION NUCLEAR PLANT & Identifier: & PLN-2803 & \\
REACTOR PRESSURE VESSEL MATERIALS & Revision: & 0 & \\
RESEARCH AND DEVELOPMENT PLAN & Effective Date: & $04 / 30 / 08$ & Page: 62 of 95 \\
\hline
\end{tabular}

temperatures and for hydrogen bake-out treatments. Depending on their temperatures and their chemical compositions, weld deposits could contain metastable austenite when low-temperature holds begin. This austenite could transform during long holding periods and the resulting microstructures could be different from those expected under conditions where extended low-temperature holds are not used. The need for extended low-temperature holds should be established and their effects on microstructures and properties determined.

Hydrogen induced cold cracking is always a concern for heavy section components. To ensure RPV safety, the materials susceptibility to cold cracking needs to be investigated. The information obtained from the investigation will provide crucial guidance for developing temperature control procedures before, during, and after the welding process.

Limited existing data on Grade 91 suggest that creep may become negligible at the temperature range of 425 to $450^{\circ} \mathrm{C}$. The observation initiated the attempt to design the RPV in negligible creep regime so that expensive creep and creep crack monitoring programs can be eliminated throughout the reactor operation life of 60 years. If this design approach is taken, negligible creep behavior of heavy section welds may become the weakest area that must be thoroughly investigated for defining the desired operation temperature.

Existing data also suggest that hold times may reduce fatigue life of the Grade 91 weldment. Heavy section welds again may become the weakest area that must be investigated.

\subsubsection{Post-Weld Heat Treatment}

Post weld heat treatment (PWHT) has a great impact to the final microstructure and long-term mechanical properties of the welds. Grade 91 steel requires great care in PWHT because the material airhardens and exhibits very little ductility in the as-welded condition. Further, $1 / 4$ critical points for phase transformations can change significantly, depending on subtle variations in the chemical composition of the weld and base metal within the specifications. For the intended RPV application, the heavy section of the component and the envisioned onsite welding requirements add more difficulties to the control of the PWHT parameters to achieve the desired final microstructures that provide the expected superior high temperature strength of the material. Experiences from fossil energy programs in fabricating Grade 91 welds suggest that customized PWHT procedures must be developed in detail, and the entire process should be closely monitored with an array of thermal couples and other types of sensors.

To achieve optimum microstructures and the required superior high temperature strength, not only the PWHT, but the entire thermal progression or heat treatments for fabricating the weld must be strictly controlled with great care. This usually includes proper preheating, inter-pass temperature control, post weld hydrogen bake-out, and PWHT. Detailed procedures for each step of the thermal processing should be developed, with special considerations for onsite welding of thick sections in various weather conditions. Experience with fossil energy applications has shown that variation of heat chemistry within the ASTM specification can alter critical phase transformation temperatures, Austenite start temperature for example, by as much as $50^{\circ} \mathrm{C}$. Tabulated continuous cooling transformation diagrams can only be considered as approximate and the heat treating temperatures adjusted according to the actual heat chemistry.

\subsubsection{Type IV Cracking}

Type IV cracking occurs in the fine-grained region close to the intercritically annealed zone of the $\mathrm{HAZ}$ as a result of an accelerated formation rate of creep void in these regions. The cracking can lead to a shortened creep rupture time of HAZ compared to that of the base metal. Type IV cracking of 


\begin{tabular}{|c|lll|}
\hline NEXT GENERATION NUCLEAR PLANT & Identifier: & PLN-2803 & \\
REACTOR PRESSURE VESSEL MATERIALS & Revision: & 0 & \\
RESEARCH AND DEVELOPMENT PLAN & Effective Date: & $04 / 30 / 08$ & Page: 63 of 95 \\
\hline
\end{tabular}

transversely loaded weldment may be unavoidable in Grade 91 steel. What is worse, as the transverse load decreases the difference between the creep rupture times of the weldment and base metal may actually increase due to Type IV cracking.

The accelerated formation rate of creep voids may result from a combination of the fine-grained microstructure and coarse carbide particles contained in the region. The coarse carbide particles can serve as void nucleation sites. With the high diffusion rate along the massive grain boundaries of the fine-grained region, formation and growth of creep voids can be greatly accelerated, leading to prematured creep failure.

Although Type IV cracking arises from the heterogeneous microstructure in HAZ, it is usually impractical to eliminate it by a reaustenitization and tempering heat treatment, especially for the large scale and onsite RPV construction. Unfortunately, it may be pragmatic to define a creep strength reduction factor for design through creep testing of cross-welds. Factors that affect propensity to Type IV cracking should be investigated. Major known factors that have apparent effects on Type IV cracking may include service temperature, heat treatment temperature (preheating, tempering, and normalization temperatures), and chemical composition e.g., boron. The PWHT time, energy input, and other chemical contents may also have limited effects. More investigations are needed to study these factors and develop means to minimize or hopefully eliminate the propensity to Type IV cracking.

\subsubsection{Dissimilar Metal Weld}

Metallurgical and mechanical stability in dissimilar metal welds should always be considered and investigated. Dissimilar welds between different base metals may have different stability issues. In most cases there two issues that are closely related. Because high temperature and long-term service conditions will mostly have deteriorating effects on the metallurgical and mechanical properties, for the intended RPV application, metallurgical and mechanical stability of dissimilar welds between potential alloy couples must be accurately predicted based on prudent amount of experimental data. To identify the specific issues for joint couples of particular alloys, a combination of computational thermodynamics and kinetics modeling should first be used to assess long-term metallurgical stability. Experimentation would also be needed to confirm whether predictions were reasonable representations of actual behavior. If the analysis and data of specific couples indicated potential problems with mass transport and phase stability, one could use the same tools to help identify alternate materials that reduced or eliminated these concerns. Such activities could lead to consideration of transition pieces and alloy development for welding filler metals. Mechanical behavior and mechanical stability would be just as important, and these factors would also need incorporated into the analysis.

This is also the case for low alloys, during the fabrication as well as maintenance of the RPV, repair welding may become necessary for $9 \mathrm{Cr}-1 \mathrm{M}-\mathrm{V}$. Repair welding usually faces more technical and operational difficulties. Consequently, repair welds are normally not as high quality as the original welds. The issues of avoiding repair welding in fabrication and optimizing its quality during maintenance repair must be studied.

\subsubsection{Irradiation Effects}

As noted above, some gaps exist in understanding the irradiation behavior of $9 \mathrm{Cr}-1 \mathrm{M}-\mathrm{V}$. This will be particularly true of weldments, if post-weld heat treatment to re-austenitize and quench the fabricated components to eliminate Type IV cracking prove to be impractical. The fine-grained region of mixed austenite/ferrite microstructure close to the intercritically annealed zone of the HAZ may have quite different response to irradiation compared to the tempered martensite microstructure in optimally quenched and tempered $9 \mathrm{Cr}-1 \mathrm{M}-\mathrm{V}$ steel. 


\begin{tabular}{|c|lll|}
\hline NEXT GENERATION NUCLEAR PLANT & Identifier: & PLN-2803 & \\
REACTOR PRESSURE VESSEL MATERIALS & Revision: & 0 & \\
RESEARCH AND DEVELOPMENT PLAN & Effective Date: & $04 / 30 / 08$ & Page: 64 of 95 \\
\hline
\end{tabular}

\subsection{Damage Sources}

\subsubsection{Radiation}

A sufficient database exists of radiation effects on the A 508/A 533 steels from LWR experience. The NGNP lifetime fluence is anticipated to be approximately an order of magnitude lower than that for LWR vessels. The temperature at which the exposure occurs in the NGNP is expected to be above that for LWR vessels. There is less concern about the potential for embrittlement from these moderately higher temperatures.

\subsubsection{Oxidation/Corrosion}

Data for oxidation and corrosion alloys in NGNP helium atmosphere are very limited. Long-term aging in air will be required to investigate the potential for environmental degradation on the exterior of the vessel. Experimental characterization of the behavior in NGNP He will be required in both quasistatic environments for scoping studies and using He with the expected levels of impurities at velocities on the order of $50 \mathrm{~m} / \mathrm{s}$ that are thought to characterize flow in some sections of the NGNP. The potential for particle erosion at high velocity must also be examined.

\subsubsection{Emissivity}

For the passive heat removal system to function properly, it is necessary that the reactor pressure vessel be able to radiate heat to the external environment under accident conditions. While a target emittance has not yet been established, it is necessary to have a stable, high-emissivity layer on the proposed pressure vessel material. While there is significant light water reactor experience with A $508 / 533 \mathrm{~B}$, the higher temperature involved in the NGNP, requires an evaluation of the rate of formation and long-term stability of the emissivity layer on the outer surface of the reactor pressure vessel, which is exposed to air. There is considerable less information available for the proposed chrome variant reactor vessel materials at the proposed temperatures. While, the emissivities of steel can be increased by the formation of an oxide film, ${ }^{25}$ as shown in Figure 5, the conditions under which this film can be created and the stability of this film in air (including the effect of humidity) at operating temperature needs to be established. As demonstrated in Figure 5, and emittance $>0.85$ is not readily established in air. In addition the effects of field welding on the emissivity layer must be evaluated. 


\begin{tabular}{|c|lll|}
\hline NEXT GENERATION NUCLEAR PLANT & Identifier: & PLN-2803 & \\
REACTOR PRESSURE VESSEL MATERIALS & Revision: & 0 & \\
RESEARCH AND DEVELOPMENT PLAN & Effective Date: & $04 / 30 / 08$ & Page: 65 of 95 \\
\hline
\end{tabular}

ORNL-DWG 85-16776

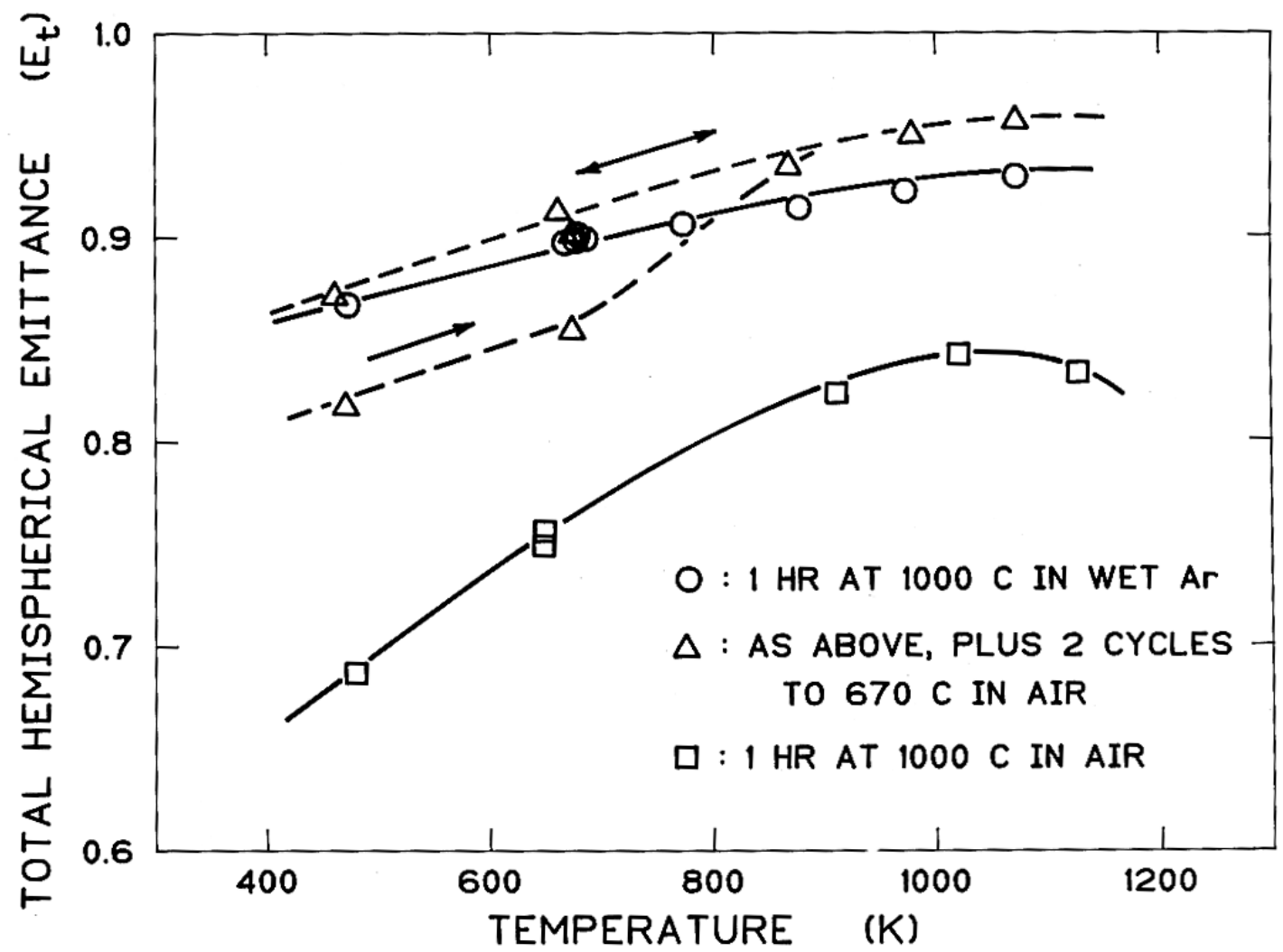

Figure 5. Effect of environment and temperature on the emissivity of type 304 stainless steel.

Additionally, unlike light water reactors, the interior surface of the reactor vessel needs an effective emissivity layer in order to absorb the internal radiant energy, which is then radiated to the external environment, especially under accident conditions. As a result of the much lower oxygen partial pressure and humidity in the operating helium environment, it will be even more difficult to establish an emittance $>0.85$, should such a high valve be required, on the interior of the RPV. Haque et al. ${ }^{26}$ assumed emittance of 0.6 to 0.8 in their sensitivity analysis of the peak fuel temperature for depressurized cooldown (inlet/outlet temperature $490 / 850^{\circ} \mathrm{C}$ ). Thus, an understanding of the formation and stability of this emissivity layer film in proposed helium operating environment (relative to the external environment, this is a very dry environment) at operating temperature needs to be established. Again, the effects of field welding on the formation and stability of this layer needs to be evaluated.

\subsubsection{Baseline Case}

Standard tabulations of emissivity values suggest that most steels with surface oxidation have emissivity values that are acceptable for the NGNP. Testing of emissivity of candidate materials for the NGNP is currently ongoing at University of Wisconsin under a NERI project. To ensure the capability of passive heat removal throughout the design lifetime of 60 years, the long-term stability of the emissivity layers must be established. Required long-term testing is proposed in Section 6. 


\begin{tabular}{|c|lll|}
\hline NEXT GENERATION NUCLEAR PLANT & Identifier: & PLN-2803 \\
REACTOR PRESSURE VESSEL MATERIALS & Revision: & 0 & \\
RESEARCH AND DEVELOPMENT PLAN & Effective Date: & $04 / 30 / 08$ & Page: 66 of 95 \\
\hline
\end{tabular}

\subsection{Alternative Cases}

As noted above, tabulations of emissivity values suggest that alloy composition does not significantly impact the emissivity of oxidized steel. The scoping studies at University of Wisconsin will address the need for further testing. To ensure the capability of passive heat removal throughout the design lifetime of 60 years, the long-term stability of the emissivity layers for the alternative case must also be established if this concept is down-selected. Required long-term testing is proposed in Section 6.

\subsection{Inspection}

\subsubsection{Baseline Case}

Section III, "Rules for Construction of Nuclear Facilities Components," of the ASME BPVC states the requirements for the design, construction, stamping and over pressure protection of items used in nuclear power plants and other nuclear facilities. Section III is comprised of the following Divisions and Subsections.

Subsection NCA — General Requirements for Division 1 and Division 2

Division 1

- Subsection NB-Class 1 Components

- Subsection NC-Class 2 Components

- Subsection ND-Class 3 Components

- Subsection NE_Class MC Components

- Subsection NF-Supports

- Subsection NG-Core Support Structures

- Subsection NH-Class 1 Components in Elevated Temperature Service

Division 2-Code for Concrete Containments

Subsection CC - Concrete Containments

Division 3 - Containments for Transportation and Storage of Spent Nuclear Fuel and High Level Radioactive Material and Waste

- $\quad$ Subsection WA - General Requirements for Division 3

- Subsection WB - Class TP (Type B) Containment

- Subsection WC-Class SC Storage Containments.

Other sections of interest are Section V, "Nondestructive Evaluation," and Section II, "Materials," Part A, "Ferrous Material Specifications." Applicable sections in Part A include, "Specification for Quenched and Tempered Vacuum-Treated Carbon," "Alloy Steel Forgings for Pressure Vessels A 508/A 508M," and "Specification for Pressure Vessel Plates, Alloy Steel. Quenched and Tempered, ManganeseMolybdenum and Manganese-Molybdenum-Nickel A 533/A 533M."

Section III, Division 1, Subsection NB is the code that applies to the design and fabrication of the RPV. Article NB-2000, "Material," in this subsection specifies mechanical testing and examination requirements for material acceptance while NB-5000, "Examination," specifies examinations required during fabrication and assembly. Article NB-6000, "Testing," specifies required pressure testing of the 


\begin{tabular}{|c|lll|}
\hline NEXT GENERATION NUCLEAR PLANT & Identifier: & PLN-2803 \\
REACTOR PRESSURE VESSEL MATERIALS & Revision: & 0 & \\
RESEARCH AND DEVELOPMENT PLAN & Effective Date: & $04 / 30 / 08$ & Page: 67 of 95 \\
\hline
\end{tabular}

completed components and systems. Other than special instructions and acceptance criteria included in the NB code, examinations are performed using the requirements stated in Section V.

Examinations are divided into surface inspections performed using visual, liquid penetrant, magnetic particle, or eddy current and volumetric inspections using radiography or ultrasonic techniques. Current code provides acceptance criteria (Article NB-5300 Acceptance Standards) that define what type and size of indications are deemed relevant and ultimately rejectable. The text in the numbered sections below is directly extracted from ASME code and is copywrited.

\section{NB-5320 RADIOGRAPHIC ACCEPTANCE STANDARDS}

Indications shown on the radiographs of welds and characterized as imperfections are unacceptable under the following conditions:

(a) any indication characterized as a crack or zone of incomplete fusion or penetration;

(b) any other elongated indication which has a length greater than:

1) $6 \mathrm{~mm}$ for $t$ up to $19 \mathrm{~mm}$, inclusive

(2) $1 / 3 t$ for $t$ from $19 \mathrm{~mm}$ ) to $57 \mathrm{~mm}$, inclusive

(3) $19 \mathrm{~mm}$ for $t$ over $57 \mathrm{~mm}$ where $t$ is the thickness of the thinner portion of the weld;

(c) internal root weld conditions are acceptable when the density change as indicated in the radiograph is not abrupt; elongated indications on the radiograph at either edge of such conditions shall be unacceptable, as provided in (b) above;

(d) any group of aligned indications having an aggregate length greater than $t$ in a length of $12 t$, unless the minimum distance between successive indications exceeds $6 L$, in which case the aggregate length is unlimited, $L$ being the length of the largest indication;

(e) rounded indications in excess of that shown as acceptable in Appendix VI.

\section{NB-5330 ULTRASONIC ACCEPTANCE STANDARDS}

\section{NB-5331 Fabrication}

All imperfections which produce a response greater than $20 \%$ of the reference level shall be investigated to the extent that the operator can determine the shape, identity, and location of all such imperfections and evaluate them in terms of the acceptance standards given in (a) and (b) below.

(a) Imperfections are unacceptable if the indications exceed the reference level amplitude and have lengths exceeding:

(1) $6 \mathrm{~mm}$ for $t$ up to $19 \mathrm{~mm}$, inclusive

(2) $1 / 3 t$ for $t$ from $19 \mathrm{~mm}$ to $57 \mathrm{~mm}$, inclusive

(3) $19 \mathrm{~mm}$ for $t$ over $57 \mathrm{~mm}$ where $t$ is the thickness of the weld being examined; if a weld joins two members having different thicknesses at the weld, $t$ is the thinner of these two thicknesses. 


\begin{tabular}{|c|lll|}
\hline NEXT GENERATION NUCLEAR PLANT & Identifier: & PLN-2803 & \\
REACTOR PRESSURE VESSEL MATERIALS & Revision: & 0 & \\
RESEARCH AND DEVELOPMENT PLAN & Effective Date: & $04 / 30 / 08$ & Page: 68 of 95 \\
\hline
\end{tabular}

(b) Indications characterized as cracks, lack of fusion, or incomplete penetration are unacceptable regardless of length.

\section{NB-5340 MAGNETIC PARTICLE ACCEPTANCE STANDARDS}

\section{NB-5341 Evaluation of Indications}

(a) Mechanical discontinuities at the surface are revealed by the retention of the examination medium. All indications are not necessarily defects, however, since certain metallurgical discontinuities and magnetic permeability variations may produce similar indications which are not relevant.

(b) Any indication that is believed to be non-relevant shall be reexamined by the same or other nondestructive examination methods to verify whether or not actual defects are present. Surface conditioning may precede the reexamination. After an indication has been verified to be non-relevant, it is not necessary to reinvestigate repetitive non-relevant indications of the same type. Non-relevant indications that would mask defects are unacceptable.

(c) Relevant indications are indications which result from imperfections. Linear indications are indications in which the length is more than three times the width. Rounded indications are indications which are circular or elliptical with the length equal to or less than three times the width.

\section{NB-5342 Acceptance Standards}

(a) Only imperfections producing indications with major dimensions greater than $1.5 \mathrm{~mm}$ shall be considered relevant imperfections.

(b) Imperfections producing the following indications are unacceptable:

(1) any cracks and linear indications;

(2) rounded indications with dimensions greater than $5 \mathrm{~mm}$;

(3) four or more rounded indications in a line separated by $1.5 \mathrm{~mm}$ or less edge to edge;

(4) ten or more rounded indications in any $4,000 \mathrm{~mm}^{2}$ of surface with the major dimension of this area not to exceed $150 \mathrm{~mm}$ with the area taken in the most unfavorable location relative to the indications being evaluated.

\section{NB-5350 LIQUID PENETRANT ACCEPTANCE STANDARDS}

\section{NB-5351 Evaluation of Indications}

(a) Mechanical discontinuities at the surface are revealed by bleeding out of the penetrant; however, localized surface discontinuities, such as may occur from machining marks, surface conditions, or an incomplete bond between base metal and cladding, may produce similar indications which are non-relevant.

(b) Any indication which is believed to be non-relevant shall be reexamined to verify whether or not actual defects are present. Surface conditioning may 


\begin{tabular}{|c|lll|}
\hline NEXT GENERATION NUCLEAR PLANT & Identifier: & PLN-2803 & \\
REACTOR PRESSURE VESSEL MATERIALS & Revision: & 0 & \\
RESEARCH AND DEVELOPMENT PLAN & Effective Date: & $04 / 30 / 08$ & Page: 69 of 95 \\
\hline
\end{tabular}

precede the reexamination. Non-relevant indications and broad areas of pigmentation which would mask defects are unacceptable.

(c) Relevant indications are indications which result from imperfections. Linear indications are indications in which the length is more than three times the width. Rounded indications are indications which are circular or elliptical with the length equal to or less than three times the width.

\section{NB-5352 Acceptance Standards}

(a) Only imperfections producing indications with major dimensions greater than $1.5 \mathrm{~mm}$ shall be considered relevant imperfections.

(b) Imperfections producing the following indications are unacceptable:

(1) any cracks or linear indications;

(2) rounded indications with dimensions greater than $5 \mathrm{~mm}$;

(3) four or more rounded indications in a line separated by $1.5 \mathrm{~mm}$ or less edge to edge;

(4) ten or more rounded indications in any $4,000 \mathrm{~mm}^{2}$ of surface with the major dimension of this area not to exceed $150 \mathrm{~mm}$ with the area taken in the most unfavorable location relative to the indications being evaluated.

The primary circumferential and longitudinal welds (Categories A, B, and C, Figure NB-3351-1) call for radiographic volumetric examination and surface examination using liquid penetrant or magnetic particle (Article NB-5200). Attachment welds for branch, piping, and nozzles (Category D weld joints, Figure NB-3351-1) require radiographic or ultrasonic examination and surface examination using liquid penetrant or magnetic particle.

Radiographic examination of thick sections is viable using portable linear accelerators (6 MeV can penetrate up to $406 \mathrm{~mm}$ of steel) when there is sufficient room to set up and meet code sensitivity requirements (HESCO, Alameda CA is a commercial company that performs code based radiographic inspections of thick section components). However, Section V, T-274.2 allows a maximum geometric unsharpness of $1.78 \mathrm{~mm}$ for material thickness greater than $101.6 \mathrm{~mm}$. This means a defect on the order of $1.78 \mathrm{~mm}$ can be missed. Similarly, ultrasonic inspections of the attachments welds use calibration blocks that contain sensitivity notches having dimensions based on test specimen thickness. As a result, the size of defect deemed relevant during ultrasonic examination changes with thickness. Surface inspections, which are not affected by specimen thickness, utilize the acceptance criteria as stated in the code.

In general, code inspections can be performed for the fabrication of new reactor pressure vessels using A 508 and A 533 materials up to the possible thicknesses of $250 \mathrm{~mm}$. However, the applicability of the BPVC will be determined by the design of the pressure vessel, section thickness, and weld joint designs, as well as the operating conditions that define critical flaw size. If actual critical flaw sizes are smaller than what is defined in the code as being rejectable, application of the code does not assure integrity. It is also important to consider inspectability issues such as weld joint design, access, etc., that may prevent reliable inspections from being performed during fabrications or later during in-service monitoring. 


\begin{tabular}{|c|lll|}
\hline NEXT GENERATION NUCLEAR PLANT & Identifier: & PLN-2803 & \\
REACTOR PRESSURE VESSEL MATERIALS & Revision: & 0 & \\
RESEARCH AND DEVELOPMENT PLAN & Effective Date: & $04 / 30 / 08$ & Page: 70 of 95 \\
\hline
\end{tabular}

\subsubsection{Alternative Cases}

In general, the inspection requirements for $9 \mathrm{Cr}-1 \mathrm{M}-\mathrm{V}$ will be similar to those for A 508/A 533. The toughness of the material, particularly if the weldment has nonoptimal heat treatment and properties, will affect the critical flaw size.

\subsubsection{Acceptance Criteria}

Acceptance criteria defined in the BPVC above are well defined for A 508/A 533 pressure vessels. The criteria will be broadly similar for $9 \mathrm{Cr}-1 \mathrm{M}-\mathrm{V}$, but specific flaw sizes will need to be defined, since the toughness will be different for this steel.

An issue that is specific to $9 \mathrm{Cr}-1 \mathrm{M}-\mathrm{V}$ is the need to develop an additional criterion to ensure that the proper heat treatment has been carried out to result in a tempered martensite microstructure that yields the required properties. The Code currently requires a maximum hardness value to ensure that tempering of the otherwise brittle martensite has occurred. There is, however, no minimum hardness value specified. Without a minimum hardness value, the mixed microstructure containing ferrite and coarse carbides from an insufficiently rapid quench could exist in the material with the resulting diminished properties. 


\begin{tabular}{c|lll|}
\hline NEXT GENERATION NUCLEAR PLANT & Identifier: & PLN-2803 & \\
REACTOR PRESSURE VESSEL MATERIALS & Revision: & 0 & \\
RESEARCH AND DEVELOPMENT PLAN & Effective Date: & $04 / 30 / 08$ & Page: 71 of 95 \\
\hline
\end{tabular}

\section{RESEARCH AND TECHNOLOGY PLAN}

\subsection{Required Actions for Code/Licensing Issues}

This section discusses the detailed plans to address the code and licensing issues highlighted in Section 5 for the "cold" and "hot" vessel options

\subsection{1 "Cold" Vessel Option}

Details of the required testing to support the use of A 508/533 for the cooled vessel option are contained in Appendix A. A summary table (Table 12) is included here; discussion of the motivation and anticipated results of this testing is contained in the sections below. 


Idaho National Laboratory
\begin{tabular}{|c|lll|}
\hline NEXT GENERATION NUCLEAR PLANT & Identifier: & PLN-2803 & \\
REACTOR PRESSURE VESSEL MATERIALS & Revision: & 0 & \\
RESEARCH AND DEVELOPMENT PLAN & Effective Date: & $04 / 30 / 08$ & Page: 72 of 95 \\
\hline
\end{tabular}

Table 12. Summary of test plan for A 508/A 533B Material - Cold Vessel.

\begin{tabular}{|c|c|c|c|c|c|c|c|c|}
\hline \begin{tabular}{|c|} 
Test Matrix Table (A1-A33) \\
Shown in detail in \\
Appendix A
\end{tabular} & $\begin{array}{c}\text { Specimen } \\
\text { Type }\end{array}$ & $\begin{array}{c}\text { Number } \\
\text { Specimens }\end{array}$ & Environment & $\begin{array}{c}\text { Temperature } \\
\left({ }^{\circ} \mathrm{C}\right)\end{array}$ & $\begin{array}{l}\text { Product } \\
\text { Form }\end{array}$ & $\begin{array}{c}\text { Time (h) } \\
\text { (or as given) } \\
\end{array}$ & $\begin{array}{l}\text { Sample } \\
\text { Condition } \\
\text { Time (h) } \\
\end{array}$ & Notes \\
\hline $\begin{array}{l}\text { A1 Creep Rupture Tests in } \\
\text { Air }\end{array}$ & Creep & 108 & Air & $350-390$ & $\begin{array}{c}\mathrm{F} \\
\mathrm{RP}\end{array}$ & $\begin{array}{l}1147- \\
15,128 \mathrm{ERt}\end{array}$ & SSR & $\begin{array}{l}3 \text { heats of each product } \\
\text { form }\end{array}$ \\
\hline $\begin{array}{l}\text { A2 SAW and SMAW Cross- } \\
\text { Weld Creep Rupture Tests in } \\
\text { Air }\end{array}$ & Creep & 72 & Air & $350-390$ & W & $\begin{array}{l}1147- \\
15,128 \mathrm{ERt}\end{array}$ & SSR & \\
\hline $\begin{array}{l}\text { A3 Creep Rupture Tests in } \\
\text { NGNP He }\end{array}$ & Creep & 12 & NGNP He & $350-390$ & $\begin{array}{c}\mathrm{F} \\
\mathrm{RP}\end{array}$ & $\begin{array}{l}12871-15,128 \\
\text { ERt }\end{array}$ & SSR & \\
\hline $\begin{array}{l}\text { A4 SAW and SMAW Creep } \\
\text { Rupture Tests of Cross- } \\
\text { Welds in NGNP He }\end{array}$ & Creep & 24 & NGNP He & $350-390$ & $\begin{array}{l}\text { W } \\
\text { F } \\
\text { RP }\end{array}$ & $\begin{array}{l}12,871- \\
15,128 \mathrm{ERt}\end{array}$ & SSR & \\
\hline $\begin{array}{l}\text { A5 Creep Rupture Tests in } \\
\text { Air on Fatigue-SRX } \\
\text { Damaged Material }\end{array}$ & Creep & 12 & Air & $350-390$ & $\begin{array}{l}\mathrm{F} \\
\mathrm{RP}\end{array}$ & $\begin{array}{l}12,871- \\
15,128 \mathrm{ERt}\end{array}$ & $\begin{array}{l}\text { SSR } \\
\text { Damaged }^{1}\end{array}$ & $\begin{array}{l}{ }^{1} \text { by fatigue-SRX } 180 \\
\text { cycles, } 427^{\circ} \mathrm{C} \text { with } 1 \% \\
\text { strain range, tensile hold } \\
1000 \text { min. }\end{array}$ \\
\hline $\begin{array}{l}\text { A6 SAW and SMAW Creep } \\
\text { Rupture Tests of Cross- } \\
\text { Welds in Air on Fatigue- } \\
\text { SRX Damaged Material }\end{array}$ & Creep & 24 & Air & $350-390$ & $\begin{array}{l}\text { W } \\
\text { F } \\
\text { RP }\end{array}$ & $\begin{array}{l}12,871- \\
15,128 \mathrm{ERt}\end{array}$ & $\begin{array}{l}\text { SSR } \\
\text { Damaged }^{1}\end{array}$ & $\begin{array}{l}{ }^{1} \text { by fatigue-SRX } 180 \\
\text { cycles, } 427^{\circ} \mathrm{C} \text { with } 1 \% \\
\text { strain range, tensile hold } \\
1000 \text { min. }\end{array}$ \\
\hline $\begin{array}{l}\text { A7 Long-Term Qualifying } \\
\text { Creep Rupture Tests in Air }\end{array}$ & Creep & 8 & Air & 350 & $\begin{array}{l}\mathrm{F} \\
\mathrm{RP}\end{array}$ & $\begin{array}{l}43,844^{2} \text { or } \\
179,253^{3} \text { ERt }\end{array}$ & SSR & $\begin{array}{l}{ }^{2} \text { Test to Rupture. } \\
{ }^{3} \text { Stop test at } 200,000 \mathrm{~h} \text { if } \\
\text { not ruptured }\end{array}$ \\
\hline $\begin{array}{l}\text { A8 SAW and SMAW Long- } \\
\text { Term Qualifying Creep } \\
\text { Rupture Tests in Air }\end{array}$ & Creep & 16 & Air & 350 & $\begin{array}{c}\mathrm{F} \\
\mathrm{RP}\end{array}$ & $\begin{array}{l}43,844^{2} \text { or } \\
179,253^{3} \text { ERt }\end{array}$ & SSR & $\begin{array}{l}{ }^{2} \text { Test to Rupture. } \\
{ }^{3} \text { Stop test at } 200,000 \mathrm{~h} \text { if } \\
\text { not ruptured }\end{array}$ \\
\hline
\end{tabular}




Idaho National Laboratory
\begin{tabular}{|c|lll|}
\hline NEXT GENERATION NUCLEAR PLANT & Identifier: & PLN-2803 & \\
REACTOR PRESSURE VESSEL MATERIALS & Revision: & 0 & \\
RESEARCH AND DEVELOPMENT PLAN & Effective Date: & $04 / 30 / 08$ & Page: 73 of 95 \\
\hline
\end{tabular}

Table 12. (continued).

\begin{tabular}{|c|c|c|c|c|c|c|c|c|}
\hline $\begin{array}{c}\text { Test Matrix Table (A1-A33) } \\
\text { Shown in detail in } \\
\text { Appendix A }\end{array}$ & $\begin{array}{c}\text { Specimen } \\
\text { Type }\end{array}$ & $\begin{array}{c}\text { Number } \\
\text { Specimens } \\
\end{array}$ & Environment & $\begin{array}{c}\text { Temperature } \\
\left({ }^{\circ} \mathrm{C}\right)\end{array}$ & $\begin{array}{l}\text { Product } \\
\text { Form }\end{array}$ & $\begin{array}{c}\text { Time }(\mathrm{h}) \\
\text { (or as given) } \\
\end{array}$ & $\begin{array}{c}\text { Sample } \\
\text { Condition } \\
\text { Time (h) } \\
\end{array}$ & Notes \\
\hline $\begin{array}{l}\text { A9 Relaxation Strength in } \\
\text { Air to Address Creep Effects }\end{array}$ & SRX & 64 & Air & $350-538$ & $\begin{array}{c}\mathrm{F} \\
\mathrm{RP}\end{array}$ & $\begin{array}{l}2,000-12,000 \\
\text { relaxation } \mathrm{t}\end{array}$ & SSR & \\
\hline $\begin{array}{l}\text { A10 SAW and SMAW } \\
\text { Relaxation Strength in Air to } \\
\text { Address Creep Effects }\end{array}$ & SRX & 32 & Air & $350-538$ & $\mathrm{~W}$ & $\begin{array}{l}2,000-12,000 \\
\text { relaxation } \mathrm{t}\end{array}$ & SSR & \\
\hline $\begin{array}{l}\text { A11 Relaxation Strength } \\
\text { Tests of fatigue-SRX } \\
\text { Damaged A 508/A 533B in } \\
\text { Air }\end{array}$ & SRX & 64 & Air & $350-538$ & $\begin{array}{c}\mathrm{F} \\
\mathrm{RP}\end{array}$ & $\begin{array}{l}2000-12,000 \\
\text { relaxation } \mathrm{t}\end{array}$ & $\begin{array}{l}\text { SSR } \\
\text { Damaged }^{1}\end{array}$ & $\begin{array}{l}\text { Initial stress } 214-414 \mathrm{MPa} \\
2 \text { heats of each product } \\
\text { form } \\
{ }^{1} \text { by fatigue-SRX } 180 \\
\text { cycles, } 427^{\circ} \mathrm{C} \text { with } 1 \% \\
\text { strain range, tensile hold } \\
1000 \text { min. }\end{array}$ \\
\hline $\begin{array}{l}\text { A12 Relaxation Strength } \\
\text { Tests of Fatigue-SRX } \\
\text { Damaged SAW and SMAW } \\
\text { Cross-Welds in Air }\end{array}$ & SRX & 32 & Air & $350-538$ & $\begin{array}{l}\text { W } \\
\text { F } \\
\text { RP }\end{array}$ & $\begin{array}{l}2000-12,000 \\
\text { relaxation } \mathrm{t}\end{array}$ & $\begin{array}{l}\text { SSR } \\
\text { Damaged }^{1}\end{array}$ & $\begin{array}{l}\text { Initial stress of } 214 \text { or } 276 \\
\text { MPa } \\
{ }^{1} \text { by fatigue-SRX } 180 \\
\text { cycles, } 427^{\circ} \mathrm{C} \text { with } 1 \% \\
\text { strain range, tensile hold } \\
1000 \text { min. }\end{array}$ \\
\hline $\begin{array}{l}\text { A13 Fatigue-SRX Tests in } \\
\text { Air }\end{array}$ & $\begin{array}{l}\text { Fatigue- } \\
\text { SRX }\end{array}$ & 42 & Air & 350 & $\begin{array}{c}\mathrm{F} \\
\mathrm{RP}\end{array}$ & $\begin{array}{l}0-300 \mathrm{~min} \\
\text { hold time }\end{array}$ & SSR & $\begin{array}{l}\text { Both tensile and } \\
\text { compressive hold tests }\end{array}$ \\
\hline $\begin{array}{l}\text { A14 SAW and SMAW } \\
\text { Fatigue-SRX Tests in Air }\end{array}$ & $\begin{array}{l}\text { Fatigue- } \\
\text { SRX }\end{array}$ & 60 & Air & 350 & $\begin{array}{l}\text { W } \\
\text { F } \\
\text { RP }\end{array}$ & $\begin{array}{l}0-150 \mathrm{~min} \\
\text { hold time }\end{array}$ & SSR & $\begin{array}{l}\text { Both tensile and } \\
\text { compressive hold tests }\end{array}$ \\
\hline $\begin{array}{l}\text { A15 Baseline Tensile Tests in } \\
\text { Air }\end{array}$ & Tensile & 48 & Air & $20-550$ & $\begin{array}{c}\mathrm{F} \\
\mathrm{RP}\end{array}$ & & SSR & \\
\hline
\end{tabular}




Idaho National Laboratory
\begin{tabular}{|c|lll|}
\hline NEXT GENERATION NUCLEAR PLANT & Identifier: & PLN-2803 & \\
REACTOR PRESSURE VESSEL MATERIALS & Revision: & 0 & \\
RESEARCH AND DEVELOPMENT PLAN & Effective Date: & $04 / 30 / 08$ & Page: 74 of 95 \\
\hline
\end{tabular}

Table 12. (continued).

\begin{tabular}{|c|c|c|c|c|c|c|c|c|}
\hline $\begin{array}{c}\text { Test Matrix Table (A1-A33) } \\
\text { Shown in detail in } \\
\text { Appendix A }\end{array}$ & $\begin{array}{l}\text { Specimen } \\
\text { Type }\end{array}$ & $\begin{array}{l}\text { Number } \\
\text { Specimens }\end{array}$ & Environment & $\begin{array}{c}\text { Temperature } \\
\left({ }^{\circ} \mathrm{C}\right)\end{array}$ & $\begin{array}{l}\text { Product } \\
\text { Form }\end{array}$ & $\begin{array}{c}\text { Time (h) } \\
\text { (or as given) }\end{array}$ & $\begin{array}{l}\text { Sample } \\
\text { Condition } \\
\text { Time }(\mathrm{h})\end{array}$ & Notes \\
\hline $\begin{array}{l}\text { A16 Baseline Tensile Tests } \\
\text { of SAW and SMAW Cross- } \\
\text { Welds in Air }\end{array}$ & Tensile & 48 & Air & $20-550$ & $\begin{array}{l}\mathrm{W} \\
\mathrm{F} \\
\mathrm{RP}\end{array}$ & & SSR & \\
\hline $\begin{array}{l}\text { A17 Tensile Tests of Fatigue- } \\
\text { SRX Damaged A 508/A } \\
\text { 533B in Air }\end{array}$ & Tensile & 48 & Air & $20-550$ & $\begin{array}{c}\mathrm{F} \\
\mathrm{RP}\end{array}$ & & $\begin{array}{l}\text { SSR } \\
\text { Damaged }^{1}\end{array}$ & $\begin{array}{l}{ }^{1} \text { by fatigue-SRX } 180 \\
\text { cycles, } 427^{\circ} \mathrm{C} \text { with } 1 \% \\
\text { strain range, tensile hold } \\
1000 \text { min. }\end{array}$ \\
\hline $\begin{array}{l}\text { A18 Tensile Tests of Fatigue- } \\
\text { SRX Damaged Cross-Welds } \\
\text { in Air }\end{array}$ & Tensile & 48 & Air & $20-550$ & $\begin{array}{l}\text { W } \\
\text { F } \\
\text { RP }\end{array}$ & & $\begin{array}{l}\text { SSR } \\
\text { Damaged }^{1}\end{array}$ & $\begin{array}{l}{ }^{1} \text { by fatigue-SRX } 180 \\
\text { cycles, } 427^{\circ} \mathrm{C} \text { with } 1 \% \\
\text { strain range, tensile hold } \\
1000 \text { min. }\end{array}$ \\
\hline $\begin{array}{l}\text { A19 Tensile Tests of } \\
\text { Thermally Aged A } \\
\text { 508/A511B in Air }\end{array}$ & Tensile & 48 & Air & $20-550$ & $\begin{array}{c}\mathrm{F} \\
\mathrm{RP}\end{array}$ & & $\begin{array}{l}\text { SSR } \\
\text { Aged }^{4}\end{array}$ & $\begin{array}{l}{ }^{4} \mathrm{Aged} \text { at } 450^{\circ} \mathrm{C} \text { for } 20,000 \\
\mathrm{~h}\end{array}$ \\
\hline $\begin{array}{l}\text { A20 Tensile Tests of } \\
\text { Thermally Aged Cross-Welds } \\
\text { in Air }\end{array}$ & Tensile & 48 & Air & $20-550$ & $\begin{array}{l}\text { W } \\
\text { F } \\
\text { RP }\end{array}$ & & $\begin{array}{l}\text { SSR } \\
\text { Aged }^{4}\end{array}$ & $\begin{array}{l}{ }^{4} \mathrm{Aged} \text { at } 450^{\circ} \mathrm{C} \text { for } 20,000 \\
\mathrm{~h}\end{array}$ \\
\hline $\begin{array}{l}\text { A21 Tensile Tests of Long- } \\
\text { Term Thermally Aged A } \\
\text { 508/A511B in Air }\end{array}$ & Tensile & 48 & Air & $20-550$ & $\begin{array}{c}\mathrm{F} \\
\mathrm{RP}\end{array}$ & & SSR + Aged $^{5}$ & $\begin{array}{l}{ }^{5} \text { Aged at } 450^{\circ} \mathrm{C} \text { for } 70,000 \\
h\end{array}$ \\
\hline $\begin{array}{l}\text { A22 Tensile Tests of Long- } \\
\text { Term Thermally Aged SAW } \\
\text { and SMAW Cross-Welds in } \\
\text { Air }\end{array}$ & Tensile & 48 & Air & $20-550$ & $\begin{array}{l}\text { W } \\
\text { F } \\
\text { RP }\end{array}$ & & SSR + Aged $^{5}$ & $\begin{array}{l}{ }^{5} \text { Aged at } 450^{\circ} \mathrm{C} \text { for } 70,000 \\
\text { h }\end{array}$ \\
\hline
\end{tabular}




Idaho National Laboratory
\begin{tabular}{|c|lll|}
\hline NEXT GENERATION NUCLEAR PLANT & Identifier: & PLN-2803 & \\
REACTOR PRESSURE VESSEL MATERIALS & Revision: & 0 & \\
RESEARCH AND DEVELOPMENT PLAN & Effective Date: & $04 / 30 / 08$ & Page: 75 of 95 \\
\hline
\end{tabular}

Table 12. (continued).

\begin{tabular}{|c|c|c|c|c|c|c|c|c|}
\hline $\begin{array}{c}\text { Test Matrix Table (A1-A33) } \\
\text { Shown in detail in } \\
\text { Appendix A }\end{array}$ & $\begin{array}{l}\text { Specimen } \\
\text { Type }\end{array}$ & $\begin{array}{l}\text { Number } \\
\text { Specimens }\end{array}$ & Environment & $\begin{array}{c}\text { Temperature } \\
\left({ }^{\circ} \mathrm{C}\right)\end{array}$ & $\begin{array}{l}\text { Product } \\
\text { Form }\end{array}$ & $\begin{array}{c}\text { Time (h) } \\
\text { (or as given) }\end{array}$ & $\begin{array}{c}\text { Sample } \\
\text { Condition } \\
\text { Time (h) }\end{array}$ & Notes \\
\hline $\begin{array}{l}\text { A21 Baseline Toughness } \\
\text { Measurements (Master Curve } \\
\mathrm{T}_{\mathrm{o}} \text { and J-R Curve) Base } \\
\text { Metals }\end{array}$ & $\begin{array}{l}\text { Compact } \\
\text { tension }\end{array}$ & 168 & Air & $20-518^{6}$ & $\begin{array}{c}\mathrm{F} \\
\mathrm{RP}\end{array}$ & & SSR & $\begin{array}{l}2 \text { heats of each product } \\
\text { form } \\
{ }^{6} \text { some test temperatures } \\
\text { TBD }\end{array}$ \\
\hline $\begin{array}{l}\text { A24 Toughness Measurement } \\
\text { (Master Curve } T_{\mathrm{o}} \text { and } \mathrm{J}-\mathrm{R} \\
\text { Curve) for Fatigue-SRX } \\
\text { Damaged Material }\end{array}$ & $\begin{array}{l}\text { Compact } \\
\text { tension }\end{array}$ & 168 & Air & $20-538^{6}$ & $\begin{array}{c}\mathrm{F} \\
\mathrm{RP}\end{array}$ & & $\begin{array}{l}\text { SSR } \\
\text { Damaged }^{1}\end{array}$ & $\begin{array}{l}2 \text { heats of each product } \\
\text { form } \\
{ }^{1} \text { by fatigue-SRX } 180 \\
\text { cycles, at } 427^{\circ} \mathrm{C} \text { with } 1 \% \\
\text { strain range, tensile hold } \\
1000 \text { min. } \\
{ }^{6} \text { some test temperatures } \\
\text { TBD }\end{array}$ \\
\hline $\begin{array}{l}\text { A25 Toughness Measurement } \\
\text { (Master Curve } T_{\mathrm{o}} \text { and } \mathrm{J}-\mathrm{R} \\
\text { Curve) for Thermally Aged } \\
\text { Material }\end{array}$ & $\begin{array}{l}\text { Compact } \\
\text { tension }\end{array}$ & 168 & Air & $20-538^{6}$ & $\begin{array}{c}\mathrm{F} \\
\mathrm{RP}\end{array}$ & & SSR Aged ${ }^{4}$ & $\begin{array}{l}2 \text { heats of each product } \\
\text { form } \\
{ }^{4} \mathrm{Aged} \text { at } 450^{\circ} \mathrm{C} \text { for } 20,000 \\
\mathrm{~h} \\
{ }^{6} \text { some test temperatures } \\
\text { TBD }\end{array}$ \\
\hline $\begin{array}{l}\text { A26 Toughness Measurement } \\
\text { (Master Curve } T_{\mathrm{o}} \text { and } \mathrm{J}-\mathrm{R} \\
\text { Curve) for Thermally Aged } \\
\text { Material }\end{array}$ & $\begin{array}{l}\text { Compact } \\
\text { tension }\end{array}$ & 168 & Air & $20-538$ & $\begin{array}{c}\mathrm{F} \\
\mathrm{RP}\end{array}$ & & SSR Aged ${ }^{7}$ & $\begin{array}{l}2 \text { heats of each product } \\
\text { form } \\
{ }^{6} \text { some test temperatures } \\
\text { TBD } \\
{ }^{7} \text { Aged at } 450^{\circ} \mathrm{C} \text { for } 70,000 \\
\text { h }\end{array}$ \\
\hline $\begin{array}{l}\text { A27 SAW and SMAW } \\
\text { Baseline Toughness } \\
\text { Measurements (Master Curve } \\
\mathrm{T}_{\mathrm{o}} \text { and J-R Curve) Weldment }\end{array}$ & $\begin{array}{l}\text { Compact } \\
\text { tension }\end{array}$ & 168 & Air & $20-538^{6}$ & $\begin{array}{l}\text { W } \\
\text { F } \\
\text { RP }\end{array}$ & & SSR & $\begin{array}{l}{ }^{6} \text { some test temperatures } \\
\text { TBD }\end{array}$ \\
\hline
\end{tabular}




Idaho National Laboratory
\begin{tabular}{|c|lll|}
\hline NEXT GENERATION NUCLEAR PLANT & Identifier: & PLN-2803 & \\
REACTOR PRESSURE VESSEL MATERIALS & Revision: & 0 & \\
RESEARCH AND DEVELOPMENT PLAN & Effective Date: & $04 / 30 / 08$ & Page: 76 of 95 \\
\hline
\end{tabular}

Table 12. (continued).

\begin{tabular}{|c|c|c|c|c|c|c|c|c|}
\hline $\begin{array}{c}\text { Test Matrix Table (A1-A33) } \\
\text { Shown in detail in } \\
\text { Appendix A }\end{array}$ & $\begin{array}{l}\text { Specimen } \\
\text { Type }\end{array}$ & $\begin{array}{l}\text { Number } \\
\text { Specimens }\end{array}$ & Environment & $\begin{array}{c}\text { Temperature } \\
\left({ }^{\circ} \mathrm{C}\right)\end{array}$ & $\begin{array}{c}\text { Product } \\
\text { Form }\end{array}$ & $\begin{array}{l}\text { Time (h) } \\
\text { (or as given) }\end{array}$ & $\begin{array}{c}\text { Sample } \\
\text { Condition } \\
\text { Time (h) }\end{array}$ & Notes \\
\hline $\begin{array}{l}\text { A28 SAW and SMAW } \\
\text { Baseline Toughness } \\
\text { Measurements (Master Curve } \\
\mathrm{T}_{\mathrm{o}} \text { and J-R Curve) Weldment } \\
\text { HAZ }\end{array}$ & $\begin{array}{l}\text { Compact } \\
\text { tension }\end{array}$ & 168 & Air & $20-538^{6}$ & $\begin{array}{c}\text { W } \\
\text { F } \\
\text { RP }\end{array}$ & & SSR & $\begin{array}{l}{ }^{6} \text { some test temperatures } \\
\text { TBD }\end{array}$ \\
\hline $\begin{array}{l}\text { A29 Cyclic Stress-Strain } \\
\text { Curves for A } 508\end{array}$ & Cyclic & 75 & Air & $20-538$ & $\mathrm{~F}$ & & SSR & 3 heats of forged A 508 \\
\hline $\begin{array}{l}\text { A30 Creep Rupture Tests in } \\
\text { Air }\end{array}$ & Creep & 48 & Air & $350-593$ & $\begin{array}{c}\mathrm{F} \\
\mathrm{RP}\end{array}$ & $\begin{array}{l}974-3,752 \\
\text { ER t }\end{array}$ & SSR & $\begin{array}{l}3 \text { heats of } F \text { and } 1 \text { heat of } \\
\text { RP }\end{array}$ \\
\hline $\begin{array}{l}\text { A31 SAW and SMAW } \\
\text { Cross-Weld Creep Rupture } \\
\text { Tests in Air }\end{array}$ & Creep & 48 & Air & $350-593$ & $\begin{array}{l}\text { W } \\
\text { F } \\
\text { RP }\end{array}$ & $\begin{array}{l}974-3,752 \\
\text { ER t }\end{array}$ & SSR & \\
\hline $\begin{array}{l}\text { A32 A 508/A 533B Fatigue- } \\
\text { SRX Tests in Air }\end{array}$ & $\begin{array}{l}\text { Fatigue- } \\
\text { SRX }\end{array}$ & 72 & Air & $427-538$ & $\begin{array}{c}\mathrm{F} \\
\mathrm{RP}\end{array}$ & $\begin{array}{l}0-300 \text { min. } \\
\text { hold time }\end{array}$ & SSR & $\begin{array}{l}\text { Both tensile and } \\
\text { compressive hold tests }\end{array}$ \\
\hline $\begin{array}{l}\text { A33 SAW and SMAW } \\
\text { Cross-Weld Fatigue-SRX } \\
\text { Tests in Air }\end{array}$ & $\begin{array}{l}\text { Fatigue- } \\
\text { SRX }\end{array}$ & 60 & Air & $427-538$ & $\begin{array}{l}\mathrm{W} \\
\mathrm{F} \\
\mathrm{RP}\end{array}$ & $\begin{array}{l}0-150 \text { min. } \\
\text { hold time }\end{array}$ & SSR & $\begin{array}{l}\text { Both tensile and } \\
\text { compressive hold tests }\end{array}$ \\
\hline
\end{tabular}




\begin{tabular}{|c|lll|}
\hline NEXT GENERATION NUCLEAR PLANT & Identifier: & PLN-2803 & \\
$\begin{array}{c}\text { REACTOR PRESSURE VESSEL MATERIALS } \\
\text { RESEARCH AND DEVELOPMENT PLAN }\end{array}$ & $\begin{array}{l}\text { Revision: } \\
\text { Effective Date: }\end{array}$ & $04 / 30 / 08$ & Page: 77 of 95 \\
\hline
\end{tabular}

\subsubsection{Creep Effects on RPV Under Normal Operating Conditions}

As discussed in Section 5, the Code Case N-499 database does not provide adequate creep rupture data to address the issue of whether or not creep effects for the RPV need to be considered under normal operating temperature of $350^{\circ} \mathrm{C}$. Longer term creep rupture data are needed and testing is proposed to address this issue. The base metal and weldment creep rupture test plans are developed to generate data in time to support conceptual and preliminary design (CPD) activities, and final design/licensing (FDL) efforts. To meet this goal, parallel test efforts are required.

Testing to support CPD activities is given in Tables A1 and A2 of Appendix A for base metals and weldments, respectively. The test temperatures are $350^{\circ} \mathrm{C}, 371^{\circ} \mathrm{C}$ and $390^{\circ} \mathrm{C}$, to cover the normal operating temperature of $350^{\circ} \mathrm{C}$ and to provide some acceleration of the creep process. These are air tests. The base metals and weldments should receive a simulated stress relief (SSR) treatment before they are machined into test specimens. There are two heats for each of the two product forms, A 508 forging and A 533B rolled plate, in the base metal test plan. The weldment test matrix includes both submerged arc welding (SAW) and shield metal arc welding (SMAW). The welds to be tested are cross-welds and creep test specimens should be machined from thick-section welds. The longest average creep rupture time is estimated to be about two years. This estimation is based on the best estimate statistical correlation (i.e., without accounting for data scatter) developed from the Code Case N-499 database, as discussed in Section 5.

Environmental creep rupture tests are also planned to assess the potential impact of NGNP helium on the creep rupture strengths of A 508/533B steels and their weldments. The test matrices are shown in Tables A3 and A4. The test specimens should also be in the SSR condition. The temperature and applied stress conditions are designed to be a subset of those used in the air tests of Tables A1 and A2 so that an assessment of the potential impact of NGNP helium on the creep rupture strengths can be made.

Limited temperature excursions above the subsection NB cut-off temperature of $371^{\circ} \mathrm{C}$ but within the time-and-temperature restrictions of Code Case N-499 could occur for the RPV. Code Case N-499 permits excursions to within $427^{\circ} \mathrm{C}$ for a total of 3000 accumulated hours, while excursions beyond $427^{\circ} \mathrm{C}$ and within $538^{\circ} \mathrm{C}$ are limited to three occurrences. There is a concern that creep-fatigue damage accumulated during these excursions would degrade the creep rupture strengths of the base metals and their weldments, if it is concluded that creep effects need to be considered at the normal operating temperature of $350^{\circ} \mathrm{C}$. Creep rupture tests on A 508/533B steels and their associated weldments are proposed in Tables A5 and A6. The creep specimens in the SSR condition will be given a "damage" treatment by subjecting the specimen to strain-controlled cycling, with a tensile strain hold of 1000 minutes, for 180 cycles at $427^{\circ} \mathrm{C}$. This will accumulate creep-fatigue damage for about 3000 hours. Since the stress relaxes during the strain hold, this form of cycling is called fatigue-stress relaxation. Creep rupture tests are then performed on the "damaged" specimens per the temperature and applied stress conditions given in Tables A5 and A6.

The tests listed in Tables A1 through A6 can be completed in about two years if testing capacity is available. The data assembled from these tests will be used to assess whether the creep effects need to be considered for the RPV during normal operations.

Longer term creep rupture tests in air are proposed in Tables A7 and A8 for the A 508/533B steels and their weldments, respectively. The test temperature is at the normal operating temperature of $350^{\circ} \mathrm{C}$. Five-year and 20-year data are targeted for these tests. The temperature and applied stress combinations are selected based on the best estimate of the statistical model developed from the Code Case N-499 database. The tests to generate the five-year data can be performed using standard laboratory equipment 


\begin{tabular}{|c|lll|}
\hline NEXT GENERATION NUCLEAR PLANT & Identifier: & PLN-2803 & \\
REACTOR PRESSURE VESSEL MATERIALS & Revision: & 0 & \\
RESEARCH AND DEVELOPMENT PLAN & Effective Date: & $04 / 30 / 08$ & Page: 78 of 95 \\
\hline
\end{tabular}

but the 20-year creep rupture tests are best performed in a dedicated Long Term Aging Facility. The five-year data will be used to check the adequacy of the extrapolation based on the statistical analysis of the shorter term data developed from Tables A1 and A2. This is to support FDL. The 20-year tests are designed to lead the reactor operations. This would provide lead time to develop mitigation strategy if an unanticipated rupture event occurs in one of the tests.

\subsubsection{Relaxation Strengths}

As discussed in Section 5, the relaxation strength is required to provide the limit to ensure that shakedown takes place so ratcheting does not occur. Tables A9 and A10 show the testing proposed for A 508/533B steels and their associated weldments. Relaxation strengths are to be determined from the stress relaxation curves developed from the testing performed for these two tables. The relaxation strengths are developed at $350^{\circ} \mathrm{C}, 371^{\circ} \mathrm{C}, 427^{\circ} \mathrm{C}, 538^{\circ} \mathrm{C}$, covering the normal operating temperature and the temperatures permitted in Code Case N-499. The specimens are in the SSR condition. Longer relaxation durations are selected for the two lower temperatures as the relaxation process is slower at those temperatures. Shorter durations are selected for the two higher temperatures to cover the range of applications permitted by Code Case N-499. Adjustment to the initial stress and relaxation period will be made before the commencement of the tests if necessary.

Tables A11 and A12 provide the test conditions for determining the relaxation strengths for creepfatigue damaged base metals and their associated weldments. The test conditions are the same as those in Tables A9 and A10. The same "damage" treatment of strain-controlled cycling, with a tensile strain hold of 1000 minutes, for 180 cycles at $427^{\circ} \mathrm{C}$ will be used on specimens that are in the SSR condition. Any change to the initial stress and relaxation period for the tests in Table A9 and A10 will also be made in these tests so that comparison of the relaxation strengths of "undamaged" and "damaged" materials can be made.

\subsubsection{Creep-Fatigue Tests}

To assist the assessment of whether creep needs to be considered for the RPV under normal operating temperature, creep-fatigue tests at $350^{\circ} \mathrm{C}$ are proposed in Tables A13 and A14 for fatigue-stress relaxation for A 508/533B steels and their associated weldments. The strain hold times will be adjusted after initial results are obtained, if deemed necessary. The continuous cycling data will be compared with those with strain hold times to provide additional information on the assessment of the creep effects at $350^{\circ} \mathrm{C}$.

\subsubsection{Effects on Tensile Properties}

Potential degradation of tensile properties due to thermal aging and creep-fatigue damage accumulated during short-term high temperature excursions would impact the ratcheting resistance. Tensile tests are proposed to determine the baseline tensile properties in the SSR condition (Tables A15 and A16), the creep-fatigue damaged condition (Tables 17 and 18), and the thermally aged conditions (Tables A19, A20, A21 and A22).

Each set of tensile properties includes test data at $20^{\circ} \mathrm{C}, 150^{\circ} \mathrm{C}, 250^{\circ} \mathrm{C}, 350^{\circ} \mathrm{C}, 450^{\circ} \mathrm{C}$, and $550^{\circ} \mathrm{C}$. Two heats each of A 508/533B steels and two welding processes (SAW and SMAW) are involved in all the base metals and weldments tensile testing respectively. The damaged condition is introduced by subjecting the specimens to the same "damage" treatment as described in the previous subsections. Two thermal aging protocols, 20,000 hours at $450^{\circ} \mathrm{C}$ and 70,000 hours at $450^{\circ} \mathrm{C}$, are employed. The aging temperature of $450^{\circ} \mathrm{C}$ is selected to accelerate the aging process. Adjustment to this aging condition will be made, if needed, at the commencement of the aging program. The 70,000-hour aging pre-conditioning would best be conducted in the dedicated Long Term Aging Facility. 


\begin{tabular}{|c|lll|}
\hline NEXT GENERATION NUCLEAR PLANT & Identifier: & PLN-2803 & \\
REACTOR PRESSURE VESSEL MATERIALS & Revision: & 0 & \\
RESEARCH AND DEVELOPMENT PLAN & Effective Date: & $04 / 30 / 08$ & Page: 79 of 95 \\
\hline
\end{tabular}

In addition to providing data to assess the potential tensile properties degradation, these tensile data will be needed in the analysis of the fracture toughness data which is described in the next subsection.

\subsubsection{Fracture Toughness}

A 508/533B steels and their associated weldments are body-centered cubic materials that exhibit ductile-brittle transition behavior. In the transition and lower shelf regions where the temperatures are low, the fracture mechanism is a brittle failure mode of transgranular cleavage, while the fracture mechanism changes to a void nucleation and growth type of ductile tearing mode at higher temperatures. In the brittle regime, the toughness of the material can be characterized by the "Master Curve" reference temperature $T_{0}$ while the resistance to ductile tearing and tearing instability are characterized by $J_{I C}$ and the resistance curve, or the J-R curve. It is reiterated that the ASME Code does not provide detailed guidance in dealing with fracture and this issue is traditionally handled between NRC and nuclear plant "owner" for LWR.

Fracture toughness and J-R curve have been studied extensively for these LWR pressure vessel materials. However, the LWR data do not cover most of the conditions that the NGNP RPV would likely encounter as the temperatures of interest for LWR are $300^{\circ} \mathrm{C}$ and below. The issues for NGNP RPV in the low temperature, brittle regime is the potential negative impact on the fracture toughness due to long-term thermal embrittlement (thermal aging) accumulated during the normal operations at $350^{\circ} \mathrm{C}$ for very long time ( 60 years), and creep-fatigue damage accumulated during the short-term high temperature excursions that are permitted by Code Case N-499. The former would be of concern for transients such as shutdown towards the end of design life of the reactor as it takes very long time to accrue thermal embrittlement. The latter could possibly be of concern towards the latter part of the reactor design life as more creep-fatigue damage would be accumulated toward that stage.

The high temperature toughness, as characterized by $J_{I C}$ and the J-R curve, decreases as the temperature is increased. The decrease is small to about $400^{\circ} \mathrm{C}$ and it is expected to drop more rapidly as the yield and tensile strengths of these materials start to drop more significantly at temperatures beyond $400^{\circ} \mathrm{C}$. This could be a potential threat to NGNP RPV as Code Case N-499 permits short term high temperature excursions to within $473^{\circ} \mathrm{C}$ and $538^{\circ} \mathrm{C}$ with restrictions. Thus $J_{I C}$ and J-R curve data are needed to address this issue which is related to the leak-before-break issue on the NRC concerns list discussed in Sections 4 and 5.

Testing efforts to address these issues are proposed in Tables A23 to A26 for A 508/533B and their associated weldments. Two heats of each of A 508/533B are included. The testing protocols for these four tables are the same except that the material conditions are different. Table A23 generate baseline data where the material condition is SSR, that is, there is no pre-conditioning such as thermal aging or creepfatigue damage. Tables A24, A25, and A26 correspond to pre-conditioning of creep-fatigue damage, thermal aging for 20,000 hours at $450^{\circ} \mathrm{C}$, and 70,000 hours at $450^{\circ} \mathrm{C}$, respectively. The creep-fatigue damage protocol is again the same as described in previous sub-sections. For each table, both Master Curve $T_{0}$, and J-R curves at $20^{\circ} \mathrm{C}, 150^{\circ} \mathrm{C}, 350^{\circ} \mathrm{C}, 427^{\circ} \mathrm{C}$ and $538^{\circ} \mathrm{C}$, are determined. Due to the constraint in the amount of material from creep-fatigue pre-conditioning, 0.5T disk-shaped compact tension specimens will be used. If it is determined at the commencement of this test program that more preconditioned materials can be made available, the use of $0.6 \mathrm{~T}$ or $0.7 \mathrm{~T}$ disk-shaped compact tension specimens will be considered.

The details for the testing of weldments are given in Tables A27 and A28. For Table 27 the crack is aligned within the weldment, and with the crack propagation direction to be the same as the welding direction. For the testing in Table 28, the crack is aligned within the heat affected zone (HAZ) and also 


\begin{tabular}{|c|lll|}
\hline NEXT GENERATION NUCLEAR PLANT & Identifier: & PLN-2803 & \\
REACTOR PRESSURE VESSEL MATERIALS & Revision: & 0 & \\
RESEARCH AND DEVELOPMENT PLAN & Effective Date: & $04 / 30 / 08$ & Page: 80 of 95 \\
\hline
\end{tabular}

propagate in the direction of welding. The weldments are in the stress relieved condition. Two welding processes, SAW and SMAW, are included in these tables. The intent of these testing in the SSR condition is to provide baseline toughness values for the weldment and HAZ. Any degradation in the base metal toughness due to creep-fatigue damage and thermal embrittlement will be applied to the baseline toughness value of the weldment and HAZ.

As noted in the previous subsection, tensile data are required to process the toughness data. It is planned that the heats of base metal and weld consumables for the disk-shaped compact tension specimens are the same as those used in the tensile testing described in Tables A15 to A22. It is also important that they receive the same pre-conditioning as those in Tables A15 to A22. If circumstances arise that this is not the case, tensile tests for the same material heats and material conditions as the diskshaped compact tension specimen are required.

\subsubsection{Cyclic Stress-Strain Curve}

Cyclic stress-strain curves are required to determine the cyclic response. Cyclic hardening, cyclic softening, or cyclic neutral material behavior is important in establishing the negligible creep criterion. Cyclic stress-strain curves had been determined for A 533B to support the Code Case N-499 effort and they are available for use. Table A29 proposes testing to develop cyclic stress-strain curves at $20^{\circ} \mathrm{C}$, $350^{\circ} \mathrm{C}, 371^{\circ} \mathrm{C}, 427^{\circ} \mathrm{C}$ and $538^{\circ} \mathrm{C}$ for A 508 steel. Three heats of A 508 are involved.

\subsubsection{Testing to Support Re-evaluation of Code Case N-499}

As described in Section 5, data that supported this code case were from A 533B steel. The intersection point of the creep-fatigue damage interaction diagram was not determined per A 508/533B and associated weldment creep-fatigue data. Thus, in order to address these database issues, tests are proposed in Tables A30 to A32. Short term creep rupture tests that cover the applicable durations of the code case for base metal and weldment are presented in Tables 30 and 31 . Test temperatures are $350^{\circ} \mathrm{C}$, $371^{\circ} \mathrm{C}, 427^{\circ} \mathrm{C}, 482^{\circ} \mathrm{C}, 538^{\circ} \mathrm{C}$, and $593^{\circ} \mathrm{C}$. They are selected to match the Code Case N-499 database. Creep-fatigue tests for base metals and weldment are proposed in Tables 32 and 33. Strain hold times of 30,150 , and 300 minutes will be applied during strain-controlled cycling. This will provide data to check if increasing hold time would degrade the fatigue performance. These data will also be used to verify the intersection point of the creep-fatigue interaction diagram in Code Case N-499.

\subsection{2 "Hot" Vessel Option}

Detailed testing plans to support the use of Grade 91 steel are contained in Appendix B. A summary table (Table 13) of the required testing for this option in included in this section; discussion of the rational for testing and expected results is included in the sections below. 


Idaho National Laboratory
\begin{tabular}{|c|lll|}
\hline NEXT GENERATION NUCLEAR PLANT & Identifier: & PLN-2803 & \\
REACTOR PRESSURE VESSEL MATERIALS & Revision: & 0 & \\
RESEARCH AND DEVELOPMENT PLAN & Effective Date: & $04 / 30 / 08$ & Page: 81 of 95 \\
\hline
\end{tabular}

Table 13. Summary of test plan for Grade 91 steel.

\begin{tabular}{|c|c|c|c|c|c|c|c|c|c|}
\hline $\begin{array}{l}\text { Test Matrix Table (B1-B16) } \\
\text { Shown in detail in Appendix B }\end{array}$ & 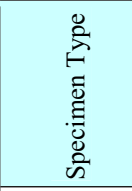 & 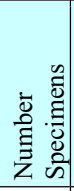 & 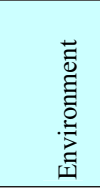 & 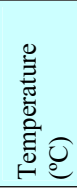 & $\begin{array}{l}\Xi \\
0 \\
0 \\
0 \\
0 \\
0 \\
0 \\
0 \\
0\end{array}$ & $\begin{array}{l}\text { Strain } \\
\text { Rate } \\
(\mathrm{m} / \mathrm{m} / \mathrm{s})\end{array}$ & Time & $\begin{array}{l}\text { Specimen } \\
\text { Condition }\end{array}$ & Notes \\
\hline $\begin{array}{l}\text { B1 Creep Tests at } 425^{\circ} \mathrm{C} \text { to Support } \\
\text { Determination of Negligible Creep } \\
\text { Temperature for Grade } 91 \text { Steel }\end{array}$ & $\begin{array}{l}\text { Creep } \\
\text { Rupture }\end{array}$ & 96 & Air & 425 & $\begin{array}{l}\mathrm{F} \\
\mathrm{RP}\end{array}$ & $1 \mathrm{E}-03$ & & $\begin{array}{l}\text { AR, Aged, } \\
\text { Sim. PWHT } \\
\text { combinations }\end{array}$ & $\begin{array}{l}3 \text { heats of each product form } \\
375 \text { or } 400 \mathrm{MPa} \text { applied stress }\end{array}$ \\
\hline $\begin{array}{l}\text { B2 Creep tests at } 450^{\circ} \mathrm{C} \text { to Support } \\
\text { Determination of Negligible Creep } \\
\text { Temperature for Grade } 91 \text { Steel }\end{array}$ & $\begin{array}{l}\text { Creep } \\
\text { Rupture }\end{array}$ & 108 & Air & 450 & $\begin{array}{l}\mathrm{F} \\
\mathrm{RP}\end{array}$ & $1 \mathrm{E}-03$ & & $\begin{array}{l}\text { AR, C-F } \\
\text { soft., Sim. } \\
\text { PWHT } \\
\text { combinations }\end{array}$ & $\begin{array}{l}3 \text { heats of each product form } \\
325-425 \mathrm{MPa} \text { applied stress }\end{array}$ \\
\hline $\begin{array}{l}\text { B3 Creep tests at } 475^{\circ} \mathrm{C} \text { to Support } \\
\text { Determination of Negligible Creep } \\
\text { Temperature for Grade } 91 \text { Steel }\end{array}$ & $\begin{array}{l}\text { Creep } \\
\text { Rupture }\end{array}$ & 108 & Air & 475 & $\begin{array}{l}\mathrm{F} \\
\mathrm{RP}\end{array}$ & $1 \mathrm{E}-03$ & & $\begin{array}{l}\text { AR, C-F } \\
\text { soft, Sim. } \\
\text { PWHT } \\
\text { combinations }\end{array}$ & $\begin{array}{l}3 \text { heats of each product form } \\
\text { Strain range } 0.15-2.0 \%\end{array}$ \\
\hline $\begin{array}{l}\text { B4 Creep to Extend Grade } 91 \text { Steel } \\
\text { Database }\end{array}$ & $\begin{array}{l}\text { Creep } \\
\text { Rupture }\end{array}$ & 144 & Air & $\begin{array}{l}500 \\
525\end{array}$ & $\begin{array}{l}\mathrm{F} \\
\mathrm{RP}\end{array}$ & $1 \mathrm{E}-03$ & & $\begin{array}{l}\text { AR, C-F } \\
\text { soft., Sim. } \\
\text { PWHT } \\
\text { Combos. } \\
\end{array}$ & $\begin{array}{l}3 \text { heats of each product form } \\
\text { Strain range } 0.7 \%\end{array}$ \\
\hline $\begin{array}{l}\text { B5 Creep-Fatigue Tests to Support } \\
\text { Negligible Creep Temperature } \\
\text { Determination }\end{array}$ & $\begin{array}{l}\text { Creep- } \\
\text { Fatigue }\end{array}$ & 216 & Air & $\begin{array}{l}450 \\
\text { or } \\
500\end{array}$ & $\begin{array}{l}\mathrm{F} \\
\mathrm{RP}\end{array}$ & $1 \mathrm{E}-03$ & $\begin{array}{l}0-300 \\
\text { min. } \\
\text { hold } \\
\text { time }\end{array}$ & AR & $\begin{array}{l}2 \text { heats of each product form } \\
\text { Both tensile and compressive } \\
\text { hold tests }\end{array}$ \\
\hline B6 Fatigue-Relaxation Tests at $500^{\circ} \mathrm{C}$ & $\begin{array}{l}\text { Fatigue- } \\
\text { Relaxation }\end{array}$ & 198 & $\begin{array}{l}\text { Air } \\
\text { NGNP- } \\
\text { He }\end{array}$ & 500 & $\mathrm{~F}$ & $1 \mathrm{E}-03$ & $\begin{array}{l}0-120 \\
\text { min hold } \\
\text { time }\end{array}$ & AR & $\begin{array}{l}\text { Both tensile and compressive } \\
\text { hold tests } \\
\text { Strain range } 0.5-1.0 \%\end{array}$ \\
\hline
\end{tabular}




Idaho National Laboratory
\begin{tabular}{|c|lll|}
\hline NEXT GENERATION NUCLEAR PLANT & Identifier: & PLN-2803 & \\
REACTOR PRESSURE VESSEL MATERIALS & Revision: & 0 & \\
RESEARCH AND DEVELOPMENT PLAN & Effective Date: & $04 / 30 / 08$ & Page: 82 of 95 \\
\hline
\end{tabular}

Table 13. (continued).

\begin{tabular}{|c|c|c|c|c|c|c|c|c|c|}
\hline $\begin{array}{l}\text { Test Matrix Table (B1-B16) } \\
\text { Shown in detail in Appendix B }\end{array}$ & 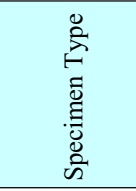 & 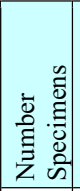 & 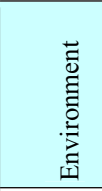 & 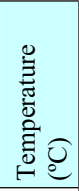 & 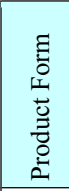 & $\begin{array}{l}\text { Strain } \\
\text { Rate } \\
(\mathrm{m} / \mathrm{m} / \mathrm{s})\end{array}$ & Time & $\begin{array}{l}\text { Specimen } \\
\text { Condition } \\
\end{array}$ & Notes \\
\hline $\begin{array}{l}\text { B7 Creep-Fatigue Tests at } 500^{\circ} \mathrm{C} \text { (stress } \\
\text { control) }\end{array}$ & $\begin{array}{l}\text { Creep- } \\
\text { Fatigue }\end{array}$ & 90 & $\begin{array}{l}\text { Air } \\
\text { NGNP- } \\
\text { He }\end{array}$ & 500 & $F$ & $1 \mathrm{E}-03$ & $\begin{array}{l}0-120 \\
\text { min hold } \\
\text { time }\end{array}$ & AR & $\begin{array}{l}\text { Both tensile and compressive } \\
\text { hold tests } \\
\text { Strain range } 0.5-1.0 \%\end{array}$ \\
\hline $\begin{array}{l}\text { B8 Fatigue-Relaxation Tests for Grade } \\
91 \text { Steel at } 550^{\circ} \mathrm{C}\end{array}$ & $\begin{array}{l}\text { Fatigue- } \\
\text { Relaxation }\end{array}$ & 90 & Air & 550 & $\mathrm{~F}$ & $1 \mathrm{E}-03$ & $\begin{array}{l}0-180 \\
\text { min hold } \\
\text { time }\end{array}$ & $\begin{array}{l}\text { AR, } \\
\text { Sim. PWHT }\end{array}$ & $\begin{array}{l}\text { Both tensile and compressive } \\
\text { hold tests } \\
\text { Strain range } 0.4-0.7 \%\end{array}$ \\
\hline $\begin{array}{l}\text { B9 Creep-Fatigue Tests for Grade } 91 \\
\text { Steel at } 550^{\circ} \mathrm{C}\end{array}$ & $\begin{array}{l}\text { Creep- } \\
\text { Fatigue }\end{array}$ & 27 & Air & 550 & $F$ & $1 \mathrm{E}-03$ & $\begin{array}{l}0-180 \\
\text { min hold } \\
\text { time }\end{array}$ & AR & $\begin{array}{l}\text { Both tensile and compressive } \\
\text { hold tests } \\
\text { Strain range } 0.4-0.7 \%\end{array}$ \\
\hline $\begin{array}{l}\text { B10 Fatigue-Relaxation Tests at } 500^{\circ} \mathrm{C} \\
\text { for Aged Grade } 91 \text { Steel }\end{array}$ & $\begin{array}{l}\text { Fatigue- } \\
\text { Relaxation }\end{array}$ & 99 & Air & 500 & $F$ & $1 \mathrm{E}-03$ & $\begin{array}{l}0-120 \\
\text { min hold } \\
\text { time }\end{array}$ & $\begin{array}{l}\text { Aged at } 650 \\
20,000 \mathrm{~h}\end{array}$ & $\begin{array}{l}\text { Both tensile and compressive } \\
\text { hold tests } \\
\text { Strain range } 0.4-1.0 \%\end{array}$ \\
\hline $\begin{array}{l}\text { B11 Creep-Fatigue Tests at } 500^{\circ} \mathrm{C} \text { for } \\
\text { Aged Grade } 91 \text { Steel }\end{array}$ & $\begin{array}{l}\text { Creep- } \\
\text { Fatigue }\end{array}$ & 45 & Air & 500 & $F$ & $1 \mathrm{E}-03$ & $\begin{array}{l}0-120 \\
\text { min hold } \\
\text { time }\end{array}$ & $\begin{array}{l}\text { Aged at } 650 \\
20,000 \mathrm{~h}\end{array}$ & $\begin{array}{l}\text { Both tensile and compressive } \\
\text { hold tests } \\
\text { Strain range } 0.5-1.0 \%\end{array}$ \\
\hline $\begin{array}{l}\text { B12 Fatigue-Relaxation Tests at } 550^{\circ} \mathrm{C} \\
\text { for SAW, GTAW and SMAW Cross- } \\
\text { Welds }\end{array}$ & $\begin{array}{l}\text { Fatigue- } \\
\text { Relaxation }\end{array}$ & 135 & Air & 550 & $\begin{array}{l}\text { W } \\
F\end{array}$ & $1 \mathrm{E}-03$ & $\begin{array}{l}0-180 \\
\text { min hold } \\
\text { time }\end{array}$ & PWHT & $\begin{array}{l}\text { Both tensile and compressive } \\
\text { hold tests } \\
\text { Strain range } 0.4-0.7 \%\end{array}$ \\
\hline $\begin{array}{l}\text { B13 Weld Stress Rupture Factor for } \\
\text { SAW, GTAW and SMAW Cross-Welds }\end{array}$ & $\begin{array}{l}\text { Creep } \\
\text { Rupture }\end{array}$ & 84 & Air & $\begin{array}{l}425- \\
650\end{array}$ & $\begin{array}{l}\text { W } \\
F\end{array}$ & $1 \mathrm{E}-03$ & $\begin{array}{l}1000- \\
100,000 \\
\text { h ERt }\end{array}$ & PWHT & 52-460 MPa applied stress \\
\hline $\begin{array}{l}\text { B14 Short \& Medium Term Creep Tests } \\
\text { on Creep Fatigue Softened Samples }\end{array}$ & Creep & 6 & Air & 550 & $F$ & $1 \mathrm{E}-03$ & $\begin{array}{l}1000- \\
10,000 \mathrm{~h} \\
\text { ERt }\end{array}$ & $\begin{array}{l}\text { Crp-Fatigue } \\
\text { Softened }\end{array}$ & \\
\hline
\end{tabular}


Form 412.09 (Rev. 10)

Idaho National Laboratory
\begin{tabular}{|c|lll|}
\hline NEXT GENERATION NUCLEAR PLANT & Identifier: & PLN-2803 & \\
REACTOR PRESSURE VESSEL MATERIALS & Revision: & 0 & \\
RESEARCH AND DEVELOPMENT PLAN & Effective Date: & $04 / 30 / 08$ & Page: 83 of 95 \\
\hline
\end{tabular}

Table 13. (continued).

\begin{tabular}{|c|c|c|c|c|c|c|c|c|c|}
\hline $\begin{array}{l}\text { Test Matrix Table (B1-B16) } \\
\text { Shown in detail in Appendix B }\end{array}$ & 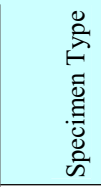 & 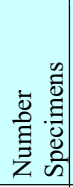 & 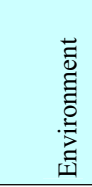 & 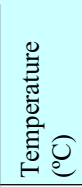 & 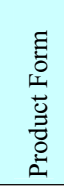 & $\begin{array}{l}\text { Strain } \\
\text { Rate } \\
(\mathrm{m} / \mathrm{m} / \mathrm{s})\end{array}$ & Time & $\begin{array}{l}\text { Specimen } \\
\text { Condition }\end{array}$ & Notes \\
\hline $\begin{array}{l}\text { B15 Tensile Tests for Creep Fatigue } \\
\text { Softened Samples at } 550^{\circ} \mathrm{C}\end{array}$ & Tensile & 16 & Air & $\begin{array}{l}20- \\
700\end{array}$ & $\mathrm{~F}$ & $1 \mathrm{E}-03$ & & $\begin{array}{l}\text { Crp-Fatigue } \\
\text { Softened }\end{array}$ & \\
\hline $\begin{array}{l}\text { B16 Test Matrix for Grade } 91 \text { Steel } \\
\text { Fatigue Design Curve at } 650^{\circ} \mathrm{C}\end{array}$ & Fatigue & 54 & Air & 650 & $\mathrm{~F}$ & $4 \mathrm{E}-03$ & & & $\begin{array}{l}3 \text { heats of each product form } \\
\text { Strain range } 0.15-2.07 \%\end{array}$ \\
\hline
\end{tabular}




\begin{tabular}{|c|lll|}
\hline NEXT GENERATION NUCLEAR PLANT & Identifier: & PLN-2803 & \\
REACTOR PRESSURE VESSEL MATERIALS & Revision: & 0 & \\
RESEARCH AND DEVELOPMENT PLAN & Effective Date: & $04 / 30 / 08$ & Page: 84 of 95 \\
\hline
\end{tabular}

\subsubsection{Negligible Creep Temperature for Grade 91 Steel}

Section 4 described the DOE/ASME GMP Task 3 effort on the investigation of the negligible creep criteria for Grade 91 steel. A testing program was recommended to address data needs to validate negligible creep conditions for Grade 91. An assessment was made on this test program and it is recommended that this test program be executed to support NGNP if the "hot" vessel option is down-selected for RPV.

Tables B1 to B5 of Appendix B present the test matrices for the creep, creep rupture, and creep-fatigue tests to (i) support the assessment of negligible creep conditions, (ii) expand the Grade 91 creep database, and (iii) provide creep-fatigue data to validate the negligible creep temperature recommended in the Task 3 report. The test temperatures are $425^{\circ} \mathrm{C}, 450^{\circ} \mathrm{C}$, and $475^{\circ} \mathrm{C}$. The as-received (AR) condition is the default material condition for the testing. Other pre-conditionings include simulated post weld heat treatment (PWHT), thermal aging and cyclically softened (or damaged). The simulated PWHT consists of 20 hours at $750^{\circ} \mathrm{C}$. The cyclically softening protocol consists of strain controlled continuous cycling with $0.5 \%$ strain range until the stress-strain conditions are consistent with the cyclic stress-strain curve at temperature. For the aging protocol, the Materials R\&D team recommends that the condition of 10,000 hours at $475^{\circ} \mathrm{C}$ proposed by Task 3 be changed to 20,000 hours at $650^{\circ} \mathrm{C}$ to accelerate the aging process as the intended RPV application is for 60 years.

Test matrix to expand the creep database is presented in Table B4. The material conditions include $\mathrm{AR}$, simulated PWHT and cyclic softening. The test temperatures are $500^{\circ} \mathrm{C}$ and $525^{\circ} \mathrm{C}$. Creep-fatigue text matrix is shown in Table B5. Tests with only tension hold and with only compression hold are included. The test temperatures are $450^{\circ} \mathrm{C}$ and $500^{\circ} \mathrm{C}$ and the strain range is $0.7 \%$.

\subsubsection{Creep-Fatigue Testing}

The objectives of the Grade 91 testing effort recommend by Task 3 are to improve the understanding of the cyclic behavior at high temperature, and to validate creep-fatigue procedure. The test program proposed by Task 3 was assessed and it is recommended that this test program be executed to support NGNP if the "hot" vessel option is down-selected for RPV.

There are two "creep-fatigue" protocols recommended by Task 3. One involves keeping the strain constant during hold time and hence the stress relaxes during hold time. This is referred to as fatiguerelaxation test. The other involves keeping the stress constant during hold time and the material will creep. This is called creep-fatigue test.

Tables B6 to B9 present the test matrices for the fatigue-relaxation and creep-fatigue tests at $500^{\circ} \mathrm{C}$, with strain ranges of $0.5 \%, 0.7 \%$ and $1 \%$, and $550^{\circ} \mathrm{C}$, with strain ranges of $0.4 \%, 0.5 \%$ and $0.7 \%$, respectively. Tension hold only tests and compression hold only tests are both included in the table. All the tests have As-Received as the material pre-condition, except one set at $550^{\circ} \mathrm{C}$ where the pre-condition is simulated PWHT. Some tests are performed in air while others are in NGNP helium.

Tables $\mathrm{B} 10$ and $\mathrm{B} 11$ present the fatigue-relaxation and creep-fatigue test matrices at $500^{\circ} \mathrm{C}$ for aged material where the aging protocol is 20,000 hours at $650^{\circ} \mathrm{C}$ from the $\mathrm{AR}$ condition. The choice of $650^{\circ} \mathrm{C}$ is to accelerate the aging process so that the equivalent thermal embrittlement at temperatures lower than $650^{\circ} \mathrm{C}$ would correspond to times longer than 20,000 hours.

Fatigue-relaxation tests for thick section cross-welds, produced by SA, GTA, and SMA welding processes are given in Table B12. The weldments will be given a simulated PWHT before test specimens are machined. 


\begin{tabular}{|c|lll|}
\hline NEXT GENERATION NUCLEAR PLANT & Identifier: & PLN-2803 & \\
REACTOR PRESSURE VESSEL MATERIALS & Revision: & 0 & \\
RESEARCH AND DEVELOPMENT PLAN & Effective Date: & $04 / 30 / 08$ & Page: 85 of 95 \\
\hline
\end{tabular}

Table B13 presents the creep rupture tests of thick section welds, again produced by SA, GTA, and SMA welding processes. All weldments will receive a simulated PWHT. The applied stresses are sized to get rupture time targets of 1000, 3000 and 10000 hours. However, there are 12 tests that have been sized for 100,000-hour rupture tests to provide qualification data. The data from Table B13 can be used to develop weld stress rupture factor to support the code qualification of thick-section welds.

Creep rupture tests on Grade 91 specimens that have been softened by creep-fatigue pre-conditioning are given in Table B14 while Table B15 presents tensile tests on similarly creep-fatigue softened Grade 91 specimens.

Table B16 presents testing to support the development of a design continuous cycling fatigue curve at $650^{\circ} \mathrm{C}$ for use in Subsection NH.

\subsubsection{Irradiation Effects}

As discussed in Section 5, longer term ( $\sim$ two years) and low flux irradiation data are needed to address the concern of synergistic effect of irradiation enhanced segregation of embrittling impurities on grain boundaries. The following irradiation program is proposed. It will include irradiation of tensile specimens, $0.5 \mathrm{~T}$ compact tension specimens for fracture toughness evaluation, and coupons for microstructural characterization at 325 and $375^{\circ} \mathrm{C}$. It is anticipated that irradiation will be performed on simulated stress relieved and thermally aged steels and welds.

Moreover, as more and more research reactors are shut down, the list of facilities capable of performing such experiments has diminished significantly. In fact, there are probably only three reactors left in North America (the MURR reactor at the University of Missouri in Columbia, Missouri, the MNR at McMaster University in Hamilton, Ontario, Canada, and the MITR-2 at Massachusetts Institute of Technology in Cambridge, Massachusetts) and two reactors in Europe (The BR2 reactor, located at the Studie Centrum Voor Kernenergie - Centre D'etude De L'Energie Nucleaire (SCK-CEN), Mol, Belgium and the LVR-15, located at the Nuclear Research Institute in Rez, Czech Republic) that are capable of performing such irradiation experiments. However, their availability for performing such irradiations is unclear at this point.

Based on previous experience with irradiating RPV steels for the US NRC program, it is estimated that design, instrumentation, assembly, and installation of an instrumented capsule for such an experiment would be $\sim \$ 1 \mathrm{M}$ and the irradiation facility operating cost would be around $\$ 0.5 \mathrm{M}$ per year. The operating cost should be considered as a very rough estimate since the reactor site for this experiment is not yet selected. The Post Irradiation Examination cost would be $\sim \$ 0.6 \mathrm{M}$. Thus the total cost is $\$ 3 \mathrm{M}$ which includes a $15 \%$ contingency.

\subsubsection{Materials to be Tested}

\subsubsection{Baseline Case}

A 508/533B steels with thickness of at least $120 \mathrm{~mm}$ will be required to adequately reflect the behavior of heavy pressure vessel sections. The A 508 will obviously be in the forged condition and the A $533 \mathrm{~B}$ in the form of rolled plate. 


\begin{tabular}{|c|lll|}
\hline NEXT GENERATION NUCLEAR PLANT & Identifier: & PLN-2803 & \\
REACTOR PRESSURE VESSEL MATERIALS & Revision: & 0 & \\
RESEARCH AND DEVELOPMENT PLAN & Effective Date: & $04 / 30 / 08$ & Page: 86 of 95 \\
\hline
\end{tabular}

\subsubsection{Alternative Cases}

Forged heavy section $9 \mathrm{Cr}-1 \mathrm{M} 0$ steel with a thickness of at least $120 \mathrm{~mm}$ would be required to adequately reflect the behavior of heavy pressure vessel sections if it is determined that the uncooled vessel option requires development.

\subsubsection{Quantity required}

A heat of a minimum 8 tons will be required for the testing program, aging studies and characterization of weldments for A 508 to confidently determine property of interest.

\subsubsection{Data Management}

Data management for this program should at least consist of three major parts: 1) Plans for efficient data generation in resources, time, and cost; 2) Maintenance of data to achieve maximum benefits to the present reactor development and future reactor operation; 3) Quality assurance.

Data generation plans will be developed with full review of existing data and consultation with major data users. Plans will be reviewed and agreed with relevant personnel before implementation. In data maintenance and quality assurance, it must be made very clear that the technical information produced from the R\&D activities in this program will need to be kept retrievable for the entire period of the reactor development, plus the reactor service life of 60 years and beyond.

Therefore, all the information generated should be documented in compliance with relevant QA requirements. Further, all the raw data generated from successful tests must be stored in a format that will allow for efficient search and analysis of the data and that will be recoverable using standard data management tools.

The major steps in preparation of data include collecting, formatting/editing, error checking, and technical approval. Traceability must be ensured in each step of the entire process. For raw test data, the following metadata must be provided in data documentation and record preparation.

- Data Project Name / ID

- Testing Organization

- Original Test Number

- Original Test Filename

- Test Operator

- Test Standards

- Data Processed by

- Applicable QA Requirements

- Record Edited by

- Record Error Checked by

- Record Technical Approval by 


\begin{tabular}{|c|lll|}
\hline NEXT GENERATION NUCLEAR PLANT & Identifier: & PLN-2803 & \\
REACTOR PRESSURE VESSEL MATERIALS & Revision: & 0 & \\
RESEARCH AND DEVELOPMENT PLAN & Effective Date: & $04 / 30 / 08$ & Page: 87 of 95 \\
\hline
\end{tabular}

\subsubsection{Welding}

\subsubsection{Baseline Case}

\section{Define Adequate Weldments-}

Welding of the conventional pressure vessel steels is adequately covered in the ASME Code.

\section{Determine Weld Procedures-}

Welding the conventional pressure vessel steels is mature technology. There is no additional development proposed for the NGNP program.

\section{Define testing schemes for prototypical Weldments-}

Test specimens for welds can be obtained from weld cradles (deposited weld metal), weld plates from procedural qualification, and weldments obtained by welding together base metals of prototypical section thickness. Testing schemes for prototypical A 508/533B weldments are well established for LWR. All proposed tensile, creep, creep-fatigue, fracture toughness tests for A 508/533B welds in support of the more challenging NGNP condition are based on weldments manufactured from prototypical section thickness.

\section{Post-Weld Heat Treatment-}

Stress relief heat treatments are typically applied after welding the conventional pressure vessel steels. This is mature technology and there is no additional development required for the NGNP program. Simulated stress relief will be applied to all A 508/533B wrought metals and associated weldments before specimens are machined. This is to ensure that the properties measured are appropriate for RPV applications.

\subsubsection{Alternative Cases}

\subsubsection{Define Adequate Weldments}

Unlike the A 508/533 steel, Grade 91 steel requires post-weld quench and temper heat treatment to achieve maximum high temperature properties. In addition to standard specifications for post-weld examination, e.g., inspection for lack of fusion, the microstructure must be characterized. The current ASME Code rules specify a maximum hardness in order to ensure that proper tempering treatment has been carried out. An additional specification will be required for minimum hardness to ensure that the quench from the austenitizing temperature was sufficient to avoid formation of ferrite and coarse carbides.

\subsubsection{Define Testing Schemes for Prototypical Weldments}

The testing schemes for prototypical Grade 91 weldments should consist of three parts. The first part is to characterize the microstructure of the welds to determine whether the desired microstructures are achieved, and d-ferrite is limited within the allowable standards stipulated by ASME Code Section III Division 1 Subsection NH. The second part is to evaluate the integrity of the fabricated weldment in optimizing the filler metals and processing parameters. The third part is to generate some verification data for the Weld Strength Factor (WSF), such as the stress-rupture factor for welds needed for Tables I-14.10 of Mandatory Appendix I-14 of ASME Code Section III Division 1 Subsection NH. The current NH already contains factor values for some specified filler metals. However, if new filler metals are 


\begin{tabular}{|c|lll|}
\hline NEXT GENERATION NUCLEAR PLANT & Identifier: & PLN-2803 & \\
REACTOR PRESSURE VESSEL MATERIALS & Revision: & 0 & \\
RESEARCH AND DEVELOPMENT PLAN & Effective Date: & $04 / 30 / 08$ & Page: 88 of 95 \\
\hline
\end{tabular}

developed, some data would be needed for verification of the existing factor values. In addition, verification data specially needed are those for large forgings not currently covered by the Code. ${ }^{27}$ Computational modeling will be required for extrapolation of the experimental data to cover the longterm data requirements.

\subsubsection{Post-Weld Heat Treatment}

For the PWHT, experiences from fabricating Grade 91 weldment in fossil energy programs suggest that customized PWHT procedures must be developed in detail to temper the weld metal, and the entire process should be closely monitored with an array of thermal couples and other types of sensors. Depending on the specific filler metal employed, PWHT must be adjusted accordingly to achieve the desired microstructure and mechanical properties. Normally, PWHT may be conducted at $760^{\circ} \mathrm{C} \pm 15^{\circ} \mathrm{C}$ over 1 hour for walls less than $13 \mathrm{~mm}$ thick. If the thickness is greater than $13 \mathrm{~mm}$, the hold time should be at least 2 hours. For walls thicker than $50 \mathrm{~mm}$, every additional $25 \mathrm{~mm}$ may add 1 hour of hold time. For the NGNP RPV, a specific PWHT scheme should be developed based on these suggested parameters. Special considerations should also be taken for onsite welding of thick sections in various weather conditions, including the effects on humidity, heating rate, and cooling rate.

Besides the common thermal cycle controlling steps of pre-heating, inter-pass heating, hydrogen bake-out, and PWHT, additional thermal processes for optimizing the weldment microstructures and properties can also be explored. It was reported that toughness of A 508 Grade 3 steel was significantly improved by adding an intercritical heat treatment (IHT) step between quenching and tempering of the material, and a patent has been files for the IHT as an invention ${ }^{28}$. Similar heat treatment steps could also be investigated for the fabrication of Grade 91 NGNP RPV welds.

\subsubsection{Baseline Case}

\subsubsection{Irradiation Effects}

There is an adequate database for irradiation effects on the conventional steels from the LWR experience. The NGNP pressure vessel will operate at temperatures equal to or higher than conventional LWR pressure vessels in any region that experiences a significant radiation flux and the lifetime damage to the pressure vessel is calculated to be an order of magnitude lower than LWR vessels.

\subsubsection{Alternative Cases}

Some additional irradiation testing at elevated temperature will be required for Grade 91 steel. Evaluation of scoping studies carried out under the GenIV program must be completed in order to adequately plan the necessary additional irradiation characterization required.

\subsubsection{Cost}

Estimated cost to carry out the necessary studies of A 508/533 and Grade 91 are detailed in the following tables.

Table 14 details costs associated with sample preparation and testing for A 508/533. Table 15 details the estimated total cost for testing and analysis for A 508/533. Table 16 gives estimated costs for specimen fabrication and testing of the $9 \mathrm{Cr}-1 \mathrm{M} 0$ steel. Table 17 provides the total estimated cost for testing and analysis of the Grade 91 steel instead of the A 508/533. Table 18 outlines the total cost of carrying out the testing and analysis for both materials. 


Idaho National Laboratory
\begin{tabular}{|c|lll|}
\hline NEXT GENERATION NUCLEAR PLANT & Identifier: & PLN-2803 & \\
REACTOR PRESSURE VESSEL MATERIALS & Revision: & 0 & \\
RESEARCH AND DEVELOPMENT PLAN & Effective Date: & $04 / 30 / 08$ & Page: 89 of 95 \\
\hline
\end{tabular}

Table 14. Costs associated with sample preparation and testing for A 508/533.

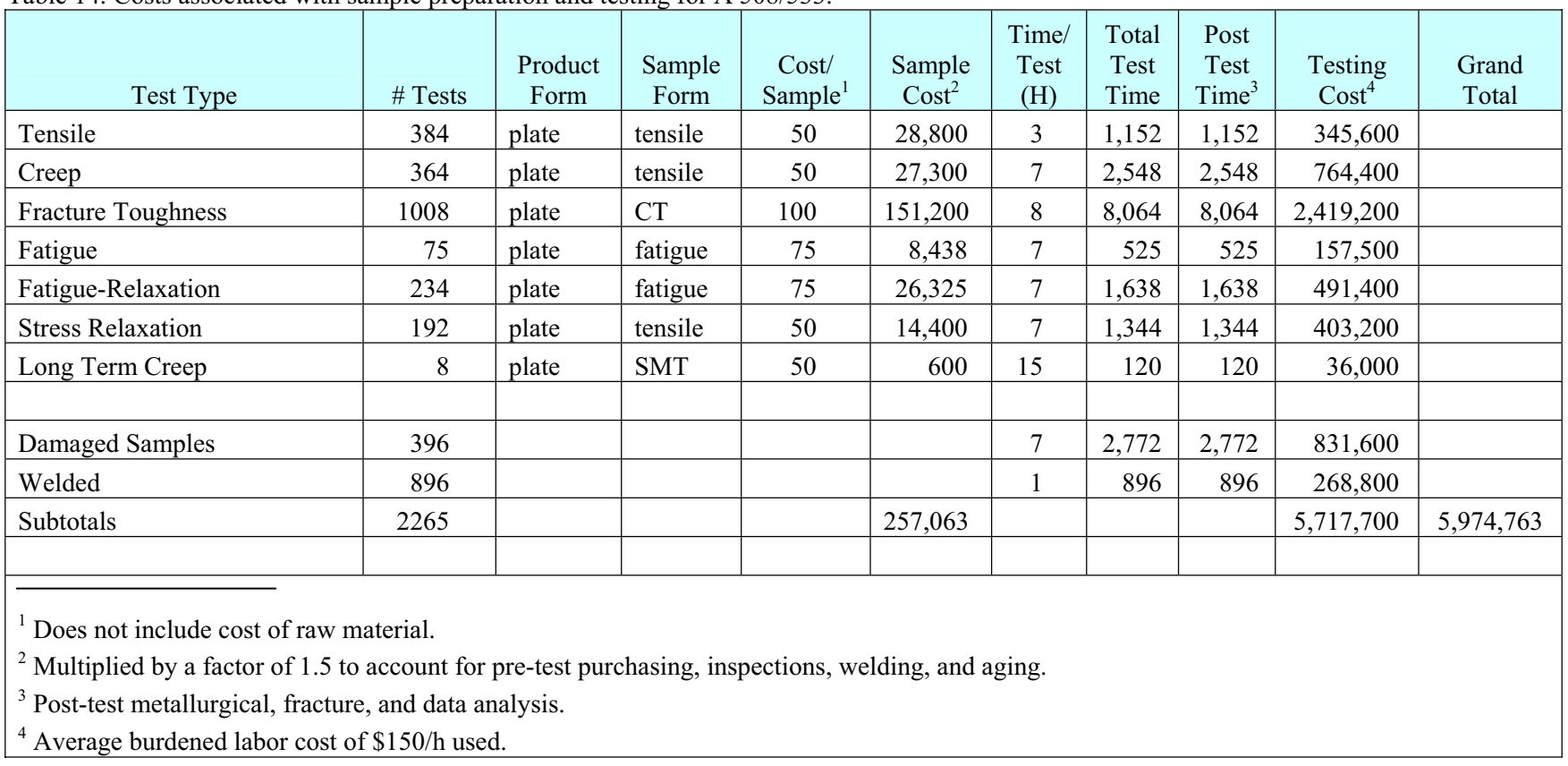


Idaho National Laboratory

\begin{tabular}{|c|lll|}
\hline NEXT GENERATION NUCLEAR PLANT & Identifier: & PLN-2803 & \\
REACTOR PRESSURE VESSEL MATERIALS & Revision: & 0 & \\
RESEARCH AND DEVELOPMENT PLAN & Effective Date: & $04 / 30 / 08$ & Page: 90 of 95 \\
\hline
\end{tabular}

Table 15. Estimated total cost for testing and analysis for A 508/533.

\begin{tabular}{|c|c|c|}
\hline (All values in FY08 burdened \$) & Cost $(\$)$ & Subtotals \\
\hline Material Cost & & 632,063 \\
\hline Raw Material & & 175,000 \\
\hline $508 / 533$ & 175,000 & \\
\hline Cost to Machine Samples & 257,063 & \\
\hline Consumables & 200,000 & \\
\hline Adder for Purchasing $(30 \%)$ & 189,619 & 821,681 \\
\hline Labor for Testing & & $6,217,700$ \\
\hline Mechanical Property Testing & $5,717,700$ & \\
\hline Corrosion Testing & 500,000 & \\
\hline Equipment Purchase & & $3,325,000$ \\
\hline Load Frames & $1,500,000$ & \\
\hline Fixtures & 75,000 & \\
\hline Furnaces & 250,000 & \\
\hline Repair, Upgrade, and Refurbishing & $1,500,000$ & \\
\hline Adder for Purchasing (30\%) & 997,500 & $4,322,500$ \\
\hline Other Labor & & $4,000,000$ \\
\hline Analysis and Reporting & 900,000 & \\
\hline Engineering Design Support & 600,000 & \\
\hline Project Engineer & 900,000 & \\
\hline ASME Code Interface & $1,600,000$ & \\
\hline Subtotal for Labor & & $10,217,700$ \\
\hline Subtotal for Materials \& Equipment & & $5,144,181$ \\
\hline Subtotal & & $15,361,881$ \\
\hline Quality Assurance (10\%) & $1,536,188$ & \\
\hline Program Management $(10 \%)$ & $1,536,188$ & \\
\hline Total & $18,434,258$ & \\
\hline
\end{tabular}




Idaho National Laboratory
\begin{tabular}{|c|lll|}
\hline NEXT GENERATION NUCLEAR PLANT & Identifier: & PLN-2803 & \\
REACTOR PRESSURE VESSEL MATERIALS & Revision: & 0 & \\
RESEARCH AND DEVELOPMENT PLAN & Effective Date: & $04 / 30 / 08$ & Page: 91 of 95 \\
\hline
\end{tabular}

Table 16. Estimated costs for specimen fabrication and testing of the $9 \mathrm{Cr}-1 \mathrm{M} 0$ steel.

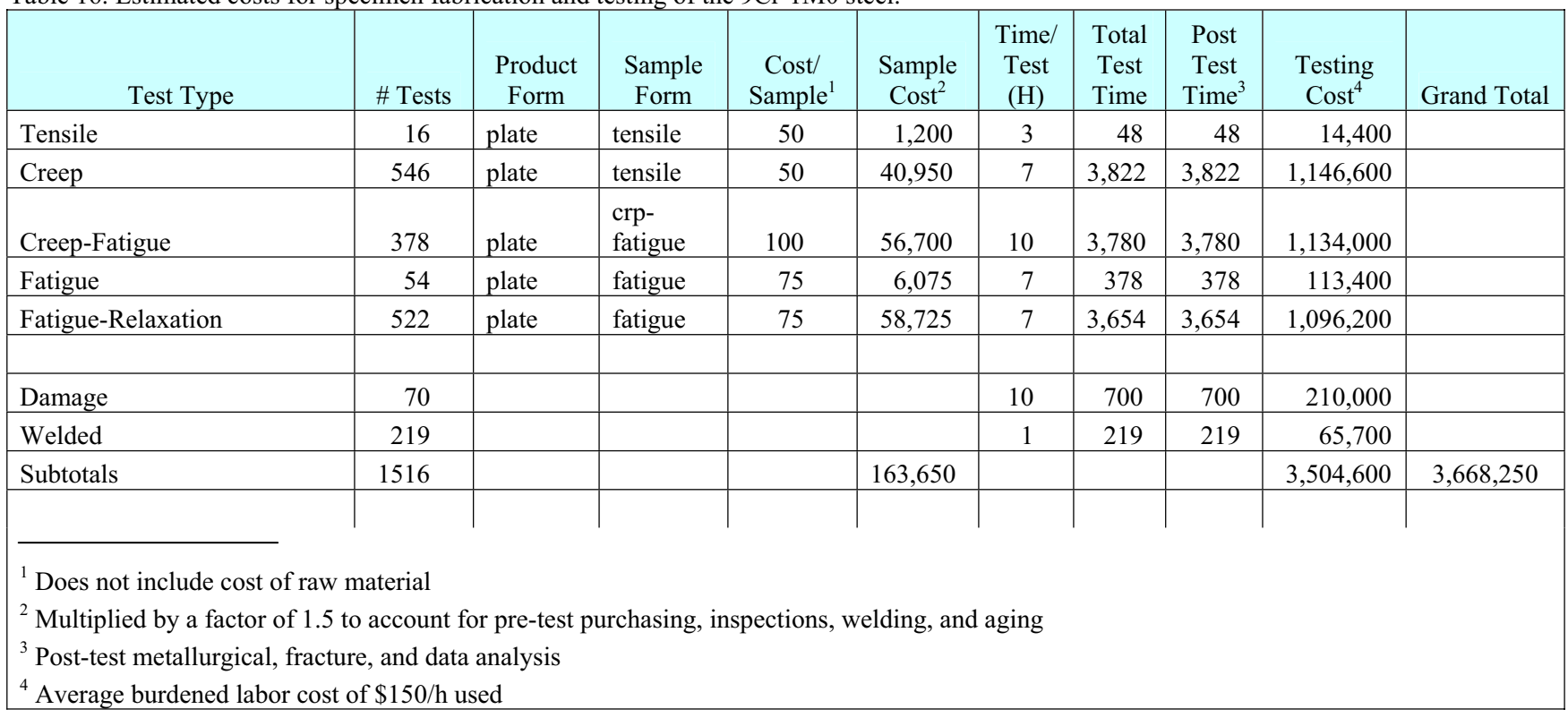


Idaho National Laboratory

\begin{tabular}{|c|lll|}
\hline NEXT GENERATION NUCLEAR PLANT & Identifier: & PLN-2803 & \\
REACTOR PRESSURE VESSEL MATERIALS & Revision: & 0 & \\
RESEARCH AND DEVELOPMENT PLAN & Effective Date: & $04 / 30 / 08$ & Page: 92 of 95 \\
\hline
\end{tabular}

Table 17. Estimated cost for testing and analysis of the Grade 91 steel instead of the A 508/533.

\begin{tabular}{|c|c|c|}
\hline (All values in FY08 burdened \$) & Cost $(\$)$ & Subtotals \\
\hline Material Cost & & 488,650 \\
\hline Raw Material & & 125,000 \\
\hline G91 & 125,000 & \\
\hline Cost To Machine Samples & 163,650 & \\
\hline Consumables & 200,000 & \\
\hline Adder For Purchasing $(30 \%)$ & 146,595 & 635,245 \\
\hline Labor For Testing & & $4,004,600$ \\
\hline Mechanical Property Testing & $3,504,600$ & \\
\hline Corrosion Testing & 500,000 & \\
\hline Equipment Purchase & & $3,325,000$ \\
\hline Load Frames & $1,500,000$ & \\
\hline Fixtures & 75,000 & \\
\hline Furnaces & 250,000 & \\
\hline Repair, Upgrade, And Refurbishing & $1,500,000$ & \\
\hline Adder For Purchasing $(30 \%)$ & 997,500 & $4,322,500$ \\
\hline Other Labor & & $4,000,000$ \\
\hline Analysis And Reporting & 900,000 & \\
\hline Engineering Design Support & 600,000 & \\
\hline Project Engineer & 900,000 & \\
\hline $\begin{array}{l}\text { ASME Code } \\
\text { Interface }\end{array}$ & $1,600,000$ & \\
\hline Subtotal For Labor & & $8,004,600$ \\
\hline Subtotal For Materials \& Equipment & & $4,957,745$ \\
\hline Subtotal & & $12,962,345$ \\
\hline Quality Assurance (10\%) & $1,296,235$ & \\
\hline Program Management $(10 \%)$ & $1,296,235$ & \\
\hline Total & $15,554,814$ & \\
\hline
\end{tabular}


Idaho National Laboratory

\begin{tabular}{c|lll|} 
NEXT GENERATION NUCLEAR PLANT & Identifier: & PLN-2803 & \\
REACTOR PRESSURE VESSEL MATERIALS & Revision: & 0 & \\
RESEARCH AND DEVELOPMENT PLAN & Effective Date: & $04 / 30 / 08$ & Page: 93 of 95 \\
\hline
\end{tabular}

Table 18. The total cost of carrying out testing and analysis for both materials.

\begin{tabular}{|c|c|c|c|}
\hline \multicolumn{2}{|c|}{ (All Values In Fy08 Burdened \$) } & Cost $(\$)$ & Subtotals \\
\hline \multicolumn{2}{|l|}{ Material Cost } & & 920,713 \\
\hline \multicolumn{2}{|l|}{ Raw Material } & & 300,000 \\
\hline \multicolumn{2}{|l|}{$508 / 533$} & 175,000 & \\
\hline \multicolumn{2}{|l|}{ G91 } & 125,000 & \\
\hline Cost To Machine Samples & $508 / 533$ & 257,063 & \\
\hline Cost To Machine Samples & G91 & 163,650 & \\
\hline \multicolumn{2}{|l|}{ Consumables } & 200,000 & \\
\hline \multicolumn{2}{|l|}{ Adder For Purchasing $(30 \%)$} & 276,214 & $1,196,926$ \\
\hline \multicolumn{2}{|l|}{ Labor For Testing } & & $9,722,300$ \\
\hline Mechanical Property Testing & $508 / 533$ & $5,717,700$ & \\
\hline Mechanical Property Testing & G91 & $3,504,600$ & \\
\hline \multicolumn{2}{|l|}{ Corrosion Testing } & 500,000 & \\
\hline \multicolumn{2}{|l|}{ Equipment Purchase } & & $3,325,000$ \\
\hline \multicolumn{2}{|l|}{ Load Frames } & $1,500,000$ & \\
\hline \multicolumn{2}{|l|}{ Fixtures } & 75,000 & \\
\hline \multicolumn{2}{|l|}{ Furnaces } & 250,000 & \\
\hline \multicolumn{2}{|c|}{ Repair, Upgrade And Refurbishing } & $1,500,000$ & \\
\hline \multicolumn{2}{|l|}{ Adder For Purchasing $(30 \%)$} & 997,500 & $4,322,500$ \\
\hline \multicolumn{2}{|l|}{ Other Labor } & & $4,000,000$ \\
\hline \multicolumn{2}{|l|}{ Analysis And Reporting } & 900,000 & \\
\hline \multicolumn{2}{|l|}{ Engineering Design Support } & 600,000 & \\
\hline \multicolumn{2}{|l|}{ Project Engineer } & 900,000 & \\
\hline \multicolumn{2}{|l|}{ ASME Code Interface } & $1,600,000$ & \\
\hline \multicolumn{2}{|l|}{ Subtotal For Labor } & & $13,722,300$ \\
\hline \multicolumn{2}{|c|}{ Subtotal For Materials \& Equipment } & & $5,519,426$ \\
\hline \multicolumn{2}{|l|}{ Subtotal } & & $19,241,726$ \\
\hline \multicolumn{2}{|l|}{ Quality Assurance (10\%) } & $1,924,173$ & \\
\hline \multicolumn{2}{|l|}{ Program Management $(10 \%)$} & $1,924,173$ & \\
\hline \multicolumn{2}{|l|}{ Total } & $23,090,072$ & \\
\hline
\end{tabular}




\begin{tabular}{|c|lll|}
\hline NEXT GENERATION NUCLEAR PLANT & Identifier: & PLN-2803 & \\
REACTOR PRESSURE VESSEL MATERIALS & Revision: & 0 & \\
RESEARCH AND DEVELOPMENT PLAN & Effective Date: & $04 / 30 / 08$ & Page: 94 of 95 \\
\hline
\end{tabular}

\section{REFERENCES}

1. INL, Next Generation Nuclear Plant Pre-Conceptual Design Report, Revision 1; INL/EXT-07-12967; November 2007.

2. Weaver, K. D., Idaho National Laboratory, NGNP Engineering White Paper: Reactor Type Trade Study; INL/EXT-07-12729.

3. Sherman, S. R., Idaho National Laboratory, INL, NGNP Engineering White Paper: NGNP Project Pre-Conceptual Heat Transfer and Transport Studies; INL/EXT-07-12730; April 2007.

4. Vandel, D. S., Idaho National Laboratory, INL, NGNP Engineering White Paper: Primary and Secondary Cycle Trade Study; INL/EXT-07-12732; April 2007.

5. Schultz, R. R., Idaho National Laboratory, INL, NGNP Engineering White Paper: Power Conversion System Trade Study; INL/EXT-07-12727; April 2007.

6. Copsey, B., Lecomte, M., and Brinkmann, G., et al., "The Framatome Anp Indirect-Cycle Very High-Temperature Reactor," ICAPP 2004, Pittsburg, PA, June 13-17, 2004.

7. Proceedings of ICAPP '05, Seoul, Korea, May 15-19, 2005.

8. $\quad$ Fazluddin, S., Smit, K., and Slabber, J., "The Use of Advanced Materials in VHTRs," 2nd International Topical Meeting on High Temperature Reactor Technology, Beijing, China, September 22-24, 2004.

9. Ion, S., Nicholls, D., Matzie, R., et al. "Pebble Bed Modular Reactor the First Generation IV Reactor to Be Constructed," http://www.world-nuclear.org/sym/2003/matzie.htm.

10. Matzner, D., "PBMR Project Status and the Way Ahead," Proceedings of the 2nd International Topical Meeting on High Temperature Reactor Technology, Beijing China, September 22-24, 2004, International Atomic Energy Agency: pp. 1-13.

11. Koster, A., Matzie, R., and Matzner, D., "PBMR: A Generation IV High Temperature Gas Cooled Reactor," Proc. Instn Mech. Engrs, J. Power and Energy, Vol. 218, Part A.

12. Gougar, H. D., Davis, C. B., Idaho National Laboratory, Reactor Pressure Vessel Temperature Analysis for Prismatic and Pebble-Bed VHTR Designs; INL/EXT-06-11057; April 2006.

13. Mizia, R. E., INL, Next Generation Nuclear Plant Reactor Pressure Vessel Acquisition Strategy; INL/EXT-08-13951; April 2008.

14. General Atomics, GA, Preconceptual Engineering Services for the Next Generation Nuclear Plant (NGNP) with Hydrogen Production; PC-000544; 7/10/2007.

15. Sections III and VIII, Division 2, Criteria of the ASME Boiler and Pressure Vessel Code for Design by Analysis In ASME, 1969.

16. Companion Guide to the ASME Boiler \& Pressure Vessel Code. New York, NY: ASME Press, 2002.

17. Shah, V. N., Majumdar, S., and Natesan, K., Argonne National Laboratory, Review and Assessment of Codes and Procedures for HTGR Components; NUREG/CR-6816; June 2003.

18. Criteria for Design of Elevated Temperature Class 1 Components in Section III, Division 1, of the ASME Boiler and Pressure Vessel Code. ASME, 1976. 
Idaho National Laboratory

NEXT GENERATION NUCLEAR PLANT

REACTOR PRESSURE VESSEL MATERIALS

RESEARCH AND DEVELOPMENT PLAN
Identifier: $\quad$ PLN-2803

Revision: $\quad 0$

Effective Date: $04 / 30 / 08 \quad$ Page: 95 of 95

19. Berman, I., Gupta, G. D., "Buckling Rules for Nuclear Components," Journal of Pressure Vessel Technology, Vol. 98, 1976, pp. 229-231.

20. Jakub, M. T., "New Rules for Construction of Section III, Class 1 Components for Elevated Temperature Service," Journal of Pressure Vessel Technology, Vol. 98, 1976, pp. 214-222.

21. Jetter, R. I., "Elevated Temperature Design - Development and Implementation of Code Case 1592," Journal of Pressure Vessel Technology, Vol. 98, 1976, pp. 222-229.

22. Sham, T.-L., Eno, D. R., Re-Analysis of Code Case N-499 Sa-533 Grade B, Class 1 Creep Data Preliminary Analysis, to Be Reported, 2008, unpublished work.

23. Brinkman, C. R., Transmitter, Data Package for Sa-533 Grade B, Class 1 Plates, Sa-508 Class 3 Forgings, and Their Weldments ORNL, Oak Ridge, TN, 1990, personal communication with M. G. S.-S. ASME: A.W. Dalcher (SG-ETC), SC-II), R. I. Jetter (SG-ETD, SC-D).

24. Eno, D. R., Young, G. A., and Sham, T.-L., ASME, A Unified View of Engineering Creep Parameters; PVP2008-61129.

25. Pawel, R. E., McElroy, D. L., and Graves, R. S., et al., Oak Ridge National Laboratory, The Emittance of an Oxidized 304 Stainless Steel; ORNL/TM-9858.

26. Haque, H., Feltes, W., and Brinkman, G., "Thermal Response of a High Temperature Reactor During Passive Cooldown Under Pressurized and Depressurized Conditions," September 22-24, 2004.

27. Ren, W., "Preliminary Considerations of Grade 91 Steel for Gen IV Nuclear Reactor Application," PVP2008-61004, Chicago, Il, July 27-31, 2008.

28. Hong, J. W., Kim, H. D., and Ahn, Y. S., et al. Intercritical Heat Treatment Process for Toughness Improvement of Sa 508 Gr.3 Steel. 6264770. 


\begin{tabular}{c|lll|} 
NEXT GENERATION NUCLEAR PLANT & Identifier: & PLN-2803 & \\
REACTOR PRESSURE VESSEL MATERIALS & Revision: & 0 & \\
RESEARCH AND DEVELOPMENT PLAN & Effective Date: & $04 / 30 / 08$ & Page: A-1 of A-102
\end{tabular}

\section{Appendix A}

\section{Test Matrices for Cold Vessel Option}




\begin{tabular}{c|lll|} 
NEXT GENERATION NUCLEAR PLANT & Identifier: & PLN-2803 & \\
REACTOR PRESSURE VESSEL MATERIALS & Revision: & 0 & \\
RESEARCH AND DEVELOPMENT PLAN & Effective Date: & $04 / 30 / 08$ & Page: A-2 of A-102
\end{tabular}




Idaho National Laboratory
\begin{tabular}{|c|lll|}
\hline NEXT GENERATION NUCLEAR PLANT & Identifier: & PLN-2803 & \\
REACTOR PRESSURE VESSEL MATERIALS & Revision: & 0 & \\
RESEARCH AND DEVELOPMENT PLAN & Effective Date: & $04 / 30 / 08$ & Page: A-3 of A-102 \\
\hline
\end{tabular}

\begin{tabular}{|c|c|c|c|c|c|c|c|c|c|c|}
\hline Spec. Type & Spec. \# & Material & $\begin{array}{l}\text { Product Form } \\
(\sim 250 \mathrm{~mm} \text { thick })\end{array}$ & Mat Cond. & Heat & Env & $\begin{array}{l}\text { Temp. } \\
\left({ }^{\circ} \mathrm{C}\right)\end{array}$ & $\begin{array}{c}\text { Applied } \\
\text { Stress (MPa) }\end{array}$ & $\begin{array}{c}\text { Best Est. } \\
\text { Rupture Time } \\
\text { (h) }\end{array}$ & $\begin{array}{l}\text { LB Rupture } \\
\text { Time (h) }\end{array}$ \\
\hline Creep & 1 & A508 & Forging & SSR & A508-Ht-1 & air & 350 & 552 & 1238 & 33 \\
\hline Creep & 2 & A508 & Forging & SSR & A508-Ht-1 & air & 350 & 552 & 1238 & 33 \\
\hline Creep & 3 & A508 & Forging & SSR & A508-Ht-1 & air & 350 & 517 & 4151 & 128 \\
\hline Creep & 4 & A508 & Forging & SSR & A508-Ht-1 & air & 350 & 517 & 4151 & 128 \\
\hline Creep & 5 & A508 & Forging & SSR & A508-Ht-1 & air & 350 & 483 & 15128 & 440 \\
\hline Creep & 6 & A508 & Forging & SSR & A508-Ht-1 & air & 350 & 483 & 15128 & 440 \\
\hline Creep & 7 & A508 & Forging & SSR & A508-Ht-1 & air & 371 & 517 & 1154 & 39 \\
\hline Creep & 8 & A508 & Forging & SSR & A508-Ht-1 & air & 371 & 517 & 1154 & 39 \\
\hline Creep & 9 & A508 & Forging & SSR & A508-Ht-1 & air & 371 & 483 & 3752 & 148 \\
\hline Creep & 10 & A508 & Forging & SSR & A508-Ht-1 & air & 371 & 483 & 3752 & 148 \\
\hline Creep & 11 & A508 & Forging & SSR & A508-Ht-1 & air & 371 & 448 & 13316 & 490 \\
\hline Creep & 12 & A508 & Forging & SSR & A508-Ht-1 & air & 371 & 448 & 13316 & 490 \\
\hline Creep & 13 & A508 & Forging & SSR & A508-Ht-1 & air & 390 & 483 & 1147 & 45 \\
\hline Creep & 14 & A508 & Forging & SSR & A508-Ht-1 & air & 390 & 483 & 1147 & 45 \\
\hline Creep & 15 & A508 & Forging & SSR & A508-Ht-1 & air & 390 & 448 & 3667 & 169 \\
\hline Creep & 16 & A508 & Forging & SSR & A508-Ht-1 & air & 390 & 448 & 3667 & 169 \\
\hline Creep & 17 & A508 & Forging & SSR & A508-Ht-1 & air & 390 & 414 & 12871 & 539 \\
\hline Creep & 18 & A508 & Forging & SSR & A508-Ht-1 & air & 390 & 414 & 12871 & 539 \\
\hline Creep & 19 & A508 & Forging & SSR & A508-Ht-2 & air & 350 & 552 & 1238 & 33 \\
\hline Creep & 20 & A508 & Forging & SSR & A508-Ht-2 & air & 350 & 552 & 1238 & 33 \\
\hline Creep & 21 & A508 & Forging & SSR & A508-Ht-2 & air & 350 & 517 & 4151 & 128 \\
\hline Creep & 22 & A508 & Forging & SSR & A508-Ht-2 & air & 350 & 517 & 4151 & 128 \\
\hline Creep & 23 & A508 & Forging & SSR & A508-Ht-2 & air & 350 & 483 & 15128 & 440 \\
\hline Creep & 24 & A508 & Forging & SSR & A508-Ht-2 & air & 350 & 483 & 15128 & 440 \\
\hline
\end{tabular}


Idaho National Laboratory

\begin{tabular}{c|ll} 
NEXT GENERATION NUCLEAR PLANT & Identifier: & PLN-2803 \\
REACTOR PRESSURE VESSEL MATERIALS & Revision: & 0
\end{tabular}

\begin{tabular}{l|ll} 
RESEARCH AND DEVELOPMENT PLAN & Effective Date: $04 / 30 / 08 \quad$ Page: A-4 of A-102 \\
\hline
\end{tabular}

\begin{tabular}{|c|c|c|c|c|c|c|c|c|c|c|}
\hline \multicolumn{11}{|c|}{ Table A1. A 508/533B Creep Rupture Tests in Air to Address Creep Effects on Cold Vessel } \\
\hline Spec. Type & Spec. \# & Material & $\begin{array}{c}\text { Product Form } \\
(\sim 250 \mathrm{~mm} \text { thick })\end{array}$ & Mat Cond. & Heat & Env & $\begin{array}{l}\text { Temp. } \\
\left({ }^{\circ} \mathrm{C}\right)\end{array}$ & $\begin{array}{c}\text { Applied } \\
\text { Stress (MPa) }\end{array}$ & $\begin{array}{l}\text { Best Est. } \\
\text { Rupture Time } \\
\text { (h) }\end{array}$ & $\begin{array}{c}\text { LB Rupture } \\
\text { Time (h) }\end{array}$ \\
\hline Creep & 25 & A508 & Forging & SSR & A508-Ht-2 & air & 371 & 517 & 1154 & 39 \\
\hline Creep & 26 & A508 & Forging & SSR & A508-Ht-2 & air & 371 & 517 & 1154 & 39 \\
\hline Creep & 27 & A508 & Forging & SSR & A508-Ht-2 & air & 371 & 483 & 3752 & 148 \\
\hline Creep & 28 & A508 & Forging & SSR & A508-Ht-2 & air & 371 & 483 & 3752 & 148 \\
\hline Creep & 29 & A508 & Forging & SSR & A508-Ht-2 & air & 371 & 448 & 13316 & 490 \\
\hline Creep & 30 & A508 & Forging & SSR & A508-Ht-2 & air & 371 & 448 & 13316 & 490 \\
\hline Creep & 31 & A508 & Forging & SSR & A508-Ht-2 & air & 390 & 483 & 1147 & 45 \\
\hline Creep & 32 & A508 & Forging & SSR & A508-Ht-2 & air & 390 & 483 & 1147 & 45 \\
\hline Creep & 33 & A508 & Forging & SSR & A508-Ht-2 & air & 390 & 448 & 3667 & 169 \\
\hline Creep & 34 & A508 & Forging & SSR & A508-Ht-2 & air & 390 & 448 & 3667 & 169 \\
\hline Creep & 35 & A508 & Forging & SSR & A508-Ht-2 & air & 390 & 414 & 12871 & 539 \\
\hline Creep & 36 & A508 & Forging & SSR & A508-Ht-2 & air & 390 & 414 & 12871 & 539 \\
\hline Creep & 37 & A508 & Forging & SSR & A508-Ht-3 & air & 350 & 552 & 1238 & 33 \\
\hline Creep & 38 & A508 & Forging & SSR & A508-Ht-3 & air & 350 & 552 & 1238 & 33 \\
\hline Creep & 39 & A508 & Forging & SSR & A508-Ht-3 & air & 350 & 517 & 4151 & 128 \\
\hline Creep & 40 & A508 & Forging & SSR & A508-Ht-3 & air & 350 & 517 & 4151 & 128 \\
\hline Creep & 41 & A508 & Forging & SSR & A508-Ht-3 & air & 350 & 483 & 15128 & 440 \\
\hline Creep & 42 & A508 & Forging & SSR & A508-Ht-3 & air & 350 & 483 & 15128 & 440 \\
\hline Creep & 43 & A508 & Forging & SSR & A508-Ht-3 & air & 371 & 517 & 1154 & 39 \\
\hline Creep & 44 & A508 & Forging & SSR & A508-Ht-3 & air & 371 & 517 & 1154 & 39 \\
\hline Creep & 45 & A508 & Forging & SSR & A508-Ht-3 & air & 371 & 483 & 3752 & 148 \\
\hline Creep & 46 & A508 & Forging & SSR & A508-Ht-3 & air & 371 & 483 & 3752 & 148 \\
\hline Creep & 47 & A508 & Forging & SSR & A508-Ht-3 & air & 371 & 448 & 13316 & 490 \\
\hline Creep & 48 & A508 & Forging & SSR & A508-Ht-3 & air & 371 & 448 & 13316 & 490 \\
\hline Creep & 49 & A508 & Forging & SSR & A508-Ht-3 & air & 390 & 483 & 1147 & 45 \\
\hline
\end{tabular}


Idaho National Laboratory

\begin{tabular}{c|ll} 
NEXT GENERATION NUCLEAR PLANT & Identifier: & PLN-2803 \\
REACTOR PRESSURE VESSEL MATERIALS & Revision: & 0
\end{tabular}

RESEARCH AND DEVELOPMENT PLAN $\quad$ Effective Date: $04 / 30 / 08 \quad$ Page: A-5 of A-102

\begin{tabular}{|c|c|c|c|c|c|c|c|c|c|c|}
\hline \multicolumn{11}{|c|}{ Table A1. A 508/533B Creep Rupture Tests in Air to Address Creep Effects on Cold Vessel } \\
\hline Spec. Type & Spec. \# & Material & $\begin{array}{c}\text { Product Form } \\
(\sim 250 \mathrm{~mm} \text { thick })\end{array}$ & Mat Cond. & Heat & Env & $\begin{array}{l}\text { Temp. } \\
\left({ }^{\circ} \mathrm{C}\right)\end{array}$ & $\begin{array}{c}\text { Applied } \\
\text { Stress (MPa) }\end{array}$ & $\begin{array}{l}\text { Best Est. } \\
\text { Rupture Time } \\
\text { (h) }\end{array}$ & $\begin{array}{c}\text { LB Rupture } \\
\text { Time (h) }\end{array}$ \\
\hline Creep & 50 & A508 & Forging & SSR & A508-Ht-3 & air & 390 & 483 & 1147 & 45 \\
\hline Creep & 51 & A508 & Forging & SSR & A508-Ht-3 & air & 390 & 448 & 3667 & 169 \\
\hline Creep & 52 & A508 & Forging & SSR & A508-Ht-3 & air & 390 & 448 & 3667 & 169 \\
\hline Creep & 53 & A508 & Forging & SSR & A508-Ht-3 & air & 390 & 414 & 12871 & 539 \\
\hline Creep & 54 & A508 & Forging & SSR & A508-Ht-3 & air & 390 & 414 & 12871 & 539 \\
\hline Creep & 55 & A533B & Rolled Plate & SSR & A533B-Ht-1 & air & 350 & 552 & 1238 & 33 \\
\hline Creep & 56 & A533B & Rolled Plate & SSR & A533B-Ht-1 & air & 350 & 552 & 1238 & 33 \\
\hline Creep & 57 & A533B & Rolled Plate & SSR & A533B-Ht-1 & air & 350 & 517 & 4151 & 128 \\
\hline Creep & 58 & A533B & Rolled Plate & SSR & A533B-Ht-1 & air & 350 & 517 & 4151 & 128 \\
\hline Creep & 59 & A533B & Rolled Plate & SSR & A533B-Ht-1 & air & 350 & 483 & 15128 & 440 \\
\hline Creep & 60 & A533B & Rolled Plate & SSR & A533B-Ht-1 & air & 350 & 483 & 15128 & 440 \\
\hline Creep & 61 & A533B & Rolled Plate & SSR & A533B-Ht-1 & air & 371 & 517 & 1154 & 39 \\
\hline Creep & 62 & A533B & Rolled Plate & SSR & A533B-Ht-1 & air & 371 & 517 & 1154 & 39 \\
\hline Creep & 63 & A533B & Rolled Plate & SSR & A533B-Ht-1 & air & 371 & 483 & 3752 & 148 \\
\hline Creep & 64 & A533B & Rolled Plate & SSR & A533B-Ht-1 & air & 371 & 483 & 3752 & 148 \\
\hline Creep & 65 & A533B & Rolled Plate & SSR & A533B-Ht-1 & air & 371 & 448 & 13316 & 490 \\
\hline Creep & 66 & A533B & Rolled Plate & SSR & A533B-Ht-1 & air & 371 & 448 & 13316 & 490 \\
\hline Creep & 67 & A533B & Rolled Plate & SSR & A533B-Ht-1 & air & 390 & 483 & 1147 & 45 \\
\hline Creep & 68 & A533B & Rolled Plate & SSR & A533B-Ht-1 & air & 390 & 483 & 1147 & 45 \\
\hline Creep & 69 & A533B & Rolled Plate & SSR & A533B-Ht-1 & air & 390 & 448 & 3667 & 169 \\
\hline Creep & 70 & A533B & Rolled Plate & SSR & A533B-Ht-1 & air & 390 & 448 & 3667 & 169 \\
\hline Creep & 71 & A533B & Rolled Plate & SSR & A533B-Ht-1 & air & 390 & 414 & 12871 & 539 \\
\hline Creep & 72 & A533B & Rolled Plate & SSR & A533B-Ht-1 & air & 390 & 414 & 12871 & 539 \\
\hline Creep & 73 & A533B & Rolled Plate & SSR & A533B-Ht-2 & air & 350 & 552 & 1238 & 33 \\
\hline Creep & 74 & A533B & Rolled Plate & SSR & A533B-Ht-2 & air & 350 & 552 & 1238 & 33 \\
\hline
\end{tabular}


Idaho National Laboratory

\begin{tabular}{c|ll} 
NEXT GENERATION NUCLEAR PLANT & Identifier: & PLN-2803 \\
REACTOR PRESSURE VESSEL MATERIALS & Revision: & 0
\end{tabular}

RESEARCH AND DEVELOPMENT PLAN $\quad$ Effective Date: $04 / 30 / 08 \quad$ Page: A-6 of A-102

\begin{tabular}{|c|c|c|c|c|c|c|c|c|c|c|}
\hline \multicolumn{11}{|c|}{ Table A1. A 508/533B Creep Rupture Tests in Air to Address Creep Effects on Cold Vessel } \\
\hline Spec. Type & Spec. \# & Material & $\begin{array}{c}\text { Product Form } \\
(\sim 250 \mathrm{~mm} \text { thick })\end{array}$ & Mat Cond. & Heat & Env & $\begin{array}{l}\text { Temp. } \\
\left({ }^{\circ} \mathrm{C}\right)\end{array}$ & $\begin{array}{c}\text { Applied } \\
\text { Stress (MPa) }\end{array}$ & $\begin{array}{l}\text { Best Est. } \\
\text { Rupture Time } \\
\text { (h) }\end{array}$ & $\begin{array}{c}\text { LB Rupture } \\
\text { Time (h) }\end{array}$ \\
\hline Creep & 75 & A533B & Rolled Plate & SSR & A533B-Ht-2 & air & 350 & 517 & 4151 & 128 \\
\hline Creep & 76 & A533B & Rolled Plate & SSR & A533B-Ht-2 & air & 350 & 517 & 4151 & 128 \\
\hline Creep & 77 & A533B & Rolled Plate & SSR & A533B-Ht-2 & air & 350 & 483 & 15128 & 440 \\
\hline Creep & 78 & A533B & Rolled Plate & SSR & A533B-Ht-2 & air & 350 & 483 & 15128 & 440 \\
\hline Creep & 79 & A533B & Rolled Plate & SSR & A533B-Ht-2 & air & 371 & 517 & 1154 & 39 \\
\hline Creep & 80 & A533B & Rolled Plate & SSR & A533B-Ht-2 & air & 371 & 517 & 1154 & 39 \\
\hline Creep & 81 & A533B & Rolled Plate & SSR & A533B-Ht-2 & air & 371 & 483 & 3752 & 148 \\
\hline Creep & 82 & A533B & Rolled Plate & SSR & A533B-Ht-2 & air & 371 & 483 & 3752 & 148 \\
\hline Creep & 83 & A533B & Rolled Plate & SSR & A533B-Ht-2 & air & 371 & 448 & 13316 & 490 \\
\hline Creep & 84 & A533B & Rolled Plate & SSR & A533B-Ht-2 & air & 371 & 448 & 13316 & 490 \\
\hline Creep & 85 & A533B & Rolled Plate & SSR & A533B-Ht-2 & air & 390 & 483 & 1147 & 45 \\
\hline Creep & 86 & A533B & Rolled Plate & SSR & A533B-Ht-2 & air & 390 & 483 & 1147 & 45 \\
\hline Creep & 87 & A533B & Rolled Plate & SSR & A533B-Ht-2 & air & 390 & 448 & 3667 & 169 \\
\hline Creep & 88 & A533B & Rolled Plate & SSR & A533B-Ht-2 & air & 390 & 448 & 3667 & 169 \\
\hline Creep & 89 & A533B & Rolled Plate & SSR & A533B-Ht-2 & air & 390 & 414 & 12871 & 539 \\
\hline Creep & 90 & A533B & Rolled Plate & SSR & A533B-Ht-2 & air & 390 & 414 & 12871 & 539 \\
\hline Creep & 91 & A533B & Rolled Plate & SSR & A533B-Ht-3 & air & 350 & 552 & 1238 & 33 \\
\hline Creep & 92 & A533B & Rolled Plate & SSR & A533B-Ht-3 & air & 350 & 552 & 1238 & 33 \\
\hline Creep & 93 & A533B & Rolled Plate & SSR & A533B-Ht-3 & air & 350 & 517 & 4151 & 128 \\
\hline Creep & 94 & A533B & Rolled Plate & SSR & A533B-Ht-3 & air & 350 & 517 & 4151 & 128 \\
\hline Creep & 95 & A533B & Rolled Plate & SSR & A533B-Ht-3 & air & 350 & 483 & 15128 & 440 \\
\hline Creep & 96 & A533B & Rolled Plate & SSR & A533B-Ht-3 & air & 350 & 483 & 15128 & 440 \\
\hline Creep & 97 & A533B & Rolled Plate & SSR & A533B-Ht-3 & air & 371 & 517 & 1154 & 39 \\
\hline Creep & 98 & A533B & Rolled Plate & SSR & A533B-Ht-3 & air & 371 & 517 & 1154 & 39 \\
\hline Creep & 99 & A533B & Rolled Plate & SSR & A533B-Ht-3 & air & 371 & 483 & 3752 & 148 \\
\hline
\end{tabular}


Idaho National Laboratory

\begin{tabular}{|c|lll|}
\hline NEXT GENERATION NUCLEAR PLANT & Identifier: & PLN-2803 & \\
REACTOR PRESSURE VESSEL MATERIALS & Revision: & 0 & \\
RESEARCH AND DEVELOPMENT PLAN & Effective Date: & $04 / 30 / 08$ & Page: A-7 of A-102 \\
\hline
\end{tabular}

\begin{tabular}{|c|c|c|c|c|c|c|c|c|c|c|}
\hline Spec. Type & Spec. \# & Material & $\begin{array}{c}\text { Product Form } \\
(\sim 250 \mathrm{~mm} \text { thick })\end{array}$ & Mat Cond. & Heat & Env & $\begin{array}{l}\text { Temp. } \\
\left({ }^{\circ} \mathrm{C}\right)\end{array}$ & $\begin{array}{c}\text { Applied } \\
\text { Stress (MPa) }\end{array}$ & $\begin{array}{c}\text { Best Est. } \\
\text { Rupture Time } \\
\text { (h) }\end{array}$ & $\begin{array}{l}\text { LB Rupture } \\
\text { Time (h) }\end{array}$ \\
\hline Creep & 100 & A533B & Rolled Plate & SSR & A533B-Ht-3 & air & 371 & 483 & 3752 & 148 \\
\hline Creep & 101 & A533B & Rolled Plate & SSR & A533B-Ht-3 & air & 371 & 448 & 13316 & 490 \\
\hline Creep & 102 & A533B & Rolled Plate & SSR & A533B-Ht-3 & air & 371 & 448 & 13316 & 490 \\
\hline Creep & 103 & A533B & Rolled Plate & SSR & A533B-Ht-3 & air & 390 & 483 & 1147 & 45 \\
\hline Creep & 104 & A533B & Rolled Plate & SSR & A533B-Ht-3 & air & 390 & 483 & 1147 & 45 \\
\hline Creep & 105 & A533B & Rolled Plate & SSR & A533B-Ht-3 & air & 390 & 448 & 3667 & 169 \\
\hline Creep & 106 & $\mathrm{~A} 533 \mathrm{~B}$ & Rolled Plate & SSR & A533B-Ht-3 & air & 390 & 448 & 3667 & 169 \\
\hline Creep & 107 & A533B & Rolled Plate & SSR & A533B-Ht-3 & air & 390 & 414 & 12871 & 539 \\
\hline Creep & 108 & A533B & Rolled Plate & SSR & A533B-Ht-3 & air & 390 & 414 & 12871 & 539 \\
\hline
\end{tabular}




Idaho National Laboratory
\begin{tabular}{|c|lll|}
\hline NEXT GENERATION NUCLEAR PLANT & Identifier: & PLN-2803 & \\
REACTOR PRESSURE VESSEL MATERIALS & Revision: & 0 & \\
RESEARCH AND DEVELOPMENT PLAN & Effective Date: & $04 / 30 / 08$ & Page: A-8 of A-102 \\
\hline
\end{tabular}

\begin{tabular}{|c|c|c|c|c|c|c|c|c|c|c|c|c|}
\hline $\begin{array}{l}\text { Spec. } \\
\text { Type }\end{array}$ & $\begin{array}{c}\text { Spec } \\
\# \\
\end{array}$ & $\begin{array}{c}\text { Weld } \\
\text { Con- } \\
\text { sumable }\end{array}$ & $\begin{array}{l}\text { Section } \\
\text { Thickness } \\
(\mathrm{mm})\end{array}$ & $\begin{array}{c}\text { Weld } \\
\text { Process }\end{array}$ & $\begin{array}{c}\text { Base Metal } \\
\text { Heat }\end{array}$ & $\begin{array}{c}\text { Weld to } \\
\text { be Tested }\end{array}$ & $\begin{array}{l}\text { Mat } \\
\text { Cond. }\end{array}$ & Env & $\begin{array}{l}\text { Temp. } \\
\left({ }^{\circ} \mathrm{C}\right)\end{array}$ & $\begin{array}{l}\text { Applied } \\
\text { Stress } \\
\text { (MPa) }\end{array}$ & $\begin{array}{l}\text { Best Est. } \\
\text { Rupture } \\
\text { time (h) }\end{array}$ & $\begin{array}{l}\text { LB Rupture } \\
\text { time (h) }\end{array}$ \\
\hline Creep & 1 & TBD & $\sim 250$ & SAW & A508-Ht-1 & X-Weld & SSR & air & 350 & 552 & 1238 & 33 \\
\hline Creep & 2 & TBD & $\sim 250$ & SAW & A508-Ht-1 & X-Weld & SSR & air & 350 & 552 & 1238 & 33 \\
\hline Creep & 3 & TBD & $\sim 250$ & SAW & A508-Ht-1 & X-Weld & SSR & air & 350 & 517 & 4151 & 128 \\
\hline Creep & 4 & TBD & $\sim 250$ & SAW & A508-Ht-1 & X-Weld & SSR & air & 350 & 517 & 4151 & 128 \\
\hline Creep & 5 & TBD & $\sim 250$ & SAW & A508-Ht-1 & X-Weld & SSR & air & 350 & 483 & 15128 & 440 \\
\hline Creep & 6 & TBD & $\sim 250$ & SAW & A508-Ht-1 & X-Weld & SSR & air & 350 & 483 & 15128 & 440 \\
\hline Creep & 7 & TBD & $\sim 250$ & SAW & A508-Ht-1 & X-Weld & SSR & air & 371 & 517 & 1154 & 39 \\
\hline Creep & 8 & TBD & $\sim 250$ & SAW & A508-Ht-1 & X-Weld & SSR & air & 371 & 517 & 1154 & 39 \\
\hline Creep & 9 & TBD & $\sim 250$ & SAW & A508-Ht-1 & X-Weld & SSR & air & 371 & 483 & 3752 & 148 \\
\hline Creep & 10 & TBD & $\sim 250$ & SAW & A508-Ht-1 & X-Weld & SSR & air & 371 & 483 & 3752 & 148 \\
\hline Creep & 11 & TBD & $\sim 250$ & SAW & A508-Ht-1 & X-Weld & SSR & air & 371 & 448 & 13316 & 490 \\
\hline Creep & 12 & TBD & $\sim 250$ & SAW & A508-Ht-1 & X-Weld & SSR & air & 371 & 448 & 13316 & 490 \\
\hline Creep & 13 & TBD & $\sim 250$ & SAW & A508-Ht-1 & X-Weld & SSR & air & 390 & 483 & 1147 & 45 \\
\hline Creep & 14 & TBD & $\sim 250$ & SAW & A508-Ht-1 & X-Weld & SSR & air & 390 & 483 & 1147 & 45 \\
\hline Creep & 15 & TBD & $\sim 250$ & SAW & A508-Ht-1 & X-Weld & SSR & air & 390 & 448 & 3667 & 169 \\
\hline Creep & 16 & TBD & $\sim 250$ & SAW & A508-Ht-1 & X-Weld & SSR & air & 390 & 448 & 3667 & 169 \\
\hline Creep & 17 & TBD & $\sim 250$ & SAW & A508-Ht-1 & X-Weld & SSR & air & 390 & 414 & 12871 & 539 \\
\hline Creep & 18 & TBD & $\sim 250$ & SAW & A508-Ht-1 & X-Weld & SSR & air & 390 & 414 & 12871 & 539 \\
\hline Creep & 19 & TBD & $\sim 50$ & SMAW & A508-Ht-1 & X-Weld & SSR & air & 350 & 552 & 1238 & 33 \\
\hline Creep & 20 & TBD & $\sim 50$ & SMAW & A508-Ht-1 & X-Weld & SSR & air & 350 & 552 & 1238 & 33 \\
\hline Creep & 21 & TBD & $\sim 50$ & SMAW & A508-Ht-1 & X-Weld & SSR & air & 350 & 517 & 4151 & 128 \\
\hline Creep & 22 & TBD & $\sim 50$ & SMAW & A508-Ht-1 & X-Weld & SSR & air & 350 & 517 & 4151 & 128 \\
\hline Creep & 23 & TBD & $\sim 50$ & SMAW & A508-Ht-1 & X-Weld & SSR & air & 350 & 483 & 15128 & 440 \\
\hline Creep & 24 & TBD & $\sim 50$ & SMAW & A508-Ht-1 & X-Weld & SSR & air & 350 & 483 & 15128 & 440 \\
\hline Creep & 25 & TBD & $\sim 50$ & SMAW & A508-Ht-1 & X-Weld & SSR & air & 371 & 517 & 1154 & 39 \\
\hline
\end{tabular}




Idaho National Laboratory
\begin{tabular}{|c|lll|}
\hline NEXT GENERATION NUCLEAR PLANT & Identifier: & PLN-2803 & \\
REACTOR PRESSURE VESSEL MATERIALS & Revision: & 0 & \\
RESEARCH AND DEVELOPMENT PLAN & Effective Date: & $04 / 30 / 08$ & Page: A-9 of A-102 \\
\hline
\end{tabular}

\begin{tabular}{|c|c|c|c|c|c|c|c|c|c|c|c|c|}
\hline \multicolumn{13}{|c|}{ Table A2. SAW and SMAW Cross-Weld Creep Rupture Tests in Air to Address Creep Effects on Cold Vessel } \\
\hline $\begin{array}{l}\text { Spec. } \\
\text { Type }\end{array}$ & $\begin{array}{c}\text { Spec } \\
\# \\
\end{array}$ & $\begin{array}{c}\text { Weld } \\
\text { Con- } \\
\text { sumable } \\
\end{array}$ & $\begin{array}{l}\text { Section } \\
\text { Thickness } \\
(\mathrm{mm})\end{array}$ & $\begin{array}{c}\text { Weld } \\
\text { Process }\end{array}$ & $\begin{array}{c}\text { Base Metal } \\
\text { Heat }\end{array}$ & $\begin{array}{c}\text { Weld to } \\
\text { be Tested }\end{array}$ & $\begin{array}{l}\text { Mat } \\
\text { Cond. }\end{array}$ & Env & $\begin{array}{l}\text { Temp. } \\
\left({ }^{\circ} \mathrm{C}\right)\end{array}$ & $\begin{array}{l}\text { Applied } \\
\text { Stress } \\
(\mathrm{MPa})\end{array}$ & $\begin{array}{l}\text { Best Est. } \\
\text { Rupture } \\
\text { time (h) }\end{array}$ & $\begin{array}{l}\text { LB Rupture } \\
\text { time (h) }\end{array}$ \\
\hline Creep & 26 & TBD & $\sim 50$ & SMAW & A508-Ht-1 & X-Weld & SSR & air & 371 & 517 & 1154 & 39 \\
\hline Creep & 27 & TBD & $\sim 50$ & SMAW & A508-Ht-1 & X-Weld & SSR & air & 371 & 483 & 3752 & 148 \\
\hline Creep & 28 & TBD & $\sim 50$ & SMAW & A508-Ht-1 & X-Weld & SSR & air & 371 & 483 & 3752 & 148 \\
\hline Creep & 29 & TBD & $\sim 50$ & SMAW & A508-Ht-1 & X-Weld & SSR & air & 371 & 448 & 13316 & 490 \\
\hline Creep & 30 & TBD & $\sim 50$ & SMAW & A508-Ht-1 & X-Weld & SSR & air & 371 & 448 & 13316 & 490 \\
\hline Creep & 31 & TBD & $\sim 50$ & SMAW & A508-Ht-1 & X-Weld & SSR & air & 390 & 483 & 1147 & 45 \\
\hline Creep & 32 & TBD & $\sim 50$ & SMAW & A508-Ht-1 & X-Weld & SSR & air & 390 & 483 & 1147 & 45 \\
\hline Creep & 33 & TBD & $\sim 50$ & SMAW & A508-Ht-1 & X-Weld & SSR & air & 390 & 448 & 3667 & 169 \\
\hline Creep & 34 & TBD & $\sim 50$ & SMAW & A508-Ht-1 & X-Weld & SSR & air & 390 & 448 & 3667 & 169 \\
\hline Creep & 35 & TBD & $\sim 50$ & SMAW & A508-Ht-1 & X-Weld & SSR & air & 390 & 414 & 12871 & 539 \\
\hline Creep & 36 & TBD & $\sim 50$ & SMAW & A508-Ht-1 & X-Weld & SSR & air & 390 & 414 & 12871 & 539 \\
\hline Creep & 37 & TBD & $\sim 250$ & SAW & A533B-Ht-1 & X-Weld & SSR & air & 350 & 552 & 1238 & 33 \\
\hline Creep & 38 & TBD & $\sim 250$ & SAW & A533B-Ht-1 & X-Weld & SSR & air & 350 & 552 & 1238 & 33 \\
\hline Creep & 39 & TBD & $\sim 250$ & SAW & A533B-Ht-1 & X-Weld & SSR & air & 350 & 517 & 4151 & 128 \\
\hline Creep & 40 & TBD & $\sim 250$ & SAW & A533B-Ht-1 & X-Weld & SSR & air & 350 & 517 & 4151 & 128 \\
\hline Creep & 41 & TBD & $\sim 250$ & SAW & A533B-Ht-1 & X-Weld & SSR & air & 350 & 483 & 15128 & 440 \\
\hline Creep & 42 & TBD & $\sim 250$ & SAW & A533B-Ht-1 & X-Weld & SSR & air & 350 & 483 & 15128 & 440 \\
\hline Creep & 43 & TBD & $\sim 250$ & SAW & A533B-Ht-1 & X-Weld & SSR & air & 371 & 517 & 1154 & 39 \\
\hline Creep & 44 & TBD & $\sim 250$ & SAW & A533B-Ht-1 & X-Weld & SSR & air & 371 & 517 & 1154 & 39 \\
\hline Creep & 45 & TBD & $\sim 250$ & SAW & A533B-Ht-1 & X-Weld & SSR & air & 371 & 483 & 3752 & 148 \\
\hline Creep & 46 & TBD & $\sim 250$ & SAW & A533B-Ht-1 & X-Weld & SSR & air & 371 & 483 & 3752 & 148 \\
\hline Creep & 47 & TBD & $\sim 250$ & SAW & A533B-Ht-1 & X-Weld & SSR & air & 371 & 448 & 13316 & 490 \\
\hline Creep & 48 & TBD & $\sim 250$ & SAW & A533B-Ht-1 & X-Weld & SSR & air & 371 & 448 & 13316 & 490 \\
\hline Creep & 49 & TBD & $\sim 250$ & SAW & A533B-Ht-1 & X-Weld & SSR & air & 390 & 483 & 1147 & 45 \\
\hline Creep & 50 & TBD & $\sim 250$ & SAW & A533B-Ht-1 & X-Weld & SSR & air & 390 & 483 & 1147 & 45 \\
\hline
\end{tabular}




Idaho National Laboratory
\begin{tabular}{|c|lll|}
\hline NEXT GENERATION NUCLEAR PLANT & Identifier: & PLN-2803 & \\
REACTOR PRESSURE VESSEL MATERIALS & Revision: & 0 & \\
RESEARCH AND DEVELOPMENT PLAN & Effective Date: & $04 / 30 / 08$ & Page: A-10 of A-102 \\
\hline
\end{tabular}

\begin{tabular}{|c|c|c|c|c|c|c|c|c|c|c|c|c|}
\hline $\begin{array}{l}\text { Spec. } \\
\text { Type }\end{array}$ & $\begin{array}{c}\text { Spec } \\
\#\end{array}$ & $\begin{array}{c}\text { Weld } \\
\text { Con- } \\
\text { sumable }\end{array}$ & $\begin{array}{l}\text { Section } \\
\text { Thickness } \\
\text { (mm) }\end{array}$ & $\begin{array}{c}\text { Weld } \\
\text { Process }\end{array}$ & $\begin{array}{c}\text { Base Metal } \\
\text { Heat }\end{array}$ & $\begin{array}{l}\text { Weld to } \\
\text { be Tested }\end{array}$ & $\begin{array}{l}\text { Mat } \\
\text { Cond. }\end{array}$ & Env & $\begin{array}{l}\text { Temp. } \\
\left({ }^{\circ} \mathrm{C}\right)\end{array}$ & $\begin{array}{l}\text { Applied } \\
\text { Stress } \\
(\mathrm{MPa})\end{array}$ & $\begin{array}{l}\text { Best Est. } \\
\text { Rupture } \\
\text { time (h) }\end{array}$ & $\begin{array}{l}\text { LB Rupture } \\
\text { time (h) }\end{array}$ \\
\hline Creep & 51 & TBD & $\sim 250$ & SAW & A533B-Ht-1 & X-Weld & SSR & air & 390 & 448 & 3667 & 169 \\
\hline Creep & 52 & TBD & $\sim 250$ & SAW & A533B-Ht-1 & X-Weld & SSR & air & 390 & 448 & 3667 & 169 \\
\hline Creep & 53 & TBD & $\sim 250$ & SAW & A533B-Ht-1 & X-Weld & SSR & air & 390 & 414 & 12871 & 539 \\
\hline Creep & 54 & TBD & $\sim 250$ & SAW & A533B-Ht-1 & X-Weld & SSR & air & 390 & 414 & 12871 & 539 \\
\hline Creep & 55 & TBD & $\sim 50$ & SMAW & A533B-Ht-1 & X-Weld & SSR & air & 350 & 552 & 1238 & 33 \\
\hline Creep & 56 & TBD & $\sim 50$ & SMAW & A533B-Ht-1 & X-Weld & SSR & air & 350 & 552 & 1238 & 33 \\
\hline Creep & 57 & TBD & $\sim 50$ & SMAW & A533B-Ht-1 & X-Weld & SSR & air & 350 & 517 & 4151 & 128 \\
\hline Creep & 58 & TBD & $\sim 50$ & SMAW & A533B-Ht-1 & X-Weld & SSR & air & 350 & 517 & 4151 & 128 \\
\hline Creep & 59 & TBD & $\sim 50$ & SMAW & A533B-Ht-1 & X-Weld & SSR & air & 350 & 483 & 15128 & 440 \\
\hline Creep & 60 & TBD & $\sim 50$ & SMAW & A533B-Ht-1 & X-Weld & SSR & air & 350 & 483 & 15128 & 440 \\
\hline Creep & 61 & TBD & $\sim 50$ & SMAW & A533B-Ht-1 & X-Weld & SSR & air & 371 & 517 & 1154 & 39 \\
\hline Creep & 62 & TBD & $\sim 50$ & SMAW & A533B-Ht-1 & X-Weld & SSR & air & 371 & 517 & 1154 & 39 \\
\hline Creep & 63 & TBD & $\sim 50$ & SMAW & A533B-Ht-1 & X-Weld & SSR & air & 371 & 483 & 3752 & 148 \\
\hline Creep & 64 & TBD & $\sim 50$ & SMAW & A533B-Ht-1 & X-Weld & SSR & air & 371 & 483 & 3752 & 148 \\
\hline Creep & 65 & TBD & $\sim 50$ & SMAW & A533B-Ht-1 & X-Weld & SSR & air & 371 & 448 & 13316 & 490 \\
\hline Creep & 66 & TBD & $\sim 50$ & SMAW & A533B-Ht-1 & X-Weld & SSR & air & 371 & 448 & 13316 & 490 \\
\hline Creep & 67 & TBD & $\sim 50$ & SMAW & A533B-Ht-1 & X-Weld & SSR & air & 390 & 483 & 1147 & 45 \\
\hline Creep & 68 & TBD & $\sim 50$ & SMAW & A533B-Ht-1 & X-Weld & SSR & air & 390 & 483 & 1147 & 45 \\
\hline Creep & 69 & TBD & $\sim 50$ & SMAW & A533B-Ht-1 & X-Weld & SSR & air & 390 & 448 & 3667 & 169 \\
\hline Creep & 70 & TBD & $\sim 50$ & SMAW & A533B-Ht-1 & X-Weld & SSR & air & 390 & 448 & 3667 & 169 \\
\hline Creep & 71 & TBD & $\sim 50$ & SMAW & A533B-Ht-1 & X-Weld & SSR & air & 390 & 414 & 12871 & 539 \\
\hline Creep & 72 & TBD & $\sim 50$ & SMAW & A533B-Ht-1 & X-Weld & SSR & air & 390 & 414 & 12871 & 539 \\
\hline
\end{tabular}




Idaho National Laboratory
\begin{tabular}{|c|lll|}
\hline NEXT GENERATION NUCLEAR PLANT & Identifier: & PLN-2803 & \\
REACTOR PRESSURE VESSEL MATERIALS & Revision: & 0 & \\
RESEARCH AND DEVELOPMENT PLAN & Effective Date: & $04 / 30 / 08$ & Page: A-11 of A-102 \\
\hline
\end{tabular}

\begin{tabular}{|c|c|c|c|c|c|c|c|c|c|c|}
\hline Spec. Type & Spec \# & Mat & $\begin{array}{l}\text { Product Form } \\
(\sim 250 \mathrm{~mm} \text { thick })\end{array}$ & Mat Cond. & Heat \# & Env & $\begin{array}{l}\text { Temp. } \\
\left({ }^{\circ} \mathrm{C}\right)\end{array}$ & $\begin{array}{l}\text { Applied } \\
\text { Stress } \\
\text { (MPa) }\end{array}$ & $\begin{array}{l}\text { Best Est. } \\
\text { Rupture time } \\
\text { (h) }\end{array}$ & $\begin{array}{c}\text { LB Rupture } \\
\text { time (h) }\end{array}$ \\
\hline Creep & 1 & A508 & Forging & SSR & A508-Ht-1 & NGNP He & 350 & 483 & 15128 & 440 \\
\hline Creep & 2 & A508 & Forging & SSR & A508-Ht-1 & NGNP He & 350 & 483 & 15128 & 440 \\
\hline Creep & 3 & A508 & Forging & SSR & A508-Ht-1 & NGNP He & 371 & 448 & 13316 & 490 \\
\hline Creep & 4 & A508 & Forging & SSR & A508-Ht-1 & NGNP He & 371 & 448 & 13316 & 490 \\
\hline Creep & 5 & A508 & Forging & SSR & A508-Ht-1 & NGNP He & 390 & 414 & 12871 & 539 \\
\hline Creep & 6 & A508 & Forging & SSR & A508-Ht-1 & NGNP He & 390 & 414 & 12871 & 539 \\
\hline Creep & 7 & A533B & Rolled Plate & SSR & A533B-Ht-1 & NGNP He & 350 & 483 & 15128 & 440 \\
\hline Creep & 8 & A533B & Rolled Plate & SSR & A533B-Ht-1 & NGNP He & 350 & 483 & 15128 & 440 \\
\hline Creep & 9 & A533B & Rolled Plate & SSR & A533B-Ht-1 & NGNP He & 371 & 448 & 13316 & 490 \\
\hline Creep & 10 & A533B & Rolled Plate & SSR & A533B-Ht-1 & NGNP He & 371 & 448 & 13316 & 490 \\
\hline Creep & 11 & A533B & Rolled Plate & SSR & A533B-Ht-1 & NGNP He & 390 & 414 & 12871 & 539 \\
\hline Creep & 12 & A533B & Rolled Plate & SSR & A533B-Ht-1 & NGNP He & 390 & 414 & 12871 & 539 \\
\hline
\end{tabular}




Idaho National Laboratory
\begin{tabular}{|c|lll|}
\hline NEXT GENERATION NUCLEAR PLANT & Identifier: & PLN-2803 & \\
REACTOR PRESSURE VESSEL MATERIALS & Revision: & 0 & \\
RESEARCH AND DEVELOPMENT PLAN & Effective Date: & $04 / 30 / 08$ & Page: A-12 of A-102 \\
\hline
\end{tabular}

\begin{tabular}{|c|c|c|c|c|c|c|c|c|c|c|c|c|}
\hline $\begin{array}{l}\text { Spec. } \\
\text { Type }\end{array}$ & $\begin{array}{c}\text { Spec } \\
\#\end{array}$ & $\begin{array}{c}\text { Weld } \\
\text { Con- } \\
\text { sumable }\end{array}$ & $\begin{array}{l}\text { Section } \\
\text { Thickness } \\
(\mathrm{mm})\end{array}$ & $\begin{array}{c}\text { Weld } \\
\text { Process }\end{array}$ & $\begin{array}{c}\text { Base Metal } \\
\text { Heat }\end{array}$ & $\begin{array}{l}\text { Weld to } \\
\text { be Tested }\end{array}$ & $\begin{array}{l}\text { Mat } \\
\text { Cond. }\end{array}$ & Env & $\begin{array}{c}\text { Temp. } \\
\left({ }^{\circ} \mathrm{C}\right)\end{array}$ & $\begin{array}{l}\text { Applied } \\
\text { Stress } \\
\text { (MPa) }\end{array}$ & $\begin{array}{l}\text { Best Est. } \\
\text { Rupture } \\
\text { time (h) }\end{array}$ & $\begin{array}{c}\text { LB } \\
\text { Rupture } \\
\text { time (h) }\end{array}$ \\
\hline Creep & 1 & TBD & $\sim 250$ & SAW & A508-Ht-1 & X-Weld & SSR & NGNP He & 350 & 483 & 15128 & 440 \\
\hline Creep & 2 & TBD & $\sim 250$ & SAW & A508-Ht-1 & X-Weld & SSR & NGNP He & 350 & 483 & 15128 & 440 \\
\hline Creep & 3 & TBD & $\sim 250$ & SAW & A508-Ht-1 & X-Weld & SSR & NGNP He & 371 & 448 & 13316 & 490 \\
\hline Creep & 4 & TBD & $\sim 250$ & SAW & A508-Ht-1 & X-Weld & SSR & NGNP He & 371 & 448 & 13316 & 490 \\
\hline Creep & 5 & TBD & $\sim 250$ & SAW & A508-Ht-1 & X-Weld & SSR & NGNP He & 390 & 414 & 12871 & 539 \\
\hline Creep & 6 & TBD & $\sim 250$ & SAW & A508-Ht-1 & X-Weld & SSR & NGNP He & 390 & 414 & 12871 & 539 \\
\hline Creep & 7 & TBD & $\sim 50$ & SMAW & A508-Ht-1 & X-Weld & SSR & NGNP He & 350 & 483 & 15128 & 440 \\
\hline Creep & 8 & TBD & $\sim 50$ & SMAW & A508-Ht-1 & X-Weld & SSR & NGNP He & 350 & 483 & 15128 & 440 \\
\hline Creep & 9 & TBD & $\sim 50$ & SMAW & A508-Ht-1 & X-Weld & SSR & NGNP He & 371 & 448 & 13316 & 490 \\
\hline Creep & 10 & TBD & $\sim 50$ & SMAW & A508-Ht-1 & X-Weld & SSR & NGNP He & 371 & 448 & 13316 & 490 \\
\hline Creep & 11 & TBD & $\sim 50$ & SMAW & A508-Ht-1 & X-Weld & SSR & NGNP He & 390 & 414 & 12871 & 539 \\
\hline Creep & 12 & TBD & $\sim 50$ & SMAW & A508-Ht-1 & X-Weld & SSR & NGNP He & 390 & 414 & 12871 & 539 \\
\hline Creep & 13 & TBD & $\sim 250$ & SAW & A533B-Ht-1 & X-Weld & SSR & NGNP He & 350 & 483 & 15128 & 440 \\
\hline Creep & 14 & TBD & $\sim 250$ & SAW & A533B-Ht-1 & X-Weld & SSR & NGNP He & 350 & 483 & 15128 & 440 \\
\hline Creep & 15 & TBD & $\sim 250$ & SAW & A533B-Ht-1 & X-Weld & SSR & NGNP He & 371 & 448 & 13316 & 490 \\
\hline Creep & 16 & TBD & $\sim 250$ & SAW & A533B-Ht-1 & X-Weld & SSR & NGNP He & 371 & 448 & 13316 & 490 \\
\hline Creep & 17 & TBD & $\sim 250$ & SAW & A533B-Ht-1 & X-Weld & SSR & NGNP He & 390 & 414 & 12871 & 539 \\
\hline Creep & 18 & TBD & $\sim 250$ & SAW & A533B-Ht-1 & X-Weld & SSR & NGNP He & 390 & 414 & 12871 & 539 \\
\hline Creep & 19 & TBD & $\sim 50$ & SMAW & A533B-Ht-1 & X-Weld & SSR & NGNP He & 350 & 483 & 15128 & 440 \\
\hline Creep & 20 & TBD & $\sim 50$ & SMAW & A533B-Ht-1 & X-Weld & SSR & NGNP He & 350 & 483 & 15128 & 440 \\
\hline Creep & 21 & TBD & $\sim 50$ & SMAW & A533B-Ht-1 & X-Weld & SSR & NGNP He & 371 & 448 & 13316 & 490 \\
\hline Creep & 22 & TBD & $\sim 50$ & SMAW & A533B-Ht-1 & X-Weld & SSR & NGNP He & 371 & 448 & 13316 & 490 \\
\hline Creep & 23 & TBD & $\sim 50$ & SMAW & A533B-Ht-1 & X-Weld & SSR & NGNP He & 390 & 414 & 12871 & 539 \\
\hline Creep & 24 & TBD & $\sim 50$ & SMAW & A533B-Ht-1 & X-Weld & SSR & NGNP He & 390 & 414 & 12871 & 539 \\
\hline
\end{tabular}




Idaho National Laboratory
\begin{tabular}{|c|lll|}
\hline NEXT GENERATION NUCLEAR PLANT & Identifier: & PLN-2803 & \\
REACTOR PRESSURE VESSEL MATERIALS & Revision: & 0 & \\
RESEARCH AND DEVELOPMENT PLAN & Effective Date: & $04 / 30 / 08$ & Page: A-13 of A-102 \\
\hline
\end{tabular}

\begin{tabular}{|c|c|c|c|c|c|c|c|c|c|c|}
\hline \multicolumn{11}{|c|}{ Table A5. Creep Rupture Tests in Air on Fatigue-SRX Damaged A 508/533B Material } \\
\hline $\begin{array}{l}\text { Spec. } \\
\text { Type }\end{array}$ & Spec. \# & Mat & $\begin{array}{l}\text { Product Form } \\
(\sim 250 \mathrm{~mm} \\
\text { thick })\end{array}$ & Mat Cond. ${ }^{(1)}$ & Heat & Env & $\begin{array}{l}\text { Temp. } \\
\left({ }^{\circ} \mathrm{C}\right)\end{array}$ & $\begin{array}{c}\text { Applied } \\
\text { Stress (MPa) }\end{array}$ & $\begin{array}{c}\text { Best Est. } \\
\text { Rupture time (h) }\end{array}$ & $\begin{array}{c}\text { LB Rupture } \\
\text { time (h) }\end{array}$ \\
\hline Creep & 1 & A508 & Forging & SSR + Damaged & A508-Ht-1 & air & 350 & 483 & 15128 & 440 \\
\hline Creep & 2 & A508 & Forging & SSR + Damaged & A508-Ht-1 & air & 350 & 483 & 15128 & 440 \\
\hline Creep & 3 & A508 & Forging & SSR + Damaged & A508-Ht-1 & air & 371 & 448 & 13316 & 490 \\
\hline Creep & 4 & A508 & Forging & SSR + Damaged & A508-Ht-1 & air & 371 & 448 & 13316 & 490 \\
\hline Creep & 5 & A508 & Forging & SSR + Damaged & A508-Ht-1 & air & 390 & 414 & 12871 & 539 \\
\hline Creep & 6 & A508 & Forging & SSR + Damaged & A508-Ht-1 & air & 390 & 414 & 12871 & 539 \\
\hline Creep & 7 & A533B & Rolled Plate & SSR + Damaged & A533B-Ht-1 & air & 350 & 483 & 15128 & 440 \\
\hline Creep & 8 & $\mathrm{~A} 533 \mathrm{~B}$ & Rolled Plate & SSR + Damaged & A533B-Ht-1 & air & 350 & 483 & 15128 & 440 \\
\hline Creep & 9 & A533B & Rolled Plate & SSR + Damaged & A533B-Ht-1 & air & 371 & 448 & 13316 & 490 \\
\hline Creep & 10 & A533B & Rolled Plate & SSR + Damaged & A533B-Ht-1 & air & 371 & 448 & 13316 & 490 \\
\hline Creep & 11 & A533B & Rolled Plate & SSR + Damaged & A533B-Ht-1 & air & 390 & 414 & 12871 & 539 \\
\hline Creep & 12 & A533B & Rolled Plate & SSR + Damaged & A533B-Ht-1 & air & 390 & 414 & 12871 & 539 \\
\hline
\end{tabular}




Idaho National Laboratory
\begin{tabular}{|c|lll|}
\hline NEXT GENERATION NUCLEAR PLANT & Identifier: & PLN-2803 & \\
REACTOR PRESSURE VESSEL MATERIALS & Revision: & 0 & \\
RESEARCH AND DEVELOPMENT PLAN & Effective Date: & $04 / 30 / 08$ & Page: A-14 of A-102 \\
\hline
\end{tabular}

\begin{tabular}{|c|c|c|c|c|c|c|c|c|c|c|c|c|}
\hline \multicolumn{13}{|c|}{ Table A6. Creep Rupture Tests in Air on Fatigue-SRX Damaged SAW \& SMAW } \\
\hline $\begin{array}{l}\text { Spec. } \\
\text { Type }\end{array}$ & $\begin{array}{c}\text { Spec } \\
\#\end{array}$ & $\begin{array}{c}\text { Weld } \\
\text { Con- } \\
\text { sumable }\end{array}$ & $\begin{array}{l}\text { Section } \\
\text { Thickness } \\
(\mathrm{mm})\end{array}$ & $\begin{array}{c}\text { Weld } \\
\text { Process }\end{array}$ & $\begin{array}{c}\text { Base Metal } \\
\text { Heat }\end{array}$ & $\begin{array}{l}\text { Weld to } \\
\text { be } \\
\text { Tested }\end{array}$ & Mat Cond ${ }^{(1)}$ & Env & $\begin{array}{l}\text { Temp. } \\
\left({ }^{\circ} \mathrm{C}\right)\end{array}$ & $\begin{array}{l}\text { Applied } \\
\text { Stress } \\
\text { (MPa) }\end{array}$ & $\begin{array}{l}\text { Best Est. } \\
\text { Rupture } \\
\text { time (h) }\end{array}$ & $\begin{array}{c}\text { LB } \\
\text { Rupture } \\
\text { time (h) }\end{array}$ \\
\hline Creep & 1 & TBD & $\sim 250$ & SAW & A508-Ht-1 & X-Weld & SSR + Damaged & Air & 350 & 483 & 15128 & 440 \\
\hline Creep & 2 & TBD & $\sim 250$ & SAW & A508-Ht-1 & X-Weld & SSR + Damaged & Air & 350 & 483 & 15128 & 440 \\
\hline Creep & 3 & TBD & $\sim 250$ & SAW & A508-Ht-1 & X-Weld & SSR + Damaged & Air & 371 & 448 & 13316 & 490 \\
\hline Creep & 4 & TBD & $\sim 250$ & SAW & A508-Ht-1 & X-Weld & SSR + Damaged & Air & 371 & 448 & 13316 & 490 \\
\hline Creep & 5 & TBD & $\sim 250$ & SAW & A508-Ht-1 & X-Weld & SSR + Damaged & Air & 390 & 414 & 12871 & 539 \\
\hline Creep & 6 & TBD & $\sim 250$ & SAW & A508-Ht-1 & X-Weld & SSR + Damaged & Air & 390 & 414 & 12871 & 539 \\
\hline Creep & 7 & TBD & $\sim 50$ & SMAW & A508-Ht-1 & X-Weld & SSR + Damaged & Air & 350 & 483 & 15128 & 440 \\
\hline Creep & 8 & TBD & $\sim 50$ & SMAW & A508-Ht-1 & X-Weld & SSR + Damaged & Air & 350 & 483 & 15128 & 440 \\
\hline Creep & 9 & TBD & $\sim 50$ & SMAW & A508-Ht-1 & X-Weld & SSR + Damaged & Air & 371 & 448 & 13316 & 490 \\
\hline Creep & 10 & TBD & $\sim 50$ & SMAW & A508-Ht-1 & X-Weld & SSR + Damaged & Air & 371 & 448 & 13316 & 490 \\
\hline Creep & 11 & TBD & $\sim 50$ & SMAW & A508-Ht-1 & X-Weld & SSR + Damaged & Air & 390 & 414 & 12871 & 539 \\
\hline Creep & 12 & TBD & $\sim 50$ & SMAW & A508-Ht-1 & X-Weld & SSR + Damaged & Air & 390 & 414 & 12871 & 539 \\
\hline Creep & 13 & TBD & $\sim 250$ & SAW & A533B-Ht-1 & X-Weld & SSR + Damaged & Air & 350 & 483 & 15128 & 440 \\
\hline Creep & 14 & TBD & $\sim 250$ & SAW & A533B-Ht-1 & X-Weld & SSR + Damaged & Air & 350 & 483 & 15128 & 440 \\
\hline Creep & 15 & TBD & $\sim 250$ & SAW & A533B-Ht-1 & X-Weld & SSR + Damaged & Air & 371 & 448 & 13316 & 490 \\
\hline Creep & 16 & TBD & $\sim 250$ & SAW & A533B-Ht-1 & X-Weld & SSR + Damaged & Air & 371 & 448 & 13316 & 490 \\
\hline Creep & 17 & TBD & $\sim 250$ & SAW & A533B-Ht-1 & X-Weld & SSR + Damaged & Air & 390 & 414 & 12871 & 539 \\
\hline Creep & 18 & TBD & $\sim 250$ & SAW & A533B-Ht-1 & X-Weld & SSR + Damaged & Air & 390 & 414 & 12871 & 539 \\
\hline Creep & 19 & TBD & $\sim 50$ & SMAW & A533B-Ht-1 & X-Weld & SSR + Damaged & Air & 350 & 483 & 15128 & 440 \\
\hline Creep & 20 & TBD & $\sim 50$ & SMAW & A533B-Ht-1 & X-Weld & SSR + Damaged & Air & 350 & 483 & 15128 & 440 \\
\hline Creep & 21 & TBD & $\sim 50$ & SMAW & A533B-Ht-1 & X-Weld & SSR + Damaged & Air & 371 & 448 & 13316 & 490 \\
\hline Creep & 22 & TBD & $\sim 50$ & SMAW & A533B-Ht-1 & X-Weld & SSR + Damaged & Air & 371 & 448 & 13316 & 490 \\
\hline Creep & 23 & TBD & $\sim 50$ & SMAW & A533B-Ht-1 & X-Weld & SSR + Damaged & Air & 390 & 414 & 12871 & 539 \\
\hline Creep & 24 & TBD & $\sim 50$ & SMAW & A533B-Ht-1 & X-Weld & SSR + Damaged & Air & 390 & 414 & 12871 & 539 \\
\hline
\end{tabular}




Idaho National Laboratory
\begin{tabular}{|c|lll|}
\hline NEXT GENERATION NUCLEAR PLANT & Identifier: & PLN-2803 & \\
REACTOR PRESSURE VESSEL MATERIALS & Revision: & 0 & \\
RESEARCH AND DEVELOPMENT PLAN & Effective Date: & $04 / 30 / 08$ & Page: A-15 of A-102 \\
\hline
\end{tabular}

\begin{tabular}{|c|c|c|c|c|c|c|c|c|c|c|c|}
\hline Test Prgm & $\begin{array}{l}\text { Spec. } \\
\text { Type }\end{array}$ & Spec \# & Mat & $\begin{array}{l}\text { Product Form } \\
(\sim 250 \mathrm{~mm} \\
\text { thick })\end{array}$ & Mat Cond. & Heat & Env & $\begin{array}{l}\text { Temp, } \\
\left({ }^{\circ} \mathrm{C}\right)\end{array}$ & $\begin{array}{c}\text { Applied } \\
\text { Stress (MPa) }\end{array}$ & $\begin{array}{l}\text { Best Est. } \\
\text { Rupture time } \\
\text { (h) }\end{array}$ & Remark \\
\hline Creep-QUAL & Creep & 1 & A508 & Forging & SSR & A508-Ht-1 & air & 350 & 456 & 43844 & Note (1) \\
\hline Creep-QUAL & Creep & 2 & A508 & Forging & SSR & A508-Ht-1 & air & 350 & 456 & 43844 & Note (1) \\
\hline Creep-QUAL & Creep & 3 & A508 & Forging & SSR & A508-Ht-1 & air & 350 & 423 & 179253 & Note (2) \\
\hline Creep-QUAL & Creep & 4 & A508 & Forging & SSR & A508-Ht-1 & air & 350 & 423 & 179253 & Note (2) \\
\hline Creep-QUAL & Creep & 5 & A533B & Rolled Plate & SSR & A533B-Ht-1 & air & 350 & 456 & 43844 & Note (1) \\
\hline Creep-QUAL & Creep & 6 & A533B & Rolled Plate & SSR & A533B-Ht-1 & air & 350 & 456 & 43844 & Note (1) \\
\hline Creep-QUAL & Creep & 7 & A533B & Rolled Plate & SSR & A533B-Ht-1 & air & 350 & 423 & 179253 & Note (2) \\
\hline Creep-QUAL & Creep & 8 & A533B & Rolled Plate & SSR & A533B-Ht-1 & air & 350 & 423 & 179253 & Note (2) \\
\hline
\end{tabular}




Idaho National Laboratory
\begin{tabular}{|c|lll|}
\hline NEXT GENERATION NUCLEAR PLANT & Identifier: & PLN-2803 & \\
REACTOR PRESSURE VESSEL MATERIALS & Revision: & 0 & \\
RESEARCH AND DEVELOPMENT PLAN & Effective Date: & $04 / 30 / 08$ & Page: A-16 of A-102 \\
\hline
\end{tabular}

\begin{tabular}{|c|c|c|c|c|c|c|c|c|c|c|c|c|c|}
\hline Creep-QUAL & Creep & 1 & TBD & $\sim 250$ & SAW & A508-Ht-1 & X-Weld & SSR & air & 350 & 456 & 43844 & Note (1) \\
\hline Creep-QUAL & Creep & 2 & TBD & $\sim 250$ & SAW & A508-Ht-1 & X-Weld & SSR & air & 350 & 456 & 43844 & Note (1) \\
\hline Creep-QUAL & Creep & 5 & TBD & $\sim 50$ & SMAW & A508-Ht-1 & X-Weld & SSR & air & 350 & 456 & 43844 & Note (1) \\
\hline Creep-QUAL & Creep & 6 & TBD & $\sim 50$ & SMAW & A508-Ht-1 & X-Weld & SSR & air & 350 & 456 & 43844 & Note (1) \\
\hline Creep-QUAL & Creep & 7 & TBD & $\sim 50$ & SMAW & A508-Ht-1 & X-Weld & SSR & air & 350 & 423 & 179253 & Note (2) \\
\hline Creep-QUAL & Creep & 8 & TBD & $\sim 50$ & SMAW & A508-Ht-1 & X-Weld & SSR & air & 350 & 423 & 179253 & Note (2) \\
\hline Creep-QUAL & Creep & 9 & TBD & $\sim 250$ & SAW & A533B-Ht-1 & X-Weld & SSR & air & 350 & 456 & 43844 & Note (1) \\
\hline Creep-QUAL & Creep & 14 & TBD & $\sim 50$ & SMAW & A533B-Ht-1 & X-Weld & SSR & air & 350 & 456 & 43844 & Note (1) \\
\hline Creep-QUAL & Creep & 15 & TBD & $\sim 50$ & SMAW & A533B-Ht-1 & X-Weld & SSR & air & 350 & 423 & 179253 & Note (2) \\
\hline Creep-QUAL & Creep & 16 & TBD & $\sim 50$ & SMAW & A533B-Ht-1 & X-Weld & SSR & air & 350 & 423 & 179253 & Note (2) \\
\hline
\end{tabular}




Idaho National Laboratory
\begin{tabular}{|c|lll|}
\hline NEXT GENERATION NUCLEAR PLANT & Identifier: & PLN-2803 & \\
REACTOR PRESSURE VESSEL MATERIALS & Revision: & 0 & \\
RESEARCH AND DEVELOPMENT PLAN & Effective Date: & $04 / 30 / 08$ & Page: A-17 of A-102 \\
\hline
\end{tabular}

\begin{tabular}{|c|c|c|c|c|c|c|c|c|c|c|}
\hline \multicolumn{11}{|c|}{ Table A9. A 508/533B Relaxation Strength in Air to Address Creep Effects on Cold Vessel } \\
\hline Spec. \# & Test Type & Mat & Product Form & Mat Cond & Heat & $\begin{array}{c}\text { Loading Stress } \\
\text { Rate }(\mathrm{MPa} / \mathrm{s})\end{array}$ & Env & $\begin{array}{l}\text { Temp. } \\
\left({ }^{\circ} \mathrm{C}\right)\end{array}$ & $\begin{array}{l}\text { Initial } \\
\text { Stress } \\
\text { (MPa) }\end{array}$ & $\begin{array}{c}\text { Relaxation } \\
\text { Time (h) }\end{array}$ \\
\hline 1 & SRX & A508 & Forging (thick) & SSR & A508-Ht-1 & 0.5 & air & 350 & 276 & 12000 \\
\hline 2 & SRX & A508 & Forging (thick) & SSR & A508-Ht-1 & 0.5 & air & 350 & 276 & 12000 \\
\hline 3 & SRX & A508 & Forging (thick) & SSR & A508-Ht-1 & 0.5 & air & 350 & 414 & 12000 \\
\hline 4 & SRX & A508 & Forging (thick) & SSR & A508-Ht-1 & 0.5 & air & 350 & 414 & 12000 \\
\hline 5 & SRX & A508 & Forging (thick) & SSR & A508-Ht-1 & 0.5 & air & 371 & 276 & 12000 \\
\hline 6 & SRX & A508 & Forging (thick) & SSR & A508-Ht-1 & 0.5 & air & 371 & 276 & 12000 \\
\hline 7 & SRX & A508 & Forging (thick) & SSR & A508-Ht-1 & 0.5 & air & 371 & 414 & 12000 \\
\hline 8 & SRX & A508 & Forging (thick) & SSR & A508-Ht-1 & 0.5 & air & 371 & 414 & 12000 \\
\hline 9 & SRX & A508 & Forging (thick) & SSR & A508-Ht-1 & 0.5 & air & 427 & 276 & 4000 \\
\hline 10 & SRX & A508 & Forging (thick) & SSR & A508-Ht-1 & 0.5 & air & 427 & 276 & 4000 \\
\hline 11 & SRX & A508 & Forging (thick) & SSR & A508-Ht-1 & 0.5 & air & 427 & 414 & 4000 \\
\hline 12 & SRX & A508 & Forging (thick) & SSR & A508-Ht-1 & 0.5 & air & 427 & 414 & 4000 \\
\hline 13 & SRX & A508 & Forging (thick) & SSR & A508-Ht-1 & 0.5 & air & 538 & 214 & 2000 \\
\hline 14 & SRX & A508 & Forging (thick) & SSR & A508-Ht-1 & 0.5 & air & 538 & 214 & 2000 \\
\hline 15 & SRX & A508 & Forging (thick) & SSR & A508-Ht-1 & 0.5 & air & 538 & 320 & 2000 \\
\hline 16 & SRX & A508 & Forging (thick) & SSR & A508-Ht-1 & 0.5 & air & 538 & 320 & 2000 \\
\hline 17 & SRX & A508 & Forging (thick) & SSR & A508-Ht-2 & 0.5 & air & 350 & 276 & 12000 \\
\hline 18 & SRX & A508 & Forging (thick) & SSR & A508-Ht-2 & 0.5 & air & 350 & 276 & 12000 \\
\hline 19 & SRX & A508 & Forging (thick) & SSR & A508-Ht-2 & 0.5 & air & 350 & 414 & 12000 \\
\hline 20 & SRX & A508 & Forging (thick) & SSR & A508-Ht-2 & 0.5 & air & 350 & 414 & 12000 \\
\hline 21 & SRX & A508 & Forging (thick) & SSR & A508-Ht-2 & 0.5 & air & 371 & 276 & 12000 \\
\hline 22 & SRX & A508 & Forging (thick) & SSR & A508-Ht-2 & 0.5 & air & 371 & 276 & 12000 \\
\hline 23 & SRX & A508 & Forging (thick) & SSR & A508-Ht-2 & 0.5 & air & 371 & 414 & 12000 \\
\hline 24 & SRX & A508 & Forging (thick) & SSR & A508-Ht-2 & 0.5 & air & 371 & 414 & 12000 \\
\hline
\end{tabular}


Idaho National Laboratory

NEXT GENERATION NUCLEAR PLANT $\quad$ Identifier: PLN-2803

REACTOR PRESSURE VESSEL MATERIALS Revision: 0

\begin{tabular}{l|ll} 
RESEARCH AND DEVELOPMENT PLAN & Effective Date: $04 / 30 / 08 \quad$ Page: A-18 of A-102 \\
\hline
\end{tabular}

\begin{tabular}{|c|c|c|c|c|c|c|c|c|c|c|}
\hline Spec. \# & Test Type & Mat & Product Form & Mat Cond & Heat & $\begin{array}{c}\text { Loading Stress } \\
\text { Rate }(\mathrm{MPa} / \mathrm{s})\end{array}$ & Env & $\begin{array}{l}\text { Temp. } \\
\left({ }^{\circ} \mathrm{C}\right)\end{array}$ & $\begin{array}{l}\text { Initial } \\
\text { Stress } \\
(\mathrm{MPa}) \\
\end{array}$ & $\begin{array}{c}\text { Relaxation } \\
\text { Time (h) }\end{array}$ \\
\hline 25 & SRX & A508 & Forging (thick) & SSR & A508-Ht-2 & 0.5 & air & 427 & 276 & 4000 \\
\hline 26 & SRX & A508 & Forging (thick) & SSR & A508-Ht-2 & 0.5 & air & 427 & 276 & 4000 \\
\hline 27 & SRX & A508 & Forging (thick) & SSR & A508-Ht-2 & 0.5 & air & 427 & 414 & 4000 \\
\hline 28 & SRX & A508 & Forging (thick) & SSR & A508-Ht-2 & 0.5 & air & 427 & 414 & 4000 \\
\hline 29 & SRX & A508 & Forging (thick) & SSR & A508-Ht-2 & 0.5 & air & 538 & 214 & 2000 \\
\hline 30 & SRX & A508 & Forging (thick) & SSR & A508-Ht-2 & 0.5 & air & 538 & 214 & 2000 \\
\hline 31 & SRX & A508 & Forging (thick) & SSR & A508-Ht-2 & 0.5 & air & 538 & 320 & 2000 \\
\hline 32 & SRX & A508 & Forging (thick) & SSR & A508-Ht-2 & 0.5 & air & 538 & 320 & 2000 \\
\hline 33 & SRX & A533B & Rolled Plate (thick) & SSR & A533B-Ht-1 & 0.5 & air & 350 & 276 & 12000 \\
\hline 34 & SRX & A533B & Rolled Plate (thick) & SSR & A533B-Ht-1 & 0.5 & air & 350 & 276 & 12000 \\
\hline 35 & SRX & A533B & Rolled Plate (thick) & SSR & A533B-Ht-1 & 0.5 & air & 350 & 414 & 12000 \\
\hline 36 & SRX & A533B & Rolled Plate (thick) & SSR & A533B-Ht-1 & 0.5 & air & 350 & 414 & 12000 \\
\hline 37 & SRX & A533B & Rolled Plate (thick) & $\mathrm{SSR}$ & A533B-Ht-1 & 0.5 & air & 371 & 276 & 12000 \\
\hline 38 & SRX & A533B & Rolled Plate (thick) & SSR & A533B-Ht-1 & 0.5 & air & 371 & 276 & 12000 \\
\hline 39 & SRX & A533B & Rolled Plate (thick) & SSR & A533B-Ht-1 & 0.5 & air & 371 & 414 & 12000 \\
\hline 40 & SRX & A533B & Rolled Plate (thick) & SSR & A533B-Ht-1 & 0.5 & air & 371 & 414 & 12000 \\
\hline 41 & SRX & A533B & Rolled Plate (thick) & SSR & A533B-Ht-1 & 0.5 & air & 427 & 276 & 4000 \\
\hline 42 & SRX & A533B & Rolled Plate (thick) & SSR & A533B-Ht-1 & 0.5 & air & 427 & 276 & 4000 \\
\hline 43 & SRX & A533B & Rolled Plate (thick) & SSR & A533B-Ht-1 & 0.5 & air & 427 & 414 & 4000 \\
\hline 44 & SRX & A533B & Rolled Plate (thick) & SSR & A533B-Ht-1 & 0.5 & air & 427 & 414 & 4000 \\
\hline 45 & SRX & A533B & Rolled Plate (thick) & SSR & A533B-Ht-1 & 0.5 & air & 538 & 214 & 2000 \\
\hline 46 & SRX & A533B & Rolled Plate (thick) & SSR & A533B-Ht-1 & 0.5 & air & 538 & 214 & 2000 \\
\hline 47 & SRX & A533B & Rolled Plate (thick) & SSR & A533B-Ht-1 & 0.5 & air & 538 & 320 & 2000 \\
\hline 48 & SRX & A533B & Rolled Plate (thick) & SSR & A533B-Ht-1 & 0.5 & air & 538 & 320 & 2000 \\
\hline 49 & SRX & A533B & Rolled Plate (thick) & SSR & A533B-Ht-2 & 0.5 & air & 350 & 276 & 12000 \\
\hline
\end{tabular}


Idaho National Laboratory

\begin{tabular}{c|lll|} 
NEXT GENERATION NUCLEAR PLANT & Identifier: & PLN-2803 & \\
REACTOR PRESSURE VESSEL MATERIALS & Revision: & 0 & \\
RESEARCH AND DEVELOPMENT PLAN & Effective Date: & $04 / 30 / 08$ & Page: A-19 of A-102 \\
\hline
\end{tabular}

\begin{tabular}{|c|c|c|c|c|c|c|c|c|c|c|}
\hline \multicolumn{11}{|c|}{ Table A9. A 508/533B Relaxation Strength in Air to Address Creep Effects on Cold Vessel } \\
\hline Spec. \# & Test Type & Mat & Product Form & Mat Cond & Heat & $\begin{array}{c}\text { Loading Stress } \\
\text { Rate }(\mathrm{MPa} / \mathrm{s})\end{array}$ & Env & $\begin{array}{c}\text { Temp. } \\
\left({ }^{\circ} \mathrm{C}\right)\end{array}$ & $\begin{array}{l}\text { Initial } \\
\text { Stress } \\
(\mathrm{MPa})\end{array}$ & $\begin{array}{c}\text { Relaxation } \\
\text { Time (h) }\end{array}$ \\
\hline 50 & SRX & A533B & Rolled Plate (thick) & SSR & A533B-Ht-2 & 0.5 & air & 350 & 276 & 12000 \\
\hline 51 & SRX & A533B & Rolled Plate (thick) & SSR & A533B-Ht-2 & 0.5 & air & 350 & 414 & 12000 \\
\hline 52 & SRX & A533B & Rolled Plate (thick) & SSR & A533B-Ht-2 & 0.5 & air & 350 & 414 & 12000 \\
\hline 53 & SRX & A533B & Rolled Plate (thick) & SSR & A533B-Ht-2 & 0.5 & air & 371 & 276 & 12000 \\
\hline 54 & SRX & A533B & Rolled Plate (thick) & SSR & A533B-Ht-2 & 0.5 & air & 371 & 276 & 12000 \\
\hline 55 & SRX & A533B & Rolled Plate (thick) & SSR & A533B-Ht-2 & 0.5 & air & 371 & 414 & 12000 \\
\hline 56 & SRX & A533B & Rolled Plate (thick) & SSR & A533B-Ht-2 & 0.5 & air & 371 & 414 & 12000 \\
\hline 57 & SRX & A533B & Rolled Plate (thick) & SSR & A533B-Ht-2 & 0.5 & air & 427 & 276 & 4000 \\
\hline 58 & SRX & A533B & Rolled Plate (thick) & SSR & A533B-Ht-2 & 0.5 & air & 427 & 276 & 4000 \\
\hline 59 & SRX & A533B & Rolled Plate (thick) & SSR & A533B-Ht-2 & 0.5 & air & 427 & 414 & 4000 \\
\hline 60 & SRX & A533B & Rolled Plate (thick) & SSR & A533B-Ht-2 & 0.5 & air & 427 & 414 & 4000 \\
\hline 61 & SRX & A533B & Rolled Plate (thick) & SSR & A533B-Ht-2 & 0.5 & air & 538 & 214 & 2000 \\
\hline 62 & SRX & A533B & Rolled Plate (thick) & SSR & A533B-Ht-2 & 0.5 & air & 538 & 214 & 2000 \\
\hline 63 & SRX & A533B & Rolled Plate (thick) & SSR & A533B-Ht-2 & 0.5 & air & 538 & 320 & 2000 \\
\hline 64 & SRX & A533B & Rolled Plate (thick) & SSR & A533B-Ht-2 & 0.5 & air & 538 & 320 & 2000 \\
\hline
\end{tabular}




Idaho National Laboratory
\begin{tabular}{|c|lll|}
\hline NEXT GENERATION NUCLEAR PLANT & Identifier: & PLN-2803 & \\
REACTOR PRESSURE VESSEL MATERIALS & Revision: & 0 & \\
RESEARCH AND DEVELOPMENT PLAN & Effective Date: & $04 / 30 / 08$ & Page: A-20 of A-102 \\
\hline
\end{tabular}

\begin{tabular}{|c|c|c|c|c|c|c|c|c|c|c|c|c|}
\hline Spec. \# & $\begin{array}{l}\text { Test } \\
\text { Type }\end{array}$ & $\begin{array}{c}\text { Weld } \\
\text { Con- } \\
\text { sumable }\end{array}$ & $\begin{array}{l}\text { Section } \\
\text { Thickness } \\
(\mathrm{mm})\end{array}$ & $\begin{array}{c}\text { Weld } \\
\text { Process }\end{array}$ & Base Metal Heat & $\begin{array}{c}\text { Weld to be } \\
\text { Tested }\end{array}$ & $\begin{array}{c}\text { Mat } \\
\text { Cond }\end{array}$ & $\begin{array}{c}\text { Loading } \\
\text { Stress } \\
\text { Rate } \\
(\mathrm{MPa} / \mathrm{s}) \\
\end{array}$ & Env & $\begin{array}{l}\text { Temp. } \\
\left({ }^{\circ} \mathrm{C}\right)\end{array}$ & $\begin{array}{l}\text { Initial } \\
\text { Stress } \\
\text { (MPa) }\end{array}$ & $\begin{array}{c}\text { Relaxation } \\
\text { Time (h) }\end{array}$ \\
\hline 1 & SRX & TBD & $\sim 250$ & SAW & A508-Ht-1 & X-Weld & SSR & 0.5 & air & 350 & 276 & 12000 \\
\hline 2 & SRX & TBD & $\sim 250$ & SAW & A508-Ht-1 & X-Weld & SSR & 0.5 & air & 350 & 276 & 12000 \\
\hline 3 & SRX & TBD & $\sim 250$ & SAW & A508-Ht-1 & X-Weld & SSR & 0.5 & air & 371 & 276 & 12000 \\
\hline 4 & SRX & TBD & $\sim 250$ & SAW & A508-Ht-1 & X-Weld & SSR & 0.5 & air & 371 & 276 & 12000 \\
\hline 5 & SRX & TBD & $\sim 250$ & SAW & A508-Ht-1 & X-Weld & SSR & 0.5 & air & 427 & 276 & 4000 \\
\hline 6 & SRX & TBD & $\sim 250$ & SAW & A508-Ht-1 & X-Weld & SSR & 0.5 & air & 427 & 276 & 4000 \\
\hline 7 & SRX & TBD & $\sim 250$ & SAW & A508-Ht-1 & X-Weld & SSR & 0.5 & air & 538 & 214 & 2000 \\
\hline 8 & SRX & TBD & $\sim 250$ & SAW & A508-Ht-1 & X-Weld & SSR & 0.5 & air & 538 & 214 & 2000 \\
\hline 9 & SRX & TBD & $\sim 50$ & SMAW & A508-Ht-1 & X-Weld & SSR & 0.5 & air & 350 & 276 & 12000 \\
\hline 10 & SRX & TBD & $\sim 50$ & SMAW & A508-Ht-1 & X-Weld & SSR & 0.5 & air & 350 & 276 & 12000 \\
\hline 11 & SRX & TBD & $\sim 50$ & SMAW & A508-Ht-1 & X-Weld & SSR & 0.5 & air & 371 & 276 & 12000 \\
\hline 12 & SRX & TBD & $\sim 50$ & SMAW & A508-Ht-1 & X-Weld & SSR & 0.5 & air & 371 & 276 & 12000 \\
\hline 13 & SRX & TBD & $\sim 50$ & SMAW & A508-Ht-1 & X-Weld & SSR & 0.5 & air & 427 & 276 & 4000 \\
\hline 14 & SRX & TBD & $\sim 50$ & SMAW & A508-Ht-1 & X-Weld & SSR & 0.5 & air & 427 & 276 & 4000 \\
\hline 15 & SRX & TBD & $\sim 50$ & SMAW & A508-Ht-1 & X-Weld & SSR & 0.5 & air & 538 & 214 & 2000 \\
\hline 16 & SRX & TBD & $\sim 50$ & SMAW & A508-Ht-1 & X-Weld & SSR & 0.5 & air & 538 & 214 & 2000 \\
\hline 17 & SRX & TBD & $\sim 250$ & SAW & A533B-Ht-1 & X-Weld & SSR & 0.5 & air & 350 & 276 & 12000 \\
\hline 18 & SRX & TBD & $\sim 250$ & SAW & A533B-Ht-1 & X-Weld & SSR & 0.5 & air & 350 & 276 & 12000 \\
\hline 19 & SRX & TBD & $\sim 250$ & SAW & A533B-Ht-1 & X-Weld & SSR & 0.5 & air & 371 & 276 & 12000 \\
\hline 20 & SRX & TBD & $\sim 250$ & SAW & A533B-Ht-1 & X-Weld & SSR & 0.5 & air & 371 & 276 & 12000 \\
\hline 21 & SRX & TBD & $\sim 250$ & SAW & A533B-Ht-1 & X-Weld & SSR & 0.5 & air & 427 & 276 & 4000 \\
\hline 22 & SRX & TBD & $\sim 250$ & SAW & A533B-Ht-1 & X-Weld & SSR & 0.5 & air & 427 & 276 & 4000 \\
\hline 23 & SRX & TBD & $\sim 250$ & SAW & A533B-Ht-1 & X-Weld & SSR & 0.5 & air & 538 & 214 & 2000 \\
\hline
\end{tabular}


Idaho National Laboratory

\begin{tabular}{|c|lll|}
\hline NEXT GENERATION NUCLEAR PLANT & Identifier: & PLN-2803 & \\
REACTOR PRESSURE VESSEL MATERIALS & Revision: & 0 & \\
RESEARCH AND DEVELOPMENT PLAN & Effective Date: & $04 / 30 / 08$ & Page: A-21 of A-102 \\
\hline
\end{tabular}

\begin{tabular}{|c|c|c|c|c|c|c|c|c|c|c|c|c|}
\hline \multicolumn{13}{|c|}{ Table A10. SAW and SMAW Relaxation Strength in Air to Address Creep Effects on Cold Vessel } \\
\hline Spec. \# & $\begin{array}{l}\text { Test } \\
\text { Type }\end{array}$ & $\begin{array}{c}\text { Weld } \\
\text { Con- } \\
\text { sumable }\end{array}$ & $\begin{array}{c}\text { Section } \\
\text { Thickness } \\
(\mathrm{mm})\end{array}$ & $\begin{array}{c}\text { Weld } \\
\text { Process }\end{array}$ & Base Metal Heat & $\begin{array}{c}\text { Weld to be } \\
\text { Tested }\end{array}$ & $\begin{array}{l}\text { Mat } \\
\text { Cond }\end{array}$ & $\begin{array}{l}\text { Loading } \\
\text { Stress } \\
\text { Rate } \\
(\mathrm{MPa} / \mathrm{s}) \\
\end{array}$ & Env & $\begin{array}{c}\text { Temp. } \\
\left({ }^{\circ} \mathrm{C}\right)\end{array}$ & $\begin{array}{l}\text { Initial } \\
\text { Stress } \\
(\mathrm{MPa}) \\
\end{array}$ & $\begin{array}{c}\text { Relaxation } \\
\text { Time (h) }\end{array}$ \\
\hline 24 & SRX & TBD & $\sim 250$ & SAW & A533B-Ht-1 & X-Weld & SSR & 0.5 & air & 538 & 214 & 2000 \\
\hline 25 & SRX & TBD & $\sim 50$ & SMAW & A533B-Ht-1 & X-Weld & SSR & 0.5 & air & 350 & 276 & 12000 \\
\hline 26 & SRX & TBD & $\sim 50$ & SMAW & A533B-Ht-1 & X-Weld & SSR & 0.5 & air & 350 & 276 & 12000 \\
\hline 27 & SRX & TBD & $\sim 50$ & SMAW & A533B-Ht-1 & X-Weld & SSR & 0.5 & air & 371 & 276 & 12000 \\
\hline 28 & SRX & TBD & $\sim 50$ & SMAW & A533B-Ht-1 & X-Weld & SSR & 0.5 & air & 371 & 276 & 12000 \\
\hline 29 & SRX & TBD & $\sim 50$ & SMAW & A533B-Ht-1 & X-Weld & SSR & 0.5 & air & 427 & 276 & 4000 \\
\hline 30 & SRX & TBD & $\sim 50$ & SMAW & A533B-Ht-1 & X-Weld & SSR & 0.5 & air & 427 & 276 & 4000 \\
\hline 31 & SRX & TBD & $\sim 50$ & SMAW & A533B-Ht-1 & X-Weld & SSR & 0.5 & air & 538 & 214 & 2000 \\
\hline 32 & SRX & TBD & $\sim 50$ & SMAW & A533B-Ht-1 & X-Weld & SSR & 0.5 & air & 538 & 214 & 2000 \\
\hline
\end{tabular}




Idaho National Laboratory
\begin{tabular}{|c|lll|}
\hline NEXT GENERATION NUCLEAR PLANT & Identifier: & PLN-2803 & \\
REACTOR PRESSURE VESSEL MATERIALS & Revision: & 0 & \\
RESEARCH AND DEVELOPMENT PLAN & Effective Date: & $04 / 30 / 08$ & Page: A-22 of A-102 \\
\hline
\end{tabular}

\begin{tabular}{|c|c|c|c|c|c|c|c|c|c|c|}
\hline Spec.\# & Test Type & Material & Product Form & Mat Cond ${ }^{(1)}$ & Heat & $\begin{array}{c}\text { Loading } \\
\text { Stress Rate } \\
(\mathrm{MPa} / \mathrm{s})\end{array}$ & Env & $\begin{array}{l}\text { Temp. } \\
\left({ }^{\circ} \mathrm{C}\right)\end{array}$ & $\begin{array}{l}\text { Initial } \\
\text { Stress } \\
(\mathrm{MPa}) \\
\end{array}$ & $\begin{array}{c}\text { Relaxation } \\
\text { Time (h) }\end{array}$ \\
\hline 1 & SRX & A508 & Forging (thick) & SSR + Damaged & A508-Ht-1 & 0.5 & air & 350 & 276 & 12000 \\
\hline 2 & SRX & A508 & Forging (thick) & SSR + Damaged & A508-Ht-1 & 0.5 & air & 350 & 276 & 12000 \\
\hline 3 & SRX & A508 & Forging (thick) & SSR + Damaged & A508-Ht-1 & 0.5 & air & 350 & 414 & 12000 \\
\hline 4 & SRX & A508 & Forging (thick) & SSR + Damaged & A508-Ht-1 & 0.5 & air & 350 & 414 & 12000 \\
\hline 5 & SRX & A508 & Forging (thick) & SSR + Damaged & A508-Ht-1 & 0.5 & air & 371 & 276 & 12000 \\
\hline 6 & SRX & A508 & Forging (thick) & SSR + Damaged & A508-Ht-1 & 0.5 & air & 371 & 276 & 12000 \\
\hline 7 & SRX & A508 & Forging (thick) & SSR + Damaged & A508-Ht-1 & 0.5 & air & 371 & 414 & 12000 \\
\hline 8 & SRX & A508 & Forging (thick) & SSR + Damaged & A508-Ht-1 & 0.5 & air & 371 & 414 & 12000 \\
\hline 9 & SRX & A508 & Forging (thick) & SSR + Damaged & A508-Ht-1 & 0.5 & air & 427 & 276 & 4000 \\
\hline 10 & SRX & A508 & Forging (thick) & SSR + Damaged & A508-Ht-1 & 0.5 & air & 427 & 276 & 4000 \\
\hline 11 & SRX & A508 & Forging (thick) & SSR + Damaged & A508-Ht-1 & 0.5 & air & 427 & 414 & 4000 \\
\hline 12 & SRX & A508 & Forging (thick) & SSR + Damaged & A508-Ht-1 & 0.5 & air & 427 & 414 & 4000 \\
\hline 13 & SRX & A508 & Forging (thick) & SSR + Damaged & A508-Ht-1 & 0.5 & air & 538 & 214 & 2000 \\
\hline 14 & SRX & A508 & Forging (thick) & SSR + Damaged & A508-Ht-1 & 0.5 & air & 538 & 214 & 2000 \\
\hline 15 & SRX & A508 & Forging (thick) & SSR + Damaged & A508-Ht-1 & 0.5 & air & 538 & 320 & 2000 \\
\hline 16 & SRX & A508 & Forging (thick) & SSR + Damaged & A508-Ht-1 & 0.5 & air & 538 & 320 & 2000 \\
\hline 17 & SRX & A508 & Forging (thick) & SSR + Damaged & A508-Ht-2 & 0.5 & air & 350 & 276 & 12000 \\
\hline 18 & SRX & A508 & Forging (thick) & SSR + Damaged & A508-Ht-2 & 0.5 & air & 350 & 276 & 12000 \\
\hline 19 & SRX & A508 & Forging (thick) & SSR + Damaged & A508-Ht-2 & 0.5 & air & 350 & 414 & 12000 \\
\hline 20 & SRX & A508 & Forging (thick) & SSR + Damaged & A508-Ht-2 & 0.5 & air & 350 & 414 & 12000 \\
\hline 21 & SRX & A508 & Forging (thick) & SSR + Damaged & A508-Ht-2 & 0.5 & air & 371 & 276 & 12000 \\
\hline 22 & SRX & A508 & Forging (thick) & SSR + Damaged & A508-Ht-2 & 0.5 & air & 371 & 276 & 12000 \\
\hline 23 & SRX & A508 & Forging (thick) & SSR + Damaged & A508-Ht-2 & 0.5 & air & 371 & 414 & 12000 \\
\hline 24 & SRX & A508 & Forging (thick) & SSR + Damaged & A508-Ht-2 & 0.5 & air & 371 & 414 & 12000 \\
\hline
\end{tabular}




Idaho National Laboratory
\begin{tabular}{|c|lll|}
\hline NEXT GENERATION NUCLEAR PLANT & Identifier: & PLN-2803 & \\
REACTOR PRESSURE VESSEL MATERIALS & Revision: & 0 & \\
RESEARCH AND DEVELOPMENT PLAN & Effective Date: & $04 / 30 / 08$ & Page: A-23 of A-102 \\
\hline
\end{tabular}

\begin{tabular}{|c|c|c|c|c|c|c|c|c|c|c|}
\hline Spec. \# & Test Type & Material & Product Form & Mat Cond ${ }^{(1)}$ & Heat & $\begin{array}{l}\text { Loading } \\
\text { Stress Rate } \\
(\mathrm{MPa} / \mathrm{s})\end{array}$ & Env & $\begin{array}{l}\text { Temp. } \\
\left({ }^{\circ} \mathrm{C}\right)\end{array}$ & $\begin{array}{l}\text { Initial } \\
\text { Stress } \\
\text { (MPa) }\end{array}$ & $\begin{array}{c}\text { Relaxation } \\
\text { Time (h) }\end{array}$ \\
\hline 25 & SRX & A508 & Forging (thick) & SSR + Damaged & A508-Ht-2 & 0.5 & air & 427 & 276 & 4000 \\
\hline 26 & SRX & A508 & Forging (thick) & SSR + Damaged & A508-Ht-2 & 0.5 & air & 427 & 276 & 4000 \\
\hline 27 & SRX & A508 & Forging (thick) & SSR + Damaged & A508-Ht-2 & 0.5 & air & 427 & 414 & 4000 \\
\hline 28 & SRX & A508 & Forging (thick) & SSR + Damaged & A508-Ht-2 & 0.5 & air & 427 & 414 & 4000 \\
\hline 29 & SRX & A508 & Forging (thick) & SSR + Damaged & A508-Ht-2 & 0.5 & air & 538 & 214 & 2000 \\
\hline 30 & SRX & A508 & Forging (thick) & SSR + Damaged & A508-Ht-2 & 0.5 & air & 538 & 214 & 2000 \\
\hline 31 & SRX & A508 & Forging (thick) & SSR + Damaged & A508-Ht-2 & 0.5 & air & 538 & 320 & 2000 \\
\hline 32 & SRX & A508 & Forging (thick) & SSR + Damaged & A508-Ht-2 & 0.5 & air & 538 & 320 & 2000 \\
\hline 33 & SRX & A533B & Rolled Plate (thick) & SSR + Damaged & A533B-Ht-1 & 0.5 & air & 350 & 276 & 12000 \\
\hline 34 & SRX & A533B & Rolled Plate (thick) & SSR + Damaged & A533B-Ht-1 & 0.5 & air & 350 & 276 & 12000 \\
\hline 35 & SRX & A533B & Rolled Plate (thick) & SSR + Damaged & A533B-Ht-1 & 0.5 & air & 350 & 414 & 12000 \\
\hline 36 & SRX & A533B & Rolled Plate (thick) & SSR + Damaged & A533B-Ht-1 & 0.5 & air & 350 & 414 & 12000 \\
\hline 37 & SRX & A533B & Rolled Plate (thick) & SSR + Damaged & A533B-Ht-1 & 0.5 & air & 371 & 276 & 12000 \\
\hline 38 & SRX & A533B & Rolled Plate (thick) & SSR + Damaged & A533B-Ht-1 & 0.5 & air & 371 & 276 & 12000 \\
\hline 39 & SRX & $\mathrm{A} 533 \mathrm{~B}$ & Rolled Plate (thick) & SSR + Damaged & A533B-Ht-1 & 0.5 & air & 371 & 414 & 12000 \\
\hline 40 & SRX & A533B & Rolled Plate (thick) & SSR + Damaged & A533B-Ht-1 & 0.5 & air & 371 & 414 & 12000 \\
\hline 41 & SRX & A533B & Rolled Plate (thick) & SSR + Damaged & A533B-Ht-1 & 0.5 & air & 427 & 276 & 4000 \\
\hline 42 & SRX & $\mathrm{A} 533 \mathrm{~B}$ & Rolled Plate (thick) & SSR + Damaged & A533B-Ht-1 & 0.5 & air & 427 & 276 & 4000 \\
\hline 43 & SRX & A533B & Rolled Plate (thick) & SSR + Damaged & A533B-Ht-1 & 0.5 & air & 427 & 414 & 4000 \\
\hline 44 & SRX & A533B & Rolled Plate (thick) & SSR + Damaged & A533B-Ht-1 & 0.5 & air & 427 & 414 & 4000 \\
\hline 45 & SRX & A533B & Rolled Plate (thick) & SSR + Damaged & A533B-Ht-1 & 0.5 & air & 538 & 214 & 2000 \\
\hline 46 & SRX & A533B & Rolled Plate (thick) & SSR + Damaged & A533B-Ht-1 & 0.5 & air & 538 & 214 & 2000 \\
\hline 47 & SRX & $\mathrm{A} 533 \mathrm{~B}$ & Rolled Plate (thick) & SSR + Damaged & A533B-Ht-1 & 0.5 & air & 538 & 320 & 2000 \\
\hline 48 & SRX & A533B & Rolled Plate (thick) & SSR + Damaged & A533B-Ht-1 & 0.5 & air & 538 & 320 & 2000 \\
\hline 49 & SRX & A533B & Rolled Plate (thick) & SSR + Damaged & A533B-Ht-2 & 0.5 & air & 350 & 276 & 12000 \\
\hline
\end{tabular}




Idaho National Laboratory
\begin{tabular}{|c|lll|}
\hline NEXT GENERATION NUCLEAR PLANT & Identifier: & PLN-2803 & \\
REACTOR PRESSURE VESSEL MATERIALS & Revision: & 0 & \\
RESEARCH AND DEVELOPMENT PLAN & Effective Date: & $04 / 30 / 08$ & Page: A-24 of A-102 \\
\hline
\end{tabular}

\begin{tabular}{|c|c|c|c|c|c|c|c|c|c|c|}
\hline Spec. \# & Test Type & Material & Product Form & Mat Cond ${ }^{(1)}$ & Heat & $\begin{array}{l}\text { Loading } \\
\text { Stress Rate } \\
(\mathrm{MPa} / \mathrm{s})\end{array}$ & Env & $\begin{array}{l}\text { Temp. } \\
\left({ }^{\circ} \mathrm{C}\right)\end{array}$ & $\begin{array}{l}\text { Initial } \\
\text { Stress } \\
\text { (MPa) }\end{array}$ & $\begin{array}{l}\text { Relaxation } \\
\text { Time (h) }\end{array}$ \\
\hline 50 & SRX & A533B & Rolled Plate (thick) & SSR + Damaged & A533B-Ht-2 & 0.5 & air & 350 & 276 & 12000 \\
\hline 51 & SRX & A533B & Rolled Plate (thick) & SSR + Damaged & A533B-Ht-2 & 0.5 & air & 350 & 414 & 12000 \\
\hline 52 & SRX & $\mathrm{A} 533 \mathrm{~B}$ & Rolled Plate (thick) & SSR + Damaged & A533B-Ht-2 & 0.5 & air & 350 & 414 & 12000 \\
\hline 53 & SRX & A533B & Rolled Plate (thick) & SSR + Damaged & A533B-Ht-2 & 0.5 & air & 371 & 276 & 12000 \\
\hline 54 & SRX & A533B & Rolled Plate (thick) & SSR + Damaged & A533B-Ht-2 & 0.5 & air & 371 & 276 & 12000 \\
\hline 55 & SRX & A533B & Rolled Plate (thick) & SSR + Damaged & A533B-Ht-2 & 0.5 & air & 371 & 414 & 12000 \\
\hline 56 & SRX & A533B & Rolled Plate (thick) & SSR + Damaged & A533B-Ht-2 & 0.5 & air & 371 & 414 & 12000 \\
\hline 57 & SRX & A533B & Rolled Plate (thick) & SSR + Damaged & A533B-Ht-2 & 0.5 & air & 427 & 276 & 4000 \\
\hline 58 & SRX & A533B & Rolled Plate (thick) & SSR + Damaged & A533B-Ht-2 & 0.5 & air & 427 & 276 & 4000 \\
\hline 59 & SRX & A533B & Rolled Plate (thick) & SSR + Damaged & A533B-Ht-2 & 0.5 & air & 427 & 414 & 4000 \\
\hline 60 & SRX & A533B & Rolled Plate (thick) & SSR + Damaged & A533B-Ht-2 & 0.5 & air & 427 & 414 & 4000 \\
\hline 61 & SRX & A533B & Rolled Plate (thick) & SSR + Damaged & A533B-Ht-2 & 0.5 & air & 538 & 214 & 2000 \\
\hline 62 & SRX & A533B & Rolled Plate (thick) & SSR + Damaged & A533B-Ht-2 & 0.5 & air & 538 & 214 & 2000 \\
\hline 63 & SRX & $\mathrm{A} 533 \mathrm{~B}$ & Rolled Plate (thick) & SSR + Damaged & A533B-Ht-2 & 0.5 & air & 538 & 320 & 2000 \\
\hline 64 & SRX & A533B & Rolled Plate (thick) & SSR + Damaged & A533B-Ht-2 & 0.5 & air & 538 & 320 & 2000 \\
\hline
\end{tabular}




Idaho National Laboratory
\begin{tabular}{|c|lll|}
\hline NEXT GENERATION NUCLEAR PLANT & Identifier: & PLN-2803 & \\
REACTOR PRESSURE VESSEL MATERIALS & Revision: & 0 & \\
RESEARCH AND DEVELOPMENT PLAN & Effective Date: & $04 / 30 / 08$ & Page: A-25 of A-102 \\
\hline
\end{tabular}

\begin{tabular}{|c|c|c|c|c|c|c|c|c|c|c|c|c|}
\hline Spec. \# & $\begin{array}{l}\text { Test } \\
\text { Type } \\
\end{array}$ & $\begin{array}{c}\text { Weld } \\
\text { Con- } \\
\text { sumable }\end{array}$ & $\begin{array}{c}\text { Section } \\
\text { Thickness } \\
(\mathrm{mm})\end{array}$ & $\begin{array}{c}\text { Weld } \\
\text { Process }\end{array}$ & Base Metal Heat & $\begin{array}{l}\text { Weld to } \\
\text { be } \\
\text { Tested }\end{array}$ & Mat Cond ${ }^{(1)}$ & $\begin{array}{c}\text { Loading } \\
\text { Stress } \\
\text { Rate } \\
(\mathrm{MPa} / \mathrm{s}) \\
\end{array}$ & Env & $\begin{array}{c}\text { Temp. } \\
\left({ }^{\circ} \mathrm{C}\right)\end{array}$ & $\begin{array}{l}\text { Initial } \\
\text { Stress } \\
(\mathrm{MPa}) \\
\end{array}$ & $\begin{array}{c}\text { Relaxation } \\
\text { Time (h) }\end{array}$ \\
\hline 1 & SRX & TBD & $\sim 250$ & SAW & A508-Ht-1 & X-Weld & SSR + Damaged & 0.5 & air & 350 & 276 & 12000 \\
\hline 2 & SRX & TBD & $\sim 250$ & SAW & A508-Ht-1 & X-Weld & SSR + Damaged & 0.5 & air & 350 & 276 & 12000 \\
\hline 3 & SRX & TBD & $\sim 250$ & SAW & A508-Ht-1 & X-Weld & SSR + Damaged & 0.5 & air & 371 & 276 & 12000 \\
\hline 4 & SRX & TBD & $\sim 250$ & SAW & A508-Ht-1 & X-Weld & SSR + Damaged & 0.5 & air & 371 & 276 & 12000 \\
\hline 5 & SRX & TBD & $\sim 250$ & SAW & A508-Ht-1 & X-Weld & SSR + Damaged & 0.5 & air & 427 & 276 & 4000 \\
\hline 6 & SRX & TBD & $\sim 250$ & SAW & A508-Ht-1 & X-Weld & SSR + Damaged & 0.5 & air & 427 & 276 & 4000 \\
\hline 7 & SRX & TBD & $\sim 250$ & SAW & A508-Ht-1 & X-Weld & SSR + Damaged & 0.5 & air & 538 & 214 & 2000 \\
\hline 8 & SRX & TBD & $\sim 250$ & SAW & A508-Ht-1 & X-Weld & SSR + Damaged & 0.5 & air & 538 & 214 & 2000 \\
\hline 9 & SRX & TBD & $\sim 50$ & SMAW & A508-Ht-1 & X-Weld & SSR + Damaged & 0.5 & air & 350 & 276 & 12000 \\
\hline 10 & SRX & TBD & $\sim 50$ & SMAW & A508-Ht-1 & X-Weld & SSR + Damaged & 0.5 & air & 350 & 276 & 12000 \\
\hline 11 & SRX & TBD & $\sim 50$ & SMAW & A508-Ht-1 & X-Weld & SSR + Damaged & 0.5 & air & 371 & 276 & 12000 \\
\hline 12 & SRX & TBD & $\sim 50$ & SMAW & A508-Ht-1 & X-Weld & SSR + Damaged & 0.5 & air & 371 & 276 & 12000 \\
\hline 13 & SRX & TBD & $\sim 50$ & SMAW & A508-Ht-1 & X-Weld & SSR + Damaged & 0.5 & air & 427 & 276 & 4000 \\
\hline 14 & SRX & TBD & $\sim 50$ & SMAW & A508-Ht-1 & X-Weld & SSR + Damaged & 0.5 & air & 427 & 276 & 4000 \\
\hline 15 & SRX & TBD & $\sim 50$ & SMAW & A508-Ht-1 & X-Weld & SSR + Damaged & 0.5 & air & 538 & 214 & 2000 \\
\hline 16 & SRX & TBD & $\sim 50$ & SMAW & A508-Ht-1 & X-Weld & SSR + Damaged & 0.5 & air & 538 & 214 & 2000 \\
\hline 17 & SRX & TBD & $\sim 250$ & SAW & A533B-Ht-1 & X-Weld & SSR + Damaged & 0.5 & air & 350 & 276 & 12000 \\
\hline 18 & SRX & TBD & $\sim 250$ & SAW & A533B-Ht-1 & X-Weld & SSR + Damaged & 0.5 & air & 350 & 276 & 12000 \\
\hline 19 & SRX & TBD & $\sim 250$ & SAW & A533B-Ht-1 & X-Weld & SSR + Damaged & 0.5 & air & 371 & 276 & 12000 \\
\hline 20 & SRX & TBD & $\sim 250$ & SAW & A533B-Ht-1 & X-Weld & SSR + Damaged & 0.5 & air & 371 & 276 & 12000 \\
\hline 21 & SRX & TBD & $\sim 250$ & SAW & A533B-Ht-1 & X-Weld & SSR + Damaged & 0.5 & air & 427 & 276 & 4000 \\
\hline 22 & SRX & TBD & $\sim 250$ & SAW & A533B-Ht-1 & X-Weld & SSR + Damaged & 0.5 & air & 427 & 276 & 4000 \\
\hline 23 & SRX & TBD & $\sim 250$ & SAW & A533B-Ht-1 & X-Weld & SSR + Damaged & 0.5 & air & 538 & 214 & 2000 \\
\hline
\end{tabular}




Idaho National Laboratory
\begin{tabular}{|c|lll|}
\hline NEXT GENERATION NUCLEAR PLANT & Identifier: & PLN-2803 & \\
REACTOR PRESSURE VESSEL MATERIALS & Revision: & 0 & \\
RESEARCH AND DEVELOPMENT PLAN & Effective Date: & $04 / 30 / 08$ & Page: A-26 of A-102 \\
\hline
\end{tabular}

\begin{tabular}{|c|c|c|c|c|c|c|c|c|c|c|c|c|}
\hline Spec. \# & $\begin{array}{l}\text { Test } \\
\text { Type }\end{array}$ & $\begin{array}{c}\text { Weld } \\
\text { Con- } \\
\text { sumable }\end{array}$ & $\begin{array}{l}\text { Section } \\
\text { Thickness } \\
(\mathrm{mm})\end{array}$ & $\begin{array}{c}\text { Weld } \\
\text { Process }\end{array}$ & Base Metal Heat & $\begin{array}{l}\text { Weld to } \\
\text { be } \\
\text { Tested }\end{array}$ & Mat Cond ${ }^{(1)}$ & $\begin{array}{c}\text { Loading } \\
\text { Stress } \\
\text { Rate } \\
(\mathrm{MPa} / \mathrm{s}) \\
\end{array}$ & Env & $\begin{array}{l}\text { Temp. } \\
\left({ }^{\circ} \mathrm{C}\right)\end{array}$ & $\begin{array}{l}\text { Initial } \\
\text { Stress } \\
(\mathrm{MPa}) \\
\end{array}$ & $\begin{array}{c}\text { Relaxation } \\
\text { Time (h) }\end{array}$ \\
\hline 24 & SRX & TBD & $\sim 250$ & SAW & A533B-Ht-1 & X-Weld & SSR + Damaged & 0.5 & air & 538 & 214 & 2000 \\
\hline 25 & SRX & TBD & $\sim 50$ & SMAW & A533B-Ht-1 & X-Weld & SSR + Damaged & 0.5 & air & 350 & 276 & 12000 \\
\hline 26 & SRX & TBD & $\sim 50$ & SMAW & A533B-Ht-1 & X-Weld & SSR + Damaged & 0.5 & air & 350 & 276 & 12000 \\
\hline 27 & SRX & TBD & $\sim 50$ & SMAW & A533B-Ht-1 & X-Weld & SSR + Damaged & 0.5 & air & 371 & 276 & 12000 \\
\hline 28 & SRX & TBD & $\sim 50$ & SMAW & A533B-Ht-1 & X-Weld & SSR + Damaged & 0.5 & air & 371 & 276 & 12000 \\
\hline 29 & SRX & TBD & $\sim 50$ & SMAW & A533B-Ht-1 & X-Weld & SSR + Damaged & 0.5 & air & 427 & 276 & 4000 \\
\hline 30 & SRX & TBD & $\sim 50$ & SMAW & A533B-Ht-1 & X-Weld & SSR + Damaged & 0.5 & air & 427 & 276 & 4000 \\
\hline 31 & SRX & TBD & $\sim 50$ & SMAW & A533B-Ht-1 & X-Weld & SSR + Damaged & 0.5 & air & 538 & 214 & 2000 \\
\hline 32 & SRX & TBD & $\sim 50$ & SMAW & A533B-Ht-1 & X-Weld & SSR + Damaged & 0.5 & air & 538 & 214 & 2000 \\
\hline
\end{tabular}




Idaho National Laboratory
\begin{tabular}{|c|lll|}
\hline NEXT GENERATION NUCLEAR PLANT & Identifier: & PLN-2803 & \\
REACTOR PRESSURE VESSEL MATERIALS & Revision: & 0 & \\
RESEARCH AND DEVELOPMENT PLAN & Effective Date: & $04 / 30 / 08$ & Page: A-27 of A-102 \\
\hline
\end{tabular}

\begin{tabular}{|c|c|c|c|c|c|c|c|c|c|c|c|c|}
\hline \multicolumn{13}{|c|}{ Table A13. A 508/533B Fatigue-SRX Tests in Air to Address Creep Effects on Cold Vessel } \\
\hline Spec. \# & Test Type & Mat & Product Form & $\begin{array}{c}\text { Mat } \\
\text { Cond }\end{array}$ & Heat & $\begin{array}{l}\text { Strain } \\
\text { Rate } \\
(\mathrm{m} / \mathrm{m} / \mathrm{s})\end{array}$ & Env & $\begin{array}{c}\text { Hold } \\
\text { Cntrl } \\
\text { (stress or } \\
\text { strain) } \\
\end{array}$ & $\begin{array}{c}\text { Strain } \\
\text { Hold in } \\
\mathrm{T} / \mathrm{C}\end{array}$ & $\begin{array}{c}\text { Temp. } \\
\left({ }^{\circ} \mathrm{C}\right)\end{array}$ & $\begin{array}{c}\text { Strain } \\
\text { Range } \\
(\%)\end{array}$ & $\begin{array}{l}\text { Strain } \\
\text { Hold } \\
\text { Time } \\
(\min ) \\
\end{array}$ \\
\hline 1 & Fatigue-SRX & A508 & Forging (thick) & SSR & A508-Ht-1 & $1 \mathrm{E}-03$ & air & strain & N/A & 350 & 1.0 & 0 \\
\hline 2 & Fatigue-SRX & A508 & Forging (thick) & SSR & A508-Ht-1 & $1 \mathrm{E}-03$ & air & strain & N/A & 350 & 1.0 & 0 \\
\hline 3 & Fatigue-SRX & A508 & Forging (thick) & SSR & A508-Ht-1 & $1 \mathrm{E}-03$ & air & strain & N/A & 350 & 1.0 & 0 \\
\hline 4 & Fatigue-SRX & A508 & Forging (thick) & SSR & A508-Ht-1 & $1 \mathrm{E}-03$ & air & strain & tension & 350 & 1.0 & 30 \\
\hline 5 & Fatigue-SRX & A508 & Forging (thick) & SSR & A508-Ht-1 & $1 \mathrm{E}-03$ & air & strain & tension & 350 & 1.0 & 30 \\
\hline 6 & Fatigue-SRX & A508 & Forging (thick) & SSR & A508-Ht-1 & $1 \mathrm{E}-03$ & air & strain & tension & 350 & 1.0 & 30 \\
\hline 7 & Fatigue-SRX & A508 & Forging (thick) & SSR & A508-Ht-1 & $1 \mathrm{E}-03$ & air & strain & tension & 350 & 1.0 & 150 \\
\hline 8 & Fatigue-SRX & A508 & Forging (thick) & SSR & A508-Ht-1 & $1 \mathrm{E}-03$ & air & strain & tension & 350 & 1.0 & 150 \\
\hline 9 & Fatigue-SRX & A508 & Forging (thick) & SSR & A508-Ht-1 & $1 \mathrm{E}-03$ & air & strain & tension & 350 & 1.0 & 150 \\
\hline 10 & Fatigue-SRX & A508 & Forging (thick) & SSR & A508-Ht-1 & $1 \mathrm{E}-03$ & air & strain & tension & 350 & 1.0 & 300 \\
\hline 11 & Fatigue-SRX & A508 & Forging (thick) & SSR & A508-Ht-1 & $1 \mathrm{E}-03$ & air & strain & tension & 350 & 1.0 & 300 \\
\hline 12 & Fatigue-SRX & A508 & Forging (thick) & SSR & A508-Ht-1 & $1 \mathrm{E}-03$ & air & strain & tension & 350 & 1.0 & 300 \\
\hline 13 & Fatigue-SRX & A508 & Forging (thick) & SSR & A508-Ht-1 & $1 \mathrm{E}-03$ & air & strain & comp. & 350 & 1.0 & 30 \\
\hline 14 & Fatigue-SRX & A508 & Forging (thick) & SSR & A508-Ht-1 & $1 \mathrm{E}-03$ & air & strain & comp. & 350 & 1.0 & 30 \\
\hline 15 & Fatigue-SRX & A508 & Forging (thick) & SSR & A508-Ht-1 & $1 \mathrm{E}-03$ & air & strain & comp. & 350 & 1.0 & 30 \\
\hline 16 & Fatigue-SRX & A508 & Forging (thick) & SSR & A508-Ht-1 & $1 \mathrm{E}-03$ & air & strain & comp. & 350 & 1.0 & 150 \\
\hline 17 & Fatigue-SRX & A508 & Forging (thick) & SSR & A508-Ht-1 & $1 \mathrm{E}-03$ & air & strain & comp. & 350 & 1.0 & 150 \\
\hline 18 & Fatigue-SRX & A508 & Forging (thick) & SSR & A508-Ht-1 & $1 \mathrm{E}-03$ & air & strain & comp. & 350 & 1.0 & 150 \\
\hline 19 & Fatigue-SRX & A508 & Forging (thick) & SSR & A508-Ht-1 & $1 \mathrm{E}-03$ & air & strain & comp. & 350 & 1.0 & 300 \\
\hline 20 & Fatigue-SRX & A508 & Forging (thick) & SSR & A508-Ht-1 & $1 \mathrm{E}-03$ & air & strain & comp. & 350 & 1.0 & 300 \\
\hline 21 & Fatigue-SRX & A508 & Forging (thick) & SSR & A508-Ht-1 & $1 \mathrm{E}-03$ & air & strain & comp. & 350 & 1.0 & 300 \\
\hline 22 & Fatigue-SRX & A533B & Rolled Plate (thick) & SSR & A533B-Ht-1 & $1 \mathrm{E}-03$ & air & strain & N/A & 350 & 1.0 & 0 \\
\hline 23 & Fatigue-SRX & A533B & Rolled Plate (thick) & SSR & A533B-Ht-1 & $1 \mathrm{E}-03$ & air & strain & $\mathrm{N} / \mathrm{A}$ & 350 & 1.0 & 0 \\
\hline
\end{tabular}




Idaho National Laboratory
\begin{tabular}{|c|lll|}
\hline NEXT GENERATION NUCLEAR PLANT & Identifier: & PLN-2803 & \\
REACTOR PRESSURE VESSEL MATERIALS & Revision: & 0 & \\
RESEARCH AND DEVELOPMENT PLAN & Effective Date: & $04 / 30 / 08$ & Page: A-28 of A-102 \\
\hline
\end{tabular}

\begin{tabular}{|c|c|c|c|c|c|c|c|c|c|c|c|c|}
\hline \multicolumn{13}{|c|}{ Table A13. A 508/533B Fatigue-SRX Tests in Air to Address Creep Effects on Cold Vessel } \\
\hline Spec. \# & Test Type & Mat & Product Form & $\begin{array}{c}\text { Mat } \\
\text { Cond }\end{array}$ & Heat & $\begin{array}{c}\text { Strain } \\
\text { Rate } \\
(\mathrm{m} / \mathrm{m} / \mathrm{s})\end{array}$ & Env & $\begin{array}{l}\text { Hold } \\
\text { Cntrl } \\
\text { (stress or } \\
\text { strain) }\end{array}$ & $\begin{array}{l}\text { Strain } \\
\text { Hold in } \\
\mathrm{T} / \mathrm{C}\end{array}$ & $\begin{array}{l}\text { Temp. } \\
\left({ }^{\circ} \mathrm{C}\right)\end{array}$ & $\begin{array}{c}\text { Strain } \\
\text { Range } \\
(\%)\end{array}$ & $\begin{array}{l}\text { Strain } \\
\text { Hold } \\
\text { Time } \\
(\mathrm{min}) \\
\end{array}$ \\
\hline 24 & Fatigue-SRX & A533B & Rolled Plate (thick) & SSR & A533B-Ht-1 & $1 \mathrm{E}-03$ & air & strain & N/A & 350 & 1.0 & 0 \\
\hline 25 & Fatigue-SRX & A533B & Rolled Plate (thick) & SSR & A533B-Ht-1 & $1 \mathrm{E}-03$ & air & strain & tension & 350 & 1.0 & 30 \\
\hline 26 & Fatigue-SRX & A533B & Rolled Plate (thick) & SSR & A533B-Ht-1 & $1 \mathrm{E}-03$ & air & strain & tension & 350 & 1.0 & 30 \\
\hline 27 & Fatigue-SRX & A533B & Rolled Plate (thick) & SSR & A533B-Ht-1 & $1 \mathrm{E}-03$ & air & strain & tension & 350 & 1.0 & 30 \\
\hline 28 & Fatigue-SRX & A533B & Rolled Plate (thick) & SSR & A533B-Ht-1 & $1 \mathrm{E}-03$ & air & strain & tension & 350 & 1.0 & 150 \\
\hline 29 & Fatigue-SRX & A533B & Rolled Plate (thick) & SSR & A533B-Ht-1 & $1 \mathrm{E}-03$ & air & strain & tension & 350 & 1.0 & 150 \\
\hline 30 & Fatigue-SRX & A533B & Rolled Plate (thick) & SSR & A533B-Ht-1 & $1 \mathrm{E}-03$ & air & strain & tension & 350 & 1.0 & 150 \\
\hline 31 & Fatigue-SRX & A533B & Rolled Plate (thick) & SSR & A533B-Ht-1 & $1 \mathrm{E}-03$ & air & strain & tension & 350 & 1.0 & 300 \\
\hline 32 & Fatigue-SRX & A533B & Rolled Plate (thick) & SSR & A533B-Ht-1 & $1 \mathrm{E}-03$ & air & strain & tension & 350 & 1.0 & 300 \\
\hline 33 & Fatigue-SRX & A533B & Rolled Plate (thick) & SSR & A533B-Ht-1 & $1 \mathrm{E}-03$ & air & strain & tension & 350 & 1.0 & 300 \\
\hline 34 & Fatigue-SRX & A533B & Rolled Plate (thick) & SSR & A533B-Ht-1 & $1 \mathrm{E}-03$ & air & strain & comp. & 350 & 1.0 & 30 \\
\hline 35 & Fatigue-SRX & A533B & Rolled Plate (thick) & SSR & A533B-Ht-1 & $1 \mathrm{E}-03$ & air & strain & comp. & 350 & 1.0 & 30 \\
\hline 36 & Fatigue-SRX & A533B & Rolled Plate (thick) & SSR & A533B-Ht-1 & $1 \mathrm{E}-03$ & air & strain & comp. & 350 & 1.0 & 30 \\
\hline 37 & Fatigue-SRX & A533B & Rolled Plate (thick) & SSR & A533B-Ht-1 & $1 \mathrm{E}-03$ & air & strain & comp. & 350 & 1.0 & 150 \\
\hline 38 & Fatigue-SRX & A533B & Rolled Plate (thick) & SSR & A533B-Ht-1 & $1 \mathrm{E}-03$ & air & strain & comp. & 350 & 1.0 & 150 \\
\hline 39 & Fatigue-SRX & A533B & Rolled Plate (thick) & SSR & A533B-Ht-1 & $1 \mathrm{E}-03$ & air & strain & comp. & 350 & 1.0 & 150 \\
\hline 40 & Fatigue-SRX & A533B & Rolled Plate (thick) & SSR & A533B-Ht-1 & $1 \mathrm{E}-03$ & air & strain & comp. & 350 & 1.0 & 300 \\
\hline 41 & Fatigue-SRX & A533B & Rolled Plate (thick) & SSR & A533B-Ht-1 & $1 \mathrm{E}-03$ & air & strain & comp. & 350 & 1.0 & 300 \\
\hline 42 & Fatigue-SRX & A533B & Rolled Plate (thick) & SSR & A533B-Ht-1 & $1 \mathrm{E}-03$ & air & strain & comp. & 350 & 1.0 & 300 \\
\hline
\end{tabular}




Idaho National Laboratory
\begin{tabular}{|c|lll|}
\hline NEXT GENERATION NUCLEAR PLANT & Identifier: & PLN-2803 & \\
REACTOR PRESSURE VESSEL MATERIALS & Revision: & 0 & \\
RESEARCH AND DEVELOPMENT PLAN & Effective Date: & $04 / 30 / 08$ & Page: A-29 of A-102 \\
\hline
\end{tabular}

\begin{tabular}{|c|c|c|c|c|c|c|c|c|c|c|c|c|c|c|}
\hline Spec. \# & Test Type & $\begin{array}{c}\text { Weld } \\
\text { Con- } \\
\text { sumable }\end{array}$ & $\begin{array}{l}\text { Section } \\
\text { Thickness } \\
(\mathrm{mm})\end{array}$ & $\begin{array}{c}\text { Weld } \\
\text { Process }\end{array}$ & $\begin{array}{c}\text { Base Metal } \\
\text { Heat }\end{array}$ & $\begin{array}{l}\text { Weld to } \\
\text { be } \\
\text { Tested }\end{array}$ & $\begin{array}{l}\text { Mat } \\
\text { Cond. }\end{array}$ & $\begin{array}{c}\text { Strain } \\
\text { Rate } \\
(\mathrm{m} / \mathrm{m} / \mathrm{s} \\
)\end{array}$ & Env & $\begin{array}{c}\text { Hold } \\
\text { Cntrl } \\
\text { (stress } \\
\text { or } \\
\text { strain) }\end{array}$ & $\begin{array}{c}\text { Strain } \\
\text { Hold } \\
\text { in } \mathrm{T} / \mathrm{C}\end{array}$ & $\begin{array}{l}\text { Temp. } \\
\left({ }^{\circ} \mathrm{C}\right)\end{array}$ & $\begin{array}{c}\text { Strain } \\
\text { Range } \\
(\%)\end{array}$ & $\begin{array}{l}\text { Strain } \\
\text { Hold } \\
\text { Time } \\
(\mathrm{min}) \\
\end{array}$ \\
\hline 1 & Fatigue-SRX & TBD & $\sim 250$ & SAW & A508-Ht-1 & X-Weld & SSR & $1 \mathrm{E}-03$ & air & strain & $\mathrm{N} / \mathrm{A}$ & 350 & 1.0 & 0 \\
\hline 2 & Fatigue-SRX & TBD & $\sim 250$ & SAW & A508-Ht-1 & X-Weld & SSR & $1 \mathrm{E}-03$ & air & strain & $\mathrm{N} / \mathrm{A}$ & 350 & 1.0 & 0 \\
\hline 3 & Fatigue-SRX & TBD & $\sim 250$ & SAW & A508-Ht-1 & X-Weld & SSR & $1 \mathrm{E}-03$ & air & strain & $\mathrm{N} / \mathrm{A}$ & 350 & 1.0 & 0 \\
\hline 4 & Fatigue-SRX & TBD & $\sim 250$ & SAW & A508-Ht-1 & X-Weld & SSR & $1 \mathrm{E}-03$ & air & strain & tension & 350 & 1.0 & 30 \\
\hline 5 & Fatigue-SRX & TBD & $\sim 250$ & SAW & A508-Ht-1 & X-Weld & SSR & $1 \mathrm{E}-03$ & air & strain & tension & 350 & 1.0 & 30 \\
\hline 6 & Fatigue-SRX & TBD & $\sim 250$ & SAW & A508-Ht-1 & X-Weld & SSR & $1 \mathrm{E}-03$ & air & strain & tension & 350 & 1.0 & 30 \\
\hline 7 & Fatigue-SRX & TBD & $\sim 250$ & SAW & A508-Ht-1 & X-Weld & SSR & $1 \mathrm{E}-03$ & air & strain & tension & 350 & 1.0 & 150 \\
\hline 8 & Fatigue-SRX & TBD & $\sim 250$ & SAW & A508-Ht-1 & X-Weld & SSR & $1 \mathrm{E}-03$ & air & strain & tension & 350 & 1.0 & 150 \\
\hline 9 & Fatigue-SRX & TBD & $\sim 250$ & SAW & A508-Ht-1 & X-Weld & SSR & $1 \mathrm{E}-03$ & air & strain & tension & 350 & 1.0 & 150 \\
\hline 10 & Fatigue-SRX & TBD & $\sim 250$ & SAW & A508-Ht-1 & X-Weld & SSR & $1 \mathrm{E}-03$ & air & strain & comp. & 350 & 1.0 & 30 \\
\hline 11 & Fatigue-SRX & TBD & $\sim 250$ & SAW & A508-Ht-1 & X-Weld & SSR & $1 \mathrm{E}-03$ & air & strain & comp. & 350 & 1.0 & 30 \\
\hline 12 & Fatigue-SRX & TBD & $\sim 250$ & SAW & A508-Ht-1 & X-Weld & SSR & $1 \mathrm{E}-03$ & air & strain & comp. & 350 & 1.0 & 30 \\
\hline 13 & Fatigue-SRX & TBD & $\sim 250$ & SAW & A508-Ht-1 & X-Weld & SSR & $1 \mathrm{E}-03$ & air & strain & comp. & 350 & 1.0 & 150 \\
\hline 14 & Fatigue-SRX & TBD & $\sim 250$ & SAW & A508-Ht-1 & X-Weld & SSR & $1 \mathrm{E}-03$ & air & strain & comp. & 350 & 1.0 & 150 \\
\hline 15 & Fatigue-SRX & TBD & $\sim 250$ & SAW & A508-Ht-1 & X-Weld & SSR & $1 \mathrm{E}-03$ & air & strain & comp. & 350 & 1.0 & 150 \\
\hline 16 & Fatigue-SRX & TBD & $\sim 50$ & SMAW & A508-Ht-1 & X-Weld & SSR & $1 \mathrm{E}-03$ & air & strain & N/A & 350 & 1.0 & 0 \\
\hline 17 & Fatigue-SRX & TBD & $\sim 50$ & SMAW & A508-Ht-1 & X-Weld & SSR & $1 \mathrm{E}-03$ & air & strain & $\mathrm{N} / \mathrm{A}$ & 350 & 1.0 & 0 \\
\hline 18 & Fatigue-SRX & TBD & $\sim 50$ & SMAW & A508-Ht-1 & X-Weld & SSR & $1 \mathrm{E}-03$ & air & strain & $\mathrm{N} / \mathrm{A}$ & 350 & 1.0 & 0 \\
\hline 19 & Fatigue-SRX & TBD & $\sim 50$ & SMAW & A508-Ht-1 & X-Weld & SSR & $1 \mathrm{E}-03$ & air & strain & tension & 350 & 1.0 & 30 \\
\hline 20 & Fatigue-SRX & TBD & $\sim 50$ & SMAW & A508-Ht-1 & X-Weld & SSR & $1 \mathrm{E}-03$ & air & strain & tension & 350 & 1.0 & 30 \\
\hline 21 & Fatigue-SRX & TBD & $\sim 50$ & SMAW & A508-Ht-1 & X-Weld & SSR & $1 \mathrm{E}-03$ & air & strain & tension & 350 & 1.0 & 30 \\
\hline 22 & Fatigue-SRX & TBD & $\sim 50$ & SMAW & A508-Ht-1 & X-Weld & SSR & $1 \mathrm{E}-03$ & air & strain & tension & 350 & 1.0 & 150 \\
\hline
\end{tabular}




Idaho National Laboratory
\begin{tabular}{|c|lll|}
\hline NEXT GENERATION NUCLEAR PLANT & Identifier: & PLN-2803 & \\
REACTOR PRESSURE VESSEL MATERIALS & Revision: & 0 & \\
RESEARCH AND DEVELOPMENT PLAN & Effective Date: & $04 / 30 / 08$ & Page: A-30 of A-102 \\
\hline
\end{tabular}

\begin{tabular}{|c|c|c|c|c|c|c|c|c|c|c|c|c|c|c|}
\hline Spec. \# & Test Type & $\begin{array}{c}\text { Weld } \\
\text { Con- } \\
\text { sumable }\end{array}$ & $\begin{array}{l}\text { Section } \\
\text { Thickness } \\
(\mathrm{mm})\end{array}$ & $\begin{array}{l}\text { Weld } \\
\text { Process }\end{array}$ & $\begin{array}{c}\text { Base Metal } \\
\text { Heat }\end{array}$ & $\begin{array}{l}\text { Weld to } \\
\text { be } \\
\text { Tested }\end{array}$ & $\begin{array}{l}\text { Mat } \\
\text { Cond. }\end{array}$ & $\begin{array}{c}\text { Strain } \\
\text { Rate } \\
(\mathrm{m} / \mathrm{m} / \mathrm{s} \\
)\end{array}$ & Env & $\begin{array}{l}\text { Hold } \\
\text { Cntrl } \\
\text { (stress } \\
\text { or } \\
\text { strain) }\end{array}$ & $\begin{array}{c}\text { Strain } \\
\text { Hold } \\
\text { in T/C }\end{array}$ & $\begin{array}{l}\text { Temp. } \\
\left({ }^{\circ} \mathrm{C}\right)\end{array}$ & $\begin{array}{l}\text { Strain } \\
\text { Range } \\
(\%)\end{array}$ & $\begin{array}{l}\text { Strain } \\
\text { Hold } \\
\text { Time } \\
\text { (min) }\end{array}$ \\
\hline 23 & Fatigue-SRX & TBD & $\sim 50$ & SMAW & A508-Ht-1 & X-Weld & SSR & $1 \mathrm{E}-03$ & air & strain & tension & 350 & 1.0 & 150 \\
\hline 24 & Fatigue-SRX & TBD & $\sim 50$ & SMAW & A508-Ht-1 & X-Weld & SSR & $1 \mathrm{E}-03$ & air & strain & tension & 350 & 1.0 & 150 \\
\hline 25 & Fatigue-SRX & TBD & $\sim 50$ & SMAW & A508-Ht-1 & X-Weld & SSR & $1 \mathrm{E}-03$ & air & strain & comp. & 350 & 1.0 & 30 \\
\hline 26 & Fatigue-SRX & TBD & $\sim 50$ & SMAW & A508-Ht-1 & X-Weld & SSR & $1 \mathrm{E}-03$ & air & strain & comp. & 350 & 1.0 & 30 \\
\hline 27 & Fatigue-SRX & TBD & $\sim 50$ & SMAW & A508-Ht-1 & X-Weld & SSR & $1 \mathrm{E}-03$ & air & strain & comp. & 350 & 1.0 & 30 \\
\hline 28 & Fatigue-SRX & TBD & $\sim 50$ & SMAW & A508-Ht-1 & X-Weld & SSR & $1 \mathrm{E}-03$ & air & strain & comp. & 350 & 1.0 & 150 \\
\hline 29 & Fatigue-SRX & TBD & $\sim 50$ & SMAW & A508-Ht-1 & X-Weld & SSR & $1 \mathrm{E}-03$ & air & strain & comp. & 350 & 1.0 & 150 \\
\hline 30 & Fatigue-SRX & TBD & $\sim 50$ & SMAW & A508-Ht-1 & X-Weld & SSR & $1 \mathrm{E}-03$ & air & strain & comp. & 350 & 1.0 & 150 \\
\hline 31 & Fatigue-SRX & TBD & $\sim 250$ & SAW & A533B-Ht-1 & X-Weld & SSR & $1 \mathrm{E}-03$ & air & strain & N/A & 350 & 1.0 & 0 \\
\hline 32 & Fatigue-SRX & TBD & $\sim 250$ & SAW & A533B-Ht-1 & X-Weld & SSR & $1 \mathrm{E}-03$ & air & strain & $\mathrm{N} / \mathrm{A}$ & 350 & 1.0 & 0 \\
\hline 33 & Fatigue-SRX & TBD & $\sim 250$ & SAW & A533B-Ht-1 & X-Weld & SSR & $1 \mathrm{E}-03$ & air & strain & N/A & 350 & 1.0 & 0 \\
\hline 34 & Fatigue-SRX & TBD & $\sim 250$ & SAW & A533B-Ht-1 & X-Weld & SSR & $1 \mathrm{E}-03$ & air & strain & tension & 350 & 1.0 & 30 \\
\hline 35 & Fatigue-SRX & TBD & $\sim 250$ & SAW & A533B-Ht-1 & X-Weld & SSR & $1 \mathrm{E}-03$ & air & strain & tension & 350 & 1.0 & 30 \\
\hline 36 & Fatigue-SRX & TBD & $\sim 250$ & SAW & A533B-Ht-1 & X-Weld & SSR & $1 \mathrm{E}-03$ & air & strain & tension & 350 & 1.0 & 30 \\
\hline 37 & Fatigue-SRX & TBD & $\sim 250$ & SAW & A533B-Ht-1 & X-Weld & SSR & $1 \mathrm{E}-03$ & air & strain & tension & 350 & 1.0 & 150 \\
\hline 38 & Fatigue-SRX & TBD & $\sim 250$ & SAW & A533B-Ht-1 & X-Weld & SSR & $1 \mathrm{E}-03$ & air & strain & tension & 350 & 1.0 & 150 \\
\hline 39 & Fatigue-SRX & TBD & $\sim 250$ & SAW & A533B-Ht-1 & X-Weld & SSR & $1 \mathrm{E}-03$ & air & strain & tension & 350 & 1.0 & 150 \\
\hline 40 & Fatigue-SRX & TBD & $\sim 250$ & SAW & A533B-Ht-1 & X-Weld & SSR & $1 \mathrm{E}-03$ & air & strain & comp. & 350 & 1.0 & 30 \\
\hline 41 & Fatigue-SRX & TBD & $\sim 250$ & SAW & A533B-Ht-1 & X-Weld & SSR & $1 \mathrm{E}-03$ & air & strain & comp. & 350 & 1.0 & 30 \\
\hline 42 & Fatigue-SRX & TBD & $\sim 250$ & SAW & A533B-Ht-1 & X-Weld & SSR & $1 \mathrm{E}-03$ & air & strain & comp. & 350 & 1.0 & 30 \\
\hline 43 & Fatigue-SRX & TBD & $\sim 250$ & SAW & A533B-Ht-1 & X-Weld & SSR & $1 \mathrm{E}-03$ & air & strain & comp. & 350 & 1.0 & 150 \\
\hline 44 & Fatigue-SRX & TBD & $\sim 250$ & SAW & A533B-Ht-1 & X-Weld & SSR & $1 \mathrm{E}-03$ & air & strain & comp. & 350 & 1.0 & 150 \\
\hline 45 & Fatigue-SRX & TBD & $\sim 250$ & SAW & A533B-Ht-1 & X-Weld & SSR & $1 \mathrm{E}-03$ & air & strain & comp. & 350 & 1.0 & 150 \\
\hline
\end{tabular}


Idaho National Laboratory

\begin{tabular}{|c|lll|}
\hline NEXT GENERATION NUCLEAR PLANT & Identifier: & PLN-2803 & \\
REACTOR PRESSURE VESSEL MATERIALS & Revision: & 0 & \\
RESEARCH AND DEVELOPMENT PLAN & Effective Date: & $04 / 30 / 08$ & Page: A-31 of A-102 \\
\hline
\end{tabular}

\begin{tabular}{|c|c|c|c|c|c|c|c|c|c|c|c|c|c|c|}
\hline Spec. \# & Test Type & $\begin{array}{c}\text { Weld } \\
\text { Con- } \\
\text { sumable }\end{array}$ & $\begin{array}{c}\text { Section } \\
\text { Thickness } \\
(\mathrm{mm})\end{array}$ & $\begin{array}{c}\text { Weld } \\
\text { Process }\end{array}$ & $\begin{array}{c}\text { Base Metal } \\
\text { Heat }\end{array}$ & $\begin{array}{c}\text { Weld to } \\
\text { be } \\
\text { Tested }\end{array}$ & $\begin{array}{l}\text { Mat } \\
\text { Cond. }\end{array}$ & $\begin{array}{l}\text { Strain } \\
\text { Rate } \\
(\mathrm{m} / \mathrm{m} / \mathrm{s} \\
)\end{array}$ & Env & $\begin{array}{l}\text { Hold } \\
\text { Cntrl } \\
\text { (stress } \\
\text { or } \\
\text { strain) }\end{array}$ & $\begin{array}{c}\text { Strain } \\
\text { Hold } \\
\text { in } \mathrm{T} / \mathrm{C}\end{array}$ & $\begin{array}{l}\text { Temp. } \\
\left({ }^{\circ} \mathrm{C}\right)\end{array}$ & $\begin{array}{c}\text { Strain } \\
\text { Range } \\
(\%)\end{array}$ & $\begin{array}{l}\text { Strain } \\
\text { Hold } \\
\text { Time } \\
(\mathrm{min})\end{array}$ \\
\hline 46 & Fatigue-SRX & TBD & $\sim 50$ & SMAW & A533B-Ht-1 & X-Weld & SSR & $1 \mathrm{E}-03$ & air & strain & N/A & 350 & 1.0 & 0 \\
\hline 47 & Fatigue-SRX & TBD & $\sim 50$ & SMAW & A533B-Ht-1 & X-Weld & SSR & $1 \mathrm{E}-03$ & air & strain & N/A & 350 & 1.0 & 0 \\
\hline 48 & Fatigue-SRX & TBD & $\sim 50$ & SMAW & A533B-Ht-1 & X-Weld & SSR & $1 \mathrm{E}-03$ & air & strain & N/A & 350 & 1.0 & 0 \\
\hline 49 & Fatigue-SRX & TBD & $\sim 50$ & SMAW & A533B-Ht-1 & X-Weld & SSR & $1 \mathrm{E}-03$ & air & strain & tension & 350 & 1.0 & 30 \\
\hline 50 & Fatigue-SRX & TBD & $\sim 50$ & SMAW & A533B-Ht-1 & X-Weld & SSR & $1 \mathrm{E}-03$ & air & strain & tension & 350 & 1.0 & 30 \\
\hline 51 & Fatigue-SRX & TBD & $\sim 50$ & SMAW & A533B-Ht-1 & X-Weld & SSR & $1 \mathrm{E}-03$ & air & strain & tension & 350 & 1.0 & 30 \\
\hline 52 & Fatigue-SRX & TBD & $\sim 50$ & SMAW & A533B-Ht-1 & X-Weld & SSR & $1 \mathrm{E}-03$ & air & strain & tension & 350 & 1.0 & 150 \\
\hline 53 & Fatigue-SRX & TBD & $\sim 50$ & SMAW & A533B-Ht-1 & X-Weld & SSR & $1 \mathrm{E}-03$ & air & strain & tension & 350 & 1.0 & 150 \\
\hline 54 & Fatigue-SRX & TBD & $\sim 50$ & SMAW & A533B-Ht-1 & X-Weld & SSR & $1 \mathrm{E}-03$ & air & strain & tension & 350 & 1.0 & 150 \\
\hline 55 & Fatigue-SRX & TBD & $\sim 50$ & SMAW & A533B-Ht-1 & X-Weld & SSR & $1 \mathrm{E}-03$ & air & strain & comp. & 350 & 1.0 & 30 \\
\hline 56 & Fatigue-SRX & TBD & $\sim 50$ & SMAW & A533B-Ht-1 & X-Weld & SSR & $1 \mathrm{E}-03$ & air & strain & comp. & 350 & 1.0 & 30 \\
\hline 57 & Fatigue-SRX & TBD & $\sim 50$ & SMAW & A533B-Ht-1 & X-Weld & SSR & $1 \mathrm{E}-03$ & air & strain & comp. & 350 & 1.0 & 30 \\
\hline 58 & Fatigue-SRX & TBD & $\sim 50$ & SMAW & A533B-Ht-1 & X-Weld & SSR & $1 \mathrm{E}-03$ & air & strain & comp. & 350 & 1.0 & 150 \\
\hline 59 & Fatigue-SRX & TBD & $\sim 50$ & SMAW & A533B-Ht-1 & X-Weld & SSR & $1 \mathrm{E}-03$ & air & strain & comp. & 350 & 1.0 & 150 \\
\hline 60 & Fatigue-SRX & TBD & $\sim 50$ & SMAW & A533B-Ht-1 & X-Weld & SSR & $1 \mathrm{E}-03$ & air & strain & comp. & 350 & 1.0 & 150 \\
\hline
\end{tabular}




Idaho National Laboratory
\begin{tabular}{|c|lll|}
\hline NEXT GENERATION NUCLEAR PLANT & Identifier: & PLN-2803 & \\
REACTOR PRESSURE VESSEL MATERIALS & Revision: & 0 & \\
RESEARCH AND DEVELOPMENT PLAN & Effective Date: & $04 / 30 / 08$ & Page: A-32 of A-102 \\
\hline
\end{tabular}

\begin{tabular}{|c|c|c|c|c|c|c|c|c|}
\hline \multicolumn{9}{|c|}{ Table A15. Baseline Tensile Tests of A 508/533B in Air to Address Creep Effects on Cold Vessel } \\
\hline Spec.\# & Test Type & Mat & Product Form & Mat Cond & Heat & $\begin{array}{c}\text { Strain Rate } \\
(\mathrm{m} / \mathrm{m} / \mathrm{s})\end{array}$ & Env & Temp. $\left({ }^{\circ} \mathrm{C}\right)$ \\
\hline 1 & Tensile-Baseline & A508 & Forging (thick) & SSR & A508-Ht-1 & $1 \mathrm{E}-03$ & air & 20 \\
\hline 2 & Tensile-Baseline & A508 & Forging (thick) & SSR & A508-Ht-1 & $1 \mathrm{E}-03$ & air & 20 \\
\hline 3 & Tensile-Baseline & A508 & Forging (thick) & SSR & A508-Ht-1 & $1 \mathrm{E}-03$ & air & 150 \\
\hline 4 & Tensile-Baseline & A508 & Forging (thick) & SSR & A508-Ht-1 & $1 \mathrm{E}-03$ & air & 150 \\
\hline 5 & Tensile-Baseline & A508 & Forging (thick) & SSR & A508-Ht-1 & $1 \mathrm{E}-03$ & air & 250 \\
\hline 6 & Tensile-Baseline & A508 & Forging (thick) & SSR & A508-Ht-1 & $1 \mathrm{E}-03$ & air & 250 \\
\hline 7 & Tensile-Baseline & A508 & Forging (thick) & SSR & A508-Ht-1 & $1 \mathrm{E}-03$ & air & 350 \\
\hline 8 & Tensile-Baseline & A508 & Forging (thick) & SSR & A508-Ht-1 & $1 \mathrm{E}-03$ & air & 350 \\
\hline 9 & Tensile-Baseline & A508 & Forging (thick) & SSR & A508-Ht-1 & $1 \mathrm{E}-03$ & air & 450 \\
\hline 10 & Tensile-Baseline & A508 & Forging (thick) & SSR & A508-Ht-1 & $1 \mathrm{E}-03$ & air & 450 \\
\hline 11 & Tensile-Baseline & A508 & Forging (thick) & SSR & A508-Ht-1 & $1 \mathrm{E}-03$ & air & 550 \\
\hline 12 & Tensile-Baseline & A508 & Forging (thick) & SSR & A508-Ht-1 & $1 \mathrm{E}-03$ & air & 550 \\
\hline 13 & Tensile-Baseline & A508 & Forging (thick) & SSR & A508-Ht-2 & $1 \mathrm{E}-03$ & air & 20 \\
\hline 14 & Tensile-Baseline & A508 & Forging (thick) & SSR & A508-Ht-2 & $1 \mathrm{E}-03$ & air & 20 \\
\hline 15 & Tensile-Baseline & A508 & Forging (thick) & SSR & A508-Ht-2 & $1 \mathrm{E}-03$ & air & 150 \\
\hline 16 & Tensile-Baseline & A508 & Forging (thick) & SSR & A508-Ht-2 & $1 \mathrm{E}-03$ & air & 150 \\
\hline 17 & Tensile-Baseline & A508 & Forging (thick) & SSR & A508-Ht-2 & $1 \mathrm{E}-03$ & air & 250 \\
\hline 18 & Tensile-Baseline & A508 & Forging (thick) & SSR & A508-Ht-2 & $1 \mathrm{E}-03$ & air & 250 \\
\hline 19 & Tensile-Baseline & A508 & Forging (thick) & SSR & A508-Ht-2 & $1 \mathrm{E}-03$ & air & 350 \\
\hline 20 & Tensile-Baseline & A508 & Forging (thick) & SSR & A508-Ht-2 & $1 \mathrm{E}-03$ & air & 350 \\
\hline 21 & Tensile-Baseline & A508 & Forging (thick) & SSR & A508-Ht-2 & $1 \mathrm{E}-03$ & air & 450 \\
\hline 22 & Tensile-Baseline & A508 & Forging (thick) & SSR & A508-Ht-2 & $1 \mathrm{E}-03$ & air & 450 \\
\hline 23 & Tensile-Baseline & A508 & Forging (thick) & SSR & A508-Ht-2 & $1 \mathrm{E}-03$ & air & 550 \\
\hline 24 & Tensile-Baseline & A508 & Forging (thick) & SSR & A508-Ht-2 & $1 \mathrm{E}-03$ & air & 550 \\
\hline 25 & Tensile-Baseline & A533B & Rolled Plate (thick) & SSR & A533B-Ht-1 & $1 \mathrm{E}-03$ & air & 20 \\
\hline
\end{tabular}




Idaho National Laboratory
\begin{tabular}{|c|lll|}
\hline NEXT GENERATION NUCLEAR PLANT & Identifier: & PLN-2803 & \\
REACTOR PRESSURE VESSEL MATERIALS & Revision: & 0 & \\
RESEARCH AND DEVELOPMENT PLAN & Effective Date: & $04 / 30 / 08$ & Page: A-33 of A-102 \\
\hline
\end{tabular}

\begin{tabular}{|c|c|c|c|c|c|c|c|c|}
\hline \multicolumn{9}{|c|}{ Table A15. Baseline Tensile Tests of A 508/533B in Air to Address Creep Effects on Cold Vessel } \\
\hline Spec. \# & Test Type & Mat & Product Form & Mat Cond & Heat & $\begin{array}{l}\text { Strain Rate } \\
(\mathrm{m} / \mathrm{m} / \mathrm{s})\end{array}$ & Env & Temp. $\left({ }^{\circ} \mathrm{C}\right)$ \\
\hline 26 & Tensile-Baseline & A533B & Rolled Plate (thick) & SSR & A533B-Ht-1 & $1 \mathrm{E}-03$ & air & 20 \\
\hline 27 & Tensile-Baseline & A533B & Rolled Plate (thick) & SSR & A533B-Ht-1 & $1 \mathrm{E}-03$ & air & 150 \\
\hline 28 & Tensile-Baseline & A533B & Rolled Plate (thick) & SSR & A533B-Ht-1 & $1 \mathrm{E}-03$ & air & 150 \\
\hline 29 & Tensile-Baseline & A533B & Rolled Plate (thick) & SSR & A533B-Ht-1 & $1 \mathrm{E}-03$ & air & 250 \\
\hline 30 & Tensile-Baseline & A533B & Rolled Plate (thick) & SSR & A533B-Ht-1 & $1 \mathrm{E}-03$ & air & 250 \\
\hline 31 & Tensile-Baseline & A533B & Rolled Plate (thick) & SSR & A533B-Ht-1 & $1 \mathrm{E}-03$ & air & 350 \\
\hline 32 & Tensile-Baseline & A533B & Rolled Plate (thick) & SSR & A533B-Ht-1 & $1 \mathrm{E}-03$ & air & 350 \\
\hline 33 & Tensile-Baseline & A533B & Rolled Plate (thick) & SSR & A533B-Ht-1 & $1 \mathrm{E}-03$ & air & 450 \\
\hline 34 & Tensile-Baseline & A533B & Rolled Plate (thick) & SSR & A533B-Ht-1 & $1 \mathrm{E}-03$ & air & 450 \\
\hline 35 & Tensile-Baseline & A533B & Rolled Plate (thick) & SSR & A533B-Ht-1 & $1 \mathrm{E}-03$ & air & 550 \\
\hline 36 & Tensile-Baseline & A533B & Rolled Plate (thick) & SSR & A533B-Ht-1 & $1 \mathrm{E}-03$ & air & 550 \\
\hline 37 & Tensile-Baseline & A533B & Rolled Plate (thick) & SSR & A533B-Ht-2 & $1 \mathrm{E}-03$ & air & 20 \\
\hline 38 & Tensile-Baseline & A533B & Rolled Plate (thick) & SSR & A533B-Ht-2 & $1 \mathrm{E}-03$ & air & 20 \\
\hline 39 & Tensile-Baseline & A533B & Rolled Plate (thick) & SSR & A533B-Ht-2 & $1 \mathrm{E}-03$ & air & 150 \\
\hline 40 & Tensile-Baseline & A533B & Rolled Plate (thick) & SSR & A533B-Ht-2 & $1 \mathrm{E}-03$ & air & 150 \\
\hline 41 & Tensile-Baseline & A533B & Rolled Plate (thick) & SSR & A533B-Ht-2 & $1 \mathrm{E}-03$ & air & 250 \\
\hline 42 & Tensile-Baseline & A533B & Rolled Plate (thick) & SSR & A533B-Ht-2 & $1 \mathrm{E}-03$ & air & 250 \\
\hline 43 & Tensile-Baseline & A533B & Rolled Plate (thick) & SSR & A533B-Ht-2 & $1 \mathrm{E}-03$ & air & 350 \\
\hline 44 & Tensile-Baseline & A533B & Rolled Plate (thick) & SSR & A533B-Ht-2 & $1 \mathrm{E}-03$ & air & 350 \\
\hline 45 & Tensile-Baseline & A533B & Rolled Plate (thick) & SSR & A533B-Ht-2 & $1 \mathrm{E}-03$ & air & 450 \\
\hline 46 & Tensile-Baseline & A533B & Rolled Plate (thick) & SSR & A533B-Ht-2 & $1 \mathrm{E}-03$ & air & 450 \\
\hline 47 & Tensile-Baseline & A533B & Rolled Plate (thick) & SSR & A533B-Ht-2 & $1 \mathrm{E}-03$ & air & 550 \\
\hline 48 & Tensile-Baseline & A533B & Rolled Plate (thick) & SSR & A533B-Ht-2 & $1 \mathrm{E}-03$ & air & 550 \\
\hline
\end{tabular}




Idaho National Laboratory
\begin{tabular}{|c|lll|}
\hline NEXT GENERATION NUCLEAR PLANT & Identifier: & PLN-2803 & \\
REACTOR PRESSURE VESSEL MATERIALS & Revision: & 0 & \\
RESEARCH AND DEVELOPMENT PLAN & Effective Date: & $04 / 30 / 08$ & Page: A-34 of A-102 \\
\hline
\end{tabular}

\begin{tabular}{|c|c|c|c|c|c|c|c|c|c|c|}
\hline Spec. \# & Test Type & $\begin{array}{c}\text { Weld } \\
\text { Consumable }\end{array}$ & $\begin{array}{c}\text { Section } \\
\text { Thickness (mm) }\end{array}$ & $\begin{array}{l}\text { Weld } \\
\text { Process }\end{array}$ & $\begin{array}{c}\text { Base Metal } \\
\text { Heat }\end{array}$ & $\begin{array}{l}\text { Weld to be } \\
\text { Tested }\end{array}$ & Mat Cond & $\begin{array}{l}\text { Strain Rate } \\
(\mathrm{m} / \mathrm{m} / \mathrm{s})\end{array}$ & Env & $\begin{array}{l}\text { Temp. } \\
\left({ }^{\circ} \mathrm{C}\right)\end{array}$ \\
\hline 1 & Tensile & TBD & $\sim 250$ & SAW & A508-Ht-1 & X-Weld & SSR & $1 \mathrm{E}-03$ & air & 20 \\
\hline 2 & Tensile & TBD & $\sim 250$ & SAW & A508-Ht-1 & X-Weld & SSR & $1 \mathrm{E}-03$ & air & 20 \\
\hline 3 & Tensile & TBD & $\sim 250$ & SAW & A508-Ht-1 & X-Weld & SSR & $1 \mathrm{E}-03$ & air & 150 \\
\hline 4 & Tensile & TBD & $\sim 250$ & SAW & A508-Ht-1 & X-Weld & SSR & $1 \mathrm{E}-03$ & air & 150 \\
\hline 5 & Tensile & TBD & $\sim 250$ & SAW & A508-Ht-1 & X-Weld & SSR & $1 \mathrm{E}-03$ & air & 250 \\
\hline 6 & Tensile & TBD & $\sim 250$ & SAW & A508-Ht-1 & X-Weld & SSR & $1 \mathrm{E}-03$ & air & 250 \\
\hline 7 & Tensile & TBD & $\sim 250$ & SAW & A508-Ht-1 & X-Weld & SSR & $1 \mathrm{E}-03$ & air & 350 \\
\hline 8 & Tensile & TBD & $\sim 250$ & SAW & A508-Ht-1 & X-Weld & SSR & $1 \mathrm{E}-03$ & air & 350 \\
\hline 9 & Tensile & TBD & $\sim 250$ & SAW & A508-Ht-1 & X-Weld & SSR & $1 \mathrm{E}-03$ & air & 450 \\
\hline 10 & Tensile & TBD & $\sim 250$ & SAW & A508-Ht-1 & X-Weld & SSR & $1 \mathrm{E}-03$ & air & 450 \\
\hline 11 & Tensile & TBD & $\sim 250$ & SAW & A508-Ht-1 & X-Weld & SSR & $1 \mathrm{E}-03$ & air & 550 \\
\hline 12 & Tensile & TBD & $\sim 250$ & SAW & A508-Ht-1 & X-Weld & SSR & $1 \mathrm{E}-03$ & air & 550 \\
\hline 13 & Tensile & TBD & $\sim 50$ & SMAW & A508-Ht-1 & X-Weld & SSR & $1 \mathrm{E}-03$ & air & 20 \\
\hline 14 & Tensile & TBD & $\sim 50$ & SMAW & A508-Ht-1 & X-Weld & SSR & $1 \mathrm{E}-03$ & air & 20 \\
\hline 15 & Tensile & TBD & $\sim 50$ & SMAW & A508-Ht-1 & X-Weld & SSR & $1 \mathrm{E}-03$ & air & 150 \\
\hline 16 & Tensile & TBD & $\sim 50$ & SMAW & A508-Ht-1 & X-Weld & SSR & $1 \mathrm{E}-03$ & air & 150 \\
\hline 17 & Tensile & TBD & $\sim 50$ & SMAW & A508-Ht-1 & X-Weld & SSR & $1 \mathrm{E}-03$ & air & 250 \\
\hline 18 & Tensile & TBD & $\sim 50$ & SMAW & A508-Ht-1 & X-Weld & SSR & $1 \mathrm{E}-03$ & air & 250 \\
\hline 19 & Tensile & TBD & $\sim 50$ & SMAW & A508-Ht-1 & X-Weld & SSR & $1 \mathrm{E}-03$ & air & 350 \\
\hline 20 & Tensile & TBD & $\sim 50$ & SMAW & A508-Ht-1 & X-Weld & SSR & $1 \mathrm{E}-03$ & air & 350 \\
\hline 21 & Tensile & TBD & $\sim 50$ & SMAW & A508-Ht-1 & X-Weld & SSR & $1 \mathrm{E}-03$ & air & 450 \\
\hline 22 & Tensile & TBD & $\sim 50$ & SMAW & A508-Ht-1 & X-Weld & SSR & $1 \mathrm{E}-03$ & air & 450 \\
\hline 23 & Tensile & TBD & $\sim 50$ & SMAW & A508-Ht-1 & X-Weld & SSR & $1 \mathrm{E}-03$ & air & 550 \\
\hline 24 & Tensile & TBD & $\sim 50$ & SMAW & A508-Ht-1 & X-Weld & SSR & $1 \mathrm{E}-03$ & air & 550 \\
\hline 25 & Tensile & TBD & $\sim 250$ & SAW & A533B-Ht-1 & X-Weld & SSR & $1 \mathrm{E}-03$ & air & 20 \\
\hline
\end{tabular}




Idaho National Laboratory
\begin{tabular}{|c|lll|}
\hline NEXT GENERATION NUCLEAR PLANT & Identifier: & PLN-2803 & \\
REACTOR PRESSURE VESSEL MATERIALS & Revision: & 0 & \\
RESEARCH AND DEVELOPMENT PLAN & Effective Date: & $04 / 30 / 08$ & Page: A-35 of A-102 \\
\hline
\end{tabular}

\begin{tabular}{|c|c|c|c|c|c|c|c|c|c|c|}
\hline Spec. \# & Test Type & $\begin{array}{c}\text { Weld } \\
\text { Consumable }\end{array}$ & $\begin{array}{c}\text { Section } \\
\text { Thickness (mm) }\end{array}$ & $\begin{array}{l}\text { Weld } \\
\text { Process }\end{array}$ & $\begin{array}{c}\text { Base Metal } \\
\text { Heat }\end{array}$ & $\begin{array}{l}\text { Weld to be } \\
\text { Tested }\end{array}$ & Mat Cond & $\begin{array}{c}\text { Strain Rate } \\
(\mathrm{m} / \mathrm{m} / \mathrm{s})\end{array}$ & Env & $\begin{array}{r}\text { Temp } \\
\left({ }^{\circ} \mathrm{C}\right)\end{array}$ \\
\hline 26 & Tensile & TBD & $\sim 250$ & SAW & A533B-Ht-1 & X-Weld & SSR & $1 \mathrm{E}-03$ & air & 20 \\
\hline 27 & Tensile & TBD & $\sim 250$ & SAW & A533B-Ht-1 & X-Weld & SSR & $1 \mathrm{E}-03$ & air & 150 \\
\hline 28 & Tensile & TBD & $\sim 250$ & SAW & A533B-Ht-1 & X-Weld & SSR & $1 \mathrm{E}-03$ & air & 150 \\
\hline 29 & Tensile & TBD & $\sim 250$ & SAW & A533B-Ht-1 & X-Weld & SSR & $1 \mathrm{E}-03$ & air & 250 \\
\hline 30 & Tensile & TBD & $\sim 250$ & SAW & A533B-Ht-1 & X-Weld & SSR & $1 \mathrm{E}-03$ & air & 250 \\
\hline 31 & Tensile & TBD & $\sim 250$ & SAW & A533B-Ht-1 & X-Weld & SSR & $1 \mathrm{E}-03$ & air & 350 \\
\hline 32 & Tensile & TBD & $\sim 250$ & SAW & A533B-Ht-1 & X-Weld & SSR & $1 \mathrm{E}-03$ & air & 350 \\
\hline 33 & Tensile & TBD & $\sim 250$ & SAW & A533B-Ht-1 & X-Weld & SSR & $1 \mathrm{E}-03$ & air & 450 \\
\hline 34 & Tensile & TBD & $\sim 250$ & SAW & A533B-Ht-1 & X-Weld & SSR & $1 \mathrm{E}-03$ & air & 450 \\
\hline 35 & Tensile & TBD & $\sim 250$ & SAW & A533B-Ht-1 & X-Weld & SSR & $1 \mathrm{E}-03$ & air & 550 \\
\hline 36 & Tensile & TBD & $\sim 250$ & SAW & A533B-Ht-1 & X-Weld & SSR & $1 \mathrm{E}-03$ & air & 550 \\
\hline 37 & Tensile & TBD & $\sim 50$ & SMAW & A533B-Ht-1 & X-Weld & SSR & $1 \mathrm{E}-03$ & air & 20 \\
\hline 38 & Tensile & TBD & $\sim 50$ & SMAW & A533B-Ht-1 & X-Weld & SSR & $1 \mathrm{E}-03$ & air & 20 \\
\hline 39 & Tensile & TBD & $\sim 50$ & SMAW & A533B-Ht-1 & X-Weld & SSR & $1 \mathrm{E}-03$ & air & 150 \\
\hline 40 & Tensile & TBD & $\sim 50$ & SMAW & A533B-Ht-1 & X-Weld & SSR & $1 \mathrm{E}-03$ & air & 150 \\
\hline 41 & Tensile & TBD & $\sim 50$ & SMAW & A533B-Ht-1 & X-Weld & SSR & $1 \mathrm{E}-03$ & air & 250 \\
\hline 42 & Tensile & TBD & $\sim 50$ & SMAW & A533B-Ht-1 & X-Weld & SSR & $1 \mathrm{E}-03$ & air & 250 \\
\hline 43 & Tensile & TBD & $\sim 50$ & SMAW & A533B-Ht-1 & X-Weld & SSR & $1 \mathrm{E}-03$ & air & 350 \\
\hline 44 & Tensile & TBD & $\sim 50$ & SMAW & A533B-Ht-1 & X-Weld & SSR & $1 \mathrm{E}-03$ & air & 350 \\
\hline 45 & Tensile & TBD & $\sim 50$ & SMAW & A533B-Ht-1 & X-Weld & SSR & $1 \mathrm{E}-03$ & air & 450 \\
\hline 46 & Tensile & TBD & $\sim 50$ & SMAW & A533B-Ht-1 & X-Weld & SSR & $1 \mathrm{E}-03$ & air & 450 \\
\hline 47 & Tensile & TBD & $\sim 50$ & SMAW & A533B-Ht-1 & X-Weld & SSR & $1 \mathrm{E}-03$ & air & 550 \\
\hline 48 & Tensile & TBD & $\sim 50$ & SMAW & A533B-Ht-1 & X-Weld & SSR & $1 \mathrm{E}-03$ & air & 550 \\
\hline
\end{tabular}




Idaho National Laboratory
\begin{tabular}{|c|lll|}
\hline NEXT GENERATION NUCLEAR PLANT & Identifier: & PLN-2803 & \\
REACTOR PRESSURE VESSEL MATERIALS & Revision: & 0 & \\
RESEARCH AND DEVELOPMENT PLAN & Effective Date: & $04 / 30 / 08$ & Page: A-36 of A-102 \\
\hline
\end{tabular}

\begin{tabular}{|c|c|c|c|c|c|c|c|c|}
\hline Spec. \# & Test Type & Mat & Product Form & Mat Cond ${ }^{(1)}$ & Heat & $\begin{array}{c}\text { Strain Rate } \\
(\mathrm{m} / \mathrm{m} / \mathrm{s})\end{array}$ & Env & Temp. $\left({ }^{\circ} \mathrm{C}\right)$ \\
\hline 1 & Tensile & A508 & Forging (thick) & SSR + Damaged & A508-Ht-1 & $1 \mathrm{E}-03$ & air & 20 \\
\hline 2 & Tensile & A508 & Forging (thick) & SSR + Damaged & A508-Ht-1 & $1 \mathrm{E}-03$ & air & 20 \\
\hline 3 & Tensile & A508 & Forging (thick) & SSR + Damaged & A508-Ht-1 & $1 \mathrm{E}-03$ & air & 150 \\
\hline 4 & Tensile & A508 & Forging (thick) & SSR + Damaged & A508-Ht-1 & $1 \mathrm{E}-03$ & air & 150 \\
\hline 5 & Tensile & A508 & Forging (thick) & SSR + Damaged & A508-Ht-1 & $1 \mathrm{E}-03$ & air & 250 \\
\hline 6 & Tensile & A508 & Forging (thick) & SSR + Damaged & A508-Ht-1 & $1 \mathrm{E}-03$ & air & 250 \\
\hline 7 & Tensile & A508 & Forging (thick) & SSR + Damaged & A508-Ht-1 & $1 \mathrm{E}-03$ & air & 350 \\
\hline 8 & Tensile & A508 & Forging (thick) & SSR + Damaged & A508-Ht-1 & $1 \mathrm{E}-03$ & air & 350 \\
\hline 9 & Tensile & $\mathrm{A} 508$ & Forging (thick) & SSR + Damaged & A508-Ht-1 & $1 \mathrm{E}-03$ & air & 450 \\
\hline 10 & Tensile & A508 & Forging (thick) & SSR + Damaged & A508-Ht-1 & $1 \mathrm{E}-03$ & air & 450 \\
\hline 11 & Tensile & A508 & Forging (thick) & SSR + Damaged & A508-Ht-1 & $1 \mathrm{E}-03$ & air & 550 \\
\hline 12 & Tensile & A508 & Forging (thick) & SSR + Damaged & A508-Ht-1 & $1 \mathrm{E}-03$ & air & 550 \\
\hline 13 & Tensile & A508 & Forging (thick) & SSR + Damaged & A508-Ht-2 & $1 \mathrm{E}-03$ & air & 20 \\
\hline 14 & Tensile & A508 & Forging (thick) & SSR + Damaged & A508-Ht-2 & $1 \mathrm{E}-03$ & air & 20 \\
\hline 15 & Tensile & A508 & Forging (thick) & SSR + Damaged & A508-Ht-2 & $1 \mathrm{E}-03$ & air & 150 \\
\hline 16 & Tensile & A508 & Forging (thick) & SSR + Damaged & A508-Ht-2 & $1 \mathrm{E}-03$ & air & 150 \\
\hline 17 & Tensile & A508 & Forging (thick) & SSR + Damaged & A508-Ht-2 & $1 \mathrm{E}-03$ & air & 250 \\
\hline 18 & Tensile & A508 & Forging (thick) & SSR + Damaged & A508-Ht-2 & $1 \mathrm{E}-03$ & air & 250 \\
\hline 19 & Tensile & A508 & Forging (thick) & SSR + Damaged & A508-Ht-2 & $1 \mathrm{E}-03$ & air & 350 \\
\hline 20 & Tensile & A508 & Forging (thick) & SSR + Damaged & A508-Ht-2 & $1 \mathrm{E}-03$ & air & 350 \\
\hline 21 & Tensile & A508 & Forging (thick) & SSR + Damaged & A508-Ht-2 & $1 \mathrm{E}-03$ & air & 450 \\
\hline 22 & Tensile & A508 & Forging (thick) & SSR + Damaged & A508-Ht-2 & $1 \mathrm{E}-03$ & air & 450 \\
\hline 23 & Tensile & A508 & Forging (thick) & SSR + Damaged & A508-Ht-2 & $1 \mathrm{E}-03$ & air & 550 \\
\hline 24 & Tensile & A508 & Forging (thick) & SSR + Damaged & A508-Ht-2 & $1 \mathrm{E}-03$ & air & 550 \\
\hline 25 & Tensile & A533B & Rolled Plate (thick) & SSR + Damaged & A533B-Ht-1 & $1 \mathrm{E}-03$ & air & 20 \\
\hline
\end{tabular}




Idaho National Laboratory
\begin{tabular}{|c|lll|}
\hline NEXT GENERATION NUCLEAR PLANT & Identifier: & PLN-2803 & \\
REACTOR PRESSURE VESSEL MATERIALS & Revision: & 0 & \\
RESEARCH AND DEVELOPMENT PLAN & Effective Date: & $04 / 30 / 08$ & Page: A-37 of A-102 \\
\hline
\end{tabular}

\begin{tabular}{|c|c|c|c|c|c|c|c|c|}
\hline Spec. \# & Test Type & Mat & Product Form & Mat Cond ${ }^{(1)}$ & Heat & $\begin{array}{c}\text { Strain Rate } \\
(\mathrm{m} / \mathrm{m} / \mathrm{s})\end{array}$ & Env & Temp. $\left({ }^{\circ} \mathrm{C}\right)$ \\
\hline 26 & Tensile & A533B & Rolled Plate (thick) & SSR + Damaged & A533B-Ht-1 & $1 \mathrm{E}-03$ & air & 20 \\
\hline 27 & Tensile & A533B & Rolled Plate (thick) & SSR + Damaged & A533B-Ht-1 & $1 \mathrm{E}-03$ & air & 150 \\
\hline 28 & Tensile & A533B & Rolled Plate (thick) & SSR + Damaged & A533B-Ht-1 & $1 \mathrm{E}-03$ & air & 150 \\
\hline 29 & Tensile & A533B & Rolled Plate (thick) & SSR + Damaged & A533B-Ht-1 & $1 \mathrm{E}-03$ & air & 250 \\
\hline 30 & Tensile & A533B & Rolled Plate (thick) & SSR + Damaged & A533B-Ht-1 & $1 \mathrm{E}-03$ & air & 250 \\
\hline 31 & Tensile & A533B & Rolled Plate (thick) & SSR + Damaged & A533B-Ht-1 & $1 \mathrm{E}-03$ & air & 350 \\
\hline 32 & Tensile & A533B & Rolled Plate (thick) & SSR + Damaged & A533B-Ht-1 & $1 \mathrm{E}-03$ & air & 350 \\
\hline 33 & Tensile & A533B & Rolled Plate (thick) & SSR + Damaged & A533B-Ht-1 & $1 \mathrm{E}-03$ & air & 450 \\
\hline 34 & Tensile & A533B & Rolled Plate (thick) & SSR + Damaged & A533B-Ht-1 & $1 \mathrm{E}-03$ & air & 450 \\
\hline 35 & Tensile & A533B & Rolled Plate (thick) & SSR + Damaged & A533B-Ht-1 & $1 \mathrm{E}-03$ & air & 550 \\
\hline 36 & Tensile & A533B & Rolled Plate (thick) & SSR + Damaged & A533B-Ht-1 & $1 \mathrm{E}-03$ & air & 550 \\
\hline 37 & Tensile & A533B & Rolled Plate (thick) & SSR + Damaged & A533B-Ht-2 & $1 \mathrm{E}-03$ & air & 20 \\
\hline 38 & Tensile & A533B & Rolled Plate (thick) & SSR + Damaged & A533B-Ht-2 & $1 \mathrm{E}-03$ & air & 20 \\
\hline 39 & Tensile & A533B & Rolled Plate (thick) & SSR + Damaged & A533B-Ht-2 & $1 \mathrm{E}-03$ & air & 150 \\
\hline 40 & Tensile & A533B & Rolled Plate (thick) & SSR + Damaged & A533B-Ht-2 & $1 \mathrm{E}-03$ & air & 150 \\
\hline 41 & Tensile & A533B & Rolled Plate (thick) & SSR + Damaged & A533B-Ht-2 & $1 \mathrm{E}-03$ & air & 250 \\
\hline 42 & Tensile & A533B & Rolled Plate (thick) & SSR + Damaged & A533B-Ht-2 & $1 \mathrm{E}-03$ & air & 250 \\
\hline 43 & Tensile & A533B & Rolled Plate (thick) & SSR + Damaged & A533B-Ht-2 & $1 \mathrm{E}-03$ & air & 350 \\
\hline 44 & Tensile & A533B & Rolled Plate (thick) & SSR + Damaged & A533B-Ht-2 & $1 \mathrm{E}-03$ & air & 350 \\
\hline 45 & Tensile & A533B & Rolled Plate (thick) & SSR + Damaged & A533B-Ht-2 & $1 \mathrm{E}-03$ & air & 450 \\
\hline 46 & Tensile & A533B & Rolled Plate (thick) & SSR + Damaged & A533B-Ht-2 & $1 \mathrm{E}-03$ & air & 450 \\
\hline 47 & Tensile & A533B & Rolled Plate (thick) & SSR + Damaged & A533B-Ht-2 & $1 \mathrm{E}-03$ & air & 550 \\
\hline 48 & Tensile & A533B & Rolled Plate (thick) & SSR + Damaged & A533B-Ht-2 & $1 \mathrm{E}-03$ & air & 550 \\
\hline
\end{tabular}




Idaho National Laboratory
\begin{tabular}{|c|lll|}
\hline NEXT GENERATION NUCLEAR PLANT & Identifier: & PLN-2803 & \\
REACTOR PRESSURE VESSEL MATERIALS & Revision: & 0 & \\
RESEARCH AND DEVELOPMENT PLAN & Effective Date: & $04 / 30 / 08$ & Page: A-38 of A-102 \\
\hline
\end{tabular}

\begin{tabular}{|c|c|c|c|c|c|c|c|c|c|c|}
\hline Spec. \# & Test Type & $\begin{array}{c}\text { Weld } \\
\text { Consumable }\end{array}$ & $\begin{array}{c}\text { Section } \\
\text { Thickness } \\
(\mathrm{mm})\end{array}$ & $\begin{array}{c}\text { Weld } \\
\text { Process }\end{array}$ & Base Metal Heat & $\begin{array}{c}\text { Weld to be } \\
\text { Tested }\end{array}$ & Mat Cond $^{(1)}$ & $\begin{array}{c}\text { Strain Rate } \\
(\mathrm{m} / \mathrm{m} / \mathrm{s})\end{array}$ & Env & $\begin{array}{c}\text { Temp. } \\
\left({ }^{\circ} \mathrm{C}\right)\end{array}$ \\
\hline 1 & Tensile & TBD & $\sim 250$ & SAW & A508-Ht-1 & X-Weld & SSR + Damaged & $1 \mathrm{E}-03$ & air & 20 \\
\hline 2 & Tensile & TBD & $\sim 250$ & SAW & A508-Ht-1 & X-Weld & SSR + Damaged & $1 \mathrm{E}-03$ & air & 20 \\
\hline 3 & Tensile & TBD & $\sim 250$ & SAW & A508-Ht-1 & X-Weld & SSR + Damaged & $1 \mathrm{E}-03$ & air & 150 \\
\hline 4 & Tensile & TBD & $\sim 250$ & SAW & A508-Ht-1 & X-Weld & SSR + Damaged & $1 \mathrm{E}-03$ & air & 150 \\
\hline 5 & Tensile & TBD & $\sim 250$ & SAW & A508-Ht-1 & X-Weld & SSR + Damaged & $1 \mathrm{E}-03$ & air & 250 \\
\hline 6 & Tensile & TBD & $\sim 250$ & SAW & A508-Ht-1 & X-Weld & SSR + Damaged & $1 \mathrm{E}-03$ & air & 250 \\
\hline 7 & Tensile & TBD & $\sim 250$ & SAW & A508-Ht-1 & X-Weld & SSR + Damaged & $1 \mathrm{E}-03$ & air & 350 \\
\hline 8 & Tensile & TBD & $\sim 250$ & SAW & A508-Ht-1 & X-Weld & SSR + Damaged & $1 \mathrm{E}-03$ & air & 350 \\
\hline 9 & Tensile & TBD & $\sim 250$ & SAW & A508-Ht-1 & X-Weld & SSR + Damaged & $1 \mathrm{E}-03$ & air & 450 \\
\hline 10 & Tensile & TBD & $\sim 250$ & SAW & A508-Ht-1 & X-Weld & SSR + Damaged & $1 \mathrm{E}-03$ & air & 450 \\
\hline 11 & Tensile & TBD & $\sim 250$ & SAW & A508-Ht-1 & X-Weld & SSR + Damaged & $1 \mathrm{E}-03$ & air & 550 \\
\hline 12 & Tensile & TBD & $\sim 250$ & SAW & A508-Ht-1 & X-Weld & SSR + Damaged & $1 \mathrm{E}-03$ & air & 550 \\
\hline 13 & Tensile & TBD & $\sim 50$ & SMAW & A508-Ht-1 & X-Weld & SSR + Damaged & $1 \mathrm{E}-03$ & air & 20 \\
\hline 14 & Tensile & TBD & $\sim 50$ & SMAW & A508-Ht-1 & X-Weld & SSR + Damaged & $1 \mathrm{E}-03$ & air & 20 \\
\hline 15 & Tensile & TBD & $\sim 50$ & SMAW & A508-Ht-1 & X-Weld & SSR + Damaged & $1 \mathrm{E}-03$ & air & 150 \\
\hline 16 & Tensile & TBD & $\sim 50$ & SMAW & A508-Ht-1 & X-Weld & SSR + Damaged & $1 \mathrm{E}-03$ & air & 150 \\
\hline 17 & Tensile & TBD & $\sim 50$ & SMAW & A508-Ht-1 & X-Weld & SSR + Damaged & $1 \mathrm{E}-03$ & air & 250 \\
\hline 18 & Tensile & TBD & $\sim 50$ & SMAW & A508-Ht-1 & X-Weld & SSR + Damaged & $1 \mathrm{E}-03$ & air & 250 \\
\hline 19 & Tensile & TBD & $\sim 50$ & SMAW & A508-Ht-1 & X-Weld & SSR + Damaged & $1 \mathrm{E}-03$ & air & 350 \\
\hline 20 & Tensile & TBD & $\sim 50$ & SMAW & A508-Ht-1 & X-Weld & SSR + Damaged & $1 \mathrm{E}-03$ & air & 350 \\
\hline 21 & Tensile & TBD & $\sim 50$ & SMAW & A508-Ht-1 & X-Weld & SSR + Damaged & $1 \mathrm{E}-03$ & air & 450 \\
\hline 22 & Tensile & TBD & $\sim 50$ & SMAW & A508-Ht-1 & X-Weld & SSR + Damaged & $1 \mathrm{E}-03$ & air & 450 \\
\hline 23 & Tensile & TBD & $\sim 50$ & SMAW & A508-Ht-1 & X-Weld & SSR + Damaged & $1 \mathrm{E}-03$ & air & 550 \\
\hline 24 & Tensile & TBD & $\sim 50$ & SMAW & A508-Ht-1 & X-Weld & SSR + Damaged & $1 \mathrm{E}-03$ & air & 550 \\
\hline 25 & Tensile & TBD & $\sim 250$ & SAW & A533B-Ht-1 & X-Weld & SSR + Damaged & $1 \mathrm{E}-03$ & air & 20 \\
\hline
\end{tabular}




Idaho National Laboratory
\begin{tabular}{|c|lll|}
\hline NEXT GENERATION NUCLEAR PLANT & Identifier: & PLN-2803 & \\
REACTOR PRESSURE VESSEL MATERIALS & Revision: & 0 & \\
RESEARCH AND DEVELOPMENT PLAN & Effective Date: & $04 / 30 / 08$ & Page: A-39 of A-102 \\
\hline
\end{tabular}

\begin{tabular}{|c|c|c|c|c|c|c|c|c|c|c|}
\hline Spec. \# & Test Type & $\begin{array}{c}\text { Weld } \\
\text { Consumable }\end{array}$ & $\begin{array}{l}\text { Section } \\
\text { Thickness } \\
(\mathrm{mm})\end{array}$ & $\begin{array}{l}\text { Weld } \\
\text { Process }\end{array}$ & Base Metal Heat & $\begin{array}{l}\text { Weld to be } \\
\text { Tested }\end{array}$ & Mat Cond ${ }^{(1)}$ & $\begin{array}{l}\text { Strain Rate } \\
(\mathrm{m} / \mathrm{m} / \mathrm{s})\end{array}$ & Env & $\begin{array}{l}\text { Temp. } \\
\left({ }^{\circ} \mathrm{C}\right)\end{array}$ \\
\hline 26 & Tensile & TBD & $\sim 250$ & SAW & A533B-Ht-1 & X-Weld & SSR + Damaged & $1 \mathrm{E}-03$ & air & 20 \\
\hline 27 & Tensile & TBD & $\sim 250$ & SAW & A533B-Ht-1 & X-Weld & SSR + Damaged & $1 \mathrm{E}-03$ & air & 150 \\
\hline 28 & Tensile & TBD & $\sim 250$ & SAW & A533B-Ht-1 & X-Weld & SSR + Damaged & $1 \mathrm{E}-03$ & air & 150 \\
\hline 29 & Tensile & TBD & $\sim 250$ & SAW & A533B-Ht-1 & X-Weld & SSR + Damaged & $1 \mathrm{E}-03$ & air & 250 \\
\hline 30 & Tensile & TBD & $\sim 250$ & SAW & A533B-Ht-1 & X-Weld & SSR + Damaged & $1 \mathrm{E}-03$ & air & 250 \\
\hline 31 & Tensile & TBD & $\sim 250$ & SAW & A533B-Ht-1 & X-Weld & SSR + Damaged & $1 \mathrm{E}-03$ & air & 350 \\
\hline 32 & Tensile & TBD & $\sim 250$ & SAW & A533B-Ht-1 & X-Weld & SSR + Damaged & $1 \mathrm{E}-03$ & air & 350 \\
\hline 33 & Tensile & TBD & $\sim 250$ & SAW & A533B-Ht-1 & X-Weld & SSR + Damaged & $1 \mathrm{E}-03$ & air & 450 \\
\hline 34 & Tensile & TBD & $\sim 250$ & SAW & A533B-Ht-1 & X-Weld & SSR + Damaged & $1 \mathrm{E}-03$ & air & 450 \\
\hline 35 & Tensile & TBD & $\sim 250$ & SAW & A533B-Ht-1 & X-Weld & SSR + Damaged & $1 \mathrm{E}-03$ & air & 550 \\
\hline 36 & Tensile & TBD & $\sim 250$ & SAW & A533B-Ht-1 & X-Weld & SSR + Damaged & $1 \mathrm{E}-03$ & air & 550 \\
\hline 37 & Tensile & TBD & $\sim 50$ & SMAW & A533B-Ht-1 & X-Weld & SSR + Damaged & $1 \mathrm{E}-03$ & air & 20 \\
\hline 38 & Tensile & TBD & $\sim 50$ & SMAW & A533B-Ht-1 & X-Weld & SSR + Damaged & $1 \mathrm{E}-03$ & air & 20 \\
\hline 39 & Tensile & TBD & $\sim 50$ & SMAW & A533B-Ht-1 & X-Weld & SSR + Damaged & $1 \mathrm{E}-03$ & air & 150 \\
\hline 40 & Tensile & TBD & $\sim 50$ & SMAW & A533B-Ht-1 & X-Weld & SSR + Damaged & $1 \mathrm{E}-03$ & air & 150 \\
\hline 41 & Tensile & TBD & $\sim 50$ & SMAW & A533B-Ht-1 & X-Weld & SSR + Damaged & $1 \mathrm{E}-03$ & air & 250 \\
\hline 42 & Tensile & TBD & $\sim 50$ & SMAW & A533B-Ht-1 & X-Weld & SSR + Damaged & $1 \mathrm{E}-03$ & air & 250 \\
\hline 43 & Tensile & TBD & $\sim 50$ & SMAW & A533B-Ht-1 & X-Weld & SSR + Damaged & $1 \mathrm{E}-03$ & air & 350 \\
\hline 44 & Tensile & TBD & $\sim 50$ & SMAW & A533B-Ht-1 & X-Weld & SSR + Damaged & $1 \mathrm{E}-03$ & air & 350 \\
\hline 45 & Tensile & TBD & $\sim 50$ & SMAW & A533B-Ht-1 & X-Weld & SSR + Damaged & $1 \mathrm{E}-03$ & air & 450 \\
\hline 46 & Tensile & TBD & $\sim 50$ & SMAW & A533B-Ht-1 & X-Weld & SSR + Damaged & $1 \mathrm{E}-03$ & air & 450 \\
\hline 47 & Tensile & TBD & $\sim 50$ & SMAW & A533B-Ht-1 & X-Weld & SSR + Damaged & $1 \mathrm{E}-03$ & air & 550 \\
\hline 48 & Tensile & TBD & $\sim 50$ & SMAW & A533B-Ht-1 & X-Weld & SSR + Damaged & $1 \mathrm{E}-03$ & air & 550 \\
\hline
\end{tabular}




Idaho National Laboratory
\begin{tabular}{|c|lll|}
\hline NEXT GENERATION NUCLEAR PLANT & Identifier: & PLN-2803 & \\
REACTOR PRESSURE VESSEL MATERIALS & Revision: & 0 & \\
RESEARCH AND DEVELOPMENT PLAN & Effective Date: & $04 / 30 / 08$ & Page: A-40 of A-102 \\
\hline
\end{tabular}

\begin{tabular}{|c|c|c|c|c|c|c|c|c|c|c|}
\hline Spec. \# & Test Type & Mat & Product Form & Mat Cond & $\begin{array}{c}\text { Aging } \\
\text { Temp. } \\
\left({ }^{\circ} \mathrm{C}\right)\end{array}$ & $\begin{array}{c}\text { Aging } \\
\text { Time (h) }\end{array}$ & Heat & $\begin{array}{l}\text { Strain Rate } \\
(\mathrm{m} / \mathrm{m} / \mathrm{s})\end{array}$ & Env & $\begin{array}{l}\text { Temp. } \\
\left({ }^{\circ} \mathrm{C}\right)\end{array}$ \\
\hline 1 & Tensile & A508 & Forging (thick) & SSR + Aged & 450 & 20000 & A508-Ht-1 & $1 \mathrm{E}-03$ & air & 20 \\
\hline 2 & Tensile & A508 & Forging (thick) & SSR + Aged & 450 & 20000 & A508-Ht-1 & $1 \mathrm{E}-03$ & air & 20 \\
\hline 3 & Tensile & A508 & Forging (thick) & SSR + Aged & 450 & 20000 & A508-Ht-1 & $1 \mathrm{E}-03$ & air & 150 \\
\hline 4 & Tensile & A508 & Forging (thick) & SSR + Aged & 450 & 20000 & A508-Ht-1 & $1 \mathrm{E}-03$ & air & 150 \\
\hline 5 & Tensile & A508 & Forging (thick) & SSR + Aged & 450 & 20000 & A508-Ht-1 & $1 \mathrm{E}-03$ & air & 250 \\
\hline 6 & Tensile & A508 & Forging (thick) & SSR + Aged & 450 & 20000 & A508-Ht-1 & $1 \mathrm{E}-03$ & air & 250 \\
\hline 7 & Tensile & A508 & Forging (thick) & SSR + Aged & 450 & 20000 & A508-Ht-1 & $1 \mathrm{E}-03$ & air & 350 \\
\hline 8 & Tensile & A508 & Forging (thick) & SSR + Aged & 450 & 20000 & A508-Ht-1 & $1 \mathrm{E}-03$ & air & 350 \\
\hline 9 & Tensile & A508 & Forging (thick) & SSR + Aged & 450 & 20000 & A508-Ht-1 & $1 \mathrm{E}-03$ & air & 450 \\
\hline 10 & Tensile & A508 & Forging (thick) & SSR + Aged & 450 & 20000 & A508-Ht-1 & $1 \mathrm{E}-03$ & air & 450 \\
\hline 11 & Tensile & A508 & Forging (thick) & SSR + Aged & 450 & 20000 & A508-Ht-1 & $1 \mathrm{E}-03$ & air & 550 \\
\hline 12 & Tensile & A508 & Forging (thick) & SSR + Aged & 450 & 20000 & A508-Ht-1 & $1 \mathrm{E}-03$ & air & 550 \\
\hline 13 & Tensile & A508 & Forging (thick) & SSR + Aged & 450 & 20000 & A508-Ht-2 & $1 \mathrm{E}-03$ & air & 20 \\
\hline 14 & Tensile & A508 & Forging (thick) & SSR + Aged & 450 & 20000 & A508-Ht-2 & $1 \mathrm{E}-03$ & air & 20 \\
\hline 15 & Tensile & A508 & Forging (thick) & SSR + Aged & 450 & 20000 & A508-Ht-2 & $1 \mathrm{E}-03$ & air & 150 \\
\hline 16 & Tensile & A508 & Forging (thick) & SSR + Aged & 450 & 20000 & A508-Ht-2 & $1 \mathrm{E}-03$ & air & 150 \\
\hline 17 & Tensile & A508 & Forging (thick) & SSR + Aged & 450 & 20000 & A508-Ht-2 & $1 \mathrm{E}-03$ & air & 250 \\
\hline 18 & Tensile & A508 & Forging (thick) & SSR + Aged & 450 & 20000 & A508-Ht-2 & $1 \mathrm{E}-03$ & air & 250 \\
\hline 19 & Tensile & A508 & Forging (thick) & SSR + Aged & 450 & 20000 & A508-Ht-2 & $1 \mathrm{E}-03$ & air & 350 \\
\hline 20 & Tensile & A508 & Forging (thick) & SSR + Aged & 450 & 20000 & A508-Ht-2 & $1 \mathrm{E}-03$ & air & 350 \\
\hline 21 & Tensile & A508 & Forging (thick) & SSR + Aged & 450 & 20000 & A508-Ht-2 & $1 \mathrm{E}-03$ & air & 450 \\
\hline 22 & Tensile & A508 & Forging (thick) & SSR + Aged & 450 & 20000 & A508-Ht-2 & $1 \mathrm{E}-03$ & air & 450 \\
\hline 23 & Tensile & A508 & Forging (thick) & SSR + Aged & 450 & 20000 & A508-Ht-2 & $1 \mathrm{E}-03$ & air & 550 \\
\hline 24 & Tensile & A508 & Forging (thick) & SSR + Aged & 450 & 20000 & A508-Ht-2 & $1 \mathrm{E}-03$ & air & 550 \\
\hline
\end{tabular}




Idaho National Laboratory
\begin{tabular}{|c|lll|}
\hline NEXT GENERATION NUCLEAR PLANT & Identifier: & PLN-2803 & \\
REACTOR PRESSURE VESSEL MATERIALS & Revision: & 0 & \\
RESEARCH AND DEVELOPMENT PLAN & Effective Date: & $04 / 30 / 08$ & Page: A-41 of A-102 \\
\hline
\end{tabular}

\begin{tabular}{|c|c|c|c|c|c|c|c|c|c|c|}
\hline Spec. \# & Test Type & Mat & Product Form & Mat Cond & $\begin{array}{c}\text { Aging } \\
\text { Temp. } \\
\left({ }^{\circ} \mathrm{C}\right)\end{array}$ & $\begin{array}{c}\text { Aging } \\
\text { Time (h) }\end{array}$ & Heat & $\begin{array}{l}\text { Strain Rate } \\
(\mathrm{m} / \mathrm{m} / \mathrm{s})\end{array}$ & Env & $\begin{array}{l}\text { Temp. } \\
\left({ }^{\circ} \mathrm{C}\right)\end{array}$ \\
\hline 25 & Tensile & A533B & Rolled Plate (thick) & SSR + Aged & 450 & 20000 & A533B-Ht-1 & $1 \mathrm{E}-03$ & air & 20 \\
\hline 26 & Tensile & A533B & Rolled Plate (thick) & SSR + Aged & 450 & 20000 & A533B-Ht-1 & $1 \mathrm{E}-03$ & air & 20 \\
\hline 27 & Tensile & A533B & Rolled Plate (thick) & SSR + Aged & 450 & 20000 & A533B-Ht-1 & $1 \mathrm{E}-03$ & air & 150 \\
\hline 28 & Tensile & A533B & Rolled Plate (thick) & SSR + Aged & 450 & 20000 & A533B-Ht-1 & $1 \mathrm{E}-03$ & air & 150 \\
\hline 29 & Tensile & A533B & Rolled Plate (thick) & SSR + Aged & 450 & 20000 & A533B-Ht-1 & $1 \mathrm{E}-03$ & air & 250 \\
\hline 30 & Tensile & A533B & Rolled Plate (thick) & SSR + Aged & 450 & 20000 & A533B-Ht-1 & $1 \mathrm{E}-03$ & air & 250 \\
\hline 31 & Tensile & A533B & Rolled Plate (thick) & SSR + Aged & 450 & 20000 & A533B-Ht-1 & $1 \mathrm{E}-03$ & air & 350 \\
\hline 32 & Tensile & A533B & Rolled Plate (thick) & SSR + Aged & 450 & 20000 & A533B-Ht-1 & $1 \mathrm{E}-03$ & air & 350 \\
\hline 33 & Tensile & A533B & Rolled Plate (thick) & SSR + Aged & 450 & 20000 & A533B-Ht-1 & $1 \mathrm{E}-03$ & air & 450 \\
\hline 34 & Tensile & A533B & Rolled Plate (thick) & SSR + Aged & 450 & 20000 & A533B-Ht-1 & $1 \mathrm{E}-03$ & air & 450 \\
\hline 35 & Tensile & A533B & Rolled Plate (thick) & SSR + Aged & 450 & 20000 & A533B-Ht-1 & $1 \mathrm{E}-03$ & air & 550 \\
\hline 36 & Tensile & A533B & Rolled Plate (thick) & SSR + Aged & 450 & 20000 & A533B-Ht-1 & $1 \mathrm{E}-03$ & air & 550 \\
\hline 37 & Tensile & A533B & Rolled Plate (thick) & SSR + Aged & 450 & 20000 & A533B-Ht-2 & $1 \mathrm{E}-03$ & air & 20 \\
\hline 38 & Tensile & A533B & Rolled Plate (thick) & SSR + Aged & 450 & 20000 & A533B-Ht-2 & $1 \mathrm{E}-03$ & air & 20 \\
\hline 39 & Tensile & A533B & Rolled Plate (thick) & SSR + Aged & 450 & 20000 & A533B-Ht-2 & $1 \mathrm{E}-03$ & air & 150 \\
\hline 40 & Tensile & A533B & Rolled Plate (thick) & SSR + Aged & 450 & 20000 & A533B-Ht-2 & $1 \mathrm{E}-03$ & air & 150 \\
\hline 41 & Tensile & A533B & Rolled Plate (thick) & SSR + Aged & 450 & 20000 & A533B-Ht-2 & $1 \mathrm{E}-03$ & air & 250 \\
\hline 42 & Tensile & A533B & Rolled Plate (thick) & SSR + Aged & 450 & 20000 & A533B-Ht-2 & $1 \mathrm{E}-03$ & air & 250 \\
\hline 43 & Tensile & A533B & Rolled Plate (thick) & SSR + Aged & 450 & 20000 & A533B-Ht-2 & $1 \mathrm{E}-03$ & air & 350 \\
\hline 44 & Tensile & A533B & Rolled Plate (thick) & SSR + Aged & 450 & 20000 & A533B-Ht-2 & $1 \mathrm{E}-03$ & air & 350 \\
\hline 45 & Tensile & A533B & Rolled Plate (thick) & SSR + Aged & 450 & 20000 & A533B-Ht-2 & $1 \mathrm{E}-03$ & air & 450 \\
\hline 46 & Tensile & A533B & Rolled Plate (thick) & SSR + Aged & 450 & 20000 & A533B-Ht-2 & $1 \mathrm{E}-03$ & air & 450 \\
\hline 47 & Tensile & A533B & Rolled Plate (thick) & SSR + Aged & 450 & 20000 & A533B-Ht-2 & $1 \mathrm{E}-03$ & air & 550 \\
\hline 48 & Tensile & A533B & Rolled Plate (thick) & SSR + Aged & 450 & 20000 & A533B-Ht-2 & $1 \mathrm{E}-03$ & air & 550 \\
\hline
\end{tabular}




Idaho National Laboratory
\begin{tabular}{|c|lll|}
\hline NEXT GENERATION NUCLEAR PLANT & Identifier: & PLN-2803 & \\
REACTOR PRESSURE VESSEL MATERIALS & Revision: & 0 & \\
RESEARCH AND DEVELOPMENT PLAN & Effective Date: & $04 / 30 / 08$ & Page: A-42 of A-102 \\
\hline
\end{tabular}

\begin{tabular}{|c|c|c|c|c|c|c|c|c|c|c|c|c|}
\hline $\begin{array}{c}\text { Spec. } \\
\#\end{array}$ & $\begin{array}{l}\text { Test } \\
\text { Type }\end{array}$ & $\begin{array}{c}\text { Weld } \\
\text { Con- } \\
\text { sumable } \\
\end{array}$ & $\begin{array}{l}\text { Section } \\
\text { Thickness } \\
(\mathrm{mm})\end{array}$ & Weld Process & $\begin{array}{c}\text { Base Metal } \\
\text { Heat }\end{array}$ & $\begin{array}{c}\text { Weld to be } \\
\text { Tested }\end{array}$ & Mat Cond & $\begin{array}{l}\text { Aging } \\
\text { Temp. } \\
\left({ }^{\circ} \mathrm{C}\right)\end{array}$ & $\begin{array}{c}\text { Aging } \\
\text { Time (h) }\end{array}$ & $\begin{array}{c}\text { Strain } \\
\text { Rate } \\
(\mathrm{m} / \mathrm{m} / \mathrm{s})\end{array}$ & Env & $\begin{array}{l}\text { Temp. } \\
\left({ }^{\circ} \mathrm{C}\right)\end{array}$ \\
\hline 1 & Tensile & TBD & $\sim 250$ & SAW & A508-Ht-1 & X-Weld & SSR + Aged & 450 & 20000 & $1 \mathrm{E}-03$ & air & 20 \\
\hline 2 & Tensile & TBD & $\sim 250$ & SAW & A508-Ht-1 & X-Weld & SSR + Aged & 450 & 20000 & $1 \mathrm{E}-03$ & air & 20 \\
\hline 3 & Tensile & TBD & $\sim 250$ & SAW & A508-Ht-1 & X-Weld & SSR + Aged & 450 & 20000 & $1 \mathrm{E}-03$ & air & 150 \\
\hline 4 & Tensile & TBD & $\sim 250$ & SAW & A508-Ht-1 & X-Weld & SSR + Aged & 450 & 20000 & $1 \mathrm{E}-03$ & air & 150 \\
\hline 5 & Tensile & TBD & $\sim 250$ & SAW & A508-Ht-1 & X-Weld & SSR + Aged & 450 & 20000 & $1 \mathrm{E}-03$ & air & 250 \\
\hline 6 & Tensile & TBD & $\sim 250$ & SAW & A508-Ht-1 & X-Weld & SSR + Aged & 450 & 20000 & $1 \mathrm{E}-03$ & air & 250 \\
\hline 7 & Tensile & TBD & $\sim 250$ & SAW & A508-Ht-1 & X-Weld & SSR + Aged & 450 & 20000 & $1 \mathrm{E}-03$ & air & 350 \\
\hline 8 & Tensile & TBD & $\sim 250$ & SAW & A508-Ht-1 & X-Weld & SSR + Aged & 450 & 20000 & $1 \mathrm{E}-03$ & air & 350 \\
\hline 9 & Tensile & TBD & $\sim 250$ & SAW & A508-Ht-1 & X-Weld & SSR + Aged & 450 & 20000 & $1 \mathrm{E}-03$ & air & 450 \\
\hline 10 & Tensile & TBD & $\sim 250$ & SAW & A508-Ht-1 & X-Weld & SSR + Aged & 450 & 20000 & $1 \mathrm{E}-03$ & air & 450 \\
\hline 11 & Tensile & TBD & $\sim 250$ & SAW & A508-Ht-1 & X-Weld & SSR + Aged & 450 & 20000 & $1 \mathrm{E}-03$ & air & 550 \\
\hline 12 & Tensile & TBD & $\sim 250$ & SAW & A508-Ht-1 & X-Weld & SSR + Aged & 450 & 20000 & $1 \mathrm{E}-03$ & air & 550 \\
\hline 13 & Tensile & TBD & $\sim 50$ & SMAW & A508-Ht-1 & X-Weld & SSR + Aged & 450 & 20000 & $1 \mathrm{E}-03$ & air & 20 \\
\hline 14 & Tensile & TBD & $\sim 50$ & SMAW & A508-Ht-1 & X-Weld & SSR + Aged & 450 & 20000 & $1 \mathrm{E}-03$ & air & 20 \\
\hline 15 & Tensile & TBD & $\sim 50$ & SMAW & A508-Ht-1 & X-Weld & SSR + Aged & 450 & 20000 & $1 \mathrm{E}-03$ & air & 150 \\
\hline 16 & Tensile & TBD & $\sim 50$ & SMAW & A508-Ht-1 & X-Weld & SSR + Aged & 450 & 20000 & $1 \mathrm{E}-03$ & air & 150 \\
\hline 17 & Tensile & TBD & $\sim 50$ & SMAW & A508-Ht-1 & X-Weld & SSR + Aged & 450 & 20000 & $1 \mathrm{E}-03$ & air & 250 \\
\hline 18 & Tensile & TBD & $\sim 50$ & SMAW & A508-Ht-1 & X-Weld & SSR + Aged & 450 & 20000 & $1 \mathrm{E}-03$ & air & 250 \\
\hline 19 & Tensile & TBD & $\sim 50$ & SMAW & A508-Ht-1 & X-Weld & SSR + Aged & 450 & 20000 & $1 \mathrm{E}-03$ & air & 350 \\
\hline 20 & Tensile & TBD & $\sim 50$ & SMAW & A508-Ht-1 & X-Weld & SSR + Aged & 450 & 20000 & $1 \mathrm{E}-03$ & air & 350 \\
\hline 21 & Tensile & TBD & $\sim 50$ & SMAW & A508-Ht-1 & X-Weld & SSR + Aged & 450 & 20000 & 1E-03 & air & 450 \\
\hline 22 & Tensile & TBD & $\sim 50$ & SMAW & A508-Ht-1 & X-Weld & SSR + Aged & 450 & 20000 & $1 \mathrm{E}-03$ & air & 450 \\
\hline 23 & Tensile & TBD & $\sim 50$ & SMAW & A508-Ht-1 & X-Weld & SSR + Aged & 450 & 20000 & $1 \mathrm{E}-03$ & air & 550 \\
\hline 24 & Tensile & TBD & $\sim 50$ & SMAW & A508-Ht-1 & X-Weld & SSR + Aged & 450 & 20000 & $1 \mathrm{E}-03$ & air & 550 \\
\hline
\end{tabular}


Idaho National Laboratory

\begin{tabular}{c|lll|} 
NEXT GENERATION NUCLEAR PLANT & Identifier: & PLN-2803 & \\
REACTOR PRESSURE VESSEL MATERIALS & Revision: & 0 & \\
RESEARCH AND DEVELOPMENT PLAN & Effective Date: & $04 / 30 / 08$ & Page: A-43 of A-102 \\
\hline
\end{tabular}

\begin{tabular}{|c|c|c|c|c|c|c|c|c|c|c|c|c|}
\hline $\begin{array}{c}\text { Spec. } \\
\#\end{array}$ & $\begin{array}{l}\text { Test } \\
\text { Type }\end{array}$ & $\begin{array}{c}\text { Weld } \\
\text { Con- } \\
\text { sumable }\end{array}$ & $\begin{array}{c}\text { Section } \\
\text { Thickness } \\
(\mathrm{mm})\end{array}$ & Weld Process & $\begin{array}{c}\text { Base Metal } \\
\text { Heat }\end{array}$ & $\begin{array}{c}\text { Weld to be } \\
\text { Tested }\end{array}$ & Mat Cond & $\begin{array}{l}\text { Aging } \\
\text { Temp. } \\
\left({ }^{\circ} \mathrm{C}\right)\end{array}$ & $\begin{array}{c}\text { Aging } \\
\text { Time (h) }\end{array}$ & $\begin{array}{c}\text { Strain } \\
\text { Rate } \\
(\mathrm{m} / \mathrm{m} / \mathrm{s})\end{array}$ & Env & $\begin{array}{c}\text { Temp. } \\
\left({ }^{\circ} \mathrm{C}\right)\end{array}$ \\
\hline 25 & Tensile & TBD & $\sim 250$ & SAW & A533B-Ht-1 & X-Weld & $\mathrm{SSR}+$ Aged & 450 & 20000 & $1 \mathrm{E}-03$ & air & 20 \\
\hline 26 & Tensile & TBD & $\sim 250$ & SAW & A533B-Ht-1 & X-Weld & $\mathrm{SSR}+$ Aged & 450 & 20000 & $1 \mathrm{E}-03$ & air & 20 \\
\hline 27 & Tensile & TBD & $\sim 250$ & SAW & A533B-Ht-1 & X-Weld & $\mathrm{SSR}+$ Aged & 450 & 20000 & $1 \mathrm{E}-03$ & air & 150 \\
\hline 28 & Tensile & TBD & $\sim 250$ & SAW & A533B-Ht-1 & X-Weld & SSR + Aged & 450 & 20000 & $1 \mathrm{E}-03$ & air & 150 \\
\hline 29 & Tensile & TBD & $\sim 250$ & SAW & A533B-Ht-1 & X-Weld & SSR + Aged & 450 & 20000 & $1 \mathrm{E}-03$ & air & 250 \\
\hline 30 & Tensile & TBD & $\sim 250$ & SAW & A533B-Ht-1 & X-Weld & SSR + Aged & 450 & 20000 & $1 \mathrm{E}-03$ & air & 250 \\
\hline 31 & Tensile & TBD & $\sim 250$ & SAW & A533B-Ht-1 & X-Weld & SSR + Aged & 450 & 20000 & $1 \mathrm{E}-03$ & air & 350 \\
\hline 32 & Tensile & TBD & $\sim 250$ & SAW & A533B-Ht-1 & X-Weld & SSR + Aged & 450 & 20000 & $1 \mathrm{E}-03$ & air & 350 \\
\hline 33 & Tensile & TBD & $\sim 250$ & SAW & A533B-Ht-1 & X-Weld & SSR + Aged & 450 & 20000 & $1 \mathrm{E}-03$ & air & 450 \\
\hline 34 & Tensile & TBD & $\sim 250$ & SAW & A533B-Ht-1 & X-Weld & SSR + Aged & 450 & 20000 & $1 \mathrm{E}-03$ & air & 450 \\
\hline 35 & Tensile & TBD & $\sim 250$ & SAW & A533B-Ht-1 & X-Weld & SSR + Aged & 450 & 20000 & $1 \mathrm{E}-03$ & air & 550 \\
\hline 36 & Tensile & TBD & $\sim 250$ & SAW & A533B-Ht-1 & X-Weld & SSR + Aged & 450 & 20000 & $1 \mathrm{E}-03$ & air & 550 \\
\hline 37 & Tensile & TBD & $\sim 50$ & SMAW & A533B-Ht-1 & X-Weld & SSR + Aged & 450 & 20000 & $1 \mathrm{E}-03$ & air & 20 \\
\hline 38 & Tensile & TBD & $\sim 50$ & SMAW & A533B-Ht-1 & X-Weld & SSR + Aged & 450 & 20000 & $1 \mathrm{E}-03$ & air & 20 \\
\hline 39 & Tensile & TBD & $\sim 50$ & SMAW & A533B-Ht-1 & X-Weld & SSR + Aged & 450 & 20000 & $1 \mathrm{E}-03$ & air & 150 \\
\hline 40 & Tensile & TBD & $\sim 50$ & SMAW & A533B-Ht-1 & X-Weld & SSR + Aged & 450 & 20000 & $1 \mathrm{E}-03$ & air & 150 \\
\hline 41 & Tensile & TBD & $\sim 50$ & SMAW & A533B-Ht-1 & X-Weld & SSR + Aged & 450 & 20000 & $1 \mathrm{E}-03$ & air & 250 \\
\hline 42 & Tensile & TBD & $\sim 50$ & SMAW & A533B-Ht-1 & X-Weld & SSR + Aged & 450 & 20000 & $1 \mathrm{E}-03$ & air & 250 \\
\hline 43 & Tensile & TBD & $\sim 50$ & SMAW & A533B-Ht-1 & X-Weld & SSR + Aged & 450 & 20000 & $1 \mathrm{E}-03$ & air & 350 \\
\hline 44 & Tensile & TBD & $\sim 50$ & SMAW & A533B-Ht-1 & X-Weld & SSR + Aged & 450 & 20000 & $1 \mathrm{E}-03$ & air & 350 \\
\hline 45 & Tensile & TBD & $\sim 50$ & SMAW & A533B-Ht-1 & X-Weld & SSR + Aged & 450 & 20000 & $1 \mathrm{E}-03$ & air & 450 \\
\hline 46 & Tensile & TBD & $\sim 50$ & SMAW & A533B-Ht-1 & X-Weld & SSR + Aged & 450 & 20000 & $1 \mathrm{E}-03$ & air & 450 \\
\hline 47 & Tensile & TBD & $\sim 50$ & SMAW & A533B-Ht-1 & X-Weld & SSR + Aged & 450 & 20000 & $1 \mathrm{E}-03$ & air & 550 \\
\hline 48 & Tensile & TBD & $\sim 50$ & SMAW & A533B-Ht-1 & X-Weld & SSR + Aged & 450 & 20000 & $1 \mathrm{E}-03$ & air & 550 \\
\hline
\end{tabular}




Idaho National Laboratory
\begin{tabular}{|c|lll|}
\hline NEXT GENERATION NUCLEAR PLANT & Identifier: & PLN-2803 & \\
REACTOR PRESSURE VESSEL MATERIALS & Revision: & 0 & \\
RESEARCH AND DEVELOPMENT PLAN & Effective Date: & $04 / 30 / 08$ & Page: A-44 of A-102 \\
\hline
\end{tabular}

\begin{tabular}{|c|c|c|c|c|c|c|c|c|c|c|}
\hline Spec. \# & Test Type & Material & Product Form & Mat Cond & $\begin{array}{c}\text { Aging } \\
\text { Temp. }\left({ }^{\circ} \mathrm{C}\right)\end{array}$ & $\begin{array}{l}\text { Aging Time } \\
\text { (h) }\end{array}$ & Heat & $\begin{array}{l}\text { Strain Rate } \\
(\mathrm{m} / \mathrm{m} / \mathrm{s})\end{array}$ & Env & $\begin{array}{l}\text { Temp. } \\
\left({ }^{\circ} \mathrm{C}\right)\end{array}$ \\
\hline 1 & Tensile & A508 & Forging (thick) & SSR + Aged & 450 & 70000 & A508-Ht-1 & $1 \mathrm{E}-03$ & air & 20 \\
\hline 2 & Tensile & A508 & Forging (thick) & SSR + Aged & 450 & 70000 & A508-Ht-1 & $1 \mathrm{E}-03$ & air & 20 \\
\hline 3 & Tensile & A508 & Forging (thick) & SSR + Aged & 450 & 70000 & A508-Ht-1 & $1 \mathrm{E}-03$ & air & 150 \\
\hline 4 & Tensile & A508 & Forging (thick) & SSR + Aged & 450 & 70000 & A508-Ht-1 & $1 \mathrm{E}-03$ & air & 150 \\
\hline 5 & Tensile & A508 & Forging (thick) & SSR + Aged & 450 & 70000 & A508-Ht-1 & $1 \mathrm{E}-03$ & air & 250 \\
\hline 6 & Tensile & A508 & Forging (thick) & SSR + Aged & 450 & 70000 & A508-Ht-1 & $1 \mathrm{E}-03$ & air & 250 \\
\hline 7 & Tensile & A508 & Forging (thick) & SSR + Aged & 450 & 70000 & A508-Ht-1 & $1 \mathrm{E}-03$ & air & 350 \\
\hline 8 & Tensile & $\mathrm{A} 508$ & Forging (thick) & SSR + Aged & 450 & 70000 & A508-Ht-1 & $1 \mathrm{E}-03$ & air & 350 \\
\hline 9 & Tensile & A508 & Forging (thick) & SSR + Aged & 450 & 70000 & A508-Ht-1 & $1 \mathrm{E}-03$ & air & 450 \\
\hline 10 & Tensile & A508 & Forging (thick) & SSR + Aged & 450 & 70000 & A508-Ht-1 & $1 \mathrm{E}-03$ & air & 450 \\
\hline 11 & Tensile & A508 & Forging (thick) & SSR + Aged & 450 & 70000 & A508-Ht-1 & $1 \mathrm{E}-03$ & air & 550 \\
\hline 12 & Tensile & A508 & Forging (thick) & SSR + Aged & 450 & 70000 & A508-Ht-1 & $1 \mathrm{E}-03$ & air & 550 \\
\hline 13 & Tensile & A508 & Forging (thick) & SSR + Aged & 450 & 70000 & A508-Ht-2 & $1 \mathrm{E}-03$ & air & 20 \\
\hline 14 & Tensile & A508 & Forging (thick) & SSR + Aged & 450 & 70000 & A508-Ht-2 & $1 \mathrm{E}-03$ & air & 20 \\
\hline 15 & Tensile & A508 & Forging (thick) & SSR + Aged & 450 & 70000 & A508-Ht-2 & $1 \mathrm{E}-03$ & air & 150 \\
\hline 16 & Tensile & A508 & Forging (thick) & SSR + Aged & 450 & 70000 & A508-Ht-2 & $1 \mathrm{E}-03$ & air & 150 \\
\hline 17 & Tensile & A508 & Forging (thick) & SSR + Aged & 450 & 70000 & A508-Ht-2 & $1 \mathrm{E}-03$ & air & 250 \\
\hline 18 & Tensile & A508 & Forging (thick) & SSR + Aged & 450 & 70000 & A508-Ht-2 & $1 \mathrm{E}-03$ & air & 250 \\
\hline 19 & Tensile & A508 & Forging (thick) & SSR + Aged & 450 & 70000 & A508-Ht-2 & $1 \mathrm{E}-03$ & air & 350 \\
\hline 20 & Tensile & A508 & Forging (thick) & SSR + Aged & 450 & 70000 & A508-Ht-2 & $1 \mathrm{E}-03$ & air & 350 \\
\hline 21 & Tensile & A508 & Forging (thick) & SSR + Aged & 450 & 70000 & A508-Ht-2 & $1 \mathrm{E}-03$ & air & 450 \\
\hline 22 & Tensile & A508 & Forging (thick) & SSR + Aged & 450 & 70000 & A508-Ht-2 & $1 \mathrm{E}-03$ & air & 450 \\
\hline 23 & Tensile & A508 & Forging (thick) & SSR + Aged & 450 & 70000 & A508-Ht-2 & $1 \mathrm{E}-03$ & air & 550 \\
\hline 24 & Tensile & A508 & Forging (thick) & SSR + Aged & 450 & 70000 & A508-Ht-2 & $1 \mathrm{E}-03$ & air & 550 \\
\hline 25 & Tensile & A533B & Rolled Plate (thick) & SSR + Aged & 450 & 70000 & A533B-Ht-1 & $1 \mathrm{E}-03$ & air & 20 \\
\hline
\end{tabular}




Idaho National Laboratory
\begin{tabular}{|c|lll|}
\hline NEXT GENERATION NUCLEAR PLANT & Identifier: & PLN-2803 & \\
REACTOR PRESSURE VESSEL MATERIALS & Revision: & 0 & \\
RESEARCH AND DEVELOPMENT PLAN & Effective Date: & $04 / 30 / 08$ & Page: A-45 of A-102 \\
\hline
\end{tabular}

\begin{tabular}{|c|c|c|c|c|c|c|c|c|c|c|}
\hline Spec. \# & Test Type & Material & Product Form & Mat Cond & $\begin{array}{c}\text { Aging } \\
\text { Temp. }\left({ }^{\circ} \mathrm{C}\right)\end{array}$ & $\begin{array}{l}\text { Aging Time } \\
\text { (h) }\end{array}$ & Heat & $\begin{array}{l}\text { Strain Rate } \\
(\mathrm{m} / \mathrm{m} / \mathrm{s})\end{array}$ & Env & $\begin{array}{l}\text { Temp. } \\
\left({ }^{\circ} \mathrm{C}\right)\end{array}$ \\
\hline 26 & Tensile & A533B & Rolled Plate (thick) & SSR + Aged & 450 & 70000 & A533B-Ht-1 & $1 \mathrm{E}-03$ & air & 20 \\
\hline 27 & Tensile & A533B & Rolled Plate (thick) & SSR + Aged & 450 & 70000 & A533B-Ht-1 & $1 \mathrm{E}-03$ & air & 150 \\
\hline 28 & Tensile & A533B & Rolled Plate (thick) & SSR + Aged & 450 & 70000 & A533B-Ht-1 & $1 \mathrm{E}-03$ & air & 150 \\
\hline 29 & Tensile & A533B & Rolled Plate (thick) & SSR + Aged & 450 & 70000 & A533B-Ht-1 & $1 \mathrm{E}-03$ & air & 250 \\
\hline 30 & Tensile & A533B & Rolled Plate (thick) & SSR + Aged & 450 & 70000 & A533B-Ht-1 & $1 \mathrm{E}-03$ & air & 250 \\
\hline 31 & Tensile & A533B & Rolled Plate (thick) & SSR + Aged & 450 & 70000 & A533B-Ht-1 & $1 \mathrm{E}-03$ & air & 350 \\
\hline 32 & Tensile & A533B & Rolled Plate (thick) & SSR + Aged & 450 & 70000 & A533B-Ht-1 & $1 \mathrm{E}-03$ & air & 350 \\
\hline 33 & Tensile & A533B & Rolled Plate (thick) & SSR + Aged & 450 & 70000 & A533B-Ht-1 & $1 \mathrm{E}-03$ & air & 450 \\
\hline 34 & Tensile & A533B & Rolled Plate (thick) & SSR + Aged & 450 & 70000 & A533B-Ht-1 & $1 \mathrm{E}-03$ & air & 450 \\
\hline 35 & Tensile & A533B & Rolled Plate (thick) & SSR + Aged & 450 & 70000 & A533B-Ht-1 & $1 \mathrm{E}-03$ & air & 550 \\
\hline 36 & Tensile & A533B & Rolled Plate (thick) & SSR + Aged & 450 & 70000 & A533B-Ht-1 & $1 \mathrm{E}-03$ & air & 550 \\
\hline 37 & Tensile & A533B & Rolled Plate (thick) & SSR + Aged & 450 & 70000 & A533B-Ht-2 & $1 \mathrm{E}-03$ & air & 20 \\
\hline 38 & Tensile & A533B & Rolled Plate (thick) & SSR + Aged & 450 & 70000 & A533B-Ht-2 & $1 \mathrm{E}-03$ & air & 20 \\
\hline 39 & Tensile & A533B & Rolled Plate (thick) & SSR + Aged & 450 & 70000 & A533B-Ht-2 & $1 \mathrm{E}-03$ & air & 150 \\
\hline 40 & Tensile & A533B & Rolled Plate (thick) & SSR + Aged & 450 & 70000 & A533B-Ht-2 & $1 \mathrm{E}-03$ & air & 150 \\
\hline 41 & Tensile & A533B & Rolled Plate (thick) & SSR + Aged & 450 & 70000 & A533B-Ht-2 & $1 \mathrm{E}-03$ & air & 250 \\
\hline 42 & Tensile & A533B & Rolled Plate (thick) & SSR + Aged & 450 & 70000 & A533B-Ht-2 & $1 \mathrm{E}-03$ & air & 250 \\
\hline 43 & Tensile & A533B & Rolled Plate (thick) & SSR + Aged & 450 & 70000 & A533B-Ht-2 & $1 \mathrm{E}-03$ & air & 350 \\
\hline 44 & Tensile & A533B & Rolled Plate (thick) & SSR + Aged & 450 & 70000 & A533B-Ht-2 & $1 \mathrm{E}-03$ & air & 350 \\
\hline 45 & Tensile & A533B & Rolled Plate (thick) & SSR + Aged & 450 & 70000 & A533B-Ht-2 & $1 \mathrm{E}-03$ & air & 450 \\
\hline 46 & Tensile & A533B & Rolled Plate (thick) & SSR + Aged & 450 & 70000 & A533B-Ht-2 & $1 \mathrm{E}-03$ & air & 450 \\
\hline 47 & Tensile & A533B & Rolled Plate (thick) & SSR + Aged & 450 & 70000 & A533B-Ht-2 & $1 \mathrm{E}-03$ & air & 550 \\
\hline 48 & Tensile & A533B & Rolled Plate (thick) & SSR + Aged & 450 & 70000 & A533B-Ht-2 & $1 \mathrm{E}-03$ & air & 550 \\
\hline
\end{tabular}




Idaho National Laboratory
\begin{tabular}{|c|lll|}
\hline NEXT GENERATION NUCLEAR PLANT & Identifier: & PLN-2803 & \\
REACTOR PRESSURE VESSEL MATERIALS & Revision: & 0 & \\
RESEARCH AND DEVELOPMENT PLAN & Effective Date: & $04 / 30 / 08$ & Page: A-46 of A-102 \\
\hline
\end{tabular}

\begin{tabular}{|c|c|c|c|c|c|c|c|c|c|c|c|c|}
\hline $\begin{array}{c}\text { Spec. } \\
\#\end{array}$ & $\begin{array}{l}\text { Test } \\
\text { Type }\end{array}$ & $\begin{array}{c}\text { Weld } \\
\text { Con- } \\
\text { sumable }\end{array}$ & $\begin{array}{l}\text { Section } \\
\text { Thickness } \\
(\mathrm{mm})\end{array}$ & $\begin{array}{c}\text { Weld } \\
\text { Process }\end{array}$ & $\begin{array}{c}\text { Base Metal } \\
\text { Heat }\end{array}$ & $\begin{array}{l}\text { Weld to } \\
\text { be Tested }\end{array}$ & Mat Cond & $\begin{array}{l}\text { Aging } \\
\text { Temp. } \\
\left({ }^{\circ} \mathrm{C}\right)\end{array}$ & $\begin{array}{c}\text { Aging } \\
\text { Time (h) }\end{array}$ & $\begin{array}{c}\text { Strain } \\
\text { Rate } \\
(\mathrm{m} / \mathrm{m} / \mathrm{s})\end{array}$ & Env & $\begin{array}{l}\text { Temp. } \\
\left({ }^{\circ} \mathrm{C}\right)\end{array}$ \\
\hline 1 & Tensile & TBD & $\sim 250$ & SAW & A508-Ht-1 & X-Weld & SSR + Aged & 450 & 70000 & $1 \mathrm{E}-03$ & air & 20 \\
\hline 2 & Tensile & TBD & $\sim 250$ & SAW & A508-Ht-1 & X-Weld & SSR + Aged & 450 & 70000 & $1 \mathrm{E}-03$ & air & 20 \\
\hline 3 & Tensile & TBD & $\sim 250$ & SAW & A508-Ht-1 & X-Weld & SSR + Aged & 450 & 70000 & $1 \mathrm{E}-03$ & air & 150 \\
\hline 4 & Tensile & TBD & $\sim 250$ & SAW & A508-Ht-1 & X-Weld & SSR + Aged & 450 & 70000 & $1 \mathrm{E}-03$ & air & 150 \\
\hline 5 & Tensile & TBD & $\sim 250$ & SAW & A508-Ht-1 & X-Weld & SSR + Aged & 450 & 70000 & $1 \mathrm{E}-03$ & air & 250 \\
\hline 6 & Tensile & TBD & $\sim 250$ & SAW & A508-Ht-1 & X-Weld & SSR + Aged & 450 & 70000 & $1 \mathrm{E}-03$ & air & 250 \\
\hline 7 & Tensile & TBD & $\sim 250$ & SAW & A508-Ht-1 & X-Weld & SSR + Aged & 450 & 70000 & $1 \mathrm{E}-03$ & air & 350 \\
\hline 8 & Tensile & TBD & $\sim 250$ & SAW & A508-Ht-1 & X-Weld & SSR + Aged & 450 & 70000 & $1 \mathrm{E}-03$ & air & 350 \\
\hline 9 & Tensile & TBD & $\sim 250$ & SAW & A508-Ht-1 & X-Weld & SSR + Aged & 450 & 70000 & $1 \mathrm{E}-03$ & air & 450 \\
\hline 10 & Tensile & TBD & $\sim 250$ & SAW & A508-Ht-1 & X-Weld & SSR + Aged & 450 & 70000 & $1 \mathrm{E}-03$ & air & 450 \\
\hline 11 & Tensile & TBD & $\sim 250$ & SAW & A508-Ht-1 & X-Weld & SSR + Aged & 450 & 70000 & $1 \mathrm{E}-03$ & air & 550 \\
\hline 12 & Tensile & TBD & $\sim 250$ & SAW & A508-Ht-1 & X-Weld & SSR + Aged & 450 & 70000 & $1 \mathrm{E}-03$ & air & 550 \\
\hline 13 & Tensile & TBD & $\sim 50$ & SMAW & A508-Ht-1 & X-Weld & SSR + Aged & 450 & 70000 & $1 \mathrm{E}-03$ & air & 20 \\
\hline 14 & Tensile & TBD & $\sim 50$ & SMAW & A508-Ht-1 & X-Weld & SSR + Aged & 450 & 70000 & $1 \mathrm{E}-03$ & air & 20 \\
\hline 15 & Tensile & TBD & $\sim 50$ & SMAW & A508-Ht-1 & X-Weld & SSR + Aged & 450 & 70000 & $1 \mathrm{E}-03$ & air & 150 \\
\hline 16 & Tensile & TBD & $\sim 50$ & SMAW & A508-Ht-1 & X-Weld & SSR + Aged & 450 & 70000 & $1 \mathrm{E}-03$ & air & 150 \\
\hline 17 & Tensile & TBD & $\sim 50$ & SMAW & A508-Ht-1 & X-Weld & SSR + Aged & 450 & 70000 & $1 \mathrm{E}-03$ & air & 250 \\
\hline 18 & Tensile & TBD & $\sim 50$ & SMAW & A508-Ht-1 & X-Weld & SSR + Aged & 450 & 70000 & $1 \mathrm{E}-03$ & air & 250 \\
\hline 19 & Tensile & TBD & $\sim 50$ & SMAW & A508-Ht-1 & X-Weld & SSR + Aged & 450 & 70000 & $1 \mathrm{E}-03$ & air & 350 \\
\hline 20 & Tensile & TBD & $\sim 50$ & SMAW & A508-Ht-1 & X-Weld & SSR + Aged & 450 & 70000 & $1 \mathrm{E}-03$ & air & 350 \\
\hline 21 & Tensile & TBD & $\sim 50$ & SMAW & A508-Ht-1 & X-Weld & SSR + Aged & 450 & 70000 & 1E-03 & air & 450 \\
\hline 22 & Tensile & TBD & $\sim 50$ & SMAW & A508-Ht-1 & X-Weld & SSR + Aged & 450 & 70000 & $1 \mathrm{E}-03$ & air & 450 \\
\hline 23 & Tensile & TBD & $\sim 50$ & SMAW & A508-Ht-1 & X-Weld & SSR + Aged & 450 & 70000 & $1 \mathrm{E}-03$ & air & 550 \\
\hline 24 & Tensile & TBD & $\sim 50$ & SMAW & A508-Ht-1 & X-Weld & SSR + Aged & 450 & 70000 & $1 \mathrm{E}-03$ & air & 550 \\
\hline
\end{tabular}




Idaho National Laboratory
\begin{tabular}{|c|lll|}
\hline NEXT GENERATION NUCLEAR PLANT & Identifier: & PLN-2803 & \\
REACTOR PRESSURE VESSEL MATERIALS & Revision: & 0 & \\
RESEARCH AND DEVELOPMENT PLAN & Effective Date: & $04 / 30 / 08$ & Page: A-47 of A-102 \\
\hline
\end{tabular}

\begin{tabular}{|c|c|c|c|c|c|c|c|c|c|c|c|c|}
\hline $\begin{array}{c}\text { Spec. } \\
\#\end{array}$ & $\begin{array}{l}\text { Test } \\
\text { Type }\end{array}$ & $\begin{array}{c}\text { Weld } \\
\text { Con- } \\
\text { sumable }\end{array}$ & $\begin{array}{l}\text { Section } \\
\text { Thickness } \\
(\mathrm{mm})\end{array}$ & $\begin{array}{l}\text { Weld } \\
\text { Process }\end{array}$ & $\begin{array}{c}\text { Base Metal } \\
\text { Heat }\end{array}$ & $\begin{array}{l}\text { Weld to } \\
\text { be Tested }\end{array}$ & Mat Cond & $\begin{array}{l}\text { Aging } \\
\text { Temp. } \\
\left({ }^{\circ} \mathrm{C}\right)\end{array}$ & $\begin{array}{c}\text { Aging } \\
\text { Time (h) }\end{array}$ & $\begin{array}{l}\text { Strain } \\
\text { Rate } \\
(\mathrm{m} / \mathrm{m} / \mathrm{s})\end{array}$ & Env & $\begin{array}{l}\text { Temp. } \\
\left({ }^{\circ} \mathrm{C}\right)\end{array}$ \\
\hline 25 & Tensile & TBD & $\sim 250$ & SAW & A533B-Ht-1 & X-Weld & SSR + Aged & 450 & 70000 & $1 \mathrm{E}-03$ & air & 20 \\
\hline 26 & Tensile & TBD & $\sim 250$ & SAW & A533B-Ht-1 & X-Weld & SSR + Aged & 450 & 70000 & $1 \mathrm{E}-03$ & air & 20 \\
\hline 27 & Tensile & TBD & $\sim 250$ & SAW & A533B-Ht-1 & X-Weld & SSR + Aged & 450 & 70000 & $1 \mathrm{E}-03$ & air & 150 \\
\hline 28 & Tensile & TBD & $\sim 250$ & SAW & A533B-Ht-1 & X-Weld & SSR + Aged & 450 & 70000 & $1 \mathrm{E}-03$ & air & 150 \\
\hline 29 & Tensile & TBD & $\sim 250$ & SAW & A533B-Ht-1 & X-Weld & SSR + Aged & 450 & 70000 & $1 \mathrm{E}-03$ & air & 250 \\
\hline 30 & Tensile & TBD & $\sim 250$ & SAW & A533B-Ht-1 & X-Weld & SSR + Aged & 450 & 70000 & $1 \mathrm{E}-03$ & air & 250 \\
\hline 31 & Tensile & TBD & $\sim 250$ & SAW & A533B-Ht-1 & X-Weld & SSR + Aged & 450 & 70000 & $1 \mathrm{E}-03$ & air & 350 \\
\hline 32 & Tensile & TBD & $\sim 250$ & SAW & A533B-Ht-1 & X-Weld & SSR + Aged & 450 & 70000 & $1 \mathrm{E}-03$ & air & 350 \\
\hline 33 & Tensile & TBD & $\sim 250$ & SAW & A533B-Ht-1 & X-Weld & SSR + Aged & 450 & 70000 & $1 \mathrm{E}-03$ & air & 450 \\
\hline 34 & Tensile & TBD & $\sim 250$ & SAW & A533B-Ht-1 & X-Weld & SSR + Aged & 450 & 70000 & $1 \mathrm{E}-03$ & air & 450 \\
\hline 35 & Tensile & TBD & $\sim 250$ & SAW & A533B-Ht-1 & X-Weld & SSR + Aged & 450 & 70000 & $1 \mathrm{E}-03$ & air & 550 \\
\hline 36 & Tensile & TBD & $\sim 250$ & SAW & A533B-Ht-1 & X-Weld & SSR + Aged & 450 & 70000 & $1 \mathrm{E}-03$ & air & 550 \\
\hline 37 & Tensile & TBD & $\sim 50$ & SMAW & A533B-Ht-1 & X-Weld & SSR + Aged & 450 & 70000 & $1 \mathrm{E}-03$ & air & 20 \\
\hline 38 & Tensile & TBD & $\sim 50$ & SMAW & A533B-Ht-1 & X-Weld & SSR + Aged & 450 & 70000 & $1 \mathrm{E}-03$ & air & 20 \\
\hline 39 & Tensile & TBD & $\sim 50$ & SMAW & A533B-Ht-1 & X-Weld & SSR + Aged & 450 & 70000 & $1 \mathrm{E}-03$ & air & 150 \\
\hline 40 & Tensile & TBD & $\sim 50$ & SMAW & A533B-Ht-1 & X-Weld & SSR + Aged & 450 & 70000 & $1 \mathrm{E}-03$ & air & 150 \\
\hline 41 & Tensile & TBD & $\sim 50$ & SMAW & A533B-Ht-1 & X-Weld & SSR + Aged & 450 & 70000 & $1 \mathrm{E}-03$ & air & 250 \\
\hline 42 & Tensile & TBD & $\sim 50$ & SMAW & A533B-Ht-1 & X-Weld & SSR + Aged & 450 & 70000 & $1 \mathrm{E}-03$ & air & 250 \\
\hline 43 & Tensile & TBD & $\sim 50$ & SMAW & A533B-Ht-1 & X-Weld & SSR + Aged & 450 & 70000 & $1 \mathrm{E}-03$ & air & 350 \\
\hline 44 & Tensile & TBD & $\sim 50$ & SMAW & A533B-Ht-1 & X-Weld & SSR + Aged & 450 & 70000 & $1 \mathrm{E}-03$ & air & 350 \\
\hline 45 & Tensile & TBD & $\sim 50$ & SMAW & A533B-Ht-1 & X-Weld & SSR + Aged & 450 & 70000 & $1 \mathrm{E}-03$ & air & 450 \\
\hline 46 & Tensile & TBD & $\sim 50$ & SMAW & A533B-Ht-1 & X-Weld & SSR + Aged & 450 & 70000 & $1 \mathrm{E}-03$ & air & 450 \\
\hline 47 & Tensile & TBD & $\sim 50$ & SMAW & A533B-Ht-1 & X-Weld & SSR + Aged & 450 & 70000 & $1 \mathrm{E}-03$ & air & 550 \\
\hline 48 & Tensile & TBD & $\sim 50$ & SMAW & A533B-Ht-1 & X-Weld & SSR + Aged & 450 & 70000 & $1 \mathrm{E}-03$ & air & 550 \\
\hline
\end{tabular}




Idaho National Laboratory
\begin{tabular}{|c|lll|}
\hline NEXT GENERATION NUCLEAR PLANT & Identifier: & PLN-2803 & \\
REACTOR PRESSURE VESSEL MATERIALS & Revision: & 0 & \\
RESEARCH AND DEVELOPMENT PLAN & Effective Date: & $04 / 30 / 08$ & Page: A-48 of A-102 \\
\hline
\end{tabular}

\begin{tabular}{|c|c|c|c|c|c|c|c|c|c|}
\hline \multicolumn{10}{|c|}{ Table A23. Baseline Toughness Measurement (Master Curve To and J-R Curve) for A 508/533B } \\
\hline Spec.\# & Test Type & $\begin{array}{c}\text { Test } \\
\text { Method }\end{array}$ & Spec. Type & Mat & $\begin{array}{l}\text { Product Form } \\
(\sim 250 \mathrm{~mm} \text { thick })\end{array}$ & Heat \# & Mat Cond. & Env. & $\begin{array}{c}\text { Test Temp. } \\
\left({ }^{\circ} \mathrm{C}\right)\end{array}$ \\
\hline 1 & MC To baseline & E-1921 & $0.5 \mathrm{~T} \mathrm{D}-\mathrm{CT}$ & A508 & Forging & A508-Ht-1 & SSR & Air & TBD \\
\hline 2 & MC To baseline & E-1921 & $0.5 \mathrm{~T} \mathrm{D}-\mathrm{CT}$ & A508 & Forging & A508-Ht-1 & SSR & Air & TBD \\
\hline 3 & MC To baseline & E-1921 & $0.5 \mathrm{~T}$ D-CT & A508 & Forging & A508-Ht-1 & SSR & Air & TBD \\
\hline 4 & MC To baseline & E-1921 & $0.5 \mathrm{~T}$ D-CT & A508 & Forging & A508-Ht-1 & SSR & Air & TBD \\
\hline 5 & MC To baseline & E-1921 & $0.5 \mathrm{~T}$ D-CT & A508 & Forging & A508-Ht-1 & SSR & Air & TBD \\
\hline 6 & MC To baseline & E-1921 & $0.5 \mathrm{~T}$ D-CT & A508 & Forging & A508-Ht-1 & SSR & Air & TBD \\
\hline 7 & MC To baseline & E-1921 & $0.5 \mathrm{~T}$ D-CT & A508 & Forging & A508-Ht-1 & SSR & Air & TBD \\
\hline 8 & MC To baseline & E-1921 & $0.5 \mathrm{~T}$ D-CT & A508 & Forging & A508-Ht-1 & SSR & Air & TBD \\
\hline 9 & MC To baseline & E-1921 & $0.5 \mathrm{~T}$ D-CT & A508 & Forging & A508-Ht-1 & SSR & Air & TBD \\
\hline 10 & MC To baseline & E-1921 & $0.5 \mathrm{~T}$ D-CT & A508 & Forging & A508-Ht-1 & SSR & Air & TBD \\
\hline 11 & MC To baseline & E-1921 & $0.5 \mathrm{~T}$ D-CT & A508 & Forging & A508-Ht-1 & SSR & Air & TBD \\
\hline 12 & MC To baseline & E-1921 & $0.5 \mathrm{~T}$ D-CT & A508 & Forging & A508-Ht-1 & SSR & Air & TBD \\
\hline 13 & $\mathrm{~J}-\mathrm{R}$ baseline & E-1820 & $0.5 \mathrm{~T}$ D-CT & A508 & Forging & A508-Ht-1 & SSR & Air & 20 \\
\hline 14 & J-R baseline & E-1820 & $0.5 \mathrm{~T}$ D-CT & A508 & Forging & A508-Ht-1 & SSR & Air & 20 \\
\hline 15 & $\mathrm{~J}$-R baseline & E-1820 & $0.5 \mathrm{~T}$ D-CT & A508 & Forging & A508-Ht-1 & SSR & Air & 20 \\
\hline 16 & $\mathrm{~J}-\mathrm{R}$ baseline & E-1820 & $0.5 \mathrm{~T}$ D-CT & A508 & Forging & A508-Ht-1 & SSR & Air & 20 \\
\hline 17 & $\mathrm{~J}-\mathrm{R}$ baseline & E-1820 & $0.5 \mathrm{~T}$ D-CT & A508 & Forging & A508-Ht-1 & SSR & Air & 20 \\
\hline 18 & $\mathrm{~J}-\mathrm{R}$ baseline & E-1820 & $0.5 \mathrm{~T}$ D-CT & A508 & Forging & A508-Ht-1 & SSR & Air & 20 \\
\hline 19 & J-R baseline & E-1820 & $0.5 \mathrm{~T}$ D-CT & A508 & Forging & A508-Ht-1 & SSR & Air & 150 \\
\hline 20 & $\mathrm{~J}-\mathrm{R}$ baseline & E-1820 & $0.5 \mathrm{~T}$ D-CT & A508 & Forging & A508-Ht-1 & SSR & Air & 150 \\
\hline 21 & $\mathrm{~J}-\mathrm{R}$ baseline & E-1820 & $0.5 \mathrm{~T}$ D-CT & A508 & Forging & A508-Ht-1 & SSR & Air & 150 \\
\hline 22 & $\mathrm{~J}-\mathrm{R}$ baseline & E-1820 & $0.5 \mathrm{~T}$ D-CT & A508 & Forging & A508-Ht-1 & SSR & Air & 150 \\
\hline 23 & $\mathrm{~J}$-R baseline & E-1820 & $0.5 \mathrm{~T}$ D-CT & A508 & Forging & A508-Ht-1 & SSR & Air & 150 \\
\hline 24 & J-R baseline & E-1820 & $0.5 \mathrm{~T}$ D-CT & A508 & Forging & A508-Ht-1 & SSR & Air & 150 \\
\hline 25 & J-R baseline & E-1820 & $0.5 \mathrm{~T}$ D-CT & A508 & Forging & A508-Ht-1 & SSR & Air & 350 \\
\hline
\end{tabular}




Idaho National Laboratory
\begin{tabular}{|c|lll|}
\hline NEXT GENERATION NUCLEAR PLANT & Identifier: & PLN-2803 & \\
REACTOR PRESSURE VESSEL MATERIALS & Revision: & 0 & \\
RESEARCH AND DEVELOPMENT PLAN & Effective Date: & $04 / 30 / 08$ & Page: A-49 of A-102 \\
\hline
\end{tabular}

\begin{tabular}{|c|c|c|c|c|c|c|c|c|c|}
\hline Spec.\# & Test Type & $\begin{array}{c}\text { Test } \\
\text { Method }\end{array}$ & Spec. Type & Mat & $\begin{array}{l}\text { Product Form } \\
(\sim 250 \mathrm{~mm} \text { thick })\end{array}$ & Heat \# & Mat Cond. & Env. & $\begin{array}{c}\text { Test Temp. } \\
\left({ }^{\circ} \mathrm{C}\right)\end{array}$ \\
\hline 26 & J-R baseline & E-1820 & $0.5 \mathrm{~T}$ D-CT & A508 & Forging & A508-Ht-1 & SSR & Air & 350 \\
\hline 27 & J-R baseline & E-1820 & $0.5 \mathrm{~T}$ D-CT & A508 & Forging & A508-Ht-1 & SSR & Air & 350 \\
\hline 28 & $\mathrm{~J}$-R baseline & E-1820 & $0.5 \mathrm{~T}$ D-CT & A508 & Forging & A508-Ht-1 & SSR & Air & 350 \\
\hline 29 & $\mathrm{~J}$-R baseline & E-1820 & $0.5 \mathrm{~T} \mathrm{D}-\mathrm{CT}$ & A508 & Forging & A508-Ht-1 & SSR & Air & 350 \\
\hline 30 & $\mathrm{~J}-\mathrm{R}$ baseline & E-1820 & $0.5 \mathrm{~T}$ D-CT & A508 & Forging & A508-Ht-1 & SSR & Air & 350 \\
\hline 31 & $\mathrm{~J}-\mathrm{R}$ baseline & E-1820 & $0.5 \mathrm{~T}$ D-CT & A508 & Forging & A508-Ht-1 & SSR & Air & 427 \\
\hline 32 & J-R baseline & E-1820 & $0.5 \mathrm{~T}$ D-CT & A508 & Forging & A508-Ht-1 & SSR & Air & 427 \\
\hline 33 & $\mathrm{~J}$-R baseline & E-1820 & $0.5 \mathrm{~T}$ D-CT & A508 & Forging & A508-Ht-1 & SSR & Air & 427 \\
\hline 34 & J-R baseline & E-1820 & $0.5 \mathrm{~T}$ D-CT & A508 & Forging & A508-Ht-1 & SSR & Air & 427 \\
\hline 35 & J-R baseline & E-1820 & $0.5 \mathrm{~T}$ D-CT & A508 & Forging & A508-Ht-1 & SSR & Air & 427 \\
\hline 36 & $\mathrm{~J}$-R baseline & E-1820 & $0.5 \mathrm{~T}$ D-CT & A508 & Forging & A508-Ht-1 & SSR & Air & 427 \\
\hline 37 & $\mathrm{~J}-\mathrm{R}$ baseline & E-1820 & $0.5 \mathrm{~T}$ D-CT & A508 & Forging & A508-Ht-1 & SSR & Air & 538 \\
\hline 38 & $\mathrm{~J}$-R baseline & E-1820 & $0.5 \mathrm{~T}$ D-CT & A508 & Forging & A508-Ht-1 & SSR & Air & 538 \\
\hline 39 & $\mathrm{~J}$-R baseline & E-1820 & $0.5 \mathrm{~T}$ D-CT & A508 & Forging & A508-Ht-1 & SSR & Air & 538 \\
\hline 40 & $\mathrm{~J}-\mathrm{R}$ baseline & E-1820 & $0.5 \mathrm{~T}$ D-CT & A508 & Forging & A508-Ht-1 & SSR & Air & 538 \\
\hline 41 & J-R baseline & E-1820 & $0.5 \mathrm{~T}$ D-CT & A508 & Forging & A508-Ht-1 & SSR & Air & 538 \\
\hline 42 & J-R baseline & E-1820 & $0.5 \mathrm{~T}$ D-CT & A508 & Forging & A508-Ht-1 & SSR & Air & 538 \\
\hline 43 & MC To baseline & E-1921 & $0.5 \mathrm{~T}$ D-CT & A508 & Forging & A508-Ht-2 & SSR & Air & TBD \\
\hline 44 & MC To baseline & E-1921 & $0.5 \mathrm{~T}$ D-CT & A508 & Forging & A508-Ht-2 & SSR & Air & TBD \\
\hline 45 & MC To baseline & E-1921 & $0.5 \mathrm{~T}$ D-CT & A508 & Forging & A508-Ht-2 & SSR & Air & TBD \\
\hline 46 & MC To baseline & E-1921 & $0.5 \mathrm{~T}$ D-CT & A508 & Forging & A508-Ht-2 & SSR & Air & TBD \\
\hline 47 & MC To baseline & E-1921 & $0.5 \mathrm{~T}$ D-CT & A508 & Forging & A508-Ht-2 & SSR & Air & TBD \\
\hline 48 & MC To baseline & E-1921 & $0.5 \mathrm{~T}$ D-CT & A508 & Forging & A508-Ht-2 & SSR & Air & TBD \\
\hline 49 & MC To baseline & E-1921 & $0.5 \mathrm{~T}$ D-CT & A508 & Forging & A508-Ht-2 & SSR & Air & TBD \\
\hline 50 & MC To baseline & E-1921 & $0.5 \mathrm{~T}$ D-CT & A508 & Forging & A508-Ht-2 & SSR & Air & TBD \\
\hline 51 & MC To baseline & E-1921 & $0.5 \mathrm{~T}$ D-CT & A508 & Forging & A508-Ht-2 & SSR & Air & TBD \\
\hline
\end{tabular}




Idaho National Laboratory
\begin{tabular}{|c|lll|}
\hline NEXT GENERATION NUCLEAR PLANT & Identifier: & PLN-2803 & \\
REACTOR PRESSURE VESSEL MATERIALS & Revision: & 0 & \\
RESEARCH AND DEVELOPMENT PLAN & Effective Date: & $04 / 30 / 08$ & Page: A-50 of A-102 \\
\hline
\end{tabular}

\begin{tabular}{|c|c|c|c|c|c|c|c|c|c|}
\hline Spec. \# & Test Type & $\begin{array}{c}\text { Test } \\
\text { Method }\end{array}$ & Spec. Type & Mat & $\begin{array}{l}\text { Product Form } \\
(\sim 250 \mathrm{~mm} \text { thick })\end{array}$ & Heat \# & Mat Cond. & Env. & $\begin{array}{c}\text { Test Temp } \\
\left({ }^{\circ} \mathrm{C}\right)\end{array}$ \\
\hline 52 & MC To baseline & E-1921 & $0.5 \mathrm{~T}$ D-CT & A508 & Forging & A508-Ht-2 & SSR & Air & TBD \\
\hline 53 & MC To baseline & E-1921 & $0.5 \mathrm{~T}$ D-CT & A508 & Forging & A508-Ht-2 & SSR & Air & TBD \\
\hline 54 & MC To baseline & E-1921 & $0.5 \mathrm{~T}$ D-CT & A508 & Forging & A508-Ht-2 & SSR & Air & TBD \\
\hline 55 & $\mathrm{~J}-\mathrm{R}$ baseline & E-1820 & $0.5 \mathrm{~T} \mathrm{D}-\mathrm{CT}$ & A508 & Forging & A508-Ht-2 & SSR & Air & 20 \\
\hline 56 & J-R baseline & E-1820 & $0.5 \mathrm{~T}$ D-CT & A508 & Forging & A508-Ht-2 & SSR & Air & 20 \\
\hline 57 & $\mathrm{~J}-\mathrm{R}$ baseline & E-1820 & $0.5 \mathrm{~T}$ D-CT & A508 & Forging & A508-Ht-2 & SSR & Air & 20 \\
\hline 58 & J-R baseline & E-1820 & $0.5 \mathrm{~T}$ D-CT & A508 & Forging & A508-Ht-2 & SSR & Air & 20 \\
\hline 59 & $\mathrm{~J}$-R baseline & E-1820 & $0.5 \mathrm{~T}$ D-CT & A508 & Forging & A508-Ht-2 & SSR & Air & 20 \\
\hline 60 & J-R baseline & E-1820 & $0.5 \mathrm{~T}$ D-CT & A508 & Forging & A508-Ht-2 & SSR & Air & 20 \\
\hline 61 & J-R baseline & E-1820 & $0.5 \mathrm{~T}$ D-CT & A508 & Forging & A508-Ht-2 & SSR & Air & 150 \\
\hline 62 & $\mathrm{~J}$-R baseline & E-1820 & $0.5 \mathrm{~T}$ D-CT & A508 & Forging & A508-Ht-2 & SSR & Air & 150 \\
\hline 63 & J-R baseline & E-1820 & $0.5 \mathrm{~T}$ D-CT & A508 & Forging & A508-Ht-2 & SSR & Air & 150 \\
\hline 64 & $\mathrm{~J}$-R baseline & E-1820 & $0.5 \mathrm{~T}$ D-CT & A508 & Forging & A508-Ht-2 & SSR & Air & 150 \\
\hline 65 & $\mathrm{~J}$-R baseline & E-1820 & $0.5 \mathrm{~T}$ D-CT & A508 & Forging & A508-Ht-2 & SSR & Air & 150 \\
\hline 66 & $\mathrm{~J}-\mathrm{R}$ baseline & E-1820 & $0.5 \mathrm{~T}$ D-CT & A508 & Forging & A508-Ht-2 & SSR & Air & 150 \\
\hline 67 & J-R baseline & E-1820 & $0.5 \mathrm{~T}$ D-CT & A508 & Forging & A508-Ht-2 & SSR & Air & 350 \\
\hline 68 & J-R baseline & E-1820 & $0.5 \mathrm{~T}$ D-CT & A508 & Forging & A508-Ht-2 & SSR & Air & 350 \\
\hline 69 & J-R baseline & E-1820 & $0.5 \mathrm{~T}$ D-CT & A508 & Forging & A508-Ht-2 & SSR & Air & 350 \\
\hline 70 & J-R baseline & E-1820 & $0.5 \mathrm{~T}$ D-CT & A508 & Forging & A508-Ht-2 & SSR & Air & 350 \\
\hline 71 & J-R baseline & E-1820 & $0.5 \mathrm{~T}$ D-CT & A508 & Forging & A508-Ht-2 & SSR & Air & 350 \\
\hline 72 & $\mathrm{~J}$-R baseline & E-1820 & $0.5 \mathrm{~T}$ D-CT & A508 & Forging & A508-Ht-2 & SSR & Air & 350 \\
\hline 73 & $\mathrm{~J}$-R baseline & E-1820 & $0.5 \mathrm{~T}$ D-CT & A508 & Forging & A508-Ht-2 & SSR & Air & 427 \\
\hline 74 & $\mathrm{~J}$-R baseline & E-1820 & $0.5 \mathrm{~T}$ D-CT & A508 & Forging & A508-Ht-2 & SSR & Air & 427 \\
\hline 75 & J-R baseline & E-1820 & $0.5 \mathrm{~T}$ D-CT & A508 & Forging & A508-Ht-2 & SSR & Air & 427 \\
\hline 76 & $\mathrm{~J}-\mathrm{R}$ baseline & E-1820 & $0.5 \mathrm{~T}$ D-CT & A508 & Forging & A508-Ht-2 & SSR & Air & 427 \\
\hline 77 & $\mathrm{~J}$-R baseline & E-1820 & $0.5 \mathrm{~T}$ D-CT & A508 & Forging & A508-Ht-2 & SSR & Air & 427 \\
\hline
\end{tabular}




Idaho National Laboratory
\begin{tabular}{|c|lll|}
\hline NEXT GENERATION NUCLEAR PLANT & Identifier: & PLN-2803 & \\
REACTOR PRESSURE VESSEL MATERIALS & Revision: & 0 & \\
RESEARCH AND DEVELOPMENT PLAN & Effective Date: & $04 / 30 / 08$ & Page: A-51 of A-102 \\
\hline
\end{tabular}

\begin{tabular}{|c|c|c|c|c|c|c|c|c|c|}
\hline Spec. \# & Test Type & $\begin{array}{c}\text { Test } \\
\text { Method }\end{array}$ & Spec. Type & Mat & $\begin{array}{l}\text { Product Form } \\
(\sim 250 \mathrm{~mm} \text { thick })\end{array}$ & Heat \# & Mat Cond. & Env. & $\begin{array}{c}\text { Test Temp } \\
\left({ }^{\circ} \mathrm{C}\right)\end{array}$ \\
\hline 78 & J-R baseline & E-1820 & $0.5 \mathrm{~T}$ D-CT & A508 & Forging & A508-Ht-2 & SSR & Air & 427 \\
\hline 79 & J-R baseline & E-1820 & $0.5 \mathrm{~T}$ D-CT & A508 & Forging & A508-Ht-2 & SSR & Air & 538 \\
\hline 80 & J-R baseline & E-1820 & $0.5 \mathrm{~T}$ D-CT & A508 & Forging & A508-Ht-2 & SSR & Air & 538 \\
\hline 81 & $\mathrm{~J}$-R baseline & E-1820 & $0.5 \mathrm{~T}$ D-CT & A508 & Forging & A508-Ht-2 & SSR & Air & 538 \\
\hline 82 & $\mathrm{~J}$-R baseline & E-1820 & $0.5 \mathrm{~T}$ D-CT & A508 & Forging & A508-Ht-2 & SSR & Air & 538 \\
\hline 83 & J-R baseline & E-1820 & $0.5 \mathrm{~T}$ D-CT & A508 & Forging & A508-Ht-2 & SSR & Air & 538 \\
\hline 84 & J-R baseline & E-1820 & $0.5 \mathrm{~T}$ D-CT & A508 & Forging & A508-Ht-2 & SSR & Air & 538 \\
\hline 85 & MC To baseline & E-1921 & $0.5 \mathrm{~T}$ D-CT & A533B & Rolled Plate & A533B-Ht-1 & SSR & Air & TBD \\
\hline 86 & MC To baseline & E-1921 & $0.5 \mathrm{~T}$ D-CT & A533B & Rolled Plate & A533B-Ht-1 & SSR & Air & TBD \\
\hline 87 & MC To baseline & E-1921 & $0.5 \mathrm{~T}$ D-CT & A533B & Rolled Plate & A533B-Ht-1 & SSR & Air & TBD \\
\hline 88 & MC To baseline & E-1921 & $0.5 \mathrm{~T}$ D-CT & A533B & Rolled Plate & A533B-Ht-1 & SSR & Air & TBD \\
\hline 89 & MC To baseline & E-1921 & $0.5 \mathrm{~T}$ D-CT & A533B & Rolled Plate & A533B-Ht-1 & SSR & Air & TBD \\
\hline 90 & MC To baseline & E-1921 & $0.5 \mathrm{~T}$ D-CT & A533B & Rolled Plate & A533B-Ht-1 & SSR & Air & TBD \\
\hline 91 & MC To baseline & E-1921 & $0.5 \mathrm{~T}$ D-CT & A533B & Rolled Plate & A533B-Ht-1 & SSR & Air & TBD \\
\hline 92 & MC To baseline & E-1921 & $0.5 \mathrm{~T}$ D-CT & A533B & Rolled Plate & A533B-Ht-1 & SSR & Air & TBD \\
\hline 93 & MC To baseline & E-1921 & $0.5 \mathrm{~T}$ D-CT & A533B & Rolled Plate & A533B-Ht-1 & SSR & Air & TBD \\
\hline 94 & MC To baseline & E-1921 & $0.5 \mathrm{~T}$ D-CT & A533B & Rolled Plate & A533B-Ht-1 & SSR & Air & TBD \\
\hline 95 & MC To baseline & E-1921 & $0.5 \mathrm{~T}$ D-CT & A533B & Rolled Plate & A533B-Ht-1 & SSR & Air & TBD \\
\hline 96 & MC To baseline & E-1921 & $0.5 \mathrm{~T}$ D-CT & A533B & Rolled Plate & A533B-Ht-1 & SSR & Air & TBD \\
\hline 97 & J-R baseline & E-1820 & $0.5 \mathrm{~T}$ D-CT & A533B & Rolled Plate & A533B-Ht-1 & SSR & Air & 20 \\
\hline 98 & J-R baseline & E-1820 & $0.5 \mathrm{~T}$ D-CT & A533B & Rolled Plate & A533B-Ht-1 & SSR & Air & 20 \\
\hline 99 & J-R baseline & E-1820 & $0.5 \mathrm{~T} \mathrm{D}-\mathrm{CT}$ & A533B & Rolled Plate & A533B-Ht-1 & SSR & Air & 20 \\
\hline 100 & $\mathrm{~J}$-R baseline & E-1820 & $0.5 \mathrm{~T}$ D-CT & A533B & Rolled Plate & A533B-Ht-1 & SSR & Air & 20 \\
\hline 101 & J-R baseline & E-1820 & $0.5 \mathrm{~T}$ D-CT & A533B & Rolled Plate & A533B-Ht-1 & SSR & Air & 20 \\
\hline 102 & J-R baseline & E-1820 & $0.5 \mathrm{~T}$ D-CT & A533B & Rolled Plate & A533B-Ht-1 & SSR & Air & 20 \\
\hline 103 & $\mathrm{~J}$-R baseline & E-1820 & $0.5 \mathrm{~T}$ D-CT & A533B & Rolled Plate & A533B-Ht-1 & SSR & Air & 150 \\
\hline
\end{tabular}




Idaho National Laboratory
\begin{tabular}{|c|lll|}
\hline NEXT GENERATION NUCLEAR PLANT & Identifier: & PLN-2803 & \\
REACTOR PRESSURE VESSEL MATERIALS & Revision: & 0 & \\
RESEARCH AND DEVELOPMENT PLAN & Effective Date: & $04 / 30 / 08$ & Page: A-52 of A-102 \\
\hline
\end{tabular}

\begin{tabular}{|c|c|c|c|c|c|c|c|c|c|}
\hline Spec.\# & Test Type & $\begin{array}{c}\text { Test } \\
\text { Method }\end{array}$ & Spec. Type & Mat & $\begin{array}{l}\text { Product Form } \\
(\sim 250 \mathrm{~mm} \text { thick })\end{array}$ & Heat \# & Mat Cond. & Env. & $\begin{array}{c}\text { Test Temp. } \\
\left({ }^{\circ} \mathrm{C}\right)\end{array}$ \\
\hline 104 & J-R baseline & E-1820 & $0.5 \mathrm{~T}$ D-CT & A533B & Rolled Plate & A533B-Ht-1 & SSR & Air & 150 \\
\hline 105 & $\mathrm{~J}-\mathrm{R}$ baseline & E-1820 & $0.5 \mathrm{~T}$ D-CT & A533B & Rolled Plate & A533B-Ht-1 & SSR & Air & 150 \\
\hline 106 & $\mathrm{~J}-\mathrm{R}$ baseline & E-1820 & $0.5 \mathrm{~T}$ D-CT & A533B & Rolled Plate & A533B-Ht-1 & SSR & Air & 150 \\
\hline 107 & $\mathrm{~J}-\mathrm{R}$ baseline & E-1820 & $0.5 \mathrm{~T}$ D-CT & A533B & Rolled Plate & A533B-Ht-1 & SSR & Air & 150 \\
\hline 108 & $\mathrm{~J}-\mathrm{R}$ baseline & E-1820 & $0.5 \mathrm{~T}$ D-CT & A533B & Rolled Plate & A533B-Ht-1 & SSR & Air & 150 \\
\hline 109 & $\mathrm{~J}-\mathrm{R}$ baseline & E-1820 & $0.5 \mathrm{~T}$ D-CT & A533B & Rolled Plate & A533B-Ht-1 & SSR & Air & 350 \\
\hline 110 & $\mathrm{~J}-\mathrm{R}$ baseline & E-1820 & $0.5 \mathrm{~T}$ D-CT & A533B & Rolled Plate & A533B-Ht-1 & SSR & Air & 350 \\
\hline 111 & $\mathrm{~J}$-R baseline & E-1820 & $0.5 \mathrm{~T}$ D-CT & A533B & Rolled Plate & A533B-Ht-1 & SSR & Air & 350 \\
\hline 112 & $\mathrm{~J}$-R baseline & E-1820 & $0.5 \mathrm{~T}$ D-CT & A533B & Rolled Plate & A533B-Ht-1 & SSR & Air & 350 \\
\hline 113 & J-R baseline & E-1820 & $0.5 \mathrm{~T}$ D-CT & A533B & Rolled Plate & A533B-Ht-1 & SSR & Air & 350 \\
\hline 114 & $\mathrm{~J}$-R baseline & E-1820 & $0.5 \mathrm{~T}$ D-CT & A533B & Rolled Plate & A533B-Ht-1 & SSR & Air & 350 \\
\hline 115 & $\mathrm{~J}-\mathrm{R}$ baseline & E-1820 & $0.5 \mathrm{~T}$ D-CT & A533B & Rolled Plate & A533B-Ht-1 & SSR & Air & 427 \\
\hline 116 & $\mathrm{~J}$-R baseline & E-1820 & $0.5 \mathrm{~T}$ D-CT & A533B & Rolled Plate & A533B-Ht-1 & SSR & Air & 427 \\
\hline 117 & $\mathrm{~J}$-R baseline & E-1820 & $0.5 \mathrm{~T}$ D-CT & A533B & Rolled Plate & A533B-Ht-1 & SSR & Air & 427 \\
\hline 118 & $\mathrm{~J}-\mathrm{R}$ baseline & E-1820 & $0.5 \mathrm{~T}$ D-CT & A533B & Rolled Plate & A533B-Ht-1 & SSR & Air & 427 \\
\hline 119 & J-R baseline & E-1820 & $0.5 \mathrm{~T}$ D-CT & A533B & Rolled Plate & A533B-Ht-1 & SSR & Air & 427 \\
\hline 120 & $\mathrm{~J}$-R baseline & E-1820 & $0.5 \mathrm{~T}$ D-CT & A533B & Rolled Plate & A533B-Ht-1 & SSR & Air & 427 \\
\hline 121 & J-R baseline & E-1820 & $0.5 \mathrm{~T}$ D-CT & A533B & Rolled Plate & A533B-Ht-1 & SSR & Air & 538 \\
\hline 122 & J-R baseline & E-1820 & $0.5 \mathrm{~T}$ D-CT & A533B & Rolled Plate & A533B-Ht-1 & SSR & Air & 538 \\
\hline 123 & J-R baseline & E-1820 & $0.5 \mathrm{~T}$ D-CT & A533B & Rolled Plate & A533B-Ht-1 & SSR & Air & 538 \\
\hline 124 & J-R baseline & E-1820 & $0.5 \mathrm{~T}$ D-CT & A533B & Rolled Plate & A533B-Ht-1 & SSR & Air & 538 \\
\hline 125 & $\mathrm{~J}$-R baseline & E-1820 & $0.5 \mathrm{~T} \mathrm{D}-\mathrm{CT}$ & A533B & Rolled Plate & A533B-Ht-1 & SSR & Air & 538 \\
\hline 126 & $\mathrm{~J}$-R baseline & E-1820 & $0.5 \mathrm{~T}$ D-CT & A533B & Rolled Plate & A533B-Ht-1 & SSR & Air & 538 \\
\hline 127 & MC To baseline & E-1921 & $0.5 \mathrm{~T}$ D-CT & A533B & Rolled Plate & A533B-Ht-2 & SSR & Air & TBD \\
\hline 128 & MC To baseline & E-1921 & $0.5 \mathrm{~T}$ D-CT & A533B & Rolled Plate & A533B-Ht-2 & SSR & Air & TBD \\
\hline 129 & MC To baseline & E-1921 & $0.5 \mathrm{~T}$ D-CT & A533B & Rolled Plate & A533B-Ht-2 & SSR & Air & TBD \\
\hline
\end{tabular}




Idaho National Laboratory
\begin{tabular}{|c|lll|}
\hline NEXT GENERATION NUCLEAR PLANT & Identifier: & PLN-2803 & \\
REACTOR PRESSURE VESSEL MATERIALS & Revision: & 0 & \\
RESEARCH AND DEVELOPMENT PLAN & Effective Date: & $04 / 30 / 08$ & Page: A- 53 of A-102 \\
\hline
\end{tabular}

\begin{tabular}{|c|c|c|c|c|c|c|c|c|c|}
\hline Spec. \# & Test Type & $\begin{array}{c}\text { Test } \\
\text { Method }\end{array}$ & Spec. Type & Mat & $\begin{array}{l}\text { Product Form } \\
(\sim 250 \mathrm{~mm} \text { thick })\end{array}$ & Heat \# & Mat Cond. & Env. & $\begin{array}{c}\text { Test Temp. } \\
\left({ }^{\circ} \mathrm{C}\right)\end{array}$ \\
\hline 130 & MC To baseline & E-1921 & $0.5 \mathrm{~T}$ D-CT & A533B & Rolled Plate & A533B-Ht-2 & SSR & Air & TBD \\
\hline 131 & MC To baseline & E-1921 & $0.5 \mathrm{~T}$ D-CT & A533B & Rolled Plate & A533B-Ht-2 & SSR & Air & TBD \\
\hline 132 & MC To baseline & E-1921 & $0.5 \mathrm{~T}$ D-CT & A533B & Rolled Plate & A533B-Ht-2 & SSR & Air & TBD \\
\hline 133 & MC To baseline & E-1921 & $0.5 \mathrm{~T}$ D-CT & A533B & Rolled Plate & A533B-Ht-2 & SSR & Air & TBD \\
\hline 134 & MC To baseline & E-1921 & $0.5 \mathrm{~T}$ D-CT & A533B & Rolled Plate & A533B-Ht-2 & SSR & Air & TBD \\
\hline 135 & MC To baseline & E-1921 & $0.5 \mathrm{~T}$ D-CT & A533B & Rolled Plate & A533B-Ht-2 & SSR & Air & TBD \\
\hline 136 & MC To baseline & E-1921 & $0.5 \mathrm{~T}$ D-CT & A533B & Rolled Plate & A533B-Ht-2 & SSR & Air & TBD \\
\hline 137 & MC To baseline & E-1921 & $0.5 \mathrm{~T}$ D-CT & A533B & Rolled Plate & A533B-Ht-2 & SSR & Air & TBD \\
\hline 138 & MC To baseline & E-1921 & $0.5 \mathrm{~T}$ D-CT & A533B & Rolled Plate & A533B-Ht-2 & SSR & Air & TBD \\
\hline 139 & J-R baseline & E-1820 & $0.5 \mathrm{~T}$ D-CT & A533B & Rolled Plate & A533B-Ht-2 & SSR & Air & 20 \\
\hline 140 & $\mathrm{~J}$-R baseline & E-1820 & $0.5 \mathrm{~T}$ D-CT & A533B & Rolled Plate & A533B-Ht-2 & SSR & Air & 20 \\
\hline 141 & J-R baseline & E-1820 & $0.5 \mathrm{~T}$ D-CT & A533B & Rolled Plate & A533B-Ht-2 & SSR & Air & 20 \\
\hline 142 & $\mathrm{~J}$-R baseline & E-1820 & $0.5 \mathrm{~T}$ D-CT & A533B & Rolled Plate & A533B-Ht-2 & SSR & Air & 20 \\
\hline 143 & $\mathrm{~J}$-R baseline & E-1820 & $0.5 \mathrm{~T}$ D-CT & A533B & Rolled Plate & A533B-Ht-2 & SSR & Air & 20 \\
\hline 144 & $\mathrm{~J}-\mathrm{R}$ baseline & E-1820 & $0.5 \mathrm{~T}$ D-CT & A533B & Rolled Plate & A533B-Ht-2 & SSR & Air & 20 \\
\hline 145 & J-R baseline & E-1820 & $0.5 \mathrm{~T}$ D-CT & A533B & Rolled Plate & A533B-Ht-2 & SSR & Air & 150 \\
\hline 146 & $\mathrm{~J}$-R baseline & E-1820 & $0.5 \mathrm{~T}$ D-CT & A533B & Rolled Plate & A533B-Ht-2 & SSR & Air & 150 \\
\hline 147 & J-R baseline & E-1820 & $0.5 \mathrm{~T}$ D-CT & A533B & Rolled Plate & A533B-Ht-2 & SSR & Air & 150 \\
\hline 148 & $\mathrm{~J}$-R baseline & E-1820 & $0.5 \mathrm{~T}$ D-CT & A533B & Rolled Plate & A533B-Ht-2 & SSR & Air & 150 \\
\hline 149 & J-R baseline & E-1820 & $0.5 \mathrm{~T}$ D-CT & A533B & Rolled Plate & A533B-Ht-2 & SSR & Air & 150 \\
\hline 150 & $\mathrm{~J}$-R baseline & E-1820 & $0.5 \mathrm{~T}$ D-CT & A533B & Rolled Plate & A533B-Ht-2 & SSR & Air & 150 \\
\hline 151 & $\mathrm{~J}$-R baseline & E-1820 & $0.5 \mathrm{~T} \mathrm{D}-\mathrm{CT}$ & A533B & Rolled Plate & A533B-Ht-2 & SSR & Air & 350 \\
\hline 152 & $\mathrm{~J}$-R baseline & E-1820 & $0.5 \mathrm{~T}$ D-CT & A533B & Rolled Plate & A533B-Ht-2 & SSR & Air & 350 \\
\hline 153 & J-R baseline & E-1820 & $0.5 \mathrm{~T}$ D-CT & A533B & Rolled Plate & A533B-Ht-2 & SSR & Air & 350 \\
\hline 154 & J-R baseline & E-1820 & $0.5 \mathrm{~T}$ D-CT & A533B & Rolled Plate & A533B-Ht-2 & SSR & Air & 350 \\
\hline 155 & $\mathrm{~J}$-R baseline & E-1820 & $0.5 \mathrm{~T} \mathrm{D}-\mathrm{CT}$ & A533B & Rolled Plate & A533B-Ht-2 & SSR & Air & 350 \\
\hline
\end{tabular}




Idaho National Laboratory
\begin{tabular}{|c|lll|}
\hline NEXT GENERATION NUCLEAR PLANT & Identifier: & PLN-2803 & \\
REACTOR PRESSURE VESSEL MATERIALS & Revision: & 0 & \\
RESEARCH AND DEVELOPMENT PLAN & Effective Date: & $04 / 30 / 08$ & Page: A- 54 of A-102 \\
\hline
\end{tabular}

\begin{tabular}{|c|c|c|c|c|c|c|c|c|c|}
\hline Spec.\# & Test Type & $\begin{array}{c}\text { Test } \\
\text { Method }\end{array}$ & Spec. Type & Mat & $\begin{array}{l}\text { Product Form } \\
(\sim 250 \mathrm{~mm} \text { thick })\end{array}$ & Heat \# & Mat Cond. & Env. & $\begin{array}{l}\text { Test Temp. } \\
\left({ }^{\circ} \mathrm{C}\right)\end{array}$ \\
\hline 156 & $\mathrm{~J}-\mathrm{R}$ baseline & E-1820 & $0.5 \mathrm{~T} \mathrm{D}-\mathrm{CT}$ & A533B & Rolled Plate & A533B-Ht-2 & SSR & Air & 350 \\
\hline 157 & J-R baseline & E-1820 & $0.5 \mathrm{~T}$ D-CT & A533B & Rolled Plate & A533B-Ht-2 & SSR & Air & 427 \\
\hline 158 & $\mathrm{~J}$-R baseline & E-1820 & $0.5 \mathrm{~T}$ D-CT & A533B & Rolled Plate & A533B-Ht-2 & SSR & Air & 427 \\
\hline 159 & $\mathrm{~J}-\mathrm{R}$ baseline & E-1820 & $0.5 \mathrm{~T} \mathrm{D}-\mathrm{CT}$ & A533B & Rolled Plate & A533B-Ht-2 & SSR & Air & 427 \\
\hline 160 & J-R baseline & E-1820 & $0.5 \mathrm{~T}$ D-CT & A533B & Rolled Plate & A533B-Ht-2 & SSR & Air & 427 \\
\hline 161 & $\mathrm{~J}-\mathrm{R}$ baseline & E-1820 & $0.5 \mathrm{~T} \mathrm{D}-\mathrm{CT}$ & A533B & Rolled Plate & A533B-Ht-2 & SSR & Air & 427 \\
\hline 162 & J-R baseline & E-1820 & $0.5 \mathrm{~T}$ D-CT & A533B & Rolled Plate & A533B-Ht-2 & SSR & Air & 427 \\
\hline 163 & J-R baseline & E-1820 & $0.5 \mathrm{~T}$ D-CT & A533B & Rolled Plate & A533B-Ht-2 & SSR & Air & 538 \\
\hline 164 & $\mathrm{~J}-\mathrm{R}$ baseline & E-1820 & $0.5 \mathrm{~T}$ D-CT & A533B & Rolled Plate & A533B-Ht-2 & SSR & Air & 538 \\
\hline 165 & J-R baseline & E-1820 & $0.5 \mathrm{~T}$ D-CT & A533B & Rolled Plate & A533B-Ht-2 & SSR & Air & 538 \\
\hline 166 & J-R baseline & E-1820 & $0.5 \mathrm{~T}$ D-CT & A533B & Rolled Plate & A533B-Ht-2 & SSR & Air & 538 \\
\hline 167 & J-R baseline & E-1820 & $0.5 \mathrm{~T}$ D-CT & A533B & Rolled Plate & A533B-Ht-2 & SSR & Air & 538 \\
\hline 168 & $\mathrm{~J}-\mathrm{R}$ baseline & E-1820 & $0.5 \mathrm{~T}$ D-CT & A533B & Rolled Plate & A533B-Ht-2 & SSR & Air & 538 \\
\hline
\end{tabular}




Idaho National Laboratory
\begin{tabular}{|c|lll|}
\hline NEXT GENERATION NUCLEAR PLANT & Identifier: & PLN-2803 & \\
REACTOR PRESSURE VESSEL MATERIALS & Revision: & 0 & \\
RESEARCH AND DEVELOPMENT PLAN & Effective Date: & $04 / 30 / 08$ & Page: A- 55 of A-102 \\
\hline
\end{tabular}

\begin{tabular}{|c|c|c|c|c|c|c|c|c|c|}
\hline Spec. \# & Test Type & $\begin{array}{c}\text { Test } \\
\text { Method }\end{array}$ & Spec. Type & Mat & $\begin{array}{l}\text { Product Form } \\
(\sim 250 \mathrm{~mm} \text { thick })\end{array}$ & Heat \# & Mat Cond. ${ }^{(1)}$ & Env. & $\begin{array}{c}\text { Test Temp. } \\
\left({ }^{\circ} \mathrm{C}\right)\end{array}$ \\
\hline 1 & MC To, Damaged & E-1921 & $0.5 \mathrm{~T}$ D-CT & A508 & Forging & A508-Ht-1 & SSR + Damaged & Air & TBD \\
\hline 2 & MC To, Damaged & E-1921 & $0.5 \mathrm{~T}$ D-CT & A508 & Forging & A508-Ht-1 & SSR + Damaged & Air & TBD \\
\hline 3 & MC To, Damaged & E-1921 & $0.5 \mathrm{~T}$ D-CT & A508 & Forging & A508-Ht-1 & SSR + Damaged & Air & TBD \\
\hline 4 & MC To, Damaged & E-1921 & $0.5 \mathrm{~T}$ D-CT & A508 & Forging & A508-Ht-1 & SSR + Damaged & Air & TBD \\
\hline 5 & MC To, Damaged & E-1921 & $0.5 \mathrm{~T}$ D-CT & A508 & Forging & A508-Ht-1 & SSR + Damaged & Air & TBD \\
\hline 6 & MC To, Damaged & E-1921 & $0.5 \mathrm{~T}$ D-CT & A508 & Forging & A508-Ht-1 & SSR + Damaged & Air & TBD \\
\hline 7 & MC To, Damaged & E-1921 & $0.5 \mathrm{~T}$ D-CT & A508 & Forging & A508-Ht-1 & SSR + Damaged & Air & TBD \\
\hline 8 & MC To, Damaged & E-1921 & $0.5 \mathrm{~T}$ D-CT & A508 & Forging & A508-Ht-1 & SSR + Damaged & Air & TBD \\
\hline 9 & MC To, Damaged & E-1921 & $0.5 \mathrm{~T}$ D-CT & A508 & Forging & A508-Ht-1 & SSR + Damaged & Air & TBD \\
\hline 10 & MC To, Damaged & E-1921 & $0.5 \mathrm{~T}$ D-CT & A508 & Forging & A508-Ht-1 & SSR + Damaged & Air & TBD \\
\hline 11 & MC To, Damaged & E-1921 & $0.5 \mathrm{~T}$ D-CT & A508 & Forging & A508-Ht-1 & SSR + Damaged & Air & TBD \\
\hline 12 & MC To, Damaged & E-1921 & $0.5 \mathrm{~T}$ D-CT & A508 & Forging & A508-Ht-1 & SSR + Damaged & Air & TBD \\
\hline 13 & J-R, Damaged & E-1820 & $0.5 \mathrm{~T}$ D-CT & A508 & Forging & A508-Ht-1 & SSR + Damaged & Air & 20 \\
\hline 14 & J-R, Damaged & E-1820 & $0.5 \mathrm{~T}$ D-CT & A508 & Forging & A508-Ht-1 & SSR + Damaged & Air & 20 \\
\hline 15 & J-R, Damaged & E-1820 & $0.5 \mathrm{~T}$ D-CT & A508 & Forging & A508-Ht-1 & SSR + Damaged & Air & 20 \\
\hline 16 & J-R, Damaged & E-1820 & $0.5 \mathrm{~T}$ D-CT & A508 & Forging & A508-Ht-1 & SSR + Damaged & Air & 20 \\
\hline 17 & J-R, Damaged & E-1820 & $0.5 \mathrm{~T}$ D-CT & A508 & Forging & A508-Ht-1 & SSR + Damaged & Air & 20 \\
\hline 18 & J-R, Damaged & E-1820 & $0.5 \mathrm{~T}$ D-CT & A508 & Forging & A508-Ht-1 & SSR + Damaged & Air & 20 \\
\hline 19 & J-R, Damaged & E-1820 & $0.5 \mathrm{~T}$ D-CT & A508 & Forging & A508-Ht-1 & SSR + Damaged & Air & 150 \\
\hline 20 & J-R, Damaged & E-1820 & $0.5 \mathrm{~T}$ D-CT & A508 & Forging & A508-Ht-1 & SSR + Damaged & Air & 150 \\
\hline 21 & J-R, Damaged & E-1820 & $0.5 \mathrm{~T}$ D-CT & A508 & Forging & A508-Ht-1 & SSR + Damaged & Air & 150 \\
\hline 22 & J-R, Damaged & E-1820 & $0.5 \mathrm{~T} \mathrm{D}-\mathrm{CT}$ & A508 & Forging & A508-Ht-1 & SSR + Damaged & Air & 150 \\
\hline 23 & J-R, Damaged & E-1820 & $0.5 \mathrm{~T}$ D-CT & A508 & Forging & A508-Ht-1 & SSR + Damaged & Air & 150 \\
\hline 24 & J-R, Damaged & E-1820 & $0.5 \mathrm{~T}$ D-CT & A508 & Forging & A508-Ht-1 & SSR + Damaged & Air & 150 \\
\hline 25 & J-R, Damaged & E-1820 & $0.5 \mathrm{~T}$ D-CT & A508 & Forging & A508-Ht-1 & SSR + Damaged & Air & 350 \\
\hline
\end{tabular}




Idaho National Laboratory
\begin{tabular}{|c|lll|}
\hline NEXT GENERATION NUCLEAR PLANT & Identifier: & PLN-2803 & \\
REACTOR PRESSURE VESSEL MATERIALS & Revision: & 0 & \\
RESEARCH AND DEVELOPMENT PLAN & Effective Date: & $04 / 30 / 08$ & Page: A-56 of A-102 \\
\hline
\end{tabular}

\begin{tabular}{|c|c|c|c|c|c|c|c|c|c|}
\hline Spec.\# & Test Type & $\begin{array}{c}\text { Test } \\
\text { Method }\end{array}$ & Spec. Type & Mat & $\begin{array}{l}\text { Product Form } \\
(\sim 250 \mathrm{~mm} \text { thick })\end{array}$ & Heat \# & Mat Cond. ${ }^{(1)}$ & Env. & $\begin{array}{c}\text { Test Temp } \\
\left({ }^{\circ} \mathrm{C}\right)\end{array}$ \\
\hline 26 & J-R, Damaged & E-1820 & $0.5 \mathrm{~T} \mathrm{D}-\mathrm{CT}$ & A508 & Forging & A508-Ht-1 & SSR + Damaged & Air & 350 \\
\hline 27 & J-R, Damaged & E-1820 & $0.5 \mathrm{~T}$ D-CT & A508 & Forging & A508-Ht-1 & SSR + Damaged & Air & 350 \\
\hline 28 & J-R, Damaged & E-1820 & $0.5 \mathrm{~T}$ D-CT & A508 & Forging & A508-Ht-1 & SSR + Damaged & Air & 350 \\
\hline 29 & J-R, Damaged & E-1820 & $0.5 \mathrm{~T} \mathrm{D}-\mathrm{CT}$ & A508 & Forging & A508-Ht-1 & SSR + Damaged & Air & 350 \\
\hline 30 & J-R, Damaged & E-1820 & $0.5 \mathrm{~T}$ D-CT & A508 & Forging & A508-Ht-1 & SSR + Damaged & Air & 350 \\
\hline 31 & J-R, Damaged & E-1820 & $0.5 \mathrm{~T} \mathrm{D}-\mathrm{CT}$ & A508 & Forging & A508-Ht-1 & SSR + Damaged & Air & 427 \\
\hline 32 & J-R, Damaged & E-1820 & $0.5 \mathrm{~T}$ D-CT & A508 & Forging & A508-Ht-1 & SSR + Damaged & Air & 427 \\
\hline 33 & J-R, Damaged & E-1820 & $0.5 \mathrm{~T}$ D-CT & A508 & Forging & A508-Ht-1 & SSR + Damaged & Air & 427 \\
\hline 34 & J-R, Damaged & E-1820 & $0.5 \mathrm{~T}$ D-CT & A508 & Forging & A508-Ht-1 & SSR + Damaged & Air & 427 \\
\hline 35 & J-R, Damaged & E-1820 & $0.5 \mathrm{~T}$ D-CT & A508 & Forging & A508-Ht-1 & SSR + Damaged & Air & 427 \\
\hline 36 & J-R, Damaged & E-1820 & $0.5 \mathrm{~T}$ D-CT & A508 & Forging & A508-Ht-1 & SSR + Damaged & Air & 427 \\
\hline 37 & J-R, Damaged & E-1820 & $0.5 \mathrm{~T}$ D-CT & A508 & Forging & A508-Ht-1 & SSR + Damaged & Air & 538 \\
\hline 38 & J-R, Damaged & E-1820 & $0.5 \mathrm{~T} \mathrm{D}-\mathrm{CT}$ & A508 & Forging & A508-Ht-1 & SSR + Damaged & Air & 538 \\
\hline 39 & J-R, Damaged & E-1820 & $0.5 \mathrm{~T}$ D-CT & A508 & Forging & A508-Ht-1 & SSR + Damaged & Air & 538 \\
\hline 40 & J-R, Damaged & E-1820 & $0.5 \mathrm{~T}$ D-CT & A508 & Forging & A508-Ht-1 & SSR + Damaged & Air & 538 \\
\hline 41 & J-R, Damaged & E-1820 & $0.5 \mathrm{~T}$ D-CT & A508 & Forging & A508-Ht-1 & SSR + Damaged & Air & 538 \\
\hline 42 & J-R, Damaged & E-1820 & $0.5 \mathrm{~T}$ D-CT & A508 & Forging & A508-Ht-1 & SSR + Damaged & Air & 538 \\
\hline 43 & MC To, Damaged & E-1921 & $0.5 \mathrm{~T} \mathrm{D}-\mathrm{CT}$ & A508 & Forging & A508-Ht-2 & SSR + Damaged & Air & TBD \\
\hline 44 & MC To, Damaged & E-1921 & $0.5 \mathrm{~T} \mathrm{D}-\mathrm{CT}$ & A508 & Forging & A508-Ht-2 & SSR + Damaged & Air & TBD \\
\hline 45 & MC To, Damaged & E-1921 & $0.5 \mathrm{~T}$ D-CT & A508 & Forging & A508-Ht-2 & SSR + Damaged & Air & TBD \\
\hline 46 & MC To, Damaged & E-1921 & $0.5 \mathrm{~T}$ D-CT & A508 & Forging & A508-Ht-2 & SSR + Damaged & Air & TBD \\
\hline 47 & MC To, Damaged & E-1921 & $0.5 \mathrm{~T}$ D-CT & A508 & Forging & A508-Ht-2 & SSR + Damaged & Air & TBD \\
\hline 48 & MC To, Damaged & E-1921 & $0.5 \mathrm{~T} \mathrm{D}-\mathrm{CT}$ & A508 & Forging & A508-Ht-2 & SSR + Damaged & Air & TBD \\
\hline 49 & MC To, Damaged & E-1921 & $0.5 \mathrm{~T}$ D-CT & A508 & Forging & A508-Ht-2 & SSR + Damaged & Air & TBD \\
\hline 50 & MC To, Damaged & E-1921 & $0.5 \mathrm{~T}$ D-CT & A508 & Forging & A508-Ht-2 & SSR + Damaged & Air & TBD \\
\hline 51 & MC To, Damaged & E-1921 & $0.5 \mathrm{~T} \mathrm{D}-\mathrm{CT}$ & A508 & Forging & A508-Ht-2 & SSR + Damaged & Air & TBD \\
\hline
\end{tabular}




Idaho National Laboratory
\begin{tabular}{|c|lll|}
\hline NEXT GENERATION NUCLEAR PLANT & Identifier: & PLN-2803 & \\
REACTOR PRESSURE VESSEL MATERIALS & Revision: & 0 & \\
RESEARCH AND DEVELOPMENT PLAN & Effective Date: & $04 / 30 / 08$ & Page: A-57 of A-102 \\
\hline
\end{tabular}

\begin{tabular}{|c|c|c|c|c|c|c|c|c|c|}
\hline Spec. \# & Test Type & $\begin{array}{c}\text { Test } \\
\text { Method }\end{array}$ & Spec. Type & Mat & $\begin{array}{l}\text { Product Form } \\
(\sim 250 \mathrm{~mm} \text { thick })\end{array}$ & Heat \# & Mat Cond. ${ }^{(1)}$ & Env. & $\begin{array}{c}\text { Test Temp. } \\
\left({ }^{\circ} \mathrm{C}\right)\end{array}$ \\
\hline 52 & MC To, Damaged & E-1921 & $0.5 \mathrm{~T}$ D-CT & A508 & Forging & A508-Ht-2 & SSR + Damaged & Air & TBD \\
\hline 53 & MC To, Damaged & E-1921 & $0.5 \mathrm{~T}$ D-CT & A508 & Forging & A508-Ht-2 & SSR + Damaged & Air & TBD \\
\hline 54 & MC To, Damaged & E-1921 & $0.5 \mathrm{~T}$ D-CT & A508 & Forging & A508-Ht-2 & SSR + Damaged & Air & TBD \\
\hline 55 & J-R, Damaged & E-1820 & $0.5 \mathrm{~T}$ D-CT & A508 & Forging & A508-Ht-2 & SSR + Damaged & Air & 20 \\
\hline 56 & J-R, Damaged & E-1820 & $0.5 \mathrm{~T}$ D-CT & A508 & Forging & A508-Ht-2 & SSR + Damaged & Air & 20 \\
\hline 57 & J-R, Damaged & E-1820 & $0.5 \mathrm{~T}$ D-CT & A508 & Forging & A508-Ht-2 & SSR + Damaged & Air & 20 \\
\hline 58 & J-R, Damaged & E-1820 & $0.5 \mathrm{~T}$ D-CT & A508 & Forging & A508-Ht-2 & SSR + Damaged & Air & 20 \\
\hline 59 & J-R, Damaged & E-1820 & $0.5 \mathrm{~T}$ D-CT & A508 & Forging & A508-Ht-2 & SSR + Damaged & Air & 20 \\
\hline 60 & J-R, Damaged & E-1820 & $0.5 \mathrm{~T}$ D-CT & A508 & Forging & A508-Ht-2 & SSR + Damaged & Air & 20 \\
\hline 61 & J-R, Damaged & E-1820 & $0.5 \mathrm{~T}$ D-CT & A508 & Forging & A508-Ht-2 & SSR + Damaged & Air & 150 \\
\hline 62 & J-R, Damaged & E-1820 & $0.5 \mathrm{~T}$ D-CT & A508 & Forging & A508-Ht-2 & SSR + Damaged & Air & 150 \\
\hline 63 & J-R, Damaged & E-1820 & $0.5 \mathrm{~T}$ D-CT & A508 & Forging & A508-Ht-2 & SSR + Damaged & Air & 150 \\
\hline 64 & J-R, Damaged & E-1820 & $0.5 \mathrm{~T}$ D-CT & A508 & Forging & A508-Ht-2 & SSR + Damaged & Air & 150 \\
\hline 65 & J-R, Damaged & E-1820 & $0.5 \mathrm{~T}$ D-CT & A508 & Forging & A508-Ht-2 & SSR + Damaged & Air & 150 \\
\hline 66 & J-R, Damaged & E-1820 & $0.5 \mathrm{~T}$ D-CT & A508 & Forging & A508-Ht-2 & SSR + Damaged & Air & 150 \\
\hline 67 & J-R, Damaged & E-1820 & $0.5 \mathrm{~T}$ D-CT & A508 & Forging & A508-Ht-2 & SSR + Damaged & Air & 350 \\
\hline 68 & J-R, Damaged & E-1820 & $0.5 \mathrm{~T}$ D-CT & A508 & Forging & A508-Ht-2 & SSR + Damaged & Air & 350 \\
\hline 69 & J-R, Damaged & E-1820 & $0.5 \mathrm{~T}$ D-CT & A508 & Forging & A508-Ht-2 & SSR + Damaged & Air & 350 \\
\hline 70 & J-R, Damaged & E-1820 & $0.5 \mathrm{~T}$ D-CT & A508 & Forging & A508-Ht-2 & SSR + Damaged & Air & 350 \\
\hline 71 & J-R, Damaged & E-1820 & $0.5 \mathrm{~T}$ D-CT & A508 & Forging & A508-Ht-2 & SSR + Damaged & Air & 350 \\
\hline 72 & J-R, Damaged & E-1820 & $0.5 \mathrm{~T}$ D-CT & A508 & Forging & A508-Ht-2 & SSR + Damaged & Air & 350 \\
\hline 73 & J-R, Damaged & E-1820 & $0.5 \mathrm{~T}$ D-CT & A508 & Forging & A508-Ht-2 & SSR + Damaged & Air & 427 \\
\hline 74 & J-R, Damaged & E-1820 & $0.5 \mathrm{~T}$ D-CT & A508 & Forging & A508-Ht-2 & SSR + Damaged & Air & 427 \\
\hline 75 & J-R, Damaged & E-1820 & $0.5 \mathrm{~T}$ D-CT & A508 & Forging & A508-Ht-2 & SSR + Damaged & Air & 427 \\
\hline 76 & J-R, Damaged & E-1820 & $0.5 \mathrm{~T}$ D-CT & A508 & Forging & A508-Ht-2 & SSR + Damaged & Air & 427 \\
\hline 77 & J-R, Damaged & E-1820 & $0.5 \mathrm{~T}$ D-CT & A508 & Forging & A508-Ht-2 & SSR + Damaged & Air & 427 \\
\hline
\end{tabular}




Idaho National Laboratory
\begin{tabular}{|c|lll|}
\hline NEXT GENERATION NUCLEAR PLANT & Identifier: & PLN-2803 & \\
REACTOR PRESSURE VESSEL MATERIALS & Revision: & 0 & \\
RESEARCH AND DEVELOPMENT PLAN & Effective Date: & $04 / 30 / 08$ & Page: A-58 of A-102 \\
\hline
\end{tabular}

\begin{tabular}{|c|c|c|c|c|c|c|c|c|c|}
\hline Spec. \# & Test Type & $\begin{array}{c}\text { Test } \\
\text { Method }\end{array}$ & Spec. Type & Mat & $\begin{array}{l}\text { Product Form } \\
(\sim 250 \mathrm{~mm} \text { thick })\end{array}$ & Heat \# & Mat Cond. ${ }^{(1)}$ & Env. & $\begin{array}{c}\text { Test Temp. } \\
\left({ }^{\circ} \mathrm{C}\right)\end{array}$ \\
\hline 78 & J-R, Damaged & E-1820 & $0.5 \mathrm{~T}$ D-CT & A508 & Forging & A508-Ht-2 & SSR + Damaged & Air & 427 \\
\hline 79 & J-R, Damaged & E-1820 & $0.5 \mathrm{~T}$ D-CT & A508 & Forging & A508-Ht-2 & SSR + Damaged & Air & 538 \\
\hline 80 & J-R, Damaged & E-1820 & $0.5 \mathrm{~T}$ D-CT & A508 & Forging & A508-Ht-2 & SSR + Damaged & Air & 538 \\
\hline 81 & J-R, Damaged & E-1820 & $0.5 \mathrm{~T} \mathrm{D}-\mathrm{CT}$ & A508 & Forging & A508-Ht-2 & SSR + Damaged & Air & 538 \\
\hline 82 & J-R, Damaged & E-1820 & $0.5 \mathrm{~T}$ D-CT & A508 & Forging & A508-Ht-2 & SSR + Damaged & Air & 538 \\
\hline 83 & J-R, Damaged & E-1820 & $0.5 \mathrm{~T} \mathrm{D}-\mathrm{CT}$ & A508 & Forging & A508-Ht-2 & SSR + Damaged & Air & 538 \\
\hline 84 & J-R, Damaged & E-1820 & $0.5 \mathrm{~T} \mathrm{D}-\mathrm{CT}$ & A508 & Forging & A508-Ht-2 & SSR + Damaged & Air & 538 \\
\hline 85 & MC To, Damaged & E-1921 & $0.5 \mathrm{~T}$ D-CT & A533B & Rolled Plate & A533B-Ht-1 & SSR + Damaged & Air & TBD \\
\hline 86 & MC To, Damaged & E-1921 & $0.5 \mathrm{~T} \mathrm{D}-\mathrm{CT}$ & A533B & Rolled Plate & A533B-Ht-1 & SSR + Damaged & Air & TBD \\
\hline 87 & MC To, Damaged & E-1921 & $0.5 \mathrm{~T} \mathrm{D}-\mathrm{CT}$ & A533B & Rolled Plate & A533B-Ht-1 & SSR + Damaged & Air & TBD \\
\hline 88 & MC To, Damaged & E-1921 & $0.5 \mathrm{~T}$ D-CT & A533B & Rolled Plate & A533B-Ht-1 & SSR + Damaged & Air & TBD \\
\hline 89 & MC To, Damaged & E-1921 & $0.5 \mathrm{~T} \mathrm{D}-\mathrm{CT}$ & A533B & Rolled Plate & A533B-Ht-1 & SSR + Damaged & Air & TBD \\
\hline 90 & MC To, Damaged & E-1921 & $0.5 \mathrm{~T}$ D-CT & A533B & Rolled Plate & A533B-Ht-1 & SSR + Damaged & Air & TBD \\
\hline 91 & MC To, Damaged & E-1921 & $0.5 \mathrm{~T} \mathrm{D}-\mathrm{CT}$ & A533B & Rolled Plate & A533B-Ht-1 & SSR + Damaged & Air & TBD \\
\hline 92 & MC To, Damaged & E-1921 & $0.5 \mathrm{~T}$ D-CT & A533B & Rolled Plate & A533B-Ht-1 & SSR + Damaged & Air & TBD \\
\hline 93 & MC To, Damaged & E-1921 & $0.5 \mathrm{~T}$ D-CT & A533B & Rolled Plate & A533B-Ht-1 & SSR + Damaged & Air & TBD \\
\hline 94 & MC To, Damaged & E-1921 & $0.5 \mathrm{~T}$ D-CT & A533B & Rolled Plate & A533B-Ht-1 & SSR + Damaged & Air & TBD \\
\hline 95 & MC To, Damaged & E-1921 & $0.5 \mathrm{~T} \mathrm{D}-\mathrm{CT}$ & A533B & Rolled Plate & A533B-Ht-1 & SSR + Damaged & Air & TBD \\
\hline 96 & MC To, Damaged & E-1921 & $0.5 \mathrm{~T}$ D-CT & A533B & Rolled Plate & A533B-Ht-1 & SSR + Damaged & Air & TBD \\
\hline 97 & J-R, Damaged & E-1820 & $0.5 \mathrm{~T}$ D-CT & A533B & Rolled Plate & A533B-Ht-1 & SSR + Damaged & Air & 20 \\
\hline 98 & J-R, Damaged & E-1820 & $0.5 \mathrm{~T} \mathrm{D}-\mathrm{CT}$ & A533B & Rolled Plate & A533B-Ht-1 & SSR + Damaged & Air & 20 \\
\hline 99 & J-R, Damaged & E-1820 & $0.5 \mathrm{~T}$ D-CT & A533B & Rolled Plate & A533B-Ht-1 & SSR + Damaged & Air & 20 \\
\hline 100 & J-R, Damaged & E-1820 & $0.5 \mathrm{~T} \mathrm{D}-\mathrm{CT}$ & A533B & Rolled Plate & A533B-Ht-1 & SSR + Damaged & Air & 20 \\
\hline 101 & J-R, Damaged & E-1820 & $0.5 \mathrm{~T}$ D-CT & A533B & Rolled Plate & A533B-Ht-1 & SSR + Damaged & Air & 20 \\
\hline 102 & J-R, Damaged & E-1820 & $0.5 \mathrm{~T}$ D-CT & A533B & Rolled Plate & A533B-Ht-1 & SSR + Damaged & Air & 20 \\
\hline 103 & J-R, Damaged & E-1820 & $0.5 \mathrm{~T} \mathrm{D}-\mathrm{CT}$ & A533B & Rolled Plate & A533B-Ht-1 & SSR + Damaged & Air & 150 \\
\hline
\end{tabular}




Idaho National Laboratory
\begin{tabular}{|c|lll|}
\hline NEXT GENERATION NUCLEAR PLANT & Identifier: & PLN-2803 & \\
REACTOR PRESSURE VESSEL MATERIALS & Revision: & 0 & \\
RESEARCH AND DEVELOPMENT PLAN & Effective Date: & $04 / 30 / 08$ & Page: A- 59 of A-102 \\
\hline
\end{tabular}

\begin{tabular}{|c|c|c|c|c|c|c|c|c|c|}
\hline Spec.\# & Test Type & $\begin{array}{c}\text { Test } \\
\text { Method }\end{array}$ & Spec. Type & Mat & $\begin{array}{l}\text { Product Form } \\
(\sim 250 \mathrm{~mm} \text { thick })\end{array}$ & Heat \# & Mat Cond. ${ }^{(1)}$ & Env. & $\begin{array}{c}\text { Test Temp. } \\
\left({ }^{\circ} \mathrm{C}\right)\end{array}$ \\
\hline 104 & J-R, Damaged & E-1820 & $0.5 \mathrm{~T} \mathrm{D}-\mathrm{CT}$ & A533B & Rolled Plate & A533B-Ht-1 & SSR + Damaged & Air & 150 \\
\hline 105 & J-R, Damaged & E-1820 & $0.5 \mathrm{~T}$ D-CT & A533B & Rolled Plate & A533B-Ht-1 & SSR + Damaged & Air & 150 \\
\hline 106 & J-R, Damaged & E-1820 & $0.5 \mathrm{~T}$ D-CT & A533B & Rolled Plate & A533B-Ht-1 & SSR + Damaged & Air & 150 \\
\hline 107 & J-R, Damaged & E-1820 & $0.5 \mathrm{~T} \mathrm{D}-\mathrm{CT}$ & A533B & Rolled Plate & A533B-Ht-1 & SSR + Damaged & Air & 150 \\
\hline 108 & J-R, Damaged & E-1820 & $0.5 \mathrm{~T} \mathrm{D}-\mathrm{CT}$ & A533B & Rolled Plate & A533B-Ht-1 & SSR + Damaged & Air & 150 \\
\hline 109 & J-R, Damaged & E-1820 & $0.5 \mathrm{~T} \mathrm{D}-\mathrm{CT}$ & A533B & Rolled Plate & A533B-Ht-1 & SSR + Damaged & Air & 350 \\
\hline 110 & J-R, Damaged & E-1820 & $0.5 \mathrm{~T} \mathrm{D}-\mathrm{CT}$ & A533B & Rolled Plate & A533B-Ht-1 & SSR + Damaged & Air & 350 \\
\hline 111 & J-R, Damaged & E-1820 & $0.5 \mathrm{~T}$ D-CT & A533B & Rolled Plate & A533B-Ht-1 & SSR + Damaged & Air & 350 \\
\hline 112 & J-R, Damaged & E-1820 & $0.5 \mathrm{~T}$ D-CT & A533B & Rolled Plate & A533B-Ht-1 & SSR + Damaged & Air & 350 \\
\hline 113 & J-R, Damaged & E-1820 & $0.5 \mathrm{~T}$ D-CT & A533B & Rolled Plate & A533B-Ht-1 & SSR + Damaged & Air & 350 \\
\hline 114 & J-R, Damaged & E-1820 & $0.5 \mathrm{~T} \mathrm{D}-\mathrm{CT}$ & A533B & Rolled Plate & A533B-Ht-1 & SSR + Damaged & Air & 350 \\
\hline 115 & J-R, Damaged & E-1820 & $0.5 \mathrm{~T}$ D-CT & A533B & Rolled Plate & A533B-Ht-1 & SSR + Damaged & Air & 427 \\
\hline 116 & J-R, Damaged & E-1820 & $0.5 \mathrm{~T}$ D-CT & A533B & Rolled Plate & A533B-Ht-1 & SSR + Damaged & Air & 427 \\
\hline 117 & J-R, Damaged & E-1820 & $0.5 \mathrm{~T}$ D-CT & A533B & Rolled Plate & A533B-Ht-1 & SSR + Damaged & Air & 427 \\
\hline 118 & J-R, Damaged & E-1820 & $0.5 \mathrm{~T}$ D-CT & A533B & Rolled Plate & A533B-Ht-1 & SSR + Damaged & Air & 427 \\
\hline 119 & J-R, Damaged & E-1820 & $0.5 \mathrm{~T}$ D-CT & A533B & Rolled Plate & A533B-Ht-1 & SSR + Damaged & Air & 427 \\
\hline 120 & J-R, Damaged & E-1820 & $0.5 \mathrm{~T}$ D-CT & A533B & Rolled Plate & A533B-Ht-1 & SSR + Damaged & Air & 427 \\
\hline 121 & J-R, Damaged & E-1820 & $0.5 \mathrm{~T} \mathrm{D}-\mathrm{CT}$ & A533B & Rolled Plate & A533B-Ht-1 & SSR + Damaged & Air & 538 \\
\hline 122 & J-R, Damaged & E-1820 & $0.5 \mathrm{~T}$ D-CT & A533B & Rolled Plate & A533B-Ht-1 & SSR + Damaged & Air & 538 \\
\hline 123 & J-R, Damaged & E-1820 & $0.5 \mathrm{~T}$ D-CT & A533B & Rolled Plate & A533B-Ht-1 & SSR + Damaged & Air & 538 \\
\hline 124 & J-R, Damaged & E-1820 & $0.5 \mathrm{~T}$ D-CT & A533B & Rolled Plate & A533B-Ht-1 & SSR + Damaged & Air & 538 \\
\hline 125 & J-R, Damaged & E-1820 & $0.5 \mathrm{~T}$ D-CT & A533B & Rolled Plate & A533B-Ht-1 & SSR + Damaged & Air & 538 \\
\hline 126 & J-R, Damaged & E-1820 & $0.5 \mathrm{~T} \mathrm{D}-\mathrm{CT}$ & A533B & Rolled Plate & A533B-Ht-1 & SSR + Damaged & Air & 538 \\
\hline 127 & MC To, Damaged & E-1921 & $0.5 \mathrm{~T}$ D-CT & A533B & Rolled Plate & A533B-Ht-2 & SSR + Damaged & Air & TBD \\
\hline 128 & MC To, Damaged & E-1921 & $0.5 \mathrm{~T}$ D-CT & A533B & Rolled Plate & A533B-Ht-2 & SSR + Damaged & Air & TBD \\
\hline 129 & MC To, Damaged & E-1921 & $0.5 \mathrm{~T} \mathrm{D}-\mathrm{CT}$ & A533B & Rolled Plate & A533B-Ht-2 & SSR + Damaged & Air & TBD \\
\hline
\end{tabular}




Idaho National Laboratory
\begin{tabular}{|c|lll|}
\hline NEXT GENERATION NUCLEAR PLANT & Identifier: & PLN-2803 & \\
REACTOR PRESSURE VESSEL MATERIALS & Revision: & 0 & \\
RESEARCH AND DEVELOPMENT PLAN & Effective Date: & $04 / 30 / 08$ & Page: A- 60 of A-102 \\
\hline
\end{tabular}

\begin{tabular}{|c|c|c|c|c|c|c|c|c|c|}
\hline Spec. \# & Test Type & $\begin{array}{c}\text { Test } \\
\text { Method }\end{array}$ & Spec. Type & Mat & $\begin{array}{l}\text { Product Form } \\
(\sim 250 \mathrm{~mm} \text { thick })\end{array}$ & Heat \# & Mat Cond. ${ }^{(1)}$ & Env. & $\begin{array}{c}\text { Test Temp. } \\
\left({ }^{\circ} \mathrm{C}\right)\end{array}$ \\
\hline 130 & MC To, Damaged & E-1921 & $0.5 \mathrm{~T} \mathrm{D}-\mathrm{CT}$ & A533B & Rolled Plate & A533B-Ht-2 & SSR + Damaged & Air & TBD \\
\hline 131 & MC To, Damaged & E-1921 & $0.5 \mathrm{~T}$ D-CT & A533B & Rolled Plate & A533B-Ht-2 & SSR + Damaged & Air & TBD \\
\hline 132 & MC To, Damaged & E-1921 & $0.5 \mathrm{~T}$ D-CT & A533B & Rolled Plate & A533B-Ht-2 & SSR + Damaged & Air & TBD \\
\hline 133 & MC To, Damaged & E-1921 & $0.5 \mathrm{~T} \mathrm{D}-\mathrm{CT}$ & A533B & Rolled Plate & A533B-Ht-2 & SSR + Damaged & Air & TBD \\
\hline 134 & MC To, Damaged & E-1921 & $0.5 \mathrm{~T}$ D-CT & A533B & Rolled Plate & A533B-Ht-2 & SSR + Damaged & Air & TBD \\
\hline 135 & MC To, Damaged & E-1921 & $0.5 \mathrm{~T} \mathrm{D}-\mathrm{CT}$ & A533B & Rolled Plate & A533B-Ht-2 & SSR + Damaged & Air & TBD \\
\hline 136 & MC To, Damaged & E-1921 & $0.5 \mathrm{~T} \mathrm{D}-\mathrm{CT}$ & A533B & Rolled Plate & A533B-Ht-2 & SSR + Damaged & Air & TBD \\
\hline 137 & MC To, Damaged & E-1921 & $0.5 \mathrm{~T}$ D-CT & A533B & Rolled Plate & A533B-Ht-2 & SSR + Damaged & Air & TBD \\
\hline 138 & MC To, Damaged & E-1921 & $0.5 \mathrm{~T} \mathrm{D}-\mathrm{CT}$ & A533B & Rolled Plate & A533B-Ht-2 & SSR + Damaged & Air & TBD \\
\hline 139 & J-R, Damaged & E-1820 & $0.5 \mathrm{~T} \mathrm{D}-\mathrm{CT}$ & A533B & Rolled Plate & A533B-Ht-2 & SSR + Damaged & Air & 20 \\
\hline 140 & J-R, Damaged & E-1820 & $0.5 \mathrm{~T}$ D-CT & A533B & Rolled Plate & A533B-Ht-2 & SSR + Damaged & Air & 20 \\
\hline 141 & J-R, Damaged & E-1820 & $0.5 \mathrm{~T} \mathrm{D}-\mathrm{CT}$ & A533B & Rolled Plate & A533B-Ht-2 & SSR + Damaged & Air & 20 \\
\hline 142 & J-R, Damaged & E-1820 & $0.5 \mathrm{~T}$ D-CT & A533B & Rolled Plate & A533B-Ht-2 & SSR + Damaged & Air & 20 \\
\hline 143 & J-R, Damaged & E-1820 & $0.5 \mathrm{~T} \mathrm{D}-\mathrm{CT}$ & A533B & Rolled Plate & A533B-Ht-2 & SSR + Damaged & Air & 20 \\
\hline 144 & J-R, Damaged & E-1820 & $0.5 \mathrm{~T}$ D-CT & A533B & Rolled Plate & A533B-Ht-2 & SSR + Damaged & Air & 20 \\
\hline 145 & J-R, Damaged & E-1820 & $0.5 \mathrm{~T}$ D-CT & A533B & Rolled Plate & A533B-Ht-2 & SSR + Damaged & Air & 150 \\
\hline 146 & J-R, Damaged & E-1820 & $0.5 \mathrm{~T}$ D-CT & A533B & Rolled Plate & A533B-Ht-2 & SSR + Damaged & Air & 150 \\
\hline 147 & J-R, Damaged & E-1820 & $0.5 \mathrm{~T} \mathrm{D}-\mathrm{CT}$ & A533B & Rolled Plate & A533B-Ht-2 & SSR + Damaged & Air & 150 \\
\hline 148 & J-R, Damaged & E-1820 & $0.5 \mathrm{~T}$ D-CT & A533B & Rolled Plate & A533B-Ht-2 & SSR + Damaged & Air & 150 \\
\hline 149 & J-R, Damaged & E-1820 & $0.5 \mathrm{~T}$ D-CT & A533B & Rolled Plate & A533B-Ht-2 & SSR + Damaged & Air & 150 \\
\hline 150 & J-R, Damaged & E-1820 & $0.5 \mathrm{~T} \mathrm{D}-\mathrm{CT}$ & A533B & Rolled Plate & A533B-Ht-2 & SSR + Damaged & Air & 150 \\
\hline 151 & J-R, Damaged & E-1820 & $0.5 \mathrm{~T}$ D-CT & A533B & Rolled Plate & A533B-Ht-2 & SSR + Damaged & Air & 350 \\
\hline 152 & J-R, Damaged & E-1820 & $0.5 \mathrm{~T} \mathrm{D}-\mathrm{CT}$ & A533B & Rolled Plate & A533B-Ht-2 & SSR + Damaged & Air & 350 \\
\hline 153 & J-R, Damaged & E-1820 & $0.5 \mathrm{~T}$ D-CT & A533B & Rolled Plate & A533B-Ht-2 & SSR + Damaged & Air & 350 \\
\hline 154 & J-R, Damaged & E-1820 & $0.5 \mathrm{~T}$ D-CT & A533B & Rolled Plate & A533B-Ht-2 & SSR + Damaged & Air & 350 \\
\hline 155 & J-R, Damaged & E-1820 & $0.5 \mathrm{~T} \mathrm{D}-\mathrm{CT}$ & A533B & Rolled Plate & A533B-Ht-2 & SSR + Damaged & Air & 350 \\
\hline
\end{tabular}


Idaho National Laboratory

\begin{tabular}{|c|lll|}
\hline NEXT GENERATION NUCLEAR PLANT & Identifier: & PLN-2803 & \\
REACTOR PRESSURE VESSEL MATERIALS & Revision: & 0 & \\
RESEARCH AND DEVELOPMENT PLAN & Effective Date: & $04 / 30 / 08$ & Page: A-61 of A-102 \\
\hline
\end{tabular}

\begin{tabular}{|c|c|c|c|c|c|c|c|c|c|}
\hline Spec. \# & Test Type & $\begin{array}{c}\text { Test } \\
\text { Method }\end{array}$ & Spec. Type & Mat & $\begin{array}{c}\text { Product Form } \\
(\sim 250 \mathrm{~mm} \text { thick })\end{array}$ & Heat \# & Mat Cond. ${ }^{(1)}$ & Env. & $\begin{array}{c}\text { Test Temp. } \\
\left({ }^{\circ} \mathrm{C}\right)\end{array}$ \\
\hline 156 & J-R, Damaged & E-1820 & $0.5 \mathrm{~T} \mathrm{D}-\mathrm{CT}$ & A533B & Rolled Plate & A533B-Ht-2 & SSR + Damaged & Air & 350 \\
\hline 157 & J-R, Damaged & E-1820 & $0.5 \mathrm{~T} \mathrm{D}-\mathrm{CT}$ & A533B & Rolled Plate & A533B-Ht-2 & SSR + Damaged & Air & 427 \\
\hline 158 & J-R, Damaged & E-1820 & $0.5 \mathrm{~T}$ D-CT & A533B & Rolled Plate & A533B-Ht-2 & SSR + Damaged & Air & 427 \\
\hline 159 & J-R, Damaged & E-1820 & $0.5 \mathrm{~T} \mathrm{D}-\mathrm{CT}$ & A533B & Rolled Plate & A533B-Ht-2 & SSR + Damaged & Air & 427 \\
\hline 160 & J-R, Damaged & E-1820 & $0.5 \mathrm{~T}$ D-CT & A533B & Rolled Plate & A533B-Ht-2 & SSR + Damaged & Air & 427 \\
\hline 161 & J-R, Damaged & E-1820 & $0.5 \mathrm{~T} \mathrm{D}-\mathrm{CT}$ & A533B & Rolled Plate & A533B-Ht-2 & SSR + Damaged & Air & 427 \\
\hline 162 & J-R, Damaged & E-1820 & $0.5 \mathrm{~T}$ D-CT & A533B & Rolled Plate & A533B-Ht-2 & SSR + Damaged & Air & 427 \\
\hline 163 & J-R, Damaged & E-1820 & $0.5 \mathrm{~T} \mathrm{D}-\mathrm{CT}$ & A533B & Rolled Plate & A533B-Ht-2 & SSR + Damaged & Air & 538 \\
\hline 164 & J-R, Damaged & E-1820 & $0.5 \mathrm{~T}$ D-CT & A533B & Rolled Plate & A533B-Ht-2 & SSR + Damaged & Air & 538 \\
\hline 165 & J-R, Damaged & E-1820 & $0.5 \mathrm{~T}$ D-CT & A533B & Rolled Plate & A533B-Ht-2 & SSR + Damaged & Air & 538 \\
\hline 166 & J-R, Damaged & E-1820 & $0.5 \mathrm{~T} \mathrm{D}-\mathrm{CT}$ & A533B & Rolled Plate & A533B-Ht-2 & SSR + Damaged & Air & 538 \\
\hline 167 & J-R, Damaged & E-1820 & $0.5 \mathrm{~T} \mathrm{D}-\mathrm{CT}$ & A533B & Rolled Plate & A533B-Ht-2 & SSR + Damaged & Air & 538 \\
\hline 168 & J-R, Damaged & E-1820 & $0.5 \mathrm{~T} \mathrm{D}-\mathrm{CT}$ & A533B & Rolled Plate & A533B-Ht-2 & SSR + Damaged & Air & 538 \\
\hline \multicolumn{10}{|c|}{ Note (1) Damaged by fatigue-SRX } \\
\hline
\end{tabular}




Idaho National Laboratory
\begin{tabular}{|c|lll|}
\hline NEXT GENERATION NUCLEAR PLANT & Identifier: & PLN-2803 & \\
REACTOR PRESSURE VESSEL MATERIALS & Revision: & 0 & \\
RESEARCH AND DEVELOPMENT PLAN & Effective Date: & $04 / 30 / 08$ & Page: A-62 of A-102 \\
\hline
\end{tabular}

\begin{tabular}{|c|c|c|c|c|c|c|c|c|c|}
\hline Spec. \# & Test Type & $\begin{array}{c}\text { Test } \\
\text { Method }\end{array}$ & Spec. Type & Mat & $\begin{array}{l}\text { Product Form } \\
(\sim 250 \mathrm{~mm} \text { thick })\end{array}$ & Heat \# & Mat Cond. ${ }^{(1)}$ & Env. & $\begin{array}{c}\text { Test Temp. } \\
\left({ }^{\circ} \mathrm{C}\right)\end{array}$ \\
\hline 1 & MC To, Aged & E-1921 & $0.5 \mathrm{~T}$ D-CT & A508 & Forging & A508-Ht-1 & SSR + Aged 20k h & Air & TBD \\
\hline 2 & MC To, Aged & E-1921 & $0.5 \mathrm{~T}$ D-CT & A508 & Forging & A508-Ht-1 & SSR + Aged 20k h & Air & TBD \\
\hline 3 & MC To, Aged & E-1921 & $0.5 \mathrm{~T}$ D-CT & A508 & Forging & A508-Ht-1 & SSR + Aged 20k h & Air & TBD \\
\hline 4 & MC To, Aged & E-1921 & $0.5 \mathrm{~T}$ D-CT & A508 & Forging & A508-Ht-1 & $\mathrm{SSR}+$ Aged 20k h & Air & TBD \\
\hline 5 & MC To, Aged & E-1921 & $0.5 \mathrm{~T} \mathrm{D}-\mathrm{CT}$ & A508 & Forging & A508-Ht-1 & SSR + Aged 20k h & Air & TBD \\
\hline 6 & MC To, Aged & E-1921 & $0.5 \mathrm{~T}$ D-CT & A508 & Forging & A508-Ht-1 & SSR + Aged 20k h & Air & TBD \\
\hline 7 & MC To, Aged & E-1921 & $0.5 \mathrm{~T}$ D-CT & A508 & Forging & A508-Ht-1 & SSR + Aged 20k h & Air & TBD \\
\hline 8 & MC To, Aged & E-1921 & $0.5 \mathrm{~T}$ D-CT & A508 & Forging & A508-Ht-1 & SSR + Aged 20k h & Air & TBD \\
\hline 9 & MC To, Aged & E-1921 & $0.5 \mathrm{~T}$ D-CT & A508 & Forging & A508-Ht-1 & SSR + Aged 20k h & Air & TBD \\
\hline 10 & MC To, Aged & E-1921 & $0.5 \mathrm{~T}$ D-CT & A508 & Forging & A508-Ht-1 & SSR + Aged 20k h & Air & TBD \\
\hline 11 & MC To, Aged & E-1921 & $0.5 \mathrm{~T}$ D-CT & A508 & Forging & A508-Ht-1 & SSR + Aged 20k h & Air & TBD \\
\hline 12 & MC To, Aged & E-1921 & $0.5 \mathrm{~T}$ D-CT & A508 & Forging & A508-Ht-1 & SSR + Aged 20k h & Air & TBD \\
\hline 13 & J-R, Aged & E-1820 & $0.5 \mathrm{~T} \mathrm{D}-\mathrm{CT}$ & A508 & Forging & A508-Ht-1 & SSR + Aged 20k h & Air & 20 \\
\hline 14 & J-R, Aged & E-1820 & $0.5 \mathrm{~T}$ D-CT & A508 & Forging & A508-Ht-1 & SSR + Aged 20k h & Air & 20 \\
\hline 15 & J-R, Aged & E-1820 & $0.5 \mathrm{~T}$ D-CT & A508 & Forging & A508-Ht-1 & $\mathrm{SSR}+$ Aged 20k h & Air & 20 \\
\hline 16 & J-R, Aged & E-1820 & $0.5 \mathrm{~T}$ D-CT & A508 & Forging & A508-Ht-1 & SSR + Aged 20k h & Air & 20 \\
\hline 17 & J-R, Aged & E-1820 & $0.5 \mathrm{~T}$ D-CT & A508 & Forging & A508-Ht-1 & SSR + Aged 20k h & Air & 20 \\
\hline 18 & J-R, Aged & E-1820 & $0.5 \mathrm{~T}$ D-CT & A508 & Forging & A508-Ht-1 & SSR + Aged 20k h & Air & 20 \\
\hline 19 & J-R, Aged & E-1820 & $0.5 \mathrm{~T}$ D-CT & A508 & Forging & A508-Ht-1 & SSR + Aged 20k h & Air & 150 \\
\hline 20 & J-R, Aged & E-1820 & $0.5 \mathrm{~T}$ D-CT & A508 & Forging & A508-Ht-1 & SSR + Aged 20k h & Air & 150 \\
\hline 21 & J-R, Aged & E-1820 & $0.5 \mathrm{~T}$ D-CT & A508 & Forging & A508-Ht-1 & SSR + Aged 20k h & Air & 150 \\
\hline 22 & J-R, Aged & E-1820 & $0.5 \mathrm{~T} \mathrm{D}-\mathrm{CT}$ & A508 & Forging & A508-Ht-1 & SSR + Aged 20k h & Air & 150 \\
\hline 23 & J-R, Aged & E-1820 & $0.5 \mathrm{~T}$ D-CT & A508 & Forging & A508-Ht-1 & SSR + Aged 20k h & Air & 150 \\
\hline 24 & J-R, Aged & E-1820 & $0.5 \mathrm{~T}$ D-CT & A508 & Forging & A508-Ht-1 & SSR + Aged 20k h & Air & 150 \\
\hline 25 & J-R, Aged & E-1820 & $0.5 \mathrm{~T} \mathrm{D}-\mathrm{CT}$ & A508 & Forging & A508-Ht-1 & SSR + Aged 20k h & Air & 350 \\
\hline
\end{tabular}




Idaho National Laboratory
\begin{tabular}{|c|lll|}
\hline NEXT GENERATION NUCLEAR PLANT & Identifier: & PLN-2803 & \\
REACTOR PRESSURE VESSEL MATERIALS & Revision: & 0 & \\
RESEARCH AND DEVELOPMENT PLAN & Effective Date: & $04 / 30 / 08$ & Page: A- 63 of A-102 \\
\hline
\end{tabular}

\begin{tabular}{|c|c|c|c|c|c|c|c|c|c|}
\hline Spec. \# & Test Type & $\begin{array}{c}\text { Test } \\
\text { Method }\end{array}$ & Spec. Type & Mat & $\begin{array}{l}\text { Product Form } \\
(\sim 250 \mathrm{~mm} \text { thick })\end{array}$ & Heat \# & Mat Cond. ${ }^{(1)}$ & Env. & $\begin{array}{c}\text { Test Temp. } \\
\left({ }^{\circ} \mathrm{C}\right)\end{array}$ \\
\hline 26 & J-R, Aged & E-1820 & $0.5 \mathrm{~T} \mathrm{D}-\mathrm{CT}$ & A508 & Forging & A508-Ht-1 & SSR + Aged 20k h & Air & 350 \\
\hline 27 & J-R, Aged & E-1820 & $0.5 \mathrm{~T} \mathrm{D}-\mathrm{CT}$ & A508 & Forging & A508-Ht-1 & SSR + Aged 20k h & Air & 350 \\
\hline 28 & J-R, Aged & E-1820 & $0.5 \mathrm{~T} \mathrm{D}-\mathrm{CT}$ & A508 & Forging & A508-Ht-1 & SSR + Aged 20k h & Air & 350 \\
\hline 29 & J-R, Aged & E-1820 & $0.5 \mathrm{~T} \mathrm{D}-\mathrm{CT}$ & A508 & Forging & A508-Ht-1 & SSR + Aged 20k h & Air & 350 \\
\hline 30 & J-R, Aged & E-1820 & $0.5 \mathrm{~T} \mathrm{D}-\mathrm{CT}$ & A508 & Forging & A508-Ht-1 & SSR + Aged 20k h & Air & 350 \\
\hline 31 & J-R, Aged & E-1820 & $0.5 \mathrm{~T} \mathrm{D}-\mathrm{CT}$ & A508 & Forging & A508-Ht-1 & SSR + Aged 20k h & Air & 427 \\
\hline 32 & J-R, Aged & E-1820 & $0.5 \mathrm{~T} \mathrm{D}-\mathrm{CT}$ & A508 & Forging & A508-Ht-1 & SSR + Aged 20k h & Air & 427 \\
\hline 33 & J-R, Aged & E-1820 & $0.5 \mathrm{~T} \mathrm{D}-\mathrm{CT}$ & A508 & Forging & A508-Ht-1 & SSR + Aged 20k h & Air & 427 \\
\hline 34 & J-R, Aged & E-1820 & $0.5 \mathrm{~T} \mathrm{D}-\mathrm{CT}$ & A508 & Forging & A508-Ht-1 & SSR + Aged 20k h & Air & 427 \\
\hline 35 & J-R, Aged & E-1820 & $0.5 \mathrm{~T} \mathrm{D}-\mathrm{CT}$ & A508 & Forging & A508-Ht-1 & SSR + Aged 20k h & Air & 427 \\
\hline 36 & J-R, Aged & E-1820 & $0.5 \mathrm{~T} \mathrm{D}-\mathrm{CT}$ & A508 & Forging & A508-Ht-1 & SSR + Aged 20k h & Air & 427 \\
\hline 37 & J-R, Aged & E-1820 & $0.5 \mathrm{~T} \mathrm{D}-\mathrm{CT}$ & A508 & Forging & A508-Ht-1 & SSR + Aged 20k h & Air & 538 \\
\hline 38 & J-R, Aged & E-1820 & $0.5 \mathrm{~T} \mathrm{D}-\mathrm{CT}$ & A508 & Forging & A508-Ht-1 & SSR + Aged 20k h & Air & 538 \\
\hline 39 & J-R, Aged & E-1820 & $0.5 \mathrm{~T} \mathrm{D}-\mathrm{CT}$ & A508 & Forging & A508-Ht-1 & SSR + Aged 20k h & Air & 538 \\
\hline 40 & J-R, Aged & E-1820 & $0.5 \mathrm{~T} \mathrm{D}-\mathrm{CT}$ & A508 & Forging & A508-Ht-1 & SSR + Aged 20k h & Air & 538 \\
\hline 41 & J-R, Aged & E-1820 & $0.5 \mathrm{~T} \mathrm{D}-\mathrm{CT}$ & A508 & Forging & A508-Ht-1 & SSR + Aged 20k h & Air & 538 \\
\hline 42 & J-R, Aged & E-1820 & $0.5 \mathrm{~T} \mathrm{D}-\mathrm{CT}$ & A508 & Forging & A508-Ht-1 & SSR + Aged 20k h & Air & 538 \\
\hline 43 & MC To, Aged & E-1921 & $0.5 \mathrm{~T} \mathrm{D}-\mathrm{CT}$ & A508 & Forging & A508-Ht-2 & SSR + Aged 20k h & Air & TBD \\
\hline 44 & MC To, Aged & E-1921 & $0.5 \mathrm{~T} \mathrm{D}-\mathrm{CT}$ & A508 & Forging & A508-Ht-2 & SSR + Aged 20k h & Air & TBD \\
\hline 45 & MC To, Aged & E-1921 & $0.5 \mathrm{~T} \mathrm{D}-\mathrm{CT}$ & A508 & Forging & A508-Ht-2 & SSR + Aged 20k h & Air & TBD \\
\hline 46 & MC To, Aged & E-1921 & $0.5 \mathrm{~T} \mathrm{D}-\mathrm{CT}$ & A508 & Forging & A508-Ht-2 & SSR + Aged 20k h & Air & TBD \\
\hline 47 & MC To, Aged & E-1921 & $0.5 \mathrm{~T} \mathrm{D}-\mathrm{CT}$ & A508 & Forging & A508-Ht-2 & SSR + Aged 20k h & Air & TBD \\
\hline 48 & MC To, Aged & E-1921 & $0.5 \mathrm{~T} \mathrm{D}-\mathrm{CT}$ & A508 & Forging & A508-Ht-2 & SSR + Aged 20k h & Air & TBD \\
\hline 49 & MC To, Aged & E-1921 & $0.5 \mathrm{~T} \mathrm{D}-\mathrm{CT}$ & A508 & Forging & A508-Ht-2 & SSR + Aged 20k h & Air & TBD \\
\hline 50 & MC To, Aged & E-1921 & $0.5 \mathrm{~T} \mathrm{D}-\mathrm{CT}$ & A508 & Forging & A508-Ht-2 & SSR + Aged 20k h & Air & TBD \\
\hline 51 & MC To, Aged & E-1921 & $0.5 \mathrm{~T} \mathrm{D}-\mathrm{CT}$ & A508 & Forging & A508-Ht-2 & SSR + Aged 20k h & Air & TBD \\
\hline
\end{tabular}




Idaho National Laboratory
\begin{tabular}{|c|lll|}
\hline NEXT GENERATION NUCLEAR PLANT & Identifier: & PLN-2803 & \\
REACTOR PRESSURE VESSEL MATERIALS & Revision: & 0 & \\
RESEARCH AND DEVELOPMENT PLAN & Effective Date: & $04 / 30 / 08$ & Page: A-64 of A-102 \\
\hline
\end{tabular}

\begin{tabular}{|c|c|c|c|c|c|c|c|c|c|}
\hline Spec. \# & Test Type & $\begin{array}{c}\text { Test } \\
\text { Method }\end{array}$ & Spec. Type & Mat & $\begin{array}{l}\text { Product Form } \\
(\sim 250 \mathrm{~mm} \text { thick })\end{array}$ & Heat \# & Mat Cond. ${ }^{(1)}$ & Env. & $\begin{array}{c}\text { Test Temp. } \\
\left({ }^{\circ} \mathrm{C}\right)\end{array}$ \\
\hline 52 & MC To, Aged & E-1921 & $0.5 \mathrm{~T} \mathrm{D}-\mathrm{CT}$ & A508 & Forging & A508-Ht-2 & $\mathrm{SSR}+$ Aged 20k h & Air & TBD \\
\hline 53 & MC To, Aged & E-1921 & $0.5 \mathrm{~T} \mathrm{D}-\mathrm{CT}$ & A508 & Forging & A508-Ht-2 & SSR + Aged 20k h & Air & TBD \\
\hline 54 & MC To, Aged & E-1921 & $0.5 \mathrm{~T} \mathrm{D}-\mathrm{CT}$ & A508 & Forging & A508-Ht-2 & SSR + Aged 20k h & Air & TBD \\
\hline 55 & J-R, Aged & E-1820 & $0.5 \mathrm{~T} \mathrm{D}-\mathrm{CT}$ & A508 & Forging & A508-Ht-2 & SSR + Aged 20k h & Air & 20 \\
\hline 56 & J-R, Aged & E-1820 & $0.5 \mathrm{~T} \mathrm{D}-\mathrm{CT}$ & A508 & Forging & A508-Ht-2 & SSR + Aged 20k h & Air & 20 \\
\hline 57 & J-R, Aged & E-1820 & $0.5 \mathrm{~T} \mathrm{D}-\mathrm{CT}$ & A508 & Forging & A508-Ht-2 & SSR + Aged 20k h & Air & 20 \\
\hline 58 & J-R, Aged & E-1820 & $0.5 \mathrm{~T} \mathrm{D}-\mathrm{CT}$ & A508 & Forging & A508-Ht-2 & SSR + Aged 20k h & Air & 20 \\
\hline 59 & J-R, Aged & E-1820 & $0.5 \mathrm{~T} \mathrm{D}-\mathrm{CT}$ & A508 & Forging & A508-Ht-2 & SSR + Aged 20k h & Air & 20 \\
\hline 60 & J-R, Aged & E-1820 & $0.5 \mathrm{~T} \mathrm{D}-\mathrm{CT}$ & A508 & Forging & A508-Ht-2 & SSR + Aged 20k h & Air & 20 \\
\hline 61 & J-R, Aged & E-1820 & $0.5 \mathrm{~T} \mathrm{D}-\mathrm{CT}$ & A508 & Forging & A508-Ht-2 & SSR + Aged 20k h & Air & 150 \\
\hline 62 & J-R, Aged & E-1820 & $0.5 \mathrm{~T} \mathrm{D}-\mathrm{CT}$ & A508 & Forging & A508-Ht-2 & SSR + Aged 20k h & Air & 150 \\
\hline 63 & J-R, Aged & E-1820 & $0.5 \mathrm{~T} \mathrm{D}-\mathrm{CT}$ & A508 & Forging & A508-Ht-2 & SSR + Aged 20k h & Air & 150 \\
\hline 64 & J-R, Aged & E-1820 & $0.5 \mathrm{~T} \mathrm{D}-\mathrm{CT}$ & A508 & Forging & A508-Ht-2 & SSR + Aged 20k h & Air & 150 \\
\hline 65 & J-R, Aged & E-1820 & $0.5 \mathrm{~T} \mathrm{D}-\mathrm{CT}$ & A508 & Forging & A508-Ht-2 & SSR + Aged 20k h & Air & 150 \\
\hline 66 & J-R, Aged & E-1820 & $0.5 \mathrm{~T} \mathrm{D}-\mathrm{CT}$ & A508 & Forging & A508-Ht-2 & SSR + Aged 20k h & Air & 150 \\
\hline 67 & J-R, Aged & E-1820 & $0.5 \mathrm{~T} \mathrm{D}-\mathrm{CT}$ & A508 & Forging & A508-Ht-2 & SSR + Aged 20k h & Air & 350 \\
\hline 68 & J-R, Aged & E-1820 & $0.5 \mathrm{~T} \mathrm{D}-\mathrm{CT}$ & A508 & Forging & A508-Ht-2 & SSR + Aged 20k h & Air & 350 \\
\hline 69 & J-R, Aged & E-1820 & $0.5 \mathrm{~T} \mathrm{D}-\mathrm{CT}$ & A508 & Forging & A508-Ht-2 & SSR + Aged 20k h & Air & 350 \\
\hline 70 & J-R, Aged & E-1820 & $0.5 \mathrm{~T} \mathrm{D}-\mathrm{CT}$ & A508 & Forging & A508-Ht-2 & SSR + Aged 20k h & Air & 350 \\
\hline 71 & J-R, Aged & E-1820 & $0.5 \mathrm{~T} \mathrm{D}-\mathrm{CT}$ & A508 & Forging & A508-Ht-2 & SSR + Aged 20k h & Air & 350 \\
\hline 72 & J-R, Aged & E-1820 & $0.5 \mathrm{~T} \mathrm{D}-\mathrm{CT}$ & A508 & Forging & A508-Ht-2 & SSR + Aged 20k h & Air & 350 \\
\hline 73 & J-R, Aged & E-1820 & $0.5 \mathrm{~T} \mathrm{D}-\mathrm{CT}$ & A508 & Forging & A508-Ht-2 & SSR + Aged 20k h & Air & 427 \\
\hline 74 & J-R, Aged & E-1820 & $0.5 \mathrm{~T} \mathrm{D}-\mathrm{CT}$ & A508 & Forging & A508-Ht-2 & SSR + Aged 20k h & Air & 427 \\
\hline 75 & J-R, Aged & E-1820 & $0.5 \mathrm{~T} \mathrm{D}-\mathrm{CT}$ & A508 & Forging & A508-Ht-2 & SSR + Aged 20k h & Air & 427 \\
\hline 76 & J-R, Aged & E-1820 & $0.5 \mathrm{~T} \mathrm{D}-\mathrm{CT}$ & A508 & Forging & A508-Ht-2 & SSR + Aged 20k h & Air & 427 \\
\hline 77 & J-R, Aged & E-1820 & $0.5 \mathrm{~T} \mathrm{D}-\mathrm{CT}$ & A508 & Forging & A508-Ht-2 & SSR + Aged 20k h & Air & 427 \\
\hline
\end{tabular}




Idaho National Laboratory
\begin{tabular}{|c|lll|}
\hline NEXT GENERATION NUCLEAR PLANT & Identifier: & PLN-2803 & \\
REACTOR PRESSURE VESSEL MATERIALS & Revision: & 0 & \\
RESEARCH AND DEVELOPMENT PLAN & Effective Date: & $04 / 30 / 08$ & Page: A- 65 of A-102 \\
\hline
\end{tabular}

\begin{tabular}{|c|c|c|c|c|c|c|c|c|c|}
\hline Spec. \# & Test Type & $\begin{array}{c}\text { Test } \\
\text { Method }\end{array}$ & Spec. Type & Mat & $\begin{array}{l}\text { Product Form } \\
(\sim 250 \mathrm{~mm} \text { thick })\end{array}$ & Heat \# & Mat Cond. ${ }^{(1)}$ & Env. & $\begin{array}{c}\text { Test Temp. } \\
\left({ }^{\circ} \mathrm{C}\right)\end{array}$ \\
\hline 78 & J-R, Aged & E-1820 & $0.5 \mathrm{~T} \mathrm{D}-\mathrm{CT}$ & A508 & Forging & A508-Ht-2 & SSR + Aged 20k h & Air & 427 \\
\hline 79 & J-R, Aged & E-1820 & $0.5 \mathrm{~T} \mathrm{D}-\mathrm{CT}$ & A508 & Forging & A508-Ht-2 & SSR + Aged 20k h & Air & 538 \\
\hline 80 & J-R, Aged & E-1820 & $0.5 \mathrm{~T} \mathrm{D}-\mathrm{CT}$ & A508 & Forging & A508-Ht-2 & SSR + Aged 20k h & Air & 538 \\
\hline 81 & J-R, Aged & E-1820 & $0.5 \mathrm{~T} \mathrm{D}-\mathrm{CT}$ & A508 & Forging & A508-Ht-2 & SSR + Aged 20k h & Air & 538 \\
\hline 82 & J-R, Aged & E-1820 & $0.5 \mathrm{~T} \mathrm{D}-\mathrm{CT}$ & A508 & Forging & A508-Ht-2 & SSR + Aged 20k h & Air & 538 \\
\hline 83 & J-R, Aged & E-1820 & $0.5 \mathrm{~T} \mathrm{D}-\mathrm{CT}$ & A508 & Forging & A508-Ht-2 & SSR + Aged 20k h & Air & 538 \\
\hline 84 & J-R, Aged & E-1820 & $0.5 \mathrm{~T} \mathrm{D}-\mathrm{CT}$ & A508 & Forging & A508-Ht-2 & SSR + Aged 20k h & Air & 538 \\
\hline 85 & MC To, Aged & E-1921 & $0.5 \mathrm{~T} \mathrm{D}-\mathrm{CT}$ & A533B & Rolled Plate & A533B-Ht-1 & SSR + Aged 20k h & Air & TBD \\
\hline 86 & MC To, Aged & E-1921 & $0.5 \mathrm{~T} \mathrm{D}-\mathrm{CT}$ & A533B & Rolled Plate & A533B-Ht-1 & SSR + Aged 20k h & Air & TBD \\
\hline 87 & MC To, Aged & E-1921 & $0.5 \mathrm{~T} \mathrm{D}-\mathrm{CT}$ & A533B & Rolled Plate & A533B-Ht-1 & SSR + Aged 20k h & Air & TBD \\
\hline 88 & MC To, Aged & E-1921 & $0.5 \mathrm{~T} \mathrm{D}-\mathrm{CT}$ & A533B & Rolled Plate & A533B-Ht-1 & SSR + Aged 20k h & Air & TBD \\
\hline 89 & MC To, Aged & E-1921 & $0.5 \mathrm{~T} \mathrm{D}-\mathrm{CT}$ & A533B & Rolled Plate & A533B-Ht-1 & SSR + Aged 20k h & Air & TBD \\
\hline 90 & MC To, Aged & E-1921 & $0.5 \mathrm{~T} \mathrm{D}-\mathrm{CT}$ & A533B & Rolled Plate & A533B-Ht-1 & SSR + Aged 20k h & Air & TBD \\
\hline 91 & MC To, Aged & E-1921 & $0.5 \mathrm{~T} \mathrm{D}-\mathrm{CT}$ & A533B & Rolled Plate & A533B-Ht-1 & SSR + Aged 20k h & Air & TBD \\
\hline 92 & MC To, Aged & E-1921 & $0.5 \mathrm{~T} \mathrm{D}-\mathrm{CT}$ & A533B & Rolled Plate & A533B-Ht-1 & SSR + Aged 20k h & Air & TBD \\
\hline 93 & MC To, Aged & E-1921 & $0.5 \mathrm{~T} \mathrm{D}-\mathrm{CT}$ & A533B & Rolled Plate & A533B-Ht-1 & SSR + Aged 20k h & Air & TBD \\
\hline 94 & MC To, Aged & E-1921 & $0.5 \mathrm{~T} \mathrm{D}-\mathrm{CT}$ & A533B & Rolled Plate & A533B-Ht-1 & SSR + Aged 20k h & Air & TBD \\
\hline 95 & MC To, Aged & E-1921 & $0.5 \mathrm{~T} \mathrm{D}-\mathrm{CT}$ & A533B & Rolled Plate & A533B-Ht-1 & SSR + Aged 20k h & Air & TBD \\
\hline 96 & MC To, Aged & E-1921 & $0.5 \mathrm{~T} \mathrm{D}-\mathrm{CT}$ & $\mathrm{A} 533 \mathrm{~B}$ & Rolled Plate & A533B-Ht-1 & SSR + Aged 20k h & Air & TBD \\
\hline 97 & J-R, Aged & E-1820 & $0.5 \mathrm{~T} \mathrm{D}-\mathrm{CT}$ & A533B & Rolled Plate & A533B-Ht-1 & SSR + Aged 20k h & Air & 20 \\
\hline 98 & J-R, Aged & E-1820 & $0.5 \mathrm{~T} \mathrm{D}-\mathrm{CT}$ & A533B & Rolled Plate & A533B-Ht-1 & SSR + Aged 20k h & Air & 20 \\
\hline 99 & J-R, Aged & E-1820 & $0.5 \mathrm{~T} \mathrm{D}-\mathrm{CT}$ & A533B & Rolled Plate & A533B-Ht-1 & SSR + Aged 20k h & Air & 20 \\
\hline 100 & J-R, Aged & E-1820 & $0.5 \mathrm{~T} \mathrm{D}-\mathrm{CT}$ & A533B & Rolled Plate & A533B-Ht-1 & SSR + Aged 20k h & Air & 20 \\
\hline 101 & J-R, Aged & E-1820 & $0.5 \mathrm{~T} \mathrm{D}-\mathrm{CT}$ & A533B & Rolled Plate & A533B-Ht-1 & SSR + Aged 20k h & Air & 20 \\
\hline 102 & J-R, Aged & E-1820 & $0.5 \mathrm{~T} \mathrm{D}-\mathrm{CT}$ & A533B & Rolled Plate & A533B-Ht-1 & SSR + Aged 20k h & Air & 20 \\
\hline 103 & J-R, Aged & E-1820 & $0.5 \mathrm{~T} \mathrm{D}-\mathrm{CT}$ & $\mathrm{A} 533 \mathrm{~B}$ & Rolled Plate & A533B-Ht-1 & SSR + Aged 20k h & Air & 150 \\
\hline
\end{tabular}




Idaho National Laboratory
\begin{tabular}{|c|lll|}
\hline NEXT GENERATION NUCLEAR PLANT & Identifier: & PLN-2803 & \\
REACTOR PRESSURE VESSEL MATERIALS & Revision: & 0 & \\
RESEARCH AND DEVELOPMENT PLAN & Effective Date: & $04 / 30 / 08$ & Page: A- 66 of A-102 \\
\hline
\end{tabular}

\begin{tabular}{|c|c|c|c|c|c|c|c|c|c|}
\hline Spec. \# & Test Type & $\begin{array}{c}\text { Test } \\
\text { Method }\end{array}$ & Spec. Type & Mat & $\begin{array}{l}\text { Product Form } \\
(\sim 250 \mathrm{~mm} \text { thick })\end{array}$ & Heat \# & Mat Cond. ${ }^{(1)}$ & Env. & $\begin{array}{c}\text { Test Temp. } \\
\left({ }^{\circ} \mathrm{C}\right)\end{array}$ \\
\hline 104 & J-R, Aged & E-1820 & $0.5 \mathrm{~T} \mathrm{D}-\mathrm{CT}$ & $\mathrm{A} 533 \mathrm{~B}$ & Rolled Plate & A533B-Ht-1 & SSR + Aged 20k h & Air & 150 \\
\hline 105 & J-R, Aged & E-1820 & $0.5 \mathrm{~T} \mathrm{D}-\mathrm{CT}$ & A533B & Rolled Plate & A533B-Ht-1 & SSR + Aged 20k h & Air & 150 \\
\hline 106 & J-R, Aged & E-1820 & $0.5 \mathrm{~T} \mathrm{D}-\mathrm{CT}$ & A533B & Rolled Plate & A533B-Ht-1 & SSR + Aged 20k h & Air & 150 \\
\hline 107 & J-R, Aged & E-1820 & $0.5 \mathrm{~T} \mathrm{D}-\mathrm{CT}$ & $\mathrm{A} 533 \mathrm{~B}$ & Rolled Plate & A533B-Ht-1 & SSR + Aged 20k h & Air & 150 \\
\hline 108 & J-R, Aged & E-1820 & $0.5 \mathrm{~T} \mathrm{D}-\mathrm{CT}$ & A533B & Rolled Plate & A533B-Ht-1 & SSR + Aged 20k h & Air & 150 \\
\hline 109 & J-R, Aged & E-1820 & $0.5 \mathrm{~T} \mathrm{D}-\mathrm{CT}$ & A533B & Rolled Plate & A533B-Ht-1 & SSR + Aged 20k h & Air & 350 \\
\hline 110 & J-R, Aged & E-1820 & $0.5 \mathrm{~T} \mathrm{D}-\mathrm{CT}$ & A533B & Rolled Plate & A533B-Ht-1 & SSR + Aged 20k h & Air & 350 \\
\hline 111 & J-R, Aged & E-1820 & $0.5 \mathrm{~T} \mathrm{D}-\mathrm{CT}$ & A533B & Rolled Plate & A533B-Ht-1 & SSR + Aged 20k h & Air & 350 \\
\hline 112 & J-R, Aged & E-1820 & $0.5 \mathrm{~T} \mathrm{D}-\mathrm{CT}$ & A533B & Rolled Plate & A533B-Ht-1 & SSR + Aged 20k h & Air & 350 \\
\hline 113 & J-R, Aged & E-1820 & $0.5 \mathrm{~T} \mathrm{D}-\mathrm{CT}$ & A533B & Rolled Plate & A533B-Ht-1 & SSR + Aged 20k h & Air & 350 \\
\hline 114 & J-R, Aged & E-1820 & $0.5 \mathrm{~T} \mathrm{D}-\mathrm{CT}$ & A533B & Rolled Plate & A533B-Ht-1 & SSR + Aged 20k h & Air & 350 \\
\hline 115 & J-R, Aged & E-1820 & $0.5 \mathrm{~T} \mathrm{D}-\mathrm{CT}$ & A533B & Rolled Plate & A533B-Ht-1 & SSR + Aged 20k h & Air & 427 \\
\hline 116 & J-R, Aged & E-1820 & $0.5 \mathrm{~T} \mathrm{D}-\mathrm{CT}$ & A533B & Rolled Plate & A533B-Ht-1 & SSR + Aged 20k h & Air & 427 \\
\hline 117 & J-R, Aged & E-1820 & $0.5 \mathrm{~T} \mathrm{D}-\mathrm{CT}$ & A533B & Rolled Plate & A533B-Ht-1 & SSR + Aged 20k h & Air & 427 \\
\hline 118 & J-R, Aged & E-1820 & $0.5 \mathrm{~T} \mathrm{D}-\mathrm{CT}$ & A533B & Rolled Plate & A533B-Ht-1 & SSR + Aged 20k h & Air & 427 \\
\hline 119 & J-R, Aged & E-1820 & $0.5 \mathrm{~T} \mathrm{D}-\mathrm{CT}$ & A533B & Rolled Plate & A533B-Ht-1 & SSR + Aged 20k h & Air & 427 \\
\hline 120 & J-R, Aged & E-1820 & $0.5 \mathrm{~T} \mathrm{D}-\mathrm{CT}$ & A533B & Rolled Plate & A533B-Ht-1 & SSR + Aged 20k h & Air & 427 \\
\hline 121 & J-R, Aged & E-1820 & $0.5 \mathrm{~T} \mathrm{D}-\mathrm{CT}$ & A533B & Rolled Plate & A533B-Ht-1 & SSR + Aged 20k h & Air & 538 \\
\hline 122 & J-R, Aged & E-1820 & $0.5 \mathrm{~T} \mathrm{D}-\mathrm{CT}$ & A533B & Rolled Plate & A533B-Ht-1 & SSR + Aged 20k h & Air & 538 \\
\hline 123 & J-R, Aged & E-1820 & $0.5 \mathrm{~T} \mathrm{D}-\mathrm{CT}$ & $\mathrm{A} 533 \mathrm{~B}$ & Rolled Plate & A533B-Ht-1 & SSR + Aged 20k h & Air & 538 \\
\hline 124 & J-R, Aged & E-1820 & $0.5 \mathrm{~T} \mathrm{D}-\mathrm{CT}$ & A533B & Rolled Plate & A533B-Ht-1 & SSR + Aged 20k h & Air & 538 \\
\hline 125 & J-R, Aged & E-1820 & $0.5 \mathrm{~T} \mathrm{D}-\mathrm{CT}$ & A533B & Rolled Plate & A533B-Ht-1 & SSR + Aged 20k h & Air & 538 \\
\hline 126 & J-R, Aged & E-1820 & $0.5 \mathrm{~T} \mathrm{D}-\mathrm{CT}$ & A533B & Rolled Plate & A533B-Ht-1 & SSR + Aged 20k h & Air & 538 \\
\hline 127 & MC To, Aged & E-1921 & $0.5 \mathrm{~T} \mathrm{D}-\mathrm{CT}$ & A533B & Rolled Plate & A533B-Ht-2 & SSR + Aged 20k h & Air & TBD \\
\hline 128 & MC To, Aged & E-1921 & $0.5 \mathrm{~T} \mathrm{D}-\mathrm{CT}$ & A533B & Rolled Plate & A533B-Ht-2 & SSR + Aged 20k h & Air & TBD \\
\hline 129 & MC To, Aged & E-1921 & $0.5 \mathrm{~T} \mathrm{D}-\mathrm{CT}$ & $\mathrm{A} 533 \mathrm{~B}$ & Rolled Plate & A533B-Ht-2 & SSR + Aged 20k h & Air & TBD \\
\hline
\end{tabular}




Idaho National Laboratory
\begin{tabular}{|c|lll|}
\hline NEXT GENERATION NUCLEAR PLANT & Identifier: & PLN-2803 & \\
REACTOR PRESSURE VESSEL MATERIALS & Revision: & 0 & \\
RESEARCH AND DEVELOPMENT PLAN & Effective Date: & $04 / 30 / 08$ & Page: A-67 of A-102 \\
\hline
\end{tabular}

\begin{tabular}{|c|c|c|c|c|c|c|c|c|c|}
\hline Spec. \# & Test Type & $\begin{array}{c}\text { Test } \\
\text { Method }\end{array}$ & Spec. Type & Mat & $\begin{array}{l}\text { Product Form } \\
(\sim 250 \mathrm{~mm} \text { thick })\end{array}$ & Heat \# & Mat Cond. ${ }^{(1)}$ & Env. & $\begin{array}{c}\text { Test Temp. } \\
\left({ }^{\circ} \mathrm{C}\right)\end{array}$ \\
\hline 130 & MC To, Aged & E-1921 & $0.5 \mathrm{~T} \mathrm{D}-\mathrm{CT}$ & A533B & Rolled Plate & A533B-Ht-2 & SSR + Aged 20k h & Air & TBD \\
\hline 131 & MC To, Aged & E-1921 & $0.5 \mathrm{~T} \mathrm{D}-\mathrm{CT}$ & A533B & Rolled Plate & A533B-Ht-2 & SSR + Aged 20k h & Air & TBD \\
\hline 132 & MC To, Aged & E-1921 & $0.5 \mathrm{~T} \mathrm{D}-\mathrm{CT}$ & A533B & Rolled Plate & A533B-Ht-2 & SSR + Aged 20k h & Air & TBD \\
\hline 133 & MC To, Aged & E-1921 & $0.5 \mathrm{~T} \mathrm{D}-\mathrm{CT}$ & $\mathrm{A} 533 \mathrm{~B}$ & Rolled Plate & A533B-Ht-2 & SSR + Aged 20k h & Air & TBD \\
\hline 134 & MC To, Aged & E-1921 & $0.5 \mathrm{~T} \mathrm{D}-\mathrm{CT}$ & A533B & Rolled Plate & A533B-Ht-2 & SSR + Aged 20k h & Air & TBD \\
\hline 135 & MC To, Aged & E-1921 & $0.5 \mathrm{~T} \mathrm{D}-\mathrm{CT}$ & A533B & Rolled Plate & A533B-Ht-2 & SSR + Aged 20k h & Air & TBD \\
\hline 136 & MC To, Aged & E-1921 & $0.5 \mathrm{~T} \mathrm{D}-\mathrm{CT}$ & A533B & Rolled Plate & A533B-Ht-2 & SSR + Aged 20k h & Air & TBD \\
\hline 137 & MC To, Aged & E-1921 & $0.5 \mathrm{~T} \mathrm{D}-\mathrm{CT}$ & A533B & Rolled Plate & A533B-Ht-2 & SSR + Aged 20k h & Air & TBD \\
\hline 138 & MC To, Aged & E-1921 & $0.5 \mathrm{~T} \mathrm{D}-\mathrm{CT}$ & A533B & Rolled Plate & A533B-Ht-2 & SSR + Aged 20k h & Air & TBD \\
\hline 139 & J-R, Aged & E-1820 & $0.5 \mathrm{~T} \mathrm{D}-\mathrm{CT}$ & A533B & Rolled Plate & A533B-Ht-2 & SSR + Aged 20k h & Air & 20 \\
\hline 140 & J-R, Aged & E-1820 & $0.5 \mathrm{~T} \mathrm{D}-\mathrm{CT}$ & A533B & Rolled Plate & A533B-Ht-2 & SSR + Aged 20k h & Air & 20 \\
\hline 141 & J-R, Aged & E-1820 & $0.5 \mathrm{~T} \mathrm{D}-\mathrm{CT}$ & A533B & Rolled Plate & A533B-Ht-2 & SSR + Aged 20k h & Air & 20 \\
\hline 142 & J-R, Aged & E-1820 & $0.5 \mathrm{~T} \mathrm{D}-\mathrm{CT}$ & A533B & Rolled Plate & A533B-Ht-2 & SSR + Aged 20k h & Air & 20 \\
\hline 143 & J-R, Aged & E-1820 & $0.5 \mathrm{~T} \mathrm{D}-\mathrm{CT}$ & A533B & Rolled Plate & A533B-Ht-2 & SSR + Aged 20k h & Air & 20 \\
\hline 144 & J-R, Aged & E-1820 & $0.5 \mathrm{~T} \mathrm{D}-\mathrm{CT}$ & A533B & Rolled Plate & A533B-Ht-2 & SSR + Aged 20k h & Air & 20 \\
\hline 145 & J-R, Aged & E-1820 & $0.5 \mathrm{~T} \mathrm{D}-\mathrm{CT}$ & A533B & Rolled Plate & A533B-Ht-2 & SSR + Aged 20k h & Air & 150 \\
\hline 146 & J-R, Aged & E-1820 & $0.5 \mathrm{~T} \mathrm{D}-\mathrm{CT}$ & A533B & Rolled Plate & A533B-Ht-2 & SSR + Aged 20k h & Air & 150 \\
\hline 147 & J-R, Aged & E-1820 & $0.5 \mathrm{~T} \mathrm{D}-\mathrm{CT}$ & A533B & Rolled Plate & A533B-Ht-2 & SSR + Aged 20k h & Air & 150 \\
\hline 148 & J-R, Aged & E-1820 & $0.5 \mathrm{~T} \mathrm{D}-\mathrm{CT}$ & A533B & Rolled Plate & A533B-Ht-2 & SSR + Aged 20k h & Air & 150 \\
\hline 149 & J-R, Aged & E-1820 & $0.5 \mathrm{~T} \mathrm{D}-\mathrm{CT}$ & A533B & Rolled Plate & A533B-Ht-2 & SSR + Aged 20k h & Air & 150 \\
\hline 150 & J-R, Aged & E-1820 & $0.5 \mathrm{~T} \mathrm{D}-\mathrm{CT}$ & A533B & Rolled Plate & A533B-Ht-2 & SSR + Aged 20k h & Air & 150 \\
\hline 151 & J-R, Aged & E-1820 & $0.5 \mathrm{~T} \mathrm{D}-\mathrm{CT}$ & A533B & Rolled Plate & A533B-Ht-2 & SSR + Aged 20k h & Air & 350 \\
\hline 152 & J-R, Aged & E-1820 & $0.5 \mathrm{~T} \mathrm{D}-\mathrm{CT}$ & A533B & Rolled Plate & A533B-Ht-2 & SSR + Aged 20k h & Air & 350 \\
\hline 153 & J-R, Aged & E-1820 & $0.5 \mathrm{~T} \mathrm{D}-\mathrm{CT}$ & A533B & Rolled Plate & A533B-Ht-2 & SSR + Aged 20k h & Air & 350 \\
\hline 154 & J-R, Aged & E-1820 & $0.5 \mathrm{~T} \mathrm{D}-\mathrm{CT}$ & A533B & Rolled Plate & A533B-Ht-2 & SSR + Aged 20k h & Air & 350 \\
\hline 155 & J-R, Aged & E-1820 & $0.5 \mathrm{~T} \mathrm{D}-\mathrm{CT}$ & $\mathrm{A} 533 \mathrm{~B}$ & Rolled Plate & A533B-Ht-2 & SSR + Aged 20k h & Air & 350 \\
\hline
\end{tabular}




Idaho National Laboratory
\begin{tabular}{|c|lll|}
\hline NEXT GENERATION NUCLEAR PLANT & Identifier: & PLN-2803 & \\
REACTOR PRESSURE VESSEL MATERIALS & Revision: & 0 & \\
RESEARCH AND DEVELOPMENT PLAN & Effective Date: & $04 / 30 / 08$ & Page: A- 68 of A-102 \\
\hline
\end{tabular}

\begin{tabular}{|c|c|c|c|c|c|c|c|c|c|}
\hline Spec. \# & Test Type & $\begin{array}{c}\text { Test } \\
\text { Method }\end{array}$ & Spec. Type & Mat & $\begin{array}{l}\text { Product Form } \\
(\sim 250 \mathrm{~mm} \text { thick })\end{array}$ & Heat \# & Mat Cond. ${ }^{(1)}$ & Env. & $\begin{array}{c}\text { Test Temp. } \\
\left({ }^{\circ} \mathrm{C}\right)\end{array}$ \\
\hline 156 & J-R, Aged & E-1820 & $0.5 \mathrm{~T} \mathrm{D}-\mathrm{CT}$ & A533B & Rolled Plate & A533B-Ht-2 & SSR + Aged 20k h & Air & 350 \\
\hline 157 & J-R, Aged & E-1820 & $0.5 \mathrm{~T}$ D-CT & A533B & Rolled Plate & A533B-Ht-2 & SSR + Aged 20k h & Air & 427 \\
\hline 158 & J-R, Aged & E-1820 & $0.5 \mathrm{~T} \mathrm{D}-\mathrm{CT}$ & $\mathrm{A} 533 \mathrm{~B}$ & Rolled Plate & A533B-Ht-2 & SSR + Aged 20k h & Air & 427 \\
\hline 159 & J-R, Aged & E-1820 & $0.5 \mathrm{~T} \mathrm{D}-\mathrm{CT}$ & A533B & Rolled Plate & A533B-Ht-2 & SSR + Aged 20k h & Air & 427 \\
\hline 160 & J-R, Aged & E-1820 & $0.5 \mathrm{~T}$ D-CT & A533B & Rolled Plate & A533B-Ht-2 & SSR + Aged 20k h & Air & 427 \\
\hline 161 & J-R, Aged & E-1820 & $0.5 \mathrm{~T} \mathrm{D}-\mathrm{CT}$ & A533B & Rolled Plate & A533B-Ht-2 & SSR + Aged 20k h & Air & 427 \\
\hline 162 & J-R, Aged & E-1820 & $0.5 \mathrm{~T} \mathrm{D}-\mathrm{CT}$ & A533B & Rolled Plate & A533B-Ht-2 & SSR + Aged 20k h & Air & 427 \\
\hline 163 & J-R, Aged & E-1820 & $0.5 \mathrm{~T} \mathrm{D}-\mathrm{CT}$ & A533B & Rolled Plate & A533B-Ht-2 & SSR + Aged 20k h & Air & 538 \\
\hline 164 & J-R, Aged & E-1820 & $0.5 \mathrm{~T} \mathrm{D}-\mathrm{CT}$ & A533B & Rolled Plate & A533B-Ht-2 & SSR + Aged 20k h & Air & 538 \\
\hline 165 & J-R, Aged & E-1820 & $0.5 \mathrm{~T}$ D-CT & A533B & Rolled Plate & A533B-Ht-2 & SSR + Aged 20k h & Air & 538 \\
\hline 166 & J-R, Aged & E-1820 & $0.5 \mathrm{~T} \mathrm{D}-\mathrm{CT}$ & A533B & Rolled Plate & A533B-Ht-2 & SSR + Aged 20k h & Air & 538 \\
\hline 167 & J-R, Aged & E-1820 & $0.5 \mathrm{~T} \mathrm{D}-\mathrm{CT}$ & A533B & Rolled Plate & A533B-Ht-2 & SSR + Aged 20k h & Air & 538 \\
\hline 168 & J-R, Aged & E-1820 & $0.5 \mathrm{~T} \mathrm{D}-\mathrm{CT}$ & A533B & Rolled Plate & A533B-Ht-2 & SSR + Aged 20k h & Air & 538 \\
\hline
\end{tabular}




Idaho National Laboratory
\begin{tabular}{|c|lll|}
\hline NEXT GENERATION NUCLEAR PLANT & Identifier: & PLN-2803 & \\
REACTOR PRESSURE VESSEL MATERIALS & Revision: & 0 & \\
RESEARCH AND DEVELOPMENT PLAN & Effective Date: & $04 / 30 / 08$ & Page: A- 69 of A-102 \\
\hline
\end{tabular}

\begin{tabular}{|c|c|c|c|c|c|c|c|c|c|}
\hline Spec. \# & Test Type & $\begin{array}{c}\text { Test } \\
\text { Method }\end{array}$ & Spec. Type & Mat & $\begin{array}{l}\text { Product Form } \\
(\sim 250 \mathrm{~mm} \text { thick })\end{array}$ & Heat \# & Mat Cond. ${ }^{(1)}$ & Env. & $\begin{array}{c}\text { Test Temp. } \\
\left({ }^{\circ} \mathrm{C}\right)\end{array}$ \\
\hline 1 & MC To, Aged & E-1921 & $0.5 \mathrm{~T}$ D-CT & A508 & Forging & A508-Ht-1 & SSR + Aged 70k h & Air & TBD \\
\hline 2 & MC To, Aged & E-1921 & $0.5 \mathrm{~T}$ D-CT & A508 & Forging & A508-Ht-1 & SSR + Aged 70k h & Air & TBD \\
\hline 3 & MC To, Aged & E-1921 & $0.5 \mathrm{~T}$ D-CT & A508 & Forging & A508-Ht-1 & SSR + Aged 70k h & Air & TBD \\
\hline 4 & MC To, Aged & E-1921 & $0.5 \mathrm{~T}$ D-CT & A508 & Forging & A508-Ht-1 & $\mathrm{SSR}+$ Aged 70k h & Air & TBD \\
\hline 5 & MC To, Aged & E-1921 & $0.5 \mathrm{~T} \mathrm{D}-\mathrm{CT}$ & A508 & Forging & A508-Ht-1 & SSR + Aged 70k h & Air & TBD \\
\hline 6 & MC To, Aged & E-1921 & $0.5 \mathrm{~T}$ D-CT & A508 & Forging & A508-Ht-1 & SSR + Aged 70k h & Air & TBD \\
\hline 7 & MC To, Aged & E-1921 & $0.5 \mathrm{~T}$ D-CT & A508 & Forging & A508-Ht-1 & SSR + Aged 70k h & Air & TBD \\
\hline 8 & MC To, Aged & E-1921 & $0.5 \mathrm{~T}$ D-CT & A508 & Forging & A508-Ht-1 & SSR + Aged 70k h & Air & TBD \\
\hline 9 & MC To, Aged & E-1921 & $0.5 \mathrm{~T}$ D-CT & A508 & Forging & A508-Ht-1 & SSR + Aged 70k h & Air & TBD \\
\hline 10 & MC To, Aged & E-1921 & $0.5 \mathrm{~T}$ D-CT & A508 & Forging & A508-Ht-1 & SSR + Aged 70k h & Air & TBD \\
\hline 11 & MC To, Aged & E-1921 & $0.5 \mathrm{~T}$ D-CT & A508 & Forging & A508-Ht-1 & SSR + Aged 70k h & Air & TBD \\
\hline 12 & MC To, Aged & E-1921 & $0.5 \mathrm{~T}$ D-CT & A508 & Forging & A508-Ht-1 & SSR + Aged 70k h & Air & TBD \\
\hline 13 & J-R, Aged & E-1820 & $0.5 \mathrm{~T} \mathrm{D}-\mathrm{CT}$ & A508 & Forging & A508-Ht-1 & SSR + Aged 70k h & Air & 20 \\
\hline 14 & J-R, Aged & E-1820 & $0.5 \mathrm{~T}$ D-CT & A508 & Forging & A508-Ht-1 & SSR + Aged 70k h & Air & 20 \\
\hline 15 & J-R, Aged & E-1820 & $0.5 \mathrm{~T}$ D-CT & A508 & Forging & A508-Ht-1 & $\mathrm{SSR}+$ Aged 70k h & Air & 20 \\
\hline 16 & J-R, Aged & E-1820 & $0.5 \mathrm{~T}$ D-CT & A508 & Forging & A508-Ht-1 & SSR + Aged 70k h & Air & 20 \\
\hline 17 & J-R, Aged & E-1820 & $0.5 \mathrm{~T}$ D-CT & A508 & Forging & A508-Ht-1 & SSR + Aged 70k h & Air & 20 \\
\hline 18 & J-R, Aged & E-1820 & $0.5 \mathrm{~T}$ D-CT & A508 & Forging & A508-Ht-1 & SSR + Aged 70k h & Air & 20 \\
\hline 19 & J-R, Aged & E-1820 & $0.5 \mathrm{~T}$ D-CT & A508 & Forging & A508-Ht-1 & SSR + Aged 70k h & Air & 150 \\
\hline 20 & J-R, Aged & E-1820 & $0.5 \mathrm{~T}$ D-CT & A508 & Forging & A508-Ht-1 & SSR + Aged 70k h & Air & 150 \\
\hline 21 & J-R, Aged & E-1820 & $0.5 \mathrm{~T}$ D-CT & A508 & Forging & A508-Ht-1 & SSR + Aged 70k h & Air & 150 \\
\hline 22 & J-R, Aged & E-1820 & $0.5 \mathrm{~T} \mathrm{D}-\mathrm{CT}$ & A508 & Forging & A508-Ht-1 & SSR + Aged 70k h & Air & 150 \\
\hline 23 & J-R, Aged & E-1820 & $0.5 \mathrm{~T}$ D-CT & A508 & Forging & A508-Ht-1 & SSR + Aged 70k h & Air & 150 \\
\hline 24 & J-R, Aged & E-1820 & $0.5 \mathrm{~T}$ D-CT & A508 & Forging & A508-Ht-1 & SSR + Aged 70k h & Air & 150 \\
\hline 25 & J-R, Aged & E-1820 & $0.5 \mathrm{~T} \mathrm{D}-\mathrm{CT}$ & A508 & Forging & A508-Ht-1 & SSR + Aged 70k h & Air & 350 \\
\hline
\end{tabular}




Idaho National Laboratory
\begin{tabular}{|c|lll|}
\hline NEXT GENERATION NUCLEAR PLANT & Identifier: & PLN-2803 & \\
REACTOR PRESSURE VESSEL MATERIALS & Revision: & 0 & \\
RESEARCH AND DEVELOPMENT PLAN & Effective Date: & $04 / 30 / 08$ & Page: A-70 of A-102 \\
\hline
\end{tabular}

\begin{tabular}{|c|c|c|c|c|c|c|c|c|c|}
\hline Spec. \# & Test Type & $\begin{array}{c}\text { Test } \\
\text { Method }\end{array}$ & Spec. Type & Mat & $\begin{array}{l}\text { Product Form } \\
(\sim 250 \mathrm{~mm} \text { thick })\end{array}$ & Heat \# & Mat Cond. ${ }^{(1)}$ & Env. & $\begin{array}{c}\text { Test Temp. } \\
\left({ }^{\circ} \mathrm{C}\right)\end{array}$ \\
\hline 26 & J-R, Aged & E-1820 & $0.5 \mathrm{~T} \mathrm{D}-\mathrm{CT}$ & A508 & Forging & A508-Ht-1 & SSR + Aged 70k h & Air & 350 \\
\hline 27 & J-R, Aged & E-1820 & $0.5 \mathrm{~T} \mathrm{D}-\mathrm{CT}$ & A508 & Forging & A508-Ht-1 & SSR + Aged 70k h & Air & 350 \\
\hline 28 & J-R, Aged & E-1820 & $0.5 \mathrm{~T} \mathrm{D}-\mathrm{CT}$ & A508 & Forging & A508-Ht-1 & SSR + Aged 70k h & Air & 350 \\
\hline 29 & J-R, Aged & E-1820 & $0.5 \mathrm{~T} \mathrm{D}-\mathrm{CT}$ & A508 & Forging & A508-Ht-1 & SSR + Aged 70k h & Air & 350 \\
\hline 30 & J-R, Aged & E-1820 & $0.5 \mathrm{~T} \mathrm{D}-\mathrm{CT}$ & A508 & Forging & A508-Ht-1 & SSR + Aged 70k h & Air & 350 \\
\hline 31 & J-R, Aged & E-1820 & $0.5 \mathrm{~T} \mathrm{D}-\mathrm{CT}$ & A508 & Forging & A508-Ht-1 & SSR + Aged 70k h & Air & 427 \\
\hline 32 & J-R, Aged & E-1820 & $0.5 \mathrm{~T} \mathrm{D}-\mathrm{CT}$ & A508 & Forging & A508-Ht-1 & SSR + Aged 70k h & Air & 427 \\
\hline 33 & J-R, Aged & E-1820 & $0.5 \mathrm{~T} \mathrm{D}-\mathrm{CT}$ & A508 & Forging & A508-Ht-1 & SSR + Aged 70k h & Air & 427 \\
\hline 34 & J-R, Aged & E-1820 & $0.5 \mathrm{~T} \mathrm{D}-\mathrm{CT}$ & A508 & Forging & A508-Ht-1 & SSR + Aged 70k h & Air & 427 \\
\hline 35 & J-R, Aged & E-1820 & $0.5 \mathrm{~T} \mathrm{D}-\mathrm{CT}$ & A508 & Forging & A508-Ht-1 & SSR + Aged 70k h & Air & 427 \\
\hline 36 & J-R, Aged & E-1820 & $0.5 \mathrm{~T} \mathrm{D}-\mathrm{CT}$ & A508 & Forging & A508-Ht-1 & SSR + Aged 70k h & Air & 427 \\
\hline 37 & J-R, Aged & E-1820 & $0.5 \mathrm{~T} \mathrm{D}-\mathrm{CT}$ & A508 & Forging & A508-Ht-1 & SSR + Aged 70k h & Air & 538 \\
\hline 38 & J-R, Aged & E-1820 & $0.5 \mathrm{~T} \mathrm{D}-\mathrm{CT}$ & A508 & Forging & A508-Ht-1 & SSR + Aged 70k h & Air & 538 \\
\hline 39 & J-R, Aged & E-1820 & $0.5 \mathrm{~T} \mathrm{D}-\mathrm{CT}$ & A508 & Forging & A508-Ht-1 & SSR + Aged 70k h & Air & 538 \\
\hline 40 & J-R, Aged & E-1820 & $0.5 \mathrm{~T} \mathrm{D}-\mathrm{CT}$ & A508 & Forging & A508-Ht-1 & SSR + Aged 70k h & Air & 538 \\
\hline 41 & J-R, Aged & E-1820 & $0.5 \mathrm{~T} \mathrm{D}-\mathrm{CT}$ & A508 & Forging & A508-Ht-1 & SSR + Aged 70k h & Air & 538 \\
\hline 42 & J-R, Aged & E-1820 & $0.5 \mathrm{~T} \mathrm{D}-\mathrm{CT}$ & A508 & Forging & A508-Ht-1 & SSR + Aged 70k h & Air & 538 \\
\hline 43 & MC To, Aged & E-1921 & $0.5 \mathrm{~T} \mathrm{D}-\mathrm{CT}$ & A508 & Forging & A508-Ht-2 & SSR + Aged 70k h & Air & TBD \\
\hline 44 & MC To, Aged & E-1921 & $0.5 \mathrm{~T} \mathrm{D}-\mathrm{CT}$ & A508 & Forging & A508-Ht-2 & SSR + Aged 70k h & Air & TBD \\
\hline 45 & MC To, Aged & E-1921 & $0.5 \mathrm{~T} \mathrm{D}-\mathrm{CT}$ & A508 & Forging & A508-Ht-2 & SSR + Aged 70k h & Air & TBD \\
\hline 46 & MC To, Aged & E-1921 & $0.5 \mathrm{~T} \mathrm{D}-\mathrm{CT}$ & A508 & Forging & A508-Ht-2 & SSR + Aged 70k h & Air & TBD \\
\hline 47 & MC To, Aged & E-1921 & $0.5 \mathrm{~T} \mathrm{D}-\mathrm{CT}$ & A508 & Forging & A508-Ht-2 & SSR + Aged 70k h & Air & TBD \\
\hline 48 & MC To, Aged & E-1921 & $0.5 \mathrm{~T} \mathrm{D}-\mathrm{CT}$ & A508 & Forging & A508-Ht-2 & SSR + Aged 70k h & Air & TBD \\
\hline 49 & MC To, Aged & E-1921 & $0.5 \mathrm{~T} \mathrm{D}-\mathrm{CT}$ & A508 & Forging & A508-Ht-2 & SSR + Aged 70k h & Air & TBD \\
\hline 50 & MC To, Aged & E-1921 & $0.5 \mathrm{~T} \mathrm{D}-\mathrm{CT}$ & A508 & Forging & A508-Ht-2 & SSR + Aged 70k h & Air & TBD \\
\hline 51 & MC To, Aged & E-1921 & $0.5 \mathrm{~T} \mathrm{D}-\mathrm{CT}$ & A508 & Forging & A508-Ht-2 & SSR + Aged 70k h & Air & TBD \\
\hline
\end{tabular}




Idaho National Laboratory
\begin{tabular}{|c|lll|}
\hline NEXT GENERATION NUCLEAR PLANT & Identifier: & PLN-2803 & \\
REACTOR PRESSURE VESSEL MATERIALS & Revision: & 0 & \\
RESEARCH AND DEVELOPMENT PLAN & Effective Date: & $04 / 30 / 08$ & Page: A-71 of A-102 \\
\hline
\end{tabular}

\begin{tabular}{|c|c|c|c|c|c|c|c|c|c|}
\hline Spec. \# & Test Type & $\begin{array}{c}\text { Test } \\
\text { Method }\end{array}$ & Spec. Type & Mat & $\begin{array}{l}\text { Product Form } \\
(\sim 250 \mathrm{~mm} \text { thick })\end{array}$ & Heat \# & Mat Cond. ${ }^{(1)}$ & Env. & $\begin{array}{c}\text { Test Temp. } \\
\left({ }^{\circ} \mathrm{C}\right)\end{array}$ \\
\hline 52 & MC To, Aged & E-1921 & $0.5 \mathrm{~T} \mathrm{D}-\mathrm{CT}$ & A508 & Forging & A508-Ht-2 & SSR + Aged 70k h & Air & TBD \\
\hline 53 & MC To, Aged & E-1921 & $0.5 \mathrm{~T} \mathrm{D}-\mathrm{CT}$ & A508 & Forging & A508-Ht-2 & SSR + Aged 70k h & Air & TBD \\
\hline 54 & MC To, Aged & E-1921 & $0.5 \mathrm{~T} \mathrm{D}-\mathrm{CT}$ & A508 & Forging & A508-Ht-2 & SSR + Aged 70k h & Air & TBD \\
\hline 55 & J-R, Aged & E-1820 & $0.5 \mathrm{~T} \mathrm{D}-\mathrm{CT}$ & A508 & Forging & A508-Ht-2 & SSR + Aged 70k h & Air & 20 \\
\hline 56 & J-R, Aged & E-1820 & $0.5 \mathrm{~T} \mathrm{D}-\mathrm{CT}$ & A508 & Forging & A508-Ht-2 & SSR + Aged 70k h & Air & 20 \\
\hline 57 & J-R, Aged & E-1820 & $0.5 \mathrm{~T} \mathrm{D}-\mathrm{CT}$ & A508 & Forging & A508-Ht-2 & SSR + Aged 70k h & Air & 20 \\
\hline 58 & J-R, Aged & E-1820 & $0.5 \mathrm{~T} \mathrm{D}-\mathrm{CT}$ & A508 & Forging & A508-Ht-2 & SSR + Aged 70k h & Air & 20 \\
\hline 59 & J-R, Aged & E-1820 & $0.5 \mathrm{~T} \mathrm{D}-\mathrm{CT}$ & A508 & Forging & A508-Ht-2 & SSR + Aged 70k h & Air & 20 \\
\hline 60 & J-R, Aged & E-1820 & $0.5 \mathrm{~T} \mathrm{D}-\mathrm{CT}$ & A508 & Forging & A508-Ht-2 & SSR + Aged 70k h & Air & 20 \\
\hline 61 & J-R, Aged & E-1820 & $0.5 \mathrm{~T} \mathrm{D}-\mathrm{CT}$ & A508 & Forging & A508-Ht-2 & SSR + Aged 70k h & Air & 150 \\
\hline 62 & J-R, Aged & E-1820 & $0.5 \mathrm{~T} \mathrm{D}-\mathrm{CT}$ & A508 & Forging & A508-Ht-2 & SSR + Aged 70k h & Air & 150 \\
\hline 63 & J-R, Aged & E-1820 & $0.5 \mathrm{~T} \mathrm{D}-\mathrm{CT}$ & A508 & Forging & A508-Ht-2 & SSR + Aged 70k h & Air & 150 \\
\hline 64 & J-R, Aged & E-1820 & $0.5 \mathrm{~T} \mathrm{D}-\mathrm{CT}$ & A508 & Forging & A508-Ht-2 & SSR + Aged 70k h & Air & 150 \\
\hline 65 & J-R, Aged & E-1820 & $0.5 \mathrm{~T} \mathrm{D}-\mathrm{CT}$ & A508 & Forging & A508-Ht-2 & SSR + Aged 70k h & Air & 150 \\
\hline 66 & J-R, Aged & E-1820 & $0.5 \mathrm{~T} \mathrm{D}-\mathrm{CT}$ & A508 & Forging & A508-Ht-2 & SSR + Aged 70k h & Air & 150 \\
\hline 67 & J-R, Aged & E-1820 & $0.5 \mathrm{~T} \mathrm{D}-\mathrm{CT}$ & A508 & Forging & A508-Ht-2 & SSR + Aged 70k h & Air & 350 \\
\hline 68 & J-R, Aged & E-1820 & $0.5 \mathrm{~T} \mathrm{D}-\mathrm{CT}$ & A508 & Forging & A508-Ht-2 & SSR + Aged 70k h & Air & 350 \\
\hline 69 & J-R, Aged & E-1820 & $0.5 \mathrm{~T} \mathrm{D}-\mathrm{CT}$ & A508 & Forging & A508-Ht-2 & SSR + Aged 70k h & Air & 350 \\
\hline 70 & J-R, Aged & E-1820 & $0.5 \mathrm{~T} \mathrm{D}-\mathrm{CT}$ & A508 & Forging & A508-Ht-2 & SSR + Aged 70k h & Air & 350 \\
\hline 71 & J-R, Aged & E-1820 & $0.5 \mathrm{~T} \mathrm{D}-\mathrm{CT}$ & A508 & Forging & A508-Ht-2 & SSR + Aged 70k h & Air & 350 \\
\hline 72 & J-R, Aged & E-1820 & $0.5 \mathrm{~T} \mathrm{D}-\mathrm{CT}$ & A508 & Forging & A508-Ht-2 & SSR + Aged 70k h & Air & 350 \\
\hline 73 & J-R, Aged & E-1820 & $0.5 \mathrm{~T} \mathrm{D}-\mathrm{CT}$ & A508 & Forging & A508-Ht-2 & SSR + Aged 70k h & Air & 427 \\
\hline 74 & J-R, Aged & E-1820 & $0.5 \mathrm{~T} \mathrm{D}-\mathrm{CT}$ & A508 & Forging & A508-Ht-2 & SSR + Aged 70k h & Air & 427 \\
\hline 75 & J-R, Aged & E-1820 & $0.5 \mathrm{~T} \mathrm{D}-\mathrm{CT}$ & A508 & Forging & A508-Ht-2 & SSR + Aged 70k h & Air & 427 \\
\hline 76 & J-R, Aged & E-1820 & $0.5 \mathrm{~T} \mathrm{D}-\mathrm{CT}$ & A508 & Forging & A508-Ht-2 & SSR + Aged 70k h & Air & 427 \\
\hline 77 & J-R, Aged & E-1820 & $0.5 \mathrm{~T} \mathrm{D}-\mathrm{CT}$ & A508 & Forging & A508-Ht-2 & SSR + Aged 70k h & Air & 427 \\
\hline
\end{tabular}




Idaho National Laboratory
\begin{tabular}{|c|lll|}
\hline NEXT GENERATION NUCLEAR PLANT & Identifier: & PLN-2803 & \\
REACTOR PRESSURE VESSEL MATERIALS & Revision: & 0 & \\
RESEARCH AND DEVELOPMENT PLAN & Effective Date: & $04 / 30 / 08$ & Page: A-72 of A-102 \\
\hline
\end{tabular}

\begin{tabular}{|c|c|c|c|c|c|c|c|c|c|}
\hline Spec. \# & Test Type & $\begin{array}{c}\text { Test } \\
\text { Method }\end{array}$ & Spec. Type & Mat & $\begin{array}{l}\text { Product Form } \\
(\sim 250 \mathrm{~mm} \text { thick })\end{array}$ & Heat \# & Mat Cond. ${ }^{(1)}$ & Env. & $\begin{array}{c}\text { Test Temp. } \\
\left({ }^{\circ} \mathrm{C}\right)\end{array}$ \\
\hline 78 & J-R, Aged & E-1820 & $0.5 \mathrm{~T} \mathrm{D}-\mathrm{CT}$ & A508 & Forging & A508-Ht-2 & SSR + Aged 70k h & Air & 427 \\
\hline 79 & J-R, Aged & E-1820 & $0.5 \mathrm{~T} \mathrm{D}-\mathrm{CT}$ & A508 & Forging & A508-Ht-2 & SSR + Aged 70k h & Air & 538 \\
\hline 80 & J-R, Aged & E-1820 & $0.5 \mathrm{~T} \mathrm{D}-\mathrm{CT}$ & A508 & Forging & A508-Ht-2 & SSR + Aged 70k h & Air & 538 \\
\hline 81 & J-R, Aged & E-1820 & $0.5 \mathrm{~T} \mathrm{D}-\mathrm{CT}$ & A508 & Forging & A508-Ht-2 & SSR + Aged 70k h & Air & 538 \\
\hline 82 & J-R, Aged & E-1820 & $0.5 \mathrm{~T} \mathrm{D}-\mathrm{CT}$ & A508 & Forging & A508-Ht-2 & SSR + Aged 70k h & Air & 538 \\
\hline 83 & J-R, Aged & E-1820 & $0.5 \mathrm{~T} \mathrm{D}-\mathrm{CT}$ & A508 & Forging & A508-Ht-2 & SSR + Aged 70k h & Air & 538 \\
\hline 84 & J-R, Aged & E-1820 & $0.5 \mathrm{~T} \mathrm{D}-\mathrm{CT}$ & A508 & Forging & A508-Ht-2 & SSR + Aged 70k h & Air & 538 \\
\hline 85 & MC To, Aged & E-1921 & $0.5 \mathrm{~T} \mathrm{D}-\mathrm{CT}$ & A533B & Rolled Plate & A533B-Ht-1 & SSR + Aged 70k h & Air & TBD \\
\hline 86 & MC To, Aged & E-1921 & $0.5 \mathrm{~T} \mathrm{D}-\mathrm{CT}$ & A533B & Rolled Plate & A533B-Ht-1 & SSR + Aged 70k h & Air & TBD \\
\hline 87 & MC To, Aged & E-1921 & $0.5 \mathrm{~T} \mathrm{D}-\mathrm{CT}$ & A533B & Rolled Plate & A533B-Ht-1 & SSR + Aged 70k h & Air & TBD \\
\hline 88 & MC To, Aged & E-1921 & $0.5 \mathrm{~T} \mathrm{D}-\mathrm{CT}$ & A533B & Rolled Plate & A533B-Ht-1 & SSR + Aged 70k h & Air & TBD \\
\hline 89 & MC To, Aged & E-1921 & $0.5 \mathrm{~T} \mathrm{D}-\mathrm{CT}$ & A533B & Rolled Plate & A533B-Ht-1 & SSR + Aged 70k h & Air & TBD \\
\hline 90 & MC To, Aged & E-1921 & $0.5 \mathrm{~T} \mathrm{D}-\mathrm{CT}$ & A533B & Rolled Plate & A533B-Ht-1 & SSR + Aged 70k h & Air & TBD \\
\hline 91 & MC To, Aged & E-1921 & $0.5 \mathrm{~T} \mathrm{D}-\mathrm{CT}$ & A533B & Rolled Plate & A533B-Ht-1 & SSR + Aged 70k h & Air & TBD \\
\hline 92 & MC To, Aged & E-1921 & $0.5 \mathrm{~T} \mathrm{D}-\mathrm{CT}$ & A533B & Rolled Plate & A533B-Ht-1 & SSR + Aged 70k h & Air & TBD \\
\hline 93 & MC To, Aged & E-1921 & $0.5 \mathrm{~T} \mathrm{D}-\mathrm{CT}$ & A533B & Rolled Plate & A533B-Ht-1 & SSR + Aged 70k h & Air & TBD \\
\hline 94 & MC To, Aged & E-1921 & $0.5 \mathrm{~T} \mathrm{D}-\mathrm{CT}$ & A533B & Rolled Plate & A533B-Ht-1 & SSR + Aged 70k h & Air & TBD \\
\hline 95 & MC To, Aged & E-1921 & $0.5 \mathrm{~T} \mathrm{D}-\mathrm{CT}$ & A533B & Rolled Plate & A533B-Ht-1 & SSR + Aged 70k h & Air & TBD \\
\hline 96 & MC To, Aged & E-1921 & $0.5 \mathrm{~T} \mathrm{D}-\mathrm{CT}$ & $\mathrm{A} 533 \mathrm{~B}$ & Rolled Plate & A533B-Ht-1 & SSR + Aged 70k h & Air & TBD \\
\hline 97 & J-R, Aged & E-1820 & $0.5 \mathrm{~T} \mathrm{D}-\mathrm{CT}$ & A533B & Rolled Plate & A533B-Ht-1 & SSR + Aged 70k h & Air & 20 \\
\hline 98 & J-R, Aged & E-1820 & $0.5 \mathrm{~T} \mathrm{D}-\mathrm{CT}$ & A533B & Rolled Plate & A533B-Ht-1 & SSR + Aged 70k h & Air & 20 \\
\hline 99 & J-R, Aged & E-1820 & $0.5 \mathrm{~T} \mathrm{D}-\mathrm{CT}$ & A533B & Rolled Plate & A533B-Ht-1 & SSR + Aged 70k h & Air & 20 \\
\hline 100 & J-R, Aged & E-1820 & $0.5 \mathrm{~T} \mathrm{D}-\mathrm{CT}$ & A533B & Rolled Plate & A533B-Ht-1 & SSR + Aged 70k h & Air & 20 \\
\hline 101 & J-R, Aged & E-1820 & $0.5 \mathrm{~T} \mathrm{D}-\mathrm{CT}$ & A533B & Rolled Plate & A533B-Ht-1 & SSR + Aged 70k h & Air & 20 \\
\hline 102 & J-R, Aged & E-1820 & $0.5 \mathrm{~T} \mathrm{D}-\mathrm{CT}$ & A533B & Rolled Plate & A533B-Ht-1 & SSR + Aged 70k h & Air & 20 \\
\hline 103 & J-R, Aged & E-1820 & $0.5 \mathrm{~T} \mathrm{D}-\mathrm{CT}$ & $\mathrm{A} 533 \mathrm{~B}$ & Rolled Plate & A533B-Ht-1 & SSR + Aged 70k h & Air & 150 \\
\hline
\end{tabular}




Idaho National Laboratory
\begin{tabular}{|c|lll|}
\hline NEXT GENERATION NUCLEAR PLANT & Identifier: & PLN-2803 & \\
REACTOR PRESSURE VESSEL MATERIALS & Revision: & 0 & \\
RESEARCH AND DEVELOPMENT PLAN & Effective Date: & $04 / 30 / 08$ & Page: A-73 of A-102 \\
\hline
\end{tabular}

\begin{tabular}{|c|c|c|c|c|c|c|c|c|c|}
\hline Spec. \# & Test Type & $\begin{array}{c}\text { Test } \\
\text { Method }\end{array}$ & Spec. Type & Mat & $\begin{array}{l}\text { Product Form } \\
(\sim 250 \mathrm{~mm} \text { thick })\end{array}$ & Heat \# & Mat Cond. ${ }^{(1)}$ & Env. & $\begin{array}{c}\text { Test Temp. } \\
\left({ }^{\circ} \mathrm{C}\right)\end{array}$ \\
\hline 104 & J-R, Aged & E-1820 & $0.5 \mathrm{~T} \mathrm{D}-\mathrm{CT}$ & $\mathrm{A} 533 \mathrm{~B}$ & Rolled Plate & A533B-Ht-1 & SSR + Aged 70k h & Air & 150 \\
\hline 105 & J-R, Aged & E-1820 & $0.5 \mathrm{~T} \mathrm{D}-\mathrm{CT}$ & A533B & Rolled Plate & A533B-Ht-1 & SSR + Aged 70k h & Air & 150 \\
\hline 106 & J-R, Aged & E-1820 & $0.5 \mathrm{~T} \mathrm{D}-\mathrm{CT}$ & A533B & Rolled Plate & A533B-Ht-1 & SSR + Aged 70k h & Air & 150 \\
\hline 107 & J-R, Aged & E-1820 & $0.5 \mathrm{~T} \mathrm{D}-\mathrm{CT}$ & $\mathrm{A} 533 \mathrm{~B}$ & Rolled Plate & A533B-Ht-1 & SSR + Aged 70k h & Air & 150 \\
\hline 108 & J-R, Aged & E-1820 & $0.5 \mathrm{~T} \mathrm{D}-\mathrm{CT}$ & A533B & Rolled Plate & A533B-Ht-1 & SSR + Aged 70k h & Air & 150 \\
\hline 109 & J-R, Aged & E-1820 & $0.5 \mathrm{~T} \mathrm{D}-\mathrm{CT}$ & A533B & Rolled Plate & A533B-Ht-1 & SSR + Aged 70k h & Air & 350 \\
\hline 110 & J-R, Aged & E-1820 & $0.5 \mathrm{~T} \mathrm{D}-\mathrm{CT}$ & A533B & Rolled Plate & A533B-Ht-1 & SSR + Aged 70k h & Air & 350 \\
\hline 111 & J-R, Aged & E-1820 & $0.5 \mathrm{~T} \mathrm{D}-\mathrm{CT}$ & A533B & Rolled Plate & A533B-Ht-1 & SSR + Aged 70k h & Air & 350 \\
\hline 112 & J-R, Aged & E-1820 & $0.5 \mathrm{~T} \mathrm{D}-\mathrm{CT}$ & A533B & Rolled Plate & A533B-Ht-1 & SSR + Aged 70k h & Air & 350 \\
\hline 113 & J-R, Aged & E-1820 & $0.5 \mathrm{~T} \mathrm{D}-\mathrm{CT}$ & A533B & Rolled Plate & A533B-Ht-1 & SSR + Aged 70k h & Air & 350 \\
\hline 114 & J-R, Aged & E-1820 & $0.5 \mathrm{~T} \mathrm{D}-\mathrm{CT}$ & A533B & Rolled Plate & A533B-Ht-1 & SSR + Aged 70k h & Air & 350 \\
\hline 115 & J-R, Aged & E-1820 & $0.5 \mathrm{~T} \mathrm{D}-\mathrm{CT}$ & A533B & Rolled Plate & A533B-Ht-1 & SSR + Aged 70k h & Air & 427 \\
\hline 116 & J-R, Aged & E-1820 & $0.5 \mathrm{~T} \mathrm{D}-\mathrm{CT}$ & A533B & Rolled Plate & A533B-Ht-1 & SSR + Aged 70k h & Air & 427 \\
\hline 117 & J-R, Aged & E-1820 & $0.5 \mathrm{~T} \mathrm{D}-\mathrm{CT}$ & A533B & Rolled Plate & A533B-Ht-1 & SSR + Aged 70k h & Air & 427 \\
\hline 118 & J-R, Aged & E-1820 & $0.5 \mathrm{~T} \mathrm{D}-\mathrm{CT}$ & A533B & Rolled Plate & A533B-Ht-1 & SSR + Aged 70k h & Air & 427 \\
\hline 119 & J-R, Aged & E-1820 & $0.5 \mathrm{~T} \mathrm{D}-\mathrm{CT}$ & A533B & Rolled Plate & A533B-Ht-1 & SSR + Aged 70k h & Air & 427 \\
\hline 120 & J-R, Aged & E-1820 & $0.5 \mathrm{~T} \mathrm{D}-\mathrm{CT}$ & A533B & Rolled Plate & A533B-Ht-1 & SSR + Aged 70k h & Air & 427 \\
\hline 121 & J-R, Aged & E-1820 & $0.5 \mathrm{~T} \mathrm{D}-\mathrm{CT}$ & A533B & Rolled Plate & A533B-Ht-1 & SSR + Aged 70k h & Air & 538 \\
\hline 122 & J-R, Aged & E-1820 & $0.5 \mathrm{~T} \mathrm{D}-\mathrm{CT}$ & A533B & Rolled Plate & A533B-Ht-1 & SSR + Aged 70k h & Air & 538 \\
\hline 123 & J-R, Aged & E-1820 & $0.5 \mathrm{~T} \mathrm{D}-\mathrm{CT}$ & $\mathrm{A} 533 \mathrm{~B}$ & Rolled Plate & A533B-Ht-1 & SSR + Aged 70k h & Air & 538 \\
\hline 124 & J-R, Aged & E-1820 & $0.5 \mathrm{~T} \mathrm{D}-\mathrm{CT}$ & A533B & Rolled Plate & A533B-Ht-1 & SSR + Aged 70k h & Air & 538 \\
\hline 125 & J-R, Aged & E-1820 & $0.5 \mathrm{~T} \mathrm{D}-\mathrm{CT}$ & A533B & Rolled Plate & A533B-Ht-1 & SSR + Aged 70k h & Air & 538 \\
\hline 126 & J-R, Aged & E-1820 & $0.5 \mathrm{~T} \mathrm{D}-\mathrm{CT}$ & A533B & Rolled Plate & A533B-Ht-1 & SSR + Aged 70k h & Air & 538 \\
\hline 127 & MC To, Aged & E-1921 & $0.5 \mathrm{~T} \mathrm{D}-\mathrm{CT}$ & A533B & Rolled Plate & A533B-Ht-2 & SSR + Aged 70k h & Air & TBD \\
\hline 128 & MC To, Aged & E-1921 & $0.5 \mathrm{~T} \mathrm{D}-\mathrm{CT}$ & A533B & Rolled Plate & A533B-Ht-2 & SSR + Aged 70k h & Air & TBD \\
\hline 129 & MC To, Aged & E-1921 & $0.5 \mathrm{~T} \mathrm{D}-\mathrm{CT}$ & $\mathrm{A} 533 \mathrm{~B}$ & Rolled Plate & A533B-Ht-2 & SSR + Aged 70k h & Air & TBD \\
\hline
\end{tabular}




Idaho National Laboratory
\begin{tabular}{|c|lll|}
\hline NEXT GENERATION NUCLEAR PLANT & Identifier: & PLN-2803 & \\
REACTOR PRESSURE VESSEL MATERIALS & Revision: & 0 & \\
RESEARCH AND DEVELOPMENT PLAN & Effective Date: & $04 / 30 / 08$ & Page: A-74 of A-102 \\
\hline
\end{tabular}

\begin{tabular}{|c|c|c|c|c|c|c|c|c|c|}
\hline Spec.\# & Test Type & $\begin{array}{c}\text { Test } \\
\text { Method }\end{array}$ & Spec. Type & Mat & $\begin{array}{l}\text { Product Form } \\
(\sim 250 \mathrm{~mm} \text { thick })\end{array}$ & Heat \# & Mat Cond. ${ }^{(1)}$ & Env. & $\begin{array}{c}\text { Test Temp. } \\
\left({ }^{\circ} \mathrm{C}\right)\end{array}$ \\
\hline 130 & MC To, Aged & E-1921 & $0.5 \mathrm{~T}$ D-CT & A533B & Rolled Plate & A533B-Ht-2 & SSR + Aged 70k h & Air & TBD \\
\hline 131 & MC To, Aged & E-1921 & $0.5 \mathrm{~T} \mathrm{D}-\mathrm{CT}$ & A533B & Rolled Plate & A533B-Ht-2 & SSR + Aged 70k h & Air & TBD \\
\hline 132 & MC To, Aged & E-1921 & $0.5 \mathrm{~T} \mathrm{D}-\mathrm{CT}$ & A533B & Rolled Plate & A533B-Ht-2 & SSR + Aged 70k h & Air & TBD \\
\hline 133 & MC To, Aged & E-1921 & $0.5 \mathrm{~T} \mathrm{D}-\mathrm{CT}$ & $\mathrm{A} 533 \mathrm{~B}$ & Rolled Plate & A533B-Ht-2 & SSR + Aged 70k h & Air & TBD \\
\hline 134 & MC To, Aged & E-1921 & $0.5 \mathrm{~T}$ D-CT & A533B & Rolled Plate & A533B-Ht-2 & SSR + Aged 70k h & Air & TBD \\
\hline 135 & MC To, Aged & E-1921 & $0.5 \mathrm{~T} \mathrm{D}-\mathrm{CT}$ & A533B & Rolled Plate & A533B-Ht-2 & SSR + Aged 70k h & Air & TBD \\
\hline 136 & MC To, Aged & E-1921 & $0.5 \mathrm{~T}$ D-CT & A533B & Rolled Plate & A533B-Ht-2 & SSR + Aged 70k h & Air & TBD \\
\hline 137 & MC To, Aged & E-1921 & $0.5 \mathrm{~T} \mathrm{D}-\mathrm{CT}$ & $\mathrm{A} 533 \mathrm{~B}$ & Rolled Plate & A533B-Ht-2 & SSR + Aged 70k h & Air & TBD \\
\hline 138 & MC To, Aged & E-1921 & $0.5 \mathrm{~T} \mathrm{D}-\mathrm{CT}$ & A533B & Rolled Plate & A533B-Ht-2 & SSR + Aged 70k h & Air & TBD \\
\hline 139 & J-R, Aged & E-1820 & $0.5 \mathrm{~T} \mathrm{D}-\mathrm{CT}$ & A533B & Rolled Plate & A533B-Ht-2 & SSR + Aged 70k h & Air & 20 \\
\hline 140 & J-R, Aged & E-1820 & $0.5 \mathrm{~T} \mathrm{D}-\mathrm{CT}$ & A533B & Rolled Plate & A533B-Ht-2 & SSR + Aged 70k h & Air & 20 \\
\hline 141 & J-R, Aged & E-1820 & $0.5 \mathrm{~T} \mathrm{D}-\mathrm{CT}$ & A533B & Rolled Plate & A533B-Ht-2 & SSR + Aged 70k h & Air & 20 \\
\hline 142 & J-R, Aged & E-1820 & $0.5 \mathrm{~T} \mathrm{D}-\mathrm{CT}$ & A533B & Rolled Plate & A533B-Ht-2 & SSR + Aged 70k h & Air & 20 \\
\hline 143 & J-R, Aged & E-1820 & $0.5 \mathrm{~T} \mathrm{D}-\mathrm{CT}$ & A533B & Rolled Plate & A533B-Ht-2 & SSR + Aged 70k h & Air & 20 \\
\hline 144 & J-R, Aged & E-1820 & $0.5 \mathrm{~T} \mathrm{D}-\mathrm{CT}$ & A533B & Rolled Plate & A533B-Ht-2 & SSR + Aged 70k h & Air & 20 \\
\hline 145 & J-R, Aged & E-1820 & $0.5 \mathrm{~T}$ D-CT & A533B & Rolled Plate & A533B-Ht-2 & SSR + Aged 70k h & Air & 150 \\
\hline 146 & J-R, Aged & E-1820 & $0.5 \mathrm{~T}$ D-CT & A533B & Rolled Plate & A533B-Ht-2 & SSR + Aged 70k h & Air & 150 \\
\hline 147 & J-R, Aged & E-1820 & $0.5 \mathrm{~T} \mathrm{D}-\mathrm{CT}$ & A533B & Rolled Plate & A533B-Ht-2 & SSR + Aged 70k h & Air & 150 \\
\hline 148 & J-R, Aged & E-1820 & $0.5 \mathrm{~T} \mathrm{D}-\mathrm{CT}$ & A533B & Rolled Plate & A533B-Ht-2 & SSR + Aged 70k h & Air & 150 \\
\hline 149 & J-R, Aged & E-1820 & $0.5 \mathrm{~T} \mathrm{D}-\mathrm{CT}$ & A533B & Rolled Plate & A533B-Ht-2 & SSR + Aged 70k h & Air & 150 \\
\hline 150 & J-R, Aged & E-1820 & $0.5 \mathrm{~T} \mathrm{D}-\mathrm{CT}$ & A533B & Rolled Plate & A533B-Ht-2 & SSR + Aged 70k h & Air & 150 \\
\hline 151 & J-R, Aged & E-1820 & $0.5 \mathrm{~T} \mathrm{D}-\mathrm{CT}$ & A533B & Rolled Plate & A533B-Ht-2 & SSR + Aged 70k h & Air & 350 \\
\hline 152 & J-R, Aged & E-1820 & $0.5 \mathrm{~T} \mathrm{D}-\mathrm{CT}$ & A533B & Rolled Plate & A533B-Ht-2 & SSR + Aged 70k h & Air & 350 \\
\hline 153 & J-R, Aged & E-1820 & $0.5 \mathrm{~T}$ D-CT & A533B & Rolled Plate & A533B-Ht-2 & SSR + Aged 70k h & Air & 350 \\
\hline 154 & J-R, Aged & E-1820 & $0.5 \mathrm{~T}$ D-CT & A533B & Rolled Plate & A533B-Ht-2 & SSR + Aged 70k h & Air & 350 \\
\hline 155 & J-R, Aged & E-1820 & $0.5 \mathrm{~T} \mathrm{D}-\mathrm{CT}$ & A533B & Rolled Plate & A533B-Ht-2 & SSR + Aged 70k h & Air & 350 \\
\hline
\end{tabular}




Idaho National Laboratory
\begin{tabular}{|c|lll|}
\hline NEXT GENERATION NUCLEAR PLANT & Identifier: & PLN-2803 & \\
REACTOR PRESSURE VESSEL MATERIALS & Revision: & 0 & \\
RESEARCH AND DEVELOPMENT PLAN & Effective Date: & $04 / 30 / 08$ & Page: A-75 of A-102 \\
\hline
\end{tabular}

\begin{tabular}{|c|c|c|c|c|c|c|c|c|c|}
\hline Spec.\# & Test Type & $\begin{array}{c}\text { Test } \\
\text { Method }\end{array}$ & Spec. Type & Mat & $\begin{array}{l}\text { Product Form } \\
(\sim 250 \mathrm{~mm} \text { thick })\end{array}$ & Heat \# & Mat Cond. ${ }^{(1)}$ & Env. & $\begin{array}{c}\text { Test Temp. } \\
\left({ }^{\circ} \mathrm{C}\right)\end{array}$ \\
\hline 156 & J-R, Aged & E-1820 & $0.5 \mathrm{~T} \mathrm{D}-\mathrm{CT}$ & A533B & Rolled Plate & A533B-Ht-2 & SSR + Aged 70k h & Air & 350 \\
\hline 157 & J-R, Aged & E-1820 & $0.5 \mathrm{~T}$ D-CT & A533B & Rolled Plate & A533B-Ht-2 & $\mathrm{SSR}+$ Aged 70k h & Air & 427 \\
\hline 158 & J-R, Aged & E-1820 & $0.5 \mathrm{~T} \mathrm{D}-\mathrm{CT}$ & $\mathrm{A} 533 \mathrm{~B}$ & Rolled Plate & A533B-Ht-2 & SSR + Aged 70k h & Air & 427 \\
\hline 159 & J-R, Aged & E-1820 & $0.5 \mathrm{~T}$ D-CT & $\mathrm{A} 533 \mathrm{~B}$ & Rolled Plate & A533B-Ht-2 & $\mathrm{SSR}+$ Aged 70k h & Air & 427 \\
\hline 160 & J-R, Aged & E-1820 & $0.5 \mathrm{~T}$ D-CT & A533B & Rolled Plate & A533B-Ht-2 & SSR + Aged 70k h & Air & 427 \\
\hline 161 & J-R, Aged & E-1820 & $0.5 \mathrm{~T} \mathrm{D}-\mathrm{CT}$ & A533B & Rolled Plate & A533B-Ht-2 & SSR + Aged 70k h & Air & 427 \\
\hline 162 & J-R, Aged & E-1820 & $0.5 \mathrm{~T}$ D-CT & A533B & Rolled Plate & A533B-Ht-2 & SSR + Aged 70k h & Air & 427 \\
\hline 163 & J-R, Aged & E-1820 & $0.5 \mathrm{~T} \mathrm{D}-\mathrm{CT}$ & $\mathrm{A} 533 \mathrm{~B}$ & Rolled Plate & A533B-Ht-2 & SSR + Aged 70k h & Air & 538 \\
\hline 164 & J-R, Aged & E-1820 & $0.5 \mathrm{~T} \mathrm{D}-\mathrm{CT}$ & A533B & Rolled Plate & A533B-Ht-2 & SSR + Aged 70k h & Air & 538 \\
\hline 165 & J-R, Aged & E-1820 & $0.5 \mathrm{~T}$ D-CT & A533B & Rolled Plate & A533B-Ht-2 & SSR + Aged 70k h & Air & 538 \\
\hline 166 & J-R, Aged & E-1820 & $0.5 \mathrm{~T} \mathrm{D}-\mathrm{CT}$ & A533B & Rolled Plate & A533B-Ht-2 & SSR + Aged 70k h & Air & 538 \\
\hline 167 & J-R, Aged & E-1820 & $0.5 \mathrm{~T} \mathrm{D}-\mathrm{CT}$ & A533B & Rolled Plate & A533B-Ht-2 & SSR + Aged 70k h & Air & 538 \\
\hline 168 & J-R, Aged & E-1820 & $0.5 \mathrm{~T} \mathrm{D}-\mathrm{CT}$ & A533B & Rolled Plate & A533B-Ht-2 & SSR + Aged 70k h & Air & 538 \\
\hline
\end{tabular}




Idaho National Laboratory
\begin{tabular}{|c|lll|}
\hline NEXT GENERATION NUCLEAR PLANT & Identifier: & PLN-2803 & \\
REACTOR PRESSURE VESSEL MATERIALS & Revision: & 0 & \\
RESEARCH AND DEVELOPMENT PLAN & Effective Date: & $04 / 30 / 08$ & Page: A-76 of A-102 \\
\hline
\end{tabular}

\begin{tabular}{|c|c|c|c|c|c|c|c|c|c|c|c|}
\hline Spec. \# & $\begin{array}{l}\text { Test } \\
\text { Type } \\
\end{array}$ & $\begin{array}{c}\text { Test } \\
\text { Method } \\
\end{array}$ & Spec. Type & $\begin{array}{c}\text { Weld } \\
\text { Consumable } \\
\end{array}$ & $\begin{array}{c}\text { Section } \\
\text { Thickness } \\
(\mathrm{mm})\end{array}$ & $\begin{array}{c}\text { Weld } \\
\text { Process }\end{array}$ & $\begin{array}{c}\text { Base Metal } \\
\text { Heat \# }\end{array}$ & $\begin{array}{l}\text { Weld } \\
\text { Location } \\
\text { to be } \\
\text { Tested }\end{array}$ & $\begin{array}{l}\text { Mat } \\
\text { Cond. }\end{array}$ & Env. & $\begin{array}{c}\text { Test } \\
\text { Temp. } \\
\left({ }^{\circ} \mathrm{C}\right) \\
\end{array}$ \\
\hline 1 & MC To & E-1921 & $0.5 \mathrm{~T}$ D-CT & TBD & $\sim 250$ & SAW & A508-Ht-1 & X Weld & SSR & Air & TBD \\
\hline 2 & MC To & E-1921 & $0.5 \mathrm{~T} \mathrm{D}-\mathrm{CT}$ & TBD & $\sim 250$ & SAW & A508-Ht-1 & X Weld & SSR & Air & TBD \\
\hline 3 & MC To & E-1921 & $0.5 \mathrm{~T} \mathrm{D}-\mathrm{CT}$ & TBD & $\sim 250$ & SAW & A508-Ht-1 & X Weld & SSR & Air & TBD \\
\hline 4 & $\mathrm{MC}$ To & E-1921 & $0.5 \mathrm{~T} \mathrm{D}-\mathrm{CT}$ & TBD & $\sim 250$ & SAW & A508-Ht-1 & $\mathrm{X}$ Weld & SSR & Air & TBD \\
\hline 5 & MC To & E-1921 & $0.5 \mathrm{~T} \mathrm{D}-\mathrm{CT}$ & TBD & $\sim 250$ & SAW & A508-Ht-1 & $\mathrm{X}$ Weld & SSR & Air & TBD \\
\hline 6 & MC To & E-1921 & $0.5 \mathrm{~T}$ D-CT & TBD & $\sim 250$ & SAW & A508-Ht-1 & X Weld & SSR & Air & TBD \\
\hline 7 & MC To & E-1921 & $0.5 \mathrm{~T} \mathrm{D}-\mathrm{CT}$ & TBD & $\sim 250$ & SAW & A508-Ht-1 & $\mathrm{X}$ Weld & SSR & Air & TBD \\
\hline 8 & MC To & E-1921 & $0.5 \mathrm{~T}$ D-CT & TBD & $\sim 250$ & SAW & A508-Ht-1 & X Weld & SSR & Air & TBD \\
\hline 9 & MC To & E-1921 & $0.5 \mathrm{~T}$ D-CT & TBD & $\sim 250$ & SAW & A508-Ht-1 & X Weld & SSR & Air & TBD \\
\hline 10 & MC To & E-1921 & $0.5 \mathrm{~T} \mathrm{D}-\mathrm{CT}$ & TBD & $\sim 250$ & SAW & A508-Ht-1 & $\mathrm{X}$ Weld & SSR & Air & TBD \\
\hline 11 & MC To & E-1921 & $0.5 \mathrm{~T}$ D-CT & TBD & $\sim 250$ & SAW & A508-Ht-1 & X Weld & SSR & Air & TBD \\
\hline 12 & MC To & E-1921 & 0.5T D-CT & TBD & $\sim 250$ & SAW & A508-Ht-1 & X Weld & SSR & Air & TBD \\
\hline 13 & $\mathrm{~J}-\mathrm{R}$ & E-1820 & $0.5 \mathrm{~T}$ D-CT & TBD & $\sim 250$ & SAW & A508-Ht-1 & X Weld & SSR & Air & 20 \\
\hline 14 & $\mathrm{~J}-\mathrm{R}$ & E-1820 & $0.5 \mathrm{~T} \mathrm{D}-\mathrm{CT}$ & TBD & $\sim 250$ & SAW & A508-Ht-1 & $\mathrm{X}$ Weld & SSR & Air & 20 \\
\hline 15 & $\mathrm{~J}-\mathrm{R}$ & E-1820 & $0.5 \mathrm{~T} \mathrm{D}-\mathrm{CT}$ & TBD & $\sim 250$ & SAW & A508-Ht-1 & $\mathrm{X}$ Weld & SSR & Air & 20 \\
\hline 16 & $\mathrm{~J}-\mathrm{R}$ & E-1820 & $0.5 \mathrm{~T} \mathrm{D}-\mathrm{CT}$ & TBD & $\sim 250$ & SAW & A508-Ht-1 & $\mathrm{X}$ Weld & SSR & Air & 20 \\
\hline 17 & $\mathrm{~J}-\mathrm{R}$ & E-1820 & $0.5 \mathrm{~T}$ D-CT & TBD & $\sim 250$ & SAW & A508-Ht-1 & X Weld & SSR & Air & 20 \\
\hline 18 & $\mathrm{~J}-\mathrm{R}$ & E-1820 & $0.5 \mathrm{~T}$ D-CT & TBD & $\sim 250$ & SAW & A508-Ht-1 & X Weld & SSR & Air & 20 \\
\hline 19 & $\mathrm{~J}-\mathrm{R}$ & E-1820 & $0.5 \mathrm{~T} \mathrm{D}-\mathrm{CT}$ & TBD & $\sim 250$ & SAW & A508-Ht-1 & $\mathrm{X}$ Weld & SSR & Air & 150 \\
\hline 20 & $\mathrm{~J}-\mathrm{R}$ & E-1820 & $0.5 \mathrm{~T}$ D-CT & TBD & $\sim 250$ & SAW & A508-Ht-1 & X Weld & SSR & Air & 150 \\
\hline 21 & $\mathrm{~J}-\mathrm{R}$ & E-1820 & $0.5 \mathrm{~T} \mathrm{D}-\mathrm{CT}$ & TBD & $\sim 250$ & SAW & A508-Ht-1 & $\mathrm{X}$ Weld & SSR & Air & 150 \\
\hline 22 & $\mathrm{~J}-\mathrm{R}$ & E-1820 & $0.5 \mathrm{~T} \mathrm{D}-\mathrm{CT}$ & TBD & $\sim 250$ & SAW & A508-Ht-1 & $\mathrm{X}$ Weld & SSR & Air & 150 \\
\hline 23 & $\mathrm{~J}-\mathrm{R}$ & E-1820 & $0.5 \mathrm{~T}$ D-CT & TBD & $\sim 250$ & SAW & A508-Ht-1 & X Weld & SSR & Air & 150 \\
\hline 24 & $\mathrm{~J}-\mathrm{R}$ & E-1820 & $0.5 \mathrm{~T} \mathrm{D}-\mathrm{CT}$ & TBD & $\sim 250$ & SAW & A508-Ht-1 & X Weld & SSR & Air & 150 \\
\hline
\end{tabular}




Idaho National Laboratory
\begin{tabular}{|c|lll|}
\hline NEXT GENERATION NUCLEAR PLANT & Identifier: & PLN-2803 & \\
REACTOR PRESSURE VESSEL MATERIALS & Revision: & 0 & \\
RESEARCH AND DEVELOPMENT PLAN & Effective Date: & $04 / 30 / 08$ & Page: A-77 of A-102 \\
\hline
\end{tabular}

\begin{tabular}{|c|c|c|c|c|c|c|c|c|c|c|c|}
\hline Spec. \# & $\begin{array}{l}\text { Test } \\
\text { Type }\end{array}$ & $\begin{array}{c}\text { Test } \\
\text { Method }\end{array}$ & Spec. Type & $\begin{array}{c}\text { Weld } \\
\text { Consumable }\end{array}$ & $\begin{array}{l}\text { Section } \\
\text { Thickness } \\
(\mathrm{mm})\end{array}$ & $\begin{array}{c}\text { Weld } \\
\text { Process }\end{array}$ & $\begin{array}{c}\text { Base Metal } \\
\text { Heat \# }\end{array}$ & $\begin{array}{l}\text { Weld } \\
\text { Location } \\
\text { to be } \\
\text { Tested }\end{array}$ & $\begin{array}{l}\text { Mat } \\
\text { Cond. }\end{array}$ & Env. & $\begin{array}{l}\text { Test } \\
\text { Temp. } \\
\left({ }^{\circ} \mathrm{C}\right)\end{array}$ \\
\hline 25 & $\mathrm{~J}-\mathrm{R}$ & E-1820 & $0.5 \mathrm{~T}$ D-CT & TBD & $\sim 250$ & SAW & A508-Ht-1 & X Weld & SSR & Air & 350 \\
\hline 26 & $\mathrm{~J}-\mathrm{R}$ & E-1820 & $0.5 \mathrm{~T}$ D-CT & TBD & $\sim 250$ & SAW & A508-Ht-1 & X Weld & SSR & Air & 350 \\
\hline 27 & $\mathrm{~J}-\mathrm{R}$ & E-1820 & $0.5 \mathrm{~T}$ D-CT & TBD & $\sim 250$ & SAW & A508-Ht-1 & X Weld & SSR & Air & 350 \\
\hline 28 & $\mathrm{~J}-\mathrm{R}$ & E-1820 & $0.5 \mathrm{~T}$ D-CT & TBD & $\sim 250$ & SAW & A508-Ht-1 & X Weld & SSR & Air & 350 \\
\hline 29 & $\mathrm{~J}-\mathrm{R}$ & E-1820 & $0.5 \mathrm{~T}$ D-CT & TBD & $\sim 250$ & SAW & A508-Ht-1 & X Weld & SSR & Air & 350 \\
\hline 30 & $\mathrm{~J}-\mathrm{R}$ & E-1820 & $0.5 \mathrm{~T}$ D-CT & TBD & $\sim 250$ & SAW & A508-Ht-1 & X Weld & SSR & Air & 350 \\
\hline 31 & $\mathrm{~J}-\mathrm{R}$ & E-1820 & $0.5 \mathrm{~T}$ D-CT & TBD & $\sim 250$ & SAW & A508-Ht-1 & X Weld & SSR & Air & 427 \\
\hline 32 & $\mathrm{~J}-\mathrm{R}$ & E-1820 & $0.5 \mathrm{~T}$ D-CT & TBD & $\sim 250$ & SAW & A508-Ht-1 & X Weld & SSR & Air & 427 \\
\hline 33 & $\mathrm{~J}-\mathrm{R}$ & E-1820 & $0.5 \mathrm{~T}$ D-CT & TBD & $\sim 250$ & SAW & A508-Ht-1 & X Weld & SSR & Air & 427 \\
\hline 34 & $\mathrm{~J}-\mathrm{R}$ & E-1820 & $0.5 \mathrm{~T}$ D-CT & TBD & $\sim 250$ & SAW & A508-Ht-1 & X Weld & SSR & Air & 427 \\
\hline 35 & $\mathrm{~J}-\mathrm{R}$ & E-1820 & $0.5 \mathrm{~T}$ D-CT & TBD & $\sim 250$ & SAW & A508-Ht-1 & X Weld & SSR & Air & 427 \\
\hline 36 & $\mathrm{~J}-\mathrm{R}$ & E-1820 & $0.5 \mathrm{~T}$ D-CT & TBD & $\sim 250$ & SAW & A508-Ht-1 & X Weld & SSR & Air & 427 \\
\hline 37 & $\mathrm{~J}-\mathrm{R}$ & E-1820 & $0.5 \mathrm{~T}$ D-CT & TBD & $\sim 250$ & SAW & A508-Ht-1 & X Weld & SSR & Air & 538 \\
\hline 38 & $\mathrm{~J}-\mathrm{R}$ & E-1820 & $0.5 \mathrm{~T}$ D-CT & TBD & $\sim 250$ & SAW & A508-Ht-1 & X Weld & SSR & Air & 538 \\
\hline 39 & $\mathrm{~J}-\mathrm{R}$ & E-1820 & $0.5 \mathrm{~T}$ D-CT & TBD & $\sim 250$ & SAW & A508-Ht-1 & X Weld & SSR & Air & 538 \\
\hline 40 & $\mathrm{~J}-\mathrm{R}$ & E-1820 & $0.5 \mathrm{~T}$ D-CT & TBD & $\sim 250$ & SAW & A508-Ht-1 & X Weld & SSR & Air & 538 \\
\hline 41 & $\mathrm{~J}-\mathrm{R}$ & E-1820 & $0.5 \mathrm{~T}$ D-CT & TBD & $\sim 250$ & SAW & A508-Ht-1 & X Weld & SSR & Air & 538 \\
\hline 42 & $\mathrm{~J}-\mathrm{R}$ & E-1820 & $0.5 \mathrm{~T}$ D-CT & TBD & $\sim 250$ & SAW & A508-Ht-1 & X Weld & SSR & Air & 538 \\
\hline 43 & MC To & E-1921 & $0.5 \mathrm{~T}$ D-CT & TBD & $\sim 50$ & SMAW & A508-Ht-2 & X Weld & SSR & Air & TBD \\
\hline 44 & MC To & E-1921 & $0.5 \mathrm{~T}$ D-CT & TBD & $\sim 50$ & SMAW & A508-Ht-2 & X Weld & SSR & Air & TBD \\
\hline 45 & MC To & E-1921 & $0.5 \mathrm{~T}$ D-CT & TBD & $\sim 50$ & SMAW & A508-Ht-2 & X Weld & SSR & Air & TBD \\
\hline 46 & MC To & E-1921 & $0.5 \mathrm{~T}$ D-CT & TBD & $\sim 50$ & SMAW & A508-Ht-2 & X Weld & SSR & Air & TBD \\
\hline 47 & MC To & E-1921 & $0.5 \mathrm{~T}$ D-CT & TBD & $\sim 50$ & SMAW & A508-Ht-2 & X Weld & SSR & Air & TBD \\
\hline 48 & MC To & E-1921 & $0.5 \mathrm{~T}$ D-CT & TBD & $\sim 50$ & SMAW & A508-Ht-2 & X Weld & SSR & Air & TBD \\
\hline
\end{tabular}




Idaho National Laboratory
\begin{tabular}{|c|lll|}
\hline NEXT GENERATION NUCLEAR PLANT & Identifier: & PLN-2803 & \\
REACTOR PRESSURE VESSEL MATERIALS & Revision: & 0 & \\
RESEARCH AND DEVELOPMENT PLAN & Effective Date: & $04 / 30 / 08$ & Page: A-78 of A-102 \\
\hline
\end{tabular}

\begin{tabular}{|c|c|c|c|c|c|c|c|c|c|c|c|}
\hline Spec. \# & $\begin{array}{l}\text { Test } \\
\text { Type }\end{array}$ & $\begin{array}{c}\text { Test } \\
\text { Method }\end{array}$ & Spec. Type & $\begin{array}{c}\text { Weld } \\
\text { Consumable }\end{array}$ & $\begin{array}{l}\text { Section } \\
\text { Thickness } \\
(\mathrm{mm})\end{array}$ & $\begin{array}{c}\text { Weld } \\
\text { Process }\end{array}$ & $\begin{array}{c}\text { Base Metal } \\
\text { Heat \# }\end{array}$ & $\begin{array}{l}\text { Weld } \\
\text { Location } \\
\text { to be } \\
\text { Tested }\end{array}$ & $\begin{array}{l}\text { Mat } \\
\text { Cond. }\end{array}$ & Env. & $\begin{array}{l}\text { Test } \\
\text { Temp. } \\
\left({ }^{\circ} \mathrm{C}\right)\end{array}$ \\
\hline 49 & MC To & E-1921 & $0.5 \mathrm{~T}$ D-CT & TBD & $\sim 50$ & SMAW & A508-Ht-2 & X Weld & SSR & Air & TBD \\
\hline 50 & MC To & E-1921 & $0.5 \mathrm{~T}$ D-CT & TBD & $\sim 50$ & SMAW & A508-Ht-2 & X Weld & SSR & Air & TBD \\
\hline 51 & MC To & E-1921 & $0.5 \mathrm{~T}$ D-CT & TBD & $\sim 50$ & SMAW & A508-Ht-2 & X Weld & SSR & Air & TBD \\
\hline 52 & MC To & E-1921 & $0.5 \mathrm{~T}$ D-CT & TBD & $\sim 50$ & SMAW & A508-Ht-2 & X Weld & SSR & Air & TBD \\
\hline 53 & MC To & E-1921 & $0.5 \mathrm{~T}$ D-CT & TBD & $\sim 50$ & SMAW & A508-Ht-2 & X Weld & SSR & Air & TBD \\
\hline 54 & MC To & E-1921 & $0.5 \mathrm{~T}$ D-CT & TBD & $\sim 50$ & SMAW & A508-Ht-2 & X Weld & SSR & Air & TBD \\
\hline 55 & $\mathrm{~J}-\mathrm{R}$ & E-1820 & $0.5 \mathrm{~T}$ D-CT & TBD & $\sim 50$ & SMAW & A508-Ht-2 & X Weld & SSR & Air & 20 \\
\hline 56 & $\mathrm{~J}-\mathrm{R}$ & E-1820 & $0.5 \mathrm{~T}$ D-CT & TBD & $\sim 50$ & SMAW & A508-Ht-2 & X Weld & SSR & Air & 20 \\
\hline 57 & $\mathrm{~J}-\mathrm{R}$ & E-1820 & $0.5 \mathrm{~T}$ D-CT & TBD & $\sim 50$ & SMAW & A508-Ht-2 & X Weld & SSR & Air & 20 \\
\hline 58 & $\mathrm{~J}-\mathrm{R}$ & E-1820 & $0.5 \mathrm{~T}$ D-CT & TBD & $\sim 50$ & SMAW & A508-Ht-2 & X Weld & SSR & Air & 20 \\
\hline 59 & $\mathrm{~J}-\mathrm{R}$ & E-1820 & $0.5 \mathrm{~T}$ D-CT & TBD & $\sim 50$ & SMAW & A508-Ht-2 & X Weld & SSR & Air & 20 \\
\hline 60 & $\mathrm{~J}-\mathrm{R}$ & E-1820 & $0.5 \mathrm{~T}$ D-CT & TBD & $\sim 50$ & SMAW & A508-Ht-2 & X Weld & SSR & Air & 20 \\
\hline 61 & $\mathrm{~J}-\mathrm{R}$ & E-1820 & $0.5 \mathrm{~T}$ D-CT & TBD & $\sim 50$ & SMAW & A508-Ht-2 & X Weld & SSR & Air & 150 \\
\hline 62 & $\mathrm{~J}-\mathrm{R}$ & E-1820 & $0.5 \mathrm{~T}$ D-CT & TBD & $\sim 50$ & SMAW & A508-Ht-2 & X Weld & SSR & Air & 150 \\
\hline 63 & $\mathrm{~J}-\mathrm{R}$ & E-1820 & $0.5 \mathrm{~T}$ D-CT & TBD & $\sim 50$ & SMAW & A508-Ht-2 & X Weld & SSR & Air & 150 \\
\hline 64 & $\mathrm{~J}-\mathrm{R}$ & E-1820 & $0.5 \mathrm{~T}$ D-CT & TBD & $\sim 50$ & SMAW & A508-Ht-2 & X Weld & SSR & Air & 150 \\
\hline 65 & $\mathrm{~J}-\mathrm{R}$ & E-1820 & $0.5 \mathrm{~T}$ D-CT & TBD & $\sim 50$ & SMAW & A508-Ht-2 & X Weld & SSR & Air & 150 \\
\hline 66 & $\mathrm{~J}-\mathrm{R}$ & E-1820 & $0.5 \mathrm{~T}$ D-CT & TBD & $\sim 50$ & SMAW & A508-Ht-2 & X Weld & SSR & Air & 150 \\
\hline 67 & J-R & E-1820 & $0.5 \mathrm{~T}$ D-CT & TBD & $\sim 50$ & SMAW & A508-Ht-2 & X Weld & SSR & Air & 350 \\
\hline 68 & $\mathrm{~J}-\mathrm{R}$ & E-1820 & $0.5 \mathrm{~T}$ D-CT & TBD & $\sim 50$ & SMAW & A508-Ht-2 & X Weld & SSR & Air & 350 \\
\hline 69 & $\mathrm{~J}-\mathrm{R}$ & E-1820 & $0.5 \mathrm{~T}$ D-CT & TBD & $\sim 50$ & SMAW & A508-Ht-2 & X Weld & SSR & Air & 350 \\
\hline 70 & $\mathrm{~J}-\mathrm{R}$ & E-1820 & $0.5 \mathrm{~T}$ D-CT & TBD & $\sim 50$ & SMAW & A508-Ht-2 & X Weld & SSR & Air & 350 \\
\hline 71 & $\mathrm{~J}-\mathrm{R}$ & E-1820 & $0.5 \mathrm{~T}$ D-CT & TBD & $\sim 50$ & SMAW & A508-Ht-2 & X Weld & SSR & Air & 350 \\
\hline 72 & $\mathrm{~J}-\mathrm{R}$ & E-1820 & $0.5 \mathrm{~T}$ D-CT & TBD & $\sim 50$ & SMAW & A508-Ht-2 & X Weld & SSR & Air & 350 \\
\hline
\end{tabular}




Idaho National Laboratory
\begin{tabular}{|c|lll|}
\hline NEXT GENERATION NUCLEAR PLANT & Identifier: & PLN-2803 & \\
REACTOR PRESSURE VESSEL MATERIALS & Revision: & 0 & \\
RESEARCH AND DEVELOPMENT PLAN & Effective Date: & $04 / 30 / 08$ & Page: A-79 of A-102 \\
\hline
\end{tabular}

\begin{tabular}{|c|c|c|c|c|c|c|c|c|c|c|c|}
\hline Spec. \# & $\begin{array}{l}\text { Test } \\
\text { Type }\end{array}$ & $\begin{array}{c}\text { Test } \\
\text { Method }\end{array}$ & Spec. Type & $\begin{array}{c}\text { Weld } \\
\text { Consumable }\end{array}$ & $\begin{array}{l}\text { Section } \\
\text { Thickness } \\
(\mathrm{mm})\end{array}$ & $\begin{array}{c}\text { Weld } \\
\text { Process }\end{array}$ & $\begin{array}{c}\text { Base Metal } \\
\text { Heat \# }\end{array}$ & $\begin{array}{l}\text { Weld } \\
\text { Location } \\
\text { to be } \\
\text { Tested }\end{array}$ & $\begin{array}{l}\text { Mat } \\
\text { Cond. }\end{array}$ & Env. & $\begin{array}{l}\text { Test } \\
\text { Temp. } \\
\left({ }^{\circ} \mathrm{C}\right)\end{array}$ \\
\hline 73 & $\mathrm{~J}-\mathrm{R}$ & E-1820 & $0.5 \mathrm{~T}$ D-CT & TBD & $\sim 50$ & SMAW & A508-Ht-2 & X Weld & SSR & Air & 427 \\
\hline 74 & $\mathrm{~J}-\mathrm{R}$ & E-1820 & $0.5 \mathrm{~T}$ D-CT & TBD & $\sim 50$ & SMAW & A508-Ht-2 & X Weld & SSR & Air & 427 \\
\hline 75 & $\mathrm{~J}-\mathrm{R}$ & E-1820 & $0.5 \mathrm{~T}$ D-CT & TBD & $\sim 50$ & SMAW & A508-Ht-2 & X Weld & SSR & Air & 427 \\
\hline 76 & $\mathrm{~J}-\mathrm{R}$ & E-1820 & $0.5 \mathrm{~T}$ D-CT & TBD & $\sim 50$ & SMAW & A508-Ht-2 & X Weld & SSR & Air & 427 \\
\hline 77 & $\mathrm{~J}-\mathrm{R}$ & E-1820 & $0.5 \mathrm{~T}$ D-CT & TBD & $\sim 50$ & SMAW & A508-Ht-2 & X Weld & SSR & Air & 427 \\
\hline 78 & $\mathrm{~J}-\mathrm{R}$ & E-1820 & $0.5 \mathrm{~T}$ D-CT & TBD & $\sim 50$ & SMAW & A508-Ht-2 & X Weld & SSR & Air & 427 \\
\hline 79 & $\mathrm{~J}-\mathrm{R}$ & E-1820 & $0.5 \mathrm{~T}$ D-CT & TBD & $\sim 50$ & SMAW & A508-Ht-2 & X Weld & SSR & Air & 538 \\
\hline 80 & $\mathrm{~J}-\mathrm{R}$ & E-1820 & $0.5 \mathrm{~T}$ D-CT & TBD & $\sim 50$ & SMAW & A508-Ht-2 & X Weld & SSR & Air & 538 \\
\hline 81 & $\mathrm{~J}-\mathrm{R}$ & E-1820 & $0.5 \mathrm{~T}$ D-CT & TBD & $\sim 50$ & SMAW & A508-Ht-2 & X Weld & SSR & Air & 538 \\
\hline 82 & $\mathrm{~J}-\mathrm{R}$ & E-1820 & $0.5 \mathrm{~T}$ D-CT & TBD & $\sim 50$ & SMAW & A508-Ht-2 & X Weld & SSR & Air & 538 \\
\hline 83 & $\mathrm{~J}-\mathrm{R}$ & E-1820 & $0.5 \mathrm{~T}$ D-CT & TBD & $\sim 50$ & SMAW & A508-Ht-2 & X Weld & SSR & Air & 538 \\
\hline 84 & $\mathrm{~J}-\mathrm{R}$ & E-1820 & $0.5 \mathrm{~T}$ D-CT & TBD & $\sim 50$ & SMAW & A508-Ht-2 & X Weld & SSR & Air & 538 \\
\hline 85 & MC To & E-1921 & $0.5 \mathrm{~T}$ D-CT & TBD & $\sim 250$ & SAW & A533B-Ht-1 & X Weld & SSR & Air & TBD \\
\hline 86 & MC To & E-1921 & $0.5 \mathrm{~T}$ D-CT & TBD & $\sim 250$ & SAW & A533B-Ht-1 & X Weld & SSR & Air & TBD \\
\hline 87 & MC To & E-1921 & $0.5 \mathrm{~T}$ D-CT & TBD & $\sim 250$ & SAW & A533B-Ht-1 & X Weld & SSR & Air & TBD \\
\hline 88 & MC To & E-1921 & $0.5 \mathrm{~T}$ D-CT & TBD & $\sim 250$ & SAW & A533B-Ht-1 & X Weld & SSR & Air & TBD \\
\hline 89 & MC To & E-1921 & $0.5 \mathrm{~T}$ D-CT & TBD & $\sim 250$ & SAW & A533B-Ht-1 & X Weld & SSR & Air & TBD \\
\hline 90 & MC To & E-1921 & $0.5 \mathrm{~T}$ D-CT & TBD & $\sim 250$ & SAW & A533B-Ht-1 & X Weld & SSR & Air & TBD \\
\hline 91 & MC To & E-1921 & $0.5 \mathrm{~T}$ D-CT & TBD & $\sim 250$ & SAW & A533B-Ht-1 & X Weld & SSR & Air & TBD \\
\hline 92 & MC To & E-1921 & $0.5 \mathrm{~T}$ D-CT & TBD & $\sim 250$ & SAW & A533B-Ht-1 & X Weld & SSR & Air & TBD \\
\hline 93 & MC To & E-1921 & $0.5 \mathrm{~T}$ D-CT & TBD & $\sim 250$ & SAW & A533B-Ht-1 & X Weld & SSR & Air & TBD \\
\hline 94 & MC To & E-1921 & $0.5 \mathrm{~T}$ D-CT & TBD & $\sim 250$ & SAW & A533B-Ht-1 & X Weld & SSR & Air & TBD \\
\hline 95 & MC To & E-1921 & $0.5 \mathrm{~T}$ D-CT & TBD & $\sim 250$ & SAW & A533B-Ht-1 & X Weld & SSR & Air & TBD \\
\hline 96 & MC To & E-1921 & $0.5 \mathrm{~T}$ D-CT & TBD & $\sim 250$ & SAW & A533B-Ht-1 & X Weld & SSR & Air & TBD \\
\hline
\end{tabular}




Idaho National Laboratory
\begin{tabular}{|c|lll|}
\hline NEXT GENERATION NUCLEAR PLANT & Identifier: & PLN-2803 & \\
REACTOR PRESSURE VESSEL MATERIALS & Revision: & 0 & \\
RESEARCH AND DEVELOPMENT PLAN & Effective Date: & $04 / 30 / 08$ & Page: A-80 of A-102 \\
\hline
\end{tabular}

\begin{tabular}{|c|c|c|c|c|c|c|c|c|c|c|c|}
\hline Spec. \# & $\begin{array}{l}\text { Test } \\
\text { Type }\end{array}$ & $\begin{array}{c}\text { Test } \\
\text { Method }\end{array}$ & Spec. Type & $\begin{array}{c}\text { Weld } \\
\text { Consumable }\end{array}$ & $\begin{array}{l}\text { Section } \\
\text { Thickness } \\
(\mathrm{mm})\end{array}$ & $\begin{array}{c}\text { Weld } \\
\text { Process }\end{array}$ & $\begin{array}{c}\text { Base Metal } \\
\text { Heat \# }\end{array}$ & $\begin{array}{l}\text { Weld } \\
\text { Location } \\
\text { to be } \\
\text { Tested }\end{array}$ & $\begin{array}{l}\text { Mat } \\
\text { Cond. }\end{array}$ & Env. & $\begin{array}{l}\text { Test } \\
\text { Temp. } \\
\left({ }^{\circ} \mathrm{C}\right)\end{array}$ \\
\hline 97 & $\mathrm{~J}-\mathrm{R}$ & E-1820 & $0.5 \mathrm{~T}$ D-CT & TBD & $\sim 250$ & SAW & A533B-Ht-1 & X Weld & SSR & Air & 20 \\
\hline 98 & $\mathrm{~J}-\mathrm{R}$ & E-1820 & $0.5 \mathrm{~T}$ D-CT & TBD & $\sim 250$ & SAW & A533B-Ht-1 & X Weld & SSR & Air & 20 \\
\hline 99 & J-R & E-1820 & $0.5 \mathrm{~T}$ D-CT & TBD & $\sim 250$ & SAW & A533B-Ht-1 & X Weld & SSR & Air & 20 \\
\hline 100 & $\mathrm{~J}-\mathrm{R}$ & E-1820 & $0.5 \mathrm{~T}$ D-CT & TBD & $\sim 250$ & SAW & A533B-Ht-1 & X Weld & SSR & Air & 20 \\
\hline 101 & J-R & E-1820 & $0.5 \mathrm{~T}$ D-CT & TBD & $\sim 250$ & SAW & A533B-Ht-1 & X Weld & SSR & Air & 20 \\
\hline 102 & J-R & E-1820 & $0.5 \mathrm{~T}$ D-CT & TBD & $\sim 250$ & SAW & A533B-Ht-1 & X Weld & SSR & Air & 20 \\
\hline 103 & $\mathrm{~J}-\mathrm{R}$ & E-1820 & $0.5 \mathrm{~T}$ D-CT & TBD & $\sim 250$ & SAW & A533B-Ht-1 & X Weld & SSR & Air & 150 \\
\hline 104 & J-R & E-1820 & $0.5 \mathrm{~T}$ D-CT & TBD & $\sim 250$ & SAW & A533B-Ht-1 & X Weld & SSR & Air & 150 \\
\hline 105 & J-R & E-1820 & $0.5 \mathrm{~T}$ D-CT & TBD & $\sim 250$ & SAW & A533B-Ht-1 & X Weld & SSR & Air & 150 \\
\hline 106 & J-R & E-1820 & $0.5 \mathrm{~T}$ D-CT & TBD & $\sim 250$ & SAW & A533B-Ht-1 & X Weld & SSR & Air & 150 \\
\hline 107 & $\mathrm{~J}-\mathrm{R}$ & E-1820 & $0.5 \mathrm{~T}$ D-CT & TBD & $\sim 250$ & SAW & A533B-Ht-1 & X Weld & SSR & Air & 150 \\
\hline 108 & $\mathrm{~J}-\mathrm{R}$ & E-1820 & $0.5 \mathrm{~T}$ D-CT & TBD & $\sim 250$ & SAW & A533B-Ht-1 & X Weld & SSR & Air & 150 \\
\hline 109 & $\mathrm{~J}-\mathrm{R}$ & E-1820 & $0.5 \mathrm{~T}$ D-CT & TBD & $\sim 250$ & SAW & A533B-Ht-1 & X Weld & SSR & Air & 350 \\
\hline 110 & J-R & E-1820 & $0.5 \mathrm{~T}$ D-CT & TBD & $\sim 250$ & SAW & A533B-Ht-1 & X Weld & SSR & Air & 350 \\
\hline 111 & J-R & E-1820 & $0.5 \mathrm{~T}$ D-CT & TBD & $\sim 250$ & SAW & A533B-Ht-1 & X Weld & SSR & Air & 350 \\
\hline 112 & $\mathrm{~J}-\mathrm{R}$ & E-1820 & $0.5 \mathrm{~T}$ D-CT & TBD & $\sim 250$ & SAW & A533B-Ht-1 & X Weld & SSR & Air & 350 \\
\hline 113 & $\mathrm{~J}-\mathrm{R}$ & E-1820 & $0.5 \mathrm{~T}$ D-CT & TBD & $\sim 250$ & SAW & A533B-Ht-1 & X Weld & SSR & Air & 350 \\
\hline 114 & $\mathrm{~J}-\mathrm{R}$ & E-1820 & $0.5 \mathrm{~T}$ D-CT & TBD & $\sim 250$ & SAW & A533B-Ht-1 & X Weld & SSR & Air & 350 \\
\hline 115 & J-R & E-1820 & $0.5 \mathrm{~T}$ D-CT & TBD & $\sim 250$ & SAW & A533B-Ht-1 & X Weld & SSR & Air & 427 \\
\hline 116 & J-R & E-1820 & $0.5 \mathrm{~T}$ D-CT & TBD & $\sim 250$ & SAW & A533B-Ht-1 & X Weld & SSR & Air & 427 \\
\hline 117 & $\mathrm{~J}-\mathrm{R}$ & E-1820 & $0.5 \mathrm{~T}$ D-CT & TBD & $\sim 250$ & SAW & A533B-Ht-1 & X Weld & SSR & Air & 427 \\
\hline 118 & $\mathrm{~J}-\mathrm{R}$ & E-1820 & $0.5 \mathrm{~T}$ D-CT & TBD & $\sim 250$ & SAW & A533B-Ht-1 & X Weld & SSR & Air & 427 \\
\hline 119 & $\mathrm{~J}-\mathrm{R}$ & E-1820 & $0.5 \mathrm{~T}$ D-CT & TBD & $\sim 250$ & SAW & A533B-Ht-1 & X Weld & SSR & Air & 427 \\
\hline 120 & $\mathrm{~J}-\mathrm{R}$ & E-1820 & $0.5 \mathrm{~T}$ D-CT & TBD & $\sim 250$ & SAW & A533B-Ht-1 & X Weld & SSR & Air & 427 \\
\hline
\end{tabular}




Idaho National Laboratory
\begin{tabular}{|c|lll|}
\hline NEXT GENERATION NUCLEAR PLANT & Identifier: & PLN-2803 & \\
REACTOR PRESSURE VESSEL MATERIALS & Revision: & 0 & \\
RESEARCH AND DEVELOPMENT PLAN & Effective Date: & $04 / 30 / 08$ & Page: A-81 of A-102 \\
\hline
\end{tabular}

\begin{tabular}{|c|c|c|c|c|c|c|c|c|c|c|c|}
\hline Spec. \# & $\begin{array}{l}\text { Test } \\
\text { Type } \\
\end{array}$ & $\begin{array}{c}\text { Test } \\
\text { Method }\end{array}$ & Spec. Type & $\begin{array}{c}\text { Weld } \\
\text { Consumable }\end{array}$ & $\begin{array}{c}\text { Section } \\
\text { Thickness } \\
(\mathrm{mm})\end{array}$ & $\begin{array}{c}\text { Weld } \\
\text { Process }\end{array}$ & $\begin{array}{c}\text { Base Metal } \\
\text { Heat \# }\end{array}$ & $\begin{array}{l}\text { Weld } \\
\text { Location } \\
\text { to be } \\
\text { Tested }\end{array}$ & $\begin{array}{l}\text { Mat } \\
\text { Cond. }\end{array}$ & Env. & $\begin{array}{c}\text { Test } \\
\text { Temp. } \\
\left({ }^{\circ} \mathrm{C}\right) \\
\end{array}$ \\
\hline 121 & $\mathrm{~J}-\mathrm{R}$ & E-1820 & $0.5 \mathrm{~T} \mathrm{D}-\mathrm{CT}$ & TBD & $\sim 250$ & SAW & A533B-Ht-1 & $\mathrm{X}$ Weld & SSR & Air & 538 \\
\hline 122 & $\mathrm{~J}-\mathrm{R}$ & E-1820 & $0.5 \mathrm{~T}$ D-CT & TBD & $\sim 250$ & SAW & A533B-Ht-1 & X Weld & SSR & Air & 538 \\
\hline 123 & $\mathrm{~J}-\mathrm{R}$ & E-1820 & $0.5 \mathrm{~T}$ D-CT & TBD & $\sim 250$ & SAW & A533B-Ht-1 & X Weld & SSR & Air & 538 \\
\hline 124 & $\mathrm{~J}-\mathrm{R}$ & E-1820 & $0.5 \mathrm{~T}$ D-CT & TBD & $\sim 250$ & SAW & A533B-Ht-1 & X Weld & SSR & Air & 538 \\
\hline 125 & $\mathrm{~J}-\mathrm{R}$ & E-1820 & $0.5 \mathrm{~T}$ D-CT & TBD & $\sim 250$ & SAW & A533B-Ht-1 & X Weld & SSR & Air & 538 \\
\hline 126 & $\mathrm{~J}-\mathrm{R}$ & E-1820 & $0.5 \mathrm{~T}$ D-CT & TBD & $\sim 250$ & SAW & A533B-Ht-1 & X Weld & SSR & Air & 538 \\
\hline 127 & MC To & E-1921 & $0.5 \mathrm{~T}$ D-CT & TBD & $\sim 50$ & SMAW & A533B-Ht-2 & X Weld & SSR & Air & TBD \\
\hline 128 & MC To & E-1921 & $0.5 \mathrm{~T}$ D-CT & TBD & $\sim 50$ & SMAW & A533B-Ht-2 & X Weld & SSR & Air & TBD \\
\hline 129 & MC To & E-1921 & $0.5 \mathrm{~T}$ D-CT & TBD & $\sim 50$ & SMAW & A533B-Ht-2 & X Weld & SSR & Air & TBD \\
\hline 130 & MC To & E-1921 & $0.5 \mathrm{~T}$ D-CT & TBD & $\sim 50$ & SMAW & A533B-Ht-2 & X Weld & SSR & Air & TBD \\
\hline 131 & MC To & E-1921 & $0.5 \mathrm{~T}$ D-CT & TBD & $\sim 50$ & SMAW & A533B-Ht-2 & X Weld & SSR & Air & TBD \\
\hline 132 & MC To & E-1921 & $0.5 \mathrm{~T}$ D-CT & TBD & $\sim 50$ & SMAW & A533B-Ht-2 & X Weld & SSR & Air & TBD \\
\hline 133 & MC To & E-1921 & $0.5 \mathrm{~T} \mathrm{D}-\mathrm{CT}$ & TBD & $\sim 50$ & SMAW & A533B-Ht-2 & X Weld & SSR & Air & TBD \\
\hline 134 & MC To & E-1921 & $0.5 \mathrm{~T}$ D-CT & TBD & $\sim 50$ & SMAW & A533B-Ht-2 & X Weld & SSR & Air & TBD \\
\hline 135 & MC To & E-1921 & $0.5 \mathrm{~T}$ D-CT & TBD & $\sim 50$ & SMAW & A533B-Ht-2 & X Weld & SSR & Air & TBD \\
\hline 136 & MC To & E-1921 & 0.5T D-CT & TBD & $\sim 50$ & SMAW & A533B-Ht-2 & X Weld & SSR & Air & TBD \\
\hline 137 & MC To & E-1921 & $0.5 \mathrm{~T}$ D-CT & TBD & $\sim 50$ & SMAW & A533B-Ht-2 & X Weld & SSR & Air & TBD \\
\hline 138 & MC To & E-1921 & $0.5 \mathrm{~T}$ D-CT & TBD & $\sim 50$ & SMAW & A533B-Ht-2 & X Weld & SSR & Air & TBD \\
\hline 139 & $\mathrm{~J}-\mathrm{R}$ & E-1820 & $0.5 \mathrm{~T}$ D-CT & TBD & $\sim 50$ & SMAW & A533B-Ht-2 & X Weld & SSR & Air & 20 \\
\hline 140 & $\mathrm{~J}-\mathrm{R}$ & E-1820 & 0.5T D-CT & TBD & $\sim 50$ & SMAW & A533B-Ht-2 & X Weld & SSR & Air & 20 \\
\hline 141 & J-R & E-1820 & 0.5T D-CT & TBD & $\sim 50$ & SMAW & A533B-Ht-2 & X Weld & SSR & Air & 20 \\
\hline 142 & $\mathrm{~J}-\mathrm{R}$ & E-1820 & $0.5 \mathrm{~T}$ D-CT & TBD & $\sim 50$ & SMAW & A533B-Ht-2 & X Weld & SSR & Air & 20 \\
\hline 143 & J-R & E-1820 & $0.5 \mathrm{~T}$ D-CT & TBD & $\sim 50$ & SMAW & A533B-Ht-2 & X Weld & SSR & Air & 20 \\
\hline 144 & $\mathrm{~J}-\mathrm{R}$ & E-1820 & $0.5 \mathrm{~T}$ D-CT & TBD & $\sim 50$ & SMAW & A533B-Ht-2 & X Weld & SSR & Air & 20 \\
\hline 145 & $\mathrm{~J}-\mathrm{R}$ & E-1820 & $0.5 \mathrm{~T}$ D-CT & TBD & $\sim 50$ & SMAW & A533B-Ht-2 & X Weld & SSR & Air & 150 \\
\hline 146 & $\mathrm{~J}-\mathrm{R}$ & E-1820 & $0.5 \mathrm{~T}$ D-CT & TBD & $\sim 50$ & SMAW & A533B-Ht-2 & X Weld & SSR & Air & 150 \\
\hline
\end{tabular}




Idaho National Laboratory
\begin{tabular}{|c|lll|}
\hline NEXT GENERATION NUCLEAR PLANT & Identifier: & PLN-2803 & \\
REACTOR PRESSURE VESSEL MATERIALS & Revision: & 0 & \\
RESEARCH AND DEVELOPMENT PLAN & Effective Date: & $04 / 30 / 08$ & Page: A-82 of A-102 \\
\hline
\end{tabular}

\begin{tabular}{|c|c|c|c|c|c|c|c|c|c|c|c|}
\hline Spec. \# & $\begin{array}{c}\text { Test } \\
\text { Type }\end{array}$ & $\begin{array}{c}\text { Test } \\
\text { Method }\end{array}$ & Spec. Type & $\begin{array}{c}\text { Weld } \\
\text { Consumable }\end{array}$ & $\begin{array}{l}\text { Section } \\
\text { Thickness } \\
(\mathrm{mm})\end{array}$ & $\begin{array}{c}\text { Weld } \\
\text { Process }\end{array}$ & $\begin{array}{c}\text { Base Metal } \\
\text { Heat \# }\end{array}$ & $\begin{array}{l}\text { Weld } \\
\text { Location } \\
\text { to be } \\
\text { Tested }\end{array}$ & $\begin{array}{l}\text { Mat } \\
\text { Cond. }\end{array}$ & Env. & $\begin{array}{l}\text { Test } \\
\text { Temp. } \\
\left({ }^{\circ} \mathrm{C}\right)\end{array}$ \\
\hline 147 & $\mathrm{~J}-\mathrm{R}$ & E-1820 & $0.5 \mathrm{~T} \mathrm{D}-\mathrm{CT}$ & TBD & $\sim 50$ & SMAW & A533B-Ht-2 & X Weld & SSR & Air & 150 \\
\hline 148 & $\mathrm{~J}-\mathrm{R}$ & E-1820 & $0.5 \mathrm{~T}$ D-CT & TBD & $\sim 50$ & SMAW & A533B-Ht-2 & X Weld & SSR & Air & 150 \\
\hline 149 & $\mathrm{~J}-\mathrm{R}$ & E-1820 & $0.5 \mathrm{~T}$ D-CT & TBD & $\sim 50$ & SMAW & A533B-Ht-2 & $\mathrm{X}$ Weld & SSR & Air & 150 \\
\hline 150 & $\mathrm{~J}-\mathrm{R}$ & E-1820 & $0.5 \mathrm{~T}$ D-CT & TBD & $\sim 50$ & SMAW & A533B-Ht-2 & X Weld & SSR & Air & 150 \\
\hline 151 & $\mathrm{~J}-\mathrm{R}$ & E-1820 & $0.5 \mathrm{~T}$ D-CT & TBD & $\sim 50$ & SMAW & A533B-Ht-2 & X Weld & SSR & Air & 350 \\
\hline 152 & $\mathrm{~J}-\mathrm{R}$ & E-1820 & 0.5T D-CT & TBD & $\sim 50$ & SMAW & A533B-Ht-2 & X Weld & SSR & Air & 350 \\
\hline 153 & J-R & E-1820 & $0.5 \mathrm{~T}$ D-CT & TBD & $\sim 50$ & SMAW & A533B-Ht-2 & X Weld & SSR & Air & 350 \\
\hline 154 & $\mathrm{~J}-\mathrm{R}$ & E-1820 & $0.5 \mathrm{~T} \mathrm{D}-\mathrm{CT}$ & TBD & $\sim 50$ & SMAW & A533B-Ht-2 & X Weld & SSR & Air & 350 \\
\hline 155 & $\mathrm{~J}-\mathrm{R}$ & E-1820 & 0.5T D-CT & TBD & $\sim 50$ & SMAW & A533B-Ht-2 & X Weld & SSR & Air & 350 \\
\hline 156 & $\mathrm{~J}-\mathrm{R}$ & E-1820 & $0.5 \mathrm{~T}$ D-CT & TBD & $\sim 50$ & SMAW & A533B-Ht-2 & X Weld & SSR & Air & 350 \\
\hline 157 & $\mathrm{~J}-\mathrm{R}$ & E-1820 & $0.5 \mathrm{~T}$ D-CT & TBD & $\sim 50$ & SMAW & A533B-Ht-2 & X Weld & SSR & Air & 427 \\
\hline 158 & $\mathrm{~J}-\mathrm{R}$ & E-1820 & $0.5 \mathrm{~T} \mathrm{D}-\mathrm{CT}$ & TBD & $\sim 50$ & SMAW & A533B-Ht-2 & X Weld & SSR & Air & 427 \\
\hline 159 & J-R & E-1820 & $0.5 \mathrm{~T}$ D-CT & TBD & $\sim 50$ & SMAW & A533B-Ht-2 & X Weld & SSR & Air & 427 \\
\hline 160 & $\mathrm{~J}-\mathrm{R}$ & E-1820 & $0.5 \mathrm{~T}$ D-CT & TBD & $\sim 50$ & SMAW & A533B-Ht-2 & X Weld & SSR & Air & 427 \\
\hline 161 & $\mathrm{~J}-\mathrm{R}$ & E-1820 & 0.5T D-CT & TBD & $\sim 50$ & SMAW & A533B-Ht-2 & X Weld & SSR & Air & 427 \\
\hline 162 & $\mathrm{~J}-\mathrm{R}$ & E-1820 & $0.5 \mathrm{~T}$ D-CT & TBD & $\sim 50$ & SMAW & A533B-Ht-2 & X Weld & SSR & Air & 427 \\
\hline 163 & $\mathrm{~J}-\mathrm{R}$ & E-1820 & $0.5 \mathrm{~T}$ D-CT & TBD & $\sim 50$ & SMAW & A533B-Ht-2 & X Weld & SSR & Air & 538 \\
\hline 164 & $\mathrm{~J}-\mathrm{R}$ & E-1820 & $0.5 \mathrm{~T}$ D-CT & TBD & $\sim 50$ & SMAW & A533B-Ht-2 & X Weld & SSR & Air & 538 \\
\hline 165 & $\mathrm{~J}-\mathrm{R}$ & E-1820 & 0.5T D-CT & TBD & $\sim 50$ & SMAW & A533B-Ht-2 & X Weld & SSR & Air & 538 \\
\hline 166 & $\mathrm{~J}-\mathrm{R}$ & E-1820 & $0.5 \mathrm{~T}$ D-CT & TBD & $\sim 50$ & SMAW & A533B-Ht-2 & X Weld & SSR & Air & 538 \\
\hline 167 & $\mathrm{~J}-\mathrm{R}$ & E-1820 & $0.5 \mathrm{~T}$ D-CT & TBD & $\sim 50$ & SMAW & A533B-Ht-2 & X Weld & SSR & Air & 538 \\
\hline 168 & $\mathrm{~J}-\mathrm{R}$ & E-1820 & $0.5 \mathrm{~T}$ D-CT & TBD & $\sim 50$ & SMAW & A533B-Ht-2 & X Weld & SSR & Air & 538 \\
\hline
\end{tabular}




Idaho National Laboratory
\begin{tabular}{|c|lll|}
\hline NEXT GENERATION NUCLEAR PLANT & Identifier: & PLN-2803 & \\
REACTOR PRESSURE VESSEL MATERIALS & Revision: & 0 & \\
RESEARCH AND DEVELOPMENT PLAN & Effective Date: & $04 / 30 / 08$ & Page: A-83 of A-102 \\
\hline
\end{tabular}

\begin{tabular}{|c|c|c|c|c|c|c|c|c|c|c|c|}
\hline Spec. \# & Test Type & $\begin{array}{c}\text { Test } \\
\text { Method }\end{array}$ & Spec. Type & $\begin{array}{c}\text { Weld } \\
\text { Consumable }\end{array}$ & $\begin{array}{l}\text { Section } \\
\text { Thickness } \\
\text { (mm) }\end{array}$ & $\begin{array}{l}\text { Weld } \\
\text { Process }\end{array}$ & $\begin{array}{c}\text { Base Metal } \\
\text { Heat \# }\end{array}$ & $\begin{array}{l}\text { Weld } \\
\text { Location } \\
\text { to be } \\
\text { Tested }\end{array}$ & $\begin{array}{l}\text { Mat } \\
\text { Cond. }\end{array}$ & Env. & $\begin{array}{l}\text { Test } \\
\text { Temp. } \\
\left({ }^{\circ} \mathrm{C}\right)\end{array}$ \\
\hline 1 & MC To & E-1921 & $0.5 \mathrm{~T}$ D-CT & TBD & $\sim 250$ & SAW & A508-Ht-1 & HAZ & SSR & Air & TBD \\
\hline 2 & MC To & E-1921 & $0.5 \mathrm{~T}$ D-CT & TBD & $\sim 250$ & SAW & A508-Ht-1 & HAZ & SSR & Air & TBD \\
\hline 3 & MC To & E-1921 & $0.5 \mathrm{~T}$ D-CT & TBD & $\sim 250$ & SAW & A508-Ht-1 & HAZ & SSR & Air & TBD \\
\hline 4 & MC To & E-1921 & $0.5 \mathrm{~T}$ D-CT & TBD & $\sim 250$ & SAW & A508-Ht-1 & HAZ & SSR & Air & TBD \\
\hline 5 & MC To & E-1921 & $0.5 \mathrm{~T}$ D-CT & TBD & $\sim 250$ & SAW & A508-Ht-1 & HAZ & SSR & Air & TBD \\
\hline 6 & MC To & E-1921 & $0.5 \mathrm{~T}$ D-CT & TBD & $\sim 250$ & SAW & A508-Ht-1 & HAZ & SSR & Air & TBD \\
\hline 7 & MC To & E-1921 & $0.5 \mathrm{~T}$ D-CT & TBD & $\sim 250$ & SAW & A508-Ht-1 & HAZ & SSR & Air & TBD \\
\hline 8 & MC To & E-1921 & $0.5 \mathrm{~T}$ D-CT & TBD & $\sim 250$ & SAW & A508-Ht-1 & HAZ & SSR & Air & TBD \\
\hline 9 & MC To & E-1921 & $0.5 \mathrm{~T}$ D-CT & TBD & $\sim 250$ & SAW & A508-Ht-1 & HAZ & SSR & Air & TBD \\
\hline 10 & MC To & E-1921 & $0.5 \mathrm{~T}$ D-CT & TBD & $\sim 250$ & SAW & A508-Ht-1 & HAZ & SSR & Air & TBD \\
\hline 11 & MC To & E-1921 & $0.5 \mathrm{~T}$ D-CT & TBD & $\sim 250$ & SAW & A508-Ht-1 & HAZ & SSR & Air & TBD \\
\hline 12 & MC To & E-1921 & $0.5 \mathrm{~T}$ D-CT & TBD & $\sim 250$ & SAW & A508-Ht-1 & HAZ & SSR & Air & TBD \\
\hline 13 & $\mathrm{~J}-\mathrm{R}$ & E-1820 & $0.5 \mathrm{~T}$ D-CT & TBD & $\sim 250$ & SAW & A508-Ht-1 & HAZ & SSR & Air & 20 \\
\hline 14 & $\mathrm{~J}-\mathrm{R}$ & E-1820 & $0.5 \mathrm{~T}$ D-CT & TBD & $\sim 250$ & SAW & A508-Ht-1 & HAZ & SSR & Air & 20 \\
\hline 15 & $\mathrm{~J}-\mathrm{R}$ & E-1820 & $0.5 \mathrm{~T}$ D-CT & TBD & $\sim 250$ & SAW & A508-Ht-1 & HAZ & SSR & Air & 20 \\
\hline 16 & $\mathrm{~J}-\mathrm{R}$ & E-1820 & $0.5 \mathrm{~T}$ D-CT & TBD & $\sim 250$ & SAW & A508-Ht-1 & HAZ & SSR & Air & 20 \\
\hline 17 & $\mathrm{~J}-\mathrm{R}$ & E-1820 & $0.5 \mathrm{~T}$ D-CT & TBD & $\sim 250$ & SAW & A508-Ht-1 & HAZ & SSR & Air & 20 \\
\hline 18 & $\mathrm{~J}-\mathrm{R}$ & E-1820 & $0.5 \mathrm{~T}$ D-CT & TBD & $\sim 250$ & SAW & A508-Ht-1 & HAZ & SSR & Air & 20 \\
\hline 19 & $\mathrm{~J}-\mathrm{R}$ & E-1820 & $0.5 \mathrm{~T}$ D-CT & TBD & $\sim 250$ & SAW & A508-Ht-1 & HAZ & SSR & Air & 150 \\
\hline 20 & $\mathrm{~J}-\mathrm{R}$ & E-1820 & $0.5 \mathrm{~T}$ D-CT & TBD & $\sim 250$ & SAW & A508-Ht-1 & HAZ & SSR & Air & 150 \\
\hline 21 & $\mathrm{~J}-\mathrm{R}$ & E-1820 & $0.5 \mathrm{~T}$ D-CT & TBD & $\sim 250$ & SAW & A508-Ht-1 & HAZ & SSR & Air & 150 \\
\hline 22 & $\mathrm{~J}-\mathrm{R}$ & E-1820 & $0.5 \mathrm{~T}$ D-CT & TBD & $\sim 250$ & SAW & A508-Ht-1 & HAZ & SSR & Air & 150 \\
\hline 23 & $\mathrm{~J}-\mathrm{R}$ & E-1820 & $0.5 \mathrm{~T}$ D-CT & TBD & $\sim 250$ & SAW & A508-Ht-1 & HAZ & SSR & Air & 150 \\
\hline 24 & $\mathrm{~J}-\mathrm{R}$ & E-1820 & $0.5 \mathrm{~T}$ D-CT & TBD & $\sim 250$ & SAW & A508-Ht-1 & HAZ & SSR & Air & 150 \\
\hline
\end{tabular}




Idaho National Laboratory
\begin{tabular}{|c|lll|}
\hline NEXT GENERATION NUCLEAR PLANT & Identifier: & PLN-2803 & \\
REACTOR PRESSURE VESSEL MATERIALS & Revision: & 0 & \\
RESEARCH AND DEVELOPMENT PLAN & Effective Date: & $04 / 30 / 08$ & Page: A-84 of A-102 \\
\hline
\end{tabular}

\begin{tabular}{|c|c|c|c|c|c|c|c|c|c|c|c|}
\hline Spec. \# & Test Type & $\begin{array}{c}\text { Test } \\
\text { Method }\end{array}$ & Spec. Type & $\begin{array}{c}\text { Weld } \\
\text { Consumable }\end{array}$ & $\begin{array}{l}\text { Section } \\
\text { Thickness } \\
(\mathrm{mm})\end{array}$ & $\begin{array}{c}\text { Weld } \\
\text { Process }\end{array}$ & $\begin{array}{c}\text { Base Metal } \\
\text { Heat \# }\end{array}$ & $\begin{array}{l}\text { Weld } \\
\text { Location } \\
\text { to be } \\
\text { Tested }\end{array}$ & $\begin{array}{c}\text { Mat } \\
\text { Cond. }\end{array}$ & Env. & $\begin{array}{l}\text { Test } \\
\text { Temp. } \\
\left({ }^{\circ} \mathrm{C}\right)\end{array}$ \\
\hline 25 & $J-R$ & E-1820 & $0.5 \mathrm{~T}$ D-CT & TBD & $\sim 250$ & SAW & A508-Ht-1 & HAZ & SSR & Air & 350 \\
\hline 26 & $\mathrm{~J}-\mathrm{R}$ & E-1820 & $0.5 \mathrm{~T}$ D-CT & TBD & $\sim 250$ & SAW & A508-Ht-1 & HAZ & SSR & Air & 350 \\
\hline 27 & $\mathrm{~J}-\mathrm{R}$ & E-1820 & $0.5 \mathrm{~T}$ D-CT & TBD & $\sim 250$ & SAW & A508-Ht-1 & HAZ & SSR & Air & 350 \\
\hline 28 & $\mathrm{~J}-\mathrm{R}$ & E-1820 & $0.5 \mathrm{~T}$ D-CT & TBD & $\sim 250$ & SAW & A508-Ht-1 & HAZ & SSR & Air & 350 \\
\hline 29 & $\mathrm{~J}-\mathrm{R}$ & E-1820 & $0.5 \mathrm{~T}$ D-CT & TBD & $\sim 250$ & SAW & A508-Ht-1 & HAZ & SSR & Air & 350 \\
\hline 30 & $\mathrm{~J}-\mathrm{R}$ & E-1820 & $0.5 \mathrm{~T}$ D-CT & TBD & $\sim 250$ & SAW & A508-Ht-1 & HAZ & SSR & Air & 350 \\
\hline 31 & $\mathrm{~J}-\mathrm{R}$ & E-1820 & $0.5 \mathrm{~T}$ D-CT & TBD & $\sim 250$ & SAW & A508-Ht-1 & HAZ & SSR & Air & 427 \\
\hline 32 & $\mathrm{~J}-\mathrm{R}$ & E-1820 & $0.5 \mathrm{~T}$ D-CT & TBD & $\sim 250$ & SAW & A508-Ht-1 & HAZ & SSR & Air & 427 \\
\hline 33 & J-R & E-1820 & $0.5 \mathrm{~T} \mathrm{D}-\mathrm{CT}$ & TBD & $\sim 250$ & SAW & A508-Ht-1 & HAZ & SSR & Air & 427 \\
\hline 34 & $\mathrm{~J}-\mathrm{R}$ & E-1820 & $0.5 \mathrm{~T}$ D-CT & TBD & $\sim 250$ & SAW & A508-Ht-1 & HAZ & SSR & Air & 427 \\
\hline 35 & $\mathrm{~J}-\mathrm{R}$ & E-1820 & $0.5 \mathrm{~T}$ D-CT & TBD & $\sim 250$ & SAW & A508-Ht-1 & HAZ & SSR & Air & 427 \\
\hline 36 & $\mathrm{~J}-\mathrm{R}$ & E-1820 & $0.5 \mathrm{~T}$ D-CT & TBD & $\sim 250$ & SAW & A508-Ht-1 & HAZ & SSR & Air & 427 \\
\hline 37 & $\mathrm{~J}-\mathrm{R}$ & E-1820 & $0.5 \mathrm{~T}$ D-CT & TBD & $\sim 250$ & SAW & A508-Ht-1 & HAZ & SSR & Air & 538 \\
\hline 38 & J-R & E-1820 & $0.5 \mathrm{~T}$ D-CT & TBD & $\sim 250$ & SAW & A508-Ht-1 & HAZ & SSR & Air & 538 \\
\hline 39 & $\mathrm{~J}-\mathrm{R}$ & E-1820 & $0.5 \mathrm{~T}$ D-CT & TBD & $\sim 250$ & SAW & A508-Ht-1 & HAZ & SSR & Air & 538 \\
\hline 40 & $\mathrm{~J}-\mathrm{R}$ & E-1820 & $0.5 \mathrm{~T}$ D-CT & TBD & $\sim 250$ & SAW & A508-Ht-1 & HAZ & SSR & Air & 538 \\
\hline 41 & $\mathrm{~J}-\mathrm{R}$ & E-1820 & $0.5 \mathrm{~T}$ D-CT & TBD & $\sim 250$ & SAW & A508-Ht-1 & HAZ & SSR & Air & 538 \\
\hline 42 & $\mathrm{~J}-\mathrm{R}$ & E-1820 & $0.5 \mathrm{~T}$ D-CT & TBD & $\sim 250$ & SAW & A508-Ht-1 & HAZ & SSR & Air & 538 \\
\hline 43 & MC To & E-1921 & $0.5 \mathrm{~T}$ D-CT & TBD & $\sim 50$ & SMAW & A508-Ht-2 & HAZ & SSR & Air & TBD \\
\hline 44 & MC To & E-1921 & $0.5 \mathrm{~T}$ D-CT & TBD & $\sim 50$ & SMAW & A508-Ht-2 & HAZ & SSR & Air & TBD \\
\hline 45 & MC To & E-1921 & $0.5 \mathrm{~T}$ D-CT & TBD & $\sim 50$ & SMAW & A508-Ht-2 & HAZ & SSR & Air & TBD \\
\hline 46 & MC To & E-1921 & $0.5 \mathrm{~T}$ D-CT & TBD & $\sim 50$ & SMAW & A508-Ht-2 & HAZ & SSR & Air & TBD \\
\hline 47 & MC To & E-1921 & $0.5 \mathrm{~T}$ D-CT & TBD & $\sim 50$ & SMAW & A508-Ht-2 & HAZ & SSR & Air & TBD \\
\hline 48 & MC To & E-1921 & $0.5 \mathrm{~T}$ D-CT & TBD & $\sim 50$ & SMAW & A508-Ht-2 & HAZ & SSR & Air & TBD \\
\hline
\end{tabular}




Idaho National Laboratory
\begin{tabular}{|c|lll|}
\hline NEXT GENERATION NUCLEAR PLANT & Identifier: & PLN-2803 & \\
REACTOR PRESSURE VESSEL MATERIALS & Revision: & 0 & \\
RESEARCH AND DEVELOPMENT PLAN & Effective Date: & $04 / 30 / 08$ & Page: A-85 of A-102 \\
\hline
\end{tabular}

\begin{tabular}{|c|c|c|c|c|c|c|c|c|c|c|c|}
\hline Spec.\# & Test Type & $\begin{array}{c}\text { Test } \\
\text { Method }\end{array}$ & Spec. Type & $\begin{array}{c}\text { Weld } \\
\text { Consumable }\end{array}$ & $\begin{array}{l}\text { Section } \\
\text { Thickness } \\
(\mathrm{mm})\end{array}$ & $\begin{array}{c}\text { Weld } \\
\text { Process }\end{array}$ & $\begin{array}{c}\text { Base Metal } \\
\text { Heat \# }\end{array}$ & $\begin{array}{l}\text { Weld } \\
\text { Location } \\
\text { to be } \\
\text { Tested }\end{array}$ & $\begin{array}{c}\text { Mat } \\
\text { Cond. }\end{array}$ & Env. & $\begin{array}{l}\text { Test } \\
\text { Temp. } \\
\left({ }^{\circ} \mathrm{C}\right)\end{array}$ \\
\hline 49 & MC To & E-1921 & $0.5 \mathrm{~T}$ D-CT & TBD & $\sim 50$ & SMAW & A508-Ht-2 & HAZ & SSR & Air & TBD \\
\hline 50 & MC To & E-1921 & $0.5 \mathrm{~T}$ D-CT & TBD & $\sim 50$ & SMAW & A508-Ht-2 & HAZ & SSR & Air & TBD \\
\hline 51 & MC To & E-1921 & $0.5 \mathrm{~T}$ D-CT & TBD & $\sim 50$ & SMAW & A508-Ht-2 & HAZ & SSR & Air & TBD \\
\hline 52 & MC To & E-1921 & $0.5 \mathrm{~T}$ D-CT & TBD & $\sim 50$ & SMAW & A508-Ht-2 & HAZ & SSR & Air & TBD \\
\hline 53 & MC To & E-1921 & $0.5 \mathrm{~T}$ D-CT & TBD & $\sim 50$ & SMAW & A508-Ht-2 & HAZ & SSR & Air & TBD \\
\hline 54 & MC To & E-1921 & $0.5 \mathrm{~T}$ D-CT & TBD & $\sim 50$ & SMAW & A508-Ht-2 & HAZ & SSR & Air & TBD \\
\hline 55 & $\mathrm{~J}-\mathrm{R}$ & E-1820 & $0.5 \mathrm{~T}$ D-CT & TBD & $\sim 50$ & SMAW & A508-Ht-2 & HAZ & SSR & Air & 20 \\
\hline 56 & $\mathrm{~J}-\mathrm{R}$ & E-1820 & $0.5 \mathrm{~T}$ D-CT & TBD & $\sim 50$ & SMAW & A508-Ht-2 & HAZ & SSR & Air & 20 \\
\hline 57 & $\mathrm{~J}-\mathrm{R}$ & E-1820 & $0.5 \mathrm{~T} \mathrm{D}-\mathrm{CT}$ & TBD & $\sim 50$ & SMAW & A508-Ht-2 & HAZ & SSR & Air & 20 \\
\hline 58 & $\mathrm{~J}-\mathrm{R}$ & E-1820 & $0.5 \mathrm{~T}$ D-CT & TBD & $\sim 50$ & SMAW & A508-Ht-2 & HAZ & SSR & Air & 20 \\
\hline 59 & $\mathrm{~J}-\mathrm{R}$ & E-1820 & $0.5 \mathrm{~T}$ D-CT & TBD & $\sim 50$ & SMAW & A508-Ht-2 & HAZ & SSR & Air & 20 \\
\hline 60 & $\mathrm{~J}-\mathrm{R}$ & E-1820 & $0.5 \mathrm{~T}$ D-CT & TBD & $\sim 50$ & SMAW & A508-Ht-2 & HAZ & SSR & Air & 20 \\
\hline 61 & $\mathrm{~J}-\mathrm{R}$ & E-1820 & 0.5T D-CT & TBD & $\sim 50$ & SMAW & A508-Ht-2 & HAZ & SSR & Air & 150 \\
\hline 62 & J-R & E-1820 & $0.5 \mathrm{~T}$ D-CT & TBD & $\sim 50$ & SMAW & A508-Ht-2 & HAZ & SSR & Air & 150 \\
\hline 63 & $\mathrm{~J}-\mathrm{R}$ & E-1820 & $0.5 \mathrm{~T}$ D-CT & TBD & $\sim 50$ & SMAW & A508-Ht-2 & HAZ & SSR & Air & 150 \\
\hline 64 & $\mathrm{~J}-\mathrm{R}$ & E-1820 & $0.5 \mathrm{~T}$ D-CT & TBD & $\sim 50$ & SMAW & A508-Ht-2 & HAZ & SSR & Air & 150 \\
\hline 65 & $\mathrm{~J}-\mathrm{R}$ & E-1820 & $0.5 \mathrm{~T}$ D-CT & TBD & $\sim 50$ & SMAW & A508-Ht-2 & HAZ & SSR & Air & 150 \\
\hline 66 & $\mathrm{~J}-\mathrm{R}$ & E-1820 & $0.5 \mathrm{~T}$ D-CT & TBD & $\sim 50$ & SMAW & A508-Ht-2 & HAZ & SSR & Air & 150 \\
\hline 67 & J-R & E-1820 & $0.5 \mathrm{~T}$ D-CT & TBD & $\sim 50$ & SMAW & A508-Ht-2 & HAZ & SSR & Air & 350 \\
\hline 68 & $\mathrm{~J}-\mathrm{R}$ & E-1820 & $0.5 \mathrm{~T}$ D-CT & TBD & $\sim 50$ & SMAW & A508-Ht-2 & HAZ & SSR & Air & 350 \\
\hline 69 & $\mathrm{~J}-\mathrm{R}$ & E-1820 & $0.5 \mathrm{~T}$ D-CT & TBD & $\sim 50$ & SMAW & A508-Ht-2 & HAZ & SSR & Air & 350 \\
\hline 70 & $\mathrm{~J}-\mathrm{R}$ & E-1820 & $0.5 \mathrm{~T}$ D-CT & TBD & $\sim 50$ & SMAW & A508-Ht-2 & HAZ & SSR & Air & 350 \\
\hline 71 & $\mathrm{~J}-\mathrm{R}$ & E-1820 & $0.5 \mathrm{~T}$ D-CT & TBD & $\sim 50$ & SMAW & A508-Ht-2 & HAZ & SSR & Air & 350 \\
\hline 72 & $\mathrm{~J}-\mathrm{R}$ & E-1820 & $0.5 \mathrm{~T}$ D-CT & TBD & $\sim 50$ & SMAW & A508-Ht-2 & HAZ & SSR & Air & 350 \\
\hline
\end{tabular}




Idaho National Laboratory
\begin{tabular}{|c|lll|}
\hline NEXT GENERATION NUCLEAR PLANT & Identifier: & PLN-2803 & \\
REACTOR PRESSURE VESSEL MATERIALS & Revision: & 0 & \\
RESEARCH AND DEVELOPMENT PLAN & Effective Date: & $04 / 30 / 08$ & Page: A-86 of A-102 \\
\hline
\end{tabular}

\begin{tabular}{|c|c|c|c|c|c|c|c|c|c|c|c|}
\hline Spec. \# & Test Type & $\begin{array}{c}\text { Test } \\
\text { Method }\end{array}$ & Spec. Type & $\begin{array}{c}\text { Weld } \\
\text { Consumable }\end{array}$ & $\begin{array}{l}\text { Section } \\
\text { Thickness } \\
(\mathrm{mm})\end{array}$ & $\begin{array}{c}\text { Weld } \\
\text { Process }\end{array}$ & $\begin{array}{c}\text { Base Metal } \\
\text { Heat \# }\end{array}$ & $\begin{array}{l}\text { Weld } \\
\text { Location } \\
\text { to be } \\
\text { Tested }\end{array}$ & $\begin{array}{c}\text { Mat } \\
\text { Cond. }\end{array}$ & Env. & $\begin{array}{l}\text { Test } \\
\text { Temp. } \\
\left({ }^{\circ} \mathrm{C}\right)\end{array}$ \\
\hline 73 & $\mathrm{~J}-\mathrm{R}$ & E-1820 & $0.5 \mathrm{~T}$ D-CT & TBD & $\sim 50$ & SMAW & A508-Ht-2 & HAZ & SSR & Air & 427 \\
\hline 74 & $\mathrm{~J}-\mathrm{R}$ & E-1820 & $0.5 \mathrm{~T}$ D-CT & TBD & $\sim 50$ & SMAW & A508-Ht-2 & HAZ & SSR & Air & 427 \\
\hline 75 & $\mathrm{~J}-\mathrm{R}$ & E-1820 & $0.5 \mathrm{~T}$ D-CT & TBD & $\sim 50$ & SMAW & A508-Ht-2 & HAZ & SSR & Air & 427 \\
\hline 76 & $\mathrm{~J}-\mathrm{R}$ & E-1820 & $0.5 \mathrm{~T}$ D-CT & TBD & $\sim 50$ & SMAW & A508-Ht-2 & HAZ & SSR & Air & 427 \\
\hline 77 & $\mathrm{~J}-\mathrm{R}$ & E-1820 & $0.5 \mathrm{~T}$ D-CT & TBD & $\sim 50$ & SMAW & A508-Ht-2 & HAZ & SSR & Air & 427 \\
\hline 78 & $\mathrm{~J}-\mathrm{R}$ & E-1820 & $0.5 \mathrm{~T}$ D-CT & TBD & $\sim 50$ & SMAW & A508-Ht-2 & HAZ & SSR & Air & 427 \\
\hline 79 & $\mathrm{~J}-\mathrm{R}$ & E-1820 & $0.5 \mathrm{~T}$ D-CT & TBD & $\sim 50$ & SMAW & A508-Ht-2 & HAZ & SSR & Air & 538 \\
\hline 80 & $\mathrm{~J}-\mathrm{R}$ & E-1820 & $0.5 \mathrm{~T}$ D-CT & TBD & $\sim 50$ & SMAW & A508-Ht-2 & HAZ & SSR & Air & 538 \\
\hline 81 & J-R & E-1820 & $0.5 \mathrm{~T} \mathrm{D}-\mathrm{CT}$ & TBD & $\sim 50$ & SMAW & A508-Ht-2 & HAZ & SSR & Air & 538 \\
\hline 82 & $\mathrm{~J}-\mathrm{R}$ & E-1820 & $0.5 \mathrm{~T}$ D-CT & TBD & $\sim 50$ & SMAW & A508-Ht-2 & HAZ & SSR & Air & 538 \\
\hline 83 & $\mathrm{~J}-\mathrm{R}$ & E-1820 & $0.5 \mathrm{~T}$ D-CT & TBD & $\sim 50$ & SMAW & A508-Ht-2 & HAZ & SSR & Air & 538 \\
\hline 84 & $\mathrm{~J}-\mathrm{R}$ & E-1820 & $0.5 \mathrm{~T}$ D-CT & TBD & $\sim 50$ & SMAW & A508-Ht-2 & HAZ & SSR & Air & 538 \\
\hline 85 & MC To & E-1921 & $0.5 \mathrm{~T}$ D-CT & TBD & $\sim 250$ & SAW & A533B-Ht-1 & HAZ & SSR & Air & TBD \\
\hline 86 & MC To & E-1921 & $0.5 \mathrm{~T} \mathrm{D}-\mathrm{CT}$ & TBD & $\sim 250$ & SAW & A533B-Ht-1 & HAZ & SSR & Air & TBD \\
\hline 87 & MC To & E-1921 & $0.5 \mathrm{~T}$ D-CT & TBD & $\sim 250$ & SAW & A533B-Ht-1 & HAZ & SSR & Air & TBD \\
\hline 88 & MC To & E-1921 & $0.5 \mathrm{~T}$ D-CT & TBD & $\sim 250$ & SAW & A533B-Ht-1 & HAZ & SSR & Air & TBD \\
\hline 89 & MC To & E-1921 & $0.5 \mathrm{~T}$ D-CT & TBD & $\sim 250$ & SAW & A533B-Ht-1 & HAZ & SSR & Air & TBD \\
\hline 90 & MC To & E-1921 & $0.5 \mathrm{~T}$ D-CT & TBD & $\sim 250$ & SAW & A533B-Ht-1 & HAZ & SSR & Air & TBD \\
\hline 91 & MC To & E-1921 & $0.5 \mathrm{~T}$ D-CT & TBD & $\sim 250$ & SAW & A533B-Ht-1 & HAZ & SSR & Air & TBD \\
\hline 92 & MC To & E-1921 & $0.5 \mathrm{~T}$ D-CT & TBD & $\sim 250$ & SAW & A533B-Ht-1 & HAZ & SSR & Air & TBD \\
\hline 93 & MC To & E-1921 & $0.5 \mathrm{~T}$ D-CT & TBD & $\sim 250$ & SAW & A533B-Ht-1 & HAZ & SSR & Air & TBD \\
\hline 94 & MC To & E-1921 & $0.5 \mathrm{~T}$ D-CT & TBD & $\sim 250$ & SAW & A533B-Ht-1 & HAZ & SSR & Air & TBD \\
\hline 95 & MC To & E-1921 & $0.5 \mathrm{~T}$ D-CT & TBD & $\sim 250$ & SAW & A533B-Ht-1 & HAZ & SSR & Air & TBD \\
\hline 96 & MC To & E-1921 & $0.5 \mathrm{~T}$ D-CT & TBD & $\sim 250$ & SAW & A533B-Ht-1 & HAZ & SSR & Air & TBD \\
\hline
\end{tabular}




Idaho National Laboratory
\begin{tabular}{|c|lll|}
\hline NEXT GENERATION NUCLEAR PLANT & Identifier: & PLN-2803 & \\
REACTOR PRESSURE VESSEL MATERIALS & Revision: & 0 & \\
RESEARCH AND DEVELOPMENT PLAN & Effective Date: & $04 / 30 / 08$ & Page: A-87 of A-102 \\
\hline
\end{tabular}

\begin{tabular}{|c|c|c|c|c|c|c|c|c|c|c|c|}
\hline Spec. \# & Test Type & $\begin{array}{c}\text { Test } \\
\text { Method }\end{array}$ & Spec. Type & $\begin{array}{c}\text { Weld } \\
\text { Consumable }\end{array}$ & $\begin{array}{l}\text { Section } \\
\text { Thickness } \\
(\mathrm{mm})\end{array}$ & $\begin{array}{c}\text { Weld } \\
\text { Process }\end{array}$ & $\begin{array}{c}\text { Base Metal } \\
\text { Heat \# }\end{array}$ & $\begin{array}{c}\text { Weld } \\
\text { Location } \\
\text { to be } \\
\text { Tested }\end{array}$ & $\begin{array}{l}\text { Mat } \\
\text { Cond. }\end{array}$ & Env. & $\begin{array}{r}\text { Test } \\
\text { Temp } \\
\left({ }^{\circ} \mathrm{C}\right) \\
\end{array}$ \\
\hline 97 & $\mathrm{~J}-\mathrm{R}$ & E-1820 & $0.5 \mathrm{~T}$ D-CT & TBD & $\sim 250$ & SAW & A533B-Ht-1 & HAZ & SSR & Air & 20 \\
\hline 98 & $\mathrm{~J}-\mathrm{R}$ & E-1820 & $0.5 \mathrm{~T} \mathrm{D}-\mathrm{CT}$ & TBD & $\sim 250$ & SAW & A533B-Ht-1 & HAZ & SSR & Air & 20 \\
\hline 99 & $\mathrm{~J}-\mathrm{R}$ & E-1820 & $0.5 \mathrm{~T}$ D-CT & TBD & $\sim 250$ & SAW & A533B-Ht-1 & HAZ & SSR & Air & 20 \\
\hline 100 & $\mathrm{~J}-\mathrm{R}$ & E-1820 & $0.5 \mathrm{~T}$ D-CT & TBD & $\sim 250$ & SAW & A533B-Ht-1 & HAZ & SSR & Air & 20 \\
\hline 101 & $\mathrm{~J}-\mathrm{R}$ & E-1820 & $0.5 \mathrm{~T}$ D-CT & TBD & $\sim 250$ & SAW & A533B-Ht-1 & $\mathrm{HAZ}$ & SSR & Air & 20 \\
\hline 102 & $\mathrm{~J}-\mathrm{R}$ & E-1820 & $0.5 \mathrm{~T}$ D-CT & TBD & $\sim 250$ & SAW & A533B-Ht-1 & HAZ & SSR & Air & 20 \\
\hline 103 & $\mathrm{~J}-\mathrm{R}$ & E-1820 & $0.5 \mathrm{~T}$ D-CT & TBD & $\sim 250$ & SAW & A533B-Ht-1 & HAZ & SSR & Air & 150 \\
\hline 104 & $\mathrm{~J}-\mathrm{R}$ & E-1820 & $0.5 \mathrm{~T}$ D-CT & TBD & $\sim 250$ & SAW & A533B-Ht-1 & HAZ & SSR & Air & 150 \\
\hline 105 & $\mathrm{~J}-\mathrm{R}$ & E-1820 & $0.5 \mathrm{~T}$ D-CT & TBD & $\sim 250$ & SAW & A533B-Ht-1 & HAZ & SSR & Air & 150 \\
\hline 106 & $\mathrm{~J}-\mathrm{R}$ & E-1820 & $0.5 \mathrm{~T}$ D-CT & TBD & $\sim 250$ & SAW & A533B-Ht-1 & HAZ & SSR & Air & 150 \\
\hline 107 & $\mathrm{~J}-\mathrm{R}$ & E-1820 & $0.5 \mathrm{~T}$ D-CT & TBD & $\sim 250$ & SAW & A533B-Ht-1 & HAZ & SSR & Air & 150 \\
\hline 108 & $\mathrm{~J}-\mathrm{R}$ & E-1820 & $0.5 \mathrm{~T}$ D-CT & TBD & $\sim 250$ & SAW & A533B-Ht-1 & HAZ & SSR & Air & 150 \\
\hline 109 & $\mathrm{~J}-\mathrm{R}$ & E-1820 & $0.5 \mathrm{~T}$ D-CT & TBD & $\sim 250$ & SAW & A533B-Ht-1 & HAZ & SSR & Air & 350 \\
\hline 110 & $\mathrm{~J}-\mathrm{R}$ & E-1820 & $0.5 \mathrm{~T}$ D-CT & TBD & $\sim 250$ & SAW & A533B-Ht-1 & HAZ & SSR & Air & 350 \\
\hline 111 & $\mathrm{~J}-\mathrm{R}$ & E-1820 & $0.5 \mathrm{~T}$ D-CT & TBD & $\sim 250$ & SAW & A533B-Ht-1 & HAZ & SSR & Air & 350 \\
\hline 112 & $\mathrm{~J}-\mathrm{R}$ & E-1820 & $0.5 \mathrm{~T}$ D-CT & TBD & $\sim 250$ & SAW & A533B-Ht-1 & HAZ & SSR & Air & 350 \\
\hline 113 & $\mathrm{~J}-\mathrm{R}$ & E-1820 & $0.5 \mathrm{~T}$ D-CT & TBD & $\sim 250$ & SAW & A533B-Ht-1 & HAZ & SSR & Air & 350 \\
\hline 114 & $\mathrm{~J}-\mathrm{R}$ & E-1820 & $0.5 \mathrm{~T}$ D-CT & TBD & $\sim 250$ & SAW & A533B-Ht-1 & HAZ & SSR & Air & 350 \\
\hline 115 & $\mathrm{~J}-\mathrm{R}$ & E-1820 & $0.5 \mathrm{~T}$ D-CT & TBD & $\sim 250$ & SAW & A533B-Ht-1 & HAZ & SSR & Air & 427 \\
\hline 116 & $\mathrm{~J}-\mathrm{R}$ & E-1820 & $0.5 \mathrm{~T}$ D-CT & TBD & $\sim 250$ & SAW & A533B-Ht-1 & HAZ & SSR & Air & 427 \\
\hline 117 & $\mathrm{~J}-\mathrm{R}$ & E-1820 & $0.5 \mathrm{~T}$ D-CT & TBD & $\sim 250$ & SAW & A533B-Ht-1 & HAZ & SSR & Air & 427 \\
\hline 118 & $\mathrm{~J}-\mathrm{R}$ & E-1820 & $0.5 \mathrm{~T}$ D-CT & TBD & $\sim 250$ & SAW & A533B-Ht-1 & HAZ & SSR & Air & 427 \\
\hline 119 & $\mathrm{~J}-\mathrm{R}$ & E-1820 & $0.5 \mathrm{~T}$ D-CT & TBD & $\sim 250$ & SAW & A533B-Ht-1 & HAZ & SSR & Air & 427 \\
\hline 120 & $\mathrm{~J}-\mathrm{R}$ & E-1820 & $0.5 \mathrm{~T}$ D-CT & TBD & $\sim 250$ & SAW & A533B-Ht-1 & HAZ & SSR & Air & 427 \\
\hline 121 & $\mathrm{~J}-\mathrm{R}$ & E-1820 & $0.5 \mathrm{~T}$ D-CT & TBD & $\sim 250$ & SAW & A533B-Ht-1 & HAZ & SSR & Air & 538 \\
\hline
\end{tabular}




Idaho National Laboratory
\begin{tabular}{|c|lll|}
\hline NEXT GENERATION NUCLEAR PLANT & Identifier: & PLN-2803 & \\
REACTOR PRESSURE VESSEL MATERIALS & Revision: & 0 & \\
RESEARCH AND DEVELOPMENT PLAN & Effective Date: & $04 / 30 / 08$ & Page: A-88 of A-102 \\
\hline
\end{tabular}

\begin{tabular}{|c|c|c|c|c|c|c|c|c|c|c|c|}
\hline Spec. \# & Test Type & $\begin{array}{c}\text { Test } \\
\text { Method }\end{array}$ & Spec. Type & $\begin{array}{c}\text { Weld } \\
\text { Consumable }\end{array}$ & $\begin{array}{c}\text { Section } \\
\text { Thickness } \\
(\mathrm{mm})\end{array}$ & $\begin{array}{c}\text { Weld } \\
\text { Process }\end{array}$ & $\begin{array}{c}\text { Base Metal } \\
\text { Heat \# }\end{array}$ & $\begin{array}{l}\text { Weld } \\
\text { Location } \\
\text { to be } \\
\text { Tested }\end{array}$ & $\begin{array}{c}\text { Mat } \\
\text { Cond. }\end{array}$ & Env. & $\begin{array}{c}\text { Test } \\
\text { Temp. } \\
\left({ }^{\circ} \mathrm{C}\right) \\
\end{array}$ \\
\hline 122 & $\mathrm{~J}-\mathrm{R}$ & E-1820 & $0.5 \mathrm{~T}$ D-CT & TBD & $\sim 250$ & SAW & A533B-Ht-1 & HAZ & SSR & Air & 538 \\
\hline 123 & $\mathrm{~J}-\mathrm{R}$ & E-1820 & $0.5 \mathrm{~T}$ D-CT & TBD & $\sim 250$ & SAW & A533B-Ht-1 & HAZ & SSR & Air & 538 \\
\hline 124 & $\mathrm{~J}-\mathrm{R}$ & E-1820 & $0.5 \mathrm{~T}$ D-CT & TBD & $\sim 250$ & SAW & A533B-Ht-1 & HAZ & SSR & Air & 538 \\
\hline 125 & $\mathrm{~J}-\mathrm{R}$ & E-1820 & $0.5 \mathrm{~T}$ D-CT & TBD & $\sim 250$ & SAW & A533B-Ht-1 & HAZ & SSR & Air & 538 \\
\hline 126 & $\mathrm{~J}-\mathrm{R}$ & E-1820 & $0.5 \mathrm{~T}$ D-CT & TBD & $\sim 250$ & SAW & A533B-Ht-1 & HAZ & SSR & Air & 538 \\
\hline 127 & MC To & E-1921 & $0.5 \mathrm{~T}$ D-CT & TBD & $\sim 50$ & SMAW & A533B-Ht-2 & HAZ & SSR & Air & TBD \\
\hline 128 & MC To & E-1921 & $0.5 \mathrm{~T}$ D-CT & TBD & $\sim 50$ & SMAW & A533B-Ht-2 & HAZ & SSR & Air & TBD \\
\hline 129 & MC To & E-1921 & $0.5 \mathrm{~T}$ D-CT & TBD & $\sim 50$ & SMAW & A533B-Ht-2 & HAZ & SSR & Air & TBD \\
\hline 130 & MC To & E-1921 & $0.5 \mathrm{~T}$ D-CT & TBD & $\sim 50$ & SMAW & A533B-Ht-2 & HAZ & SSR & Air & TBD \\
\hline 131 & MC To & E-1921 & $0.5 \mathrm{~T}$ D-CT & TBD & $\sim 50$ & SMAW & A533B-Ht-2 & HAZ & SSR & Air & TBD \\
\hline 132 & MC To & E-1921 & $0.5 \mathrm{~T}$ D-CT & TBD & $\sim 50$ & SMAW & A533B-Ht-2 & HAZ & SSR & Air & TBD \\
\hline 133 & MC To & E-1921 & $0.5 \mathrm{~T}$ D-CT & TBD & $\sim 50$ & SMAW & A533B-Ht-2 & HAZ & SSR & Air & TBD \\
\hline 134 & MC To & E-1921 & $0.5 \mathrm{~T}$ D-CT & TBD & $\sim 50$ & SMAW & A533B-Ht-2 & HAZ & SSR & Air & TBD \\
\hline 135 & MC To & E-1921 & $0.5 \mathrm{~T}$ D-CT & TBD & $\sim 50$ & SMAW & A533B-Ht-2 & HAZ & SSR & Air & TBD \\
\hline 136 & MC To & E-1921 & $0.5 \mathrm{~T}$ D-CT & TBD & $\sim 50$ & SMAW & A533B-Ht-2 & HAZ & SSR & Air & TBD \\
\hline 137 & MC To & E-1921 & $0.5 \mathrm{~T}$ D-CT & TBD & $\sim 50$ & SMAW & A533B-Ht-2 & HAZ & SSR & Air & TBD \\
\hline 138 & MC To & E-1921 & $0.5 \mathrm{~T}$ D-CT & TBD & $\sim 50$ & SMAW & A533B-Ht-2 & HAZ & SSR & Air & TBD \\
\hline 139 & J-R & E-1820 & $0.5 \mathrm{~T}$ D-CT & TBD & $\sim 50$ & SMAW & A533B-Ht-2 & HAZ & SSR & Air & 20 \\
\hline 140 & $\mathrm{~J}-\mathrm{R}$ & E-1820 & $0.5 \mathrm{~T} \mathrm{D}-\mathrm{CT}$ & TBD & $\sim 50$ & SMAW & A533B-Ht-2 & HAZ & SSR & Air & 20 \\
\hline 141 & $\mathrm{~J}-\mathrm{R}$ & E-1820 & $0.5 \mathrm{~T}$ D-CT & TBD & $\sim 50$ & SMAW & A533B-Ht-2 & HAZ & SSR & Air & 20 \\
\hline 142 & $\mathrm{~J}-\mathrm{R}$ & E-1820 & $0.5 \mathrm{~T}$ D-CT & TBD & $\sim 50$ & SMAW & A533B-Ht-2 & HAZ & SSR & Air & 20 \\
\hline 143 & $\mathrm{~J}-\mathrm{R}$ & E-1820 & $0.5 \mathrm{~T}$ D-CT & TBD & $\sim 50$ & SMAW & A533B-Ht-2 & HAZ & SSR & Air & 20 \\
\hline 144 & $\mathrm{~J}-\mathrm{R}$ & E-1820 & $0.5 \mathrm{~T}$ D-CT & TBD & $\sim 50$ & SMAW & A533B-Ht-2 & HAZ & SSR & Air & 20 \\
\hline 145 & $\mathrm{~J}-\mathrm{R}$ & E-1820 & $0.5 \mathrm{~T}$ D-CT & TBD & $\sim 50$ & SMAW & A533B-Ht-2 & HAZ & SSR & Air & 150 \\
\hline 146 & $\mathrm{~J}-\mathrm{R}$ & E-1820 & $0.5 \mathrm{~T}$ D-CT & TBD & $\sim 50$ & SMAW & A533B-Ht-2 & HAZ & SSR & Air & 150 \\
\hline 147 & $\mathrm{~J}-\mathrm{R}$ & E-1820 & $0.5 \mathrm{~T}$ D-CT & TBD & $\sim 50$ & SMAW & A533B-Ht-2 & HAZ & SSR & Air & 150 \\
\hline
\end{tabular}




Idaho National Laboratory
\begin{tabular}{|c|lll|}
\hline NEXT GENERATION NUCLEAR PLANT & Identifier: & PLN-2803 & \\
REACTOR PRESSURE VESSEL MATERIALS & Revision: & 0 & \\
RESEARCH AND DEVELOPMENT PLAN & Effective Date: & $04 / 30 / 08$ & Page: A-89 of A-102 \\
\hline
\end{tabular}

\begin{tabular}{|c|c|c|c|c|c|c|c|c|c|c|c|}
\hline Spec. \# & Test Type & $\begin{array}{c}\text { Test } \\
\text { Method }\end{array}$ & Spec. Type & $\begin{array}{c}\text { Weld } \\
\text { Consumable }\end{array}$ & $\begin{array}{l}\text { Section } \\
\text { Thickness } \\
(\mathrm{mm})\end{array}$ & $\begin{array}{c}\text { Weld } \\
\text { Process }\end{array}$ & $\begin{array}{c}\text { Base Metal } \\
\text { Heat \# }\end{array}$ & $\begin{array}{c}\text { Weld } \\
\text { Location } \\
\text { to be } \\
\text { Tested }\end{array}$ & $\begin{array}{c}\text { Mat } \\
\text { Cond. }\end{array}$ & Env. & $\begin{array}{l}\text { Test } \\
\text { Temp. } \\
\left({ }^{\circ} \mathrm{C}\right)\end{array}$ \\
\hline 148 & $\mathrm{~J}-\mathrm{R}$ & E-1820 & $0.5 \mathrm{~T}$ D-CT & TBD & $\sim 50$ & SMAW & A533B-Ht-2 & HAZ & SSR & Air & 150 \\
\hline 149 & $\mathrm{~J}-\mathrm{R}$ & E-1820 & $0.5 \mathrm{~T}$ D-CT & TBD & $\sim 50$ & SMAW & A533B-Ht-2 & HAZ & SSR & Air & 150 \\
\hline 150 & $\mathrm{~J}-\mathrm{R}$ & E-1820 & $0.5 \mathrm{~T}$ D-CT & TBD & $\sim 50$ & SMAW & A533B-Ht-2 & HAZ & SSR & Air & 150 \\
\hline 151 & $\mathrm{~J}-\mathrm{R}$ & E-1820 & $0.5 \mathrm{~T}$ D-CT & TBD & $\sim 50$ & SMAW & A533B-Ht-2 & HAZ & SSR & Air & 350 \\
\hline 152 & $\mathrm{~J}-\mathrm{R}$ & E-1820 & $0.5 \mathrm{~T}$ D-CT & TBD & $\sim 50$ & SMAW & A533B-Ht-2 & HAZ & SSR & Air & 350 \\
\hline 153 & $\mathrm{~J}-\mathrm{R}$ & E-1820 & $0.5 \mathrm{~T}$ D-CT & TBD & $\sim 50$ & SMAW & A533B-Ht-2 & HAZ & SSR & Air & 350 \\
\hline 154 & $\mathrm{~J}-\mathrm{R}$ & E-1820 & $0.5 \mathrm{~T}$ D-CT & TBD & $\sim 50$ & SMAW & A533B-Ht-2 & HAZ & SSR & Air & 350 \\
\hline 155 & $\mathrm{~J}-\mathrm{R}$ & E-1820 & $0.5 \mathrm{~T}$ D-CT & TBD & $\sim 50$ & SMAW & A533B-Ht-2 & HAZ & SSR & Air & 350 \\
\hline 156 & $\mathrm{~J}-\mathrm{R}$ & E-1820 & $0.5 \mathrm{~T}$ D-CT & TBD & $\sim 50$ & SMAW & A533B-Ht-2 & HAZ & SSR & Air & 350 \\
\hline 157 & $\mathrm{~J}-\mathrm{R}$ & E-1820 & $0.5 \mathrm{~T}$ D-CT & TBD & $\sim 50$ & SMAW & A533B-Ht-2 & HAZ & SSR & Air & 427 \\
\hline 158 & $\mathrm{~J}-\mathrm{R}$ & E-1820 & $0.5 \mathrm{~T}$ D-CT & TBD & $\sim 50$ & SMAW & A533B-Ht-2 & HAZ & SSR & Air & 427 \\
\hline 159 & $\mathrm{~J}-\mathrm{R}$ & E-1820 & $0.5 \mathrm{~T}$ D-CT & TBD & $\sim 50$ & SMAW & A533B-Ht-2 & HAZ & SSR & Air & 427 \\
\hline 160 & $\mathrm{~J}-\mathrm{R}$ & E-1820 & $0.5 \mathrm{~T}$ D-CT & TBD & $\sim 50$ & SMAW & A533B-Ht-2 & HAZ & SSR & Air & 427 \\
\hline 161 & J-R & E-1820 & $0.5 \mathrm{~T}$ D-CT & TBD & $\sim 50$ & SMAW & A533B-Ht-2 & HAZ & SSR & Air & 427 \\
\hline 162 & $\mathrm{~J}-\mathrm{R}$ & E-1820 & $0.5 \mathrm{~T}$ D-CT & TBD & $\sim 50$ & SMAW & A533B-Ht-2 & HAZ & SSR & Air & 427 \\
\hline 163 & J-R & E-1820 & $0.5 \mathrm{~T}$ D-CT & TBD & $\sim 50$ & SMAW & A533B-Ht-2 & HAZ & SSR & Air & 538 \\
\hline 164 & $\mathrm{~J}-\mathrm{R}$ & E-1820 & $0.5 \mathrm{~T}$ D-CT & TBD & $\sim 50$ & SMAW & A533B-Ht-2 & HAZ & SSR & Air & 538 \\
\hline 165 & J-R & E-1820 & $0.5 \mathrm{~T}$ D-CT & TBD & $\sim 50$ & SMAW & A533B-Ht-2 & HAZ & SSR & Air & 538 \\
\hline 166 & $\mathrm{~J}-\mathrm{R}$ & E-1820 & $0.5 \mathrm{~T}$ D-CT & TBD & $\sim 50$ & SMAW & A533B-Ht-2 & HAZ & SSR & Air & 538 \\
\hline 167 & $\mathrm{~J}-\mathrm{R}$ & E-1820 & $0.5 \mathrm{~T}$ D-CT & TBD & $\sim 50$ & SMAW & A533B-Ht-2 & HAZ & SSR & Air & 538 \\
\hline 168 & $\mathrm{~J}-\mathrm{R}$ & E-1820 & $0.5 \mathrm{~T}$ D-CT & TBD & $\sim 50$ & SMAW & A533B-Ht-2 & HAZ & SSR & Air & 538 \\
\hline
\end{tabular}




Idaho National Laboratory
\begin{tabular}{|c|lll|}
\hline NEXT GENERATION NUCLEAR PLANT & Identifier: & PLN-2803 & \\
REACTOR PRESSURE VESSEL MATERIALS & Revision: & 0 & \\
RESEARCH AND DEVELOPMENT PLAN & Effective Date: & $04 / 30 / 08$ & Page: A-90 of A-102 \\
\hline
\end{tabular}

\begin{tabular}{|c|c|c|c|c|c|c|c|c|}
\hline \multicolumn{9}{|c|}{ Table A29. Cyclic Stress-Strain Curves for A508 } \\
\hline Spec. \# & Test Type & Material & $\begin{array}{c}\text { Product Form } \\
(\sim 250 \mathrm{~mm} \text { thick })\end{array}$ & Mat Cond & Heat \# & Strain Rate $( \pm \mathrm{m} / \mathrm{m} / \mathrm{s})$ & Env & Temp. $\left({ }^{\circ} \mathrm{C}\right)$ \\
\hline 1 & Cyclic & A508 & Forging & SSR & A508-Ht-1 & $1 \mathrm{E}-03$ & air & 20 \\
\hline 2 & Cyclic & A508 & Forging & SSR & A508-Ht-1 & $1 \mathrm{E}-03$ & air & 20 \\
\hline 3 & Cyclic & A508 & Forging & SSR & A508-Ht-1 & $1 \mathrm{E}-03$ & air & 20 \\
\hline 4 & Cyclic & A508 & Forging & SSR & A508-Ht-1 & $1 \mathrm{E}-03$ & air & 20 \\
\hline 5 & Cyclic & A508 & Forging & SSR & A508-Ht-1 & $1 \mathrm{E}-03$ & air & 20 \\
\hline 6 & Cyclic & A508 & Forging & SSR & A508-Ht-1 & $1 \mathrm{E}-03$ & air & 350 \\
\hline 7 & Cyclic & A508 & Forging & SSR & A508-Ht-1 & 1E-03 & air & 350 \\
\hline 8 & Cyclic & A508 & Forging & SSR & A508-Ht-1 & $1 \mathrm{E}-03$ & air & 350 \\
\hline 9 & Cyclic & A508 & Forging & SSR & A508-Ht-1 & $1 \mathrm{E}-03$ & air & 350 \\
\hline 10 & Cyclic & A508 & Forging & SSR & A508-Ht-1 & $1 \mathrm{E}-03$ & air & 350 \\
\hline 11 & Cyclic & A508 & Forging & SSR & A508-Ht-1 & $1 \mathrm{E}-03$ & air & 371 \\
\hline 12 & Cyclic & A508 & Forging & SSR & A508-Ht-1 & $1 \mathrm{E}-03$ & air & 371 \\
\hline 13 & Cyclic & A508 & Forging & SSR & A508-Ht-1 & $1 \mathrm{E}-03$ & air & 371 \\
\hline 14 & Cyclic & A508 & Forging & SSR & A508-Ht-1 & $1 \mathrm{E}-03$ & air & 371 \\
\hline 15 & Cyclic & A508 & Forging & SSR & A508-Ht-1 & $1 \mathrm{E}-03$ & air & 371 \\
\hline 16 & Cyclic & A508 & Forging & SSR & A508-Ht-1 & $1 \mathrm{E}-03$ & air & 427 \\
\hline 17 & Cyclic & A508 & Forging & SSR & A508-Ht-1 & $1 \mathrm{E}-03$ & air & 427 \\
\hline 18 & Cyclic & A508 & Forging & SSR & A508-Ht-1 & $1 \mathrm{E}-03$ & air & 427 \\
\hline 19 & Cyclic & A508 & Forging & SSR & A508-Ht-1 & $1 \mathrm{E}-03$ & air & 427 \\
\hline 20 & Cyclic & A508 & Forging & SSR & A508-Ht-1 & $1 \mathrm{E}-03$ & air & 427 \\
\hline 21 & Cyclic & A508 & Forging & SSR & A508-Ht-1 & $1 \mathrm{E}-03$ & air & 538 \\
\hline 22 & Cyclic & A508 & Forging & SSR & A508-Ht-1 & $1 \mathrm{E}-03$ & air & 538 \\
\hline 23 & Cyclic & A508 & Forging & SSR & A508-Ht-1 & $1 \mathrm{E}-03$ & air & 538 \\
\hline 24 & Cyclic & A508 & Forging & SSR & A508-Ht-1 & $1 \mathrm{E}-03$ & air & 538 \\
\hline 25 & Cyclic & A508 & Forging & SSR & A508-Ht-1 & $1 \mathrm{E}-03$ & air & 538 \\
\hline
\end{tabular}




Idaho National Laboratory
\begin{tabular}{|c|lll|}
\hline NEXT GENERATION NUCLEAR PLANT & Identifier: & PLN-2803 & \\
REACTOR PRESSURE VESSEL MATERIALS & Revision: & 0 & \\
RESEARCH AND DEVELOPMENT PLAN & Effective Date: & $04 / 30 / 08$ & Page: A-91 of A-102 \\
\hline
\end{tabular}

\begin{tabular}{|c|c|c|c|c|c|c|c|c|}
\hline \multicolumn{9}{|c|}{ Table A29. Cyclic Stress-Strain Curves for A508 } \\
\hline Spec. \# & Test Type & Material & $\begin{array}{l}\text { Product Form } \\
(\sim 250 \mathrm{~mm} \text { thick })\end{array}$ & Mat Cond & Heat \# & Strain Rate $( \pm \mathrm{m} / \mathrm{m} / \mathrm{s})$ & Env & Temp. $\left({ }^{\circ} \mathrm{C}\right)$ \\
\hline 26 & Cyclic & A508 & Forging & SSR & A508-Ht-2 & $1 \mathrm{E}-03$ & air & 20 \\
\hline 27 & Cyclic & A508 & Forging & SSR & A508-Ht-2 & $1 \mathrm{E}-03$ & air & 20 \\
\hline 28 & Cyclic & $\mathrm{A} 508$ & Forging & SSR & A508-Ht-2 & $1 \mathrm{E}-03$ & air & 20 \\
\hline 29 & Cyclic & A508 & Forging & SSR & A508-Ht-2 & $1 \mathrm{E}-03$ & air & 20 \\
\hline 30 & Cyclic & A508 & Forging & SSR & A508-Ht-2 & $1 \mathrm{E}-03$ & air & 20 \\
\hline 31 & Cyclic & A508 & Forging & SSR & A508-Ht-2 & $1 \mathrm{E}-03$ & air & 350 \\
\hline 32 & Cyclic & A508 & Forging & SSR & A508-Ht-2 & $1 \mathrm{E}-03$ & air & 350 \\
\hline 33 & Cyclic & A508 & Forging & SSR & A508-Ht-2 & $1 \mathrm{E}-03$ & air & 350 \\
\hline 34 & Cyclic & A508 & Forging & SSR & A508-Ht-2 & $1 \mathrm{E}-03$ & air & 350 \\
\hline 35 & Cyclic & A508 & Forging & SSR & A508-Ht-2 & 1E-03 & air & 350 \\
\hline 36 & Cyclic & A508 & Forging & SSR & A508-Ht-2 & $1 \mathrm{E}-03$ & air & 371 \\
\hline 37 & Cyclic & A508 & Forging & SSR & A508-Ht-2 & $1 \mathrm{E}-03$ & air & 371 \\
\hline 38 & Cyclic & A508 & Forging & SSR & A508-Ht-2 & $1 \mathrm{E}-03$ & air & 371 \\
\hline 39 & Cyclic & A508 & Forging & SSR & A508-Ht-2 & $1 \mathrm{E}-03$ & air & 371 \\
\hline 40 & Cyclic & A508 & Forging & SSR & A508-Ht-2 & $1 \mathrm{E}-03$ & air & 371 \\
\hline 41 & Cyclic & A508 & Forging & SSR & A508-Ht-2 & $1 \mathrm{E}-03$ & air & 427 \\
\hline 42 & Cyclic & A508 & Forging & SSR & A508-Ht-2 & $1 \mathrm{E}-03$ & air & 427 \\
\hline 43 & Cyclic & A508 & Forging & SSR & A508-Ht-2 & $1 \mathrm{E}-03$ & air & 427 \\
\hline 44 & Cyclic & A508 & Forging & SSR & A508-Ht-2 & $1 \mathrm{E}-03$ & air & 427 \\
\hline 45 & Cyclic & A508 & Forging & SSR & A508-Ht-2 & $1 \mathrm{E}-03$ & air & 427 \\
\hline 46 & Cyclic & A508 & Forging & SSR & A508-Ht-2 & $1 \mathrm{E}-03$ & air & 538 \\
\hline 47 & Cyclic & A508 & Forging & SSR & A508-Ht-2 & $1 \mathrm{E}-03$ & air & 538 \\
\hline 48 & Cyclic & A508 & Forging & SSR & A508-Ht-2 & $1 \mathrm{E}-03$ & air & 538 \\
\hline 49 & Cyclic & A508 & Forging & SSR & A508-Ht-2 & 1E-03 & air & 538 \\
\hline 50 & Cyclic & A508 & Forging & SSR & A508-Ht-2 & 1E-03 & air & 538 \\
\hline 51 & Cyclic & A508 & Forging & SSR & A508-Ht-3 & $1 \mathrm{E}-03$ & air & 20 \\
\hline
\end{tabular}




Idaho National Laboratory
\begin{tabular}{|c|lll|}
\hline NEXT GENERATION NUCLEAR PLANT & Identifier: & PLN-2803 & \\
REACTOR PRESSURE VESSEL MATERIALS & Revision: & 0 & \\
RESEARCH AND DEVELOPMENT PLAN & Effective Date: & $04 / 30 / 08$ & Page: A-92 of A-102 \\
\hline
\end{tabular}

\begin{tabular}{|c|c|c|c|c|c|c|c|c|}
\hline Spec. \# & Test Type & Material & $\begin{array}{l}\text { Product Form } \\
(\sim 250 \mathrm{~mm} \text { thick })\end{array}$ & Mat Cond & Heat \# & Strain Rate $( \pm \mathrm{m} / \mathrm{m} / \mathrm{s})$ & Env & Temp. $\left({ }^{\circ} \mathrm{C}\right)$ \\
\hline 52 & Cyclic & A508 & Forging & SSR & A508-Ht-3 & $1 \mathrm{E}-03$ & air & 20 \\
\hline 53 & Cyclic & A508 & Forging & SSR & A508-Ht-3 & $1 \mathrm{E}-03$ & air & 20 \\
\hline 54 & Cyclic & A508 & Forging & SSR & A508-Ht-3 & $1 \mathrm{E}-03$ & air & 20 \\
\hline 55 & Cyclic & A508 & Forging & SSR & A508-Ht-3 & $1 \mathrm{E}-03$ & air & 20 \\
\hline 56 & Cyclic & A508 & Forging & SSR & A508-Ht-3 & $1 \mathrm{E}-03$ & air & 350 \\
\hline 57 & Cyclic & A508 & Forging & SSR & A508-Ht-3 & $1 \mathrm{E}-03$ & air & 350 \\
\hline 58 & Cyclic & A508 & Forging & SSR & A508-Ht-3 & $1 \mathrm{E}-03$ & air & 350 \\
\hline 59 & Cyclic & A508 & Forging & SSR & A508-Ht-3 & $1 \mathrm{E}-03$ & air & 350 \\
\hline 60 & Cyclic & A508 & Forging & SSR & A508-Ht-3 & $1 \mathrm{E}-03$ & air & 350 \\
\hline 61 & Cyclic & A508 & Forging & SSR & A508-Ht-3 & $1 \mathrm{E}-03$ & air & 371 \\
\hline 62 & Cyclic & A508 & Forging & SSR & A508-Ht-3 & $1 \mathrm{E}-03$ & air & 371 \\
\hline 63 & Cyclic & A508 & Forging & SSR & A508-Ht-3 & $1 \mathrm{E}-03$ & air & 371 \\
\hline 64 & Cyclic & A508 & Forging & SSR & A508-Ht-3 & $1 \mathrm{E}-03$ & air & 371 \\
\hline 65 & Cyclic & A508 & Forging & SSR & A508-Ht-3 & $1 \mathrm{E}-03$ & air & 371 \\
\hline 66 & Cyclic & A508 & Forging & SSR & A508-Ht-3 & $1 \mathrm{E}-03$ & air & 427 \\
\hline 67 & Cyclic & A508 & Forging & SSR & A508-Ht-3 & $1 \mathrm{E}-03$ & air & 427 \\
\hline 68 & Cyclic & A508 & Forging & SSR & A508-Ht-3 & $1 \mathrm{E}-03$ & air & 427 \\
\hline 69 & Cyclic & A508 & Forging & SSR & A508-Ht-3 & $1 \mathrm{E}-03$ & air & 427 \\
\hline 70 & Cyclic & A508 & Forging & SSR & A $508-\mathrm{Ht}-3$ & $1 \mathrm{E}-03$ & air & 427 \\
\hline 71 & Cyclic & A508 & Forging & SSR & A508-Ht-3 & $1 \mathrm{E}-03$ & air & 538 \\
\hline 72 & Cyclic & A508 & Forging & SSR & A508-Ht-3 & $1 \mathrm{E}-03$ & air & 538 \\
\hline 73 & Cyclic & A508 & Forging & SSR & A508-Ht-3 & $1 \mathrm{E}-03$ & air & 538 \\
\hline 74 & Cyclic & A508 & Forging & SSR & A508-Ht-3 & $1 \mathrm{E}-03$ & air & 538 \\
\hline 75 & Cyclic & A508 & Forging & SSR & A508-Ht-3 & $1 \mathrm{E}-03$ & air & 538 \\
\hline
\end{tabular}




Idaho National Laboratory
\begin{tabular}{|c|lll|}
\hline NEXT GENERATION NUCLEAR PLANT & Identifier: & PLN-2803 & \\
REACTOR PRESSURE VESSEL MATERIALS & Revision: & 0 & \\
RESEARCH AND DEVELOPMENT PLAN & Effective Date: & $04 / 30 / 08$ & Page: A-93 of A-102 \\
\hline
\end{tabular}

\begin{tabular}{|c|c|c|c|c|c|c|c|c|c|c|}
\hline Spec. Type & Spec. \# & Mat & $\begin{array}{l}\text { Product Form } \\
(\sim 250 \mathrm{~mm} \text { thick })\end{array}$ & Mat Cond. & Heat & Env & $\begin{array}{l}\text { Temp. } \\
\left({ }^{\circ} \mathrm{C}\right)\end{array}$ & $\begin{array}{l}\text { Applied } \\
\text { Stress } \\
\text { (MPa) }\end{array}$ & $\begin{array}{l}\text { Best Est. } \\
\text { Rupture time } \\
\text { (h) }\end{array}$ & $\begin{array}{c}\text { LB Rupture } \\
\text { time (h) }\end{array}$ \\
\hline Creep & 1 & A508 & Forging & SSR & A508-Ht-1 & air & 350 & 524 & 3238 & 98 \\
\hline Creep & 2 & A508 & Forging & SSR & A508-Ht-1 & air & 350 & 524 & 3238 & 98 \\
\hline Creep & 3 & A508 & Forging & SSR & A508-Ht-1 & air & 371 & 483 & 3752 & 148 \\
\hline Creep & 4 & A508 & Forging & SSR & A508-Ht-1 & air & 371 & 483 & 3752 & 148 \\
\hline Creep & 5 & A508 & Forging & SSR & A508-Ht-1 & air & 427 & 414 & 1044 & 43 \\
\hline Creep & 6 & A508 & Forging & SSR & A508-Ht-1 & air & 427 & 414 & 1044 & 43 \\
\hline Creep & 7 & A508 & Forging & SSR & A508-Ht-1 & air & 482 & 296 & 1056 & 38 \\
\hline Creep & 8 & A508 & Forging & SSR & A508-Ht-1 & air & 482 & 296 & 1056 & 38 \\
\hline Creep & 9 & A508 & Forging & SSR & A508-Ht-1 & air & 538 & 172 & 998 & 34 \\
\hline Creep & 10 & A508 & Forging & SSR & A508-Ht-1 & air & 538 & 172 & 998 & 34 \\
\hline Creep & 11 & A508 & Forging & SSR & A508-Ht-1 & air & 593 & 62 & 974 & 30 \\
\hline Creep & 12 & A508 & Forging & SSR & A508-Ht-1 & air & 593 & 62 & 974 & 30 \\
\hline Creep & 13 & A508 & Forging & SSR & A508-Ht-2 & air & 350 & 524 & 3238 & 98 \\
\hline Creep & 14 & A508 & Forging & SSR & A508-Ht-2 & air & 350 & 524 & 3238 & 98 \\
\hline Creep & 15 & A508 & Forging & SSR & A508-Ht-2 & air & 371 & 483 & 3752 & 148 \\
\hline Creep & 16 & A508 & Forging & SSR & A508-Ht-2 & air & 371 & 483 & 3752 & 148 \\
\hline Creep & 17 & A508 & Forging & SSR & A508-Ht-2 & air & 427 & 414 & 1044 & 43 \\
\hline Creep & 18 & A508 & Forging & SSR & A508-Ht-2 & air & 427 & 414 & 1044 & 43 \\
\hline Creep & 19 & A508 & Forging & SSR & A508-Ht-2 & air & 482 & 296 & 1056 & 38 \\
\hline Creep & 20 & A508 & Forging & SSR & A508-Ht-2 & air & 482 & 296 & 1056 & 38 \\
\hline Creep & 21 & A508 & Forging & SSR & A508-Ht-2 & air & 538 & 172 & 998 & 34 \\
\hline Creep & 22 & A508 & Forging & SSR & A508-Ht-2 & air & 538 & 172 & 998 & 34 \\
\hline Creep & 23 & A508 & Forging & SSR & A508-Ht-2 & air & 593 & 62 & 974 & 30 \\
\hline Creep & 24 & A508 & Forging & SSR & A508-Ht-2 & air & 593 & 62 & 974 & 30 \\
\hline
\end{tabular}


Idaho National Laboratory

\begin{tabular}{c|lll|} 
NEXT GENERATION NUCLEAR PLANT & Identifier: & PLN-2803 & \\
REACTOR PRESSURE VESSEL MATERIALS & Revision: & 0 & \\
RESEARCH AND DEVELOPMENT PLAN & Effective Date: & $04 / 30 / 08$ & Page: A-94 of A-102 \\
\hline
\end{tabular}

\begin{tabular}{|c|c|c|c|c|c|c|c|c|c|c|}
\hline \multicolumn{11}{|c|}{ Table A30. A 508/533B Creep Rupture Tests in Air to Support Code Case N-499 } \\
\hline Spec. Type & Spec. \# & Mat & $\begin{array}{c}\text { Product Form } \\
(\sim 250 \mathrm{~mm} \text { thick })\end{array}$ & Mat Cond. & Heat & Env & $\begin{array}{c}\text { Temp. } \\
\left({ }^{\circ} \mathrm{C}\right)\end{array}$ & $\begin{array}{l}\text { Applied } \\
\text { Stress } \\
(\mathrm{MPa})\end{array}$ & $\begin{array}{l}\text { Best Est. } \\
\text { Rupture time } \\
\text { (h) }\end{array}$ & $\begin{array}{l}\text { LB Rupture } \\
\text { time (h) }\end{array}$ \\
\hline Creep & 25 & A508 & Forging & SSR & A508-Ht-3 & air & 350 & 524 & 3238 & 98 \\
\hline Creep & 26 & A508 & Forging & SSR & A508-Ht-3 & air & 350 & 524 & 3238 & 98 \\
\hline Creep & 27 & A508 & Forging & SSR & A508-Ht-3 & air & 371 & 483 & 3752 & 148 \\
\hline Creep & 28 & A508 & Forging & SSR & A508-Ht-3 & air & 371 & 483 & 3752 & 148 \\
\hline Creep & 29 & A508 & Forging & SSR & A508-Ht-3 & air & 427 & 414 & 1044 & 43 \\
\hline Creep & 30 & A508 & Forging & SSR & A508-Ht-3 & air & 427 & 414 & 1044 & 43 \\
\hline Creep & 31 & A508 & Forging & SSR & A508-Ht-3 & air & 482 & 296 & 1056 & 38 \\
\hline Creep & 32 & A508 & Forging & SSR & A508-Ht-3 & air & 482 & 296 & 1056 & 38 \\
\hline Creep & 33 & A508 & Forging & SSR & A508-Ht-3 & air & 538 & 172 & 998 & 34 \\
\hline Creep & 34 & A508 & Forging & SSR & A508-Ht-3 & air & 538 & 172 & 998 & 34 \\
\hline Creep & 35 & A508 & Forging & SSR & A508-Ht-3 & air & 593 & 62 & 974 & 30 \\
\hline Creep & 36 & A508 & Forging & SSR & A508-Ht-3 & air & 593 & 62 & 974 & 30 \\
\hline Creep & 37 & A533B & Rolled Plate & SSR & A533B-Ht-1 & air & 350 & 524 & 3238 & 98 \\
\hline Creep & 38 & A533B & Rolled Plate & SSR & A533B-Ht-1 & air & 350 & 524 & 3238 & 98 \\
\hline Creep & 39 & A533B & Rolled Plate & SSR & A533B-Ht-1 & air & 371 & 483 & 3752 & 148 \\
\hline Creep & 40 & A533B & Rolled Plate & SSR & A533B-Ht-1 & air & 371 & 483 & 3752 & 148 \\
\hline Creep & 41 & A533B & Rolled Plate & SSR & A533B-Ht-1 & air & 427 & 414 & 1044 & 43 \\
\hline Creep & 42 & A533B & Rolled Plate & SSR & A533B-Ht-1 & air & 427 & 414 & 1044 & 43 \\
\hline Creep & 43 & A533B & Rolled Plate & SSR & A533B-Ht-1 & air & 482 & 296 & 1056 & 38 \\
\hline Creep & 44 & A533B & Rolled Plate & SSR & A533B-Ht-1 & air & 482 & 296 & 1056 & 38 \\
\hline Creep & 45 & A533B & Rolled Plate & SSR & A533B-Ht-1 & air & 538 & 172 & 998 & 34 \\
\hline Creep & 46 & A533B & Rolled Plate & SSR & A533B-Ht-1 & air & 538 & 172 & 998 & 34 \\
\hline Creep & 47 & A533B & Rolled Plate & SSR & A533B-Ht-1 & air & 593 & 62 & 974 & 30 \\
\hline Creep & 48 & A533B & Rolled Plate & SSR & A533B-Ht-1 & air & 593 & 62 & 974 & 30 \\
\hline
\end{tabular}




Idaho National Laboratory
\begin{tabular}{|c|lll|}
\hline NEXT GENERATION NUCLEAR PLANT & Identifier: & PLN-2803 & \\
REACTOR PRESSURE VESSEL MATERIALS & Revision: & 0 & \\
RESEARCH AND DEVELOPMENT PLAN & Effective Date: & $04 / 30 / 08$ & Page: A-95 of A-102 \\
\hline
\end{tabular}

\begin{tabular}{|c|c|c|c|c|c|c|c|c|c|c|c|c|}
\hline \multicolumn{13}{|c|}{ Table A31. SAW and SMAW Creep Rupture Tests in Air to Support Code Case N-499 } \\
\hline $\begin{array}{l}\text { Spec. } \\
\text { Type }\end{array}$ & $\begin{array}{c}\text { Spec. } \\
\# \\
\end{array}$ & $\begin{array}{c}\text { Weld } \\
\text { Con- } \\
\text { sumable }\end{array}$ & $\begin{array}{l}\text { Product Form } \\
(\sim 250 \mathrm{~mm} \text { thick })\end{array}$ & $\begin{array}{l}\text { Weld } \\
\text { Process }\end{array}$ & $\begin{array}{c}\text { Base Metal } \\
\text { Heat }\end{array}$ & $\begin{array}{c}\text { Weld to } \\
\text { be Tested }\end{array}$ & $\begin{array}{c}\text { Mat } \\
\text { Cond } \\
\end{array}$ & Env & $\begin{array}{c}\text { Temp. } \\
\left({ }^{\circ} \mathrm{C}\right)\end{array}$ & $\begin{array}{l}\text { Applied } \\
\text { Stress } \\
\text { (MPa) }\end{array}$ & $\begin{array}{l}\text { Best Est. } \\
\text { Rupture } \\
\text { time (h) }\end{array}$ & $\begin{array}{c}\text { LB } \\
\text { Rupture } \\
\text { time (h) }\end{array}$ \\
\hline Creep & 1 & TBD & Thick Section Weld & SAW & A508-Ht-1 & X-Weld & SSR & air & 350 & 524 & 3238 & 98 \\
\hline Creep & 2 & TBD & Thick Section Weld & SAW & A508-Ht-1 & X-Weld & SSR & air & 350 & 524 & 3238 & 98 \\
\hline Creep & 3 & TBD & Thick Section Weld & SAW & A508-Ht-1 & X-Weld & SSR & air & 371 & 483 & 3752 & 148 \\
\hline Creep & 4 & TBD & Thick Section Weld & SAW & A508-Ht-1 & X-Weld & SSR & air & 371 & 483 & 3752 & 148 \\
\hline Creep & 5 & TBD & Thick Section Weld & SAW & A508-Ht-1 & X-Weld & SSR & air & 427 & 414 & 1044 & 43 \\
\hline Creep & 6 & TBD & Thick Section Weld & SAW & A508-Ht-1 & X-Weld & SSR & air & 427 & 414 & 1044 & 43 \\
\hline Creep & 7 & TBD & Thick Section Weld & SAW & A508-Ht-1 & X-Weld & SSR & air & 482 & 296 & 1056 & 38 \\
\hline Creep & 8 & TBD & Thick Section Weld & SAW & A508-Ht-1 & X-Weld & SSR & air & 482 & 296 & 1056 & 38 \\
\hline Creep & 9 & TBD & Thick Section Weld & SAW & A508-Ht-1 & X-Weld & SSR & air & 538 & 172 & 998 & 34 \\
\hline Creep & 10 & TBD & Thick Section Weld & SAW & A508-Ht-1 & X-Weld & SSR & air & 538 & 172 & 998 & 34 \\
\hline Creep & 11 & TBD & Thick Section Weld & SAW & A508-Ht-1 & X-Weld & SSR & air & 593 & 62 & 974 & 30 \\
\hline Creep & 12 & TBD & Thick Section Weld & SAW & A508-Ht-1 & X-Weld & SSR & air & 593 & 62 & 974 & 30 \\
\hline Creep & 13 & TBD & Thick Section Weld & SMAW & A508-Ht-1 & X-Weld & SSR & air & 350 & 524 & 3238 & 98 \\
\hline Creep & 14 & TBD & Thick Section Weld & SMAW & A508-Ht-1 & X-Weld & SSR & air & 350 & 524 & 3238 & 98 \\
\hline Creep & 15 & TBD & Thick Section Weld & SMAW & A508-Ht-1 & X-Weld & SSR & air & 371 & 483 & 3752 & 148 \\
\hline Creep & 16 & TBD & Thick Section Weld & SMAW & A508-Ht-1 & X-Weld & SSR & air & 371 & 483 & 3752 & 148 \\
\hline Creep & 17 & TBD & Thick Section Weld & SMAW & A508-Ht-1 & X-Weld & SSR & air & 427 & 414 & 1044 & 43 \\
\hline Creep & 18 & TBD & Thick Section Weld & SMAW & A508-Ht-1 & X-Weld & SSR & air & 427 & 414 & 1044 & 43 \\
\hline Creep & 19 & TBD & Thick Section Weld & SMAW & A508-Ht-1 & X-Weld & SSR & air & 482 & 296 & 1056 & 38 \\
\hline Creep & 20 & TBD & Thick Section Weld & SMAW & A508-Ht-1 & X-Weld & SSR & air & 482 & 296 & 1056 & 38 \\
\hline Creep & 21 & TBD & Thick Section Weld & SMAW & A508-Ht-1 & X-Weld & SSR & air & 538 & 172 & 998 & 34 \\
\hline Creep & 22 & TBD & Thick Section Weld & SMAW & A508-Ht-1 & X-Weld & SSR & air & 538 & 172 & 998 & 34 \\
\hline Creep & 23 & TBD & Thick Section Weld & SMAW & A508-Ht-1 & X-Weld & SSR & air & 593 & 62 & 974 & 30 \\
\hline Creep & 24 & TBD & Thick Section Weld & SMAW & A508-Ht-1 & X-Weld & SSR & air & 593 & 62 & 974 & 30 \\
\hline
\end{tabular}




Idaho National Laboratory
\begin{tabular}{|c|lll|}
\hline NEXT GENERATION NUCLEAR PLANT & Identifier: & PLN-2803 & \\
REACTOR PRESSURE VESSEL MATERIALS & Revision: & 0 & \\
RESEARCH AND DEVELOPMENT PLAN & Effective Date: & $04 / 30 / 08$ & Page: A-96 of A-102 \\
\hline
\end{tabular}

\begin{tabular}{|c|c|c|c|c|c|c|c|c|c|c|c|c|}
\hline $\begin{array}{l}\text { Spec. } \\
\text { Type }\end{array}$ & $\begin{array}{c}\text { Spec. } \\
\#\end{array}$ & $\begin{array}{c}\text { Weld } \\
\text { Con- } \\
\text { sumable }\end{array}$ & $\begin{array}{l}\text { Product Form } \\
(\sim 250 \mathrm{~mm} \text { thick })\end{array}$ & $\begin{array}{c}\text { Weld } \\
\text { Process }\end{array}$ & $\begin{array}{c}\text { Base Metal } \\
\text { Heat }\end{array}$ & $\begin{array}{l}\text { Weld to } \\
\text { be Tested }\end{array}$ & $\begin{array}{l}\text { Mat } \\
\text { Cond }\end{array}$ & Env & $\begin{array}{l}\text { Temp. } \\
\left({ }^{\circ} \mathrm{C}\right)\end{array}$ & $\begin{array}{l}\text { Applied } \\
\text { Stress } \\
(\mathrm{MPa}) \\
\end{array}$ & $\begin{array}{l}\text { Best Est. } \\
\text { Rupture } \\
\text { time (h) }\end{array}$ & $\begin{array}{c}\text { LB } \\
\text { Rupture } \\
\text { time (h) } \\
\end{array}$ \\
\hline Creep & 25 & TBD & Thick Section Weld & SAW & A533B-Ht-1 & X-Weld & SSR & air & 350 & 524 & 3238 & 98 \\
\hline Creep & 26 & TBD & Thick Section Weld & SAW & A533B-Ht-1 & X-Weld & SSR & air & 350 & 524 & 3238 & 98 \\
\hline Creep & 27 & TBD & Thick Section Weld & SAW & A533B-Ht-1 & X-Weld & SSR & air & 371 & 483 & 3752 & 148 \\
\hline Creep & 28 & TBD & Thick Section Weld & SAW & A533B-Ht-1 & X-Weld & SSR & air & 371 & 483 & 3752 & 148 \\
\hline Creep & 29 & TBD & Thick Section Weld & SAW & A533B-Ht-1 & X-Weld & SSR & air & 427 & 414 & 1044 & 43 \\
\hline Creep & 30 & TBD & Thick Section Weld & SAW & A533B-Ht-1 & X-Weld & SSR & air & 427 & 414 & 1044 & 43 \\
\hline Creep & 31 & TBD & Thick Section Weld & SAW & A533B-Ht-1 & X-Weld & SSR & air & 482 & 296 & 1056 & 38 \\
\hline Creep & 32 & TBD & Thick Section Weld & SAW & A533B-Ht-1 & X-Weld & SSR & air & 482 & 296 & 1056 & 38 \\
\hline Creep & 33 & TBD & Thick Section Weld & SAW & A533B-Ht-1 & X-Weld & SSR & air & 538 & 172 & 998 & 34 \\
\hline Creep & 34 & TBD & Thick Section Weld & SAW & A533B-Ht-1 & X-Weld & SSR & air & 538 & 172 & 998 & 34 \\
\hline Creep & 35 & TBD & Thick Section Weld & SAW & A533B-Ht-1 & X-Weld & SSR & air & 593 & 62 & 974 & 30 \\
\hline Creep & 36 & TBD & Thick Section Weld & SAW & A533B-Ht-1 & X-Weld & SSR & air & 593 & 62 & 974 & 30 \\
\hline Creep & 37 & TBD & Thick Section Weld & SMAW & A533B-Ht-1 & X-Weld & SSR & air & 350 & 524 & 3238 & 98 \\
\hline Creep & 38 & TBD & Thick Section Weld & SMAW & A533B-Ht-1 & X-Weld & SSR & air & 350 & 524 & 3238 & 98 \\
\hline Creep & 39 & TBD & Thick Section Weld & SMAW & A533B-Ht-1 & X-Weld & SSR & air & 371 & 483 & 3752 & 148 \\
\hline Creep & 40 & TBD & Thick Section Weld & SMAW & A533B-Ht-1 & X-Weld & SSR & air & 371 & 483 & 3752 & 148 \\
\hline Creep & 41 & TBD & Thick Section Weld & SMAW & A533B-Ht-1 & X-Weld & SSR & air & 427 & 414 & 1044 & 43 \\
\hline Creep & 42 & TBD & Thick Section Weld & SMAW & A533B-Ht-1 & X-Weld & SSR & air & 427 & 414 & 1044 & 43 \\
\hline Creep & 43 & TBD & Thick Section Weld & SMAW & A533B-Ht-1 & X-Weld & SSR & air & 482 & 296 & 1056 & 38 \\
\hline Creep & 44 & TBD & Thick Section Weld & SMAW & A533B-Ht-1 & X-Weld & SSR & air & 482 & 296 & 1056 & 38 \\
\hline Creep & 45 & TBD & Thick Section Weld & SMAW & A533B-Ht-1 & X-Weld & SSR & air & 538 & 172 & 998 & 34 \\
\hline Creep & 46 & TBD & Thick Section Weld & SMAW & A533B-Ht-1 & X-Weld & SSR & air & 538 & 172 & 998 & 34 \\
\hline Creep & 47 & TBD & Thick Section Weld & SMAW & A533B-Ht-1 & X-Weld & SSR & air & 593 & 62 & 974 & 30 \\
\hline Creep & 48 & TBD & Thick Section Weld & SMAW & A533B-Ht-1 & X-Weld & SSR & air & 593 & 62 & 974 & 30 \\
\hline
\end{tabular}




Idaho National Laboratory
\begin{tabular}{|c|lll|}
\hline NEXT GENERATION NUCLEAR PLANT & Identifier: & PLN-2803 & \\
REACTOR PRESSURE VESSEL MATERIALS & Revision: & 0 & \\
RESEARCH AND DEVELOPMENT PLAN & Effective Date: & $04 / 30 / 08$ & Page: A-97 of A-102 \\
\hline
\end{tabular}

\begin{tabular}{|c|c|c|c|c|c|c|c|c|c|c|c|c|}
\hline \multicolumn{13}{|c|}{ Table A32. A 508/533B Fatigue-SRX Tests in Air to Support Code Case N-499 } \\
\hline Spec. \# & Test Type & Mat & Product Form & $\begin{array}{c}\text { Mat } \\
\text { Cond }\end{array}$ & Heat & $\begin{array}{c}\text { Strain } \\
\text { Rate } \\
(\mathrm{m} / \mathrm{m} / \mathrm{s})\end{array}$ & Env & $\begin{array}{l}\text { Hold } \\
\text { Cntrl } \\
\text { (stress } \\
\text { or } \\
\text { strain) }\end{array}$ & $\begin{array}{l}\text { Strain } \\
\text { Hold in } \\
\text { T/C }\end{array}$ & $\begin{array}{c}\text { Temp. } \\
\left({ }^{\circ} \mathrm{C}\right)\end{array}$ & $\begin{array}{c}\text { Strain } \\
\text { Range } \\
(\%)\end{array}$ & $\begin{array}{l}\text { Strain } \\
\text { Hold } \\
\text { Time } \\
(\mathrm{min}) \\
\end{array}$ \\
\hline 1 & Fatigue-SRX & A508 & Forging (thick) & SSR & A508-Ht-1 & $1 \mathrm{E}-03$ & air & strain & N/A & 427 & 1.0 & 0 \\
\hline 2 & Fatigue-SRX & A508 & Forging (thick) & SSR & A508-Ht-1 & $1 \mathrm{E}-03$ & air & strain & N/A & 427 & 1.0 & 0 \\
\hline 3 & Fatigue-SRX & A508 & Forging (thick) & SSR & A508-Ht-1 & $1 \mathrm{E}-03$ & air & strain & N/A & 427 & 1.0 & 0 \\
\hline 4 & Fatigue-SRX & A508 & Forging (thick) & SSR & A508-Ht-1 & $1 \mathrm{E}-03$ & air & strain & tension & 427 & 1.0 & 30 \\
\hline 5 & Fatigue-SRX & A508 & Forging (thick) & SSR & A508-Ht-1 & $1 \mathrm{E}-03$ & air & strain & tension & 427 & 1.0 & 30 \\
\hline 6 & Fatigue-SRX & A508 & Forging (thick) & SSR & A508-Ht-1 & $1 \mathrm{E}-03$ & air & strain & tension & 427 & 1.0 & 30 \\
\hline 7 & Fatigue-SRX & A508 & Forging (thick) & SSR & A508-Ht-1 & $1 \mathrm{E}-03$ & air & strain & tension & 427 & 1.0 & 150 \\
\hline 8 & Fatigue-SRX & A508 & Forging (thick) & SSR & A508-Ht-1 & $1 \mathrm{E}-03$ & air & strain & tension & 427 & 1.0 & 150 \\
\hline 9 & Fatigue-SRX & A508 & Forging (thick) & SSR & A508-Ht-1 & $1 \mathrm{E}-03$ & air & strain & tension & 427 & 1.0 & 150 \\
\hline 10 & Fatigue-SRX & A508 & Forging (thick) & SSR & A508-Ht-1 & $1 \mathrm{E}-03$ & air & strain & tension & 427 & 1.0 & 30 \\
\hline 11 & Fatigue-SRX & A508 & Forging (thick) & SSR & A508-Ht-1 & $1 \mathrm{E}-03$ & air & strain & tension & 427 & 1.0 & 30 \\
\hline 12 & Fatigue-SRX & A508 & Forging (thick) & SSR & A508-Ht-1 & $1 \mathrm{E}-03$ & air & strain & tension & 427 & 1.0 & 30 \\
\hline 13 & Fatigue-SRX & A508 & Forging (thick) & SSR & A508-Ht-1 & $1 \mathrm{E}-03$ & air & strain & comp. & 427 & 1.0 & 150 \\
\hline 14 & Fatigue-SRX & A508 & Forging (thick) & SSR & A508-Ht-1 & $1 \mathrm{E}-03$ & air & strain & comp. & 427 & 1.0 & 150 \\
\hline 15 & Fatigue-SRX & A508 & Forging (thick) & SSR & A508-Ht-1 & $1 \mathrm{E}-03$ & air & strain & comp. & 427 & 1.0 & 150 \\
\hline 16 & Fatigue-SRX & A508 & Forging (thick) & SSR & A508-Ht-1 & $1 \mathrm{E}-03$ & air & strain & comp. & 427 & 1.0 & 0 \\
\hline 17 & Fatigue-SRX & A508 & Forging (thick) & SSR & A508-Ht-1 & $1 \mathrm{E}-03$ & air & strain & comp. & 427 & 1.0 & 0 \\
\hline 18 & Fatigue-SRX & A508 & Forging (thick) & SSR & A508-Ht-1 & $1 \mathrm{E}-03$ & air & strain & comp. & 427 & 1.0 & 0 \\
\hline 19 & Fatigue-SRX & A508 & Forging (thick) & SSR & A508-Ht-1 & $1 \mathrm{E}-03$ & air & strain & comp. & 427 & 1.0 & 30 \\
\hline 20 & Fatigue-SRX & A508 & Forging (thick) & SSR & A508-Ht-1 & $1 \mathrm{E}-03$ & air & strain & comp. & 427 & 1.0 & 30 \\
\hline 21 & Fatigue-SRX & A508 & Forging (thick) & SSR & A508-Ht-1 & $1 \mathrm{E}-03$ & air & strain & comp. & 427 & 1.0 & 30 \\
\hline 22 & Fatigue-SRX & A508 & Forging (thick) & SSR & A508-Ht-1 & $1 \mathrm{E}-03$ & air & strain & N/A & 538 & 1.0 & 150 \\
\hline 23 & Fatigue-SRX & A508 & Forging (thick) & SSR & A508-Ht-1 & $1 \mathrm{E}-03$ & air & strain & N/A & 538 & 1.0 & 150 \\
\hline 24 & Fatigue-SRX & A508 & Forging (thick) & SSR & A508-Ht-1 & $1 \mathrm{E}-03$ & air & strain & N/A & 538 & 1.0 & 150 \\
\hline
\end{tabular}




Idaho National Laboratory
\begin{tabular}{|c|lll|}
\hline NEXT GENERATION NUCLEAR PLANT & Identifier: & PLN-2803 & \\
REACTOR PRESSURE VESSEL MATERIALS & Revision: & 0 & \\
RESEARCH AND DEVELOPMENT PLAN & Effective Date: & $04 / 30 / 08$ & Page: A-98 of A-102 \\
\hline
\end{tabular}

\begin{tabular}{|c|c|c|c|c|c|c|c|c|c|c|c|c|}
\hline Spec. \# & Test Type & Mat & Product Form & $\begin{array}{c}\text { Mat } \\
\text { Cond }\end{array}$ & Heat & $\begin{array}{l}\text { Strain } \\
\text { Rate } \\
(\mathrm{m} / \mathrm{m} / \mathrm{s})\end{array}$ & Env & $\begin{array}{l}\text { Hold } \\
\text { Cntrl } \\
\text { (stress } \\
\text { or } \\
\text { strain) } \\
\end{array}$ & $\begin{array}{l}\text { Strain } \\
\text { Hold in } \\
\text { T/C }\end{array}$ & $\begin{array}{c}\text { Temp. } \\
\left({ }^{\circ} \mathrm{C}\right)\end{array}$ & $\begin{array}{c}\text { Strain } \\
\text { Range } \\
(\%)\end{array}$ & $\begin{array}{l}\text { Strain } \\
\text { Hold } \\
\text { Time } \\
\text { (min) }\end{array}$ \\
\hline 25 & Fatigue-SRX & A508 & Forging (thick) & SSR & A508-Ht-1 & $1 \mathrm{E}-03$ & air & strain & tension & 538 & 1.0 & 30 \\
\hline 26 & Fatigue-SRX & A508 & Forging (thick) & SSR & A508-Ht-1 & $1 \mathrm{E}-03$ & air & strain & tension & 538 & 1.0 & 30 \\
\hline 27 & Fatigue-SRX & A508 & Forging (thick) & SSR & A508-Ht-1 & $1 \mathrm{E}-03$ & air & strain & tension & 538 & 1.0 & 30 \\
\hline 28 & Fatigue-SRX & A508 & Forging (thick) & SSR & A508-Ht-1 & $1 \mathrm{E}-03$ & air & strain & tension & 538 & 1.0 & 150 \\
\hline 29 & Fatigue-SRX & A508 & Forging (thick) & SSR & A508-Ht-1 & $1 \mathrm{E}-03$ & air & strain & tension & 538 & 1.0 & 150 \\
\hline 30 & Fatigue-SRX & A508 & Forging (thick) & SSR & A508-Ht-1 & $1 \mathrm{E}-03$ & air & strain & tension & 538 & 1.0 & 150 \\
\hline 31 & Fatigue-SRX & A508 & Forging (thick) & SSR & A508-Ht-1 & $1 \mathrm{E}-03$ & air & strain & comp. & 538 & 1.0 & 0 \\
\hline 32 & Fatigue-SRX & A508 & Forging (thick) & SSR & A508-Ht-1 & $1 \mathrm{E}-03$ & air & strain & comp. & 538 & 1.0 & 0 \\
\hline 33 & Fatigue-SRX & A508 & Forging (thick) & SSR & A508-Ht-1 & $1 \mathrm{E}-03$ & air & strain & comp. & 538 & 1.0 & 0 \\
\hline 34 & Fatigue-SRX & A508 & Forging (thick) & SSR & A508-Ht-1 & $1 \mathrm{E}-03$ & air & strain & comp. & 538 & 1.0 & 30 \\
\hline 35 & Fatigue-SRX & A508 & Forging (thick) & SSR & A508-Ht-1 & $1 \mathrm{E}-03$ & air & strain & comp. & 538 & 1.0 & 30 \\
\hline 36 & Fatigue-SRX & A508 & Forging (thick) & SSR & A508-Ht-1 & $1 \mathrm{E}-03$ & air & strain & comp. & 538 & 1.0 & 30 \\
\hline 37 & Fatigue-SRX & A533B & Rolled Plate (thick) & SSR & A533B-Ht-1 & $1 \mathrm{E}-03$ & air & strain & N/A & 427 & 1.0 & 150 \\
\hline 38 & Fatigue-SRX & A533B & Rolled Plate (thick) & SSR & A533B-Ht-1 & $1 \mathrm{E}-03$ & air & strain & N/A & 427 & 1.0 & 150 \\
\hline 39 & Fatigue-SRX & A533B & Rolled Plate (thick) & SSR & A533B-Ht-1 & $1 \mathrm{E}-03$ & air & strain & N/A & 427 & 1.0 & 150 \\
\hline 40 & Fatigue-SRX & A533B & Rolled Plate (thick) & SSR & A533B-Ht-1 & $1 \mathrm{E}-03$ & air & strain & tension & 427 & 1.0 & 30 \\
\hline 41 & Fatigue-SRX & A533B & Rolled Plate (thick) & SSR & A533B-Ht-1 & $1 \mathrm{E}-03$ & air & strain & tension & 427 & 1.0 & 30 \\
\hline 42 & Fatigue-SRX & A533B & Rolled Plate (thick) & SSR & A533B-Ht-1 & $1 \mathrm{E}-03$ & air & strain & tension & 427 & 1.0 & 30 \\
\hline 43 & Fatigue-SRX & A533B & Rolled Plate (thick) & SSR & A533B-Ht-1 & $1 \mathrm{E}-03$ & air & strain & tension & 427 & 1.0 & 150 \\
\hline 44 & Fatigue-SRX & A533B & Rolled Plate (thick) & SSR & A533B-Ht-1 & $1 \mathrm{E}-03$ & air & strain & tension & 427 & 1.0 & 150 \\
\hline 45 & Fatigue-SRX & A533B & Rolled Plate (thick) & SSR & A533B-Ht-1 & $1 \mathrm{E}-03$ & air & strain & tension & 427 & 1.0 & 150 \\
\hline 46 & Fatigue-SRX & A533B & Rolled Plate (thick) & SSR & A533B-Ht-1 & $1 \mathrm{E}-03$ & air & strain & tension & 427 & 1.0 & 0 \\
\hline 47 & Fatigue-SRX & A533B & Rolled Plate (thick) & SSR & A533B-Ht-1 & $1 \mathrm{E}-03$ & air & strain & tension & 427 & 1.0 & 0 \\
\hline 48 & Fatigue-SRX & A533B & Rolled Plate (thick) & SSR & A533B-Ht-1 & $1 \mathrm{E}-03$ & air & strain & tension & 427 & 1.0 & 0 \\
\hline 49 & Fatigue-SRX & A533B & Rolled Plate (thick) & SSR & A533B-Ht-1 & $1 \mathrm{E}-03$ & air & strain & comp. & 427 & 1.0 & 30 \\
\hline
\end{tabular}




Idaho National Laboratory
\begin{tabular}{|c|lll|}
\hline NEXT GENERATION NUCLEAR PLANT & Identifier: & PLN-2803 & \\
REACTOR PRESSURE VESSEL MATERIALS & Revision: & 0 & \\
RESEARCH AND DEVELOPMENT PLAN & Effective Date: & $04 / 30 / 08$ & Page: A-99 of A-102 \\
\hline
\end{tabular}

\begin{tabular}{|c|c|c|c|c|c|c|c|c|c|c|c|c|}
\hline Spec. \# & Test Type & Mat & Product Form & $\begin{array}{c}\text { Mat } \\
\text { Cond }\end{array}$ & Heat & $\begin{array}{c}\text { Strain } \\
\text { Rate } \\
(\mathrm{m} / \mathrm{m} / \mathrm{s})\end{array}$ & Env & $\begin{array}{c}\text { Hold } \\
\text { Cntrl } \\
\text { (stress } \\
\text { or } \\
\text { strain) }\end{array}$ & $\begin{array}{l}\text { Strain } \\
\text { Hold in } \\
\text { T/C }\end{array}$ & $\begin{array}{l}\text { Temp. } \\
\left({ }^{\circ} \mathrm{C}\right)\end{array}$ & $\begin{array}{c}\text { Strain } \\
\text { Range } \\
(\%)\end{array}$ & $\begin{array}{l}\text { Strain } \\
\text { Hold } \\
\text { Time } \\
(\mathrm{min}) \\
\end{array}$ \\
\hline 50 & Fatigue-SRX & A533B & Rolled Plate (thick) & SSR & A533B-Ht-1 & $1 \mathrm{E}-03$ & air & strain & comp. & 427 & 1.0 & 30 \\
\hline 51 & Fatigue-SRX & A533B & Rolled Plate (thick) & SSR & A533B-Ht-1 & $1 \mathrm{E}-03$ & air & strain & comp. & 427 & 1.0 & 30 \\
\hline 52 & Fatigue-SRX & A533B & Rolled Plate (thick) & SSR & A533B-Ht-1 & $1 \mathrm{E}-03$ & air & strain & comp. & 427 & 1.0 & 150 \\
\hline 53 & Fatigue-SRX & A533B & Rolled Plate (thick) & SSR & A533B-Ht-1 & $1 \mathrm{E}-03$ & air & strain & comp. & 427 & 1.0 & 150 \\
\hline 54 & Fatigue-SRX & A533B & Rolled Plate (thick) & SSR & A533B-Ht-1 & $1 \mathrm{E}-03$ & air & strain & comp. & 427 & 1.0 & 150 \\
\hline 55 & Fatigue-SRX & A533B & Rolled Plate (thick) & SSR & A533B-Ht-1 & $1 \mathrm{E}-03$ & air & strain & comp. & 427 & 1.0 & 30 \\
\hline 56 & Fatigue-SRX & A533B & Rolled Plate (thick) & SSR & A533B-Ht-1 & $1 \mathrm{E}-03$ & air & strain & comp. & 427 & 1.0 & 30 \\
\hline 57 & Fatigue-SRX & A533B & Rolled Plate (thick) & SSR & A533B-Ht-1 & $1 \mathrm{E}-03$ & air & strain & comp. & 427 & 1.0 & 30 \\
\hline 58 & Fatigue-SRX & A533B & Rolled Plate (thick) & SSR & A533B-Ht-1 & $1 \mathrm{E}-03$ & air & strain & N/A & 538 & 1.0 & 150 \\
\hline 59 & Fatigue-SRX & A533B & Rolled Plate (thick) & SSR & A533B-Ht-1 & $1 \mathrm{E}-03$ & air & strain & N/A & 538 & 1.0 & 150 \\
\hline 60 & Fatigue-SRX & A533B & Rolled Plate (thick) & SSR & A533B-Ht-1 & $1 \mathrm{E}-03$ & air & strain & $\mathrm{N} / \mathrm{A}$ & 538 & 1.0 & 150 \\
\hline 61 & Fatigue-SRX & A533B & Rolled Plate (thick) & SSR & A533B-Ht-1 & $1 \mathrm{E}-03$ & air & strain & tension & 538 & 1.0 & 0 \\
\hline 62 & Fatigue-SRX & A533B & Rolled Plate (thick) & SSR & A533B-Ht-1 & $1 \mathrm{E}-03$ & air & strain & tension & 538 & 1.0 & 0 \\
\hline 63 & Fatigue-SRX & A533B & Rolled Plate (thick) & SSR & A533B-Ht-1 & $1 \mathrm{E}-03$ & air & strain & tension & 538 & 1.0 & 0 \\
\hline 64 & Fatigue-SRX & A533B & Rolled Plate (thick) & SSR & A533B-Ht-1 & $1 \mathrm{E}-03$ & air & strain & tension & 538 & 1.0 & 30 \\
\hline 65 & Fatigue-SRX & A533B & Rolled Plate (thick) & SSR & A533B-Ht-1 & $1 \mathrm{E}-03$ & air & strain & tension & 538 & 1.0 & 30 \\
\hline 66 & Fatigue-SRX & A533B & Rolled Plate (thick) & SSR & A533B-Ht-1 & $1 \mathrm{E}-03$ & air & strain & tension & 538 & 1.0 & 30 \\
\hline 67 & Fatigue-SRX & A533B & Rolled Plate (thick) & SSR & A533B-Ht-1 & $1 \mathrm{E}-03$ & air & strain & comp. & 538 & 1.0 & 150 \\
\hline 68 & Fatigue-SRX & A533B & Rolled Plate (thick) & SSR & A533B-Ht-1 & $1 \mathrm{E}-03$ & air & strain & comp. & 538 & 1.0 & 150 \\
\hline 69 & Fatigue-SRX & A533B & Rolled Plate (thick) & SSR & A533B-Ht-1 & $1 \mathrm{E}-03$ & air & strain & comp. & 538 & 1.0 & 150 \\
\hline 70 & Fatigue-SRX & A533B & Rolled Plate (thick) & SSR & A533B-Ht-1 & $1 \mathrm{E}-03$ & air & strain & comp. & 538 & 1.0 & 30 \\
\hline 71 & Fatigue-SRX & A533B & Rolled Plate (thick) & SSR & A533B-Ht-1 & $1 \mathrm{E}-03$ & air & strain & comp. & 538 & 1.0 & 30 \\
\hline 72 & Fatigue-SRX & A533B & Rolled Plate (thick) & SSR & A533B-Ht-1 & $1 \mathrm{E}-03$ & air & strain & comp. & 538 & 1.0 & 30 \\
\hline
\end{tabular}




Idaho National Laboratory
\begin{tabular}{|c|lll|}
\hline NEXT GENERATION NUCLEAR PLANT & Identifier: & PLN-2803 & \\
REACTOR PRESSURE VESSEL MATERIALS & Revision: & 0 & \\
RESEARCH AND DEVELOPMENT PLAN & Effective Date: & $04 / 30 / 08$ & Page: A-100 of A-102 \\
\hline
\end{tabular}

\begin{tabular}{|c|c|c|c|c|c|c|c|c|c|c|c|c|c|c|}
\hline \multicolumn{15}{|c|}{ Table A33. SAW and SMAW Fatigue-SRX Tests in Air to Support Code Case N-499 } \\
\hline Spec. \# & Test Type & $\begin{array}{c}\text { Weld } \\
\text { Con- } \\
\text { sumable }\end{array}$ & $\begin{array}{l}\text { Section } \\
\text { Thickness } \\
(\mathrm{mm})\end{array}$ & $\begin{array}{l}\text { Weld } \\
\text { Process }\end{array}$ & $\begin{array}{c}\text { Base Metal } \\
\text { Heat }\end{array}$ & $\begin{array}{l}\text { Weld to } \\
\text { be } \\
\text { Tested }\end{array}$ & $\begin{array}{l}\text { Mat } \\
\text { Cond. }\end{array}$ & $\begin{array}{l}\text { Strain } \\
\text { Rate } \\
(\mathrm{m} / \mathrm{m} / \mathrm{s})\end{array}$ & Env & $\begin{array}{l}\text { Hold } \\
\text { Cntrl } \\
\text { (stress } \\
\text { or } \\
\text { strain) }\end{array}$ & $\begin{array}{c}\text { Strain } \\
\text { Hold } \\
\text { in T/C }\end{array}$ & $\begin{array}{l}\text { Temp. } \\
\left({ }^{\circ} \mathrm{C}\right)\end{array}$ & $\begin{array}{l}\text { Strain } \\
\text { Range } \\
(\%)\end{array}$ & $\begin{array}{l}\text { Strain } \\
\text { Hold } \\
\text { Time } \\
\text { (min) }\end{array}$ \\
\hline 1 & Fatigue-SRX & TBD & $\sim 250$ & SAW & A508-Ht-1 & X-Weld & SSR & $1 \mathrm{E}-03$ & air & strain & $\mathrm{N} / \mathrm{A}$ & 427 & 1.0 & 0 \\
\hline 2 & Fatigue-SRX & TBD & $\sim 250$ & SAW & A508-Ht-1 & X-Weld & SSR & $1 \mathrm{E}-03$ & air & strain & N/A & 427 & 1.0 & 0 \\
\hline 3 & Fatigue-SRX & TBD & $\sim 250$ & SAW & A508-Ht-1 & X-Weld & SSR & $1 \mathrm{E}-03$ & air & strain & N/A & 427 & 1.0 & 0 \\
\hline 4 & Fatigue-SRX & TBD & $\sim 250$ & SAW & A508-Ht-1 & X-Weld & SSR & $1 \mathrm{E}-03$ & air & strain & tension & 427 & 1.0 & 30 \\
\hline 5 & Fatigue-SRX & TBD & $\sim 250$ & SAW & A508-Ht-1 & X-Weld & SSR & $1 \mathrm{E}-03$ & air & strain & tension & 427 & 1.0 & 30 \\
\hline 6 & Fatigue-SRX & TBD & $\sim 250$ & SAW & A508-Ht-1 & X-Weld & SSR & $1 \mathrm{E}-03$ & air & strain & tension & 427 & 1.0 & 30 \\
\hline 7 & Fatigue-SRX & TBD & $\sim 250$ & SAW & A508-Ht-1 & X-Weld & SSR & $1 \mathrm{E}-03$ & air & strain & tension & 427 & 1.0 & 150 \\
\hline 8 & Fatigue-SRX & TBD & $\sim 250$ & SAW & A508-Ht-1 & X-Weld & SSR & $1 \mathrm{E}-03$ & air & strain & tension & 427 & 1.0 & 150 \\
\hline 9 & Fatigue-SRX & TBD & $\sim 250$ & SAW & A508-Ht-1 & X-Weld & SSR & $1 \mathrm{E}-03$ & air & strain & tension & 427 & 1.0 & 150 \\
\hline 10 & Fatigue-SRX & TBD & $\sim 250$ & SAW & A508-Ht-1 & X-Weld & SSR & $1 \mathrm{E}-03$ & air & strain & comp. & 427 & 1.0 & 30 \\
\hline 11 & Fatigue-SRX & TBD & $\sim 250$ & SAW & A508-Ht-1 & X-Weld & SSR & $1 \mathrm{E}-03$ & air & strain & comp. & 427 & 1.0 & 30 \\
\hline 12 & Fatigue-SRX & TBD & $\sim 250$ & SAW & A508-Ht-1 & X-Weld & SSR & $1 \mathrm{E}-03$ & air & strain & comp. & 427 & 1.0 & 30 \\
\hline 13 & Fatigue-SRX & TBD & $\sim 250$ & SAW & A508-Ht-1 & X-Weld & SSR & $1 \mathrm{E}-03$ & air & strain & comp. & 427 & 1.0 & 150 \\
\hline 14 & Fatigue-SRX & TBD & $\sim 250$ & SAW & A508-Ht-1 & X-Weld & SSR & $1 \mathrm{E}-03$ & air & strain & comp. & 427 & 1.0 & 150 \\
\hline 15 & Fatigue-SRX & TBD & $\sim 250$ & SAW & A508-Ht-1 & X-Weld & SSR & $1 \mathrm{E}-03$ & air & strain & comp. & 427 & 1.0 & 150 \\
\hline 16 & Fatigue-SRX & TBD & $\sim 50$ & SMAW & A508-Ht-1 & X-Weld & SSR & $1 \mathrm{E}-03$ & air & strain & $\mathrm{N} / \mathrm{A}$ & 538 & 1.0 & 0 \\
\hline 17 & Fatigue-SRX & TBD & $\sim 50$ & SMAW & A508-Ht-1 & X-Weld & SSR & $1 \mathrm{E}-03$ & air & strain & N/A & 538 & 1.0 & 0 \\
\hline 18 & Fatigue-SRX & TBD & $\sim 50$ & SMAW & A508-Ht-1 & X-Weld & SSR & $1 \mathrm{E}-03$ & air & strain & N/A & 538 & 1.0 & 0 \\
\hline 19 & Fatigue-SRX & TBD & $\sim 50$ & SMAW & A508-Ht-1 & X-Weld & SSR & $1 \mathrm{E}-03$ & air & strain & tension & 538 & 1.0 & 30 \\
\hline 20 & Fatigue-SRX & TBD & $\sim 50$ & SMAW & A508-Ht-1 & X-Weld & SSR & $1 \mathrm{E}-03$ & air & strain & tension & 538 & 1.0 & 30 \\
\hline 21 & Fatigue-SRX & TBD & $\sim 50$ & SMAW & A508-Ht-1 & X-Weld & SSR & $1 \mathrm{E}-03$ & air & strain & tension & 538 & 1.0 & 30 \\
\hline 22 & Fatigue-SRX & TBD & $\sim 50$ & SMAW & A508-Ht-1 & X-Weld & SSR & $1 \mathrm{E}-03$ & air & strain & tension & 538 & 1.0 & 150 \\
\hline 23 & Fatigue-SRX & TBD & $\sim 50$ & SMAW & A508-Ht-1 & X-Weld & SSR & $1 \mathrm{E}-03$ & air & strain & tension & 538 & 1.0 & 150 \\
\hline
\end{tabular}




Idaho National Laboratory
\begin{tabular}{|c|lll|}
\hline NEXT GENERATION NUCLEAR PLANT & Identifier: & PLN-2803 & \\
REACTOR PRESSURE VESSEL MATERIALS & Revision: & 0 & \\
RESEARCH AND DEVELOPMENT PLAN & Effective Date: & $04 / 30 / 08$ & Page: A-101 of A-102 \\
\hline
\end{tabular}

\begin{tabular}{|c|c|c|c|c|c|c|c|c|c|c|c|c|c|c|}
\hline Spec. \# & Test Type & $\begin{array}{c}\text { Weld } \\
\text { Con- } \\
\text { sumable }\end{array}$ & $\begin{array}{l}\text { Section } \\
\text { Thickness } \\
(\mathrm{mm})\end{array}$ & $\begin{array}{l}\text { Weld } \\
\text { Process }\end{array}$ & $\begin{array}{c}\text { Base Metal } \\
\text { Heat }\end{array}$ & $\begin{array}{l}\text { Weld to } \\
\text { be } \\
\text { Tested }\end{array}$ & $\begin{array}{l}\text { Mat } \\
\text { Cond. }\end{array}$ & $\begin{array}{c}\text { Strain } \\
\text { Rate } \\
(\mathrm{m} / \mathrm{m} / \mathrm{s})\end{array}$ & Env & $\begin{array}{l}\text { Hold } \\
\text { Cntrl } \\
\text { (stress } \\
\text { or } \\
\text { strain) }\end{array}$ & $\begin{array}{c}\text { Strain } \\
\text { Hold } \\
\text { in } \mathrm{T} / \mathrm{C}\end{array}$ & $\begin{array}{l}\text { Temp. } \\
\left({ }^{\circ} \mathrm{C}\right)\end{array}$ & $\begin{array}{c}\text { Strain } \\
\text { Range } \\
(\%)\end{array}$ & $\begin{array}{l}\text { Strain } \\
\text { Hold } \\
\text { Time } \\
(\mathrm{min})\end{array}$ \\
\hline 24 & Fatigue-SRX & TBD & $\sim 50$ & SMAW & A508-Ht-1 & X-Weld & SSR & $1 \mathrm{E}-03$ & air & strain & tension & 538 & 1.0 & 150 \\
\hline 25 & Fatigue-SRX & TBD & $\sim 50$ & SMAW & A508-Ht-1 & X-Weld & SSR & $1 \mathrm{E}-03$ & air & strain & comp. & 538 & 1.0 & 30 \\
\hline 26 & Fatigue-SRX & TBD & $\sim 50$ & SMAW & A508-Ht-1 & X-Weld & SSR & $1 \mathrm{E}-03$ & air & strain & comp. & 538 & 1.0 & 30 \\
\hline 27 & Fatigue-SRX & TBD & $\sim 50$ & SMAW & A508-Ht-1 & X-Weld & SSR & $1 \mathrm{E}-03$ & air & strain & comp. & 538 & 1.0 & 30 \\
\hline 28 & Fatigue-SRX & TBD & $\sim 50$ & SMAW & A508-Ht-1 & X-Weld & SSR & $1 \mathrm{E}-03$ & air & strain & comp. & 538 & 1.0 & 150 \\
\hline 29 & Fatigue-SRX & TBD & $\sim 50$ & SMAW & A508-Ht-1 & X-Weld & SSR & $1 \mathrm{E}-03$ & air & strain & comp. & 538 & 1.0 & 150 \\
\hline 30 & Fatigue-SRX & TBD & $\sim 50$ & SMAW & A508-Ht-1 & X-Weld & SSR & $1 \mathrm{E}-03$ & air & strain & comp. & 538 & 1.0 & 150 \\
\hline 31 & Fatigue-SRX & TBD & $\sim 250$ & SAW & A533B-Ht-1 & X-Weld & SSR & $1 \mathrm{E}-03$ & air & strain & N/A & 538 & 1.0 & 0 \\
\hline 32 & Fatigue-SRX & TBD & $\sim 250$ & SAW & A533B-Ht-1 & X-Weld & SSR & $1 \mathrm{E}-03$ & air & strain & N/A & 538 & 1.0 & 0 \\
\hline 33 & Fatigue-SRX & TBD & $\sim 250$ & SAW & A533B-Ht-1 & X-Weld & SSR & $1 \mathrm{E}-03$ & air & strain & N/A & 538 & 1.0 & 0 \\
\hline 34 & Fatigue-SRX & TBD & $\sim 250$ & SAW & A533B-Ht-1 & X-Weld & SSR & $1 \mathrm{E}-03$ & air & strain & tension & 538 & 1.0 & 30 \\
\hline 35 & Fatigue-SRX & TBD & $\sim 250$ & SAW & A533B-Ht-1 & X-Weld & SSR & $1 \mathrm{E}-03$ & air & strain & tension & 538 & 1.0 & 30 \\
\hline 36 & Fatigue-SRX & TBD & $\sim 250$ & SAW & A533B-Ht-1 & X-Weld & SSR & $1 \mathrm{E}-03$ & air & strain & tension & 538 & 1.0 & 30 \\
\hline 37 & Fatigue-SRX & TBD & $\sim 250$ & SAW & A533B-Ht-1 & X-Weld & SSR & $1 \mathrm{E}-03$ & air & strain & tension & 538 & 1.0 & 150 \\
\hline 38 & Fatigue-SRX & TBD & $\sim 250$ & SAW & A533B-Ht-1 & X-Weld & SSR & $1 \mathrm{E}-03$ & air & strain & tension & 538 & 1.0 & 150 \\
\hline 39 & Fatigue-SRX & TBD & $\sim 250$ & SAW & A533B-Ht-1 & X-Weld & SSR & $1 \mathrm{E}-03$ & air & strain & tension & 538 & 1.0 & 150 \\
\hline 40 & Fatigue-SRX & TBD & $\sim 250$ & SAW & A533B-Ht-1 & X-Weld & SSR & $1 \mathrm{E}-03$ & air & strain & comp. & 538 & 1.0 & 30 \\
\hline 41 & Fatigue-SRX & TBD & $\sim 250$ & SAW & A533B-Ht-1 & X-Weld & SSR & $1 \mathrm{E}-03$ & air & strain & comp. & 538 & 1.0 & 30 \\
\hline 42 & Fatigue-SRX & TBD & $\sim 250$ & SAW & A533B-Ht-1 & X-Weld & SSR & $1 \mathrm{E}-03$ & air & strain & comp. & 538 & 1.0 & 30 \\
\hline 43 & Fatigue-SRX & TBD & $\sim 250$ & SAW & A533B-Ht-1 & X-Weld & SSR & $1 \mathrm{E}-03$ & air & strain & comp. & 538 & 1.0 & 150 \\
\hline 44 & Fatigue-SRX & TBD & $\sim 250$ & SAW & A533B-Ht-1 & X-Weld & SSR & $1 \mathrm{E}-03$ & air & strain & comp. & 538 & 1.0 & 150 \\
\hline 45 & Fatigue-SRX & TBD & $\sim 250$ & SAW & A533B-Ht-1 & X-Weld & SSR & $1 \mathrm{E}-03$ & air & strain & comp. & 538 & 1.0 & 150 \\
\hline 46 & Fatigue-SRX & TBD & $\sim 50$ & SMAW & A533B-Ht-1 & X-Weld & SSR & $1 \mathrm{E}-03$ & air & strain & N/A & 427 & 1.0 & 0 \\
\hline 47 & Fatigue-SRX & TBD & $\sim 50$ & SMAW & A533B-Ht-1 & X-Weld & SSR & $1 \mathrm{E}-03$ & air & strain & N/A & 427 & 1.0 & 0 \\
\hline
\end{tabular}


Idaho National Laboratory

\begin{tabular}{|c|lll|}
\hline NEXT GENERATION NUCLEAR PLANT & Identifier: & PLN-2803 & \\
REACTOR PRESSURE VESSEL MATERIALS & Revision: & 0 & \\
RESEARCH AND DEVELOPMENT PLAN & Effective Date: & $04 / 30 / 08$ & Page: A-102 of A-102 \\
\hline
\end{tabular}

\begin{tabular}{|c|c|c|c|c|c|c|c|c|c|c|c|c|c|c|}
\hline \multicolumn{15}{|c|}{ Table A33. SAW and SMAW Fatigue-SRX Tests in Air to Support Code Case N-499 } \\
\hline Spec. \# & Test Type & $\begin{array}{c}\text { Weld } \\
\text { Con- } \\
\text { sumable }\end{array}$ & $\begin{array}{l}\text { Section } \\
\text { Thickness } \\
(\mathrm{mm})\end{array}$ & $\begin{array}{c}\text { Weld } \\
\text { Process }\end{array}$ & $\begin{array}{c}\text { Base Metal } \\
\text { Heat }\end{array}$ & $\begin{array}{c}\text { Weld to } \\
\text { be } \\
\text { Tested }\end{array}$ & $\begin{array}{l}\text { Mat } \\
\text { Cond. }\end{array}$ & $\begin{array}{c}\text { Strain } \\
\text { Rate } \\
(\mathrm{m} / \mathrm{m} / \mathrm{s})\end{array}$ & Env & $\begin{array}{l}\text { Hold } \\
\text { Cntrl } \\
\text { (stress } \\
\text { or } \\
\text { strain) }\end{array}$ & $\begin{array}{l}\text { Strain } \\
\text { Hold } \\
\text { in } \mathrm{T} / \mathrm{C}\end{array}$ & $\begin{array}{l}\text { Temp. } \\
\left({ }^{\circ} \mathrm{C}\right)\end{array}$ & $\begin{array}{c}\text { Strain } \\
\text { Range } \\
(\%)\end{array}$ & $\begin{array}{l}\text { Strain } \\
\text { Hold } \\
\text { Time } \\
\text { (min) }\end{array}$ \\
\hline 48 & Fatigue-SRX & TBD & $\sim 50$ & SMAW & A533B-Ht-1 & X-Weld & SSR & $1 \mathrm{E}-03$ & air & strain & N/A & 427 & 1.0 & 0 \\
\hline 49 & Fatigue-SRX & TBD & $\sim 50$ & SMAW & A533B-Ht-1 & X-Weld & SSR & $1 \mathrm{E}-03$ & air & strain & tension & 427 & 1.0 & 30 \\
\hline 50 & Fatigue-SRX & TBD & $\sim 50$ & SMAW & A533B-Ht-1 & X-Weld & SSR & $1 \mathrm{E}-03$ & air & strain & tension & 427 & 1.0 & 30 \\
\hline 51 & Fatigue-SRX & TBD & $\sim 50$ & SMAW & A533B-Ht-1 & X-Weld & SSR & $1 \mathrm{E}-03$ & air & strain & tension & 427 & 1.0 & 30 \\
\hline 52 & Fatigue-SRX & TBD & $\sim 50$ & SMAW & A533B-Ht-1 & X-Weld & SSR & $1 \mathrm{E}-03$ & air & strain & tension & 427 & 1.0 & 150 \\
\hline 53 & Fatigue-SRX & TBD & $\sim 50$ & SMAW & A533B-Ht-1 & X-Weld & SSR & $1 \mathrm{E}-03$ & air & strain & tension & 427 & 1.0 & 150 \\
\hline 54 & Fatigue-SRX & TBD & $\sim 50$ & SMAW & A533B-Ht-1 & X-Weld & SSR & $1 \mathrm{E}-03$ & air & strain & tension & 427 & 1.0 & 150 \\
\hline 55 & Fatigue-SRX & TBD & $\sim 50$ & SMAW & A533B-Ht-1 & X-Weld & SSR & $1 \mathrm{E}-03$ & air & strain & comp. & 427 & 1.0 & 30 \\
\hline 56 & Fatigue-SRX & TBD & $\sim 50$ & SMAW & A533B-Ht-1 & X-Weld & SSR & $1 \mathrm{E}-03$ & air & strain & comp. & 427 & 1.0 & 30 \\
\hline 57 & Fatigue-SRX & TBD & $\sim 50$ & SMAW & A533B-Ht-1 & X-Weld & SSR & $1 \mathrm{E}-03$ & air & strain & comp. & 427 & 1.0 & 30 \\
\hline 58 & Fatigue-SRX & TBD & $\sim 50$ & SMAW & A533B-Ht-1 & X-Weld & SSR & $1 \mathrm{E}-03$ & air & strain & comp. & 427 & 1.0 & 150 \\
\hline 59 & Fatigue-SRX & TBD & $\sim 50$ & SMAW & A533B-Ht-1 & X-Weld & SSR & $1 \mathrm{E}-03$ & air & strain & comp. & 427 & 1.0 & 150 \\
\hline 60 & Fatigue-SRX & TBD & $\sim 50$ & SMAW & A533B-Ht-1 & X-Weld & SSR & $1 \mathrm{E}-03$ & air & strain & comp. & 427 & 1.0 & 150 \\
\hline
\end{tabular}




\begin{tabular}{c|lll|} 
NEXT GENERATION NUCLEAR PLANT & Identifier: & PLN-2803 & \\
REACTOR PRESSURE VESSEL MATERIALS & Revision: & 0 & \\
RESEARCH AND DEVELOPMENT PLAN & Effective Date: & $04 / 30 / 08$ & Page: B-1 of B-68
\end{tabular}

\section{Appendix B}

\section{Test Matrices for Hot Vessel Option}




\begin{tabular}{c|lll} 
NEXT GENERATION NUCLEAR PLANT & Identifier: & PLN-2803 & \\
REACTOR PRESSURE VESSEL MATERIALS & Revision: & 0 & \\
RESEARCH AND DEVELOPMENT PLAN & Effective Date: & $04 / 30 / 08$ & Page: B-2 of B-68
\end{tabular}




Idaho National Laboratory
\begin{tabular}{|c|lll|}
\hline NEXT GENERATION NUCLEAR PLANT & Identifier: & PLN-2803 & \\
REACTOR PRESSURE VESSEL MATERIALS & Revision: & 0 & \\
RESEARCH AND DEVELOPMENT PLAN & Effective Date: & $04 / 30 / 08$ & Page: B-3 of B-68 \\
\hline
\end{tabular}

\begin{tabular}{|c|c|c|c|c|c|c|c|c|}
\hline Spec. \# & Test Type & Material & Product Form & Mat Cond ${ }^{(1)}$ & Heat & Env & Temp. $\left({ }^{\circ} \mathrm{C}\right)$ & Applied Stress (MPa) \\
\hline 1 & Creep Rupture & Grade 91 & Forging (thick) & $\mathrm{AR}$ & Heat-1 & air & 425 & 400 \\
\hline 2 & Creep Rupture & Grade 91 & Forging (thick) & $\mathrm{AR}$ & Heat-1 & air & 425 & 400 \\
\hline 3 & Creep Rupture & Grade 91 & Forging (thick) & $\mathrm{AR}$ & Heat-1 & air & 425 & 375 \\
\hline 4 & Creep Rupture & Grade 91 & Forging (thick) & $\mathrm{AR}$ & Heat-1 & air & 425 & 375 \\
\hline 5 & Creep Rupture & Grade 91 & Forging (thick) & AR + Aged & Heat-1 & air & 425 & 400 \\
\hline 6 & Creep Rupture & Grade 91 & Forging (thick) & AR + Aged & Heat-1 & air & 425 & 400 \\
\hline 7 & Creep Rupture & Grade 91 & Forging (thick) & AR + Aged & Heat-1 & air & 425 & 375 \\
\hline 8 & Creep Rupture & Grade 91 & Forging (thick) & AR + Aged & Heat-1 & air & 425 & 375 \\
\hline 9 & Creep Rupture & Grade 91 & Forging (thick) & Sim. PWHT & Heat-1 & air & 425 & 400 \\
\hline 10 & Creep Rupture & Grade 91 & Forging (thick) & Sim. PWHT & Heat-1 & air & 425 & 400 \\
\hline 11 & Creep Rupture & Grade 91 & Forging (thick) & Sim. PWHT & Heat-1 & air & 425 & 375 \\
\hline 12 & Creep Rupture & Grade 91 & Forging (thick) & Sim. PWHT & Heat-1 & air & 425 & 375 \\
\hline 13 & Creep Rupture & Grade 91 & Forging (thick) & Sim. PWHT + Aged & Heat-1 & air & 425 & 400 \\
\hline 14 & Creep Rupture & Grade 91 & Forging (thick) & Sim. PWHT + Aged & Heat-1 & air & 425 & 400 \\
\hline 15 & Creep Rupture & Grade 91 & Forging (thick) & Sim. PWHT + Aged & Heat-1 & air & 425 & 375 \\
\hline 16 & Creep Rupture & Grade 91 & Forging (thick) & Sim. PWHT + Aged & Heat-1 & air & 425 & 375 \\
\hline 17 & Creep Rupture & Grade 91 & Forging (thick) & $\mathrm{AR}$ & Heat-2 & air & 425 & 400 \\
\hline 18 & Creep Rupture & Grade 91 & Forging (thick) & AR & Heat-2 & air & 425 & 400 \\
\hline 19 & Creep Rupture & Grade 91 & Forging (thick) & $\mathrm{AR}$ & Heat-2 & air & 425 & 375 \\
\hline 20 & Creep Rupture & Grade 91 & Forging (thick) & $\mathrm{AR}$ & Heat-2 & air & 425 & 375 \\
\hline 21 & Creep Rupture & Grade 91 & Forging (thick) & AR + Aged & Heat-2 & air & 425 & 400 \\
\hline 22 & Creep Rupture & Grade 91 & Forging (thick) & $\mathrm{AR}+$ Aged & Heat-2 & air & 425 & 400 \\
\hline 23 & Creep Rupture & Grade 91 & Forging (thick) & AR + Aged & Heat-2 & air & 425 & 375 \\
\hline 24 & Creep Rupture & Grade 91 & Forging (thick) & AR + Aged & Heat-2 & air & 425 & 375 \\
\hline 25 & Creep Rupture & Grade 91 & Forging (thick) & Sim. PWHT & Heat-2 & air & 425 & 400 \\
\hline 26 & Creep Rupture & Grade 91 & Forging (thick) & Sim. PWHT & Heat-2 & air & 425 & 400 \\
\hline
\end{tabular}




Idaho National Laboratory
\begin{tabular}{|c|lll|}
\hline NEXT GENERATION NUCLEAR PLANT & Identifier: & PLN-2803 & \\
REACTOR PRESSURE VESSEL MATERIALS & Revision: & 0 & \\
RESEARCH AND DEVELOPMENT PLAN & Effective Date: & $04 / 30 / 08$ & Page: B-4 of B-68 \\
\hline
\end{tabular}

\begin{tabular}{|c|c|c|c|c|c|c|c|c|}
\hline Spec.\# & Test Type & Material & Product Form & Mat Cond ${ }^{(1)}$ & Heat & Env & Temp. $\left({ }^{\circ} \mathrm{C}\right)$ & Applied Stress (MPa) \\
\hline 27 & Creep Rupture & Grade 91 & Forging (thick) & Sim. PWHT & Heat-2 & air & 425 & 375 \\
\hline 28 & Creep Rupture & Grade 91 & Forging (thick) & Sim. PWHT & Heat-2 & air & 425 & 375 \\
\hline 29 & Creep Rupture & Grade 91 & Forging (thick) & Sim. PWHT + Aged & Heat-2 & air & 425 & 400 \\
\hline 30 & Creep Rupture & Grade 91 & Forging (thick) & Sim. PWHT + Aged & Heat-2 & air & 425 & 400 \\
\hline 31 & Creep Rupture & Grade 91 & Forging (thick) & Sim. PWHT + Aged & Heat-2 & air & 425 & 375 \\
\hline 32 & Creep Rupture & Grade 91 & Forging (thick) & Sim. PWHT + Aged & Heat-2 & air & 425 & 375 \\
\hline 33 & Creep Rupture & Grade 91 & Forging (thick) & $\mathrm{AR}$ & Heat-3 & air & 425 & 400 \\
\hline 34 & Creep Rupture & Grade 91 & Forging (thick) & $\mathrm{AR}$ & Heat-3 & air & 425 & 400 \\
\hline 35 & Creep Rupture & Grade 91 & Forging (thick) & $\mathrm{AR}$ & Heat-3 & air & 425 & 375 \\
\hline 36 & Creep Rupture & Grade 91 & Forging (thick) & $\mathrm{AR}$ & Heat-3 & air & 425 & 375 \\
\hline 37 & Creep Rupture & Grade 91 & Forging (thick) & AR + Aged & Heat-3 & air & 425 & 400 \\
\hline 38 & Creep Rupture & Grade 91 & Forging (thick) & $\mathrm{AR}+$ Aged & Heat-3 & air & 425 & 400 \\
\hline 39 & Creep Rupture & Grade 91 & Forging (thick) & AR + Aged & Heat-3 & air & 425 & 375 \\
\hline 40 & Creep Rupture & Grade 91 & Forging (thick) & AR + Aged & Heat-3 & air & 425 & 375 \\
\hline 41 & Creep Rupture & Grade 91 & Forging (thick) & Sim. PWHT & Heat-3 & air & 425 & 400 \\
\hline 42 & Creep Rupture & Grade 91 & Forging (thick) & Sim. PWHT & Heat-3 & air & 425 & 400 \\
\hline 43 & Creep Rupture & Grade 91 & Forging (thick) & Sim. PWHT & Heat-3 & air & 425 & 375 \\
\hline 44 & Creep Rupture & Grade 91 & Forging (thick) & Sim. PWHT & Heat-3 & air & 425 & 375 \\
\hline 45 & Creep Rupture & Grade 91 & Forging (thick) & Sim. PWHT + Aged & Heat-3 & air & 425 & 400 \\
\hline 46 & Creep Rupture & Grade 91 & Forging (thick) & Sim. PWHT + Aged & Heat-3 & air & 425 & 400 \\
\hline 47 & Creep Rupture & Grade 91 & Forging (thick) & Sim. PWHT + Aged & Heat-3 & air & 425 & 375 \\
\hline 48 & Creep Rupture & Grade 91 & Forging (thick) & Sim. PWHT + Aged & Heat-3 & air & 425 & 375 \\
\hline 49 & Creep Rupture & Grade 91 & Rolled Plate (thick) & $\mathrm{AR}$ & Heat-1 & air & 425 & 400 \\
\hline 50 & Creep Rupture & Grade 91 & Rolled Plate (thick) & $\mathrm{AR}$ & Heat-1 & air & 425 & 400 \\
\hline 51 & Creep Rupture & Grade 91 & Rolled Plate (thick) & $\mathrm{AR}$ & Heat-1 & air & 425 & 375 \\
\hline 52 & Creep Rupture & Grade 91 & Rolled Plate (thick) & $\mathrm{AR}$ & Heat-1 & air & 425 & 375 \\
\hline 53 & Creep Rupture & Grade 91 & Rolled Plate (thick) & AR + Aged & Heat-1 & air & 425 & 400 \\
\hline
\end{tabular}




Idaho National Laboratory
\begin{tabular}{|c|lll|}
\hline NEXT GENERATION NUCLEAR PLANT & Identifier: & PLN-2803 & \\
REACTOR PRESSURE VESSEL MATERIALS & Revision: & 0 & \\
RESEARCH AND DEVELOPMENT PLAN & Effective Date: & $04 / 30 / 08$ & Page: B-5 of B-68 \\
\hline
\end{tabular}

\begin{tabular}{|c|c|c|c|c|c|c|c|c|}
\hline Spec.\# & Test Type & Material & Product Form & Mat Cond ${ }^{(1)}$ & Heat & Env & Temp. $\left({ }^{\circ} \mathrm{C}\right)$ & Applied Stress (MPa) \\
\hline 54 & Creep Rupture & Grade 91 & Rolled Plate (thick) & $\mathrm{AR}+$ Aged & Heat-1 & air & 425 & 400 \\
\hline 55 & Creep Rupture & Grade 91 & Rolled Plate (thick) & AR + Aged & Heat-1 & air & 425 & 375 \\
\hline 56 & Creep Rupture & Grade 91 & Rolled Plate (thick) & AR + Aged & Heat-1 & air & 425 & 375 \\
\hline 57 & Creep Rupture & Grade 91 & Rolled Plate (thick) & Sim. PWHT & Heat-1 & air & 425 & 400 \\
\hline 58 & Creep Rupture & Grade 91 & Rolled Plate (thick) & Sim. PWHT & Heat-1 & air & 425 & 400 \\
\hline 59 & Creep Rupture & Grade 91 & Rolled Plate (thick) & Sim. PWHT & Heat-1 & air & 425 & 375 \\
\hline 60 & Creep Rupture & Grade 91 & Rolled Plate (thick) & Sim. PWHT & Heat-1 & air & 425 & 375 \\
\hline 61 & Creep Rupture & Grade 91 & Rolled Plate (thick) & Sim. PWHT + Aged & Heat-1 & air & 425 & 400 \\
\hline 62 & Creep Rupture & Grade 91 & Rolled Plate (thick) & Sim. PWHT + Aged & Heat-1 & air & 425 & 400 \\
\hline 63 & Creep Rupture & Grade 91 & Rolled Plate (thick) & Sim. PWHT + Aged & Heat-1 & air & 425 & 375 \\
\hline 64 & Creep Rupture & Grade 91 & Rolled Plate (thick) & Sim. PWHT + Aged & Heat-1 & air & 425 & 375 \\
\hline 65 & Creep Rupture & Grade 91 & Rolled Plate (thick) & $\mathrm{AR}$ & Heat-2 & air & 425 & 400 \\
\hline 66 & Creep Rupture & Grade 91 & Rolled Plate (thick) & $\mathrm{AR}$ & Heat-2 & air & 425 & 400 \\
\hline 67 & Creep Rupture & Grade 91 & Rolled Plate (thick) & $\mathrm{AR}$ & Heat-2 & air & 425 & 375 \\
\hline 68 & Creep Rupture & Grade 91 & Rolled Plate (thick) & $\mathrm{AR}$ & Heat-2 & air & 425 & 375 \\
\hline 69 & Creep Rupture & Grade 91 & Rolled Plate (thick) & AR + Aged & Heat-2 & air & 425 & 400 \\
\hline 70 & Creep Rupture & Grade 91 & Rolled Plate (thick) & AR + Aged & Heat-2 & air & 425 & 400 \\
\hline 71 & Creep Rupture & Grade 91 & Rolled Plate (thick) & AR + Aged & Heat-2 & air & 425 & 375 \\
\hline 72 & Creep Rupture & Grade 91 & Rolled Plate (thick) & AR + Aged & Heat-2 & air & 425 & 375 \\
\hline 73 & Creep Rupture & Grade 91 & Rolled Plate (thick) & Sim. PWHT & Heat-2 & air & 425 & 400 \\
\hline 74 & Creep Rupture & Grade 91 & Rolled Plate (thick) & Sim. PWHT & Heat-2 & air & 425 & 400 \\
\hline 75 & Creep Rupture & Grade 91 & Rolled Plate (thick) & Sim. PWHT & Heat-2 & air & 425 & 375 \\
\hline 76 & Creep Rupture & Grade 91 & Rolled Plate (thick) & Sim. PWHT & Heat-2 & air & 425 & 375 \\
\hline 77 & Creep Rupture & Grade 91 & Rolled Plate (thick) & Sim. PWHT + Aged & Heat-2 & air & 425 & 400 \\
\hline 78 & Creep Rupture & Grade 91 & Rolled Plate (thick) & Sim. PWHT + Aged & Heat-2 & air & 425 & 400 \\
\hline 79 & Creep Rupture & Grade 91 & Rolled Plate (thick) & Sim. PWHT + Aged & Heat-2 & air & 425 & 375 \\
\hline 80 & Creep Rupture & Grade 91 & Rolled Plate (thick) & Sim. PWHT + Aged & Heat-2 & air & 425 & 375 \\
\hline
\end{tabular}




Idaho National Laboratory
\begin{tabular}{|c|lll|}
\hline NEXT GENERATION NUCLEAR PLANT & Identifier: & PLN-2803 & \\
REACTOR PRESSURE VESSEL MATERIALS & Revision: & 0 & \\
RESEARCH AND DEVELOPMENT PLAN & Effective Date: & $04 / 30 / 08$ & Page: B-6 of B- 68 \\
\hline
\end{tabular}

\begin{tabular}{|c|c|c|c|c|c|c|c|c|}
\hline \multicolumn{7}{|c|}{ Table B1. Creep Tests at $425^{\circ}$ C to Support Determination of Negligible Creep Temperature for Grade 91 Steel } \\
\hline Spec. \# & Test Type & Material & Product Form & Mat Cond ${ }^{(1)}$ & Heat & Env & Temp. $\left({ }^{\circ}\right.$ C) & Applied Stress (MPa) \\
\hline 81 & Creep Rupture & Grade 91 & Rolled Plate (thick) & AR & Heat-3 & air & 425 & 400 \\
\hline 82 & Creep Rupture & Grade 91 & Rolled Plate (thick) & AR & Heat-3 & air & 425 & 400 \\
\hline 83 & Creep Rupture & Grade 91 & Rolled Plate (thick) & AR & Heat-3 & air & 425 & 375 \\
\hline 84 & Creep Rupture & Grade 91 & Rolled Plate (thick) & AR & Heat-3 & air & 425 & 375 \\
\hline 85 & Creep Rupture & Grade 91 & Rolled Plate (thick) & AR + Aged & Heat-3 & air & 425 & 400 \\
\hline 86 & Creep Rupture & Grade 91 & Rolled Plate (thick) & AR + Aged & Heat-3 & air & 425 & 400 \\
\hline 87 & Creep Rupture & Grade 91 & Rolled Plate (thick) & AR + Aged & Heat-3 & air & 425 & \\
\hline 88 & Creep Rupture & Grade 91 & Rolled Plate (thick) & AR + Aged & Heat-3 & air & 425 & \\
\hline 89 & Creep Rupture & Grade 91 & Rolled Plate (thick) & Sim. PWHT & Heat-3 & air & 425 & 375 \\
\hline 90 & Creep Rupture & Grade 91 & Rolled Plate (thick) & Sim. PWHT & Heat-3 & air & 425 & 400 \\
\hline 91 & Creep Rupture & Grade 91 & Rolled Plate (thick) & Sim. PWHT & Heat-3 & air & 425 & 400 \\
\hline 92 & Creep Rupture & Grade 91 & Rolled Plate (thick) & Sim. PWHT & Heat-3 & air & 425 & 375 \\
\hline 93 & Creep Rupture & Grade 91 & Rolled Plate (thick) & Sim. PWHT + Aged & Heat-3 & air & 425 & 375 \\
\hline 94 & Creep Rupture & Grade 91 & Rolled Plate (thick) & Sim. PWHT + Aged & Heat-3 & air & 425 & 400 \\
\hline 95 & Creep Rupture & Grade 91 & Rolled Plate (thick) & Sim. PWHT + Aged & Heat-3 & air & 425 & 400 \\
\hline 96 & Creep Rupture & Grade 91 & Rolled Plate (thick) & Sim. PWHT + Aged & Heat-3 & air & 425 & 375 \\
\hline Footnote (1): AR= As Received, Aged = Aging at 650C for 20,000 h & & & & & \\
\hline
\end{tabular}




Idaho National Laboratory
\begin{tabular}{|c|lll|}
\hline NEXT GENERATION NUCLEAR PLANT & Identifier: & PLN-2803 & \\
REACTOR PRESSURE VESSEL MATERIALS & Revision: & 0 & \\
RESEARCH AND DEVELOPMENT PLAN & Effective Date: & $04 / 30 / 08$ & Page: B-7 of B- 68 \\
\hline
\end{tabular}

\begin{tabular}{|c|c|c|c|c|c|c|c|c|}
\hline Spec. \# & Test Type & Material & Product Form & Mat Cond & Heat & Env & Temp. $\left({ }^{\circ} \mathrm{C}\right)$ & Applied Stress (MPa) \\
\hline 1 & Creep Rupture & Grade 91 & Forging (thick) & $\mathrm{AR}$ & Heat-1 & air & 450 & 425 \\
\hline 2 & Creep Rupture & Grade 91 & Forging (thick) & $\mathrm{AR}$ & Heat-1 & air & 450 & 425 \\
\hline 3 & Creep Rupture & Grade 91 & Forging (thick) & Sim. PWHT & Heat-1 & air & 450 & 425 \\
\hline 4 & Creep Rupture & Grade 91 & Forging (thick) & Sim. PWHT & Heat-1 & air & 450 & 425 \\
\hline 5 & Creep Rupture & Grade 91 & Forging (thick) & $\mathrm{AR}$ & Heat-1 & air & 450 & 400 \\
\hline 6 & Creep Rupture & Grade 91 & Forging (thick) & $\mathrm{AR}$ & Heat-1 & air & 450 & 400 \\
\hline 7 & Creep Rupture & Grade 91 & Forging (thick) & Sim. PWHT & Heat-1 & air & 450 & 400 \\
\hline 8 & Creep Rupture & Grade 91 & Forging (thick) & Sim. PWHT & Heat-1 & air & 450 & 400 \\
\hline 9 & Creep Rupture & Grade 91 & Forging (thick) & Creep-Fatigue Softened & Heat-1 & air & 450 & 400 \\
\hline 10 & Creep Rupture & Grade 91 & Forging (thick) & Creep-Fatigue Softened & Heat-1 & air & 450 & 400 \\
\hline 11 & Creep Rupture & Grade 91 & Forging (thick) & Sim. PWHT & Heat-1 & air & 450 & 375 \\
\hline 12 & Creep Rupture & Grade 91 & Forging (thick) & Sim. PWHT & Heat-1 & air & 450 & 375 \\
\hline 13 & Creep Rupture & Grade 91 & Forging (thick) & $\mathrm{AR}$ & Heat-1 & air & 450 & 350 \\
\hline 14 & Creep Rupture & Grade 91 & Forging (thick) & $\mathrm{AR}$ & Heat-1 & air & 450 & 350 \\
\hline 15 & Creep Rupture & Grade 91 & Forging (thick) & Sim. PWHT & Heat-1 & air & 450 & 350 \\
\hline 16 & Creep Rupture & Grade 91 & Forging (thick) & Sim. PWHT & Heat-1 & air & 450 & 350 \\
\hline 17 & Creep Rupture & Grade 91 & Forging (thick) & Sim. PWHT & Heat-1 & air & 450 & 325 \\
\hline 18 & Creep Rupture & Grade 91 & Forging (thick) & Sim. PWHT & Heat-1 & air & 450 & 325 \\
\hline 19 & Creep Rupture & Grade 91 & Forging (thick) & $\mathrm{AR}$ & Heat-2 & air & 450 & 425 \\
\hline 20 & Creep Rupture & Grade 91 & Forging (thick) & $\mathrm{AR}$ & Heat-2 & air & 450 & 425 \\
\hline 21 & Creep Rupture & Grade 91 & Forging (thick) & Sim. PWHT & Heat-2 & air & 450 & 425 \\
\hline 22 & Creep Rupture & Grade 91 & Forging (thick) & Sim. PWHT & Heat-2 & air & 450 & 425 \\
\hline 23 & Creep Rupture & Grade 91 & Forging (thick) & $\mathrm{AR}$ & Heat-2 & air & 450 & 400 \\
\hline 24 & Creep Rupture & Grade 91 & Forging (thick) & $\mathrm{AR}$ & Heat-2 & air & 450 & 400 \\
\hline 25 & Creep Rupture & Grade 91 & Forging (thick) & Sim. PWHT & Heat-2 & air & 450 & 400 \\
\hline 26 & Creep Rupture & Grade 91 & Forging (thick) & Sim. PWHT & Heat-2 & air & 450 & 400 \\
\hline 27 & Creep Rupture & Grade 91 & Forging (thick) & Creep-Fatigue Softened & Heat-2 & air & 450 & 400 \\
\hline
\end{tabular}




Idaho National Laboratory
\begin{tabular}{|c|lll|}
\hline NEXT GENERATION NUCLEAR PLANT & Identifier: & PLN-2803 & \\
REACTOR PRESSURE VESSEL MATERIALS & Revision: & 0 & \\
RESEARCH AND DEVELOPMENT PLAN & Effective Date: & $04 / 30 / 08$ & Page: B-8 of B- 68 \\
\hline
\end{tabular}

\begin{tabular}{|c|c|c|c|c|c|c|c|c|}
\hline Spec.\# & Test Type & Material & Product Form & Mat Cond & Heat & Env & Temp. $\left({ }^{\circ} \mathrm{C}\right)$ & Applied Stress (MPa) \\
\hline 28 & Creep Rupture & Grade 91 & Forging (thick) & Creep-Fatigue Softened & Heat-2 & air & 450 & 400 \\
\hline 29 & Creep Rupture & Grade 91 & Forging (thick) & Sim. PWHT & Heat-2 & air & 450 & 375 \\
\hline 30 & Creep Rupture & Grade 91 & Forging (thick) & Sim. PWHT & Heat-2 & air & 450 & 375 \\
\hline 31 & Creep Rupture & Grade 91 & Forging (thick) & $\mathrm{AR}$ & Heat-2 & air & 450 & 350 \\
\hline 32 & Creep Rupture & Grade 91 & Forging (thick) & $\mathrm{AR}$ & Heat-2 & air & 450 & 350 \\
\hline 33 & Creep Rupture & Grade 91 & Forging (thick) & Sim. PWHT & Heat-2 & air & 450 & 350 \\
\hline 34 & Creep Rupture & Grade 91 & Forging (thick) & Sim. PWHT & Heat-2 & air & 450 & 350 \\
\hline 35 & Creep Rupture & Grade 91 & Forging (thick) & Sim. PWHT & Heat-2 & air & 450 & 325 \\
\hline 36 & Creep Rupture & Grade 91 & Forging (thick) & Sim. PWHT & Heat-2 & air & 450 & 325 \\
\hline 37 & Creep Rupture & Grade 91 & Forging (thick) & $\mathrm{AR}$ & Heat-3 & air & 450 & 425 \\
\hline 38 & Creep Rupture & Grade 91 & Forging (thick) & $\mathrm{AR}$ & Heat-3 & air & 450 & 425 \\
\hline 39 & Creep Rupture & Grade 91 & Forging (thick) & Sim. PWHT & Heat-3 & air & 450 & 425 \\
\hline 40 & Creep Rupture & Grade 91 & Forging (thick) & Sim. PWHT & Heat-3 & air & 450 & 425 \\
\hline 41 & Creep Rupture & Grade 91 & Forging (thick) & $\mathrm{AR}$ & Heat-3 & air & 450 & 400 \\
\hline 42 & Creep Rupture & Grade 91 & Forging (thick) & $\mathrm{AR}$ & Heat-3 & air & 450 & 400 \\
\hline 43 & Creep Rupture & Grade 91 & Forging (thick) & Sim. PWHT & Heat-3 & air & 450 & 400 \\
\hline 44 & Creep Rupture & Grade 91 & Forging (thick) & Sim. PWHT & Heat-3 & air & 450 & 400 \\
\hline 45 & Creep Rupture & Grade 91 & Forging (thick) & Creep-Fatigue Softened & Heat-3 & air & 450 & 400 \\
\hline 46 & Creep Rupture & Grade 91 & Forging (thick) & Creep-Fatigue Softened & Heat-3 & air & 450 & 400 \\
\hline 47 & Creep Rupture & Grade 91 & Forging (thick) & Sim. PWHT & Heat-3 & air & 450 & 375 \\
\hline 48 & Creep Rupture & Grade 91 & Forging (thick) & Sim. PWHT & Heat-3 & air & 450 & 375 \\
\hline 49 & Creep Rupture & Grade 91 & Forging (thick) & $\mathrm{AR}$ & Heat-3 & air & 450 & 350 \\
\hline 50 & Creep Rupture & Grade 91 & Forging (thick) & $\mathrm{AR}$ & Heat-3 & air & 450 & 350 \\
\hline 51 & Creep Rupture & Grade 91 & Forging (thick) & Sim. PWHT & Heat-3 & air & 450 & 350 \\
\hline 52 & Creep Rupture & Grade 91 & Forging (thick) & Sim. PWHT & Heat-3 & air & 450 & 350 \\
\hline 53 & Creep Rupture & Grade 91 & Forging (thick) & Sim. PWHT & Heat-3 & air & 450 & 325 \\
\hline 54 & Creep Rupture & Grade 91 & Forging (thick) & Sim. PWHT & Heat-3 & air & 450 & 325 \\
\hline 55 & Creep Rupture & Grade 91 & Rolled Plate (thick) & $\mathrm{AR}$ & Heat-1 & air & 450 & 425 \\
\hline
\end{tabular}




Idaho National Laboratory
\begin{tabular}{|c|lll|}
\hline NEXT GENERATION NUCLEAR PLANT & Identifier: & PLN-2803 & \\
REACTOR PRESSURE VESSEL MATERIALS & Revision: & 0 & \\
RESEARCH AND DEVELOPMENT PLAN & Effective Date: & $04 / 30 / 08$ & Page: B-9 of B-68 \\
\hline
\end{tabular}

\begin{tabular}{|c|c|c|c|c|c|c|c|c|}
\hline Spec.\# & Test Type & Material & Product Form & Mat Cond & Heat & Env & Temp. $\left({ }^{\circ} \mathrm{C}\right)$ & Applied Stress (MPa) \\
\hline 56 & Creep Rupture & Grade 91 & Rolled Plate (thick) & $\mathrm{AR}$ & Heat-1 & air & 450 & 425 \\
\hline 57 & Creep Rupture & Grade 91 & Rolled Plate (thick) & Sim. PWHT & Heat-1 & air & 450 & 425 \\
\hline 58 & Creep Rupture & Grade 91 & Rolled Plate (thick) & Sim. PWHT & Heat-1 & air & 450 & 425 \\
\hline 59 & Creep Rupture & Grade 91 & Rolled Plate (thick) & $\mathrm{AR}$ & Heat-1 & air & 450 & 400 \\
\hline 60 & Creep Rupture & Grade 91 & Rolled Plate (thick) & $\mathrm{AR}$ & Heat-1 & air & 450 & 400 \\
\hline 61 & Creep Rupture & Grade 91 & Rolled Plate (thick) & Sim. PWHT & Heat-1 & air & 450 & 400 \\
\hline 62 & Creep Rupture & Grade 91 & Rolled Plate (thick) & Sim. PWHT & Heat-1 & air & 450 & 400 \\
\hline 63 & Creep Rupture & Grade 91 & Rolled Plate (thick) & Creep-Fatigue Softened & Heat-1 & air & 450 & 400 \\
\hline 64 & Creep Rupture & Grade 91 & Rolled Plate (thick) & Creep-Fatigue Softened & Heat-1 & air & 450 & 400 \\
\hline 65 & Creep Rupture & Grade 91 & Rolled Plate (thick) & Sim. PWHT & Heat-1 & air & 450 & 375 \\
\hline 66 & Creep Rupture & Grade 91 & Rolled Plate (thick) & Sim. PWHT & Heat-1 & air & 450 & 375 \\
\hline 67 & Creep Rupture & Grade 91 & Rolled Plate (thick) & $\mathrm{AR}$ & Heat-1 & air & 450 & 350 \\
\hline 68 & Creep Rupture & Grade 91 & Rolled Plate (thick) & $\mathrm{AR}$ & Heat-1 & air & 450 & 350 \\
\hline 69 & Creep Rupture & Grade 91 & Rolled Plate (thick) & Sim. PWHT & Heat-1 & air & 450 & 350 \\
\hline 70 & Creep Rupture & Grade 91 & Rolled Plate (thick) & Sim. PWHT & Heat-1 & air & 450 & 350 \\
\hline 71 & Creep Rupture & Grade 91 & Rolled Plate (thick) & Sim. PWHT & Heat-1 & air & 450 & 325 \\
\hline 72 & Creep Rupture & Grade 91 & Rolled Plate (thick) & Sim. PWHT & Heat-1 & air & 450 & 325 \\
\hline 73 & Creep Rupture & Grade 91 & Rolled Plate (thick) & $\mathrm{AR}$ & Heat-2 & air & 450 & 425 \\
\hline 74 & Creep Rupture & Grade 91 & Rolled Plate (thick) & $\mathrm{AR}$ & Heat-2 & air & 450 & 425 \\
\hline 75 & Creep Rupture & Grade 91 & Rolled Plate (thick) & Sim. PWHT & Heat-2 & air & 450 & 425 \\
\hline 76 & Creep Rupture & Grade 91 & Rolled Plate (thick) & Sim. PWHT & Heat-2 & air & 450 & 425 \\
\hline 77 & Creep Rupture & Grade 91 & Rolled Plate (thick) & $\mathrm{AR}$ & Heat-2 & air & 450 & 400 \\
\hline 78 & Creep Rupture & Grade 91 & Rolled Plate (thick) & $\mathrm{AR}$ & Heat-2 & air & 450 & 400 \\
\hline 79 & Creep Rupture & Grade 91 & Rolled Plate (thick) & Sim. PWHT & Heat-2 & air & 450 & 400 \\
\hline 80 & Creep Rupture & Grade 91 & Rolled Plate (thick) & Sim. PWHT & Heat-2 & air & 450 & 400 \\
\hline 81 & Creep Rupture & Grade 91 & Rolled Plate (thick) & Creep-Fatigue Softened & Heat-2 & air & 450 & 400 \\
\hline 82 & Creep Rupture & Grade 91 & Rolled Plate (thick) & Creep-Fatigue Softened & Heat-2 & air & 450 & 400 \\
\hline 83 & Creep Rupture & Grade 91 & Rolled Plate (thick) & Sim. PWHT & Heat-2 & air & 450 & 375 \\
\hline
\end{tabular}




Idaho National Laboratory
\begin{tabular}{|c|lll|}
\hline NEXT GENERATION NUCLEAR PLANT & Identifier: & PLN-2803 & \\
REACTOR PRESSURE VESSEL MATERIALS & Revision: & 0 & \\
RESEARCH AND DEVELOPMENT PLAN & Effective Date: & $04 / 30 / 08$ & Page: B-10 of B- 68 \\
\hline
\end{tabular}

\begin{tabular}{|c|c|c|c|c|c|c|c|c|}
\hline Spec. \# & Test Type & Material & Product Form & Mat Cond & Heat & Env & Temp. $\left({ }^{\circ} \mathrm{C}\right)$ & Applied Stress (MPa) \\
\hline 84 & Creep Rupture & Grade 91 & Rolled Plate (thick) & Sim. PWHT & Heat-2 & air & 450 & 375 \\
\hline 85 & Creep Rupture & Grade 91 & Rolled Plate (thick) & $\mathrm{AR}$ & Heat-2 & air & 450 & 350 \\
\hline 86 & Creep Rupture & Grade 91 & Rolled Plate (thick) & $\mathrm{AR}$ & Heat-2 & air & 450 & 350 \\
\hline 87 & Creep Rupture & Grade 91 & Rolled Plate (thick) & Sim. PWHT & Heat-2 & air & 450 & 350 \\
\hline 88 & Creep Rupture & Grade 91 & Rolled Plate (thick) & Sim. PWHT & Heat-2 & air & 450 & 350 \\
\hline 89 & Creep Rupture & Grade 91 & Rolled Plate (thick) & Sim. PWHT & Heat-2 & air & 450 & 325 \\
\hline 90 & Creep Rupture & Grade 91 & Rolled Plate (thick) & Sim. PWHT & Heat-2 & air & 450 & 325 \\
\hline 91 & Creep Rupture & Grade 91 & Rolled Plate (thick) & $\mathrm{AR}$ & Heat-3 & air & 450 & 425 \\
\hline 92 & Creep Rupture & Grade 91 & Rolled Plate (thick) & $\mathrm{AR}$ & Heat-3 & air & 450 & 425 \\
\hline 93 & Creep Rupture & Grade 91 & Rolled Plate (thick) & Sim. PWHT & Heat-3 & air & 450 & 425 \\
\hline 94 & Creep Rupture & Grade 91 & Rolled Plate (thick) & Sim. PWHT & Heat-3 & air & 450 & 425 \\
\hline 95 & Creep Rupture & Grade 91 & Rolled Plate (thick) & $\mathrm{AR}$ & Heat-3 & air & 450 & 400 \\
\hline 96 & Creep Rupture & Grade 91 & Rolled Plate (thick) & $\mathrm{AR}$ & Heat-3 & air & 450 & 400 \\
\hline 97 & Creep Rupture & Grade 91 & Rolled Plate (thick) & Sim. PWHT & Heat-3 & air & 450 & 400 \\
\hline 98 & Creep Rupture & Grade 91 & Rolled Plate (thick) & Sim. PWHT & Heat-3 & air & 450 & 400 \\
\hline 99 & Creep Rupture & Grade 91 & Rolled Plate (thick) & Creep-Fatigue Softened & Heat-3 & air & 450 & 400 \\
\hline 100 & Creep Rupture & Grade 91 & Rolled Plate (thick) & Creep-Fatigue Softened & Heat-3 & air & 450 & 400 \\
\hline 101 & Creep Rupture & Grade 91 & Rolled Plate (thick) & Sim. PWHT & Heat-3 & air & 450 & 375 \\
\hline 102 & Creep Rupture & Grade 91 & Rolled Plate (thick) & Sim. PWHT & Heat-3 & air & 450 & 375 \\
\hline 103 & Creep Rupture & Grade 91 & Rolled Plate (thick) & $\mathrm{AR}$ & Heat-3 & air & 450 & 350 \\
\hline 104 & Creep Rupture & Grade 91 & Rolled Plate (thick) & $\mathrm{AR}$ & Heat-3 & air & 450 & 350 \\
\hline 105 & Creep Rupture & Grade 91 & Rolled Plate (thick) & Sim. PWHT & Heat-3 & air & 450 & 350 \\
\hline 106 & Creep Rupture & Grade 91 & Rolled Plate (thick) & Sim. PWHT & Heat-3 & air & 450 & 350 \\
\hline 107 & Creep Rupture & Grade 91 & Rolled Plate (thick) & Sim. PWHT & Heat-3 & air & 450 & 325 \\
\hline
\end{tabular}




Idaho National Laboratory
\begin{tabular}{|c|lll|}
\hline NEXT GENERATION NUCLEAR PLANT & Identifier: & PLN-2803 & \\
REACTOR PRESSURE VESSEL MATERIALS & Revision: & 0 & \\
RESEARCH AND DEVELOPMENT PLAN & Effective Date: & $04 / 30 / 08$ & Page: B-11 of B- 68 \\
\hline
\end{tabular}

\begin{tabular}{|c|c|c|c|c|c|c|c|c|}
\hline Spec. \# & Test Type & Material & Product Form & Mat Cond & Heat & Env & Temp. $\left({ }^{\circ} \mathrm{C}\right)$ & Applied Stress (MPa) \\
\hline 1 & Creep Rupture & Grade 91 & Forging (thick) & $\mathrm{AR}$ & Heat-1 & air & 475 & 375 \\
\hline 2 & Creep Rupture & Grade 91 & Forging (thick) & $\mathrm{AR}$ & Heat-1 & air & 475 & 375 \\
\hline 3 & Creep Rupture & Grade 91 & Forging (thick) & Sim. PWHT & Heat-1 & air & 475 & 375 \\
\hline 4 & Creep Rupture & Grade 91 & Forging (thick) & Sim. PWHT & Heat-1 & air & 475 & 375 \\
\hline 5 & Creep Rupture & Grade 91 & Forging (thick) & $\mathrm{AR}$ & Heat-1 & air & 475 & 350 \\
\hline 6 & Creep Rupture & Grade 91 & Forging (thick) & $\mathrm{AR}$ & Heat-1 & air & 475 & 350 \\
\hline 7 & Creep Rupture & Grade 91 & Forging (thick) & Sim. PWHT & Heat-1 & air & 475 & 350 \\
\hline 8 & Creep Rupture & Grade 91 & Forging (thick) & Sim. PWHT & Heat-1 & air & 475 & 350 \\
\hline 9 & Creep Rupture & Grade 91 & Forging (thick) & Creep-Fatigue Softened & Heat-1 & air & 475 & 350 \\
\hline 10 & Creep Rupture & Grade 91 & Forging (thick) & Creep-Fatigue Softened & Heat-1 & air & 475 & 350 \\
\hline 11 & Creep Rupture & Grade 91 & Forging (thick) & Sim. PWHT & Heat-1 & air & 475 & 325 \\
\hline 12 & Creep Rupture & Grade 91 & Forging (thick) & Sim. PWHT & Heat-1 & air & 475 & 325 \\
\hline 13 & Creep Rupture & Grade 91 & Forging (thick) & $\mathrm{AR}$ & Heat-1 & air & 475 & 300 \\
\hline 14 & Creep Rupture & Grade 91 & Forging (thick) & $\mathrm{AR}$ & Heat-1 & air & 475 & 300 \\
\hline 15 & Creep Rupture & Grade 91 & Forging (thick) & Sim. PWHT & Heat-1 & air & 475 & 300 \\
\hline 16 & Creep Rupture & Grade 91 & Forging (thick) & Sim. PWHT & Heat-1 & air & 475 & 300 \\
\hline 17 & Creep Rupture & Grade 91 & Forging (thick) & Sim. PWHT & Heat-1 & air & 475 & 275 \\
\hline 18 & Creep Rupture & Grade 91 & Forging (thick) & Sim. PWHT & Heat-1 & air & 475 & 275 \\
\hline 19 & Creep Rupture & Grade 91 & Forging (thick) & $\mathrm{AR}$ & Heat-2 & air & 475 & 375 \\
\hline 20 & Creep Rupture & Grade 91 & Forging (thick) & $\mathrm{AR}$ & Heat-2 & air & 475 & 375 \\
\hline 21 & Creep Rupture & Grade 91 & Forging (thick) & Sim. PWHT & Heat-2 & air & 475 & 375 \\
\hline 22 & Creep Rupture & Grade 91 & Forging (thick) & Sim. PWHT & Heat-2 & air & 475 & 375 \\
\hline 23 & Creep Rupture & Grade 91 & Forging (thick) & $\mathrm{AR}$ & Heat-2 & air & 475 & 350 \\
\hline 24 & Creep Rupture & Grade 91 & Forging (thick) & $\mathrm{AR}$ & Heat-2 & air & 475 & 350 \\
\hline 25 & Creep Rupture & Grade 91 & Forging (thick) & Sim. PWHT & Heat-2 & air & 475 & 350 \\
\hline 26 & Creep Rupture & Grade 91 & Forging (thick) & Sim. PWHT & Heat-2 & air & 475 & 350 \\
\hline 27 & Creep Rupture & Grade 91 & Forging (thick) & Creep-Fatigue Softened & Heat-2 & air & 475 & 350 \\
\hline
\end{tabular}




Idaho National Laboratory
\begin{tabular}{|c|lll|}
\hline NEXT GENERATION NUCLEAR PLANT & Identifier: & PLN-2803 & \\
REACTOR PRESSURE VESSEL MATERIALS & Revision: & 0 & \\
RESEARCH AND DEVELOPMENT PLAN & Effective Date: & $04 / 30 / 08$ & Page: B-12 of B- 68 \\
\hline
\end{tabular}

Table B3. Creep Tests at $475^{\circ} \mathrm{C}$ to Support Determination of Negligible Creep Temperature for Grade 91 Steel,

\begin{tabular}{|c|c|c|c|c|c|c|c|c|}
\hline Spec. \# & Test Type & Material & Product Form & Mat Cond & Heat & Env & Temp. $\left({ }^{\circ} \mathrm{C}\right)$ & Applied Stress (MPa) \\
\hline 28 & Creep Rupture & Grade 91 & Forging (thick) & Creep-Fatigue Softened & Heat-2 & air & 475 & 350 \\
\hline 29 & Creep Rupture & Grade 91 & Forging (thick) & Sim. PWHT & Heat-2 & air & 475 & 325 \\
\hline 30 & Creep Rupture & Grade 91 & Forging (thick) & Sim. PWHT & Heat-2 & air & 475 & 325 \\
\hline 31 & Creep Rupture & Grade 91 & Forging (thick) & $\mathrm{AR}$ & Heat-2 & air & 475 & 300 \\
\hline 32 & Creep Rupture & Grade 91 & Forging (thick) & $\mathrm{AR}$ & Heat-2 & air & 475 & 300 \\
\hline 33 & Creep Rupture & Grade 91 & Forging (thick) & Sim. PWHT & Heat-2 & air & 475 & 300 \\
\hline 34 & Creep Rupture & Grade 91 & Forging (thick) & Sim. PWHT & Heat-2 & air & 475 & 300 \\
\hline 35 & Creep Rupture & Grade 91 & Forging (thick) & Sim. PWHT & Heat-2 & air & 475 & 275 \\
\hline 36 & Creep Rupture & Grade 91 & Forging (thick) & Sim. PWHT & Heat-2 & air & 475 & 275 \\
\hline 37 & Creep Rupture & Grade 91 & Forging (thick) & $\mathrm{AR}$ & Heat-3 & air & 475 & 375 \\
\hline 38 & Creep Rupture & Grade 91 & Forging (thick) & $\mathrm{AR}$ & Heat-3 & air & 475 & 375 \\
\hline 39 & Creep Rupture & Grade 91 & Forging (thick) & Sim. PWHT & Heat-3 & air & 475 & 375 \\
\hline 40 & Creep Rupture & Grade 91 & Forging (thick) & Sim. PWHT & Heat-3 & air & 475 & 375 \\
\hline 41 & Creep Rupture & Grade 91 & Forging (thick) & $\mathrm{AR}$ & Heat-3 & air & 475 & 350 \\
\hline 42 & Creep Rupture & Grade 91 & Forging (thick) & $\mathrm{AR}$ & Heat-3 & air & 475 & 350 \\
\hline 43 & Creep Rupture & Grade 91 & Forging (thick) & Sim. PWHT & Heat-3 & air & 475 & 350 \\
\hline 44 & Creep Rupture & Grade 91 & Forging (thick) & Sim. PWHT & Heat-3 & air & 475 & 350 \\
\hline 45 & Creep Rupture & Grade 91 & Forging (thick) & Creep-Fatigue Softened & Heat-3 & air & 475 & 350 \\
\hline 46 & Creep Rupture & Grade 91 & Forging (thick) & Creep-Fatigue Softened & Heat-3 & air & 475 & 350 \\
\hline 47 & Creep Rupture & Grade 91 & Forging (thick) & Sim. PWHT & Heat-3 & air & 475 & 325 \\
\hline 48 & Creep Rupture & Grade 91 & Forging (thick) & Sim. PWHT & Heat-3 & air & 475 & 325 \\
\hline 49 & Creep Rupture & Grade 91 & Forging (thick) & $\mathrm{AR}$ & Heat-3 & air & 475 & 300 \\
\hline 50 & Creep Rupture & Grade 91 & Forging (thick) & $\mathrm{AR}$ & Heat-3 & air & 475 & 300 \\
\hline 51 & Creep Rupture & Grade 91 & Forging (thick) & Sim. PWHT & Heat-3 & air & 475 & 300 \\
\hline 52 & Creep Rupture & Grade 91 & Forging (thick) & Sim. PWHT & Heat-3 & air & 475 & 300 \\
\hline 53 & Creep Rupture & Grade 91 & Forging (thick) & Sim. PWHT & Heat-3 & air & 475 & 275 \\
\hline 54 & Creep Rupture & Grade 91 & Forging (thick) & Sim. PWHT & Heat-3 & air & 475 & 275 \\
\hline 55 & Creep Rupture & Grade 91 & Rolled Plate (thick) & AR & Heat-1 & air & 475 & 375 \\
\hline
\end{tabular}




Idaho National Laboratory
\begin{tabular}{|c|lll|}
\hline NEXT GENERATION NUCLEAR PLANT & Identifier: & PLN-2803 & \\
REACTOR PRESSURE VESSEL MATERIALS & Revision: & 0 & \\
RESEARCH AND DEVELOPMENT PLAN & Effective Date: & $04 / 30 / 08$ & Page: B-13 of B- 68 \\
\hline
\end{tabular}

Table B3. Creep Tests at $475^{\circ} \mathrm{C}$ to Support Determination of Negligible Creep Temperature for Grade 91 Steel,

\begin{tabular}{|c|c|c|c|c|c|c|c|c|}
\hline Spec. \# & Test Type & Material & Product Form & Mat Cond & Heat & Env & Temp. $\left({ }^{\circ} \mathrm{C}\right)$ & Applied Stress (MPa) \\
\hline 56 & Creep Rupture & Grade 91 & Rolled Plate (thick) & $\mathrm{AR}$ & Heat-1 & air & 475 & 375 \\
\hline 57 & Creep Rupture & Grade 91 & Rolled Plate (thick) & Sim. PWHT & Heat-1 & air & 475 & 375 \\
\hline 58 & Creep Rupture & Grade 91 & Rolled Plate (thick) & Sim. PWHT & Heat-1 & air & 475 & 375 \\
\hline 59 & Creep Rupture & Grade 91 & Rolled Plate (thick) & $\mathrm{AR}$ & Heat-1 & air & 475 & 350 \\
\hline 60 & Creep Rupture & Grade 91 & Rolled Plate (thick) & $\mathrm{AR}$ & Heat-1 & air & 475 & 350 \\
\hline 61 & Creep Rupture & Grade 91 & Rolled Plate (thick) & Sim. PWHT & Heat-1 & air & 475 & 350 \\
\hline 62 & Creep Rupture & Grade 91 & Rolled Plate (thick) & Sim. PWHT & Heat-1 & air & 475 & 350 \\
\hline 63 & Creep Rupture & Grade 91 & Rolled Plate (thick) & Creep-Fatigue Softened & Heat-1 & air & 475 & 350 \\
\hline 64 & Creep Rupture & Grade 91 & Rolled Plate (thick) & Creep-Fatigue Softened & Heat-1 & air & 475 & 350 \\
\hline 65 & Creep Rupture & Grade 91 & Rolled Plate (thick) & Sim. PWHT & Heat-1 & air & 475 & 325 \\
\hline 66 & Creep Rupture & Grade 91 & Rolled Plate (thick) & Sim. PWHT & Heat-1 & air & 475 & 325 \\
\hline 67 & Creep Rupture & Grade 91 & Rolled Plate (thick) & $\mathrm{AR}$ & Heat-1 & air & 475 & 300 \\
\hline 68 & Creep Rupture & Grade 91 & Rolled Plate (thick) & $\mathrm{AR}$ & Heat-1 & air & 475 & 300 \\
\hline 69 & Creep Rupture & Grade 91 & Rolled Plate (thick) & Sim. PWHT & Heat-1 & air & 475 & 300 \\
\hline 70 & Creep Rupture & Grade 91 & Rolled Plate (thick) & Sim. PWHT & Heat-1 & air & 475 & 300 \\
\hline 71 & Creep Rupture & Grade 91 & Rolled Plate (thick) & Sim. PWHT & Heat-1 & air & 475 & 275 \\
\hline 72 & Creep Rupture & Grade 91 & Rolled Plate (thick) & Sim. PWHT & Heat-1 & air & 475 & 275 \\
\hline 73 & Creep Rupture & Grade 91 & Rolled Plate (thick) & $\mathrm{AR}$ & Heat-2 & air & 475 & 375 \\
\hline 74 & Creep Rupture & Grade 91 & Rolled Plate (thick) & $\mathrm{AR}$ & Heat-2 & air & 475 & 375 \\
\hline 75 & Creep Rupture & Grade 91 & Rolled Plate (thick) & Sim. PWHT & Heat-2 & air & 475 & 375 \\
\hline 76 & Creep Rupture & Grade 91 & Rolled Plate (thick) & Sim. PWHT & Heat-2 & air & 475 & 375 \\
\hline 77 & Creep Rupture & Grade 91 & Rolled Plate (thick) & $\mathrm{AR}$ & Heat-2 & air & 475 & 350 \\
\hline 78 & Creep Rupture & Grade 91 & Rolled Plate (thick) & $\mathrm{AR}$ & Heat-2 & air & 475 & 350 \\
\hline 79 & Creep Rupture & Grade 91 & Rolled Plate (thick) & Sim. PWHT & Heat-2 & air & 475 & 350 \\
\hline 80 & Creep Rupture & Grade 91 & Rolled Plate (thick) & Sim. PWHT & Heat-2 & air & 475 & 350 \\
\hline 81 & Creep Rupture & Grade 91 & Rolled Plate (thick) & Creep-Fatigue Softened & Heat-2 & air & 475 & 350 \\
\hline 82 & Creep Rupture & Grade 91 & Rolled Plate (thick) & Creep-Fatigue Softened & Heat-2 & air & 475 & 350 \\
\hline 83 & Creep Rupture & Grade 91 & Rolled Plate (thick) & Sim. PWHT & Heat-2 & air & 475 & 325 \\
\hline
\end{tabular}




Idaho National Laboratory
\begin{tabular}{|c|lll|}
\hline NEXT GENERATION NUCLEAR PLANT & Identifier: & PLN-2803 & \\
REACTOR PRESSURE VESSEL MATERIALS & Revision: & 0 & \\
RESEARCH AND DEVELOPMENT PLAN & Effective Date: & $04 / 30 / 08$ & Page: B-14 of B- 68 \\
\hline
\end{tabular}

Table B3. Creep Tests at $475^{\circ} \mathrm{C}$ to Support Determination of Negligible Creep Temperature for Grade 91 Steel,

\begin{tabular}{|c|c|c|c|c|c|c|c|c|}
\hline Spec. \# & Test Type & Material & Product Form & Mat Cond & Heat & Env & Temp. $\left({ }^{\circ} \mathrm{C}\right)$ & Applied Stress (MPa) \\
\hline 84 & Creep Rupture & Grade 91 & Rolled Plate (thick) & Sim. PWHT & Heat-2 & air & 475 & 325 \\
\hline 85 & Creep Rupture & Grade 91 & Rolled Plate (thick) & $\mathrm{AR}$ & Heat-2 & air & 475 & 300 \\
\hline 86 & Creep Rupture & Grade 91 & Rolled Plate (thick) & $\mathrm{AR}$ & Heat-2 & air & 475 & 300 \\
\hline 87 & Creep Rupture & Grade 91 & Rolled Plate (thick) & Sim. PWHT & Heat-2 & air & 475 & 300 \\
\hline 88 & Creep Rupture & Grade 91 & Rolled Plate (thick) & Sim. PWHT & Heat-2 & air & 475 & 300 \\
\hline 89 & Creep Rupture & Grade 91 & Rolled Plate (thick) & Sim. PWHT & Heat-2 & air & 475 & 275 \\
\hline 90 & Creep Rupture & Grade 91 & Rolled Plate (thick) & Sim. PWHT & Heat-2 & air & 475 & 275 \\
\hline 91 & Creep Rupture & Grade 91 & Rolled Plate (thick) & $\mathrm{AR}$ & Heat-3 & air & 475 & 375 \\
\hline 92 & Creep Rupture & Grade 91 & Rolled Plate (thick) & $\mathrm{AR}$ & Heat-3 & air & 475 & 375 \\
\hline 93 & Creep Rupture & Grade 91 & Rolled Plate (thick) & Sim. PWHT & Heat-3 & air & 475 & 375 \\
\hline 94 & Creep Rupture & Grade 91 & Rolled Plate (thick) & Sim. PWHT & Heat-3 & air & 475 & 375 \\
\hline 95 & Creep Rupture & Grade 91 & Rolled Plate (thick) & $\mathrm{AR}$ & Heat-3 & air & 475 & 350 \\
\hline 96 & Creep Rupture & Grade 91 & Rolled Plate (thick) & $\mathrm{AR}$ & Heat-3 & air & 475 & 350 \\
\hline 97 & Creep Rupture & Grade 91 & Rolled Plate (thick) & Sim. PWHT & Heat-3 & air & 475 & 350 \\
\hline 98 & Creep Rupture & Grade 91 & Rolled Plate (thick) & Sim. PWHT & Heat-3 & air & 475 & 350 \\
\hline 99 & Creep Rupture & Grade 91 & Rolled Plate (thick) & Creep-Fatigue Softened & Heat-3 & air & 475 & 350 \\
\hline 100 & Creep Rupture & Grade 91 & Rolled Plate (thick) & Creep-Fatigue Softened & Heat-3 & air & 475 & 350 \\
\hline 101 & Creep Rupture & Grade 91 & Rolled Plate (thick) & Sim. PWHT & Heat-3 & air & 475 & 325 \\
\hline 102 & Creep Rupture & Grade 91 & Rolled Plate (thick) & Sim. PWHT & Heat-3 & air & 475 & 325 \\
\hline 103 & Creep Rupture & Grade 91 & Rolled Plate (thick) & $\mathrm{AR}$ & Heat-3 & air & 475 & 300 \\
\hline 104 & Creep Rupture & Grade 91 & Rolled Plate (thick) & $\mathrm{AR}$ & Heat-3 & air & 475 & 300 \\
\hline 105 & Creep Rupture & Grade 91 & Rolled Plate (thick) & Sim. PWHT & Heat-3 & air & 475 & 300 \\
\hline 106 & Creep Rupture & Grade 91 & Rolled Plate (thick) & Sim. PWHT & Heat-3 & air & 475 & 300 \\
\hline 107 & Creep Rupture & Grade 91 & Rolled Plate (thick) & Sim. PWHT & Heat-3 & air & 475 & 275 \\
\hline 108 & Creep Rupture & Grade 91 & Rolled Plate (thick) & Sim. PWHT & Heat-3 & air & 475 & 275 \\
\hline
\end{tabular}




Idaho National Laboratory
\begin{tabular}{|c|lll|}
\hline NEXT GENERATION NUCLEAR PLANT & Identifier: & PLN-2803 & \\
REACTOR PRESSURE VESSEL MATERIALS & Revision: & 0 & \\
RESEARCH AND DEVELOPMENT PLAN & Effective Date: & $04 / 30 / 08$ & Page: B-15 of B- 68 \\
\hline
\end{tabular}

\begin{tabular}{|c|c|c|c|c|c|c|c|c|}
\hline Spec. \# & Test Type & Material & Product Form & Mat Cond & Heat & Env & Temp. $\left({ }^{\circ} \mathrm{C}\right)$ & Applied Stress (MPa) \\
\hline 1 & Creep Rupture & Grade 91 & Forging (thick) & $\mathrm{AR}$ & Heat-1 & air & 500 & 330 \\
\hline 2 & Creep Rupture & Grade 91 & Forging (thick) & $\mathrm{AR}$ & Heat-1 & air & 500 & 330 \\
\hline 3 & Creep Rupture & Grade 91 & Forging (thick) & Sim. PWHT & Heat-1 & air & 500 & 330 \\
\hline 4 & Creep Rupture & Grade 91 & Forging (thick) & Sim. PWHT & Heat-1 & air & 500 & 330 \\
\hline 5 & Creep Rupture & Grade 91 & Forging (thick) & Sim. PWHT & Heat-1 & air & 500 & 290 \\
\hline 6 & Creep Rupture & Grade 91 & Forging (thick) & Sim. PWHT & Heat-1 & air & 500 & 290 \\
\hline 7 & Creep Rupture & Grade 91 & Forging (thick) & Creep-Fatigue Softened & Heat-1 & air & 500 & 290 \\
\hline 8 & Creep Rupture & Grade 91 & Forging (thick) & Creep-Fatigue Softened & Heat-1 & air & 500 & 290 \\
\hline 9 & Creep Rupture & Grade 91 & Forging (thick) & $\mathrm{AR}$ & Heat-1 & air & 500 & 260 \\
\hline 10 & Creep Rupture & Grade 91 & Forging (thick) & $\mathrm{AR}$ & Heat-1 & air & 500 & 260 \\
\hline 11 & Creep Rupture & Grade 91 & Forging (thick) & Sim. PWHT & Heat-1 & air & 500 & 260 \\
\hline 12 & Creep Rupture & Grade 91 & Forging (thick) & Sim. PWHT & Heat-1 & air & 500 & 260 \\
\hline 13 & Creep Rupture & Grade 91 & Forging (thick) & $\mathrm{AR}$ & Heat-1 & air & 525 & 280 \\
\hline 14 & Creep Rupture & Grade 91 & Forging (thick) & $\mathrm{AR}$ & Heat-1 & air & 525 & 280 \\
\hline 15 & Creep Rupture & Grade 91 & Forging (thick) & Sim. PWHT & Heat-1 & air & 525 & 280 \\
\hline 16 & Creep Rupture & Grade 91 & Forging (thick) & Sim. PWHT & Heat-1 & air & 525 & 280 \\
\hline 17 & Creep Rupture & Grade 91 & Forging (thick) & Sim. PWHT & Heat-1 & air & 525 & 250 \\
\hline 18 & Creep Rupture & Grade 91 & Forging (thick) & Sim. PWHT & Heat-1 & air & 525 & 250 \\
\hline 19 & Creep Rupture & Grade 91 & Forging (thick) & Creep-Fatigue Softened & Heat-1 & air & 525 & 250 \\
\hline 20 & Creep Rupture & Grade 91 & Forging (thick) & Creep-Fatigue Softened & Heat-1 & air & 525 & 250 \\
\hline 21 & Creep Rupture & Grade 91 & Forging (thick) & $\mathrm{AR}$ & Heat-1 & air & 525 & 220 \\
\hline 22 & Creep Rupture & Grade 91 & Forging (thick) & $\mathrm{AR}$ & Heat-1 & air & 525 & 220 \\
\hline 23 & Creep Rupture & Grade 91 & Forging (thick) & Sim. PWHT & Heat-1 & air & 525 & 220 \\
\hline 24 & Creep Rupture & Grade 91 & Forging (thick) & Sim. PWHT & Heat-1 & air & 525 & 220 \\
\hline 25 & Creep Rupture & Grade 91 & Forging (thick) & $\mathrm{AR}$ & Heat-2 & air & 500 & 330 \\
\hline 26 & Creep Rupture & Grade 91 & Forging (thick) & AR & Heat-2 & air & 500 & 330 \\
\hline
\end{tabular}




Idaho National Laboratory
\begin{tabular}{|c|lll|}
\hline NEXT GENERATION NUCLEAR PLANT & Identifier: & PLN-2803 & \\
REACTOR PRESSURE VESSEL MATERIALS & Revision: & 0 & \\
RESEARCH AND DEVELOPMENT PLAN & Effective Date: & $04 / 30 / 08$ & Page: B-16 of B-68 \\
\hline
\end{tabular}

\begin{tabular}{|c|c|c|c|c|c|c|c|c|}
\hline \multicolumn{9}{|c|}{ Table B4. Creep Tests to Extend Grade 91 Steel Database } \\
\hline Spec. \# & Test Type & Material & Product Form & Mat Cond & Heat & Env & Temp. $\left({ }^{\circ} \mathrm{C}\right)$ & Applied Stress (MPa) \\
\hline 27 & Creep Rupture & Grade 91 & Forging (thick) & Sim. PWHT & Heat-2 & air & 500 & 330 \\
\hline 28 & Creep Rupture & Grade 91 & Forging (thick) & Sim. PWHT & Heat-2 & air & 500 & 330 \\
\hline 29 & Creep Rupture & Grade 91 & Forging (thick) & Sim. PWHT & Heat-2 & air & 500 & 290 \\
\hline 30 & Creep Rupture & Grade 91 & Forging (thick) & Sim. PWHT & Heat-2 & air & 500 & 290 \\
\hline 31 & Creep Rupture & Grade 91 & Forging (thick) & Creep-Fatigue Softened & Heat-2 & air & 500 & 290 \\
\hline 32 & Creep Rupture & Grade 91 & Forging (thick) & Creep-Fatigue Softened & Heat-2 & air & 500 & 290 \\
\hline 33 & Creep Rupture & Grade 91 & Forging (thick) & $\mathrm{AR}$ & Heat-2 & air & 500 & 260 \\
\hline 34 & Creep Rupture & Grade 91 & Forging (thick) & $\mathrm{AR}$ & Heat-2 & air & 500 & 260 \\
\hline 35 & Creep Rupture & Grade 91 & Forging (thick) & Sim. PWHT & Heat-2 & air & 500 & 260 \\
\hline 36 & Creep Rupture & Grade 91 & Forging (thick) & Sim. PWHT & Heat-2 & air & 500 & 260 \\
\hline 37 & Creep Rupture & Grade 91 & Forging (thick) & $\mathrm{AR}$ & Heat-2 & air & 525 & 280 \\
\hline 38 & Creep Rupture & Grade 91 & Forging (thick) & $\mathrm{AR}$ & Heat-2 & air & 525 & 280 \\
\hline 39 & Creep Rupture & Grade 91 & Forging (thick) & Sim. PWHT & Heat-2 & air & 525 & 280 \\
\hline 40 & Creep Rupture & Grade 91 & Forging (thick) & Sim. PWHT & Heat-2 & air & 525 & 280 \\
\hline 41 & Creep Rupture & Grade 91 & Forging (thick) & Sim. PWHT & Heat-2 & air & 525 & 250 \\
\hline 42 & Creep Rupture & Grade 91 & Forging (thick) & Sim. PWHT & Heat-2 & air & 525 & 250 \\
\hline 43 & Creep Rupture & Grade 91 & Forging (thick) & Creep-Fatigue Softened & Heat-2 & air & 525 & 250 \\
\hline 44 & Creep Rupture & Grade 91 & Forging (thick) & Creep-Fatigue Softened & Heat-2 & air & 525 & 250 \\
\hline 45 & Creep Rupture & Grade 91 & Forging (thick) & $\mathrm{AR}$ & Heat-2 & air & 525 & 220 \\
\hline 46 & Creep Rupture & Grade 91 & Forging (thick) & $\mathrm{AR}$ & Heat-2 & air & 525 & 220 \\
\hline 47 & Creep Rupture & Grade 91 & Forging (thick) & Sim. PWHT & Heat-2 & air & 525 & 220 \\
\hline 48 & Creep Rupture & Grade 91 & Forging (thick) & Sim. PWHT & Heat-2 & air & 525 & 220 \\
\hline 49 & Creep Rupture & Grade 91 & Forging (thick) & $\mathrm{AR}$ & Heat-3 & air & 500 & 330 \\
\hline 50 & Creep Rupture & Grade 91 & Forging (thick) & $\mathrm{AR}$ & Heat-3 & air & 500 & 330 \\
\hline 51 & Creep Rupture & Grade 91 & Forging (thick) & Sim. PWHT & Heat-3 & air & 500 & 330 \\
\hline 52 & Creep Rupture & Grade 91 & Forging (thick) & Sim. PWHT & Heat-3 & air & 500 & 330 \\
\hline 53 & Creep Rupture & Grade 91 & Forging (thick) & Sim. PWHT & Heat-3 & air & 500 & 290 \\
\hline
\end{tabular}




Idaho National Laboratory
\begin{tabular}{|c|lll|}
\hline NEXT GENERATION NUCLEAR PLANT & Identifier: & PLN-2803 & \\
REACTOR PRESSURE VESSEL MATERIALS & Revision: & 0 & \\
RESEARCH AND DEVELOPMENT PLAN & Effective Date: & $04 / 30 / 08$ & Page: B-17 of B- 68 \\
\hline
\end{tabular}

\begin{tabular}{|c|c|c|c|c|c|c|c|c|}
\hline Spec.\# & Test Type & Material & Product Form & Mat Cond & Heat & Env & Temp. $\left({ }^{\circ} \mathrm{C}\right)$ & Applied Stress (MPa) \\
\hline 54 & Creep Rupture & Grade 91 & Forging (thick) & Sim. PWHT & Heat-3 & air & 500 & 290 \\
\hline 55 & Creep Rupture & Grade 91 & Forging (thick) & Creep-Fatigue Softened & Heat-3 & air & 500 & 290 \\
\hline 56 & Creep Rupture & Grade 91 & Forging (thick) & Creep-Fatigue Softened & Heat-3 & air & 500 & 290 \\
\hline 57 & Creep Rupture & Grade 91 & Forging (thick) & $\mathrm{AR}$ & Heat-3 & air & 500 & 260 \\
\hline 58 & Creep Rupture & Grade 91 & Forging (thick) & $\mathrm{AR}$ & Heat-3 & air & 500 & 260 \\
\hline 59 & Creep Rupture & Grade 91 & Forging (thick) & Sim. PWHT & Heat-3 & air & 500 & 260 \\
\hline 60 & Creep Rupture & Grade 91 & Forging (thick) & Sim. PWHT & Heat-3 & air & 500 & 260 \\
\hline 61 & Creep Rupture & Grade 91 & Forging (thick) & $\mathrm{AR}$ & Heat-3 & air & 525 & 280 \\
\hline 62 & Creep Rupture & Grade 91 & Forging (thick) & $\mathrm{AR}$ & Heat-3 & air & 525 & 280 \\
\hline 63 & Creep Rupture & Grade 91 & Forging (thick) & Sim. PWHT & Heat-3 & air & 525 & 280 \\
\hline 64 & Creep Rupture & Grade 91 & Forging (thick) & Sim. PWHT & Heat-3 & air & 525 & 280 \\
\hline 65 & Creep Rupture & Grade 91 & Forging (thick) & Sim. PWHT & Heat-3 & air & 525 & 250 \\
\hline 66 & Creep Rupture & Grade 91 & Forging (thick) & Sim. PWHT & Heat-3 & air & 525 & 250 \\
\hline 67 & Creep Rupture & Grade 91 & Forging (thick) & Creep-Fatigue Softened & Heat-3 & air & 525 & 250 \\
\hline 68 & Creep Rupture & Grade 91 & Forging (thick) & Creep-Fatigue Softened & Heat-3 & air & 525 & 250 \\
\hline 69 & Creep Rupture & Grade 91 & Forging (thick) & $\mathrm{AR}$ & Heat-3 & air & 525 & 220 \\
\hline 70 & Creep Rupture & Grade 91 & Forging (thick) & $\mathrm{AR}$ & Heat-3 & air & 525 & 220 \\
\hline 71 & Creep Rupture & Grade 91 & Forging (thick) & Sim. PWHT & Heat-3 & air & 525 & 220 \\
\hline 72 & Creep Rupture & Grade 91 & Forging (thick) & Sim. PWHT & Heat-3 & air & 525 & 220 \\
\hline 73 & Creep Rupture & Grade 91 & Rolled Plate (thick) & $\mathrm{AR}$ & Heat-1 & air & 500 & 330 \\
\hline 74 & Creep Rupture & Grade 91 & Rolled Plate (thick) & $\mathrm{AR}$ & Heat-1 & air & 500 & 330 \\
\hline 75 & Creep Rupture & Grade 91 & Rolled Plate (thick) & Sim. PWHT & Heat-1 & air & 500 & 330 \\
\hline 76 & Creep Rupture & Grade 91 & Rolled Plate (thick) & Sim. PWHT & Heat-1 & air & 500 & 330 \\
\hline 77 & Creep Rupture & Grade 91 & Rolled Plate (thick) & Sim. PWHT & Heat-1 & air & 500 & 290 \\
\hline 78 & Creep Rupture & Grade 91 & Rolled Plate (thick) & Sim. PWHT & Heat-1 & air & 500 & 290 \\
\hline 79 & Creep Rupture & Grade 91 & Rolled Plate (thick) & Creep-Fatigue Softened & Heat-1 & air & 500 & 290 \\
\hline 80 & Creep Rupture & Grade 91 & Rolled Plate (thick) & Creep-Fatigue Softened & Heat-1 & air & 500 & 290 \\
\hline
\end{tabular}




Idaho National Laboratory
\begin{tabular}{|c|lll|}
\hline NEXT GENERATION NUCLEAR PLANT & Identifier: & PLN-2803 & \\
REACTOR PRESSURE VESSEL MATERIALS & Revision: & 0 & \\
RESEARCH AND DEVELOPMENT PLAN & Effective Date: & $04 / 30 / 08$ & Page: B-18 of B- 68 \\
\hline
\end{tabular}

\begin{tabular}{|c|c|c|c|c|c|c|c|c|}
\hline Spec.\# & Test Type & Material & Product Form & Mat Cond & Heat & Env & Temp. $\left({ }^{\circ} \mathrm{C}\right)$ & Applied Stress (MPa) \\
\hline 81 & Creep Rupture & Grade 91 & Rolled Plate (thick) & $\mathrm{AR}$ & Heat-1 & air & 500 & 260 \\
\hline 82 & Creep Rupture & Grade 91 & Rolled Plate (thick) & $\mathrm{AR}$ & Heat-1 & air & 500 & 260 \\
\hline 83 & Creep Rupture & Grade 91 & Rolled Plate (thick) & Sim. PWHT & Heat-1 & air & 500 & 260 \\
\hline 84 & Creep Rupture & Grade 91 & Rolled Plate (thick) & Sim. PWHT & Heat-1 & air & 500 & 260 \\
\hline 85 & Creep Rupture & Grade 91 & Rolled Plate (thick) & $\mathrm{AR}$ & Heat-1 & air & 525 & 280 \\
\hline 86 & Creep Rupture & Grade 91 & Rolled Plate (thick) & $\mathrm{AR}$ & Heat-1 & air & 525 & 280 \\
\hline 87 & Creep Rupture & Grade 91 & Rolled Plate (thick) & Sim. PWHT & Heat-1 & air & 525 & 280 \\
\hline 88 & Creep Rupture & Grade 91 & Rolled Plate (thick) & Sim. PWHT & Heat-1 & air & 525 & 280 \\
\hline 89 & Creep Rupture & Grade 91 & Rolled Plate (thick) & Sim. PWHT & Heat-1 & air & 525 & 250 \\
\hline 90 & Creep Rupture & Grade 91 & Rolled Plate (thick) & Sim. PWHT & Heat-1 & air & 525 & 250 \\
\hline 91 & Creep Rupture & Grade 91 & Rolled Plate (thick) & Creep-Fatigue Softened & Heat-1 & air & 525 & 250 \\
\hline 92 & Creep Rupture & Grade 91 & Rolled Plate (thick) & Creep-Fatigue Softened & Heat-1 & air & 525 & 250 \\
\hline 93 & Creep Rupture & Grade 91 & Rolled Plate (thick) & $\mathrm{AR}$ & Heat-1 & air & 525 & 220 \\
\hline 94 & Creep Rupture & Grade 91 & Rolled Plate (thick) & $\mathrm{AR}$ & Heat-1 & air & 525 & 220 \\
\hline 95 & Creep Rupture & Grade 91 & Rolled Plate (thick) & Sim. PWHT & Heat-1 & air & 525 & 220 \\
\hline 96 & Creep Rupture & Grade 91 & Rolled Plate (thick) & Sim. PWHT & Heat-1 & air & 525 & 220 \\
\hline 97 & Creep Rupture & Grade 91 & Rolled Plate (thick) & $\mathrm{AR}$ & Heat-2 & air & 500 & 330 \\
\hline 98 & Creep Rupture & Grade 91 & Rolled Plate (thick) & $\mathrm{AR}$ & Heat-2 & air & 500 & 330 \\
\hline 99 & Creep Rupture & Grade 91 & Rolled Plate (thick) & Sim. PWHT & Heat-2 & air & 500 & 330 \\
\hline 100 & Creep Rupture & Grade 91 & Rolled Plate (thick) & Sim. PWHT & Heat-2 & air & 500 & 330 \\
\hline 101 & Creep Rupture & Grade 91 & Rolled Plate (thick) & Sim. PWHT & Heat-2 & air & 500 & 290 \\
\hline 102 & Creep Rupture & Grade 91 & Rolled Plate (thick) & Sim. PWHT & Heat-2 & air & 500 & 290 \\
\hline 103 & Creep Rupture & Grade 91 & Rolled Plate (thick) & Creep-Fatigue Softened & Heat-2 & air & 500 & 290 \\
\hline 104 & Creep Rupture & Grade 91 & Rolled Plate (thick) & Creep-Fatigue Softened & Heat-2 & air & 500 & 290 \\
\hline 105 & Creep Rupture & Grade 91 & Rolled Plate (thick) & $\mathrm{AR}$ & Heat-2 & air & 500 & 260 \\
\hline 106 & Creep Rupture & Grade 91 & Rolled Plate (thick) & $\mathrm{AR}$ & Heat-2 & air & 500 & 260 \\
\hline 107 & Creep Rupture & Grade 91 & Rolled Plate (thick) & Sim. PWHT & Heat-2 & air & 500 & 260 \\
\hline
\end{tabular}




Idaho National Laboratory
\begin{tabular}{|c|lll|}
\hline NEXT GENERATION NUCLEAR PLANT & Identifier: & PLN-2803 & \\
REACTOR PRESSURE VESSEL MATERIALS & Revision: & 0 & \\
RESEARCH AND DEVELOPMENT PLAN & Effective Date: & $04 / 30 / 08$ & Page: B-19 of B- 68 \\
\hline
\end{tabular}

\begin{tabular}{|c|c|c|c|c|c|c|c|c|}
\hline \multicolumn{9}{|c|}{ Table B4. Creep Tests to Extend Grade 91 Steel Database } \\
\hline Spec.\# & Test Type & Material & Product Form & Mat Cond & Heat & Env & Temp. $\left({ }^{\circ} \mathrm{C}\right)$ & Applied Stress (MPa) \\
\hline 108 & Creep Rupture & Grade 91 & Rolled Plate (thick) & Sim. PWHT & Heat-2 & air & 500 & 260 \\
\hline 109 & Creep Rupture & Grade 91 & Rolled Plate (thick) & $\mathrm{AR}$ & Heat-2 & air & 525 & 280 \\
\hline 110 & Creep Rupture & Grade 91 & Rolled Plate (thick) & $\mathrm{AR}$ & Heat-2 & air & 525 & 280 \\
\hline 111 & Creep Rupture & Grade 91 & Rolled Plate (thick) & Sim. PWHT & Heat-2 & air & 525 & 280 \\
\hline 112 & Creep Rupture & Grade 91 & Rolled Plate (thick) & Sim. PWHT & Heat-2 & air & 525 & 280 \\
\hline 113 & Creep Rupture & Grade 91 & Rolled Plate (thick) & Sim. PWHT & Heat-2 & air & 525 & 250 \\
\hline 114 & Creep Rupture & Grade 91 & Rolled Plate (thick) & Sim. PWHT & Heat-2 & air & 525 & 250 \\
\hline 115 & Creep Rupture & Grade 91 & Rolled Plate (thick) & Creep-Fatigue Softened & Heat-2 & air & 525 & 250 \\
\hline 116 & Creep Rupture & Grade 91 & Rolled Plate (thick) & Creep-Fatigue Softened & Heat-2 & air & 525 & 250 \\
\hline 117 & Creep Rupture & Grade 91 & Rolled Plate (thick) & $\mathrm{AR}$ & Heat-2 & air & 525 & 220 \\
\hline 118 & Creep Rupture & Grade 91 & Rolled Plate (thick) & $\mathrm{AR}$ & Heat-2 & air & 525 & 220 \\
\hline 119 & Creep Rupture & Grade 91 & Rolled Plate (thick) & Sim. PWHT & Heat-2 & air & 525 & 220 \\
\hline 120 & Creep Rupture & Grade 91 & Rolled Plate (thick) & Sim. PWHT & Heat-2 & air & 525 & 220 \\
\hline 121 & Creep Rupture & Grade 91 & Rolled Plate (thick) & $\mathrm{AR}$ & Heat-3 & air & 500 & 330 \\
\hline 122 & Creep Rupture & Grade 91 & Rolled Plate (thick) & $\mathrm{AR}$ & Heat-3 & air & 500 & 330 \\
\hline 123 & Creep Rupture & Grade 91 & Rolled Plate (thick) & Sim. PWHT & Heat-3 & air & 500 & 330 \\
\hline 124 & Creep Rupture & Grade 91 & Rolled Plate (thick) & Sim. PWHT & Heat-3 & air & 500 & 330 \\
\hline 125 & Creep Rupture & Grade 91 & Rolled Plate (thick) & Sim. PWHT & Heat-3 & air & 500 & 290 \\
\hline 126 & Creep Rupture & Grade 91 & Rolled Plate (thick) & Sim. PWHT & Heat-3 & air & 500 & 290 \\
\hline 127 & Creep Rupture & Grade 91 & Rolled Plate (thick) & Creep-Fatigue Softened & Heat-3 & air & 500 & 290 \\
\hline 128 & Creep Rupture & Grade 91 & Rolled Plate (thick) & Creep-Fatigue Softened & Heat-3 & air & 500 & 290 \\
\hline 129 & Creep Rupture & Grade 91 & Rolled Plate (thick) & $\mathrm{AR}$ & Heat-3 & air & 500 & 260 \\
\hline 130 & Creep Rupture & Grade 91 & Rolled Plate (thick) & $\mathrm{AR}$ & Heat-3 & air & 500 & 260 \\
\hline 131 & Creep Rupture & Grade 91 & Rolled Plate (thick) & Sim. PWHT & Heat-3 & air & 500 & 260 \\
\hline 132 & Creep Rupture & Grade 91 & Rolled Plate (thick) & Sim. PWHT & Heat-3 & air & 500 & 260 \\
\hline 133 & Creep Rupture & Grade 91 & Rolled Plate (thick) & $\mathrm{AR}$ & Heat-3 & air & 525 & 280 \\
\hline 134 & Creep Rupture & Grade 91 & Rolled Plate (thick) & $\mathrm{AR}$ & Heat-3 & air & 525 & 280 \\
\hline
\end{tabular}




Idaho National Laboratory
\begin{tabular}{|c|lll|}
\hline NEXT GENERATION NUCLEAR PLANT & Identifier: & PLN-2803 & \\
REACTOR PRESSURE VESSEL MATERIALS & Revision: & 0 & \\
RESEARCH AND DEVELOPMENT PLAN & Effective Date: & $04 / 30 / 08$ & Page: B-20 of B-68 \\
\hline
\end{tabular}

\begin{tabular}{|c|c|c|c|c|c|c|c|c|}
\hline \multicolumn{9}{|c|}{ Table B4. Creep Tests to Extend Grade 91 Steel Database } \\
\hline Spec. \# & Test Type & Material & Product Form & Mat Cond & Heat & Env & Temp. $\left({ }^{\circ}\right.$ C) & Applied Stress (MPa) \\
\hline 135 & Creep Rupture & Grade 91 & Rolled Plate (thick) & Sim. PWHT & Heat-3 & air & 525 & 280 \\
\hline 136 & Creep Rupture & Grade 91 & Rolled Plate (thick) & Sim. PWHT & Heat-3 & air & 525 & 280 \\
\hline 137 & Creep Rupture & Grade 91 & Rolled Plate (thick) & Sim. PWHT & Heat-3 & air & 525 & 250 \\
\hline 138 & Creep Rupture & Grade 91 & Rolled Plate (thick) & Sim. PWHT & Heat-3 & air & 525 & 250 \\
\hline 139 & Creep Rupture & Grade 91 & Rolled Plate (thick) & Creep-Fatigue Softened & Heat-3 & air & 525 & \\
\hline 140 & Creep Rupture & Grade 91 & Rolled Plate (thick) & Creep-Fatigue Softened & Heat-3 & air & 525 & 250 \\
\hline 141 & Creep Rupture & Grade 91 & Rolled Plate (thick) & AR & Heat-3 & air & 525 & 250 \\
\hline 142 & Creep Rupture & Grade 91 & Rolled Plate (thick) & AR & Heat-3 & air & 525 & 220 \\
\hline 143 & Creep Rupture & Grade 91 & Rolled Plate (thick) & Sim. PWHT & Heat-3 & air & 525 & 220 \\
\hline 144 & Creep Rupture & Grade 91 & Rolled Plate (thick) & Sim. PWHT & Heat-3 & air & 525 & 220 \\
\hline
\end{tabular}




Idaho National Laboratory
\begin{tabular}{|c|lll|}
\hline NEXT GENERATION NUCLEAR PLANT & Identifier: & PLN-2803 & \\
REACTOR PRESSURE VESSEL MATERIALS & Revision: & 0 & \\
RESEARCH AND DEVELOPMENT PLAN & Effective Date: & $04 / 30 / 08$ & Page: B-21 of B-68 \\
\hline
\end{tabular}

\begin{tabular}{|c|c|c|c|c|c|c|c|c|c|c|c|c|}
\hline Spec. \# & Test Type & Material & Product Form & $\begin{array}{c}\text { Mat } \\
\text { Cond }\end{array}$ & $\begin{array}{c}\text { Grade } 91 \\
\text { Heat \# }\end{array}$ & $\begin{array}{l}\text { Strain } \\
\text { Rate } \\
(\mathrm{m} / \mathrm{m} / \mathrm{s})\end{array}$ & Env & $\begin{array}{l}\text { Hold } \\
\text { Cntrl } \\
\text { (stress or } \\
\text { strain) }\end{array}$ & $\begin{array}{l}\text { Stress } \\
\text { Hold in } \\
\text { T/C }\end{array}$ & $\begin{array}{l}\text { Temp. } \\
\left({ }^{\circ} \mathrm{C}\right)\end{array}$ & $\begin{array}{c}\text { Strain } \\
\text { Range } \\
(\%)\end{array}$ & $\begin{array}{c}\text { Stress } \\
\text { Hold } \\
\text { Time } \\
(\mathrm{min}) \\
\end{array}$ \\
\hline 1 & Creep-Fatigue & Grade 91 & Forging (thick) & $\mathrm{AR}$ & heat-1 & $1 \mathrm{E}-03$ & air & stress & N/A & 450 & 0.7 & 0 \\
\hline 2 & Creep-Fatigue & Grade 91 & Forging (thick) & $\mathrm{AR}$ & heat-1 & $1 \mathrm{E}-03$ & air & stress & N/A & 450 & 0.7 & 0 \\
\hline 3 & Creep-Fatigue & Grade 91 & Forging (thick) & $\mathrm{AR}$ & heat-1 & $1 \mathrm{E}-03$ & air & stress & N/A & 450 & 0.7 & 0 \\
\hline 4 & Creep-Fatigue & Grade 91 & Forging (thick) & $\mathrm{AR}$ & heat-1 & $1 \mathrm{E}-03$ & air & stress & tension & 450 & 0.7 & 1 \\
\hline 5 & Creep-Fatigue & Grade 91 & Forging (thick) & $\mathrm{AR}$ & heat-1 & $1 \mathrm{E}-03$ & air & stress & tension & 450 & 0.7 & 1 \\
\hline 6 & Creep-Fatigue & Grade 91 & Forging (thick) & $\mathrm{AR}$ & heat-1 & $1 \mathrm{E}-03$ & air & stress & tension & 450 & 0.7 & 1 \\
\hline 7 & Creep-Fatigue & Grade 91 & Forging (thick) & $\mathrm{AR}$ & heat-1 & $1 \mathrm{E}-03$ & air & stress & tension & 450 & 0.7 & 10 \\
\hline 8 & Creep-Fatigue & Grade 91 & Forging (thick) & $\mathrm{AR}$ & heat-1 & $1 \mathrm{E}-03$ & air & stress & tension & 450 & 0.7 & 10 \\
\hline 9 & Creep-Fatigue & Grade 91 & Forging (thick) & $\mathrm{AR}$ & heat-1 & $1 \mathrm{E}-03$ & air & stress & tension & 450 & 0.7 & 10 \\
\hline 10 & Creep-Fatigue & Grade 91 & Forging (thick) & $\mathrm{AR}$ & heat-1 & $1 \mathrm{E}-03$ & air & stress & tension & 450 & 0.7 & 60 \\
\hline 11 & Creep-Fatigue & Grade 91 & Forging (thick) & $\mathrm{AR}$ & heat-1 & $1 \mathrm{E}-03$ & air & stress & tension & 450 & 0.7 & 60 \\
\hline 12 & Creep-Fatigue & Grade 91 & Forging (thick) & $\mathrm{AR}$ & heat-1 & $1 \mathrm{E}-03$ & air & stress & tension & 450 & 0.7 & 60 \\
\hline 13 & Creep-Fatigue & Grade 91 & Forging (thick) & $\mathrm{AR}$ & heat-1 & $1 \mathrm{E}-03$ & air & stress & tension & 450 & 0.7 & $300^{*}$ \\
\hline 14 & Creep-Fatigue & Grade 91 & Forging (thick) & $\mathrm{AR}$ & heat-1 & $1 \mathrm{E}-03$ & air & stress & tension & 450 & 0.7 & $300^{*}$ \\
\hline 15 & Creep-Fatigue & Grade 91 & Forging (thick) & $\mathrm{AR}$ & heat-1 & $1 \mathrm{E}-03$ & air & stress & tension & 450 & 0.7 & $300^{*}$ \\
\hline 16 & Creep-Fatigue & Grade 91 & Forging (thick) & $\mathrm{AR}$ & heat-1 & $1 \mathrm{E}-03$ & air & stress & comp. & 450 & 0.7 & 1 \\
\hline 17 & Creep-Fatigue & Grade 91 & Forging (thick) & $\mathrm{AR}$ & heat-1 & $1 \mathrm{E}-03$ & air & stress & comp. & 450 & 0.7 & 1 \\
\hline 18 & Creep-Fatigue & Grade 91 & Forging (thick) & $\mathrm{AR}$ & heat-1 & $1 \mathrm{E}-03$ & air & stress & comp. & 450 & 0.7 & 1 \\
\hline 19 & Creep-Fatigue & Grade 91 & Forging (thick) & $\mathrm{AR}$ & heat-1 & $1 \mathrm{E}-03$ & air & stress & comp. & 450 & 0.7 & 10 \\
\hline 20 & Creep-Fatigue & Grade 91 & Forging (thick) & $\mathrm{AR}$ & heat-1 & $1 \mathrm{E}-03$ & air & stress & comp. & 450 & 0.7 & 10 \\
\hline 21 & Creep-Fatigue & Grade 91 & Forging (thick) & $\mathrm{AR}$ & heat-1 & $1 \mathrm{E}-03$ & air & stress & comp. & 450 & 0.7 & 10 \\
\hline 22 & Creep-Fatigue & Grade 91 & Forging (thick) & $\mathrm{AR}$ & heat-1 & $1 \mathrm{E}-03$ & air & stress & comp. & 450 & 0.7 & 60 \\
\hline 23 & Creep-Fatigue & Grade 91 & Forging (thick) & $\mathrm{AR}$ & heat-1 & $1 \mathrm{E}-03$ & air & stress & comp. & 450 & 0.7 & 60 \\
\hline 24 & Creep-Fatigue & Grade 91 & Forging (thick) & $\mathrm{AR}$ & heat-1 & $1 \mathrm{E}-03$ & air & stress & comp. & 450 & 0.7 & 60 \\
\hline
\end{tabular}




Idaho National Laboratory
\begin{tabular}{|c|lll|}
\hline NEXT GENERATION NUCLEAR PLANT & Identifier: & PLN-2803 & \\
REACTOR PRESSURE VESSEL MATERIALS & Revision: & 0 & \\
RESEARCH AND DEVELOPMENT PLAN & Effective Date: & $04 / 30 / 08$ & Page: B-22 of B- 68 \\
\hline
\end{tabular}

\begin{tabular}{|c|c|c|c|c|c|c|c|c|c|c|c|c|}
\hline Spec. \# & Test Type & Material & Product Form & $\begin{array}{l}\text { Mat } \\
\text { Cond }\end{array}$ & $\begin{array}{c}\text { Grade } 91 \\
\text { Heat \# }\end{array}$ & $\begin{array}{c}\text { Strain } \\
\text { Rate } \\
(\mathrm{m} / \mathrm{m} / \mathrm{s})\end{array}$ & Env & $\begin{array}{c}\text { Hold } \\
\text { Cntrl } \\
\text { (stress or } \\
\text { strain) }\end{array}$ & $\begin{array}{l}\text { Stress } \\
\text { Hold in } \\
\text { T/C }\end{array}$ & $\begin{array}{c}\text { Temp. } \\
\left({ }^{\circ} \mathrm{C}\right)\end{array}$ & $\begin{array}{c}\text { Strain } \\
\text { Range } \\
(\%)\end{array}$ & $\begin{array}{l}\text { Stress } \\
\text { Hold } \\
\text { Time } \\
(\mathrm{min}) \\
\end{array}$ \\
\hline 25 & Creep-Fatigue & Grade 91 & Forging (thick) & $\mathrm{AR}$ & heat-1 & $1 \mathrm{E}-03$ & air & stress & comp. & 450 & 0.7 & $300^{*}$ \\
\hline 26 & Creep-Fatigue & Grade 91 & Forging (thick) & $\mathrm{AR}$ & heat-1 & $1 \mathrm{E}-03$ & air & stress & comp. & 450 & 0.7 & $300^{*}$ \\
\hline 27 & Creep-Fatigue & Grade 91 & Forging (thick) & $\mathrm{AR}$ & heat-1 & $1 \mathrm{E}-03$ & air & stress & comp. & 450 & 0.7 & $300^{*}$ \\
\hline 28 & Creep-Fatigue & Grade 91 & Forging (thick) & $\mathrm{AR}$ & heat-1 & $1 \mathrm{E}-03$ & air & stress & N/A & 500 & 0.7 & 0 \\
\hline 29 & Creep-Fatigue & Grade 91 & Forging (thick) & $\mathrm{AR}$ & heat-1 & $1 \mathrm{E}-03$ & air & stress & $\mathrm{N} / \mathrm{A}$ & 500 & 0.7 & 0 \\
\hline 30 & Creep-Fatigue & Grade 91 & Forging (thick) & $\mathrm{AR}$ & heat-1 & $1 \mathrm{E}-03$ & air & stress & $\mathrm{N} / \mathrm{A}$ & 500 & 0.7 & 0 \\
\hline 31 & Creep-Fatigue & Grade 91 & Forging (thick) & $\mathrm{AR}$ & heat-1 & $1 \mathrm{E}-03$ & air & stress & tension & 500 & 0.7 & 1 \\
\hline 32 & Creep-Fatigue & Grade 91 & Forging (thick) & $\mathrm{AR}$ & heat-1 & $1 \mathrm{E}-03$ & air & stress & tension & 500 & 0.7 & 1 \\
\hline 33 & Creep-Fatigue & Grade 91 & Forging (thick) & $\mathrm{AR}$ & heat-1 & $1 \mathrm{E}-03$ & air & stress & tension & 500 & 0.7 & 1 \\
\hline 34 & Creep-Fatigue & Grade 91 & Forging (thick) & $\mathrm{AR}$ & heat-1 & $1 \mathrm{E}-03$ & air & stress & tension & 500 & 0.7 & 10 \\
\hline 35 & Creep-Fatigue & Grade 91 & Forging (thick) & $\mathrm{AR}$ & heat-1 & $1 \mathrm{E}-03$ & air & stress & tension & 500 & 0.7 & 10 \\
\hline 36 & Creep-Fatigue & Grade 91 & Forging (thick) & $\mathrm{AR}$ & heat-1 & $1 \mathrm{E}-03$ & air & stress & tension & 500 & 0.7 & 10 \\
\hline 37 & Creep-Fatigue & Grade 91 & Forging (thick) & $\mathrm{AR}$ & heat-1 & $1 \mathrm{E}-03$ & air & stress & tension & 500 & 0.7 & 60 \\
\hline 38 & Creep-Fatigue & Grade 91 & Forging (thick) & $\mathrm{AR}$ & heat-1 & $1 \mathrm{E}-03$ & air & stress & tension & 500 & 0.7 & 60 \\
\hline 39 & Creep-Fatigue & Grade 91 & Forging (thick) & $\mathrm{AR}$ & heat-1 & $1 \mathrm{E}-03$ & air & stress & tension & 500 & 0.7 & 60 \\
\hline 40 & Creep-Fatigue & Grade 91 & Forging (thick) & $\mathrm{AR}$ & heat-1 & $1 \mathrm{E}-03$ & air & stress & tension & 500 & 0.7 & $300 *$ \\
\hline 41 & Creep-Fatigue & Grade 91 & Forging (thick) & $\mathrm{AR}$ & heat-1 & $1 \mathrm{E}-03$ & air & stress & tension & 500 & 0.7 & $300^{*}$ \\
\hline 42 & Creep-Fatigue & Grade 91 & Forging (thick) & $\mathrm{AR}$ & heat-1 & $1 \mathrm{E}-03$ & air & stress & tension & 500 & 0.7 & $300^{*}$ \\
\hline 43 & Creep-Fatigue & Grade 91 & Forging (thick) & $\mathrm{AR}$ & heat-1 & $1 \mathrm{E}-03$ & air & stress & comp. & 500 & 0.7 & 1 \\
\hline 44 & Creep-Fatigue & Grade 91 & Forging (thick) & $\mathrm{AR}$ & heat-1 & $1 \mathrm{E}-03$ & air & stress & comp. & 500 & 0.7 & 1 \\
\hline 45 & Creep-Fatigue & Grade 91 & Forging (thick) & $\mathrm{AR}$ & heat-1 & $1 \mathrm{E}-03$ & air & stress & comp. & 500 & 0.7 & 1 \\
\hline 46 & Creep-Fatigue & Grade 91 & Forging (thick) & $\mathrm{AR}$ & heat-1 & $1 \mathrm{E}-03$ & air & stress & comp. & 500 & 0.7 & 10 \\
\hline 47 & Creep-Fatigue & Grade 91 & Forging (thick) & $\mathrm{AR}$ & heat-1 & $1 \mathrm{E}-03$ & air & stress & comp. & 500 & 0.7 & 10 \\
\hline 48 & Creep-Fatigue & Grade 91 & Forging (thick) & $\mathrm{AR}$ & heat-1 & $1 \mathrm{E}-03$ & air & stress & comp. & 500 & 0.7 & 10 \\
\hline
\end{tabular}




Idaho National Laboratory
\begin{tabular}{|c|lll|}
\hline NEXT GENERATION NUCLEAR PLANT & Identifier: & PLN-2803 & \\
REACTOR PRESSURE VESSEL MATERIALS & Revision: & 0 & \\
RESEARCH AND DEVELOPMENT PLAN & Effective Date: & $04 / 30 / 08$ & Page: B-23 of B- 68 \\
\hline
\end{tabular}

\begin{tabular}{|c|c|c|c|c|c|c|c|c|c|c|c|c|}
\hline Spec. \# & Test Type & Material & Product Form & $\begin{array}{c}\text { Mat } \\
\text { Cond }\end{array}$ & $\begin{array}{c}\text { Grade } 91 \\
\text { Heat \# }\end{array}$ & $\begin{array}{l}\text { Strain } \\
\text { Rate } \\
(\mathrm{m} / \mathrm{m} / \mathrm{s})\end{array}$ & Env & $\begin{array}{c}\text { Hold } \\
\text { Cntrl } \\
\text { (stress or } \\
\text { strain) }\end{array}$ & $\begin{array}{l}\text { Stress } \\
\text { Hold in } \\
\text { T/C }\end{array}$ & $\begin{array}{l}\text { Temp. } \\
\left({ }^{\circ} \mathrm{C}\right)\end{array}$ & $\begin{array}{c}\text { Strain } \\
\text { Range } \\
(\%)\end{array}$ & $\begin{array}{l}\text { Stress } \\
\text { Hold } \\
\text { Time } \\
(\mathrm{min}) \\
\end{array}$ \\
\hline 49 & Creep-Fatigue & Grade 91 & Forging (thick) & $\mathrm{AR}$ & heat-1 & $1 \mathrm{E}-03$ & air & stress & comp. & 500 & 0.7 & 60 \\
\hline 50 & Creep-Fatigue & Grade 91 & Forging (thick) & $\mathrm{AR}$ & heat-1 & $1 \mathrm{E}-03$ & air & stress & comp. & 500 & 0.7 & 60 \\
\hline 51 & Creep-Fatigue & Grade 91 & Forging (thick) & $\mathrm{AR}$ & heat-1 & $1 \mathrm{E}-03$ & air & stress & comp. & 500 & 0.7 & 60 \\
\hline 52 & Creep-Fatigue & Grade 91 & Forging (thick) & AR & heat-1 & $1 \mathrm{E}-03$ & air & stress & comp. & 500 & 0.7 & $300^{*}$ \\
\hline 53 & Creep-Fatigue & Grade 91 & Forging (thick) & $\mathrm{AR}$ & heat-1 & $1 \mathrm{E}-03$ & air & stress & comp. & 500 & 0.7 & $300^{*}$ \\
\hline 54 & Creep-Fatigue & Grade 91 & Forging (thick) & $\mathrm{AR}$ & heat-1 & $1 \mathrm{E}-03$ & air & stress & comp. & 500 & 0.7 & $300^{*}$ \\
\hline 55 & Creep-Fatigue & Grade 91 & Forging (thick) & AR & heat-2 & $1 \mathrm{E}-03$ & air & stress & N/A & 450 & 0.7 & 0 \\
\hline 56 & Creep-Fatigue & Grade 91 & Forging (thick) & AR & heat-2 & $1 \mathrm{E}-03$ & air & stress & N/A & 450 & 0.7 & 0 \\
\hline 57 & Creep-Fatigue & Grade 91 & Forging (thick) & $\mathrm{AR}$ & heat-2 & $1 \mathrm{E}-03$ & air & stress & N/A & 450 & 0.7 & 0 \\
\hline 58 & Creep-Fatigue & Grade 91 & Forging (thick) & $\mathrm{AR}$ & heat-2 & $1 \mathrm{E}-03$ & air & stress & tension & 450 & 0.7 & 1 \\
\hline 59 & Creep-Fatigue & Grade 91 & Forging (thick) & $\mathrm{AR}$ & heat-2 & $1 \mathrm{E}-03$ & air & stress & tension & 450 & 0.7 & 1 \\
\hline 60 & Creep-Fatigue & Grade 91 & Forging (thick) & $\mathrm{AR}$ & heat- 2 & $1 \mathrm{E}-03$ & air & stress & tension & 450 & 0.7 & 1 \\
\hline 61 & Creep-Fatigue & Grade 91 & Forging (thick) & AR & heat-2 & $1 \mathrm{E}-03$ & air & stress & tension & 450 & 0.7 & 10 \\
\hline 62 & Creep-Fatigue & Grade 91 & Forging (thick) & AR & heat-2 & $1 \mathrm{E}-03$ & air & stress & tension & 450 & 0.7 & 10 \\
\hline 63 & Creep-Fatigue & Grade 91 & Forging (thick) & $\mathrm{AR}$ & heat-2 & $1 \mathrm{E}-03$ & air & stress & tension & 450 & 0.7 & 10 \\
\hline 64 & Creep-Fatigue & Grade 91 & Forging (thick) & $\mathrm{AR}$ & heat-2 & $1 \mathrm{E}-03$ & air & stress & tension & 450 & 0.7 & 60 \\
\hline 65 & Creep-Fatigue & Grade 91 & Forging (thick) & $\mathrm{AR}$ & heat-2 & $1 \mathrm{E}-03$ & air & stress & tension & 450 & 0.7 & 60 \\
\hline 66 & Creep-Fatigue & Grade 91 & Forging (thick) & AR & heat-2 & $1 \mathrm{E}-03$ & air & stress & tension & 450 & 0.7 & 60 \\
\hline 67 & Creep-Fatigue & Grade 91 & Forging (thick) & $\mathrm{AR}$ & heat-2 & $1 \mathrm{E}-03$ & air & stress & tension & 450 & 0.7 & $300 *$ \\
\hline 68 & Creep-Fatigue & Grade 91 & Forging (thick) & $\mathrm{AR}$ & heat-2 & $1 \mathrm{E}-03$ & air & stress & tension & 450 & 0.7 & $300^{*}$ \\
\hline 69 & Creep-Fatigue & Grade 91 & Forging (thick) & $\mathrm{AR}$ & heat-2 & $1 \mathrm{E}-03$ & air & stress & tension & 450 & 0.7 & $300 *$ \\
\hline 70 & Creep-Fatigue & Grade 91 & Forging (thick) & $\mathrm{AR}$ & heat-2 & $1 \mathrm{E}-03$ & air & stress & comp. & 450 & 0.7 & 1 \\
\hline 71 & Creep-Fatigue & Grade 91 & Forging (thick) & $\mathrm{AR}$ & heat-2 & $1 \mathrm{E}-03$ & air & stress & comp. & 450 & 0.7 & 1 \\
\hline 72 & Creep-Fatigue & Grade 91 & Forging (thick) & $\mathrm{AR}$ & heat -2 & $1 \mathrm{E}-03$ & air & stress & comp. & 450 & 0.7 & 1 \\
\hline
\end{tabular}




Idaho National Laboratory
\begin{tabular}{|c|lll|}
\hline NEXT GENERATION NUCLEAR PLANT & Identifier: & PLN-2803 & \\
REACTOR PRESSURE VESSEL MATERIALS & Revision: & 0 & \\
RESEARCH AND DEVELOPMENT PLAN & Effective Date: & $04 / 30 / 08$ & Page: B-24 of B- 68 \\
\hline
\end{tabular}

\begin{tabular}{|c|c|c|c|c|c|c|c|c|c|c|c|c|}
\hline Spec. \# & Test Type & Material & Product Form & $\begin{array}{l}\text { Mat } \\
\text { Cond }\end{array}$ & $\begin{array}{c}\text { Grade } 91 \\
\text { Heat \# }\end{array}$ & $\begin{array}{c}\text { Strain } \\
\text { Rate } \\
(\mathrm{m} / \mathrm{m} / \mathrm{s})\end{array}$ & Env & $\begin{array}{l}\text { Hold } \\
\text { Cntrl } \\
\text { (stress or } \\
\text { strain) }\end{array}$ & $\begin{array}{l}\text { Stress } \\
\text { Hold in } \\
\text { T/C }\end{array}$ & $\begin{array}{c}\text { Temp. } \\
\left({ }^{\circ} \mathrm{C}\right)\end{array}$ & $\begin{array}{c}\text { Strain } \\
\text { Range } \\
(\%)\end{array}$ & $\begin{array}{l}\text { Stress } \\
\text { Hold } \\
\text { Time } \\
(\mathrm{min}) \\
\end{array}$ \\
\hline 73 & Creep-Fatigue & Grade 91 & Forging (thick) & $\mathrm{AR}$ & heat-2 & $1 \mathrm{E}-03$ & air & stress & comp. & 450 & 0.7 & 10 \\
\hline 74 & Creep-Fatigue & Grade 91 & Forging (thick) & $\mathrm{AR}$ & heat-2 & $1 \mathrm{E}-03$ & air & stress & comp. & 450 & 0.7 & 10 \\
\hline 75 & Creep-Fatigue & Grade 91 & Forging (thick) & $\mathrm{AR}$ & heat-2 & $1 \mathrm{E}-03$ & air & stress & comp. & 450 & 0.7 & 10 \\
\hline 76 & Creep-Fatigue & Grade 91 & Forging (thick) & $\mathrm{AR}$ & heat-2 & $1 \mathrm{E}-03$ & air & stress & comp. & 450 & 0.7 & 60 \\
\hline 77 & Creep-Fatigue & Grade 91 & Forging (thick) & $\mathrm{AR}$ & heat-2 & $1 \mathrm{E}-03$ & air & stress & comp. & 450 & 0.7 & 60 \\
\hline 78 & Creep-Fatigue & Grade 91 & Forging (thick) & $\mathrm{AR}$ & heat-2 & $1 \mathrm{E}-03$ & air & stress & comp. & 450 & 0.7 & 60 \\
\hline 79 & Creep-Fatigue & Grade 91 & Forging (thick) & $\mathrm{AR}$ & heat-2 & $1 \mathrm{E}-03$ & air & stress & comp. & 450 & 0.7 & $300^{*}$ \\
\hline 80 & Creep-Fatigue & Grade 91 & Forging (thick) & $\mathrm{AR}$ & heat-2 & $1 \mathrm{E}-03$ & air & stress & comp. & 450 & 0.7 & $300^{*}$ \\
\hline 81 & Creep-Fatigue & Grade 91 & Forging (thick) & $\mathrm{AR}$ & heat-2 & $1 \mathrm{E}-03$ & air & stress & comp. & 450 & 0.7 & $300^{*}$ \\
\hline 82 & Creep-Fatigue & Grade 91 & Forging (thick) & $\mathrm{AR}$ & heat-2 & $1 \mathrm{E}-03$ & air & stress & N/A & 500 & 0.7 & 0 \\
\hline 83 & Creep-Fatigue & Grade 91 & Forging (thick) & $\mathrm{AR}$ & heat-2 & $1 \mathrm{E}-03$ & air & stress & N/A & 500 & 0.7 & 0 \\
\hline 84 & Creep-Fatigue & Grade 91 & Forging (thick) & $\mathrm{AR}$ & heat-2 & $1 \mathrm{E}-03$ & air & stress & N/A & 500 & 0.7 & 0 \\
\hline 85 & Creep-Fatigue & Grade 91 & Forging (thick) & $\mathrm{AR}$ & heat-2 & $1 \mathrm{E}-03$ & air & stress & tension & 500 & 0.7 & 1 \\
\hline 86 & Creep-Fatigue & Grade 91 & Forging (thick) & $\mathrm{AR}$ & heat-2 & $1 \mathrm{E}-03$ & air & stress & tension & 500 & 0.7 & 1 \\
\hline 87 & Creep-Fatigue & Grade 91 & Forging (thick) & $\mathrm{AR}$ & heat-2 & $1 \mathrm{E}-03$ & air & stress & tension & 500 & 0.7 & 1 \\
\hline 88 & Creep-Fatigue & Grade 91 & Forging (thick) & $\mathrm{AR}$ & heat-2 & $1 \mathrm{E}-03$ & air & stress & tension & 500 & 0.7 & 10 \\
\hline 89 & Creep-Fatigue & Grade 91 & Forging (thick) & $\mathrm{AR}$ & heat-2 & $1 \mathrm{E}-03$ & air & stress & tension & 500 & 0.7 & 10 \\
\hline 90 & Creep-Fatigue & Grade 91 & Forging (thick) & $\mathrm{AR}$ & heat-2 & $1 \mathrm{E}-03$ & air & stress & tension & 500 & 0.7 & 10 \\
\hline 91 & Creep-Fatigue & Grade 91 & Forging (thick) & $\mathrm{AR}$ & heat-2 & $1 \mathrm{E}-03$ & air & stress & tension & 500 & 0.7 & 60 \\
\hline 92 & Creep-Fatigue & Grade 91 & Forging (thick) & $\mathrm{AR}$ & heat-2 & $1 \mathrm{E}-03$ & air & stress & tension & 500 & 0.7 & 60 \\
\hline 93 & Creep-Fatigue & Grade 91 & Forging (thick) & $\mathrm{AR}$ & heat-2 & $1 \mathrm{E}-03$ & air & stress & tension & 500 & 0.7 & 60 \\
\hline 94 & Creep-Fatigue & Grade 91 & Forging (thick) & $\mathrm{AR}$ & heat-2 & $1 \mathrm{E}-03$ & air & stress & tension & 500 & 0.7 & $300 *$ \\
\hline 95 & Creep-Fatigue & Grade 91 & Forging (thick) & $\mathrm{AR}$ & heat-2 & $1 \mathrm{E}-03$ & air & stress & tension & 500 & 0.7 & $300^{*}$ \\
\hline 96 & Creep-Fatigue & Grade 91 & Forging (thick) & $\mathrm{AR}$ & heat-2 & $1 \mathrm{E}-03$ & air & stress & tension & 500 & 0.7 & $300^{*}$ \\
\hline
\end{tabular}




Idaho National Laboratory
\begin{tabular}{|c|lll|}
\hline NEXT GENERATION NUCLEAR PLANT & Identifier: & PLN-2803 & \\
REACTOR PRESSURE VESSEL MATERIALS & Revision: & 0 & \\
RESEARCH AND DEVELOPMENT PLAN & Effective Date: & $04 / 30 / 08$ & Page: B-25 of B- 68 \\
\hline
\end{tabular}

\begin{tabular}{|c|c|c|c|c|c|c|c|c|c|c|c|c|}
\hline Spec. \# & Test Type & Material & Product Form & $\begin{array}{c}\text { Mat } \\
\text { Cond }\end{array}$ & $\begin{array}{c}\text { Grade } 91 \\
\text { Heat \# }\end{array}$ & $\begin{array}{c}\text { Strain } \\
\text { Rate } \\
(\mathrm{m} / \mathrm{m} / \mathrm{s})\end{array}$ & Env & $\begin{array}{c}\text { Hold } \\
\text { Cntrl } \\
\text { (stress or } \\
\text { strain) }\end{array}$ & $\begin{array}{l}\text { Stress } \\
\text { Hold in } \\
\text { T/C }\end{array}$ & $\begin{array}{c}\text { Temp. } \\
\left({ }^{\circ} \mathrm{C}\right)\end{array}$ & $\begin{array}{c}\text { Strain } \\
\text { Range } \\
(\%)\end{array}$ & $\begin{array}{l}\text { Stress } \\
\text { Hold } \\
\text { Time } \\
(\mathrm{min}) \\
\end{array}$ \\
\hline 97 & Creep-Fatigue & Grade 91 & Forging (thick) & $\mathrm{AR}$ & heat-2 & $1 \mathrm{E}-03$ & air & stress & comp. & 500 & 0.7 & 1 \\
\hline 98 & Creep-Fatigue & Grade 91 & Forging (thick) & $\mathrm{AR}$ & heat-2 & $1 \mathrm{E}-03$ & air & stress & comp. & 500 & 0.7 & 1 \\
\hline 99 & Creep-Fatigue & Grade 91 & Forging (thick) & $\mathrm{AR}$ & heat-2 & $1 \mathrm{E}-03$ & air & stress & comp. & 500 & 0.7 & 1 \\
\hline 100 & Creep-Fatigue & Grade 91 & Forging (thick) & AR & heat-2 & $1 \mathrm{E}-03$ & air & stress & comp. & 500 & 0.7 & 10 \\
\hline 101 & Creep-Fatigue & Grade 91 & Forging (thick) & $\mathrm{AR}$ & heat-2 & $1 \mathrm{E}-03$ & air & stress & comp. & 500 & 0.7 & 10 \\
\hline 102 & Creep-Fatigue & Grade 91 & Forging (thick) & $\mathrm{AR}$ & heat-2 & $1 \mathrm{E}-03$ & air & stress & comp. & 500 & 0.7 & 10 \\
\hline 103 & Creep-Fatigue & Grade 91 & Forging (thick) & $\mathrm{AR}$ & heat-2 & $1 \mathrm{E}-03$ & air & stress & comp. & 500 & 0.7 & 60 \\
\hline 104 & Creep-Fatigue & Grade 91 & Forging (thick) & AR & heat-2 & $1 \mathrm{E}-03$ & air & stress & comp. & 500 & 0.7 & 60 \\
\hline 105 & Creep-Fatigue & Grade 91 & Forging (thick) & $\mathrm{AR}$ & heat-2 & $1 \mathrm{E}-03$ & air & stress & comp. & 500 & 0.7 & 60 \\
\hline 106 & Creep-Fatigue & Grade 91 & Forging (thick) & $\mathrm{AR}$ & heat-2 & $1 \mathrm{E}-03$ & air & stress & comp. & 500 & 0.7 & $300^{*}$ \\
\hline 107 & Creep-Fatigue & Grade 91 & Forging (thick) & AR & heat-2 & $1 \mathrm{E}-03$ & air & stress & comp. & 500 & 0.7 & $300^{*}$ \\
\hline 108 & Creep-Fatigue & Grade 91 & Forging (thick) & AR & heat-2 & $1 \mathrm{E}-03$ & air & stress & comp. & 500 & 0.7 & $300^{*}$ \\
\hline 109 & Creep-Fatigue & Grade 91 & Rolled Plate (thick) & $\mathrm{AR}$ & heat-1 & $1 \mathrm{E}-03$ & air & stress & N/A & 450 & 0.7 & 0 \\
\hline 110 & Creep-Fatigue & Grade 91 & Rolled Plate (thick) & AR & heat-1 & $1 \mathrm{E}-03$ & air & stress & N/A & 450 & 0.7 & 0 \\
\hline 111 & Creep-Fatigue & Grade 91 & Rolled Plate (thick) & $\mathrm{AR}$ & heat-1 & $1 \mathrm{E}-03$ & air & stress & $\mathrm{N} / \mathrm{A}$ & 450 & 0.7 & 0 \\
\hline 112 & Creep-Fatigue & Grade 91 & Rolled Plate (thick) & AR & heat-1 & $1 \mathrm{E}-03$ & air & stress & tension & 450 & 0.7 & 1 \\
\hline 113 & Creep-Fatigue & Grade 91 & Rolled Plate (thick) & AR & heat-1 & $1 \mathrm{E}-03$ & air & stress & tension & 450 & 0.7 & 1 \\
\hline 114 & Creep-Fatigue & Grade 91 & Rolled Plate (thick) & AR & heat-1 & $1 \mathrm{E}-03$ & air & stress & tension & 450 & 0.7 & 1 \\
\hline 115 & Creep-Fatigue & Grade 91 & Rolled Plate (thick) & $\mathrm{AR}$ & heat-1 & $1 \mathrm{E}-03$ & air & stress & tension & 450 & 0.7 & 10 \\
\hline 116 & Creep-Fatigue & Grade 91 & Rolled Plate (thick) & $\mathrm{AR}$ & heat-1 & $1 \mathrm{E}-03$ & air & stress & tension & 450 & 0.7 & 10 \\
\hline 117 & Creep-Fatigue & Grade 91 & Rolled Plate (thick) & $\mathrm{AR}$ & heat-1 & $1 \mathrm{E}-03$ & air & stress & tension & 450 & 0.7 & 10 \\
\hline 118 & Creep-Fatigue & Grade 91 & Rolled Plate (thick) & AR & heat-1 & $1 \mathrm{E}-03$ & air & stress & tension & 450 & 0.7 & 60 \\
\hline 119 & Creep-Fatigue & Grade 91 & Rolled Plate (thick) & AR & heat-1 & $1 \mathrm{E}-03$ & air & stress & tension & 450 & 0.7 & 60 \\
\hline 120 & Creep-Fatigue & Grade 91 & Rolled Plate (thick) & $\mathrm{AR}$ & heat-1 & $1 \mathrm{E}-03$ & air & stress & tension & 450 & 0.7 & 60 \\
\hline
\end{tabular}




Idaho National Laboratory
\begin{tabular}{|c|lll|}
\hline NEXT GENERATION NUCLEAR PLANT & Identifier: & PLN-2803 & \\
REACTOR PRESSURE VESSEL MATERIALS & Revision: & 0 & \\
RESEARCH AND DEVELOPMENT PLAN & Effective Date: & $04 / 30 / 08$ & Page: B-26 of B- 68 \\
\hline
\end{tabular}

\begin{tabular}{|c|c|c|c|c|c|c|c|c|c|c|c|c|}
\hline Spec. \# & Test Type & Material & Product Form & $\begin{array}{c}\text { Mat } \\
\text { Cond }\end{array}$ & $\begin{array}{c}\text { Grade } 91 \\
\text { Heat \# }\end{array}$ & $\begin{array}{c}\text { Strain } \\
\text { Rate } \\
(\mathrm{m} / \mathrm{m} / \mathrm{s})\end{array}$ & Env & $\begin{array}{c}\text { Hold } \\
\text { Cntrl } \\
\text { (stress or } \\
\text { strain) }\end{array}$ & $\begin{array}{l}\text { Stress } \\
\text { Hold in } \\
\text { T/C }\end{array}$ & $\begin{array}{c}\text { Temp. } \\
\left({ }^{\circ} \mathrm{C}\right)\end{array}$ & $\begin{array}{c}\text { Strain } \\
\text { Range } \\
(\%)\end{array}$ & $\begin{array}{l}\text { Stress } \\
\text { Hold } \\
\text { Time } \\
(\mathrm{min}) \\
\end{array}$ \\
\hline 121 & Creep-Fatigue & Grade 91 & Rolled Plate (thick) & $\mathrm{AR}$ & heat-1 & $1 \mathrm{E}-03$ & air & stress & tension & 450 & 0.7 & $300^{*}$ \\
\hline 122 & Creep-Fatigue & Grade 91 & Rolled Plate (thick) & $\mathrm{AR}$ & heat-1 & $1 \mathrm{E}-03$ & air & stress & tension & 450 & 0.7 & $300^{*}$ \\
\hline 123 & Creep-Fatigue & Grade 91 & Rolled Plate (thick) & $\mathrm{AR}$ & heat-1 & $1 \mathrm{E}-03$ & air & stress & tension & 450 & 0.7 & $300^{*}$ \\
\hline 124 & Creep-Fatigue & Grade 91 & Rolled Plate (thick) & $\mathrm{AR}$ & heat-1 & $1 \mathrm{E}-03$ & air & stress & comp. & 450 & 0.7 & 1 \\
\hline 125 & Creep-Fatigue & Grade 91 & Rolled Plate (thick) & $\mathrm{AR}$ & heat-1 & $1 \mathrm{E}-03$ & air & stress & comp. & 450 & 0.7 & 1 \\
\hline 126 & Creep-Fatigue & Grade 91 & Rolled Plate (thick) & $\mathrm{AR}$ & heat-1 & $1 \mathrm{E}-03$ & air & stress & comp. & 450 & 0.7 & 1 \\
\hline 127 & Creep-Fatigue & Grade 91 & Rolled Plate (thick) & $\mathrm{AR}$ & heat-1 & $1 \mathrm{E}-03$ & air & stress & comp. & 450 & 0.7 & 10 \\
\hline 128 & Creep-Fatigue & Grade 91 & Rolled Plate (thick) & AR & heat-1 & $1 \mathrm{E}-03$ & air & stress & comp. & 450 & 0.7 & 10 \\
\hline 129 & Creep-Fatigue & Grade 91 & Rolled Plate (thick) & AR & heat-1 & $1 \mathrm{E}-03$ & air & stress & comp. & 450 & 0.7 & 10 \\
\hline 130 & Creep-Fatigue & Grade 91 & Rolled Plate (thick) & $\mathrm{AR}$ & heat-1 & $1 \mathrm{E}-03$ & air & stress & comp. & 450 & 0.7 & 60 \\
\hline 131 & Creep-Fatigue & Grade 91 & Rolled Plate (thick) & AR & heat-1 & $1 \mathrm{E}-03$ & air & stress & comp. & 450 & 0.7 & 60 \\
\hline 132 & Creep-Fatigue & Grade 91 & Rolled Plate (thick) & AR & heat-1 & $1 \mathrm{E}-03$ & air & stress & comp. & 450 & 0.7 & 60 \\
\hline 133 & Creep-Fatigue & Grade 91 & Rolled Plate (thick) & $\mathrm{AR}$ & heat-1 & $1 \mathrm{E}-03$ & air & stress & comp. & 450 & 0.7 & $300 *$ \\
\hline 134 & Creep-Fatigue & Grade 91 & Rolled Plate (thick) & AR & heat-1 & $1 \mathrm{E}-03$ & air & stress & comp. & 450 & 0.7 & $300^{*}$ \\
\hline 135 & Creep-Fatigue & Grade 91 & Rolled Plate (thick) & $\mathrm{AR}$ & heat-1 & $1 \mathrm{E}-03$ & air & stress & comp. & 450 & 0.7 & $300 *$ \\
\hline 136 & Creep-Fatigue & Grade 91 & Rolled Plate (thick) & AR & heat-1 & $1 \mathrm{E}-03$ & air & stress & N/A & 500 & 0.7 & 0 \\
\hline 137 & Creep-Fatigue & Grade 91 & Rolled Plate (thick) & AR & heat-1 & $1 \mathrm{E}-03$ & air & stress & N/A & 500 & 0.7 & 0 \\
\hline 138 & Creep-Fatigue & Grade 91 & Rolled Plate (thick) & AR & heat-1 & $1 \mathrm{E}-03$ & air & stress & N/A & 500 & 0.7 & 0 \\
\hline 139 & Creep-Fatigue & Grade 91 & Rolled Plate (thick) & $\mathrm{AR}$ & heat-1 & $1 \mathrm{E}-03$ & air & stress & tension & 500 & 0.7 & 1 \\
\hline 140 & Creep-Fatigue & Grade 91 & Rolled Plate (thick) & $\mathrm{AR}$ & heat-1 & $1 \mathrm{E}-03$ & air & stress & tension & 500 & 0.7 & 1 \\
\hline 141 & Creep-Fatigue & Grade 91 & Rolled Plate (thick) & $\mathrm{AR}$ & heat-1 & $1 \mathrm{E}-03$ & air & stress & tension & 500 & 0.7 & 1 \\
\hline 142 & Creep-Fatigue & Grade 91 & Rolled Plate (thick) & AR & heat-1 & $1 \mathrm{E}-03$ & air & stress & tension & 500 & 0.7 & 10 \\
\hline 143 & Creep-Fatigue & Grade 91 & Rolled Plate (thick) & AR & heat-1 & $1 \mathrm{E}-03$ & air & stress & tension & 500 & 0.7 & 10 \\
\hline 144 & Creep-Fatigue & Grade 91 & Rolled Plate (thick) & $\mathrm{AR}$ & heat-1 & $1 \mathrm{E}-03$ & air & stress & tension & 500 & 0.7 & 10 \\
\hline
\end{tabular}




Idaho National Laboratory
\begin{tabular}{|c|lll|}
\hline NEXT GENERATION NUCLEAR PLANT & Identifier: & PLN-2803 & \\
REACTOR PRESSURE VESSEL MATERIALS & Revision: & 0 & \\
RESEARCH AND DEVELOPMENT PLAN & Effective Date: & $04 / 30 / 08$ & Page: B-27 of B- 68 \\
\hline
\end{tabular}

\begin{tabular}{|c|c|c|c|c|c|c|c|c|c|c|c|c|}
\hline Spec. \# & Test Type & Material & Product Form & $\begin{array}{c}\text { Mat } \\
\text { Cond }\end{array}$ & $\begin{array}{c}\text { Grade } 91 \\
\text { Heat \# }\end{array}$ & $\begin{array}{l}\text { Strain } \\
\text { Rate } \\
(\mathrm{m} / \mathrm{m} / \mathrm{s})\end{array}$ & Env & $\begin{array}{c}\text { Hold } \\
\text { Cntrl } \\
\text { (stress or } \\
\text { strain) }\end{array}$ & $\begin{array}{l}\text { Stress } \\
\text { Hold in } \\
\text { T/C }\end{array}$ & $\begin{array}{l}\text { Temp. } \\
\left({ }^{\circ} \mathrm{C}\right)\end{array}$ & $\begin{array}{c}\text { Strain } \\
\text { Range } \\
(\%)\end{array}$ & $\begin{array}{l}\text { Stress } \\
\text { Hold } \\
\text { Time } \\
(\mathrm{min}) \\
\end{array}$ \\
\hline 145 & Creep-Fatigue & Grade 91 & Rolled Plate (thick) & $\mathrm{AR}$ & heat-1 & $1 \mathrm{E}-03$ & air & stress & tension & 500 & 0.7 & 60 \\
\hline 146 & Creep-Fatigue & Grade 91 & Rolled Plate (thick) & $\mathrm{AR}$ & heat-1 & $1 \mathrm{E}-03$ & air & stress & tension & 500 & 0.7 & 60 \\
\hline 147 & Creep-Fatigue & Grade 91 & Rolled Plate (thick) & $\mathrm{AR}$ & heat-1 & $1 \mathrm{E}-03$ & air & stress & tension & 500 & 0.7 & 60 \\
\hline 148 & Creep-Fatigue & Grade 91 & Rolled Plate (thick) & AR & heat-1 & $1 \mathrm{E}-03$ & air & stress & tension & 500 & 0.7 & $300^{*}$ \\
\hline 149 & Creep-Fatigue & Grade 91 & Rolled Plate (thick) & $\mathrm{AR}$ & heat-1 & $1 \mathrm{E}-03$ & air & stress & tension & 500 & 0.7 & $300^{*}$ \\
\hline 150 & Creep-Fatigue & Grade 91 & Rolled Plate (thick) & $\mathrm{AR}$ & heat-1 & $1 \mathrm{E}-03$ & air & stress & tension & 500 & 0.7 & $300^{*}$ \\
\hline 151 & Creep-Fatigue & Grade 91 & Rolled Plate (thick) & AR & heat-1 & $1 \mathrm{E}-03$ & air & stress & comp. & 500 & 0.7 & 1 \\
\hline 152 & Creep-Fatigue & Grade 91 & Rolled Plate (thick) & $\mathrm{AR}$ & heat-1 & $1 \mathrm{E}-03$ & air & stress & comp. & 500 & 0.7 & 1 \\
\hline 153 & Creep-Fatigue & Grade 91 & Rolled Plate (thick) & $\mathrm{AR}$ & heat-1 & $1 \mathrm{E}-03$ & air & stress & comp. & 500 & 0.7 & 1 \\
\hline 154 & Creep-Fatigue & Grade 91 & Rolled Plate (thick) & $\mathrm{AR}$ & heat-1 & $1 \mathrm{E}-03$ & air & stress & comp. & 500 & 0.7 & 10 \\
\hline 155 & Creep-Fatigue & Grade 91 & Rolled Plate (thick) & $\mathrm{AR}$ & heat-1 & $1 \mathrm{E}-03$ & air & stress & comp. & 500 & 0.7 & 10 \\
\hline 156 & Creep-Fatigue & Grade 91 & Rolled Plate (thick) & $\mathrm{AR}$ & heat-1 & $1 \mathrm{E}-03$ & air & stress & comp. & 500 & 0.7 & 10 \\
\hline 157 & Creep-Fatigue & Grade 91 & Rolled Plate (thick) & AR & heat-1 & $1 \mathrm{E}-03$ & air & stress & comp. & 500 & 0.7 & 60 \\
\hline 158 & Creep-Fatigue & Grade 91 & Rolled Plate (thick) & AR & heat-1 & $1 \mathrm{E}-03$ & air & stress & comp. & 500 & 0.7 & 60 \\
\hline 159 & Creep-Fatigue & Grade 91 & Rolled Plate (thick) & $\mathrm{AR}$ & heat-1 & $1 \mathrm{E}-03$ & air & stress & comp. & 500 & 0.7 & 60 \\
\hline 160 & Creep-Fatigue & Grade 91 & Rolled Plate (thick) & $\mathrm{AR}$ & heat-1 & $1 \mathrm{E}-03$ & air & stress & comp. & 500 & 0.7 & $300^{*}$ \\
\hline 161 & Creep-Fatigue & Grade 91 & Rolled Plate (thick) & $\mathrm{AR}$ & heat-1 & $1 \mathrm{E}-03$ & air & stress & comp. & 500 & 0.7 & $300^{*}$ \\
\hline 162 & Creep-Fatigue & Grade 91 & Rolled Plate (thick) & AR & heat-1 & $1 \mathrm{E}-03$ & air & stress & comp. & 500 & 0.7 & $300^{*}$ \\
\hline 163 & Creep-Fatigue & Grade 91 & Rolled Plate (thick) & $\mathrm{AR}$ & heat-2 & $1 \mathrm{E}-03$ & air & stress & $\mathrm{N} / \mathrm{A}$ & 450 & 0.7 & 0 \\
\hline 164 & Creep-Fatigue & Grade 91 & Rolled Plate (thick) & $\mathrm{AR}$ & heat-2 & $1 \mathrm{E}-03$ & air & stress & $\mathrm{N} / \mathrm{A}$ & 450 & 0.7 & 0 \\
\hline 165 & Creep-Fatigue & Grade 91 & Rolled Plate (thick) & $\mathrm{AR}$ & heat-2 & $1 \mathrm{E}-03$ & air & stress & N/A & 450 & 0.7 & 0 \\
\hline 166 & Creep-Fatigue & Grade 91 & Rolled Plate (thick) & $\mathrm{AR}$ & heat-2 & $1 \mathrm{E}-03$ & air & stress & tension & 450 & 0.7 & 1 \\
\hline 167 & Creep-Fatigue & Grade 91 & Rolled Plate (thick) & $\mathrm{AR}$ & heat-2 & $1 \mathrm{E}-03$ & air & stress & tension & 450 & 0.7 & 1 \\
\hline 168 & Creep-Fatigue & Grade 91 & Rolled Plate (thick) & $\mathrm{AR}$ & heat -2 & $1 \mathrm{E}-03$ & air & stress & tension & 450 & 0.7 & 1 \\
\hline
\end{tabular}




Idaho National Laboratory
\begin{tabular}{|c|lll|}
\hline NEXT GENERATION NUCLEAR PLANT & Identifier: & PLN-2803 & \\
REACTOR PRESSURE VESSEL MATERIALS & Revision: & 0 & \\
RESEARCH AND DEVELOPMENT PLAN & Effective Date: & $04 / 30 / 08$ & Page: B-28 of B- 68 \\
\hline
\end{tabular}

\begin{tabular}{|c|c|c|c|c|c|c|c|c|c|c|c|c|}
\hline Spec. \# & Test Type & Material & Product Form & $\begin{array}{c}\text { Mat } \\
\text { Cond }\end{array}$ & $\begin{array}{c}\text { Grade } 91 \\
\text { Heat \# }\end{array}$ & $\begin{array}{c}\text { Strain } \\
\text { Rate } \\
(\mathrm{m} / \mathrm{m} / \mathrm{s})\end{array}$ & Env & $\begin{array}{c}\text { Hold } \\
\text { Cntrl } \\
\text { (stress or } \\
\text { strain) }\end{array}$ & $\begin{array}{l}\text { Stress } \\
\text { Hold in } \\
\text { T/C }\end{array}$ & $\begin{array}{c}\text { Temp. } \\
\left({ }^{\circ} \mathrm{C}\right)\end{array}$ & $\begin{array}{c}\text { Strain } \\
\text { Range } \\
(\%)\end{array}$ & $\begin{array}{l}\text { Stress } \\
\text { Hold } \\
\text { Time } \\
(\mathrm{min}) \\
\end{array}$ \\
\hline 169 & Creep-Fatigue & Grade 91 & Rolled Plate (thick) & $\mathrm{AR}$ & heat-2 & $1 \mathrm{E}-03$ & air & stress & tension & 450 & 0.7 & 10 \\
\hline 170 & Creep-Fatigue & Grade 91 & Rolled Plate (thick) & $\mathrm{AR}$ & heat-2 & $1 \mathrm{E}-03$ & air & stress & tension & 450 & 0.7 & 10 \\
\hline 171 & Creep-Fatigue & Grade 91 & Rolled Plate (thick) & $\mathrm{AR}$ & heat-2 & $1 \mathrm{E}-03$ & air & stress & tension & 450 & 0.7 & 10 \\
\hline 172 & Creep-Fatigue & Grade 91 & Rolled Plate (thick) & $\mathrm{AR}$ & heat-2 & $1 \mathrm{E}-03$ & air & stress & tension & 450 & 0.7 & 60 \\
\hline 173 & Creep-Fatigue & Grade 91 & Rolled Plate (thick) & $\mathrm{AR}$ & heat-2 & $1 \mathrm{E}-03$ & air & stress & tension & 450 & 0.7 & 60 \\
\hline 174 & Creep-Fatigue & Grade 91 & Rolled Plate (thick) & $\mathrm{AR}$ & heat-2 & $1 \mathrm{E}-03$ & air & stress & tension & 450 & 0.7 & 60 \\
\hline 175 & Creep-Fatigue & Grade 91 & Rolled Plate (thick) & $\mathrm{AR}$ & heat-2 & $1 \mathrm{E}-03$ & air & stress & tension & 450 & 0.7 & $300 *$ \\
\hline 176 & Creep-Fatigue & Grade 91 & Rolled Plate (thick) & $\mathrm{AR}$ & heat-2 & $1 \mathrm{E}-03$ & air & stress & tension & 450 & 0.7 & $300^{*}$ \\
\hline 177 & Creep-Fatigue & Grade 91 & Rolled Plate (thick) & AR & heat-2 & $1 \mathrm{E}-03$ & air & stress & tension & 450 & 0.7 & $300^{*}$ \\
\hline 178 & Creep-Fatigue & Grade 91 & Rolled Plate (thick) & $\mathrm{AR}$ & heat-2 & $1 \mathrm{E}-03$ & air & stress & comp. & 450 & 0.7 & 1 \\
\hline 179 & Creep-Fatigue & Grade 91 & Rolled Plate (thick) & AR & heat-2 & $1 \mathrm{E}-03$ & air & stress & comp. & 450 & 0.7 & 1 \\
\hline 180 & Creep-Fatigue & Grade 91 & Rolled Plate (thick) & $\mathrm{AR}$ & heat-2 & $1 \mathrm{E}-03$ & air & stress & comp. & 450 & 0.7 & 1 \\
\hline 181 & Creep-Fatigue & Grade 91 & Rolled Plate (thick) & $\mathrm{AR}$ & heat-2 & $1 \mathrm{E}-03$ & air & stress & comp. & 450 & 0.7 & 10 \\
\hline 182 & Creep-Fatigue & Grade 91 & Rolled Plate (thick) & $\mathrm{AR}$ & heat-2 & $1 \mathrm{E}-03$ & air & stress & comp. & 450 & 0.7 & 10 \\
\hline 183 & Creep-Fatigue & Grade 91 & Rolled Plate (thick) & AR & heat-2 & $1 \mathrm{E}-03$ & air & stress & comp. & 450 & 0.7 & 10 \\
\hline 184 & Creep-Fatigue & Grade 91 & Rolled Plate (thick) & $\mathrm{AR}$ & heat-2 & $1 \mathrm{E}-03$ & air & stress & comp. & 450 & 0.7 & 60 \\
\hline 185 & Creep-Fatigue & Grade 91 & Rolled Plate (thick) & $\mathrm{AR}$ & heat-2 & $1 \mathrm{E}-03$ & air & stress & comp. & 450 & 0.7 & 60 \\
\hline 186 & Creep-Fatigue & Grade 91 & Rolled Plate (thick) & $\mathrm{AR}$ & heat-2 & $1 \mathrm{E}-03$ & air & stress & comp. & 450 & 0.7 & 60 \\
\hline 187 & Creep-Fatigue & Grade 91 & Rolled Plate (thick) & $\mathrm{AR}$ & heat-2 & $1 \mathrm{E}-03$ & air & stress & comp. & 450 & 0.7 & $300^{*}$ \\
\hline 188 & Creep-Fatigue & Grade 91 & Rolled Plate (thick) & $\mathrm{AR}$ & heat-2 & $1 \mathrm{E}-03$ & air & stress & comp. & 450 & 0.7 & $300 *$ \\
\hline 189 & Creep-Fatigue & Grade 91 & Rolled Plate (thick) & $\mathrm{AR}$ & heat-2 & $1 \mathrm{E}-03$ & air & stress & comp. & 450 & 0.7 & $300 *$ \\
\hline 190 & Creep-Fatigue & Grade 91 & Rolled Plate (thick) & AR & heat-2 & $1 \mathrm{E}-03$ & air & stress & N/A & 500 & 0.7 & 0 \\
\hline 191 & Creep-Fatigue & Grade 91 & Rolled Plate (thick) & AR & heat-2 & $1 \mathrm{E}-03$ & air & stress & $\mathrm{N} / \mathrm{A}$ & 500 & 0.7 & 0 \\
\hline 192 & Creep-Fatigue & Grade 91 & Rolled Plate (thick) & $\mathrm{AR}$ & heat-2 & $1 \mathrm{E}-03$ & air & stress & N/A & 500 & 0.7 & 0 \\
\hline 193 & Creep-Fatigue & Grade 91 & Rolled Plate (thick) & AR & heat-2 & $1 \mathrm{E}-03$ & air & stress & tension & 500 & 0.7 & 1 \\
\hline
\end{tabular}




Idaho National Laboratory
\begin{tabular}{|c|lll|}
\hline NEXT GENERATION NUCLEAR PLANT & Identifier: & PLN-2803 & \\
REACTOR PRESSURE VESSEL MATERIALS & Revision: & 0 & \\
RESEARCH AND DEVELOPMENT PLAN & Effective Date: & $04 / 30 / 08$ & Page: B-29 of B- 68 \\
\hline
\end{tabular}

\begin{tabular}{|c|c|c|c|c|c|c|c|c|c|c|c|c|}
\hline Spec.\# & Test Type & Material & Product Form & $\begin{array}{c}\text { Mat } \\
\text { Cond }\end{array}$ & $\begin{array}{c}\text { Grade } 91 \\
\text { Heat \# }\end{array}$ & $\begin{array}{c}\text { Strain } \\
\text { Rate } \\
(\mathrm{m} / \mathrm{m} / \mathrm{s})\end{array}$ & Env & $\begin{array}{l}\text { Hold } \\
\text { Cntrl } \\
\text { (stress or } \\
\text { strain) }\end{array}$ & $\begin{array}{l}\text { Stress } \\
\text { Hold in } \\
\text { T/C }\end{array}$ & $\begin{array}{c}\text { Temp. } \\
\left({ }^{\circ} \mathrm{C}\right)\end{array}$ & $\begin{array}{l}\text { Strain } \\
\text { Range } \\
(\%)\end{array}$ & $\begin{array}{l}\text { Stress } \\
\text { Hold } \\
\text { Time } \\
(\mathrm{min}) \\
\end{array}$ \\
\hline 194 & Creep-Fatigue & Grade 91 & Rolled Plate (thick) & $\mathrm{AR}$ & heat-2 & $1 \mathrm{E}-03$ & air & stress & tension & 500 & 0.7 & 1 \\
\hline 195 & Creep-Fatigue & Grade 91 & Rolled Plate (thick) & $\mathrm{AR}$ & heat-2 & $1 \mathrm{E}-03$ & air & stress & tension & 500 & 0.7 & 1 \\
\hline 196 & Creep-Fatigue & Grade 91 & Rolled Plate (thick) & $\mathrm{AR}$ & heat-2 & $1 \mathrm{E}-03$ & air & stress & tension & 500 & 0.7 & 10 \\
\hline 197 & Creep-Fatigue & Grade 91 & Rolled Plate (thick) & $\mathrm{AR}$ & heat-2 & $1 \mathrm{E}-03$ & air & stress & tension & 500 & 0.7 & 10 \\
\hline 198 & Creep-Fatigue & Grade 91 & Rolled Plate (thick) & $\mathrm{AR}$ & heat-2 & $1 \mathrm{E}-03$ & air & stress & tension & 500 & 0.7 & 10 \\
\hline 199 & Creep-Fatigue & Grade 91 & Rolled Plate (thick) & $\mathrm{AR}$ & heat-2 & $1 \mathrm{E}-03$ & air & stress & tension & 500 & 0.7 & 60 \\
\hline 200 & Creep-Fatigue & Grade 91 & Rolled Plate (thick) & $\mathrm{AR}$ & heat-2 & $1 \mathrm{E}-03$ & air & stress & tension & 500 & 0.7 & 60 \\
\hline 201 & Creep-Fatigue & Grade 91 & Rolled Plate (thick) & $\mathrm{AR}$ & heat-2 & $1 \mathrm{E}-03$ & air & stress & tension & 500 & 0.7 & 60 \\
\hline 202 & Creep-Fatigue & Grade 91 & Rolled Plate (thick) & $\mathrm{AR}$ & heat-2 & $1 \mathrm{E}-03$ & air & stress & tension & 500 & 0.7 & $300^{*}$ \\
\hline 203 & Creep-Fatigue & Grade 91 & Rolled Plate (thick) & $\mathrm{AR}$ & heat-2 & $1 \mathrm{E}-03$ & air & stress & tension & 500 & 0.7 & $300^{*}$ \\
\hline 204 & Creep-Fatigue & Grade 91 & Rolled Plate (thick) & $\mathrm{AR}$ & heat-2 & $1 \mathrm{E}-03$ & air & stress & tension & 500 & 0.7 & $300^{*}$ \\
\hline 205 & Creep-Fatigue & Grade 91 & Rolled Plate (thick) & $\mathrm{AR}$ & heat-2 & $1 \mathrm{E}-03$ & air & stress & comp. & 500 & 0.7 & 1 \\
\hline 206 & Creep-Fatigue & Grade 91 & Rolled Plate (thick) & $\mathrm{AR}$ & heat-2 & $1 \mathrm{E}-03$ & air & stress & comp. & 500 & 0.7 & 1 \\
\hline 207 & Creep-Fatigue & Grade 91 & Rolled Plate (thick) & $\mathrm{AR}$ & heat-2 & $1 \mathrm{E}-03$ & air & stress & comp. & 500 & 0.7 & 1 \\
\hline 208 & Creep-Fatigue & Grade 91 & Rolled Plate (thick) & $\mathrm{AR}$ & heat-2 & $1 \mathrm{E}-03$ & air & stress & comp. & 500 & 0.7 & 10 \\
\hline 209 & Creep-Fatigue & Grade 91 & Rolled Plate (thick) & $\mathrm{AR}$ & heat-2 & $1 \mathrm{E}-03$ & air & stress & comp. & 500 & 0.7 & 10 \\
\hline 210 & Creep-Fatigue & Grade 91 & Rolled Plate (thick) & $\mathrm{AR}$ & heat-2 & $1 \mathrm{E}-03$ & air & stress & comp. & 500 & 0.7 & 10 \\
\hline 211 & Creep-Fatigue & Grade 91 & Rolled Plate (thick) & $\mathrm{AR}$ & heat-2 & $1 \mathrm{E}-03$ & air & stress & comp. & 500 & 0.7 & 60 \\
\hline 212 & Creep-Fatigue & Grade 91 & Rolled Plate (thick) & $\mathrm{AR}$ & heat-2 & $1 \mathrm{E}-03$ & air & stress & comp. & 500 & 0.7 & 60 \\
\hline 213 & Creep-Fatigue & Grade 91 & Rolled Plate (thick) & $\mathrm{AR}$ & heat-2 & $1 \mathrm{E}-03$ & air & stress & comp. & 500 & 0.7 & 60 \\
\hline 214 & Creep-Fatigue & Grade 91 & Rolled Plate (thick) & $\mathrm{AR}$ & heat-2 & $1 \mathrm{E}-03$ & air & stress & comp. & 500 & 0.7 & $300^{*}$ \\
\hline 215 & Creep-Fatigue & Grade 91 & Rolled Plate (thick) & AR & heat-2 & $1 \mathrm{E}-03$ & air & stress & comp. & 500 & 0.7 & $300^{*}$ \\
\hline 216 & Creep-Fatigue & Grade 91 & Rolled Plate (thick) & AR & heat-2 & $1 \mathrm{E}-03$ & air & stress & comp. & 500 & 0.7 & $300^{*}$ \\
\hline
\end{tabular}




Idaho National Laboratory
\begin{tabular}{|c|lll|}
\hline NEXT GENERATION NUCLEAR PLANT & Identifier: & PLN-2803 & \\
REACTOR PRESSURE VESSEL MATERIALS & Revision: & 0 & \\
RESEARCH AND DEVELOPMENT PLAN & Effective Date: & $04 / 30 / 08$ & Page: B-30 of B- 68 \\
\hline
\end{tabular}

\begin{tabular}{|c|c|c|c|c|c|c|c|c|c|c|c|}
\hline \multicolumn{12}{|c|}{ Table B6. Fatigue-Relaxation Tests for Grade 91 steel at $500^{\circ} \mathrm{C}$} \\
\hline Spec. \# & Material & Product Form & $\begin{array}{l}\text { Mat } \\
\text { Cond }\end{array}$ & Heat & $\begin{array}{l}\text { Strain } \\
\text { Rate } \\
(\mathrm{m} / \mathrm{m} / \mathrm{s})\end{array}$ & Env & $\begin{array}{c}\text { Hold Cntrl } \\
\text { (stress/strain) }\end{array}$ & $\begin{array}{c}\text { Strain } \\
\text { Hold in } \\
\text { T/C }\end{array}$ & $\begin{array}{l}\text { Temp. } \\
\left({ }^{\circ} \mathrm{C}\right)\end{array}$ & $\begin{array}{c}\text { Strain } \\
\text { Range } \\
(\%)\end{array}$ & $\begin{array}{c}\text { Time During } \\
\text { Strain Hold } \\
\text { (min) }\end{array}$ \\
\hline 1 & Grade 91 & Forging (thick) & $\mathrm{AR}$ & heat-1 & $1 \mathrm{E}-03$ & air & strain & N/A & 500 & 0.5 & 0 \\
\hline 2 & Grade 91 & Forging (thick) & $\mathrm{AR}$ & heat-1 & $1 \mathrm{E}-03$ & air & strain & $\mathrm{N} / \mathrm{A}$ & 500 & 0.5 & 0 \\
\hline 3 & Grade 91 & Forging (thick) & AR & heat-1 & $1 \mathrm{E}-03$ & air & strain & N/A & 500 & 0.5 & 0 \\
\hline 4 & Grade 91 & Forging (thick) & $\mathrm{AR}$ & heat-1 & $1 \mathrm{E}-03$ & air & strain & tension & 500 & 0.5 & 10 \\
\hline 5 & Grade 91 & Forging (thick) & $\mathrm{AR}$ & heat-1 & $1 \mathrm{E}-03$ & air & strain & tension & 500 & 0.5 & 10 \\
\hline 6 & Grade 91 & Forging (thick) & $\mathrm{AR}$ & heat-1 & $1 \mathrm{E}-03$ & air & strain & tension & 500 & 0.5 & 10 \\
\hline 7 & Grade 91 & Forging (thick) & $\mathrm{AR}$ & heat-1 & $1 \mathrm{E}-03$ & air & strain & tension & 500 & 0.5 & 30 \\
\hline 8 & Grade 91 & Forging (thick) & $\mathrm{AR}$ & heat-1 & $1 \mathrm{E}-03$ & air & strain & tension & 500 & 0.5 & 30 \\
\hline 9 & Grade 91 & Forging (thick) & $\mathrm{AR}$ & heat-1 & $1 \mathrm{E}-03$ & air & strain & tension & 500 & 0.5 & 30 \\
\hline 10 & Grade 91 & Forging (thick) & $\mathrm{AR}$ & heat-1 & $1 \mathrm{E}-03$ & air & strain & tension & 500 & 0.5 & 60 \\
\hline 11 & Grade 91 & Forging (thick) & $\mathrm{AR}$ & heat-1 & $1 \mathrm{E}-03$ & air & strain & tension & 500 & 0.5 & 60 \\
\hline 12 & Grade 91 & Forging (thick) & $\mathrm{AR}$ & heat-1 & $1 \mathrm{E}-03$ & air & strain & tension & 500 & 0.5 & 60 \\
\hline 13 & Grade 91 & Forging (thick) & $\mathrm{AR}$ & heat-1 & $1 \mathrm{E}-03$ & air & strain & tension & 500 & 0.5 & 90 \\
\hline 14 & Grade 91 & Forging (thick) & $\mathrm{AR}$ & heat-1 & $1 \mathrm{E}-03$ & air & strain & tension & 500 & 0.5 & 90 \\
\hline 15 & Grade 91 & Forging (thick) & AR & heat-1 & $1 \mathrm{E}-03$ & air & strain & tension & 500 & 0.5 & 90 \\
\hline 16 & Grade 91 & Forging (thick) & $\mathrm{AR}$ & heat-1 & $1 \mathrm{E}-03$ & air & strain & tension & 500 & 0.5 & 120 \\
\hline 17 & Grade 91 & Forging (thick) & $\mathrm{AR}$ & heat-1 & $1 \mathrm{E}-03$ & air & strain & tension & 500 & 0.5 & 120 \\
\hline 18 & Grade 91 & Forging (thick) & $\mathrm{AR}$ & heat-1 & $1 \mathrm{E}-03$ & air & strain & tension & 500 & 0.5 & 120 \\
\hline 19 & Grade 91 & Forging (thick) & $\mathrm{AR}$ & heat-1 & $1 \mathrm{E}-03$ & air & strain & N/A & 500 & 0.7 & 0 \\
\hline 20 & Grade 91 & Forging (thick) & $\mathrm{AR}$ & heat-1 & $1 \mathrm{E}-03$ & air & strain & N/A & 500 & 0.7 & 0 \\
\hline 21 & Grade 91 & Forging (thick) & $\mathrm{AR}$ & heat-1 & $1 \mathrm{E}-03$ & air & strain & N/A & 500 & 0.7 & 0 \\
\hline 22 & Grade 91 & Forging (thick) & $\mathrm{AR}$ & heat-1 & $1 \mathrm{E}-03$ & air & strain & tension & 500 & 0.7 & 10 \\
\hline 23 & Grade 91 & Forging (thick) & $\mathrm{AR}$ & heat-1 & $1 \mathrm{E}-03$ & air & strain & tension & 500 & 0.7 & 10 \\
\hline 24 & Grade 91 & Forging (thick) & $\mathrm{AR}$ & heat-1 & $1 \mathrm{E}-03$ & air & strain & tension & 500 & 0.7 & 10 \\
\hline
\end{tabular}




Idaho National Laboratory
\begin{tabular}{|c|lll|}
\hline NEXT GENERATION NUCLEAR PLANT & Identifier: & PLN-2803 & \\
REACTOR PRESSURE VESSEL MATERIALS & Revision: & 0 & \\
RESEARCH AND DEVELOPMENT PLAN & Effective Date: & $04 / 30 / 08$ & Page: B-31 of B- 68 \\
\hline
\end{tabular}

\begin{tabular}{|c|c|c|c|c|c|c|c|c|c|c|c|}
\hline \multicolumn{12}{|c|}{ Table B6. Fatigue-Relaxation Tests for Grade 91 steel at $500^{\circ} \mathrm{C}$} \\
\hline Spec. \# & Material & Product Form & $\begin{array}{l}\text { Mat } \\
\text { Cond }\end{array}$ & Heat & $\begin{array}{l}\text { Strain } \\
\text { Rate } \\
(\mathrm{m} / \mathrm{m} / \mathrm{s})\end{array}$ & Env & $\begin{array}{c}\text { Hold Cntrl } \\
\text { (stress/strain) }\end{array}$ & $\begin{array}{c}\text { Strain } \\
\text { Hold in } \\
T / C\end{array}$ & $\begin{array}{l}\text { Temp. } \\
\left({ }^{\circ} \mathrm{C}\right)\end{array}$ & $\begin{array}{c}\text { Strain } \\
\text { Range } \\
(\%)\end{array}$ & $\begin{array}{l}\text { Time During } \\
\text { Strain Hold } \\
\text { (min) }\end{array}$ \\
\hline 25 & Grade 91 & Forging (thick) & $\mathrm{AR}$ & heat-1 & $1 \mathrm{E}-03$ & air & strain & tension & 500 & 0.7 & 30 \\
\hline 26 & Grade 91 & Forging (thick) & $\mathrm{AR}$ & heat-1 & $1 \mathrm{E}-03$ & air & strain & tension & 500 & 0.7 & 30 \\
\hline 27 & Grade 91 & Forging (thick) & $\mathrm{AR}$ & heat-1 & $1 \mathrm{E}-03$ & air & strain & tension & 500 & 0.7 & 30 \\
\hline 28 & Grade 91 & Forging (thick) & $\mathrm{AR}$ & heat-1 & $1 \mathrm{E}-03$ & air & strain & tension & 500 & 0.7 & 60 \\
\hline 29 & Grade 91 & Forging (thick) & $\mathrm{AR}$ & heat-1 & $1 \mathrm{E}-03$ & air & strain & tension & 500 & 0.7 & 60 \\
\hline 30 & Grade 91 & Forging (thick) & $\mathrm{AR}$ & heat-1 & $1 \mathrm{E}-03$ & air & strain & tension & 500 & 0.7 & 60 \\
\hline 31 & Grade 91 & Forging (thick) & $\mathrm{AR}$ & heat-1 & $1 \mathrm{E}-03$ & air & strain & tension & 500 & 0.7 & 90 \\
\hline 32 & Grade 91 & Forging (thick) & AR & heat-1 & $1 \mathrm{E}-03$ & air & strain & tension & 500 & 0.7 & 90 \\
\hline 33 & Grade 91 & Forging (thick) & $\mathrm{AR}$ & heat-1 & $1 \mathrm{E}-03$ & air & strain & tension & 500 & 0.7 & 90 \\
\hline 34 & Grade 91 & Forging (thick) & $\mathrm{AR}$ & heat-1 & $1 \mathrm{E}-03$ & air & strain & tension & 500 & 0.7 & 120 \\
\hline 35 & Grade 91 & Forging (thick) & $\mathrm{AR}$ & heat-1 & $1 \mathrm{E}-03$ & air & strain & tension & 500 & 0.7 & 120 \\
\hline 36 & Grade 91 & Forging (thick) & $\mathrm{AR}$ & heat-1 & $1 \mathrm{E}-03$ & air & strain & tension & 500 & 0.7 & 120 \\
\hline 37 & Grade 91 & Forging (thick) & $\mathrm{AR}$ & heat-1 & $1 \mathrm{E}-03$ & air & strain & N/A & 500 & 1.0 & 0 \\
\hline 38 & Grade 91 & Forging (thick) & $\mathrm{AR}$ & heat-1 & $1 \mathrm{E}-03$ & air & strain & N/A & 500 & 1.0 & 0 \\
\hline 39 & Grade 91 & Forging (thick) & $\mathrm{AR}$ & heat-1 & $1 \mathrm{E}-03$ & air & strain & N/A & 500 & 1.0 & 0 \\
\hline 40 & Grade 91 & Forging (thick) & $\mathrm{AR}$ & heat-1 & $1 \mathrm{E}-03$ & air & strain & tension & 500 & 1.0 & 10 \\
\hline 41 & Grade 91 & Forging (thick) & AR & heat-1 & $1 \mathrm{E}-03$ & air & strain & tension & 500 & 1.0 & 10 \\
\hline 42 & Grade 91 & Forging (thick) & $\mathrm{AR}$ & heat-1 & $1 \mathrm{E}-03$ & air & strain & tension & 500 & 1.0 & 10 \\
\hline 43 & Grade 91 & Forging (thick) & $\mathrm{AR}$ & heat-1 & $1 \mathrm{E}-03$ & air & strain & tension & 500 & 1.0 & 30 \\
\hline 44 & Grade 91 & Forging (thick) & $\mathrm{AR}$ & heat-1 & $1 \mathrm{E}-03$ & air & strain & tension & 500 & 1.0 & 30 \\
\hline 45 & Grade 91 & Forging (thick) & $\mathrm{AR}$ & heat-1 & $1 \mathrm{E}-03$ & air & strain & tension & 500 & 1.0 & 30 \\
\hline 46 & Grade 91 & Forging (thick) & $\mathrm{AR}$ & heat-1 & $1 \mathrm{E}-03$ & air & strain & tension & 500 & 1.0 & 60 \\
\hline 47 & Grade 91 & Forging (thick) & $\mathrm{AR}$ & heat-1 & $1 \mathrm{E}-03$ & air & strain & tension & 500 & 1.0 & 60 \\
\hline 48 & Grade 91 & Forging (thick) & $\mathrm{AR}$ & heat-1 & $1 \mathrm{E}-03$ & air & strain & tension & 500 & 1.0 & 60 \\
\hline 49 & Grade 91 & Forging (thick) & $\mathrm{AR}$ & heat-1 & $1 \mathrm{E}-03$ & air & strain & tension & 500 & 1.0 & 90 \\
\hline
\end{tabular}




Idaho National Laboratory
\begin{tabular}{|c|lll|}
\hline NEXT GENERATION NUCLEAR PLANT & Identifier: & PLN-2803 & \\
REACTOR PRESSURE VESSEL MATERIALS & Revision: & 0 & \\
RESEARCH AND DEVELOPMENT PLAN & Effective Date: & $04 / 30 / 08$ & Page: B-32 of B- 68 \\
\hline
\end{tabular}

\begin{tabular}{|c|c|c|c|c|c|c|c|c|c|c|c|}
\hline \multicolumn{12}{|c|}{ Table B6. Fatigue-Relaxation Tests for Grade 91 steel at $500^{\circ} \mathrm{C}$} \\
\hline Spec. \# & Material & Product Form & $\begin{array}{l}\text { Mat } \\
\text { Cond }\end{array}$ & Heat & $\begin{array}{l}\text { Strain } \\
\text { Rate } \\
(\mathrm{m} / \mathrm{m} / \mathrm{s})\end{array}$ & Env & $\begin{array}{c}\text { Hold Cntrl } \\
\text { (stress/strain) }\end{array}$ & $\begin{array}{c}\text { Strain } \\
\text { Hold in } \\
T / C\end{array}$ & $\begin{array}{l}\text { Temp. } \\
\left({ }^{\circ} \mathrm{C}\right)\end{array}$ & $\begin{array}{c}\text { Strain } \\
\text { Range } \\
(\%)\end{array}$ & $\begin{array}{l}\text { Time During } \\
\text { Strain Hold } \\
\text { (min) }\end{array}$ \\
\hline 50 & Grade 91 & Forging (thick) & $\mathrm{AR}$ & heat-1 & $1 \mathrm{E}-03$ & air & strain & tension & 500 & 1.0 & 90 \\
\hline 51 & Grade 91 & Forging (thick) & $\mathrm{AR}$ & heat-1 & $1 \mathrm{E}-03$ & air & strain & tension & 500 & 1.0 & 90 \\
\hline 52 & Grade 91 & Forging (thick) & $\mathrm{AR}$ & heat-1 & $1 \mathrm{E}-03$ & air & strain & tension & 500 & 1.0 & 120 \\
\hline 53 & Grade 91 & Forging (thick) & $\mathrm{AR}$ & heat-1 & $1 \mathrm{E}-03$ & air & strain & tension & 500 & 1.0 & 120 \\
\hline 54 & Grade 91 & Forging (thick) & $\mathrm{AR}$ & heat-1 & $1 \mathrm{E}-03$ & air & strain & tension & 500 & 1.0 & 120 \\
\hline 55 & Grade 91 & Forging (thick) & $\mathrm{AR}$ & heat-1 & $1 \mathrm{E}-03$ & air & strain & comp. & 500 & 0.5 & 10 \\
\hline 56 & Grade 91 & Forging (thick) & $\mathrm{AR}$ & heat-1 & $1 \mathrm{E}-03$ & air & strain & comp. & 500 & 0.5 & 10 \\
\hline 57 & Grade 91 & Forging (thick) & AR & heat-1 & $1 \mathrm{E}-03$ & air & strain & comp. & 500 & 0.5 & 10 \\
\hline 58 & Grade 91 & Forging (thick) & $\mathrm{AR}$ & heat-1 & $1 \mathrm{E}-03$ & air & strain & comp. & 500 & 0.5 & 30 \\
\hline 59 & Grade 91 & Forging (thick) & $\mathrm{AR}$ & heat-1 & $1 \mathrm{E}-03$ & air & strain & comp. & 500 & 0.5 & 30 \\
\hline 60 & Grade 91 & Forging (thick) & $\mathrm{AR}$ & heat-1 & $1 \mathrm{E}-03$ & air & strain & comp. & 500 & 0.5 & 30 \\
\hline 61 & Grade 91 & Forging (thick) & $\mathrm{AR}$ & heat-1 & $1 \mathrm{E}-03$ & air & strain & comp. & 500 & 0.5 & 60 \\
\hline 62 & Grade 91 & Forging (thick) & $\mathrm{AR}$ & heat-1 & $1 \mathrm{E}-03$ & air & strain & comp. & 500 & 0.5 & 60 \\
\hline 63 & Grade 91 & Forging (thick) & AR & heat-1 & $1 \mathrm{E}-03$ & air & strain & comp. & 500 & 0.5 & 60 \\
\hline 64 & Grade 91 & Forging (thick) & $\mathrm{AR}$ & heat-1 & $1 \mathrm{E}-03$ & air & strain & comp. & 500 & 0.5 & 90 \\
\hline 65 & Grade 91 & Forging (thick) & $\mathrm{AR}$ & heat-1 & $1 \mathrm{E}-03$ & air & strain & comp. & 500 & 0.5 & 90 \\
\hline 66 & Grade 91 & Forging (thick) & AR & heat-1 & $1 \mathrm{E}-03$ & air & strain & comp. & 500 & 0.5 & 90 \\
\hline 67 & Grade 91 & Forging (thick) & $\mathrm{AR}$ & heat-1 & $1 \mathrm{E}-03$ & air & strain & comp. & 500 & 0.5 & 120 \\
\hline 68 & Grade 91 & Forging (thick) & $\mathrm{AR}$ & heat-1 & $1 \mathrm{E}-03$ & air & strain & comp. & 500 & 0.5 & 120 \\
\hline 69 & Grade 91 & Forging (thick) & $\mathrm{AR}$ & heat-1 & $1 \mathrm{E}-03$ & air & strain & comp. & 500 & 0.5 & 120 \\
\hline 70 & Grade 91 & Forging (thick) & $\mathrm{AR}$ & heat-1 & $1 \mathrm{E}-03$ & air & strain & comp. & 500 & 0.7 & 10 \\
\hline 71 & Grade 91 & Forging (thick) & $\mathrm{AR}$ & heat-1 & $1 \mathrm{E}-03$ & air & strain & comp. & 500 & 0.7 & 10 \\
\hline 72 & Grade 91 & Forging (thick) & $\mathrm{AR}$ & heat-1 & $1 \mathrm{E}-03$ & air & strain & comp. & 500 & 0.7 & 10 \\
\hline 73 & Grade 91 & Forging (thick) & $\mathrm{AR}$ & heat-1 & $1 \mathrm{E}-03$ & air & strain & comp. & 500 & 0.7 & 30 \\
\hline 74 & Grade 91 & Forging (thick) & $\mathrm{AR}$ & heat-1 & $1 \mathrm{E}-03$ & air & strain & comp. & 500 & 0.7 & 30 \\
\hline
\end{tabular}




Idaho National Laboratory
\begin{tabular}{|c|lll|}
\hline NEXT GENERATION NUCLEAR PLANT & Identifier: & PLN-2803 & \\
REACTOR PRESSURE VESSEL MATERIALS & Revision: & 0 & \\
RESEARCH AND DEVELOPMENT PLAN & Effective Date: & $04 / 30 / 08$ & Page: B-33 of B- 68 \\
\hline
\end{tabular}

\begin{tabular}{|c|c|c|c|c|c|c|c|c|c|c|c|}
\hline \multicolumn{12}{|c|}{ Table B6. Fatigue-Relaxation Tests for Grade 91 steel at $500^{\circ} \mathrm{C}$} \\
\hline Spec. \# & Material & Product Form & $\begin{array}{l}\text { Mat } \\
\text { Cond }\end{array}$ & Heat & $\begin{array}{l}\text { Strain } \\
\text { Rate } \\
(\mathrm{m} / \mathrm{m} / \mathrm{s})\end{array}$ & Env & $\begin{array}{c}\text { Hold Cntrl } \\
\text { (stress/strain) }\end{array}$ & $\begin{array}{c}\text { Strain } \\
\text { Hold in } \\
T / C\end{array}$ & $\begin{array}{l}\text { Temp. } \\
\left({ }^{\circ} \mathrm{C}\right)\end{array}$ & $\begin{array}{c}\text { Strain } \\
\text { Range } \\
(\%)\end{array}$ & $\begin{array}{l}\text { Time During } \\
\text { Strain Hold } \\
\text { (min) }\end{array}$ \\
\hline 75 & Grade 91 & Forging (thick) & $\mathrm{AR}$ & heat-1 & $1 \mathrm{E}-03$ & air & strain & comp. & 500 & 0.7 & 30 \\
\hline 76 & Grade 91 & Forging (thick) & $\mathrm{AR}$ & heat-1 & $1 \mathrm{E}-03$ & air & strain & comp. & 500 & 0.7 & 60 \\
\hline 77 & Grade 91 & Forging (thick) & $\mathrm{AR}$ & heat-1 & $1 \mathrm{E}-03$ & air & strain & comp. & 500 & 0.7 & 60 \\
\hline 78 & Grade 91 & Forging (thick) & $\mathrm{AR}$ & heat-1 & $1 \mathrm{E}-03$ & air & strain & comp. & 500 & 0.7 & 60 \\
\hline 79 & Grade 91 & Forging (thick) & $\mathrm{AR}$ & heat-1 & $1 \mathrm{E}-03$ & air & strain & comp. & 500 & 0.7 & 90 \\
\hline 80 & Grade 91 & Forging (thick) & $\mathrm{AR}$ & heat-1 & $1 \mathrm{E}-03$ & air & strain & comp. & 500 & 0.7 & 90 \\
\hline 81 & Grade 91 & Forging (thick) & $\mathrm{AR}$ & heat-1 & $1 \mathrm{E}-03$ & air & strain & comp. & 500 & 0.7 & 90 \\
\hline 82 & Grade 91 & Forging (thick) & AR & heat-1 & $1 \mathrm{E}-03$ & air & strain & comp. & 500 & 0.7 & 120 \\
\hline 83 & Grade 91 & Forging (thick) & $\mathrm{AR}$ & heat-1 & $1 \mathrm{E}-03$ & air & strain & comp. & 500 & 0.7 & 120 \\
\hline 84 & Grade 91 & Forging (thick) & $\mathrm{AR}$ & heat-1 & $1 \mathrm{E}-03$ & air & strain & comp. & 500 & 0.7 & 120 \\
\hline 85 & Grade 91 & Forging (thick) & $\mathrm{AR}$ & heat-1 & $1 \mathrm{E}-03$ & air & strain & comp. & 500 & 1.0 & 10 \\
\hline 86 & Grade 91 & Forging (thick) & $\mathrm{AR}$ & heat-1 & $1 \mathrm{E}-03$ & air & strain & comp. & 500 & 1.0 & 10 \\
\hline 87 & Grade 91 & Forging (thick) & $\mathrm{AR}$ & heat-1 & $1 \mathrm{E}-03$ & air & strain & comp. & 500 & 1.0 & 10 \\
\hline 88 & Grade 91 & Forging (thick) & AR & heat-1 & $1 \mathrm{E}-03$ & air & strain & comp. & 500 & 1.0 & 30 \\
\hline 89 & Grade 91 & Forging (thick) & $\mathrm{AR}$ & heat-1 & $1 \mathrm{E}-03$ & air & strain & comp. & 500 & 1.0 & 30 \\
\hline 90 & Grade 91 & Forging (thick) & $\mathrm{AR}$ & heat-1 & $1 \mathrm{E}-03$ & air & strain & comp. & 500 & 1.0 & 30 \\
\hline 91 & Grade 91 & Forging (thick) & AR & heat-1 & $1 \mathrm{E}-03$ & air & strain & comp. & 500 & 1.0 & 60 \\
\hline 92 & Grade 91 & Forging (thick) & $\mathrm{AR}$ & heat-1 & $1 \mathrm{E}-03$ & air & strain & comp. & 500 & 1.0 & 60 \\
\hline 93 & Grade 91 & Forging (thick) & $\mathrm{AR}$ & heat-1 & $1 \mathrm{E}-03$ & air & strain & comp. & 500 & 1.0 & 60 \\
\hline 94 & Grade 91 & Forging (thick) & $\mathrm{AR}$ & heat-1 & $1 \mathrm{E}-03$ & air & strain & comp. & 500 & 1.0 & 90 \\
\hline 95 & Grade 91 & Forging (thick) & $\mathrm{AR}$ & heat-1 & $1 \mathrm{E}-03$ & air & strain & comp. & 500 & 1.0 & 90 \\
\hline 96 & Grade 91 & Forging (thick) & $\mathrm{AR}$ & heat-1 & $1 \mathrm{E}-03$ & air & strain & comp. & 500 & 1.0 & 90 \\
\hline 97 & Grade 91 & Forging (thick) & $\mathrm{AR}$ & heat-1 & $1 \mathrm{E}-03$ & air & strain & comp. & 500 & 1.0 & 120 \\
\hline 98 & Grade 91 & Forging (thick) & $\mathrm{AR}$ & heat-1 & $1 \mathrm{E}-03$ & air & strain & comp. & 500 & 1.0 & 120 \\
\hline 99 & Grade 91 & Forging (thick) & $\mathrm{AR}$ & heat-1 & $1 \mathrm{E}-03$ & air & strain & comp. & 500 & 1.0 & 120 \\
\hline
\end{tabular}




Idaho National Laboratory
\begin{tabular}{|c|lll|}
\hline NEXT GENERATION NUCLEAR PLANT & Identifier: & PLN-2803 & \\
REACTOR PRESSURE VESSEL MATERIALS & Revision: & 0 & \\
RESEARCH AND DEVELOPMENT PLAN & Effective Date: & $04 / 30 / 08$ & Page: B-34 of B- 68 \\
\hline
\end{tabular}

\begin{tabular}{|c|c|c|c|c|c|c|c|c|c|c|c|}
\hline \multicolumn{12}{|c|}{ Table B6. Fatigue-Relaxation Tests for Grade 91 steel at $500^{\circ} \mathrm{C}$} \\
\hline Spec. \# & Material & Product Form & $\begin{array}{l}\text { Mat } \\
\text { Cond }\end{array}$ & Heat & $\begin{array}{l}\text { Strain } \\
\text { Rate } \\
(\mathrm{m} / \mathrm{m} / \mathrm{s})\end{array}$ & Env & $\begin{array}{c}\text { Hold Cntrl } \\
\text { (stress/strain) }\end{array}$ & $\begin{array}{c}\text { Strain } \\
\text { Hold in } \\
T / C\end{array}$ & $\begin{array}{l}\text { Temp. } \\
\left({ }^{\circ} \mathrm{C}\right)\end{array}$ & $\begin{array}{c}\text { Strain } \\
\text { Range } \\
(\%)\end{array}$ & $\begin{array}{l}\text { Time During } \\
\text { Strain Hold } \\
\text { (min) }\end{array}$ \\
\hline 100 & Grade 91 & Forging (thick) & $\mathrm{AR}$ & heat-1 & $1 \mathrm{E}-03$ & NGNP-He & strain & $\mathrm{N} / \mathrm{A}$ & 500 & 0.5 & 0 \\
\hline 101 & Grade 91 & Forging (thick) & $\mathrm{AR}$ & heat-1 & $1 \mathrm{E}-03$ & NGNP-He & strain & N/A & 500 & 0.5 & 0 \\
\hline 102 & Grade 91 & Forging (thick) & $\mathrm{AR}$ & heat-1 & $1 \mathrm{E}-03$ & NGNP-He & strain & N/A & 500 & 0.5 & 0 \\
\hline 103 & Grade 91 & Forging (thick) & $\mathrm{AR}$ & heat-1 & $1 \mathrm{E}-03$ & NGNP-He & strain & tension & 500 & 0.5 & 10 \\
\hline 104 & Grade 91 & Forging (thick) & $\mathrm{AR}$ & heat-1 & $1 \mathrm{E}-03$ & NGNP-He & strain & tension & 500 & 0.5 & 10 \\
\hline 105 & Grade 91 & Forging (thick) & $\mathrm{AR}$ & heat-1 & $1 \mathrm{E}-03$ & NGNP-He & strain & tension & 500 & 0.5 & 10 \\
\hline 106 & Grade 91 & Forging (thick) & $\mathrm{AR}$ & heat-1 & $1 \mathrm{E}-03$ & NGNP-He & strain & tension & 500 & 0.5 & 30 \\
\hline 107 & Grade 91 & Forging (thick) & AR & heat-1 & $1 \mathrm{E}-03$ & NGNP-He & strain & tension & 500 & 0.5 & 30 \\
\hline 108 & Grade 91 & Forging (thick) & $\mathrm{AR}$ & heat-1 & $1 \mathrm{E}-03$ & NGNP-He & strain & tension & 500 & 0.5 & 30 \\
\hline 109 & Grade 91 & Forging (thick) & $\mathrm{AR}$ & heat-1 & $1 \mathrm{E}-03$ & NGNP-He & strain & tension & 500 & 0.5 & 60 \\
\hline 110 & Grade 91 & Forging (thick) & $\mathrm{AR}$ & heat-1 & $1 \mathrm{E}-03$ & NGNP-He & strain & tension & 500 & 0.5 & 60 \\
\hline 111 & Grade 91 & Forging (thick) & $\mathrm{AR}$ & heat-1 & $1 \mathrm{E}-03$ & NGNP-He & strain & tension & 500 & 0.5 & 60 \\
\hline 112 & Grade 91 & Forging (thick) & $\mathrm{AR}$ & heat-1 & $1 \mathrm{E}-03$ & NGNP-He & strain & tension & 500 & 0.5 & 90 \\
\hline 113 & Grade 91 & Forging (thick) & AR & heat-1 & $1 \mathrm{E}-03$ & NGNP-He & strain & tension & 500 & 0.5 & 90 \\
\hline 114 & Grade 91 & Forging (thick) & $\mathrm{AR}$ & heat-1 & $1 \mathrm{E}-03$ & NGNP-He & strain & tension & 500 & 0.5 & 90 \\
\hline 115 & Grade 91 & Forging (thick) & $\mathrm{AR}$ & heat-1 & $1 \mathrm{E}-03$ & NGNP-He & strain & tension & 500 & 0.5 & 120 \\
\hline 116 & Grade 91 & Forging (thick) & AR & heat-1 & $1 \mathrm{E}-03$ & NGNP-He & strain & tension & 500 & 0.5 & 120 \\
\hline 117 & Grade 91 & Forging (thick) & $\mathrm{AR}$ & heat-1 & $1 \mathrm{E}-03$ & NGNP-He & strain & tension & 500 & 0.5 & 120 \\
\hline 118 & Grade 91 & Forging (thick) & $\mathrm{AR}$ & heat-1 & $1 \mathrm{E}-03$ & NGNP-He & strain & N/A & 500 & 0.7 & 0 \\
\hline 119 & Grade 91 & Forging (thick) & $\mathrm{AR}$ & heat-1 & $1 \mathrm{E}-03$ & NGNP-He & strain & N/A & 500 & 0.7 & 0 \\
\hline 120 & Grade 91 & Forging (thick) & $\mathrm{AR}$ & heat-1 & $1 \mathrm{E}-03$ & NGNP-He & strain & $\mathrm{N} / \mathrm{A}$ & 500 & 0.7 & 0 \\
\hline 121 & Grade 91 & Forging (thick) & $\mathrm{AR}$ & heat-1 & $1 \mathrm{E}-03$ & NGNP-He & strain & tension & 500 & 0.7 & 10 \\
\hline 122 & Grade 91 & Forging (thick) & $\mathrm{AR}$ & heat-1 & $1 \mathrm{E}-03$ & NGNP-He & strain & tension & 500 & 0.7 & 10 \\
\hline 123 & Grade 91 & Forging (thick) & $\mathrm{AR}$ & heat-1 & $1 \mathrm{E}-03$ & NGNP-He & strain & tension & 500 & 0.7 & 10 \\
\hline 124 & Grade 91 & Forging (thick) & $\mathrm{AR}$ & heat-1 & $1 \mathrm{E}-03$ & NGNP-He & strain & tension & 500 & 0.7 & 30 \\
\hline
\end{tabular}




Idaho National Laboratory
\begin{tabular}{|c|lll|}
\hline NEXT GENERATION NUCLEAR PLANT & Identifier: & PLN-2803 & \\
REACTOR PRESSURE VESSEL MATERIALS & Revision: & 0 & \\
RESEARCH AND DEVELOPMENT PLAN & Effective Date: & $04 / 30 / 08$ & Page: B-35 of B- 68 \\
\hline
\end{tabular}

\begin{tabular}{|c|c|c|c|c|c|c|c|c|c|c|c|}
\hline \multicolumn{12}{|c|}{ Table B6. Fatigue-Relaxation Tests for Grade 91 steel at $500^{\circ} \mathrm{C}$} \\
\hline Spec. \# & Material & Product Form & $\begin{array}{l}\text { Mat } \\
\text { Cond }\end{array}$ & Heat & $\begin{array}{l}\text { Strain } \\
\text { Rate } \\
(\mathrm{m} / \mathrm{m} / \mathrm{s})\end{array}$ & Env & $\begin{array}{c}\text { Hold Cntrl } \\
\text { (stress/strain) }\end{array}$ & $\begin{array}{c}\text { Strain } \\
\text { Hold in } \\
T / C\end{array}$ & $\begin{array}{l}\text { Temp. } \\
\left({ }^{\circ} \mathrm{C}\right)\end{array}$ & $\begin{array}{c}\text { Strain } \\
\text { Range } \\
(\%)\end{array}$ & $\begin{array}{l}\text { Time During } \\
\text { Strain Hold } \\
\text { (min) }\end{array}$ \\
\hline 125 & Grade 91 & Forging (thick) & $\mathrm{AR}$ & heat-1 & $1 \mathrm{E}-03$ & NGNP-He & strain & tension & 500 & 0.7 & 30 \\
\hline 126 & Grade 91 & Forging (thick) & $\mathrm{AR}$ & heat-1 & $1 \mathrm{E}-03$ & NGNP-He & strain & tension & 500 & 0.7 & 30 \\
\hline 127 & Grade 91 & Forging (thick) & $\mathrm{AR}$ & heat-1 & $1 \mathrm{E}-03$ & NGNP-He & strain & tension & 500 & 0.7 & 60 \\
\hline 128 & Grade 91 & Forging (thick) & $\mathrm{AR}$ & heat-1 & $1 \mathrm{E}-03$ & NGNP-He & strain & tension & 500 & 0.7 & 60 \\
\hline 129 & Grade 91 & Forging (thick) & $\mathrm{AR}$ & heat-1 & $1 \mathrm{E}-03$ & NGNP-He & strain & tension & 500 & 0.7 & 60 \\
\hline 130 & Grade 91 & Forging (thick) & $\mathrm{AR}$ & heat-1 & $1 \mathrm{E}-03$ & NGNP-He & strain & tension & 500 & 0.7 & 90 \\
\hline 131 & Grade 91 & Forging (thick) & $\mathrm{AR}$ & heat-1 & $1 \mathrm{E}-03$ & NGNP-He & strain & tension & 500 & 0.7 & 90 \\
\hline 132 & Grade 91 & Forging (thick) & AR & heat-1 & $1 \mathrm{E}-03$ & NGNP-He & strain & tension & 500 & 0.7 & 90 \\
\hline 133 & Grade 91 & Forging (thick) & $\mathrm{AR}$ & heat-1 & $1 \mathrm{E}-03$ & NGNP-He & strain & tension & 500 & 0.7 & 120 \\
\hline 134 & Grade 91 & Forging (thick) & $\mathrm{AR}$ & heat-1 & $1 \mathrm{E}-03$ & NGNP-He & strain & tension & 500 & 0.7 & 120 \\
\hline 135 & Grade 91 & Forging (thick) & $\mathrm{AR}$ & heat-1 & $1 \mathrm{E}-03$ & NGNP-He & strain & tension & 500 & 0.7 & 120 \\
\hline 136 & Grade 91 & Forging (thick) & $\mathrm{AR}$ & heat-1 & $1 \mathrm{E}-03$ & NGNP-He & strain & $\mathrm{N} / \mathrm{A}$ & 500 & 1.0 & 0 \\
\hline 137 & Grade 91 & Forging (thick) & $\mathrm{AR}$ & heat-1 & $1 \mathrm{E}-03$ & NGNP-He & strain & N/A & 500 & 1.0 & 0 \\
\hline 138 & Grade 91 & Forging (thick) & $\mathrm{AR}$ & heat-1 & $1 \mathrm{E}-03$ & NGNP-He & strain & N/A & 500 & 1.0 & 0 \\
\hline 139 & Grade 91 & Forging (thick) & $\mathrm{AR}$ & heat-1 & $1 \mathrm{E}-03$ & NGNP-He & strain & tension & 500 & 1.0 & 10 \\
\hline 140 & Grade 91 & Forging (thick) & $\mathrm{AR}$ & heat-1 & $1 \mathrm{E}-03$ & NGNP-He & strain & tension & 500 & 1.0 & 10 \\
\hline 141 & Grade 91 & Forging (thick) & AR & heat-1 & $1 \mathrm{E}-03$ & NGNP-He & strain & tension & 500 & 1.0 & 10 \\
\hline 142 & Grade 91 & Forging (thick) & $\mathrm{AR}$ & heat-1 & $1 \mathrm{E}-03$ & NGNP-He & strain & tension & 500 & 1.0 & 30 \\
\hline 143 & Grade 91 & Forging (thick) & $\mathrm{AR}$ & heat-1 & $1 \mathrm{E}-03$ & NGNP-He & strain & tension & 500 & 1.0 & 30 \\
\hline 144 & Grade 91 & Forging (thick) & $\mathrm{AR}$ & heat-1 & $1 \mathrm{E}-03$ & NGNP-He & strain & tension & 500 & 1.0 & 30 \\
\hline 145 & Grade 91 & Forging (thick) & $\mathrm{AR}$ & heat-1 & $1 \mathrm{E}-03$ & NGNP-He & strain & tension & 500 & 1.0 & 60 \\
\hline 146 & Grade 91 & Forging (thick) & $\mathrm{AR}$ & heat-1 & $1 \mathrm{E}-03$ & NGNP-He & strain & tension & 500 & 1.0 & 60 \\
\hline 147 & Grade 91 & Forging (thick) & $\mathrm{AR}$ & heat-1 & $1 \mathrm{E}-03$ & NGNP-He & strain & tension & 500 & 1.0 & 60 \\
\hline 148 & Grade 91 & Forging (thick) & $\mathrm{AR}$ & heat-1 & $1 \mathrm{E}-03$ & NGNP-He & strain & tension & 500 & 1.0 & 90 \\
\hline 149 & Grade 91 & Forging (thick) & $\mathrm{AR}$ & heat-1 & $1 \mathrm{E}-03$ & NGNP-He & strain & tension & 500 & 1.0 & 90 \\
\hline
\end{tabular}




Idaho National Laboratory
\begin{tabular}{|c|lll|}
\hline NEXT GENERATION NUCLEAR PLANT & Identifier: & PLN-2803 & \\
REACTOR PRESSURE VESSEL MATERIALS & Revision: & 0 & \\
RESEARCH AND DEVELOPMENT PLAN & Effective Date: & $04 / 30 / 08$ & Page: B-36 of B- 68 \\
\hline
\end{tabular}

\begin{tabular}{|c|c|c|c|c|c|c|c|c|c|c|c|}
\hline \multicolumn{12}{|c|}{ Table B6. Fatigue-Relaxation Tests for Grade 91 steel at $500^{\circ} \mathrm{C}$} \\
\hline Spec. \# & Material & Product Form & $\begin{array}{l}\text { Mat } \\
\text { Cond }\end{array}$ & Heat & $\begin{array}{l}\text { Strain } \\
\text { Rate } \\
(\mathrm{m} / \mathrm{m} / \mathrm{s})\end{array}$ & Env & $\begin{array}{c}\text { Hold Cntrl } \\
\text { (stress/strain) }\end{array}$ & $\begin{array}{c}\text { Strain } \\
\text { Hold in } \\
T / C\end{array}$ & $\begin{array}{l}\text { Temp. } \\
\left({ }^{\circ} \mathrm{C}\right)\end{array}$ & $\begin{array}{c}\text { Strain } \\
\text { Range } \\
(\%)\end{array}$ & $\begin{array}{l}\text { Time During } \\
\text { Strain Hold } \\
\text { (min) }\end{array}$ \\
\hline 150 & Grade 91 & Forging (thick) & $\mathrm{AR}$ & heat-1 & $1 \mathrm{E}-03$ & NGNP-He & strain & tension & 500 & 1.0 & 90 \\
\hline 151 & Grade 91 & Forging (thick) & $\mathrm{AR}$ & heat-1 & $1 \mathrm{E}-03$ & NGNP-He & strain & tension & 500 & 1.0 & 120 \\
\hline 152 & Grade 91 & Forging (thick) & $\mathrm{AR}$ & heat-1 & $1 \mathrm{E}-03$ & NGNP-He & strain & tension & 500 & 1.0 & 120 \\
\hline 153 & Grade 91 & Forging (thick) & $\mathrm{AR}$ & heat-1 & $1 \mathrm{E}-03$ & NGNP-He & strain & tension & 500 & 1.0 & 120 \\
\hline 154 & Grade 91 & Forging (thick) & $\mathrm{AR}$ & heat-1 & $1 \mathrm{E}-03$ & NGNP-He & strain & comp. & 500 & 0.5 & 10 \\
\hline 155 & Grade 91 & Forging (thick) & $\mathrm{AR}$ & heat-1 & $1 \mathrm{E}-03$ & NGNP-He & strain & comp. & 500 & 0.5 & 10 \\
\hline 156 & Grade 91 & Forging (thick) & $\mathrm{AR}$ & heat-1 & $1 \mathrm{E}-03$ & NGNP-He & strain & comp. & 500 & 0.5 & 10 \\
\hline 157 & Grade 91 & Forging (thick) & AR & heat-1 & $1 \mathrm{E}-03$ & NGNP-He & strain & comp. & 500 & 0.5 & 30 \\
\hline 158 & Grade 91 & Forging (thick) & $\mathrm{AR}$ & heat-1 & $1 \mathrm{E}-03$ & NGNP-He & strain & comp. & 500 & 0.5 & 30 \\
\hline 159 & Grade 91 & Forging (thick) & $\mathrm{AR}$ & heat-1 & $1 \mathrm{E}-03$ & NGNP-He & strain & comp. & 500 & 0.5 & 30 \\
\hline 160 & Grade 91 & Forging (thick) & $\mathrm{AR}$ & heat-1 & $1 \mathrm{E}-03$ & NGNP-He & strain & comp. & 500 & 0.5 & 60 \\
\hline 161 & Grade 91 & Forging (thick) & $\mathrm{AR}$ & heat-1 & $1 \mathrm{E}-03$ & NGNP-He & strain & comp. & 500 & 0.5 & 60 \\
\hline 162 & Grade 91 & Forging (thick) & $\mathrm{AR}$ & heat-1 & $1 \mathrm{E}-03$ & NGNP-He & strain & comp. & 500 & 0.5 & 60 \\
\hline 163 & Grade 91 & Forging (thick) & $\mathrm{AR}$ & heat-1 & $1 \mathrm{E}-03$ & NGNP-He & strain & comp. & 500 & 0.5 & 90 \\
\hline 164 & Grade 91 & Forging (thick) & $\mathrm{AR}$ & heat-1 & $1 \mathrm{E}-03$ & NGNP-He & strain & comp. & 500 & 0.5 & 90 \\
\hline 165 & Grade 91 & Forging (thick) & $\mathrm{AR}$ & heat-1 & $1 \mathrm{E}-03$ & NGNP-He & strain & comp. & 500 & 0.5 & 90 \\
\hline 166 & Grade 91 & Forging (thick) & AR & heat-1 & $1 \mathrm{E}-03$ & NGNP-He & strain & comp. & 500 & 0.5 & 120 \\
\hline 167 & Grade 91 & Forging (thick) & $\mathrm{AR}$ & heat-1 & $1 \mathrm{E}-03$ & NGNP-He & strain & comp. & 500 & 0.5 & 120 \\
\hline 168 & Grade 91 & Forging (thick) & $\mathrm{AR}$ & heat-1 & $1 \mathrm{E}-03$ & NGNP-He & strain & comp. & 500 & 0.5 & 120 \\
\hline 169 & Grade 91 & Forging (thick) & $\mathrm{AR}$ & heat-1 & $1 \mathrm{E}-03$ & NGNP-He & strain & comp. & 500 & 0.7 & 10 \\
\hline 170 & Grade 91 & Forging (thick) & $\mathrm{AR}$ & heat-1 & $1 \mathrm{E}-03$ & NGNP-He & strain & comp. & 500 & 0.7 & 10 \\
\hline 171 & Grade 91 & Forging (thick) & $\mathrm{AR}$ & heat-1 & $1 \mathrm{E}-03$ & NGNP-He & strain & comp. & 500 & 0.7 & 10 \\
\hline 172 & Grade 91 & Forging (thick) & $\mathrm{AR}$ & heat-1 & $1 \mathrm{E}-03$ & NGNP-He & strain & comp. & 500 & 0.7 & 30 \\
\hline 173 & Grade 91 & Forging (thick) & $\mathrm{AR}$ & heat-1 & $1 \mathrm{E}-03$ & NGNP-He & strain & comp. & 500 & 0.7 & 30 \\
\hline 174 & Grade 91 & Forging (thick) & $\mathrm{AR}$ & heat-1 & $1 \mathrm{E}-03$ & NGNP-He & strain & comp. & 500 & 0.7 & 30 \\
\hline
\end{tabular}




Idaho National Laboratory
\begin{tabular}{|c|lll|}
\hline NEXT GENERATION NUCLEAR PLANT & Identifier: & PLN-2803 & \\
REACTOR PRESSURE VESSEL MATERIALS & Revision: & 0 & \\
RESEARCH AND DEVELOPMENT PLAN & Effective Date: & $04 / 30 / 08$ & Page: B-37 of B- 68 \\
\hline
\end{tabular}

\begin{tabular}{|c|c|c|c|c|c|c|c|c|c|c|c|}
\hline Spec. \# & Material & Product Form & $\begin{array}{c}\text { Mat } \\
\text { Cond }\end{array}$ & Heat & $\begin{array}{l}\text { Strain } \\
\text { Rate } \\
(\mathrm{m} / \mathrm{m} / \mathrm{s})\end{array}$ & Env & $\begin{array}{c}\text { Hold Cntrl } \\
\text { (stress/strain) }\end{array}$ & $\begin{array}{c}\text { Strain } \\
\text { Hold in } \\
\mathrm{T} / \mathrm{C}\end{array}$ & $\begin{array}{l}\text { Temp. } \\
\left({ }^{\circ} \mathrm{C}\right)\end{array}$ & $\begin{array}{c}\text { Strain } \\
\text { Range } \\
(\%)\end{array}$ & $\begin{array}{l}\text { Time During } \\
\text { Strain Hold } \\
\text { (min) }\end{array}$ \\
\hline 175 & Grade 91 & Forging (thick) & $\mathrm{AR}$ & heat-1 & $1 \mathrm{E}-03$ & NGNP-He & strain & comp. & 500 & 0.7 & 60 \\
\hline 176 & Grade 91 & Forging (thick) & $\mathrm{AR}$ & heat-1 & $1 \mathrm{E}-03$ & NGNP-He & strain & comp. & 500 & 0.7 & 60 \\
\hline 177 & Grade 91 & Forging (thick) & $\mathrm{AR}$ & heat-1 & $1 \mathrm{E}-03$ & NGNP-He & strain & comp. & 500 & 0.7 & 60 \\
\hline 178 & Grade 91 & Forging (thick) & AR & heat-1 & $1 \mathrm{E}-03$ & NGNP-He & strain & comp. & 500 & 0.7 & 90 \\
\hline 179 & Grade 91 & Forging (thick) & $\mathrm{AR}$ & heat-1 & $1 \mathrm{E}-03$ & NGNP-He & strain & comp. & 500 & 0.7 & 90 \\
\hline 180 & Grade 91 & Forging (thick) & $\mathrm{AR}$ & heat-1 & $1 \mathrm{E}-03$ & NGNP-He & strain & comp. & 500 & 0.7 & 90 \\
\hline 181 & Grade 91 & Forging (thick) & $\mathrm{AR}$ & heat-1 & $1 \mathrm{E}-03$ & NGNP-He & strain & comp. & 500 & 0.7 & 120 \\
\hline 182 & Grade 91 & Forging (thick) & $\mathrm{AR}$ & heat-1 & $1 \mathrm{E}-03$ & NGNP-He & strain & comp. & 500 & 0.7 & 120 \\
\hline 183 & Grade 91 & Forging (thick) & $\mathrm{AR}$ & heat-1 & $1 \mathrm{E}-03$ & NGNP-He & strain & comp. & 500 & 0.7 & 120 \\
\hline 184 & Grade 91 & Forging (thick) & $\mathrm{AR}$ & heat-1 & $1 \mathrm{E}-03$ & NGNP-He & strain & comp. & 500 & 1.0 & 10 \\
\hline 185 & Grade 91 & Forging (thick) & $\mathrm{AR}$ & heat-1 & $1 \mathrm{E}-03$ & NGNP-He & strain & comp. & 500 & 1.0 & 10 \\
\hline 186 & Grade 91 & Forging (thick) & $\mathrm{AR}$ & heat-1 & $1 \mathrm{E}-03$ & NGNP-He & strain & comp. & 500 & 1.0 & 10 \\
\hline 187 & Grade 91 & Forging (thick) & $\mathrm{AR}$ & heat-1 & $1 \mathrm{E}-03$ & NGNP-He & strain & comp. & 500 & 1.0 & 30 \\
\hline 188 & Grade 91 & Forging (thick) & $\mathrm{AR}$ & heat-1 & $1 \mathrm{E}-03$ & NGNP-He & strain & comp. & 500 & 1.0 & 30 \\
\hline 189 & Grade 91 & Forging (thick) & $\mathrm{AR}$ & heat-1 & $1 \mathrm{E}-03$ & NGNP-He & strain & comp. & 500 & 1.0 & 30 \\
\hline 190 & Grade 91 & Forging (thick) & $\mathrm{AR}$ & heat-1 & $1 \mathrm{E}-03$ & NGNP-He & strain & comp. & 500 & 1.0 & 60 \\
\hline 191 & Grade 91 & Forging (thick) & $\mathrm{AR}$ & heat-1 & $1 \mathrm{E}-03$ & NGNP-He & strain & comp. & 500 & 1.0 & 60 \\
\hline 192 & Grade 91 & Forging (thick) & $\mathrm{AR}$ & heat-1 & $1 \mathrm{E}-03$ & NGNP-He & strain & comp. & 500 & 1.0 & 60 \\
\hline 193 & Grade 91 & Forging (thick) & $\mathrm{AR}$ & heat-1 & $1 \mathrm{E}-03$ & NGNP-He & strain & comp. & 500 & 1.0 & 90 \\
\hline 194 & Grade 91 & Forging (thick) & $\mathrm{AR}$ & heat-1 & $1 \mathrm{E}-03$ & NGNP-He & strain & comp. & 500 & 1.0 & 90 \\
\hline 195 & Grade 91 & Forging (thick) & $\mathrm{AR}$ & heat-1 & $1 \mathrm{E}-03$ & NGNP-He & strain & comp. & 500 & 1.0 & 90 \\
\hline 196 & Grade 91 & Forging (thick) & $\mathrm{AR}$ & heat-1 & $1 \mathrm{E}-03$ & NGNP-He & strain & comp. & 500 & 1.0 & 120 \\
\hline 197 & Grade 91 & Forging (thick) & $\mathrm{AR}$ & heat-1 & $1 \mathrm{E}-03$ & NGNP-He & strain & comp. & 500 & 1.0 & 120 \\
\hline 198 & Grade 91 & Forging (thick) & $\mathrm{AR}$ & heat-1 & $1 \mathrm{E}-03$ & NGNP-He & strain & comp. & 500 & 1.0 & 120 \\
\hline
\end{tabular}




Idaho National Laboratory
\begin{tabular}{|c|lll|}
\hline NEXT GENERATION NUCLEAR PLANT & Identifier: & PLN-2803 & \\
REACTOR PRESSURE VESSEL MATERIALS & Revision: & 0 & \\
RESEARCH AND DEVELOPMENT PLAN & Effective Date: & $04 / 30 / 08$ & Page: B- 38 of B- 68 \\
\hline
\end{tabular}

\begin{tabular}{|c|c|c|c|c|c|c|c|c|c|c|c|}
\hline \multicolumn{12}{|c|}{ Table B7. Creep-Fatigue Tests for Grade 91 Steel at $500^{\circ} \mathrm{C}$} \\
\hline Spec. \# & Material & Product Form & $\begin{array}{l}\text { Mat } \\
\text { Cond }\end{array}$ & Heat & $\begin{array}{l}\text { Strain } \\
\text { Rate } \\
(\mathrm{m} / \mathrm{m} / \mathrm{s})\end{array}$ & Env & $\begin{array}{c}\text { Hold Cntrl } \\
\text { (stress/strain) }\end{array}$ & $\begin{array}{c}\text { Stress } \\
\text { Hold in } \\
\mathrm{T} / \mathrm{C}\end{array}$ & $\begin{array}{l}\text { Temp. } \\
\left({ }^{\circ} \mathrm{C}\right)\end{array}$ & $\begin{array}{c}\text { Strain } \\
\text { Range } \\
(\%)\end{array}$ & $\begin{array}{c}\text { Total Strain } \\
\text { During Stress } \\
\text { Hold }(\%)\end{array}$ \\
\hline 1 & Grade 91 & Forging (thick) & $\mathrm{AR}$ & heat-1 & $1 \mathrm{E}-03$ & air & stress & N/A & 500 & 0.5 & 0 \\
\hline 2 & Grade 91 & Forging (thick) & $\mathrm{AR}$ & heat-1 & $1 \mathrm{E}-03$ & air & stress & N/A & 500 & 0.5 & 0 \\
\hline 3 & Grade 91 & Forging (thick) & $\mathrm{AR}$ & heat-1 & $1 \mathrm{E}-03$ & air & stress & N/A & 500 & 0.5 & 0 \\
\hline 4 & Grade 91 & Forging (thick) & $\mathrm{AR}$ & heat-1 & $1 \mathrm{E}-03$ & air & stress & tension & 500 & 0.5 & 0.1 \\
\hline 5 & Grade 91 & Forging (thick) & $\mathrm{AR}$ & heat-1 & $1 \mathrm{E}-03$ & air & stress & tension & 500 & 0.5 & 0.1 \\
\hline 6 & Grade 91 & Forging (thick) & $\mathrm{AR}$ & heat-1 & $1 \mathrm{E}-03$ & air & stress & tension & 500 & 0.5 & 0.1 \\
\hline 7 & Grade 91 & Forging (thick) & $\mathrm{AR}$ & heat-1 & $1 \mathrm{E}-03$ & air & stress & tension & 500 & 0.5 & 0.3 \\
\hline 8 & Grade 91 & Forging (thick) & $\mathrm{AR}$ & heat-1 & $1 \mathrm{E}-03$ & air & stress & tension & 500 & 0.5 & 0.3 \\
\hline 9 & Grade 91 & Forging (thick) & $\mathrm{AR}$ & heat-1 & $1 \mathrm{E}-03$ & air & stress & tension & 500 & 0.5 & 0.3 \\
\hline 10 & Grade 91 & Forging (thick) & $\mathrm{AR}$ & heat-1 & $1 \mathrm{E}-03$ & air & stress & N/A & 500 & 0.7 & 0 \\
\hline 11 & Grade 91 & Forging (thick) & $\mathrm{AR}$ & heat-1 & $1 \mathrm{E}-03$ & air & stress & N/A & 500 & 0.7 & 0 \\
\hline 12 & Grade 91 & Forging (thick) & $\mathrm{AR}$ & heat-1 & $1 \mathrm{E}-03$ & air & stress & N/A & 500 & 0.7 & 0 \\
\hline 13 & Grade 91 & Forging (thick) & $\mathrm{AR}$ & heat-1 & $1 \mathrm{E}-03$ & air & stress & tension & 500 & 0.7 & 0.1 \\
\hline 14 & Grade 91 & Forging (thick) & $\mathrm{AR}$ & heat-1 & $1 \mathrm{E}-03$ & air & stress & tension & 500 & 0.7 & 0.1 \\
\hline 15 & Grade 91 & Forging (thick) & $\mathrm{AR}$ & heat-1 & $1 \mathrm{E}-03$ & air & stress & tension & 500 & 0.7 & 0.1 \\
\hline 16 & Grade 91 & Forging (thick) & $\mathrm{AR}$ & heat-1 & $1 \mathrm{E}-03$ & air & stress & tension & 500 & 0.7 & 0.3 \\
\hline 17 & Grade 91 & Forging (thick) & $\mathrm{AR}$ & heat-1 & $1 \mathrm{E}-03$ & air & stress & tension & 500 & 0.7 & 0.3 \\
\hline 18 & Grade 91 & Forging (thick) & $\mathrm{AR}$ & heat-1 & $1 \mathrm{E}-03$ & air & stress & tension & 500 & 0.7 & 0.3 \\
\hline 19 & Grade 91 & Forging (thick) & $\mathrm{AR}$ & heat-1 & $1 \mathrm{E}-03$ & air & stress & N/A & 500 & 1.0 & 0 \\
\hline 20 & Grade 91 & Forging (thick) & $\mathrm{AR}$ & heat-1 & $1 \mathrm{E}-03$ & air & stress & N/A & 500 & 1.0 & 0 \\
\hline 21 & Grade 91 & Forging (thick) & $\mathrm{AR}$ & heat-1 & $1 \mathrm{E}-03$ & air & stress & N/A & 500 & 1.0 & 0 \\
\hline 22 & Grade 91 & Forging (thick) & $\mathrm{AR}$ & heat-1 & $1 \mathrm{E}-03$ & air & stress & tension & 500 & 1.0 & 0.1 \\
\hline 23 & Grade 91 & Forging (thick) & $\mathrm{AR}$ & heat-1 & $1 \mathrm{E}-03$ & air & stress & tension & 500 & 1.0 & 0.1 \\
\hline 24 & Grade 91 & Forging (thick) & $\mathrm{AR}$ & heat-1 & $1 \mathrm{E}-03$ & air & stress & tension & 500 & 1.0 & 0.1 \\
\hline
\end{tabular}




Idaho National Laboratory
\begin{tabular}{|c|lll|}
\hline NEXT GENERATION NUCLEAR PLANT & Identifier: & PLN-2803 & \\
REACTOR PRESSURE VESSEL MATERIALS & Revision: & 0 & \\
RESEARCH AND DEVELOPMENT PLAN & Effective Date: & $04 / 30 / 08$ & Page: B-39 of B- 68 \\
\hline
\end{tabular}

\begin{tabular}{|c|c|c|c|c|c|c|c|c|c|c|c|}
\hline \multicolumn{12}{|c|}{ Table B7. Creep-Fatigue Tests for Grade 91 Steel at $500^{\circ} \mathrm{C}$} \\
\hline Spec. \# & Material & Product Form & $\begin{array}{l}\text { Mat } \\
\text { Cond }\end{array}$ & Heat & $\begin{array}{l}\text { Strain } \\
\text { Rate } \\
(\mathrm{m} / \mathrm{m} / \mathrm{s})\end{array}$ & Env & $\begin{array}{l}\text { Hold Cntrl } \\
\text { (stress/strain) }\end{array}$ & $\begin{array}{c}\text { Stress } \\
\text { Hold in } \\
\mathrm{T} / \mathrm{C}\end{array}$ & $\begin{array}{l}\text { Temp. } \\
\left({ }^{\circ} \mathrm{C}\right)\end{array}$ & $\begin{array}{c}\text { Strain } \\
\text { Range } \\
(\%)\end{array}$ & $\begin{array}{c}\text { Total Strain } \\
\text { During Stress } \\
\text { Hold }(\%)\end{array}$ \\
\hline 25 & Grade 91 & Forging (thick) & AR & heat-1 & $1 \mathrm{E}-03$ & air & stress & tension & 500 & 1.0 & 0.3 \\
\hline 26 & Grade 91 & Forging (thick) & $\mathrm{AR}$ & heat-1 & $1 \mathrm{E}-03$ & air & stress & tension & 500 & 1.0 & 0.3 \\
\hline 27 & Grade 91 & Forging (thick) & $\mathrm{AR}$ & heat-1 & $1 \mathrm{E}-03$ & air & stress & tension & 500 & 1.0 & 0.3 \\
\hline 28 & Grade 91 & Forging (thick) & $\mathrm{AR}$ & heat-1 & $1 \mathrm{E}-03$ & air & stress & comp. & 500 & 0.5 & 0.1 \\
\hline 29 & Grade 91 & Forging (thick) & $\mathrm{AR}$ & heat-1 & $1 \mathrm{E}-03$ & air & stress & comp. & 500 & 0.5 & 0.1 \\
\hline 30 & Grade 91 & Forging (thick) & $\mathrm{AR}$ & heat-1 & $1 \mathrm{E}-03$ & air & stress & comp. & 500 & 0.5 & 0.1 \\
\hline 31 & Grade 91 & Forging (thick) & $\mathrm{AR}$ & heat-1 & $1 \mathrm{E}-03$ & air & stress & comp. & 500 & 0.5 & 0.3 \\
\hline 32 & Grade 91 & Forging (thick) & $\mathrm{AR}$ & heat-1 & $1 \mathrm{E}-03$ & air & stress & comp. & 500 & 0.5 & 0.3 \\
\hline 33 & Grade 91 & Forging (thick) & $\mathrm{AR}$ & heat-1 & $1 \mathrm{E}-03$ & air & stress & comp. & 500 & 0.5 & 0.3 \\
\hline 34 & Grade 91 & Forging (thick) & $\mathrm{AR}$ & heat-1 & $1 \mathrm{E}-03$ & air & stress & comp. & 500 & 0.7 & 0.1 \\
\hline 35 & Grade 91 & Forging (thick) & $\mathrm{AR}$ & heat-1 & $1 \mathrm{E}-03$ & air & stress & comp. & 500 & 0.7 & 0.1 \\
\hline 36 & Grade 91 & Forging (thick) & $\mathrm{AR}$ & heat-1 & $1 \mathrm{E}-03$ & air & stress & comp. & 500 & 0.7 & 0.1 \\
\hline 37 & Grade 91 & Forging (thick) & $\mathrm{AR}$ & heat-1 & $1 \mathrm{E}-03$ & air & stress & comp. & 500 & 0.7 & 0.3 \\
\hline 38 & Grade 91 & Forging (thick) & $\mathrm{AR}$ & heat-1 & $1 \mathrm{E}-03$ & air & stress & comp. & 500 & 0.7 & 0.3 \\
\hline 39 & Grade 91 & Forging (thick) & $\mathrm{AR}$ & heat-1 & $1 \mathrm{E}-03$ & air & stress & comp. & 500 & 0.7 & 0.3 \\
\hline 40 & Grade 91 & Forging (thick) & $\mathrm{AR}$ & heat-1 & $1 \mathrm{E}-03$ & air & stress & comp. & 500 & 1.0 & 0.1 \\
\hline 41 & Grade 91 & Forging (thick) & $\mathrm{AR}$ & heat-1 & $1 \mathrm{E}-03$ & air & stress & comp. & 500 & 1.0 & 0.1 \\
\hline 42 & Grade 91 & Forging (thick) & $\mathrm{AR}$ & heat-1 & $1 \mathrm{E}-03$ & air & stress & comp. & 500 & 1.0 & 0.1 \\
\hline 43 & Grade 91 & Forging (thick) & $\mathrm{AR}$ & heat-1 & $1 \mathrm{E}-03$ & air & stress & comp. & 500 & 1.0 & 0.3 \\
\hline 44 & Grade 91 & Forging (thick) & $\mathrm{AR}$ & heat-1 & $1 \mathrm{E}-03$ & air & stress & comp. & 500 & 1.0 & 0.3 \\
\hline 45 & Grade 91 & Forging (thick) & $\mathrm{AR}$ & heat-1 & $1 \mathrm{E}-03$ & air & stress & comp. & 500 & 1.0 & 0.3 \\
\hline 46 & Grade 91 & Forging (thick) & $\mathrm{AR}$ & heat-1 & $1 \mathrm{E}-03$ & NGNP-He & stress & N/A & 500 & 0.5 & 0 \\
\hline 47 & Grade 91 & Forging (thick) & $\mathrm{AR}$ & heat-1 & $1 \mathrm{E}-03$ & NGNP-He & stress & $\mathrm{N} / \mathrm{A}$ & 500 & 0.5 & 0 \\
\hline 48 & Grade 91 & Forging (thick) & $\mathrm{AR}$ & heat-1 & $1 \mathrm{E}-03$ & NGNP-He & stress & $\mathrm{N} / \mathrm{A}$ & 500 & 0.5 & 0 \\
\hline 49 & Grade 91 & Forging (thick) & $\mathrm{AR}$ & heat-1 & $1 \mathrm{E}-03$ & NGNP-He & stress & tension & 500 & 0.5 & 0.1 \\
\hline
\end{tabular}




Idaho National Laboratory
\begin{tabular}{|c|lll|}
\hline NEXT GENERATION NUCLEAR PLANT & Identifier: & PLN-2803 & \\
REACTOR PRESSURE VESSEL MATERIALS & Revision: & 0 & \\
RESEARCH AND DEVELOPMENT PLAN & Effective Date: & $04 / 30 / 08$ & Page: B-40 of B- 68 \\
\hline
\end{tabular}

\begin{tabular}{|c|c|c|c|c|c|c|c|c|c|c|c|}
\hline \multicolumn{12}{|c|}{ Table B7. Creep-Fatigue Tests for Grade 91 Steel at $500^{\circ} \mathrm{C}$} \\
\hline Spec. \# & Material & Product Form & $\begin{array}{l}\text { Mat } \\
\text { Cond }\end{array}$ & Heat & $\begin{array}{l}\text { Strain } \\
\text { Rate } \\
(\mathrm{m} / \mathrm{m} / \mathrm{s})\end{array}$ & Env & $\begin{array}{l}\text { Hold Cntrl } \\
\text { (stress/strain) }\end{array}$ & $\begin{array}{c}\text { Stress } \\
\text { Hold in } \\
\mathrm{T} / \mathrm{C}\end{array}$ & $\begin{array}{l}\text { Temp. } \\
\left({ }^{\circ} \mathrm{C}\right)\end{array}$ & $\begin{array}{c}\text { Strain } \\
\text { Range } \\
(\%)\end{array}$ & $\begin{array}{c}\text { Total Strain } \\
\text { During Stress } \\
\text { Hold (\%) }\end{array}$ \\
\hline 50 & Grade 91 & Forging (thick) & $\mathrm{AR}$ & heat-1 & $1 \mathrm{E}-03$ & NGNP-He & stress & tension & 500 & 0.5 & 0.1 \\
\hline 51 & Grade 91 & Forging (thick) & $\mathrm{AR}$ & heat-1 & $1 \mathrm{E}-03$ & NGNP-He & stress & tension & 500 & 0.5 & 0.1 \\
\hline 52 & Grade 91 & Forging (thick) & AR & heat-1 & $1 \mathrm{E}-03$ & NGNP-He & stress & tension & 500 & 0.5 & 0.3 \\
\hline 53 & Grade 91 & Forging (thick) & $\mathrm{AR}$ & heat-1 & $1 \mathrm{E}-03$ & NGNP-He & stress & tension & 500 & 0.5 & 0.3 \\
\hline 54 & Grade 91 & Forging (thick) & $\mathrm{AR}$ & heat-1 & $1 \mathrm{E}-03$ & NGNP-He & stress & tension & 500 & 0.5 & 0.3 \\
\hline 55 & Grade 91 & Forging (thick) & $\mathrm{AR}$ & heat-1 & $1 \mathrm{E}-03$ & NGNP-He & stress & $\mathrm{N} / \mathrm{A}$ & 500 & 0.7 & 0 \\
\hline 56 & Grade 91 & Forging (thick) & $\mathrm{AR}$ & heat-1 & $1 \mathrm{E}-03$ & NGNP-He & stress & N/A & 500 & 0.7 & 0 \\
\hline 57 & Grade 91 & Forging (thick) & $\mathrm{AR}$ & heat-1 & $1 \mathrm{E}-03$ & NGNP-He & stress & N/A & 500 & 0.7 & 0 \\
\hline 58 & Grade 91 & Forging (thick) & $\mathrm{AR}$ & heat-1 & $1 \mathrm{E}-03$ & NGNP-He & stress & tension & 500 & 0.7 & 0.1 \\
\hline 59 & Grade 91 & Forging (thick) & $\mathrm{AR}$ & heat-1 & $1 \mathrm{E}-03$ & NGNP-He & stress & tension & 500 & 0.7 & 0.1 \\
\hline 60 & Grade 91 & Forging (thick) & $\mathrm{AR}$ & heat-1 & $1 \mathrm{E}-03$ & NGNP-He & stress & tension & 500 & 0.7 & 0.1 \\
\hline 61 & Grade 91 & Forging (thick) & $\mathrm{AR}$ & heat-1 & $1 \mathrm{E}-03$ & NGNP-He & stress & tension & 500 & 0.7 & 0.3 \\
\hline 62 & Grade 91 & Forging (thick) & $\mathrm{AR}$ & heat-1 & $1 \mathrm{E}-03$ & NGNP-He & stress & tension & 500 & 0.7 & 0.3 \\
\hline 63 & Grade 91 & Forging (thick) & $\mathrm{AR}$ & heat-1 & $1 \mathrm{E}-03$ & NGNP-He & stress & tension & 500 & 0.7 & 0.3 \\
\hline 64 & Grade 91 & Forging (thick) & $\mathrm{AR}$ & heat-1 & $1 \mathrm{E}-03$ & NGNP-He & stress & N/A & 500 & 1.0 & 0 \\
\hline 65 & Grade 91 & Forging (thick) & $\mathrm{AR}$ & heat-1 & $1 \mathrm{E}-03$ & NGNP-He & stress & N/A & 500 & 1.0 & 0 \\
\hline 66 & Grade 91 & Forging (thick) & $\mathrm{AR}$ & heat-1 & $1 \mathrm{E}-03$ & NGNP-He & stress & N/A & 500 & 1.0 & 0 \\
\hline 67 & Grade 91 & Forging (thick) & $\mathrm{AR}$ & heat-1 & $1 \mathrm{E}-03$ & NGNP-He & stress & tension & 500 & 1.0 & 0.1 \\
\hline 68 & Grade 91 & Forging (thick) & $\mathrm{AR}$ & heat-1 & $1 \mathrm{E}-03$ & NGNP-He & stress & tension & 500 & 1.0 & 0.1 \\
\hline 69 & Grade 91 & Forging (thick) & $\mathrm{AR}$ & heat-1 & $1 \mathrm{E}-03$ & NGNP-He & stress & tension & 500 & 1.0 & 0.1 \\
\hline 70 & Grade 91 & Forging (thick) & $\mathrm{AR}$ & heat-1 & $1 \mathrm{E}-03$ & NGNP-He & stress & tension & 500 & 1.0 & 0.3 \\
\hline 71 & Grade 91 & Forging (thick) & $\mathrm{AR}$ & heat-1 & $1 \mathrm{E}-03$ & NGNP-He & stress & tension & 500 & 1.0 & 0.3 \\
\hline 72 & Grade 91 & Forging (thick) & $\mathrm{AR}$ & heat-1 & $1 \mathrm{E}-03$ & NGNP-He & stress & tension & 500 & 1.0 & 0.3 \\
\hline 73 & Grade 91 & Forging (thick) & $\mathrm{AR}$ & heat-1 & $1 \mathrm{E}-03$ & NGNP-He & stress & comp. & 500 & 0.5 & 0.1 \\
\hline 74 & Grade 91 & Forging (thick) & $\mathrm{AR}$ & heat-1 & $1 \mathrm{E}-03$ & NGNP-He & stress & comp. & 500 & 0.5 & 0.1 \\
\hline
\end{tabular}


Idaho National Laboratory

\begin{tabular}{|c|lll|}
\hline NEXT GENERATION NUCLEAR PLANT & Identifier: & PLN-2803 & \\
REACTOR PRESSURE VESSEL MATERIALS & Revision: & 0 & \\
RESEARCH AND DEVELOPMENT PLAN & Effective Date: & $04 / 30 / 08$ & Page: B-41 of B-68 \\
\hline
\end{tabular}

\begin{tabular}{|c|c|c|c|c|c|c|c|c|c|c|c|}
\hline \multicolumn{12}{|c|}{ Table B7. Creep-Fatigue Tests for Grade 91 Steel at $500^{\circ} \mathrm{C}$} \\
\hline Spec. \# & Material & Product Form & $\begin{array}{l}\text { Mat } \\
\text { Cond }\end{array}$ & Heat & $\begin{array}{c}\text { Strain } \\
\text { Rate } \\
(\mathrm{m} / \mathrm{m} / \mathrm{s})\end{array}$ & Env & $\begin{array}{c}\text { Hold Cntrl } \\
\text { (stress/strain) }\end{array}$ & $\begin{array}{c}\text { Stress } \\
\text { Hold in } \\
\mathrm{T} / \mathrm{C}\end{array}$ & $\begin{array}{c}\text { Temp. } \\
\left({ }^{\circ} \mathrm{C}\right)\end{array}$ & $\begin{array}{c}\text { Strain } \\
\text { Range } \\
(\%)\end{array}$ & $\begin{array}{c}\text { Total Strain } \\
\text { During Stress } \\
\text { Hold }(\%)\end{array}$ \\
\hline 75 & Grade 91 & Forging (thick) & AR & heat-1 & $1 \mathrm{E}-03$ & NGNP-He & stress & comp. & 500 & 0.5 & 0.1 \\
\hline 76 & Grade 91 & Forging (thick) & AR & heat-1 & $1 \mathrm{E}-03$ & NGNP-He & stress & comp. & 500 & 0.5 & 0.3 \\
\hline 77 & Grade 91 & Forging (thick) & $\mathrm{AR}$ & heat-1 & $1 \mathrm{E}-03$ & NGNP-He & stress & comp. & 500 & 0.5 & 0.3 \\
\hline 78 & Grade 91 & Forging (thick) & $\mathrm{AR}$ & heat-1 & $1 \mathrm{E}-03$ & NGNP-He & stress & comp. & 500 & 0.5 & 0.3 \\
\hline 79 & Grade 91 & Forging (thick) & AR & heat-1 & $1 \mathrm{E}-03$ & NGNP-He & stress & comp. & 500 & 0.7 & 0.1 \\
\hline 80 & Grade 91 & Forging (thick) & AR & heat-1 & $1 \mathrm{E}-03$ & NGNP-He & stress & comp. & 500 & 0.7 & 0.1 \\
\hline 81 & Grade 91 & Forging (thick) & AR & heat-1 & $1 \mathrm{E}-03$ & NGNP-He & stress & comp. & 500 & 0.7 & 0.1 \\
\hline 82 & Grade 91 & Forging (thick) & $\mathrm{AR}$ & heat-1 & $1 \mathrm{E}-03$ & NGNP-He & stress & comp. & 500 & 0.7 & 0.3 \\
\hline 83 & Grade 91 & Forging (thick) & $\mathrm{AR}$ & heat-1 & $1 \mathrm{E}-03$ & NGNP-He & stress & comp. & 500 & 0.7 & 0.3 \\
\hline 84 & Grade 91 & Forging (thick) & $\mathrm{AR}$ & heat-1 & $1 \mathrm{E}-03$ & NGNP-He & stress & comp. & 500 & 0.7 & 0.3 \\
\hline 85 & Grade 91 & Forging (thick) & AR & heat-1 & $1 \mathrm{E}-03$ & NGNP-He & stress & comp. & 500 & 1.0 & 0.1 \\
\hline 86 & Grade 91 & Forging (thick) & AR & heat-1 & $1 \mathrm{E}-03$ & NGNP-He & stress & comp. & 500 & 1.0 & 0.1 \\
\hline 87 & Grade 91 & Forging (thick) & $\mathrm{AR}$ & heat-1 & $1 \mathrm{E}-03$ & NGNP-He & stress & comp. & 500 & 1.0 & 0.1 \\
\hline 88 & Grade 91 & Forging (thick) & $\mathrm{AR}$ & heat-1 & $1 \mathrm{E}-03$ & NGNP-He & stress & comp. & 500 & 1.0 & 0.3 \\
\hline 89 & Grade 91 & Forging (thick) & AR & heat-1 & $1 \mathrm{E}-03$ & NGNP-He & stress & comp. & 500 & 1.0 & 0.3 \\
\hline 90 & Grade 91 & Forging (thick) & AR & heat-1 & $1 \mathrm{E}-03$ & NGNP-He & stress & comp. & 500 & 1.0 & 0.3 \\
\hline
\end{tabular}




Idaho National Laboratory
\begin{tabular}{|c|lll|}
\hline NEXT GENERATION NUCLEAR PLANT & Identifier: & PLN-2803 & \\
REACTOR PRESSURE VESSEL MATERIALS & Revision: & 0 & \\
RESEARCH AND DEVELOPMENT PLAN & Effective Date: & $04 / 30 / 08$ & Page: B-42 of B- 68 \\
\hline
\end{tabular}

\begin{tabular}{|c|c|c|c|c|c|c|c|c|c|c|c|}
\hline Spec. \# & Material & Product Form & Mat Cond & Heat & $\begin{array}{l}\text { Strain } \\
\text { Rate } \\
(\mathrm{m} / \mathrm{m} / \mathrm{s})\end{array}$ & Env & $\begin{array}{c}\text { Hold Cntrl } \\
\text { (stress/strain) }\end{array}$ & $\begin{array}{l}\text { Strain Hold } \\
\text { in } \mathrm{T} / \mathrm{C}\end{array}$ & $\begin{array}{c}\text { Temp. } \\
\left({ }^{\circ} \mathrm{C}\right)\end{array}$ & $\begin{array}{c}\text { Strain } \\
\text { Range (\%) }\end{array}$ & $\begin{array}{l}\text { Time During } \\
\text { Strain Hold } \\
\text { (min) }\end{array}$ \\
\hline 1 & Grade 91 & Forging (thick) & $\mathrm{AR}$ & heat-1 & $1 \mathrm{E}-03$ & air & strain & N/A & 550 & 0.4 & 0 \\
\hline 2 & Grade 91 & Forging (thick) & $\mathrm{AR}$ & heat-1 & $1 \mathrm{E}-03$ & air & strain & $\mathrm{N} / \mathrm{A}$ & 550 & 0.4 & 0 \\
\hline 3 & Grade 91 & Forging (thick) & $\mathrm{AR}$ & heat-1 & $1 \mathrm{E}-03$ & air & strain & $\mathrm{N} / \mathrm{A}$ & 550 & 0.4 & 0 \\
\hline 4 & Grade 91 & Forging (thick) & $\mathrm{AR}$ & heat-1 & $1 \mathrm{E}-03$ & air & strain & tension & 550 & 0.4 & 90 \\
\hline 5 & Grade 91 & Forging (thick) & $\mathrm{AR}$ & heat-1 & $1 \mathrm{E}-03$ & air & strain & tension & 550 & 0.4 & 90 \\
\hline 6 & Grade 91 & Forging (thick) & $\mathrm{AR}$ & heat-1 & $1 \mathrm{E}-03$ & air & strain & tension & 550 & 0.4 & 90 \\
\hline 7 & Grade 91 & Forging (thick) & $\mathrm{AR}$ & heat-1 & $1 \mathrm{E}-03$ & air & strain & tension & 550 & 0.4 & 180 \\
\hline 8 & Grade 91 & Forging (thick) & $\mathrm{AR}$ & heat-1 & $1 \mathrm{E}-03$ & air & strain & tension & 550 & 0.4 & 180 \\
\hline 9 & Grade 91 & Forging (thick) & $\mathrm{AR}$ & heat-1 & $1 \mathrm{E}-03$ & air & strain & tension & 550 & 0.4 & 180 \\
\hline 10 & Grade 91 & Forging (thick) & $\mathrm{AR}$ & heat-1 & $1 \mathrm{E}-03$ & air & strain & N/A & 550 & 0.5 & 0 \\
\hline 11 & Grade 91 & Forging (thick) & $\mathrm{AR}$ & heat-1 & $1 \mathrm{E}-03$ & air & strain & N/A & 550 & 0.5 & 0 \\
\hline 12 & Grade 91 & Forging (thick) & $\mathrm{AR}$ & heat-1 & $1 \mathrm{E}-03$ & air & strain & $\mathrm{N} / \mathrm{A}$ & 550 & 0.5 & 0 \\
\hline 13 & Grade 91 & Forging (thick) & $\mathrm{AR}$ & heat-1 & $1 \mathrm{E}-03$ & air & strain & tension & 550 & 0.5 & 90 \\
\hline 14 & Grade 91 & Forging (thick) & $\mathrm{AR}$ & heat-1 & $1 \mathrm{E}-03$ & air & strain & tension & 550 & 0.5 & 90 \\
\hline 15 & Grade 91 & Forging (thick) & AR & heat-1 & $1 \mathrm{E}-03$ & air & strain & tension & 550 & 0.5 & 90 \\
\hline 16 & Grade 91 & Forging (thick) & $\mathrm{AR}$ & heat-1 & $1 \mathrm{E}-03$ & air & strain & tension & 550 & 0.5 & 180 \\
\hline 17 & Grade 91 & Forging (thick) & $\mathrm{AR}$ & heat-1 & $1 \mathrm{E}-03$ & air & strain & tension & 550 & 0.5 & 180 \\
\hline 18 & Grade 91 & Forging (thick) & $\mathrm{AR}$ & heat-1 & $1 \mathrm{E}-03$ & air & strain & tension & 550 & 0.5 & 180 \\
\hline 19 & Grade 91 & Forging (thick) & $\mathrm{AR}$ & heat-1 & $1 \mathrm{E}-03$ & air & strain & N/A & 550 & 0.7 & 0 \\
\hline 20 & Grade 91 & Forging (thick) & AR & heat-1 & $1 \mathrm{E}-03$ & air & strain & N/A & 550 & 0.7 & 0 \\
\hline 21 & Grade 91 & Forging (thick) & $\mathrm{AR}$ & heat-1 & $1 \mathrm{E}-03$ & air & strain & N/A & 550 & 0.7 & 0 \\
\hline 22 & Grade 91 & Forging (thick) & $\mathrm{AR}$ & heat-1 & $1 \mathrm{E}-03$ & air & strain & tension & 550 & 0.7 & 90 \\
\hline 23 & Grade 91 & Forging (thick) & AR & heat-1 & $1 \mathrm{E}-03$ & air & strain & tension & 550 & 0.7 & 90 \\
\hline 24 & Grade 91 & Forging (thick) & $\mathrm{AR}$ & heat-1 & $1 \mathrm{E}-03$ & air & strain & tension & 550 & 0.7 & 90 \\
\hline
\end{tabular}




Idaho National Laboratory
\begin{tabular}{|c|lll|}
\hline NEXT GENERATION NUCLEAR PLANT & Identifier: & PLN-2803 & \\
REACTOR PRESSURE VESSEL MATERIALS & Revision: & 0 & \\
RESEARCH AND DEVELOPMENT PLAN & Effective Date: & $04 / 30 / 08$ & Page: B-43 of B- 68 \\
\hline
\end{tabular}

\begin{tabular}{|c|c|c|c|c|c|c|c|c|c|c|c|}
\hline \multicolumn{12}{|c|}{ Table B8. Fatigue-Relaxation Tests for Grade $91 \mathrm{Steel}$ at $550^{\circ} \mathrm{C}$} \\
\hline Spec. \# & Material & Product Form & Mat Cond & Heat & $\begin{array}{c}\text { Strain } \\
\text { Rate } \\
(\mathrm{m} / \mathrm{m} / \mathrm{s})\end{array}$ & Env & $\begin{array}{c}\text { Hold Cntrl } \\
\text { (stress/strain) }\end{array}$ & $\begin{array}{l}\text { Strain Hold } \\
\text { in } \mathrm{T} / \mathrm{C}\end{array}$ & $\begin{array}{l}\text { Temp. } \\
\left({ }^{\circ} \mathrm{C}\right)\end{array}$ & $\begin{array}{c}\text { Strain } \\
\text { Range (\%) }\end{array}$ & $\begin{array}{l}\text { Time During } \\
\text { Strain Hold } \\
\text { (min) }\end{array}$ \\
\hline 25 & Grade 91 & Forging (thick) & $\mathrm{AR}$ & heat-1 & $1 \mathrm{E}-03$ & air & strain & tension & 550 & 0.7 & 180 \\
\hline 26 & Grade 91 & Forging (thick) & $\mathrm{AR}$ & heat-1 & $1 \mathrm{E}-03$ & air & strain & tension & 550 & 0.7 & 180 \\
\hline 27 & Grade 91 & Forging (thick) & $\mathrm{AR}$ & heat-1 & $1 \mathrm{E}-03$ & air & strain & tension & 550 & 0.7 & 180 \\
\hline 28 & Grade 91 & Forging (thick) & AR & heat-1 & $1 \mathrm{E}-03$ & air & strain & comp. & 550 & 0.4 & 90 \\
\hline 29 & Grade 91 & Forging (thick) & AR & heat-1 & $1 \mathrm{E}-03$ & air & strain & comp. & 550 & 0.4 & 90 \\
\hline 30 & Grade 91 & Forging (thick) & $\mathrm{AR}$ & heat-1 & $1 \mathrm{E}-03$ & air & strain & comp. & 550 & 0.4 & 90 \\
\hline 31 & Grade 91 & Forging (thick) & $\mathrm{AR}$ & heat-1 & $1 \mathrm{E}-03$ & air & strain & comp. & 550 & 0.4 & 180 \\
\hline 32 & Grade 91 & Forging (thick) & AR & heat-1 & $1 \mathrm{E}-03$ & air & strain & comp. & 550 & 0.4 & 180 \\
\hline 33 & Grade 91 & Forging (thick) & AR & heat-1 & $1 \mathrm{E}-03$ & air & strain & comp. & 550 & 0.4 & 180 \\
\hline 34 & Grade 91 & Forging (thick) & $\mathrm{AR}$ & heat-1 & $1 \mathrm{E}-03$ & air & strain & comp. & 550 & 0.5 & 90 \\
\hline 35 & Grade 91 & Forging (thick) & $\mathrm{AR}$ & heat-1 & $1 \mathrm{E}-03$ & air & strain & comp. & 550 & 0.5 & 90 \\
\hline 36 & Grade 91 & Forging (thick) & $\mathrm{AR}$ & heat-1 & $1 \mathrm{E}-03$ & air & strain & comp. & 550 & 0.5 & 90 \\
\hline 37 & Grade 91 & Forging (thick) & AR & heat-1 & $1 \mathrm{E}-03$ & air & strain & comp. & 550 & 0.5 & 180 \\
\hline 38 & Grade 91 & Forging (thick) & $\mathrm{AR}$ & heat-1 & $1 \mathrm{E}-03$ & air & strain & comp. & 550 & 0.5 & 180 \\
\hline 39 & Grade 91 & Forging (thick) & $\mathrm{AR}$ & heat-1 & $1 \mathrm{E}-03$ & air & strain & comp. & 550 & 0.5 & 180 \\
\hline 40 & Grade 91 & Forging (thick) & $\mathrm{AR}$ & heat-1 & $1 \mathrm{E}-03$ & air & strain & comp. & 550 & 0.7 & 90 \\
\hline 41 & Grade 91 & Forging (thick) & $\mathrm{AR}$ & heat-1 & $1 \mathrm{E}-03$ & air & strain & comp. & 550 & 0.7 & 90 \\
\hline 42 & Grade 91 & Forging (thick) & $\mathrm{AR}$ & heat-1 & $1 \mathrm{E}-03$ & air & strain & comp. & 550 & 0.7 & 90 \\
\hline 43 & Grade 91 & Forging (thick) & $\mathrm{AR}$ & heat-1 & $1 \mathrm{E}-03$ & air & strain & comp. & 550 & 0.7 & 180 \\
\hline 44 & Grade 91 & Forging (thick) & $\mathrm{AR}$ & heat-1 & $1 \mathrm{E}-03$ & air & strain & comp. & 550 & 0.7 & 180 \\
\hline 45 & Grade 91 & Forging (thick) & $\mathrm{AR}$ & heat-1 & $1 \mathrm{E}-03$ & air & strain & comp. & 550 & 0.7 & 180 \\
\hline 46 & Grade 91 & Forging (thick) & Sim. PWHT & heat-1 & $1 \mathrm{E}-03$ & air & strain & N/A & 550 & 0.4 & 0 \\
\hline 47 & Grade 91 & Forging (thick) & Sim. PWHT & heat-1 & $1 \mathrm{E}-03$ & air & strain & N/A & 550 & 0.4 & 0 \\
\hline 48 & Grade 91 & Forging (thick) & Sim. PWHT & heat-1 & $1 \mathrm{E}-03$ & air & strain & $\mathrm{N} / \mathrm{A}$ & 550 & 0.4 & 0 \\
\hline 49 & Grade 91 & Forging (thick) & Sim. PWHT & heat-1 & $1 \mathrm{E}-03$ & air & strain & tension & 550 & 0.4 & 90 \\
\hline
\end{tabular}




Idaho National Laboratory
\begin{tabular}{|c|lll|}
\hline NEXT GENERATION NUCLEAR PLANT & Identifier: & PLN-2803 & \\
REACTOR PRESSURE VESSEL MATERIALS & Revision: & 0 & \\
RESEARCH AND DEVELOPMENT PLAN & Effective Date: & $04 / 30 / 08$ & Page: B-44 of B- 68 \\
\hline
\end{tabular}

\begin{tabular}{|c|c|c|c|c|c|c|c|c|c|c|c|}
\hline \multicolumn{12}{|c|}{ Table B8. Fatigue-Relaxation Tests for Grade $91 \mathrm{Steel}$ at $550^{\circ} \mathrm{C}$} \\
\hline Spec. \# & Material & Product Form & Mat Cond & Heat & $\begin{array}{c}\text { Strain } \\
\text { Rate } \\
(\mathrm{m} / \mathrm{m} / \mathrm{s})\end{array}$ & Env & $\begin{array}{c}\text { Hold Cntrl } \\
\text { (stress/strain) }\end{array}$ & $\begin{array}{l}\text { Strain Hold } \\
\text { in } \mathrm{T} / \mathrm{C}\end{array}$ & $\begin{array}{l}\text { Temp. } \\
\left({ }^{\circ} \mathrm{C}\right)\end{array}$ & $\begin{array}{c}\text { Strain } \\
\text { Range (\%) }\end{array}$ & $\begin{array}{l}\text { Time During } \\
\text { Strain Hold } \\
\text { (min) }\end{array}$ \\
\hline 50 & Grade 91 & Forging (thick) & Sim. PWHT & heat-1 & $1 \mathrm{E}-03$ & air & strain & tension & 550 & 0.4 & 90 \\
\hline 51 & Grade 91 & Forging (thick) & Sim. PWHT & heat-1 & $1 \mathrm{E}-03$ & air & strain & tension & 550 & 0.4 & 90 \\
\hline 52 & Grade 91 & Forging (thick) & Sim. PWHT & heat-1 & $1 \mathrm{E}-03$ & air & strain & tension & 550 & 0.4 & 180 \\
\hline 53 & Grade 91 & Forging (thick) & Sim. PWHT & heat-1 & $1 \mathrm{E}-03$ & air & strain & tension & 550 & 0.4 & 180 \\
\hline 54 & Grade 91 & Forging (thick) & Sim. PWHT & heat-1 & $1 \mathrm{E}-03$ & air & strain & tension & 550 & 0.4 & 180 \\
\hline 55 & Grade 91 & Forging (thick) & Sim. PWHT & heat-1 & $1 \mathrm{E}-03$ & air & strain & $\mathrm{N} / \mathrm{A}$ & 550 & 0.5 & 0 \\
\hline 56 & Grade 91 & Forging (thick) & Sim. PWHT & heat-1 & $1 \mathrm{E}-03$ & air & strain & N/A & 550 & 0.5 & 0 \\
\hline 57 & Grade 91 & Forging (thick) & Sim. PWHT & heat-1 & $1 \mathrm{E}-03$ & air & strain & N/A & 550 & 0.5 & 0 \\
\hline 58 & Grade 91 & Forging (thick) & Sim. PWHT & heat-1 & $1 \mathrm{E}-03$ & air & strain & tension & 550 & 0.5 & 90 \\
\hline 59 & Grade 91 & Forging (thick) & Sim. PWHT & heat-1 & $1 \mathrm{E}-03$ & air & strain & tension & 550 & 0.5 & 90 \\
\hline 60 & Grade 91 & Forging (thick) & Sim. PWHT & heat-1 & $1 \mathrm{E}-03$ & air & strain & tension & 550 & 0.5 & 90 \\
\hline 61 & Grade 91 & Forging (thick) & Sim. PWHT & heat-1 & $1 \mathrm{E}-03$ & air & strain & tension & 550 & 0.5 & 180 \\
\hline 62 & Grade 91 & Forging (thick) & Sim. PWHT & heat-1 & $1 \mathrm{E}-03$ & air & strain & tension & 550 & 0.5 & 180 \\
\hline 63 & Grade 91 & Forging (thick) & Sim. PWHT & heat-1 & $1 \mathrm{E}-03$ & air & strain & tension & 550 & 0.5 & 180 \\
\hline 64 & Grade 91 & Forging (thick) & Sim. PWHT & heat-1 & $1 \mathrm{E}-03$ & air & strain & N/A & 550 & 0.7 & 0 \\
\hline 65 & Grade 91 & Forging (thick) & Sim. PWHT & heat-1 & $1 \mathrm{E}-03$ & air & strain & N/A & 550 & 0.7 & 0 \\
\hline 66 & Grade 91 & Forging (thick) & Sim. PWHT & heat-1 & $1 \mathrm{E}-03$ & air & strain & N/A & 550 & 0.7 & 0 \\
\hline 67 & Grade 91 & Forging (thick) & Sim. PWHT & heat-1 & $1 \mathrm{E}-03$ & air & strain & tension & 550 & 0.7 & 90 \\
\hline 68 & Grade 91 & Forging (thick) & Sim. PWHT & heat-1 & $1 \mathrm{E}-03$ & air & strain & tension & 550 & 0.7 & 90 \\
\hline 69 & Grade 91 & Forging (thick) & Sim. PWHT & heat-1 & $1 \mathrm{E}-03$ & air & strain & tension & 550 & 0.7 & 90 \\
\hline 70 & Grade 91 & Forging (thick) & Sim. PWHT & heat-1 & $1 \mathrm{E}-03$ & air & strain & tension & 550 & 0.7 & 180 \\
\hline 71 & Grade 91 & Forging (thick) & Sim. PWHT & heat-1 & $1 \mathrm{E}-03$ & air & strain & tension & 550 & 0.7 & 180 \\
\hline 72 & Grade 91 & Forging (thick) & Sim. PWHT & heat-1 & $1 \mathrm{E}-03$ & air & strain & tension & 550 & 0.7 & 180 \\
\hline 73 & Grade 91 & Forging (thick) & Sim. PWHT & heat-1 & $1 \mathrm{E}-03$ & air & strain & comp. & 550 & 0.4 & 90 \\
\hline 74 & Grade 91 & Forging (thick) & Sim. PWHT & heat-1 & $1 \mathrm{E}-03$ & air & strain & comp. & 550 & 0.4 & 90 \\
\hline
\end{tabular}


Idaho National Laboratory

Idaho National Laboratory
\begin{tabular}{|c|lll|}
\hline NEXT GENERATION NUCLEAR PLANT & Identifier: & PLN-2803 & \\
REACTOR PRESSURE VESSEL MATERIALS & Revision: & 0 & \\
RESEARCH AND DEVELOPMENT PLAN & Effective Date: & $04 / 30 / 08$ & Page: B-45 of B-68 \\
\hline
\end{tabular}

\begin{tabular}{|c|c|c|c|c|c|c|c|c|c|c|c|}
\hline \multicolumn{12}{|c|}{ Table B8. Fatigue-Relaxation Tests for Grade 91 Steel at $550^{\circ} \mathrm{C}$} \\
\hline Spec. \# & Material & Product Form & Mat Cond & Heat & $\begin{array}{c}\text { Strain } \\
\text { Rate } \\
(\mathrm{m} / \mathrm{m} / \mathrm{s})\end{array}$ & Env & $\begin{array}{c}\text { Hold Cntrl } \\
\text { (stress/strain) }\end{array}$ & $\begin{array}{l}\text { Strain Hold } \\
\text { in } \mathrm{T} / \mathrm{C}\end{array}$ & $\begin{array}{l}\text { Temp. } \\
\left({ }^{\circ} \mathrm{C}\right)\end{array}$ & $\begin{array}{c}\text { Strain } \\
\text { Range (\%) }\end{array}$ & $\begin{array}{c}\text { Time During } \\
\text { Strain Hold } \\
(\mathrm{min})\end{array}$ \\
\hline 75 & Grade 91 & Forging (thick) & Sim. PWHT & heat-1 & $1 \mathrm{E}-03$ & air & strain & comp. & 550 & 0.4 & 90 \\
\hline 76 & Grade 91 & Forging (thick) & Sim. PWHT & heat-1 & $1 \mathrm{E}-03$ & air & strain & comp. & 550 & 0.4 & 180 \\
\hline 77 & Grade 91 & Forging (thick) & Sim. PWHT & heat-1 & $1 \mathrm{E}-03$ & air & strain & comp. & 550 & 0.4 & 180 \\
\hline 78 & Grade 91 & Forging (thick) & Sim. PWHT & heat-1 & $1 \mathrm{E}-03$ & air & strain & comp. & 550 & 0.4 & 180 \\
\hline 79 & Grade 91 & Forging (thick) & Sim. PWHT & heat-1 & $1 \mathrm{E}-03$ & air & strain & comp. & 550 & 0.5 & 90 \\
\hline 80 & Grade 91 & Forging (thick) & Sim. PWHT & heat-1 & $1 \mathrm{E}-03$ & air & strain & comp. & 550 & 0.5 & 90 \\
\hline 81 & Grade 91 & Forging (thick) & Sim. PWHT & heat-1 & $1 \mathrm{E}-03$ & air & strain & comp. & 550 & 0.5 & 90 \\
\hline 82 & Grade 91 & Forging (thick) & Sim. PWHT & heat-1 & $1 \mathrm{E}-03$ & air & strain & comp. & 550 & 0.5 & 180 \\
\hline 83 & Grade 91 & Forging (thick) & Sim. PWHT & heat-1 & $1 \mathrm{E}-03$ & air & strain & comp. & 550 & 0.5 & 180 \\
\hline 84 & Grade 91 & Forging (thick) & Sim. PWHT & heat-1 & $1 \mathrm{E}-03$ & air & strain & comp. & 550 & 0.5 & 180 \\
\hline 85 & Grade 91 & Forging (thick) & Sim. PWHT & heat-1 & $1 \mathrm{E}-03$ & air & strain & comp. & 550 & 0.7 & 90 \\
\hline 86 & Grade 91 & Forging (thick) & Sim. PWHT & heat-1 & $1 \mathrm{E}-03$ & air & strain & comp. & 550 & 0.7 & 90 \\
\hline 87 & Grade 91 & Forging (thick) & Sim. PWHT & heat-1 & $1 \mathrm{E}-03$ & air & strain & comp. & 550 & 0.7 & 90 \\
\hline 88 & Grade 91 & Forging (thick) & Sim. PWHT & heat-1 & $1 \mathrm{E}-03$ & air & strain & comp. & 550 & 0.7 & 180 \\
\hline 89 & Grade 91 & Forging (thick) & Sim. PWHT & heat-1 & $1 \mathrm{E}-03$ & air & strain & comp. & 550 & 0.7 & 180 \\
\hline 90 & Grade 91 & Forging (thick) & Sim. PWHT & heat-1 & $1 \mathrm{E}-03$ & air & strain & comp. & 550 & 0.7 & 180 \\
\hline
\end{tabular}




Idaho National Laboratory
\begin{tabular}{|c|lll|}
\hline NEXT GENERATION NUCLEAR PLANT & Identifier: & PLN-2803 & \\
REACTOR PRESSURE VESSEL MATERIALS & Revision: & 0 & \\
RESEARCH AND DEVELOPMENT PLAN & Effective Date: & $04 / 30 / 08$ & Page: B-46 of B- 68 \\
\hline
\end{tabular}

\begin{tabular}{|c|c|c|c|c|c|c|c|c|c|c|c|}
\hline \multicolumn{12}{|c|}{ Table B9. Creep-Fatigue Tests for Grade 91 Steel at $550^{\circ} \mathrm{C}$} \\
\hline $\begin{array}{c}\text { Spec. } \\
\# \\
\end{array}$ & Material & Product Form & $\begin{array}{c}\text { Mat } \\
\text { Cond }\end{array}$ & Heat & $\begin{array}{c}\text { Strain } \\
\text { Rate } \\
(\mathrm{m} / \mathrm{m} / \mathrm{s})\end{array}$ & Env & $\begin{array}{c}\text { Hold Cntrl } \\
\text { (stress/strain) }\end{array}$ & $\begin{array}{l}\text { Stress Hold } \\
\text { in } \mathrm{T} / \mathrm{C}\end{array}$ & Temp. $\left({ }^{\circ} \mathrm{C}\right)$ & $\begin{array}{c}\text { Strain } \\
\text { Range (\%) }\end{array}$ & $\begin{array}{c}\text { Total Strain } \\
\text { During Stress } \\
\text { Hold }(\%)\end{array}$ \\
\hline 1 & Grade 91 & Forging (thick) & $\mathrm{AR}$ & heat-1 & $1 \mathrm{E}-03$ & air & stress & $\mathrm{N} / \mathrm{A}$ & 550 & 0.4 & 0 \\
\hline 2 & Grade 91 & Forging (thick) & $\mathrm{AR}$ & heat-1 & $1 \mathrm{E}-03$ & air & stress & $\mathrm{N} / \mathrm{A}$ & 550 & 0.4 & 0 \\
\hline 3 & Grade 91 & Forging (thick) & AR & heat-1 & $1 \mathrm{E}-03$ & air & stress & $\mathrm{N} / \mathrm{A}$ & 550 & 0.4 & 0 \\
\hline 4 & Grade 91 & Forging (thick) & $\mathrm{AR}$ & heat-1 & $1 \mathrm{E}-03$ & air & stress & tension & 550 & 0.4 & 0.5 \\
\hline 5 & Grade 91 & Forging (thick) & $\mathrm{AR}$ & heat-1 & $1 \mathrm{E}-03$ & air & stress & tension & 550 & 0.4 & 0.5 \\
\hline 6 & Grade 91 & Forging (thick) & $\mathrm{AR}$ & heat-1 & $1 \mathrm{E}-03$ & air & stress & tension & 550 & 0.4 & 0.5 \\
\hline 7 & Grade 91 & Forging (thick) & $\mathrm{AR}$ & heat-1 & $1 \mathrm{E}-03$ & air & stress & $\mathrm{N} / \mathrm{A}$ & 550 & 0.5 & 0 \\
\hline 8 & Grade 91 & Forging (thick) & $\mathrm{AR}$ & heat-1 & $1 \mathrm{E}-03$ & air & stress & N/A & 550 & 0.5 & 0 \\
\hline 9 & Grade 91 & Forging (thick) & $\mathrm{AR}$ & heat-1 & $1 \mathrm{E}-03$ & air & stress & N/A & 550 & 0.5 & 0 \\
\hline 10 & Grade 91 & Forging (thick) & $\mathrm{AR}$ & heat-1 & $1 \mathrm{E}-03$ & air & stress & tension & 550 & 0.5 & 0.5 \\
\hline 11 & Grade 91 & Forging (thick) & $\mathrm{AR}$ & heat-1 & $1 \mathrm{E}-03$ & air & stress & tension & 550 & 0.5 & 0.5 \\
\hline 12 & Grade 91 & Forging (thick) & $\mathrm{AR}$ & heat-1 & $1 \mathrm{E}-03$ & air & stress & tension & 550 & 0.5 & 0.5 \\
\hline 13 & Grade 91 & Forging (thick) & $\mathrm{AR}$ & heat-1 & $1 \mathrm{E}-03$ & air & stress & N/A & 550 & 0.7 & 0 \\
\hline 14 & Grade 91 & Forging (thick) & $\mathrm{AR}$ & heat-1 & $1 \mathrm{E}-03$ & air & stress & N/A & 550 & 0.7 & 0 \\
\hline 15 & Grade 91 & Forging (thick) & $\mathrm{AR}$ & heat-1 & $1 \mathrm{E}-03$ & air & stress & N/A & 550 & 0.7 & 0 \\
\hline 16 & Grade 91 & Forging (thick) & $\mathrm{AR}$ & heat-1 & $1 \mathrm{E}-03$ & air & stress & tension & 550 & 0.7 & 0.3 \\
\hline 17 & Grade 91 & Forging (thick) & $\mathrm{AR}$ & heat-1 & $1 \mathrm{E}-03$ & air & stress & tension & 550 & 0.7 & 0.3 \\
\hline 18 & Grade 91 & Forging (thick) & $\mathrm{AR}$ & heat-1 & $1 \mathrm{E}-03$ & air & stress & tension & 550 & 0.7 & 0.3 \\
\hline 19 & Grade 91 & Forging (thick) & $\mathrm{AR}$ & heat-1 & $1 \mathrm{E}-03$ & air & stress & comp. & 550 & 0.4 & 0.5 \\
\hline 20 & Grade 91 & Forging (thick) & $\mathrm{AR}$ & heat-1 & $1 \mathrm{E}-03$ & air & stress & comp. & 550 & 0.4 & 0.5 \\
\hline 21 & Grade 91 & Forging (thick) & $\mathrm{AR}$ & heat-1 & $1 \mathrm{E}-03$ & air & stress & comp. & 550 & 0.4 & 0.5 \\
\hline 22 & Grade 91 & Forging (thick) & $\mathrm{AR}$ & heat-1 & $1 \mathrm{E}-03$ & air & stress & comp. & 550 & 0.5 & 0.5 \\
\hline 23 & Grade 91 & Forging (thick) & $\mathrm{AR}$ & heat-1 & $1 \mathrm{E}-03$ & air & stress & comp. & 550 & 0.5 & 0.5 \\
\hline 24 & Grade 91 & Forging (thick) & $\mathrm{AR}$ & heat-1 & $1 \mathrm{E}-03$ & air & stress & comp. & 550 & 0.5 & 0.5 \\
\hline
\end{tabular}


Idaho National Laboratory

\begin{tabular}{|c|lll|}
\hline NEXT GENERATION NUCLEAR PLANT & Identifier: & PLN-2803 & \\
REACTOR PRESSURE VESSEL MATERIALS & Revision: & 0 & \\
RESEARCH AND DEVELOPMENT PLAN & Effective Date: & $04 / 30 / 08$ & Page: B-47 of B-68 \\
\hline
\end{tabular}

\begin{tabular}{|c|c|c|c|c|c|c|c|c|c|c|c|}
\hline \multicolumn{12}{|c|}{ Table B9. Creep-Fatigue Tests for Grade 91 Steel at $550^{\circ} \mathrm{C}$} \\
\hline $\begin{array}{c}\text { Spec. } \\
\#\end{array}$ & Material & Product Form & $\begin{array}{l}\text { Mat } \\
\text { Cond }\end{array}$ & Heat & $\begin{array}{c}\text { Strain } \\
\text { Rate } \\
(\mathrm{m} / \mathrm{m} / \mathrm{s})\end{array}$ & Env & $\begin{array}{c}\text { Hold Cntrl } \\
\text { (stress/strain) }\end{array}$ & $\begin{array}{c}\text { Stress Hold } \\
\text { in } \mathrm{T} / \mathrm{C}\end{array}$ & Temp. $\left({ }^{\circ} \mathrm{C}\right)$ & $\begin{array}{c}\text { Strain } \\
\text { Range (\%) }\end{array}$ & $\begin{array}{c}\text { Total Strain } \\
\text { During Stress } \\
\text { Hold }(\%)\end{array}$ \\
\hline 25 & Grade 91 & Forging (thick) & $\mathrm{AR}$ & heat-1 & $1 \mathrm{E}-03$ & air & stress & comp. & 550 & 0.7 & 0.3 \\
\hline 26 & Grade 91 & Forging (thick) & AR & heat-1 & $1 \mathrm{E}-03$ & air & stress & comp. & 550 & 0.7 & 0.3 \\
\hline 27 & Grade 91 & Forging (thick) & AR & heat-1 & $1 \mathrm{E}-03$ & air & stress & comp. & 550 & 0.7 & 0.3 \\
\hline
\end{tabular}




Idaho National Laboratory
\begin{tabular}{|c|lll|}
\hline NEXT GENERATION NUCLEAR PLANT & Identifier: & PLN-2803 & \\
REACTOR PRESSURE VESSEL MATERIALS & Revision: & 0 & \\
RESEARCH AND DEVELOPMENT PLAN & Effective Date: & $04 / 30 / 08$ & Page: B-48 of B- 68 \\
\hline
\end{tabular}

\begin{tabular}{|c|c|c|c|c|c|c|c|c|c|c|c|c|}
\hline Spec. \# & Material & Product Form & $\begin{array}{l}\text { Aging } \\
\text { Temp. } \\
\left({ }^{\circ} \mathrm{C}\right)\end{array}$ & $\begin{array}{l}\text { Aging } \\
\text { Time } \\
\text { (h) }\end{array}$ & Heat & $\begin{array}{c}\text { Strain } \\
\text { Rate } \\
(\mathrm{m} / \mathrm{m} / \mathrm{s})\end{array}$ & Env & $\begin{array}{c}\text { Hold Cntrl } \\
\text { (stress/strain) }\end{array}$ & $\begin{array}{c}\text { Strain } \\
\text { Hold in } \\
T / C\end{array}$ & $\begin{array}{l}\text { Temp. } \\
\left({ }^{\circ} \mathrm{C}\right)\end{array}$ & $\begin{array}{c}\text { Strain } \\
\text { Range } \\
(\%)\end{array}$ & $\begin{array}{l}\text { Time During } \\
\text { Strain Hold } \\
\text { (min) }\end{array}$ \\
\hline 1 & Grade 91 & Forging (thick) & 650 & 20000 & heat-1 & $1 \mathrm{E}-03$ & air & strain & N/A & 500 & 0.5 & 0 \\
\hline 2 & Grade 91 & Forging (thick) & 650 & 20000 & heat-1 & $1 \mathrm{E}-03$ & air & strain & $\mathrm{N} / \mathrm{A}$ & 500 & 0.5 & 0 \\
\hline 3 & Grade 91 & Forging (thick) & 650 & 20000 & heat-1 & $1 \mathrm{E}-03$ & air & strain & N/A & 500 & 0.5 & 0 \\
\hline 4 & Grade 91 & Forging (thick) & 650 & 20000 & heat-1 & $1 \mathrm{E}-03$ & air & strain & tension & 500 & 0.5 & 10 \\
\hline 5 & Grade 91 & Forging (thick) & 650 & 20000 & heat-1 & $1 \mathrm{E}-03$ & air & strain & tension & 500 & 0.5 & 10 \\
\hline 6 & Grade 91 & Forging (thick) & 650 & 20000 & heat-1 & $1 \mathrm{E}-03$ & air & strain & tension & 500 & 0.5 & 10 \\
\hline 7 & Grade 91 & Forging (thick) & 650 & 20000 & heat-1 & $1 \mathrm{E}-03$ & air & strain & tension & 500 & 0.5 & 30 \\
\hline 8 & Grade 91 & Forging (thick) & 650 & 20000 & heat-1 & $1 \mathrm{E}-03$ & air & strain & tension & 500 & 0.5 & 30 \\
\hline 9 & Grade 91 & Forging (thick) & 650 & 20000 & heat-1 & $1 \mathrm{E}-03$ & air & strain & tension & 500 & 0.5 & 30 \\
\hline 10 & Grade 91 & Forging (thick) & 650 & 20000 & heat-1 & $1 \mathrm{E}-03$ & air & strain & tension & 500 & 0.5 & 60 \\
\hline 11 & Grade 91 & Forging (thick) & 650 & 20000 & heat-1 & $1 \mathrm{E}-03$ & air & strain & tension & 500 & 0.5 & 60 \\
\hline 12 & Grade 91 & Forging (thick) & 650 & 20000 & heat-1 & $1 \mathrm{E}-03$ & air & strain & tension & 500 & 0.5 & 60 \\
\hline 13 & Grade 91 & Forging (thick) & 650 & 20000 & heat-1 & $1 \mathrm{E}-03$ & air & strain & tension & 500 & 0.5 & 90 \\
\hline 14 & Grade 91 & Forging (thick) & 650 & 20000 & heat-1 & $1 \mathrm{E}-03$ & air & strain & tension & 500 & 0.5 & 90 \\
\hline 15 & Grade 91 & Forging (thick) & 650 & 20000 & heat-1 & $1 \mathrm{E}-03$ & air & strain & tension & 500 & 0.5 & 90 \\
\hline 16 & Grade 91 & Forging (thick) & 650 & 20000 & heat-1 & $1 \mathrm{E}-03$ & air & strain & tension & 500 & 0.5 & 120 \\
\hline 17 & Grade 91 & Forging (thick) & 650 & 20000 & heat-1 & $1 \mathrm{E}-03$ & air & strain & tension & 500 & 0.5 & 120 \\
\hline 18 & Grade 91 & Forging (thick) & 650 & 20000 & heat-1 & $1 \mathrm{E}-03$ & air & strain & tension & 500 & 0.5 & 120 \\
\hline 19 & Grade 91 & Forging (thick) & 650 & 20000 & heat-1 & $1 \mathrm{E}-03$ & air & strain & N/A & 500 & 0.7 & 0 \\
\hline 20 & Grade 91 & Forging (thick) & 650 & 20000 & heat-1 & $1 \mathrm{E}-03$ & air & strain & N/A & 500 & 0.7 & 0 \\
\hline 21 & Grade 91 & Forging (thick) & 650 & 20000 & heat-1 & $1 \mathrm{E}-03$ & air & strain & N/A & 500 & 0.7 & 0 \\
\hline 22 & Grade 91 & Forging (thick) & 650 & 20000 & heat-1 & $1 \mathrm{E}-03$ & air & strain & tension & 500 & 0.7 & 10 \\
\hline 23 & Grade 91 & Forging (thick) & 650 & 20000 & heat-1 & $1 \mathrm{E}-03$ & air & strain & tension & 500 & 0.7 & 10 \\
\hline 24 & Grade 91 & Forging (thick) & 650 & 20000 & heat-1 & $1 \mathrm{E}-03$ & air & strain & tension & 500 & 0.7 & 10 \\
\hline 25 & Grade 91 & Forging (thick) & 650 & 20000 & heat-1 & $1 \mathrm{E}-03$ & air & strain & tension & 500 & 0.7 & 30 \\
\hline
\end{tabular}




Idaho National Laboratory
\begin{tabular}{|c|lll|}
\hline NEXT GENERATION NUCLEAR PLANT & Identifier: & PLN-2803 & \\
REACTOR PRESSURE VESSEL MATERIALS & Revision: & 0 & \\
RESEARCH AND DEVELOPMENT PLAN & Effective Date: & $04 / 30 / 08$ & Page: B-49 of B- 68 \\
\hline
\end{tabular}

\begin{tabular}{|c|c|c|c|c|c|c|c|c|c|c|c|c|}
\hline Spec. \# & Material & Product Form & $\begin{array}{l}\text { Aging } \\
\text { Temp. } \\
\left({ }^{\circ} \mathrm{C}\right)\end{array}$ & $\begin{array}{l}\text { Aging } \\
\text { Time } \\
\text { (h) }\end{array}$ & Heat & $\begin{array}{c}\text { Strain } \\
\text { Rate } \\
(\mathrm{m} / \mathrm{m} / \mathrm{s})\end{array}$ & Env & $\begin{array}{c}\text { Hold Cntrl } \\
\text { (stress/strain) }\end{array}$ & $\begin{array}{l}\text { Strain } \\
\text { Hold in } \\
\text { T/C }\end{array}$ & $\begin{array}{l}\text { Temp. } \\
\left({ }^{\circ} \mathrm{C}\right)\end{array}$ & $\begin{array}{c}\text { Strain } \\
\text { Range } \\
(\%)\end{array}$ & $\begin{array}{l}\text { Time During } \\
\text { Strain Hold } \\
\text { (min) }\end{array}$ \\
\hline 26 & Grade 91 & Forging (thick) & 650 & 20000 & heat-1 & $1 \mathrm{E}-03$ & air & strain & tension & 500 & 0.7 & 30 \\
\hline 27 & Grade 91 & Forging (thick) & 650 & 20000 & heat-1 & $1 \mathrm{E}-03$ & air & strain & tension & 500 & 0.7 & 30 \\
\hline 28 & Grade 91 & Forging (thick) & 650 & 20000 & heat-1 & $1 \mathrm{E}-03$ & air & strain & tension & 500 & 0.7 & 60 \\
\hline 29 & Grade 91 & Forging (thick) & 650 & 20000 & heat-1 & $1 \mathrm{E}-03$ & air & strain & tension & 500 & 0.7 & 60 \\
\hline 30 & Grade 91 & Forging (thick) & 650 & 20000 & heat-1 & $1 \mathrm{E}-03$ & air & strain & tension & 500 & 0.7 & 60 \\
\hline 31 & Grade 91 & Forging (thick) & 650 & 20000 & heat-1 & $1 \mathrm{E}-03$ & air & strain & tension & 500 & 0.7 & 90 \\
\hline 32 & Grade 91 & Forging (thick) & 650 & 20000 & heat-1 & $1 \mathrm{E}-03$ & air & strain & tension & 500 & 0.7 & 90 \\
\hline 33 & Grade 91 & Forging (thick) & 650 & 20000 & heat-1 & $1 \mathrm{E}-03$ & air & strain & tension & 500 & 0.7 & 90 \\
\hline 34 & Grade 91 & Forging (thick) & 650 & 20000 & heat-1 & $1 \mathrm{E}-03$ & air & strain & tension & 500 & 0.7 & 120 \\
\hline 35 & Grade 91 & Forging (thick) & 650 & 20000 & heat-1 & $1 \mathrm{E}-03$ & air & strain & tension & 500 & 0.7 & 120 \\
\hline 36 & Grade 91 & Forging (thick) & 650 & 20000 & heat-1 & $1 \mathrm{E}-03$ & air & strain & tension & 500 & 0.7 & 120 \\
\hline 37 & Grade 91 & Forging (thick) & 650 & 20000 & heat-1 & $1 \mathrm{E}-03$ & air & strain & N/A & 500 & 1.0 & 0 \\
\hline 38 & Grade 91 & Forging (thick) & 650 & 20000 & heat-1 & $1 \mathrm{E}-03$ & air & strain & N/A & 500 & 1.0 & 0 \\
\hline 39 & Grade 91 & Forging (thick) & 650 & 20000 & heat-1 & $1 \mathrm{E}-03$ & air & strain & N/A & 500 & 1.0 & 0 \\
\hline 40 & Grade 91 & Forging (thick) & 650 & 20000 & heat-1 & $1 \mathrm{E}-03$ & air & strain & tension & 500 & 1.0 & 10 \\
\hline 41 & Grade 91 & Forging (thick) & 650 & 20000 & heat-1 & $1 \mathrm{E}-03$ & air & strain & tension & 500 & 1.0 & 10 \\
\hline 42 & Grade 91 & Forging (thick) & 650 & 20000 & heat-1 & $1 \mathrm{E}-03$ & air & strain & tension & 500 & 1.0 & 10 \\
\hline 43 & Grade 91 & Forging (thick) & 650 & 20000 & heat-1 & $1 \mathrm{E}-03$ & air & strain & tension & 500 & 1.0 & 30 \\
\hline 44 & Grade 91 & Forging (thick) & 650 & 20000 & heat-1 & $1 \mathrm{E}-03$ & air & strain & tension & 500 & 1.0 & 30 \\
\hline 45 & Grade 91 & Forging (thick) & 650 & 20000 & heat-1 & $1 \mathrm{E}-03$ & air & strain & tension & 500 & 1.0 & 30 \\
\hline 46 & Grade 91 & Forging (thick) & 650 & 20000 & heat-1 & $1 \mathrm{E}-03$ & air & strain & tension & 500 & 1.0 & 60 \\
\hline 47 & Grade 91 & Forging (thick) & 650 & 20000 & heat-1 & $1 \mathrm{E}-03$ & air & strain & tension & 500 & 1.0 & 60 \\
\hline 48 & Grade 91 & Forging (thick) & 650 & 20000 & heat-1 & $1 \mathrm{E}-03$ & air & strain & tension & 500 & 1.0 & 60 \\
\hline 49 & Grade 91 & Forging (thick) & 650 & 20000 & heat-1 & $1 \mathrm{E}-03$ & air & strain & tension & 500 & 1.0 & 90 \\
\hline 50 & Grade 91 & Forging (thick) & 650 & 20000 & heat-1 & $1 \mathrm{E}-03$ & air & strain & tension & 500 & 1.0 & 90 \\
\hline 51 & Grade 91 & Forging (thick) & 650 & 20000 & heat-1 & $1 \mathrm{E}-03$ & air & strain & tension & 500 & 1.0 & 90 \\
\hline
\end{tabular}




Idaho National Laboratory
\begin{tabular}{|c|lll|}
\hline NEXT GENERATION NUCLEAR PLANT & Identifier: & PLN-2803 & \\
REACTOR PRESSURE VESSEL MATERIALS & Revision: & 0 & \\
RESEARCH AND DEVELOPMENT PLAN & Effective Date: & $04 / 30 / 08$ & Page: B-50 of B- 68 \\
\hline
\end{tabular}

\begin{tabular}{|c|c|c|c|c|c|c|c|c|c|c|c|c|}
\hline Spec. \# & Material & Product Form & $\begin{array}{l}\text { Aging } \\
\text { Temp. } \\
\left({ }^{\circ} \mathrm{C}\right)\end{array}$ & $\begin{array}{l}\text { Aging } \\
\text { Time } \\
\text { (h) }\end{array}$ & Heat & $\begin{array}{c}\text { Strain } \\
\text { Rate } \\
(\mathrm{m} / \mathrm{m} / \mathrm{s})\end{array}$ & Env & $\begin{array}{c}\text { Hold Cntrl } \\
\text { (stress/strain) }\end{array}$ & $\begin{array}{l}\text { Strain } \\
\text { Hold in } \\
\text { T/C }\end{array}$ & $\begin{array}{l}\text { Temp. } \\
\left({ }^{\circ} \mathrm{C}\right)\end{array}$ & $\begin{array}{c}\text { Strain } \\
\text { Range } \\
(\%)\end{array}$ & $\begin{array}{l}\text { Time During } \\
\text { Strain Hold } \\
\text { (min) }\end{array}$ \\
\hline 52 & Grade 91 & Forging (thick) & 650 & 20000 & heat-1 & $1 \mathrm{E}-03$ & air & strain & tension & 500 & 1.0 & 120 \\
\hline 53 & Grade 91 & Forging (thick) & 650 & 20000 & heat-1 & $1 \mathrm{E}-03$ & air & strain & tension & 500 & 1.0 & 120 \\
\hline 54 & Grade 91 & Forging (thick) & 650 & 20000 & heat-1 & $1 \mathrm{E}-03$ & air & strain & tension & 500 & 1.0 & 120 \\
\hline 55 & Grade 91 & Forging (thick) & 650 & 20000 & heat-1 & $1 \mathrm{E}-03$ & air & strain & comp. & 500 & 0.5 & 10 \\
\hline 56 & Grade 91 & Forging (thick) & 650 & 20000 & heat-1 & $1 \mathrm{E}-03$ & air & strain & comp. & 500 & 0.5 & 10 \\
\hline 57 & Grade 91 & Forging (thick) & 650 & 20000 & heat-1 & $1 \mathrm{E}-03$ & air & strain & comp. & 500 & 0.5 & 10 \\
\hline 58 & Grade 91 & Forging (thick) & 650 & 20000 & heat-1 & $1 \mathrm{E}-03$ & air & strain & comp. & 500 & 0.5 & 30 \\
\hline 59 & Grade 91 & Forging (thick) & 650 & 20000 & heat-1 & $1 \mathrm{E}-03$ & air & strain & comp. & 500 & 0.5 & 30 \\
\hline 60 & Grade 91 & Forging (thick) & 650 & 20000 & heat-1 & $1 \mathrm{E}-03$ & air & strain & comp. & 500 & 0.5 & 30 \\
\hline 61 & Grade 91 & Forging (thick) & 650 & 20000 & heat-1 & $1 \mathrm{E}-03$ & air & strain & comp. & 500 & 0.5 & 60 \\
\hline 62 & Grade 91 & Forging (thick) & 650 & 20000 & heat-1 & $1 \mathrm{E}-03$ & air & strain & comp. & 500 & 0.5 & 60 \\
\hline 63 & Grade 91 & Forging (thick) & 650 & 20000 & heat-1 & $1 \mathrm{E}-03$ & air & strain & comp. & 500 & 0.5 & 60 \\
\hline 64 & Grade 91 & Forging (thick) & 650 & 20000 & heat-1 & $1 \mathrm{E}-03$ & air & strain & comp. & 500 & 0.5 & 90 \\
\hline 65 & Grade 91 & Forging (thick) & 650 & 20000 & heat-1 & $1 \mathrm{E}-03$ & air & strain & comp. & 500 & 0.5 & 90 \\
\hline 66 & Grade 91 & Forging (thick) & 650 & 20000 & heat-1 & $1 \mathrm{E}-03$ & air & strain & comp. & 500 & 0.5 & 90 \\
\hline 67 & Grade 91 & Forging (thick) & 650 & 20000 & heat-1 & $1 \mathrm{E}-03$ & air & strain & comp. & 500 & 0.5 & 120 \\
\hline 68 & Grade 91 & Forging (thick) & 650 & 20000 & heat-1 & $1 \mathrm{E}-03$ & air & strain & comp. & 500 & 0.5 & 120 \\
\hline 69 & Grade 91 & Forging (thick) & 650 & 20000 & heat-1 & $1 \mathrm{E}-03$ & air & strain & comp. & 500 & 0.5 & 120 \\
\hline 70 & Grade 91 & Forging (thick) & 650 & 20000 & heat-1 & $1 \mathrm{E}-03$ & air & strain & comp. & 500 & 0.7 & 10 \\
\hline 71 & Grade 91 & Forging (thick) & 650 & 20000 & heat-1 & $1 \mathrm{E}-03$ & air & strain & comp. & 500 & 0.7 & 10 \\
\hline 72 & Grade 91 & Forging (thick) & 650 & 20000 & heat-1 & $1 \mathrm{E}-03$ & air & strain & comp. & 500 & 0.7 & 10 \\
\hline 73 & Grade 91 & Forging (thick) & 650 & 20000 & heat-1 & $1 \mathrm{E}-03$ & air & strain & comp. & 500 & 0.7 & 30 \\
\hline 74 & Grade 91 & Forging (thick) & 650 & 20000 & heat-1 & $1 \mathrm{E}-03$ & air & strain & comp. & 500 & 0.7 & 30 \\
\hline 75 & Grade 91 & Forging (thick) & 650 & 20000 & heat-1 & $1 \mathrm{E}-03$ & air & strain & comp. & 500 & 0.7 & 30 \\
\hline 76 & Grade 91 & Forging (thick) & 650 & 20000 & heat-1 & $1 \mathrm{E}-03$ & air & strain & comp. & 500 & 0.7 & 60 \\
\hline 77 & Grade 91 & Forging (thick) & 650 & 20000 & heat-1 & $1 \mathrm{E}-03$ & air & strain & comp. & 500 & 0.7 & 60 \\
\hline
\end{tabular}




Idaho National Laboratory
\begin{tabular}{|c|lll|}
\hline NEXT GENERATION NUCLEAR PLANT & Identifier: & PLN-2803 & \\
REACTOR PRESSURE VESSEL MATERIALS & Revision: & 0 & \\
RESEARCH AND DEVELOPMENT PLAN & Effective Date: & $04 / 30 / 08$ & Page: B-51 of B- 68 \\
\hline
\end{tabular}

\begin{tabular}{|c|c|c|c|c|c|c|c|c|c|c|c|c|}
\hline \multicolumn{13}{|c|}{ Table B10. Fatigue-Relaxation Tests at $500^{\circ} \mathrm{C}$ for Aged Grade 91 Steel } \\
\hline Spec. \# & Material & Product Form & $\begin{array}{l}\text { Aging } \\
\text { Temp. } \\
\left({ }^{\circ} \mathrm{C}\right)\end{array}$ & $\begin{array}{l}\text { Aging } \\
\text { Time } \\
\text { (h) }\end{array}$ & Heat & $\begin{array}{c}\text { Strain } \\
\text { Rate } \\
(\mathrm{m} / \mathrm{m} / \mathrm{s})\end{array}$ & Env & $\begin{array}{c}\text { Hold Cntrl } \\
\text { (stress/strain) }\end{array}$ & $\begin{array}{l}\text { Strain } \\
\text { Hold in } \\
\text { T/C }\end{array}$ & $\begin{array}{l}\text { Temp. } \\
\left({ }^{\circ} \mathrm{C}\right)\end{array}$ & $\begin{array}{c}\text { Strain } \\
\text { Range } \\
(\%)\end{array}$ & $\begin{array}{c}\text { Time During } \\
\text { Strain Hold } \\
\text { (min) }\end{array}$ \\
\hline 78 & Grade 91 & Forging (thick) & 650 & 20000 & heat-1 & $1 \mathrm{E}-03$ & air & strain & comp. & 500 & 0.7 & 60 \\
\hline 79 & Grade 91 & Forging (thick) & 650 & 20000 & heat-1 & $1 \mathrm{E}-03$ & air & strain & comp. & 500 & 0.7 & 90 \\
\hline 80 & Grade 91 & Forging (thick) & 650 & 20000 & heat-1 & $1 \mathrm{E}-03$ & air & strain & comp. & 500 & 0.7 & 90 \\
\hline 81 & Grade 91 & Forging (thick) & 650 & 20000 & heat-1 & $1 \mathrm{E}-03$ & air & strain & comp. & 500 & 0.7 & 90 \\
\hline 82 & Grade 91 & Forging (thick) & 650 & 20000 & heat-1 & $1 \mathrm{E}-03$ & air & strain & comp. & 500 & 0.7 & 120 \\
\hline 83 & Grade 91 & Forging (thick) & 650 & 20000 & heat-1 & $1 \mathrm{E}-03$ & air & strain & comp. & 500 & 0.7 & 120 \\
\hline 84 & Grade 91 & Forging (thick) & 650 & 20000 & heat-1 & $1 \mathrm{E}-03$ & air & strain & comp. & 500 & 0.7 & 120 \\
\hline 85 & Grade 91 & Forging (thick) & 650 & 20000 & heat-1 & $1 \mathrm{E}-03$ & air & strain & comp. & 500 & 1.0 & 10 \\
\hline 86 & Grade 91 & Forging (thick) & 650 & 20000 & heat-1 & $1 \mathrm{E}-03$ & air & strain & comp. & 500 & 1.0 & 10 \\
\hline 87 & Grade 91 & Forging (thick) & 650 & 20000 & heat-1 & $1 \mathrm{E}-03$ & air & strain & comp. & 500 & 1.0 & 10 \\
\hline 88 & Grade 91 & Forging (thick) & 650 & 20000 & heat-1 & $1 \mathrm{E}-03$ & air & strain & comp. & 500 & 1.0 & 30 \\
\hline 89 & Grade 91 & Forging (thick) & 650 & 20000 & heat-1 & $1 \mathrm{E}-03$ & air & strain & comp. & 500 & 1.0 & 30 \\
\hline 90 & Grade 91 & Forging (thick) & 650 & 20000 & heat-1 & $1 \mathrm{E}-03$ & air & strain & comp. & 500 & 1.0 & 30 \\
\hline 91 & Grade 91 & Forging (thick) & 650 & 20000 & heat-1 & $1 \mathrm{E}-03$ & air & strain & comp. & 500 & 1.0 & 60 \\
\hline 92 & Grade 91 & Forging (thick) & 650 & 20000 & heat-1 & $1 \mathrm{E}-03$ & air & strain & comp. & 500 & 1.0 & 60 \\
\hline 93 & Grade 91 & Forging (thick) & 650 & 20000 & heat-1 & $1 \mathrm{E}-03$ & air & strain & comp. & 500 & 1.0 & 60 \\
\hline 94 & Grade 91 & Forging (thick) & 650 & 20000 & heat-1 & $1 \mathrm{E}-03$ & air & strain & comp. & 500 & 1.0 & 90 \\
\hline 95 & Grade 91 & Forging (thick) & 650 & 20000 & heat-1 & $1 \mathrm{E}-03$ & air & strain & comp. & 500 & 1.0 & 90 \\
\hline 96 & Grade 91 & Forging (thick) & 650 & 20000 & heat-1 & $1 \mathrm{E}-03$ & air & strain & comp. & 500 & 1.0 & 90 \\
\hline 97 & Grade 91 & Forging (thick) & 650 & 20000 & heat-1 & $1 \mathrm{E}-03$ & air & strain & comp. & 500 & 1.0 & 120 \\
\hline 98 & Grade 91 & Forging (thick) & 650 & 20000 & heat-1 & $1 \mathrm{E}-03$ & air & strain & comp. & 500 & 1.0 & 120 \\
\hline 99 & Grade 91 & Forging (thick) & 650 & 20000 & heat-1 & $1 \mathrm{E}-03$ & air & strain & comp. & 500 & 1.0 & 120 \\
\hline
\end{tabular}




Idaho National Laboratory
\begin{tabular}{|c|lll|}
\hline NEXT GENERATION NUCLEAR PLANT & Identifier: & PLN-2803 & \\
REACTOR PRESSURE VESSEL MATERIALS & Revision: & 0 & \\
RESEARCH AND DEVELOPMENT PLAN & Effective Date: & $04 / 30 / 08$ & Page: B- 52 of B- 68 \\
\hline
\end{tabular}

\begin{tabular}{|c|c|c|c|c|c|c|c|c|c|c|c|c|}
\hline Spec.\# & Material & Product Form & $\begin{array}{l}\text { Aging } \\
\text { Temp. } \\
\left({ }^{\circ} \mathrm{C}\right)\end{array}$ & $\begin{array}{l}\text { Aging } \\
\text { Time } \\
\text { (h) }\end{array}$ & Heat & $\begin{array}{l}\text { Strain } \\
\text { Rate } \\
(\mathrm{m} / \mathrm{m} / \mathrm{s})\end{array}$ & Env & $\begin{array}{c}\text { Hold Cntrl } \\
\text { (stress/strain) }\end{array}$ & $\begin{array}{l}\text { Stress } \\
\text { Hold in } \\
\text { T/C }\end{array}$ & $\begin{array}{c}\text { Temp. } \\
\left({ }^{\circ} \mathrm{C}\right)\end{array}$ & $\begin{array}{c}\text { Strain } \\
\text { Range (\%) }\end{array}$ & $\begin{array}{c}\text { Total Strain } \\
\text { During Stress } \\
\text { Hold }(\%)\end{array}$ \\
\hline 1 & Grade 91 & Forging (thick) & 650 & 20000 & heat-1 & $1 \mathrm{E}-03$ & air & stress & N/A & 500 & 0.5 & 0 \\
\hline 2 & Grade 91 & Forging (thick) & 650 & 20000 & heat-1 & $1 \mathrm{E}-03$ & air & stress & N/A & 500 & 0.5 & 0 \\
\hline 3 & Grade 91 & Forging (thick) & 650 & 20000 & heat-1 & $1 \mathrm{E}-03$ & air & stress & N/A & 500 & 0.5 & 0 \\
\hline 4 & Grade 91 & Forging (thick) & 650 & 20000 & heat-1 & $1 \mathrm{E}-03$ & air & stress & tension & 500 & 0.5 & 0.1 \\
\hline 5 & Grade 91 & Forging (thick) & 650 & 20000 & heat-1 & $1 \mathrm{E}-03$ & air & stress & tension & 500 & 0.5 & 0.1 \\
\hline 6 & Grade 91 & Forging (thick) & 650 & 20000 & heat-1 & $1 \mathrm{E}-03$ & air & stress & tension & 500 & 0.5 & 0.1 \\
\hline 7 & Grade 91 & Forging (thick) & 650 & 20000 & heat-1 & $1 \mathrm{E}-03$ & air & stress & tension & 500 & 0.5 & 0.3 \\
\hline 8 & Grade 91 & Forging (thick) & 650 & 20000 & heat-1 & $1 \mathrm{E}-03$ & air & stress & tension & 500 & 0.5 & 0.3 \\
\hline 9 & Grade 91 & Forging (thick) & 650 & 20000 & heat-1 & $1 \mathrm{E}-03$ & air & stress & tension & 500 & 0.5 & 0.3 \\
\hline 10 & Grade 91 & Forging (thick) & 650 & 20000 & heat-1 & $1 \mathrm{E}-03$ & air & stress & $\mathrm{N} / \mathrm{A}$ & 500 & 0.7 & 0 \\
\hline 11 & Grade 91 & Forging (thick) & 650 & 20000 & heat-1 & $1 \mathrm{E}-03$ & air & stress & N/A & 500 & 0.7 & 0 \\
\hline 12 & Grade 91 & Forging (thick) & 650 & 20000 & heat-1 & $1 \mathrm{E}-03$ & air & stress & N/A & 500 & 0.7 & 0 \\
\hline 13 & Grade 91 & Forging (thick) & 650 & 20000 & heat-1 & $1 \mathrm{E}-03$ & air & stress & tension & 500 & 0.7 & 0.1 \\
\hline 14 & Grade 91 & Forging (thick) & 650 & 20000 & heat-1 & $1 \mathrm{E}-03$ & air & stress & tension & 500 & 0.7 & 0.1 \\
\hline 15 & Grade 91 & Forging (thick) & 650 & 20000 & heat-1 & $1 \mathrm{E}-03$ & air & stress & tension & 500 & 0.7 & 0.1 \\
\hline 16 & Grade 91 & Forging (thick) & 650 & 20000 & heat-1 & $1 \mathrm{E}-03$ & air & stress & tension & 500 & 0.7 & 0.3 \\
\hline 17 & Grade 91 & Forging (thick) & 650 & 20000 & heat-1 & $1 \mathrm{E}-03$ & air & stress & tension & 500 & 0.7 & 0.3 \\
\hline 18 & Grade 91 & Forging (thick) & 650 & 20000 & heat-1 & $1 \mathrm{E}-03$ & air & stress & tension & 500 & 0.7 & 0.3 \\
\hline 19 & Grade 91 & Forging (thick) & 650 & 20000 & heat-1 & $1 \mathrm{E}-03$ & air & stress & N/A & 500 & 1.0 & 0 \\
\hline 20 & Grade 91 & Forging (thick) & 650 & 20000 & heat-1 & $1 \mathrm{E}-03$ & air & stress & $\mathrm{N} / \mathrm{A}$ & 500 & 1.0 & 0 \\
\hline 21 & Grade 91 & Forging (thick) & 650 & 20000 & heat-1 & $1 \mathrm{E}-03$ & air & stress & N/A & 500 & 1.0 & 0 \\
\hline 22 & Grade 91 & Forging (thick) & 650 & 20000 & heat-1 & $1 \mathrm{E}-03$ & air & stress & tension & 500 & 1.0 & 0.1 \\
\hline 23 & Grade 91 & Forging (thick) & 650 & 20000 & heat-1 & $1 \mathrm{E}-03$ & air & stress & tension & 500 & 1.0 & 0.1 \\
\hline 24 & Grade 91 & Forging (thick) & 650 & 20000 & heat-1 & $1 \mathrm{E}-03$ & air & stress & tension & 500 & 1.0 & 0.1 \\
\hline
\end{tabular}




Idaho National Laboratory
\begin{tabular}{|c|lll|}
\hline NEXT GENERATION NUCLEAR PLANT & Identifier: & PLN-2803 & \\
REACTOR PRESSURE VESSEL MATERIALS & Revision: & 0 & \\
RESEARCH AND DEVELOPMENT PLAN & Effective Date: & $04 / 30 / 08$ & Page: B-53 of B-68 \\
\hline
\end{tabular}

\begin{tabular}{|c|c|c|c|c|c|c|c|c|c|c|c|c|}
\hline \multicolumn{13}{|c|}{ Table B11. Creep-Fatigue Tests at $500^{\circ} \mathrm{C}$ for Aged Grade 91 Steel } \\
\hline Spec.\# & Material & Product Form & $\begin{array}{c}\text { Aging } \\
\text { Temp. } \\
\left({ }^{\circ} \mathrm{C}\right)\end{array}$ & $\begin{array}{l}\text { Aging } \\
\text { Time } \\
\text { (h) }\end{array}$ & Heat & $\begin{array}{c}\text { Strain } \\
\text { Rate } \\
(\mathrm{m} / \mathrm{m} / \mathrm{s})\end{array}$ & Env & $\begin{array}{c}\text { Hold Cntrl } \\
\text { (stress/strain) }\end{array}$ & $\begin{array}{c}\text { Stress } \\
\text { Hold in } \\
T / C\end{array}$ & $\begin{array}{l}\text { Temp. } \\
\left({ }^{\circ} \mathrm{C}\right)\end{array}$ & $\begin{array}{c}\text { Strain } \\
\text { Range (\%) }\end{array}$ & $\begin{array}{c}\text { Total Strain } \\
\text { During Stress } \\
\text { Hold (\%) }\end{array}$ \\
\hline 25 & Grade 91 & Forging (thick) & 650 & 20000 & heat-1 & $1 \mathrm{E}-03$ & air & stress & tension & 500 & 1.0 & 0.3 \\
\hline 26 & Grade 91 & Forging (thick) & 650 & 20000 & heat-1 & $1 \mathrm{E}-03$ & air & stress & tension & 500 & 1.0 & 0.3 \\
\hline 27 & Grade 91 & Forging (thick) & 650 & 20000 & heat-1 & $1 \mathrm{E}-03$ & air & stress & tension & 500 & 1.0 & 0.3 \\
\hline 28 & Grade 91 & Forging (thick) & 650 & 20000 & heat-1 & $1 \mathrm{E}-03$ & air & stress & comp. & 500 & 0.5 & 0.1 \\
\hline 29 & Grade 91 & Forging (thick) & 650 & 20000 & heat-1 & $1 \mathrm{E}-03$ & air & stress & comp. & 500 & 0.5 & 0.1 \\
\hline 30 & Grade 91 & Forging (thick) & 650 & 20000 & heat-1 & $1 \mathrm{E}-03$ & air & stress & comp. & 500 & 0.5 & 0.1 \\
\hline 31 & Grade 91 & Forging (thick) & 650 & 20000 & heat-1 & $1 \mathrm{E}-03$ & air & stress & comp. & 500 & 0.5 & 0.3 \\
\hline 32 & Grade 91 & Forging (thick) & 650 & 20000 & heat-1 & $1 \mathrm{E}-03$ & air & stress & comp. & 500 & 0.5 & 0.3 \\
\hline 33 & Grade 91 & Forging (thick) & 650 & 20000 & heat-1 & $1 \mathrm{E}-03$ & air & stress & comp. & 500 & 0.5 & 0.3 \\
\hline 34 & Grade 91 & Forging (thick) & 650 & 20000 & heat-1 & $1 \mathrm{E}-03$ & air & stress & comp. & 500 & 0.7 & 0.1 \\
\hline 35 & Grade 91 & Forging (thick) & 650 & 20000 & heat-1 & $1 \mathrm{E}-03$ & air & stress & comp. & 500 & 0.7 & 0.1 \\
\hline 36 & Grade 91 & Forging (thick) & 650 & 20000 & heat-1 & $1 \mathrm{E}-03$ & air & stress & comp. & 500 & 0.7 & 0.1 \\
\hline 37 & Grade 91 & Forging (thick) & 650 & 20000 & heat-1 & $1 \mathrm{E}-03$ & air & stress & comp. & 500 & 0.7 & 0.3 \\
\hline 38 & Grade 91 & Forging (thick) & 650 & 20000 & heat-1 & $1 \mathrm{E}-03$ & air & stress & comp. & 500 & 0.7 & 0.3 \\
\hline 39 & Grade 91 & Forging (thick) & 650 & 20000 & heat-1 & $1 \mathrm{E}-03$ & air & stress & comp. & 500 & 0.7 & 0.3 \\
\hline 40 & Grade 91 & Forging (thick) & 650 & 20000 & heat-1 & $1 \mathrm{E}-03$ & air & stress & comp. & 500 & 1.0 & 0.1 \\
\hline 41 & Grade 91 & Forging (thick) & 650 & 20000 & heat-1 & $1 \mathrm{E}-03$ & air & stress & comp. & 500 & 1.0 & 0.1 \\
\hline 42 & Grade 91 & Forging (thick) & 650 & 20000 & heat-1 & $1 \mathrm{E}-03$ & air & stress & comp. & 500 & 1.0 & 0.1 \\
\hline 43 & Grade 91 & Forging (thick) & 650 & 20000 & heat-1 & $1 \mathrm{E}-03$ & air & stress & comp. & 500 & 1.0 & 0.3 \\
\hline 44 & Grade 91 & Forging (thick) & 650 & 20000 & heat-1 & $1 \mathrm{E}-03$ & air & stress & comp. & 500 & 1.0 & 0.3 \\
\hline 45 & Grade 91 & Forging (thick) & 650 & 20000 & heat-1 & $1 \mathrm{E}-03$ & air & stress & comp. & 500 & 1.0 & 0.3 \\
\hline
\end{tabular}




Idaho National Laboratory
\begin{tabular}{|c|lll|}
\hline NEXT GENERATION NUCLEAR PLANT & Identifier: & PLN-2803 & \\
REACTOR PRESSURE VESSEL MATERIALS & Revision: & 0 & \\
RESEARCH AND DEVELOPMENT PLAN & Effective Date: & $04 / 30 / 08$ & Page: B-54 of B- 68 \\
\hline
\end{tabular}

\begin{tabular}{|c|c|c|c|c|c|c|c|c|c|c|c|c|c|}
\hline \multicolumn{14}{|c|}{ Table B12. Fatigue-Relaxation Tests at $550^{\circ} \mathrm{C}$ for Grade 91 Cross Welds } \\
\hline Spec. \# & $\begin{array}{l}\text { Weld } \\
\text { Wire }\end{array}$ & Product Form & $\begin{array}{l}\text { Weld } \\
\text { Process }\end{array}$ & $\begin{array}{l}\text { Mat } \\
\text { Cond }\end{array}$ & $\begin{array}{c}\text { G91 } \\
\text { Thick } \\
\text { Section } \\
\text { Heat \# }\end{array}$ & $\begin{array}{l}\text { Weld to } \\
\text { be } \\
\text { Tested }\end{array}$ & $\begin{array}{c}\text { Strain } \\
\text { Rate } \\
(\mathrm{m} / \mathrm{m} / \mathrm{s})\end{array}$ & Env & $\begin{array}{l}\text { Hold } \\
\text { Cntrl } \\
\text { (stress or } \\
\text { strain) }\end{array}$ & $\begin{array}{l}\text { Strain } \\
\text { Hold in } \\
\mathrm{T} / \mathrm{C}\end{array}$ & $\begin{array}{c}\text { Temp. } \\
\left({ }^{\circ} \mathrm{C}\right)\end{array}$ & $\begin{array}{c}\text { Strain } \\
\text { Range } \\
(\%)\end{array}$ & $\begin{array}{c}\text { Time } \\
\text { During } \\
\text { Strain Hold } \\
(\mathrm{min})\end{array}$ \\
\hline 1 & TBD & Thick Sect. Weld & SAW & PWHT & heat-1 & X-Weld & $1 \mathrm{E}-03$ & air & strain & N/A & 550 & 0.4 & 0 \\
\hline 2 & TBD & Thick Sect. Weld & SAW & PWHT & heat-1 & X-Weld & $1 \mathrm{E}-03$ & air & strain & N/A & 550 & 0.4 & 0 \\
\hline 3 & TBD & Thick Sect. Weld & SAW & PWHT & heat-1 & X-Weld & $1 \mathrm{E}-03$ & air & strain & $\mathrm{N} / \mathrm{A}$ & 550 & 0.4 & 0 \\
\hline 4 & TBD & Thick Sect. Weld & SAW & PWHT & heat-1 & X-Weld & $1 \mathrm{E}-03$ & air & strain & tension & 550 & 0.4 & 90 \\
\hline 5 & TBD & Thick Sect. Weld & SAW & PWHT & heat-1 & X-Weld & $1 \mathrm{E}-03$ & air & strain & tension & 550 & 0.4 & 90 \\
\hline 6 & TBD & Thick Sect. Weld & SAW & PWHT & heat-1 & X-Weld & $1 \mathrm{E}-03$ & air & strain & tension & 550 & 0.4 & 90 \\
\hline 7 & TBD & Thick Sect. Weld & SAW & PWHT & heat-1 & X-Weld & $1 \mathrm{E}-03$ & air & strain & tension & 550 & 0.4 & 180 \\
\hline 8 & TBD & Thick Sect. Weld & SAW & PWHT & heat-1 & X-Weld & $1 \mathrm{E}-03$ & air & strain & tension & 550 & 0.4 & 180 \\
\hline 9 & TBD & Thick Sect. Weld & SAW & PWHT & heat-1 & X-Weld & $1 \mathrm{E}-03$ & air & strain & tension & 550 & 0.4 & 180 \\
\hline 10 & TBD & Thick Sect. Weld & SAW & PWHT & heat-1 & X-Weld & $1 \mathrm{E}-03$ & air & strain & N/A & 550 & 0.5 & 0 \\
\hline 11 & TBD & Thick Sect. Weld & SAW & PWHT & heat-1 & X-Weld & $1 \mathrm{E}-03$ & air & strain & N/A & 550 & 0.5 & 0 \\
\hline 12 & TBD & Thick Sect. Weld & SAW & PWHT & heat-1 & X-Weld & $1 \mathrm{E}-03$ & air & strain & N/A & 550 & 0.5 & 0 \\
\hline 13 & TBD & Thick Sect. Weld & SAW & PWHT & heat-1 & X-Weld & $1 \mathrm{E}-03$ & air & strain & tension & 550 & 0.5 & 90 \\
\hline 14 & TBD & Thick Sect. Weld & SAW & PWHT & heat-1 & X-Weld & $1 \mathrm{E}-03$ & air & strain & tension & 550 & 0.5 & 90 \\
\hline 15 & TBD & Thick Sect. Weld & SAW & PWHT & heat-1 & X-Weld & $1 \mathrm{E}-03$ & air & strain & tension & 550 & 0.5 & 90 \\
\hline 16 & TBD & Thick Sect. Weld & SAW & PWHT & heat-1 & X-Weld & $1 \mathrm{E}-03$ & air & strain & tension & 550 & 0.5 & 180 \\
\hline 17 & TBD & Thick Sect. Weld & SAW & PWHT & heat-1 & X-Weld & $1 \mathrm{E}-03$ & air & strain & tension & 550 & 0.5 & 180 \\
\hline 18 & TBD & Thick Sect. Weld & SAW & PWHT & heat-1 & X-Weld & $1 \mathrm{E}-03$ & air & strain & tension & 550 & 0.5 & 180 \\
\hline 19 & TBD & Thick Sect. Weld & SAW & PWHT & heat-1 & X-Weld & $1 \mathrm{E}-03$ & air & strain & N/A & 550 & 0.7 & 0 \\
\hline 20 & TBD & Thick Sect. Weld & SAW & PWHT & heat-1 & X-Weld & $1 \mathrm{E}-03$ & air & strain & N/A & 550 & 0.7 & 0 \\
\hline 21 & TBD & Thick Sect. Weld & SAW & PWHT & heat-1 & X-Weld & $1 \mathrm{E}-03$ & air & strain & N/A & 550 & 0.7 & 0 \\
\hline 22 & TBD & Thick Sect. Weld & SAW & PWHT & heat-1 & X-Weld & $1 \mathrm{E}-03$ & air & strain & tension & 550 & 0.7 & 90 \\
\hline 23 & TBD & Thick Sect. Weld & SAW & PWHT & heat-1 & X-Weld & $1 \mathrm{E}-03$ & air & strain & tension & 550 & 0.7 & 90 \\
\hline 24 & TBD & Thick Sect. Weld & SAW & PWHT & heat-1 & X-Weld & $1 \mathrm{E}-03$ & air & strain & tension & 550 & 0.7 & 90 \\
\hline
\end{tabular}




Idaho National Laboratory
\begin{tabular}{|c|lll|}
\hline NEXT GENERATION NUCLEAR PLANT & Identifier: & PLN-2803 & \\
REACTOR PRESSURE VESSEL MATERIALS & Revision: & 0 & \\
RESEARCH AND DEVELOPMENT PLAN & Effective Date: & $04 / 30 / 08$ & Page: B- 55 of B- 68 \\
\hline
\end{tabular}

\begin{tabular}{|c|c|c|c|c|c|c|c|c|c|c|c|c|c|}
\hline \multicolumn{14}{|c|}{ Table B12. Fatigue-Relaxation Tests at $550^{\circ} \mathrm{C}$ for Grade 91 Cross Welds } \\
\hline Spec. \# & $\begin{array}{l}\text { Weld } \\
\text { Wire }\end{array}$ & Product Form & $\begin{array}{l}\text { Weld } \\
\text { Process }\end{array}$ & $\begin{array}{c}\text { Mat } \\
\text { Cond }\end{array}$ & $\begin{array}{c}\text { G91 } \\
\text { Thick } \\
\text { Section } \\
\text { Heat \# }\end{array}$ & $\begin{array}{l}\text { Weld to } \\
\text { be } \\
\text { Tested }\end{array}$ & $\begin{array}{c}\text { Strain } \\
\text { Rate } \\
(\mathrm{m} / \mathrm{m} / \mathrm{s})\end{array}$ & Env & $\begin{array}{c}\text { Hold } \\
\text { Cntrl } \\
\text { (stress or } \\
\text { strain) }\end{array}$ & $\begin{array}{c}\text { Strain } \\
\text { Hold in } \\
\text { T/C }\end{array}$ & $\begin{array}{l}\text { Temp. } \\
\left({ }^{\circ} \mathrm{C}\right)\end{array}$ & $\begin{array}{l}\text { Strain } \\
\text { Range } \\
(\%)\end{array}$ & $\begin{array}{c}\text { Time } \\
\text { During } \\
\text { Strain Hold } \\
(\mathrm{min})\end{array}$ \\
\hline 25 & TBD & Thick Sect. Weld & SAW & PWHT & heat-1 & X-Weld & $1 \mathrm{E}-03$ & air & strain & tension & 550 & 0.7 & 180 \\
\hline 26 & TBD & Thick Sect. Weld & SAW & PWHT & heat-1 & X-Weld & $1 \mathrm{E}-03$ & air & strain & tension & 550 & 0.7 & 180 \\
\hline 27 & TBD & Thick Sect. Weld & SAW & PWHT & heat-1 & X-Weld & $1 \mathrm{E}-03$ & air & strain & tension & 550 & 0.7 & 180 \\
\hline 28 & TBD & Thick Sect. Weld & SAW & PWHT & heat-1 & X-Weld & $1 \mathrm{E}-03$ & air & strain & comp. & 550 & 0.4 & 90 \\
\hline 29 & TBD & Thick Sect. Weld & SAW & PWHT & heat-1 & X-Weld & $1 \mathrm{E}-03$ & air & strain & comp. & 550 & 0.4 & 90 \\
\hline 30 & TBD & Thick Sect. Weld & SAW & PWHT & heat-1 & X-Weld & $1 \mathrm{E}-03$ & air & strain & comp. & 550 & 0.4 & 90 \\
\hline 31 & TBD & Thick Sect. Weld & SAW & PWHT & heat-1 & X-Weld & $1 \mathrm{E}-03$ & air & strain & comp. & 550 & 0.4 & 180 \\
\hline 32 & TBD & Thick Sect. Weld & SAW & PWHT & heat-1 & X-Weld & $1 \mathrm{E}-03$ & air & strain & comp. & 550 & 0.4 & 180 \\
\hline 33 & TBD & Thick Sect. Weld & SAW & PWHT & heat-1 & X-Weld & $1 \mathrm{E}-03$ & air & strain & comp. & 550 & 0.4 & 180 \\
\hline 34 & TBD & Thick Sect. Weld & SAW & PWHT & heat-1 & X-Weld & $1 \mathrm{E}-03$ & air & strain & comp. & 550 & 0.5 & 90 \\
\hline 35 & TBD & Thick Sect. Weld & SAW & PWHT & heat-1 & X-Weld & $1 \mathrm{E}-03$ & air & strain & comp. & 550 & 0.5 & 90 \\
\hline 36 & TBD & Thick Sect. Weld & SAW & PWHT & heat-1 & X-Weld & $1 \mathrm{E}-03$ & air & strain & comp. & 550 & 0.5 & 90 \\
\hline 37 & TBD & Thick Sect. Weld & SAW & PWHT & heat-1 & X-Weld & $1 \mathrm{E}-03$ & air & strain & comp. & 550 & 0.5 & 180 \\
\hline 38 & TBD & Thick Sect. Weld & SAW & PWHT & heat-1 & X-Weld & $1 \mathrm{E}-03$ & air & strain & comp. & 550 & 0.5 & 180 \\
\hline 39 & TBD & Thick Sect. Weld & SAW & PWHT & heat-1 & X-Weld & $1 \mathrm{E}-03$ & air & strain & comp. & 550 & 0.5 & 180 \\
\hline 40 & TBD & Thick Sect. Weld & SAW & PWHT & heat-1 & X-Weld & $1 \mathrm{E}-03$ & air & strain & comp. & 550 & 0.7 & 90 \\
\hline 41 & TBD & Thick Sect. Weld & SAW & PWHT & heat-1 & X-Weld & $1 \mathrm{E}-03$ & air & strain & comp. & 550 & 0.7 & 90 \\
\hline 42 & TBD & Thick Sect. Weld & SAW & PWHT & heat-1 & X-Weld & $1 \mathrm{E}-03$ & air & strain & comp. & 550 & 0.7 & 90 \\
\hline 43 & TBD & Thick Sect. Weld & SAW & PWHT & heat-1 & X-Weld & $1 \mathrm{E}-03$ & air & strain & comp. & 550 & 0.7 & 180 \\
\hline 44 & TBD & Thick Sect. Weld & SAW & PWHT & heat-1 & X-Weld & $1 \mathrm{E}-03$ & air & strain & comp. & 550 & 0.7 & 180 \\
\hline 45 & TBD & Thick Sect. Weld & SAW & PWHT & heat-1 & X-Weld & $1 \mathrm{E}-03$ & air & strain & comp. & 550 & 0.7 & 180 \\
\hline 46 & TBD & Thick Sect. Weld & GTAW & PWHT & heat-1 & X-Weld & $1 \mathrm{E}-03$ & air & strain & N/A & 550 & 0.4 & 0 \\
\hline 47 & TBD & Thick Sect. Weld & GTAW & PWHT & heat-1 & X-Weld & $1 \mathrm{E}-03$ & air & strain & N/A & 550 & 0.4 & 0 \\
\hline 48 & TBD & Thick Sect. Weld & GTAW & PWHT & heat-1 & X-Weld & $1 \mathrm{E}-03$ & air & strain & N/A & 550 & 0.4 & 0 \\
\hline 49 & TBD & Thick Sect. Weld & GTAW & PWHT & heat-1 & X-Weld & $1 \mathrm{E}-03$ & air & strain & tension & 550 & 0.4 & 90 \\
\hline
\end{tabular}




Idaho National Laboratory
\begin{tabular}{|c|lll|}
\hline NEXT GENERATION NUCLEAR PLANT & Identifier: & PLN-2803 & \\
REACTOR PRESSURE VESSEL MATERIALS & Revision: & 0 & \\
RESEARCH AND DEVELOPMENT PLAN & Effective Date: & $04 / 30 / 08$ & Page: B- 56 of B- 68 \\
\hline
\end{tabular}

\begin{tabular}{|c|c|c|c|c|c|c|c|c|c|c|c|c|c|}
\hline \multicolumn{14}{|c|}{ Table B12. Fatigue-Relaxation Tests at $550^{\circ} \mathrm{C}$ for Grade 91 Cross Welds } \\
\hline Spec. \# & $\begin{array}{l}\text { Weld } \\
\text { Wire }\end{array}$ & Product Form & $\begin{array}{l}\text { Weld } \\
\text { Process }\end{array}$ & $\begin{array}{c}\text { Mat } \\
\text { Cond }\end{array}$ & $\begin{array}{c}\text { G91 } \\
\text { Thick } \\
\text { Section } \\
\text { Heat \# }\end{array}$ & $\begin{array}{l}\text { Weld to } \\
\text { be } \\
\text { Tested }\end{array}$ & $\begin{array}{c}\text { Strain } \\
\text { Rate } \\
(\mathrm{m} / \mathrm{m} / \mathrm{s})\end{array}$ & Env & $\begin{array}{c}\text { Hold } \\
\text { Cntrl } \\
\text { (stress or } \\
\text { strain) }\end{array}$ & $\begin{array}{c}\text { Strain } \\
\text { Hold in } \\
\text { T/C }\end{array}$ & $\begin{array}{l}\text { Temp. } \\
\left({ }^{\circ} \mathrm{C}\right)\end{array}$ & $\begin{array}{l}\text { Strain } \\
\text { Range } \\
(\%)\end{array}$ & $\begin{array}{c}\text { Time } \\
\text { During } \\
\text { Strain Hold } \\
(\mathrm{min})\end{array}$ \\
\hline 50 & TBD & Thick Sect. Weld & GTAW & PWHT & heat-1 & X-Weld & $1 \mathrm{E}-03$ & air & strain & tension & 550 & 0.4 & 90 \\
\hline 51 & TBD & Thick Sect. Weld & GTAW & PWHT & heat-1 & X-Weld & $1 \mathrm{E}-03$ & air & strain & tension & 550 & 0.4 & 90 \\
\hline 52 & TBD & Thick Sect. Weld & GTAW & PWHT & heat-1 & X-Weld & $1 \mathrm{E}-03$ & air & strain & tension & 550 & 0.4 & 180 \\
\hline 53 & TBD & Thick Sect. Weld & GTAW & PWHT & heat-1 & X-Weld & $1 \mathrm{E}-03$ & air & strain & tension & 550 & 0.4 & 180 \\
\hline 54 & TBD & Thick Sect. Weld & GTAW & PWHT & heat-1 & X-Weld & $1 \mathrm{E}-03$ & air & strain & tension & 550 & 0.4 & 180 \\
\hline 55 & TBD & Thick Sect. Weld & GTAW & PWHT & heat-1 & X-Weld & $1 \mathrm{E}-03$ & air & strain & N/A & 550 & 0.5 & 0 \\
\hline 56 & TBD & Thick Sect. Weld & GTAW & PWHT & heat-1 & X-Weld & $1 \mathrm{E}-03$ & air & strain & N/A & 550 & 0.5 & 0 \\
\hline 57 & TBD & Thick Sect. Weld & GTAW & PWHT & heat-1 & X-Weld & $1 \mathrm{E}-03$ & air & strain & N/A & 550 & 0.5 & 0 \\
\hline 58 & TBD & Thick Sect. Weld & GTAW & PWHT & heat-1 & X-Weld & $1 \mathrm{E}-03$ & air & strain & tension & 550 & 0.5 & 90 \\
\hline 59 & TBD & Thick Sect. Weld & GTAW & PWHT & heat-1 & X-Weld & $1 \mathrm{E}-03$ & air & strain & tension & 550 & 0.5 & 90 \\
\hline 60 & TBD & Thick Sect. Weld & GTAW & PWHT & heat-1 & X-Weld & $1 \mathrm{E}-03$ & air & strain & tension & 550 & 0.5 & 90 \\
\hline 61 & TBD & Thick Sect. Weld & GTAW & PWHT & heat-1 & X-Weld & $1 \mathrm{E}-03$ & air & strain & tension & 550 & 0.5 & 180 \\
\hline 62 & TBD & Thick Sect. Weld & GTAW & PWHT & heat-1 & X-Weld & $1 \mathrm{E}-03$ & air & strain & tension & 550 & 0.5 & 180 \\
\hline 63 & TBD & Thick Sect. Weld & GTAW & PWHT & heat-1 & X-Weld & $1 \mathrm{E}-03$ & air & strain & tension & 550 & 0.5 & 180 \\
\hline 64 & TBD & Thick Sect. Weld & GTAW & PWHT & heat-1 & X-Weld & $1 \mathrm{E}-03$ & air & strain & $\mathrm{N} / \mathrm{A}$ & 550 & 0.7 & 0 \\
\hline 65 & TBD & Thick Sect. Weld & GTAW & PWHT & heat-1 & X-Weld & $1 \mathrm{E}-03$ & air & strain & N/A & 550 & 0.7 & 0 \\
\hline 66 & TBD & Thick Sect. Weld & GTAW & PWHT & heat-1 & X-Weld & $1 \mathrm{E}-03$ & air & strain & N/A & 550 & 0.7 & 0 \\
\hline 67 & TBD & Thick Sect. Weld & GTAW & PWHT & heat-1 & X-Weld & $1 \mathrm{E}-03$ & air & strain & tension & 550 & 0.7 & 90 \\
\hline 68 & TBD & Thick Sect. Weld & GTAW & PWHT & heat-1 & X-Weld & $1 \mathrm{E}-03$ & air & strain & tension & 550 & 0.7 & 90 \\
\hline 69 & TBD & Thick Sect. Weld & GTAW & PWHT & heat-1 & X-Weld & $1 \mathrm{E}-03$ & air & strain & tension & 550 & 0.7 & 90 \\
\hline 70 & TBD & Thick Sect. Weld & GTAW & PWHT & heat-1 & X-Weld & $1 \mathrm{E}-03$ & air & strain & tension & 550 & 0.7 & 180 \\
\hline 71 & TBD & Thick Sect. Weld & GTAW & PWHT & heat-1 & X-Weld & $1 \mathrm{E}-03$ & air & strain & tension & 550 & 0.7 & 180 \\
\hline 72 & TBD & Thick Sect. Weld & GTAW & PWHT & heat-1 & X-Weld & $1 \mathrm{E}-03$ & air & strain & tension & 550 & 0.7 & 180 \\
\hline 73 & TBD & Thick Sect. Weld & GTAW & PWHT & heat-1 & X-Weld & $1 \mathrm{E}-03$ & air & strain & comp. & 550 & 0.4 & 90 \\
\hline 74 & TBD & Thick Sect. Weld & GTAW & PWHT & heat-1 & X-Weld & $1 \mathrm{E}-03$ & air & strain & comp. & 550 & 0.4 & 90 \\
\hline
\end{tabular}




Idaho National Laboratory
\begin{tabular}{|c|lll|}
\hline NEXT GENERATION NUCLEAR PLANT & Identifier: & PLN-2803 & \\
REACTOR PRESSURE VESSEL MATERIALS & Revision: & 0 & \\
RESEARCH AND DEVELOPMENT PLAN & Effective Date: & $04 / 30 / 08$ & Page: B- 57 of B- 68 \\
\hline
\end{tabular}

\begin{tabular}{|c|c|c|c|c|c|c|c|c|c|c|c|c|c|}
\hline \multicolumn{14}{|c|}{ Table B12. Fatigue-Relaxation Tests at $550^{\circ} \mathrm{C}$ for Grade 91 Cross Welds } \\
\hline Spec. \# & $\begin{array}{l}\text { Weld } \\
\text { Wire }\end{array}$ & Product Form & $\begin{array}{l}\text { Weld } \\
\text { Process }\end{array}$ & $\begin{array}{c}\text { Mat } \\
\text { Cond }\end{array}$ & $\begin{array}{c}\text { G91 } \\
\text { Thick } \\
\text { Section } \\
\text { Heat \# }\end{array}$ & $\begin{array}{l}\text { Weld to } \\
\text { be } \\
\text { Tested }\end{array}$ & $\begin{array}{c}\text { Strain } \\
\text { Rate } \\
(\mathrm{m} / \mathrm{m} / \mathrm{s})\end{array}$ & Env & $\begin{array}{c}\text { Hold } \\
\text { Cntrl } \\
\text { (stress or } \\
\text { strain) }\end{array}$ & $\begin{array}{c}\text { Strain } \\
\text { Hold in } \\
\text { T/C }\end{array}$ & $\begin{array}{l}\text { Temp. } \\
\left({ }^{\circ} \mathrm{C}\right)\end{array}$ & $\begin{array}{l}\text { Strain } \\
\text { Range } \\
(\%)\end{array}$ & $\begin{array}{c}\text { Time } \\
\text { During } \\
\text { Strain Hold } \\
(\mathrm{min})\end{array}$ \\
\hline 75 & TBD & Thick Sect. Weld & GTAW & PWHT & heat-1 & X-Weld & $1 \mathrm{E}-03$ & air & strain & comp. & 550 & 0.4 & 90 \\
\hline 76 & TBD & Thick Sect. Weld & GTAW & PWHT & heat-1 & X-Weld & $1 \mathrm{E}-03$ & air & strain & comp. & 550 & 0.4 & 180 \\
\hline 77 & TBD & Thick Sect. Weld & GTAW & PWHT & heat-1 & X-Weld & $1 \mathrm{E}-03$ & air & strain & comp. & 550 & 0.4 & 180 \\
\hline 78 & TBD & Thick Sect. Weld & GTAW & PWHT & heat-1 & X-Weld & $1 \mathrm{E}-03$ & air & strain & comp. & 550 & 0.4 & 180 \\
\hline 79 & TBD & Thick Sect. Weld & GTAW & PWHT & heat-1 & X-Weld & $1 \mathrm{E}-03$ & air & strain & comp. & 550 & 0.5 & 90 \\
\hline 80 & TBD & Thick Sect. Weld & GTAW & PWHT & heat-1 & X-Weld & $1 \mathrm{E}-03$ & air & strain & comp. & 550 & 0.5 & 90 \\
\hline 81 & TBD & Thick Sect. Weld & GTAW & PWHT & heat-1 & X-Weld & $1 \mathrm{E}-03$ & air & strain & comp. & 550 & 0.5 & 90 \\
\hline 82 & TBD & Thick Sect. Weld & GTAW & PWHT & heat-1 & X-Weld & $1 \mathrm{E}-03$ & air & strain & comp. & 550 & 0.5 & 180 \\
\hline 83 & TBD & Thick Sect. Weld & GTAW & PWHT & heat-1 & X-Weld & $1 \mathrm{E}-03$ & air & strain & comp. & 550 & 0.5 & 180 \\
\hline 84 & TBD & Thick Sect. Weld & GTAW & PWHT & heat-1 & X-Weld & $1 \mathrm{E}-03$ & air & strain & comp. & 550 & 0.5 & 180 \\
\hline 85 & TBD & Thick Sect. Weld & GTAW & PWHT & heat-1 & X-Weld & $1 \mathrm{E}-03$ & air & strain & comp. & 550 & 0.7 & 90 \\
\hline 86 & TBD & Thick Sect. Weld & GTAW & PWHT & heat-1 & X-Weld & $1 \mathrm{E}-03$ & air & strain & comp. & 550 & 0.7 & 90 \\
\hline 87 & TBD & Thick Sect. Weld & GTAW & PWHT & heat-1 & X-Weld & $1 \mathrm{E}-03$ & air & strain & comp. & 550 & 0.7 & 90 \\
\hline 88 & TBD & Thick Sect. Weld & GTAW & PWHT & heat-1 & X-Weld & $1 \mathrm{E}-03$ & air & strain & comp. & 550 & 0.7 & 180 \\
\hline 89 & TBD & Thick Sect. Weld & GTAW & PWHT & heat-1 & X-Weld & $1 \mathrm{E}-03$ & air & strain & comp. & 550 & 0.7 & 180 \\
\hline 90 & TBD & Thick Sect. Weld & GTAW & PWHT & heat-1 & X-Weld & $1 \mathrm{E}-03$ & air & strain & comp. & 550 & 0.7 & 180 \\
\hline 91 & TBD & Thick Sect. Weld & SMAW & PWHT & heat-1 & X-Weld & $1 \mathrm{E}-03$ & air & strain & N/A & 550 & 0.4 & 0 \\
\hline 92 & TBD & Thick Sect. Weld & SMAW & PWHT & heat-1 & X-Weld & $1 \mathrm{E}-03$ & air & strain & N/A & 550 & 0.4 & 0 \\
\hline 93 & TBD & Thick Sect. Weld & SMAW & PWHT & heat-1 & X-Weld & $1 \mathrm{E}-03$ & air & strain & N/A & 550 & 0.4 & 0 \\
\hline 94 & TBD & Thick Sect. Weld & SMAW & PWHT & heat-1 & X-Weld & $1 \mathrm{E}-03$ & air & strain & tension & 550 & 0.4 & 90 \\
\hline 95 & TBD & Thick Sect. Weld & SMAW & PWHT & heat-1 & X-Weld & $1 \mathrm{E}-03$ & air & strain & tension & 550 & 0.4 & 90 \\
\hline 96 & TBD & Thick Sect. Weld & SMAW & PWHT & heat-1 & X-Weld & $1 \mathrm{E}-03$ & air & strain & tension & 550 & 0.4 & 90 \\
\hline 97 & TBD & Thick Sect. Weld & SMAW & PWHT & heat-1 & X-Weld & $1 \mathrm{E}-03$ & air & strain & tension & 550 & 0.4 & 180 \\
\hline 98 & TBD & Thick Sect. Weld & SMAW & PWHT & heat-1 & X-Weld & $1 \mathrm{E}-03$ & air & strain & tension & 550 & 0.4 & 180 \\
\hline 99 & TBD & Thick Sect. Weld & SMAW & PWHT & heat-1 & X-Weld & $1 \mathrm{E}-03$ & air & strain & tension & 550 & 0.4 & 180 \\
\hline
\end{tabular}




Idaho National Laboratory
\begin{tabular}{|c|lll|}
\hline NEXT GENERATION NUCLEAR PLANT & Identifier: & PLN-2803 & \\
REACTOR PRESSURE VESSEL MATERIALS & Revision: & 0 & \\
RESEARCH AND DEVELOPMENT PLAN & Effective Date: & $04 / 30 / 08$ & Page: B- 58 of B- 68 \\
\hline
\end{tabular}

\begin{tabular}{|c|c|c|c|c|c|c|c|c|c|c|c|c|c|}
\hline \multicolumn{14}{|c|}{ Table B12. Fatigue-Relaxation Tests at $550^{\circ} \mathrm{C}$ for Grade 91 Cross Welds } \\
\hline Spec. \# & $\begin{array}{l}\text { Weld } \\
\text { Wire }\end{array}$ & Product Form & $\begin{array}{l}\text { Weld } \\
\text { Process }\end{array}$ & $\begin{array}{c}\text { Mat } \\
\text { Cond }\end{array}$ & $\begin{array}{c}\text { G91 } \\
\text { Thick } \\
\text { Section } \\
\text { Heat \# }\end{array}$ & $\begin{array}{l}\text { Weld to } \\
\text { be } \\
\text { Tested }\end{array}$ & $\begin{array}{c}\text { Strain } \\
\text { Rate } \\
(\mathrm{m} / \mathrm{m} / \mathrm{s})\end{array}$ & Env & $\begin{array}{c}\text { Hold } \\
\text { Cntrl } \\
\text { (stress or } \\
\text { strain) }\end{array}$ & $\begin{array}{c}\text { Strain } \\
\text { Hold in } \\
\text { T/C }\end{array}$ & $\begin{array}{l}\text { Temp. } \\
\left({ }^{\circ} \mathrm{C}\right)\end{array}$ & $\begin{array}{l}\text { Strain } \\
\text { Range } \\
(\%)\end{array}$ & $\begin{array}{c}\text { Time } \\
\text { During } \\
\text { Strain Hold } \\
(\mathrm{min})\end{array}$ \\
\hline 100 & TBD & Thick Sect. Weld & SMAW & PWHT & heat-1 & X-Weld & $1 \mathrm{E}-03$ & air & strain & $\mathrm{N} / \mathrm{A}$ & 550 & 0.5 & 0 \\
\hline 101 & TBD & Thick Sect. Weld & SMAW & PWHT & heat-1 & X-Weld & $1 \mathrm{E}-03$ & air & strain & $\mathrm{N} / \mathrm{A}$ & 550 & 0.5 & 0 \\
\hline 102 & TBD & Thick Sect. Weld & SMAW & PWHT & heat-1 & X-Weld & $1 \mathrm{E}-03$ & air & strain & $\mathrm{N} / \mathrm{A}$ & 550 & 0.5 & 0 \\
\hline 103 & TBD & Thick Sect. Weld & SMAW & PWHT & heat-1 & X-Weld & $1 \mathrm{E}-03$ & air & strain & tension & 550 & 0.5 & 90 \\
\hline 104 & TBD & Thick Sect. Weld & SMAW & PWHT & heat-1 & X-Weld & $1 \mathrm{E}-03$ & air & strain & tension & 550 & 0.5 & 90 \\
\hline 105 & TBD & Thick Sect. Weld & SMAW & PWHT & heat-1 & X-Weld & $1 \mathrm{E}-03$ & air & strain & tension & 550 & 0.5 & 90 \\
\hline 106 & TBD & Thick Sect. Weld & SMAW & PWHT & heat-1 & X-Weld & $1 \mathrm{E}-03$ & air & strain & tension & 550 & 0.5 & 180 \\
\hline 107 & TBD & Thick Sect. Weld & SMAW & PWHT & heat-1 & X-Weld & $1 \mathrm{E}-03$ & air & strain & tension & 550 & 0.5 & 180 \\
\hline 108 & TBD & Thick Sect. Weld & SMAW & PWHT & heat-1 & X-Weld & $1 \mathrm{E}-03$ & air & strain & tension & 550 & 0.5 & 180 \\
\hline 109 & TBD & Thick Sect. Weld & SMAW & PWHT & heat-1 & X-Weld & $1 \mathrm{E}-03$ & air & strain & N/A & 550 & 0.7 & 0 \\
\hline 110 & TBD & Thick Sect. Weld & SMAW & PWHT & heat-1 & X-Weld & $1 \mathrm{E}-03$ & air & strain & N/A & 550 & 0.7 & 0 \\
\hline 111 & TBD & Thick Sect. Weld & SMAW & PWHT & heat-1 & X-Weld & $1 \mathrm{E}-03$ & air & strain & N/A & 550 & 0.7 & 0 \\
\hline 112 & TBD & Thick Sect. Weld & SMAW & PWHT & heat-1 & X-Weld & $1 \mathrm{E}-03$ & air & strain & tension & 550 & 0.7 & 90 \\
\hline 113 & TBD & Thick Sect. Weld & SMAW & PWHT & heat-1 & X-Weld & $1 \mathrm{E}-03$ & air & strain & tension & 550 & 0.7 & 90 \\
\hline 114 & TBD & Thick Sect. Weld & SMAW & PWHT & heat-1 & X-Weld & $1 \mathrm{E}-03$ & air & strain & tension & 550 & 0.7 & 90 \\
\hline 115 & TBD & Thick Sect. Weld & SMAW & PWHT & heat-1 & X-Weld & $1 \mathrm{E}-03$ & air & strain & tension & 550 & 0.7 & 180 \\
\hline 116 & TBD & Thick Sect. Weld & SMAW & PWHT & heat-1 & X-Weld & $1 \mathrm{E}-03$ & air & strain & tension & 550 & 0.7 & 180 \\
\hline 117 & TBD & Thick Sect. Weld & SMAW & PWHT & heat-1 & X-Weld & $1 \mathrm{E}-03$ & air & strain & tension & 550 & 0.7 & 180 \\
\hline 118 & TBD & Thick Sect. Weld & SMAW & PWHT & heat-1 & X-Weld & $1 \mathrm{E}-03$ & air & strain & comp. & 550 & 0.4 & 90 \\
\hline 119 & TBD & Thick Sect. Weld & SMAW & PWHT & heat-1 & X-Weld & $1 \mathrm{E}-03$ & air & strain & comp. & 550 & 0.4 & 90 \\
\hline 120 & TBD & Thick Sect. Weld & SMAW & PWHT & heat-1 & X-Weld & $1 \mathrm{E}-03$ & air & strain & comp. & 550 & 0.4 & 90 \\
\hline 121 & TBD & Thick Sect. Weld & SMAW & PWHT & heat-1 & X-Weld & $1 \mathrm{E}-03$ & air & strain & comp. & 550 & 0.4 & 180 \\
\hline 122 & TBD & Thick Sect. Weld & SMAW & PWHT & heat-1 & X-Weld & $1 \mathrm{E}-03$ & air & strain & comp. & 550 & 0.4 & 180 \\
\hline 123 & TBD & Thick Sect. Weld & SMAW & PWHT & heat-1 & X-Weld & $1 \mathrm{E}-03$ & air & strain & comp. & 550 & 0.4 & 180 \\
\hline 124 & TBD & Thick Sect. Weld & SMAW & PWHT & heat-1 & X-Weld & $1 \mathrm{E}-03$ & air & strain & comp. & 550 & 0.5 & 90 \\
\hline
\end{tabular}




Idaho National Laboratory
\begin{tabular}{|c|lll|}
\hline NEXT GENERATION NUCLEAR PLANT & Identifier: & PLN-2803 & \\
REACTOR PRESSURE VESSEL MATERIALS & Revision: & 0 & \\
RESEARCH AND DEVELOPMENT PLAN & Effective Date: & $04 / 30 / 08$ & Page: B-59 of B- 68 \\
\hline
\end{tabular}

\begin{tabular}{|c|c|c|c|c|c|c|c|c|c|c|c|c|c|}
\hline \multicolumn{14}{|c|}{ Table B12. Fatigue-Relaxation Tests at $550^{\circ} \mathrm{C}$ for Grade 91 Cross Welds } \\
\hline Spec. \# & $\begin{array}{l}\text { Weld } \\
\text { Wire }\end{array}$ & Product Form & $\begin{array}{c}\text { Weld } \\
\text { Process }\end{array}$ & $\begin{array}{c}\text { Mat } \\
\text { Cond }\end{array}$ & $\begin{array}{c}\text { G91 } \\
\text { Thick } \\
\text { Section } \\
\text { Heat \# }\end{array}$ & $\begin{array}{l}\text { Weld to } \\
\text { be } \\
\text { Tested }\end{array}$ & $\begin{array}{c}\text { Strain } \\
\text { Rate } \\
(\mathrm{m} / \mathrm{m} / \mathrm{s})\end{array}$ & Env & $\begin{array}{c}\text { Hold } \\
\text { Cntrl } \\
\text { (stress or } \\
\text { strain) }\end{array}$ & $\begin{array}{c}\text { Strain } \\
\text { Hold in } \\
\mathrm{T} / \mathrm{C}\end{array}$ & $\begin{array}{c}\text { Temp. } \\
\left({ }^{\circ} \mathrm{C}\right)\end{array}$ & $\begin{array}{c}\text { Strain } \\
\text { Range } \\
(\%)\end{array}$ & $\begin{array}{c}\text { Time } \\
\text { During } \\
\text { Strain Hold } \\
\text { (min) }\end{array}$ \\
\hline 125 & TBD & Thick Sect. Weld & SMAW & PWHT & heat-1 & X-Weld & $1 \mathrm{E}-03$ & air & strain & comp. & 550 & 0.5 & 90 \\
\hline 126 & TBD & Thick Sect. Weld & SMAW & PWHT & heat-1 & X-Weld & $1 \mathrm{E}-03$ & air & strain & comp. & 550 & 0.5 & 90 \\
\hline 127 & TBD & Thick Sect. Weld & SMAW & PWHT & heat-1 & X-Weld & $1 \mathrm{E}-03$ & air & strain & comp. & 550 & 0.5 & 180 \\
\hline 128 & TBD & Thick Sect. Weld & SMAW & PWHT & heat-1 & X-Weld & $1 \mathrm{E}-03$ & air & strain & comp. & 550 & 0.5 & 180 \\
\hline 129 & TBD & Thick Sect. Weld & SMAW & PWHT & heat-1 & X-Weld & $1 \mathrm{E}-03$ & air & strain & comp. & 550 & 0.5 & 180 \\
\hline 130 & TBD & Thick Sect. Weld & SMAW & PWHT & heat-1 & X-Weld & $1 \mathrm{E}-03$ & air & strain & comp. & 550 & 0.7 & 90 \\
\hline 131 & TBD & Thick Sect. Weld & SMAW & PWHT & heat-1 & X-Weld & $1 \mathrm{E}-03$ & air & strain & comp. & 550 & 0.7 & 90 \\
\hline 132 & TBD & Thick Sect. Weld & SMAW & PWHT & heat-1 & X-Weld & $1 \mathrm{E}-03$ & air & strain & comp. & 550 & 0.7 & 90 \\
\hline 133 & TBD & Thick Sect. Weld & SMAW & PWHT & heat-1 & X-Weld & $1 \mathrm{E}-03$ & air & strain & comp. & 550 & 0.7 & 180 \\
\hline 134 & TBD & Thick Sect. Weld & SMAW & PWHT & heat-1 & X-Weld & $1 \mathrm{E}-03$ & air & strain & comp. & 550 & 0.7 & 180 \\
\hline 135 & TBD & Thick Sect. Weld & SMAW & PWHT & heat-1 & X-Weld & $1 \mathrm{E}-03$ & air & strain & comp. & 550 & 0.7 & 180 \\
\hline
\end{tabular}




Idaho National Laboratory
\begin{tabular}{|c|lll|}
\hline NEXT GENERATION NUCLEAR PLANT & Identifier: & PLN-2803 & \\
REACTOR PRESSURE VESSEL MATERIALS & Revision: & 0 & \\
RESEARCH AND DEVELOPMENT PLAN & Effective Date: & $04 / 30 / 08$ & Page: B-60 of B- 68 \\
\hline
\end{tabular}

\begin{tabular}{|c|c|c|c|c|c|c|c|c|c|c|c|}
\hline Test Prgm & $\begin{array}{c}\text { Spec. } \\
\#\end{array}$ & $\begin{array}{l}\text { Weld } \\
\text { Wire }\end{array}$ & Product Form & $\begin{array}{c}\text { Weld } \\
\text { Process }\end{array}$ & $\begin{array}{c}\text { Mat } \\
\text { Cond }\end{array}$ & $\begin{array}{l}\text { G91 Thick } \\
\text { Section } \\
\text { Heat \# }\end{array}$ & $\begin{array}{l}\text { Weld to be } \\
\text { Tested }\end{array}$ & Env & $\begin{array}{l}\text { Temp. } \\
\left({ }^{\circ} \mathrm{C}\right)\end{array}$ & Stress (MPa) & $\begin{array}{c}\text { Est. } \\
\text { Rupture } \\
\text { Time (h) }\end{array}$ \\
\hline Tk-Weld & 1 & TBD & Thick Sect. Weld & SAW & PWHT & heat-1 & X-Weld & air & 425 & 460 & 1000 \\
\hline Tk-Weld & 2 & TBD & Thick Sect. Weld & SAW & PWHT & heat-1 & X-Weld & air & 425 & 460 & 1000 \\
\hline Tk-Weld & 3 & TBD & Thick Sect. Weld & SAW & PWHT & heat-1 & X-Weld & air & 425 & 436 & 3000 \\
\hline Tk-Weld & 4 & TBD & Thick Sect. Weld & SAW & PWHT & heat-1 & X-Weld & air & 425 & 436 & 3000 \\
\hline Tk-Weld & 5 & TBD & Thick Sect. Weld & SAW & PWHT & heat-1 & X-Weld & air & 425 & 415 & 10000 \\
\hline Tk-Weld & 6 & TBD & Thick Sect. Weld & SAW & PWHT & heat-1 & X-Weld & air & 425 & 415 & 10000 \\
\hline Tk-Weld & 7 & TBD & Thick Sect. Weld & SAW & PWHT & heat-1 & X-Weld & air & 500 & 285 & 1000 \\
\hline Tk-Weld & 8 & TBD & Thick Sect. Weld & SAW & PWHT & heat-1 & X-Weld & air & 500 & 285 & 1000 \\
\hline Tk-Weld & 9 & TBD & Thick Sect. Weld & SAW & PWHT & heat-1 & X-Weld & air & 500 & 265 & 3000 \\
\hline Tk-Weld & 10 & TBD & Thick Sect. Weld & SAW & PWHT & heat-1 & X-Weld & air & 500 & 265 & 3000 \\
\hline Tk-Weld & 11 & TBD & Thick Sect. Weld & SAW & PWHT & heat-1 & X-Weld & air & 500 & 250 & 10000 \\
\hline Tk-Weld & 12 & TBD & Thick Sect. Weld & SAW & PWHT & heat-1 & X-Weld & air & 500 & 250 & 10000 \\
\hline Tk-Weld & 13 & TBD & Thick Sect. Weld & SAW & PWHT & heat-1 & X-Weld & air & 575 & 165 & 1000 \\
\hline Tk-Weld & 14 & TBD & Thick Sect. Weld & SAW & PWHT & heat-1 & X-Weld & air & 575 & 165 & 1000 \\
\hline Tk-Weld & 15 & TBD & Thick Sect. Weld & SAW & PWHT & heat-1 & X-Weld & air & 575 & 150 & 3000 \\
\hline Tk-Weld & 16 & TBD & Thick Sect. Weld & SAW & PWHT & heat-1 & X-Weld & air & 575 & 150 & 3000 \\
\hline Tk-Weld & 17 & TBD & Thick Sect. Weld & SAW & PWHT & heat-1 & X-Weld & air & 575 & 135 & 10000 \\
\hline Tk-Weld & 18 & TBD & Thick Sect. Weld & SAW & PWHT & heat-1 & X-Weld & air & 575 & 135 & 10000 \\
\hline Tk-Weld & 19 & TBD & Thick Sect. Weld & SAW & PWHT & heat-1 & X-Weld & air & 650 & 82 & 1000 \\
\hline Tk-Weld & 20 & TBD & Thick Sect. Weld & SAW & PWHT & heat-1 & X-Weld & air & 650 & 82 & 1000 \\
\hline Tk-Weld & 21 & TBD & Thick Sect. Weld & SAW & PWHT & heat-1 & X-Weld & air & 650 & 72 & 3000 \\
\hline Tk-Weld & 22 & TBD & Thick Sect. Weld & SAW & PWHT & heat-1 & X-Weld & air & 650 & 72 & 3000 \\
\hline Tk-Weld & 23 & TBD & Thick Sect. Weld & SAW & PWHT & heat-1 & X-Weld & air & 650 & 52 & 10000 \\
\hline Tk-Weld & 24 & TBD & Thick Sect. Weld & SAW & PWHT & heat-1 & X-Weld & air & 650 & 52 & 10000 \\
\hline Tk-Weld & 25 & TBD & Thick Sect. Weld & GTAW & PWHT & heat-1 & X-Weld & air & 425 & 460 & 1000 \\
\hline
\end{tabular}




Idaho National Laboratory
\begin{tabular}{|c|lll|}
\hline NEXT GENERATION NUCLEAR PLANT & Identifier: & PLN-2803 & \\
REACTOR PRESSURE VESSEL MATERIALS & Revision: & 0 & \\
RESEARCH AND DEVELOPMENT PLAN & Effective Date: & $04 / 30 / 08$ & Page: B-61 of B- 68 \\
\hline
\end{tabular}

\begin{tabular}{|c|c|c|c|c|c|c|c|c|c|c|c|}
\hline \multicolumn{12}{|c|}{ Table B13. Test Matrix to Determine Weld Stress Rupture Factor for Grade 91 Cross Welds } \\
\hline Test Prgm & $\begin{array}{c}\text { Spec. } \\
\#\end{array}$ & $\begin{array}{l}\text { Weld } \\
\text { Wire }\end{array}$ & Product Form & $\begin{array}{c}\text { Weld } \\
\text { Process }\end{array}$ & $\begin{array}{l}\text { Mat } \\
\text { Cond }\end{array}$ & $\begin{array}{l}\text { G91 Thick } \\
\text { Section } \\
\text { Heat \# }\end{array}$ & $\begin{array}{c}\text { Weld to be } \\
\text { Tested }\end{array}$ & Env & $\begin{array}{l}\text { Temp. } \\
\left({ }^{\circ} \mathrm{C}\right)\end{array}$ & Stress $(\mathrm{MPa})$ & $\begin{array}{c}\text { Est. } \\
\text { Rupture } \\
\text { Time (h) }\end{array}$ \\
\hline Tk-Weld & 26 & TBD & Thick Sect. Weld & GTAW & PWHT & heat-1 & X-Weld & air & 425 & 460 & 1000 \\
\hline Tk-Weld & 27 & TBD & Thick Sect. Weld & GTAW & PWHT & heat-1 & X-Weld & air & 425 & 436 & 3000 \\
\hline Tk-Weld & 28 & TBD & Thick Sect. Weld & GTAW & PWHT & heat-1 & X-Weld & air & 425 & 436 & 3000 \\
\hline Tk-Weld & 29 & TBD & Thick Sect. Weld & GTAW & PWHT & heat-1 & X-Weld & air & 425 & 415 & 10000 \\
\hline Tk-Weld & 30 & TBD & Thick Sect. Weld & GTAW & PWHT & heat-1 & X-Weld & air & 425 & 415 & 10000 \\
\hline Tk-Weld & 31 & TBD & Thick Sect. Weld & GTAW & PWHT & heat-1 & X-Weld & air & 500 & 285 & 1000 \\
\hline Tk-Weld & 32 & TBD & Thick Sect. Weld & GTAW & PWHT & heat-1 & X-Weld & air & 500 & 285 & 1000 \\
\hline Tk-Weld & 33 & TBD & Thick Sect. Weld & GTAW & PWHT & heat-1 & X-Weld & air & 500 & 265 & 3000 \\
\hline Tk-Weld & 34 & TBD & Thick Sect. Weld & GTAW & PWHT & heat-1 & X-Weld & air & 500 & 265 & 3000 \\
\hline Tk-Weld & 35 & TBD & Thick Sect. Weld & GTAW & PWHT & heat-1 & X-Weld & air & 500 & 250 & 10000 \\
\hline Tk-Weld & 36 & TBD & Thick Sect. Weld & GTAW & PWHT & heat-1 & X-Weld & air & 500 & 250 & 10000 \\
\hline Tk-Weld & 37 & TBD & Thick Sect. Weld & GTAW & PWHT & heat-1 & X-Weld & air & 575 & 165 & 1000 \\
\hline Tk-Weld & 38 & TBD & Thick Sect. Weld & GTAW & PWHT & heat-1 & X-Weld & air & 575 & 165 & 1000 \\
\hline Tk-Weld & 39 & TBD & Thick Sect. Weld & GTAW & PWHT & heat-1 & X-Weld & air & 575 & 150 & 3000 \\
\hline Tk-Weld & 40 & TBD & Thick Sect. Weld & GTAW & PWHT & heat-1 & X-Weld & air & 575 & 150 & 3000 \\
\hline Tk-Weld & 41 & TBD & Thick Sect. Weld & GTAW & PWHT & heat-1 & X-Weld & air & 575 & 135 & 10000 \\
\hline Tk-Weld & 42 & TBD & Thick Sect. Weld & GTAW & PWHT & heat-1 & X-Weld & air & 575 & 135 & 10000 \\
\hline Tk-Weld & 43 & TBD & Thick Sect. Weld & GTAW & PWHT & heat-1 & X-Weld & air & 650 & 82 & 1000 \\
\hline Tk-Weld & 44 & TBD & Thick Sect. Weld & GTAW & PWHT & heat-1 & X-Weld & air & 650 & 82 & 1000 \\
\hline Tk-Weld & 45 & TBD & Thick Sect. Weld & GTAW & PWHT & heat-1 & X-Weld & air & 650 & 72 & 3000 \\
\hline Tk-Weld & 46 & TBD & Thick Sect. Weld & GTAW & PWHT & heat-1 & X-Weld & air & 650 & 72 & 3000 \\
\hline Tk-Weld & 47 & TBD & Thick Sect. Weld & GTAW & PWHT & heat-1 & X-Weld & air & 650 & 52 & 10000 \\
\hline Tk-Weld & 48 & TBD & Thick Sect. Weld & GTAW & PWHT & heat-1 & X-Weld & air & 650 & 52 & 10000 \\
\hline Tk-Weld & 49 & TBD & Thick Sect. Weld & SMAW & PWHT & heat-1 & X-Weld & air & 425 & 460 & 1000 \\
\hline Tk-Weld & 50 & TBD & Thick Sect. Weld & SMAW & PWHT & heat-1 & X-Weld & air & 425 & 460 & 1000 \\
\hline
\end{tabular}




Idaho National Laboratory
\begin{tabular}{|c|lll|}
\hline NEXT GENERATION NUCLEAR PLANT & Identifier: & PLN-2803 & \\
REACTOR PRESSURE VESSEL MATERIALS & Revision: & 0 & \\
RESEARCH AND DEVELOPMENT PLAN & Effective Date: & $04 / 30 / 08$ & Page: B-62 of B- 68 \\
\hline
\end{tabular}

\begin{tabular}{|c|c|c|c|c|c|c|c|c|c|c|c|}
\hline \multicolumn{12}{|c|}{ Table B13. Test Matrix to Determine Weld Stress Rupture Factor for Grade 91 Cross Welds } \\
\hline Test Prgm & $\begin{array}{c}\text { Spec. } \\
\#\end{array}$ & $\begin{array}{l}\text { Weld } \\
\text { Wire }\end{array}$ & Product Form & $\begin{array}{c}\text { Weld } \\
\text { Process }\end{array}$ & $\begin{array}{c}\text { Mat } \\
\text { Cond }\end{array}$ & $\begin{array}{l}\text { G91 Thick } \\
\text { Section } \\
\text { Heat \# }\end{array}$ & $\begin{array}{c}\text { Weld to be } \\
\text { Tested }\end{array}$ & Env & $\begin{array}{l}\text { Temp. } \\
\left({ }^{\circ} \mathrm{C}\right)\end{array}$ & Stress $(\mathrm{MPa})$ & $\begin{array}{c}\text { Est. } \\
\text { Rupture } \\
\text { Time (h) }\end{array}$ \\
\hline Tk-Weld & 51 & TBD & Thick Sect. Weld & SMAW & PWHT & heat-1 & X-Weld & air & 425 & 436 & 3000 \\
\hline Tk-Weld & 52 & TBD & Thick Sect. Weld & SMAW & PWHT & heat-1 & X-Weld & air & 425 & 436 & 3000 \\
\hline Tk-Weld & 53 & TBD & Thick Sect. Weld & SMAW & PWHT & heat-1 & X-Weld & air & 425 & 415 & 10000 \\
\hline Tk-Weld & 54 & TBD & Thick Sect. Weld & SMAW & PWHT & heat-1 & X-Weld & air & 425 & 415 & 10000 \\
\hline Tk-Weld & 55 & TBD & Thick Sect. Weld & SMAW & PWHT & heat-1 & X-Weld & air & 500 & 285 & 1000 \\
\hline Tk-Weld & 56 & TBD & Thick Sect. Weld & SMAW & PWHT & heat-1 & X-Weld & air & 500 & 285 & 1000 \\
\hline Tk-Weld & 57 & TBD & Thick Sect. Weld & SMAW & PWHT & heat-1 & X-Weld & air & 500 & 265 & 3000 \\
\hline Tk-Weld & 58 & TBD & Thick Sect. Weld & SMAW & PWHT & heat-1 & X-Weld & air & 500 & 265 & 3000 \\
\hline Tk-Weld & 59 & TBD & Thick Sect. Weld & SMAW & PWHT & heat-1 & X-Weld & air & 500 & 250 & 10000 \\
\hline Tk-Weld & 60 & TBD & Thick Sect. Weld & SMAW & PWHT & heat-1 & X-Weld & air & 500 & 250 & 10000 \\
\hline Tk-Weld & 61 & TBD & Thick Sect. Weld & SMAW & PWHT & heat-1 & X-Weld & air & 575 & 165 & 1000 \\
\hline Tk-Weld & 62 & TBD & Thick Sect. Weld & SMAW & PWHT & heat-1 & X-Weld & air & 575 & 165 & 1000 \\
\hline Tk-Weld & 63 & TBD & Thick Sect. Weld & SMAW & PWHT & heat-1 & X-Weld & air & 575 & 150 & 3000 \\
\hline Tk-Weld & 64 & TBD & Thick Sect. Weld & SMAW & PWHT & heat-1 & X-Weld & air & 575 & 150 & 3000 \\
\hline Tk-Weld & 65 & TBD & Thick Sect. Weld & SMAW & PWHT & heat-1 & X-Weld & air & 575 & 135 & 10000 \\
\hline Tk-Weld & 66 & TBD & Thick Sect. Weld & SMAW & PWHT & heat-1 & X-Weld & air & 575 & 135 & 10000 \\
\hline Tk-Weld & 67 & TBD & Thick Sect. Weld & SMAW & PWHT & heat-1 & X-Weld & air & 650 & 82 & 1000 \\
\hline Tk-Weld & 68 & TBD & Thick Sect. Weld & SMAW & PWHT & heat-1 & X-Weld & air & 650 & 82 & 1000 \\
\hline Tk-Weld & 69 & TBD & Thick Sect. Weld & SMAW & PWHT & heat-1 & X-Weld & air & 650 & 72 & 3000 \\
\hline Tk-Weld & 70 & TBD & Thick Sect. Weld & SMAW & PWHT & heat-1 & X-Weld & air & 650 & 72 & 3000 \\
\hline Tk-Weld & 71 & TBD & Thick Sect. Weld & SMAW & PWHT & heat-1 & X-Weld & air & 650 & 52 & 10000 \\
\hline Tk-Weld & 72 & TBD & Thick Sect. Weld & SAW & PWHT & heat-1 & X-Weld & air & 650 & 52 & 10000 \\
\hline Tk-Weld-QUAL & 73 & TBD & Thick Sect. Weld & SAW & PWHT & heat-1 & X-Weld & air & 425 & 370 & 100000 \\
\hline Tk-Weld-QUAL & 74 & TBD & Thick Sect. Weld & SAW & PWHT & heat-1 & X-Weld & air & 425 & 370 & 100000 \\
\hline Tk-Weld-QUAL & 75 & TBD & Thick Sect. Weld & SAW & PWHT & heat-1 & X-Weld & air & 500 & 215 & 100000 \\
\hline
\end{tabular}


Idaho National Laboratory

\begin{tabular}{|c|lll|}
\hline NEXT GENERATION NUCLEAR PLANT & Identifier: & PLN-2803 & \\
REACTOR PRESSURE VESSEL MATERIALS & Revision: & 0 & \\
RESEARCH AND DEVELOPMENT PLAN & Effective Date: & $04 / 30 / 08$ & Page: B-63 of B-68 \\
\hline
\end{tabular}

\begin{tabular}{|c|c|c|c|c|c|c|c|c|c|c|c|}
\hline Test Prgm & $\begin{array}{c}\text { Spec. } \\
\# \\
\end{array}$ & $\begin{array}{l}\text { Weld } \\
\text { Wire }\end{array}$ & Product Form & $\begin{array}{c}\text { Weld } \\
\text { Process }\end{array}$ & $\begin{array}{l}\text { Mat } \\
\text { Cond }\end{array}$ & $\begin{array}{c}\text { G91 Thick } \\
\text { Section } \\
\text { Heat \# }\end{array}$ & $\begin{array}{c}\text { Weld to be } \\
\text { Tested }\end{array}$ & Env & $\begin{array}{l}\text { Temp. } \\
\left({ }^{\circ} \mathrm{C}\right)\end{array}$ & Stress (MPa) & $\begin{array}{c}\text { Est. } \\
\text { Rupture } \\
\text { Time (h) }\end{array}$ \\
\hline Tk-Weld-QUAL & 76 & TBD & Thick Sect. Weld & SAW & PWHT & heat-1 & X-Weld & air & 500 & 215 & 100000 \\
\hline Tk-Weld-QUAL & 77 & TBD & Thick Sect. Weld & GTAW & PWHT & heat-1 & X-Weld & air & 425 & 370 & 100000 \\
\hline Tk-Weld-QUAL & 78 & TBD & Thick Sect. Weld & GTAW & PWHT & heat-1 & X-Weld & air & 425 & 370 & 100000 \\
\hline Tk-Weld-QUAL & 79 & TBD & Thick Sect. Weld & GTAW & PWHT & heat-1 & X-Weld & air & 500 & 215 & 100000 \\
\hline Tk-Weld-QUAL & 80 & TBD & Thick Sect. Weld & GTAW & PWHT & heat-1 & X-Weld & air & 500 & 215 & 100000 \\
\hline Tk-Weld-QUAL & 81 & TBD & Thick Sect. Weld & SMAW & PWHT & heat-1 & X-Weld & air & 425 & 370 & 100000 \\
\hline Tk-Weld-QUAL & 82 & TBD & Thick Sect. Weld & SMAW & PWHT & heat-1 & X-Weld & air & 425 & 370 & 100000 \\
\hline Tk-Weld-QUAL & 83 & TBD & Thick Sect. Weld & SMAW & PWHT & heat-1 & X-Weld & air & 500 & 215 & 100000 \\
\hline Tk-Weld-QUAL & 84 & TBD & Thick Sect. Weld & SMAW & PWHT & heat-1 & X-Weld & air & 500 & 215 & 100000 \\
\hline
\end{tabular}


Idaho National Laboratory

\begin{tabular}{|c|lll|}
\hline NEXT GENERATION NUCLEAR PLANT & Identifier: & PLN-2803 & \\
REACTOR PRESSURE VESSEL MATERIALS & Revision: & 0 & \\
RESEARCH AND DEVELOPMENT PLAN & Effective Date: & $04 / 30 / 08$ & Page: B-64 of B-68 \\
\hline
\end{tabular}

\begin{tabular}{|c|c|c|c|c|c|c|c|c|c|}
\hline Spec. \# & Test Type & Material & Product Form & Mat Cond & $\begin{array}{c}\text { Grade } 91 \\
\text { Heat \# }\end{array}$ & Env & Temp. $\left({ }^{\circ} \mathrm{C}\right)$ & $\begin{array}{c}\text { Applied } \\
\text { Stress (MPa) }\end{array}$ & $\begin{array}{c}\text { Creep Time } \\
\text { (h) }\end{array}$ \\
\hline 1 & Creep & Grade 91 & Forging (thick) & Creep-Fatigue Softened & heat-1 & air & 550 & 240 & 1000 \\
\hline 2 & Creep & Grade 91 & Forging (thick) & Creep-Fatigue Softened & heat-1 & air & 550 & 240 & 1000 \\
\hline 3 & Creep & Grade 91 & Forging (thick) & Creep-Fatigue Softened & heat-1 & air & 550 & 227 & 3000 \\
\hline 4 & Creep & Grade 91 & Forging (thick) & Creep-Fatigue Softened & heat-1 & air & 550 & 227 & 3000 \\
\hline 5 & Creep & Grade 91 & Forging (thick) & Creep-Fatigue Softened & heat-1 & air & 550 & 209 & 10000 \\
\hline 6 & Creep & Grade 91 & Forging (thick) & Creep-Fatigue Softened & heat-1 & air & 550 & 209 & 10000 \\
\hline
\end{tabular}




Idaho National Laboratory
\begin{tabular}{|c|lll|}
\hline NEXT GENERATION NUCLEAR PLANT & Identifier: & PLN-2803 & \\
REACTOR PRESSURE VESSEL MATERIALS & Revision: & 0 & \\
RESEARCH AND DEVELOPMENT PLAN & Effective Date: & $04 / 30 / 08$ & Page: B- 65 of B- 68 \\
\hline
\end{tabular}

\begin{tabular}{|c|c|c|c|c|c|c|c|c|}
\hline Spec.\# & Test Type & Material & Product Form & Mat Cond & Grade 91 Heat \# & Env & Strain Rate $(\mathrm{m} / \mathrm{m} / \mathrm{s})$ & Temp. $\left({ }^{\circ} \mathrm{C}\right)$ \\
\hline 1 & Tensile & Grade 91 & Forging (thick) & Creep-Fatigue Softened & heat-1 & air & $1 \mathrm{E}-03$ & 20 \\
\hline 2 & Tensile & Grade 91 & Forging (thick) & Creep-Fatigue Softened & heat-1 & air & $1 \mathrm{E}-03$ & 20 \\
\hline 3 & Tensile & Grade 91 & Forging (thick) & Creep-Fatigue Softened & heat-1 & air & $1 \mathrm{E}-03$ & 100 \\
\hline 4 & Tensile & Grade 91 & Forging (thick) & Creep-Fatigue Softened & heat-1 & air & $1 \mathrm{E}-03$ & 100 \\
\hline 5 & Tensile & Grade 91 & Forging (thick) & Creep-Fatigue Softened & heat-1 & air & $1 \mathrm{E}-03$ & 200 \\
\hline 6 & Tensile & Grade 91 & Forging (thick) & Creep-Fatigue Softened & heat-1 & air & $1 \mathrm{E}-03$ & 200 \\
\hline 7 & Tensile & Grade 91 & Forging (thick) & Creep-Fatigue Softened & heat-1 & air & $1 \mathrm{E}-03$ & 300 \\
\hline 8 & Tensile & Grade 91 & Forging (thick) & Creep-Fatigue Softened & heat-1 & air & $1 \mathrm{E}-03$ & 300 \\
\hline 9 & Tensile & Grade 91 & Forging (thick) & Creep-Fatigue Softened & heat-1 & air & $1 \mathrm{E}-03$ & 400 \\
\hline 10 & Tensile & Grade 91 & Forging (thick) & Creep-Fatigue Softened & heat-1 & air & $1 \mathrm{E}-03$ & 400 \\
\hline 11 & Tensile & Grade 91 & Forging (thick) & Creep-Fatigue Softened & heat-1 & air & $1 \mathrm{E}-03$ & 500 \\
\hline 12 & Tensile & Grade 91 & Forging (thick) & Creep-Fatigue Softened & heat-1 & air & $1 \mathrm{E}-03$ & 500 \\
\hline 13 & Tensile & Grade 91 & Forging (thick) & Creep-Fatigue Softened & heat-1 & air & $1 \mathrm{E}-03$ & 600 \\
\hline 14 & Tensile & Grade 91 & Forging (thick) & Creep-Fatigue Softened & heat-1 & air & $1 \mathrm{E}-03$ & 600 \\
\hline 15 & Tensile & Grade 91 & Forging (thick) & Creep-Fatigue Softened & heat-1 & air & $1 \mathrm{E}-03$ & 700 \\
\hline 16 & Tensile & Grade 91 & Forging (thick) & Creep-Fatigue Softened & heat-1 & air & $1 \mathrm{E}-03$ & 700 \\
\hline
\end{tabular}




Idaho National Laboratory
\begin{tabular}{|c|lll|}
\hline NEXT GENERATION NUCLEAR PLANT & Identifier: & PLN-2803 & \\
REACTOR PRESSURE VESSEL MATERIALS & Revision: & 0 & \\
RESEARCH AND DEVELOPMENT PLAN & Effective Date: & $04 / 30 / 08$ & Page: B-66 of B-68 \\
\hline
\end{tabular}

\begin{tabular}{|c|c|c|c|c|c|c|c|c|c|c|}
\hline \multicolumn{11}{|c|}{ Table 16. Test Matrix for Grade 91 Steel Fatigue Design Curve at $650^{\circ} \mathrm{C}, \mathrm{AR}=$ As Received } \\
\hline Test Program & $\begin{array}{l}\text { Specimen } \\
\text { Type }\end{array}$ & Spec. \# & Material & Product Form & $\begin{array}{l}\text { Mat } \\
\text { Cond }\end{array}$ & $\begin{array}{c}\text { Grade } 91 \\
\text { Heat \# }\end{array}$ & Env. & Temp. $\left({ }^{\circ} \mathrm{C}\right)$ & $\begin{array}{c}\text { Strain Rate } \\
\text { Magnitude } \\
(\mathrm{m} / \mathrm{m} / \mathrm{s})\end{array}$ & $\begin{array}{c}\text { Strain Range } \\
(\%)\end{array}$ \\
\hline Design Curve & Fatigue & 1 & Grade 91 & Forging (thick) & $\mathrm{AR}$ & heat-1 & air & 650 & $4 \mathrm{E}-03$ & 0.15 \\
\hline Design Curve & Fatigue & 2 & Grade 91 & Forging (thick) & $\mathrm{AR}$ & heat-1 & air & 650 & 4E-03 & 0.15 \\
\hline Design Curve & Fatigue & 3 & Grade 91 & Forging (thick) & $\mathrm{AR}$ & heat-1 & air & 650 & $4 \mathrm{E}-03$ & 0.15 \\
\hline Design Curve & Fatigue & 4 & Grade 91 & Forging (thick) & $\mathrm{AR}$ & heat-1 & air & 650 & $4 \mathrm{E}-03$ & 0.25 \\
\hline Design Curve & Fatigue & 5 & Grade 91 & Forging (thick) & $\mathrm{AR}$ & heat-1 & air & 650 & $4 \mathrm{E}-03$ & 0.25 \\
\hline Design Curve & Fatigue & 6 & Grade 91 & Forging (thick) & $\mathrm{AR}$ & heat-1 & air & 650 & 4E-03 & 0.25 \\
\hline Design Curve & Fatigue & 7 & Grade 91 & Forging (thick) & $\mathrm{AR}$ & heat-1 & air & 650 & 4E-03 & 0.40 \\
\hline Design Curve & Fatigue & 8 & Grade 91 & Forging (thick) & $\mathrm{AR}$ & heat-1 & air & 650 & $4 \mathrm{E}-03$ & 0.40 \\
\hline Design Curve & Fatigue & 9 & Grade 91 & Forging (thick) & $\mathrm{AR}$ & heat-1 & air & 650 & $4 \mathrm{E}-03$ & 0.40 \\
\hline Design Curve & Fatigue & 10 & Grade 91 & Forging (thick) & $\mathrm{AR}$ & heat-1 & air & 650 & $4 \mathrm{E}-03$ & 0.60 \\
\hline Design Curve & Fatigue & 11 & Grade 91 & Forging (thick) & $\mathrm{AR}$ & heat-1 & air & 650 & $4 \mathrm{E}-03$ & 0.60 \\
\hline Design Curve & Fatigue & 12 & Grade 91 & Forging (thick) & $\mathrm{AR}$ & heat-1 & air & 650 & 4E-03 & 0.60 \\
\hline Design Curve & Fatigue & 13 & Grade 91 & Forging (thick) & $\mathrm{AR}$ & heat-1 & air & 650 & $4 \mathrm{E}-03$ & 1.00 \\
\hline Design Curve & Fatigue & 14 & Grade 91 & Forging (thick) & $\mathrm{AR}$ & heat-1 & air & 650 & $4 \mathrm{E}-03$ & 1.00 \\
\hline Design Curve & Fatigue & 15 & Grade 91 & Forging (thick) & $\mathrm{AR}$ & heat-1 & air & 650 & $4 \mathrm{E}-03$ & 1.00 \\
\hline Design Curve & Fatigue & 16 & Grade 91 & Forging (thick) & $\mathrm{AR}$ & heat-1 & air & 650 & $4 \mathrm{E}-03$ & 2.00 \\
\hline Design Curve & Fatigue & 17 & Grade 91 & Forging (thick) & $\mathrm{AR}$ & heat-1 & air & 650 & 4E-03 & 2.00 \\
\hline Design Curve & Fatigue & 18 & Grade 91 & Forging (thick) & $\mathrm{AR}$ & heat-1 & air & 650 & $4 \mathrm{E}-03$ & 2.00 \\
\hline Design Curve & Fatigue & 19 & Grade 91 & Forging (thick) & $\mathrm{AR}$ & heat-2 & air & 650 & $4 \mathrm{E}-03$ & 0.15 \\
\hline Design Curve & Fatigue & 20 & Grade 91 & Forging (thick) & $\mathrm{AR}$ & heat-2 & air & 650 & 4E-03 & 0.15 \\
\hline Design Curve & Fatigue & 21 & Grade 91 & Forging (thick) & $\mathrm{AR}$ & heat-2 & air & 650 & 4E-03 & 0.15 \\
\hline Design Curve & Fatigue & 22 & Grade 91 & Forging (thick) & $\mathrm{AR}$ & heat-2 & air & 650 & 4E-03 & 0.25 \\
\hline Design Curve & Fatigue & 23 & Grade 91 & Forging (thick) & $\mathrm{AR}$ & heat-2 & air & 650 & $4 \mathrm{E}-03$ & 0.25 \\
\hline Design Curve & Fatigue & 24 & Grade 91 & Forging (thick) & $\mathrm{AR}$ & heat-2 & air & 650 & $4 \mathrm{E}-03$ & 0.25 \\
\hline
\end{tabular}




Idaho National Laboratory
\begin{tabular}{|c|lll|}
\hline NEXT GENERATION NUCLEAR PLANT & Identifier: & PLN-2803 & \\
REACTOR PRESSURE VESSEL MATERIALS & Revision: & 0 & \\
RESEARCH AND DEVELOPMENT PLAN & Effective Date: & $04 / 30 / 08$ & Page: B-67 of B- 68 \\
\hline
\end{tabular}

\begin{tabular}{|c|c|c|c|c|c|c|c|c|c|c|}
\hline Test Program & $\begin{array}{c}\text { Specimen } \\
\text { Type }\end{array}$ & Spec. \# & Material & Product Form & $\begin{array}{l}\text { Mat } \\
\text { Cond }\end{array}$ & $\begin{array}{c}\text { Grade } 91 \\
\text { Heat \# }\end{array}$ & Env. & Temp. $\left({ }^{\circ} \mathrm{C}\right)$ & $\begin{array}{c}\text { Strain Rate } \\
\text { Magnitude } \\
(\mathrm{m} / \mathrm{m} / \mathrm{s})\end{array}$ & $\begin{array}{c}\text { Strain Range } \\
(\%)\end{array}$ \\
\hline Design Curve & Fatigue & 25 & Grade 91 & Forging (thick) & $\mathrm{AR}$ & heat-2 & air & 650 & $4 \mathrm{E}-03$ & 0.40 \\
\hline Design Curve & Fatigue & 26 & Grade 91 & Forging (thick) & $\mathrm{AR}$ & heat-2 & air & 650 & $4 \mathrm{E}-03$ & 0.40 \\
\hline Design Curve & Fatigue & 27 & Grade 91 & Forging (thick) & $\mathrm{AR}$ & heat-2 & air & 650 & 4E-03 & 0.40 \\
\hline Design Curve & Fatigue & 28 & Grade 91 & Forging (thick) & $\mathrm{AR}$ & heat-2 & air & 650 & 4E-03 & 0.60 \\
\hline Design Curve & Fatigue & 29 & Grade 91 & Forging (thick) & $\mathrm{AR}$ & heat-2 & air & 650 & 4E-03 & 0.60 \\
\hline Design Curve & Fatigue & 30 & Grade 91 & Forging (thick) & $\mathrm{AR}$ & heat-2 & air & 650 & 4E-03 & 0.60 \\
\hline Design Curve & Fatigue & 31 & Grade 91 & Forging (thick) & $\mathrm{AR}$ & heat-2 & air & 650 & $4 \mathrm{E}-03$ & 1.00 \\
\hline Design Curve & Fatigue & 32 & Grade 91 & Forging (thick) & $\mathrm{AR}$ & heat-2 & air & 650 & 4E-03 & 1.00 \\
\hline Design Curve & Fatigue & 33 & Grade 91 & Forging (thick) & $\mathrm{AR}$ & heat-2 & air & 650 & 4E-03 & 1.00 \\
\hline Design Curve & Fatigue & 34 & Grade 91 & Forging (thick) & $\mathrm{AR}$ & heat-2 & air & 650 & 4E-03 & 2.00 \\
\hline Design Curve & Fatigue & 35 & Grade 91 & Forging (thick) & $\mathrm{AR}$ & heat-2 & air & 650 & 4E-03 & 2.00 \\
\hline Design Curve & Fatigue & 36 & Grade 91 & Forging (thick) & $\mathrm{AR}$ & heat-2 & air & 650 & 4E-03 & 2.00 \\
\hline Design Curve & Fatigue & 37 & Grade 91 & Forging (thick) & $\mathrm{AR}$ & heat-3 & air & 650 & 4E-03 & 0.15 \\
\hline Design Curve & Fatigue & 38 & Grade 91 & Forging (thick) & $\mathrm{AR}$ & heat-3 & air & 650 & 4E-03 & 0.15 \\
\hline Design Curve & Fatigue & 39 & Grade 91 & Forging (thick) & $\mathrm{AR}$ & heat-3 & air & 650 & 4E-03 & 0.15 \\
\hline Design Curve & Fatigue & 40 & Grade 91 & Forging (thick) & AR & heat-3 & air & 650 & $4 \mathrm{E}-03$ & 0.25 \\
\hline Design Curve & Fatigue & 41 & Grade 91 & Forging (thick) & $\mathrm{AR}$ & heat-3 & air & 650 & $4 \mathrm{E}-03$ & 0.25 \\
\hline Design Curve & Fatigue & 42 & Grade 91 & Forging (thick) & $\mathrm{AR}$ & heat-3 & air & 650 & 4E-03 & 0.25 \\
\hline Design Curve & Fatigue & 43 & Grade 91 & Forging (thick) & $\mathrm{AR}$ & heat-3 & air & 650 & 4E-03 & 0.40 \\
\hline Design Curve & Fatigue & 44 & Grade 91 & Forging (thick) & $\mathrm{AR}$ & heat-3 & air & 650 & 4E-03 & 0.40 \\
\hline Design Curve & Fatigue & 45 & Grade 91 & Forging (thick) & $\mathrm{AR}$ & heat-3 & air & 650 & 4E-03 & 0.40 \\
\hline Design Curve & Fatigue & 46 & Grade 91 & Forging (thick) & $\mathrm{AR}$ & heat-3 & air & 650 & 4E-03 & 0.60 \\
\hline Design Curve & Fatigue & 47 & Grade 91 & Forging (thick) & $\mathrm{AR}$ & heat-3 & air & 650 & $4 \mathrm{E}-03$ & 0.60 \\
\hline Design Curve & Fatigue & 48 & Grade 91 & Forging (thick) & $\mathrm{AR}$ & heat-3 & air & 650 & $4 \mathrm{E}-03$ & 0.60 \\
\hline Design Curve & Fatigue & 49 & Grade 91 & Forging (thick) & $\mathrm{AR}$ & heat-3 & air & 650 & 4E-03 & 1.00 \\
\hline
\end{tabular}




Idaho National Laboratory
\begin{tabular}{|c|lll|}
\hline NEXT GENERATION NUCLEAR PLANT & Identifier: & PLN-2803 & \\
REACTOR PRESSURE VESSEL MATERIALS & Revision: & 0 & \\
RESEARCH AND DEVELOPMENT PLAN & Effective Date: & $04 / 30 / 08$ & Page: B- 68 of B- 68 \\
\hline
\end{tabular}

\begin{tabular}{|c|c|c|c|c|c|c|c|c|c|c|}
\hline \multicolumn{9}{|c|}{ Table 16. Test Matrix for Grade 91 Steel Fatigue Design Curve at $650^{\circ} \mathrm{C}, \mathrm{AR}=$ As Received } \\
\hline & $\begin{array}{c}\text { Specimen } \\
\text { Type }\end{array}$ & Spec. \# & Material & Product Form & $\begin{array}{c}\text { Mat } \\
\text { Cond }\end{array}$ & $\begin{array}{c}\text { Grade } 91 \\
\text { Heat \# }\end{array}$ & Env. & Temp. $\left({ }^{\circ} \mathrm{C}\right)$ & $\begin{array}{c}\text { Strain Rate } \\
\text { Magnitude } \\
(\mathrm{m} / \mathrm{m} / \mathrm{s})\end{array}$ & $\begin{array}{c}\text { Strain Range } \\
(\%)\end{array}$ \\
\hline Design Curve & Fatigue & 50 & Grade 91 & Forging (thick) & AR & heat-3 & air & 650 & $4 \mathrm{E}-03$ & 1.00 \\
\hline Design Curve & Fatigue & 51 & Grade 91 & Forging (thick) & AR & heat-3 & air & 650 & $4 \mathrm{E}-03$ & 1.00 \\
\hline Design Curve & Fatigue & 52 & Grade 91 & Forging (thick) & AR & heat-3 & air & 650 & $4 \mathrm{E}-03$ & 2.00 \\
\hline Design Curve & Fatigue & 53 & Grade 91 & Forging (thick) & AR & heat-3 & air & 650 & $4 \mathrm{E}-03$ & 2.00 \\
\hline Design Curve & Fatigue & 54 & Grade 91 & Forging (thick) & AR & heat-3 & air & 650 & $4 \mathrm{E}-03$ & 2.00 \\
\hline
\end{tabular}

